Florida International University FIU Digital Commons

7-14-2009

\title{
Seismic Performance of Hybrid Fiber Reinforced Polymer-Concrete Pier Columns
}

Yilei Shi

Florida International University, shiyilei@yahoo.com

DOI: 10.25148 /etd.FI09082407

Follow this and additional works at: https://digitalcommons.fiu.edu/etd

\section{Recommended Citation}

Shi, Yilei, "Seismic Performance of Hybrid Fiber Reinforced Polymer-Concrete Pier Columns" (2009). FIU Electronic Theses and Dissertations. 101.

https://digitalcommons.fiu.edu/etd/101 


\section{FLORIDA INTERNATIONAL UNIVERSITY \\ Miami, Florida}

\section{SEISMIC PERFORMANCE OF HYBRID FIBER REINFORCED POLYMER-CONCRETE PIER COLUMNS}

A dissertation submitted in partial fulfillment of the requirements for the degree of DOCTOR OF PHILOSOPHY in CIVIL ENGINEERING

by

Yilei Shi 
To: Dean Amir Mirmiran

College of Engineering and Computing

This dissertation, written by Yilei Shi, and entitled Seismic Performance of Hybrid Fiber Reinforced Polymer-Concrete Pier Columns, having been approved in respect to style and intellectual content, is referred to you for judgment.

We have read this dissertation and recommend that it be approved.

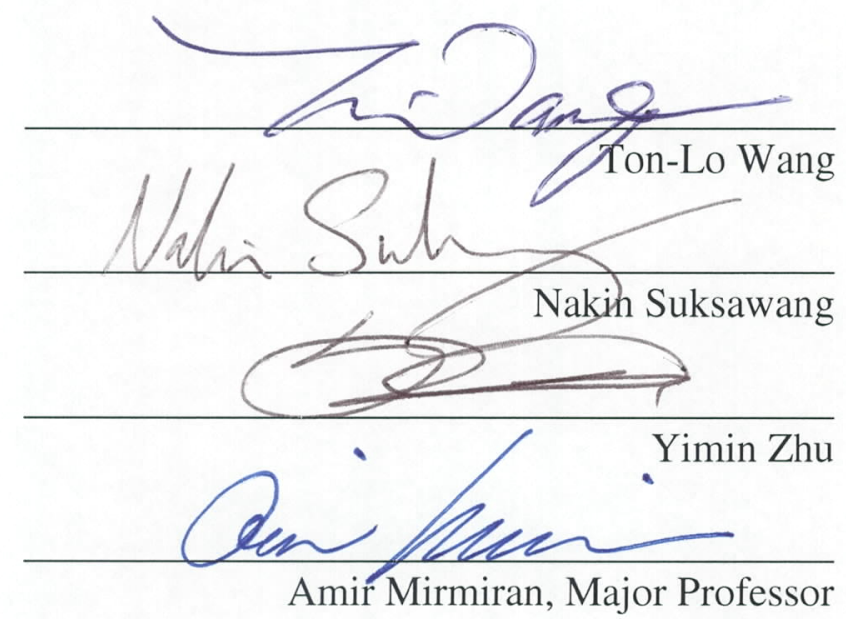

Date of Defense: July 14, 2009

The dissertation of Yilei Shi is approved.

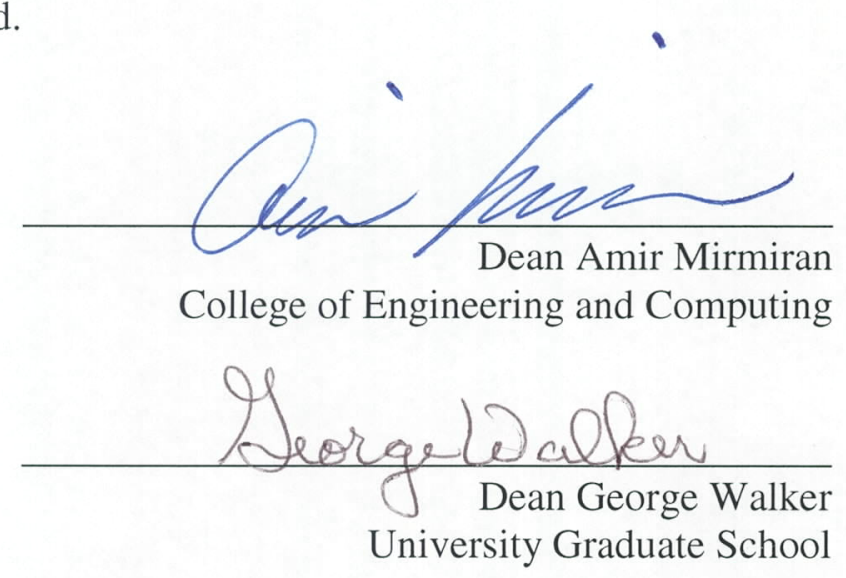

Florida International University, 2009 
(C) Copyright 2009 by Yilei Shi

All rights reserved. 


\section{ACKNOWLEDGMENTS}

The author's gratitude is first delivered to his advisor, Dr. Amir Mirmiran, for his invaluable guidance, endless support and encouraging persistence throughout the four years and beyond.

The author's appreciation is further extended to the other dissertation committee members for their grateful service: Dr. Ton-Lo Wang, Dr. Nakin Suksawang and Dr. Yimin Zhu. The author also expresses his thankfulness to Dr. Wang for his guidance during the course of teaching assistant assignments and Dr. Suksawang for his guidance in the Structures and Construction Laboratory.

The author hereby also extends his gratitude to Mr. Edgar Polo for his assistance in the laboratory; and Dr. Zhenhua Wu, Dr. Baris Yalim, Dr. Ahmet Serhat Kalayci, Dr. Bin Li, Mr. Indra Chapagain, Mr. Ruilong Li, and other former graduate students and friends who assisted me with the experimental work.

Last, but not least, this research program could not have been finished without the love, support and patience of my family; to them this dissertation is dedicated. 


\title{
ABSTRACT OF THE DISSERTATION \\ SEISMIC PERFORMANCE OF HYBRID FIBER REINFORCED POLYMER- CONCRETE PIER COLUMNS
}

\author{
by \\ Yilei Shi \\ Florida International University, 2009 \\ Miami, Florida

\section{Professor Amir Mirmiran, Major Professor}

As part of a multi-university research program funded by NSF, a comprehensive experimental and analytical study of seismic behavior of hybrid fiber reinforced polymer (FRP)-concrete column is presented in this dissertation. Experimental investigation includes cyclic tests of six large-scale concrete-filled FRP tube (CFFT) and RC columns followed by monotonic flexural tests, a nondestructive evaluation of damage using ultrasonic pulse velocity in between the two test sets and tension tests of sixty-five FRP coupons. Two analytical models using ANSYS and OpenSees were developed and favorably verified against both cyclic and monotonic flexural tests. The results of the two methods were compared. A parametric study was also carried out to investigate the effect of three main parameters on primary seismic response measures. The responses of typical CFFT columns to three representative earthquake records were also investigated.

The study shows that only specimens with carbon FRP cracked, whereas specimens with glass or hybrid FRP did not show any visible cracks throughout cyclic tests. Further monotonic flexural tests showed that carbon specimens both experienced 
flexural cracks in tension and crumpling in compression. Glass or hybrid specimens, on the other hand, all showed local buckling of FRP tubes.

Compared with conventional RC columns, CFFT column possesses higher flexural strength and energy dissipation with an extended plastic hinge region. Among all CFFT columns, the hybrid lay-up demonstrated the highest flexural strength and initial stiffness, mainly because of its high reinforcement index and FRP/concrete stiffness ratio, respectively. Moreover, at the same drift ratio, the hybrid lay-up was also considered as the best in term of energy dissipation. Specimens with glassfiber tubes, on the other hand, exhibited the highest ductility due to better flexibility of glass FRP composites. Furthermore, ductility of CFFTs showed a strong correlation with the rupture strain of FRP.

Parametric study further showed that different FRP architecture and rebar types may lead to different failure modes for CFFT columns. Transient analysis of strong ground motions showed that the column with off-axis nonlinear filament-wound glass FRP tube exhibited a superior seismic performance to all other CFFTs. Moreover, higher FRP reinforcement ratios may lead to a brittle system failure, while a well-engineered FRP reinforcement configuration may significantly enhance the seismic performance of CFFT columns. 
LIST OF TABLES __ $x i$

LIST OF FIGURES __ xiii

$1 \quad$ INTRODUCTION

1.1 RESEARCH BACKGROUND

1.2 PROBLEM STATEMENT _ 2

1.3 RESEARCH OBJECTIVES 5

1.4 RESEARCH APPORACHES__ 6

1.4.1 Experimental Studies _ 6

1.4.2 Analytical Studies 7

1.5 DISSERTATION STRUCTURE _ 7

2 LITERATURE REVIEW _ 9

2.1 OVERVIEW OF CFFT 9

2.2 AXIAL COMPRESSION BEHAVIOR OF CFFT_ 10

2.3 CONSTITUTIVE MODELING OF CFFT___ 12

2.4 AXIAL-FLEXURAL BEHAVIOR OF CFFT_ 13

2.5 CYCLIC BEHAVIOR OF CFFT _ 17

3 CYCLIC TEST _ 21

3.1 TEST MATRIX AND SPECIMEN PREPARATION _ 21

3.1.1 Test Matrix __ 21

3.1.2 Specimen Preparation 21

3.1.2.1 Preparation of FRP Tubes__ 21

3.1.2.2 Specimen Reinforcement 22

3.1.2.3 Column-Footing and Column-Head Connections __ 23

3.1.2.4 Formwork and Concrete Casting ___ 24

3.1.2.5 Epoxy Injection 25

3.2 TEST SETUP AND INSTRUMENTATION_ 26

3.2.1 Test Setup _ 26

3.2.2 Instrumentation 27

3.3 TEST PROCEDURE AND OBSERVATIONS 28

3.3.1 Test Procedure _ 28

3.3.2 Test Observations _ 29

3.3.2.1 Observed Cracks in FRP Tubes __ 29

3.3.2.2 Observed Cracks in Footings _ 30

3.3.2.3 Observed Tube-Footing Separation and FRP Tube Slippage___ 31

3.3.2.4 Observed Failure Modes_ 32

3.4 TEST RESULTS AND DISCUSSIONS 32

3.4.1 Stability of Axial Load __ 32 
3.4.2 Hysteretic Response __ 33

3.4.3 Response Envelope__ 34

3.4.4 Energy Dissipation _ 35

3.4.5 Performance Measures of Stiffness, Ductility and Pinching ___ 35

3.4.6 Load-Strain Response and Plastic Hinge Length ___ 36

3.4.7 Deflected Shapes and Normalized Moment - Curvature Responses _ 37

3.4.8 Tube-Footing Slippage __ 38

3.4.9 Residual Deflections and Residual Loads 39

3.4.10 Combined Shear and Flexural Effects of CFFT Columns __ 40

3.5 CONCLUSIONS_ 40

4 MONOTONIC FLEXURAL TEST _ 88

4.1 INTRODUCTION 88

4.2 SPECIMEN CONDITIONS 88

4.3 TEST SETUP AND INSTRUMENTATION

4.3.1 Test Setup _ 89

4.3.2 Instrumentation 89

4.4 TEST PROCEDURE AND OBSERVATIONS _ 90

4.4.1 Test Procedure _ 90

4.4.2 Test Observations _ 91

4.4.2.1 Specimen $\mathrm{RC} \longrightarrow 91$

4.4.2.2 Specimen $\mathrm{Y} \longrightarrow 91$

4.4.2.3 Specimen $\mathrm{G} \longrightarrow 91$

4.4.2.4 Specimen $\mathrm{H} \longrightarrow 92$

4.4.2.5 Specimen $\mathrm{SC} \quad 92$

4.4.2.6 Specimen LC 93

4.5 TEST RESULTS AND DISCUSSIONS _ 93

4.5.1 Moment and Shear at Peak Loads___ 93

4.5.2 Normalized Moment-Deflection Responses ___ 94

4.5.3 Maximum Normalized Moment___ 95

4.5.4 Energy Dissipation 95

4.5.5 Normalized Initial Stiffness ___ 96

4.5.6 Ductility _ 97

4.5.7 Normalized Moment-Strain Responses ___ 97

4.5.8 Normalized Moment-Curvature Responses__ 98

4.5.9 Normalized Moment and Reinforcement Index Relationship ___ 98

4.5.10 Influence of Shear Span Ratio and Reinforcement Index on Flexural and

Shear Behavior 100

4.6 CONCLUSIONS__ 102

5 COUPON TEST _ 135

5.1 TEST MATRIX AND SPECIMEN PREPARATION__ 135

5.1.1 Test Matrix _ 135 
5.1.2 Specimen Preparation 136

5.2 TEST SETUP AND INSTRUMENTATION__ 136

5.2.1 Test Setup _ 136

5.2.2 Instrumentation 136

5.3 TEST PROCEDURE AND OBSERVATIONS__ 137

5.3.1 Test Procedure — 137

5.3.2 Test Observations 137

5.4 TEST RESULTS AND DISCUSSIONS 139

5.4.1 Stress-Strain Behavior 139

5.4.2 Comparison of Mechanical Properties with Manufacturer Data___ 141

5.4.2.1 Manufacturer Data __ 141

5.4.2.2 GH and GL Coupons 141

5.4.2.3 HC and HG Coupons — 143

5.4.2.4 HH and HL Coupons 143

5.4.3 Comparison with Large-Scale Specimens __ 144

5.5 CONCLUSIONS _ 145

6 NONDESTRUCTIVE DAMAGE ASSESSMENT _ 175

6.1 INTRODUCTION 175

6.2 EXPERIMENTAL WORK__ 175

6.2.1 Test Setup and Instrumentation _ 175

6.2.2 Test Procedure and Observations 177

6.2.3 Test Results and Discussion ___ 177

6.2.3.1 Velocities in Different Directions for Each Specimen 177

6.2.3.2 Velocities in Different Specimens for Specific Sensing Directions _ 180

6.2.3.3 Relationships of Average Velocity with Strength Index and FRP

Rupture Strain

6.3 CONCLUSIONS_ 182

7 ANALYTICAL MODELING _ 209

7.1 INTRODUCTION 209

7.2 Hysteretic Modeling using OpenSees__ 210

7.2.1 Element Descriptions 210

7.2.2 Concrete Material Modeling__ 210

7.2.3 Steel Material Modeling__ 211

7.2.4 FRP Material Modeling _ 212

7.2.5 Structural Modeling — 212

7.3 Hysteretic Modeling using ANSYS 213

7.3.1 Extended Equivalent I-Section with Virtual Materials___ 213

7.3.2 Element Descriptions _ 214

7.3.3 Virtual Material Modeling _ 215

7.3.4 Structural Modeling __ 216

7.4 Model Validation —_ 216 
7.5 PARAMETRIC STUDY _ 218

7.5.1 Parameters 218

7.5.2 Response Measures__ 219

7.5.3 Parameter Impact on Response Measure __ 221

7.5.4 Re-evaluation of Total Reinforcement Index versus Normalized Moment 222

7.6 PERFORMANCE UNDER STRONG GROUND MOTIONS __ 222

8 CONCLUSIONS AND FUTURE RESEARCH _ 285

8.1 SUMMARY 285

8.2 CONCLUSIONS 286

8.3 FUTURE RESEARCH__ 288

LIST OF REFERENCES _ 289 


\section{LIST OF TABLES}

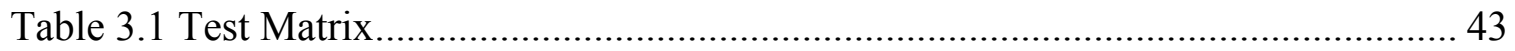

Table 3.2 Properties of FRP Tube or Laminates..................................................... 43

Table 3.3 Properties of Sikadur 35 and Sikadur 300 ................................................... 44

Table 3.4 Statistical Variables for the Applied Axial Forces ............................................ 44

Table 3.5 Comparison of System Performance Measures ............................................... 45

Table 3.6 Performance Measures of Stiffness, Ductility and Pinching of CFFT Specimens 46

Table 3.7 Comparison of Plastic Hinge Lengths ......................................................... 47

Table 4.1 Specimen Conditions after Cyclic Tests ...................................................... 104

Table 4.2 Loading Patterns for Test Specimens …………....................................... 104

Table 4.3 Comparison of Monotonic and Cyclic Tests Moments .................................. 105

Table 4.4 Comparison of Normalized Initial Stiffness from Monotonic and Cyclic Tests 106

Table 4.5 Comparison of Ductility of CFFT Specimens from Monotonic and Cyclic Tests 106

Table 4.6 FRP and Steel Strength and Stiffness Indices with Maximum Normalized Moments and Shear Forces. 107

Table 4.7 Comparison of Reinforcement Indices and Normalized Moments of Specimens

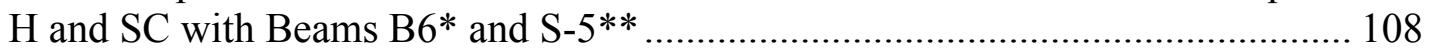

Table 5.1 Test Matrix of Coupon Specimens ………….............................................. 147

Table 5.2 Tensile Test Failure Codes (ASTM D 3039)................................................. 148

Table 5.3 Stress-Strain Data of CH Coupons .............................................................. 148

Table 5.4 Stress-Strain Data of CL Coupons.............................................................. 149

Table 5.5 Stress-Strain Data of GH Coupons ………………................................... 150

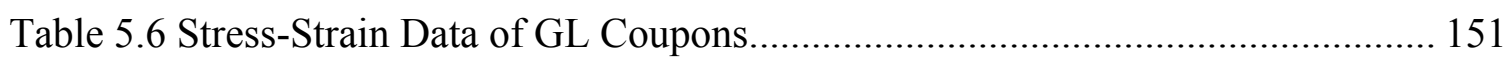

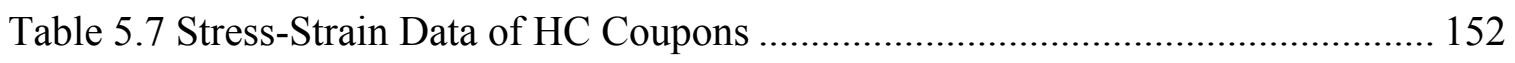

Table 5.8 Stress-Strain Data of HG Coupons ........................................................... 152

Table 5.9 Stress-Strain Data of HH Coupons ……………………………………..... 153

Table 5.10 Stress-Strain Data of HL Coupons.......................................................... 153

Table 5.11 Manufacturer Data for Tensile Properties of FRP Materials ......................... 154

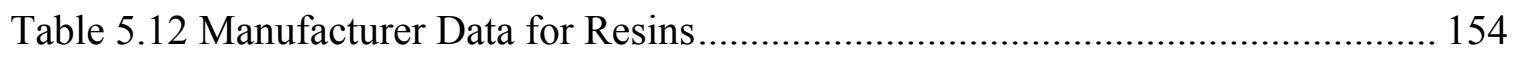


Table 5.13 Comparison with Manufacturer Data for GH Coupons............................... 155

Table 5.14 Comparison with Manufacturer Data for GL Coupons ............................. 155

Table 5.15 Comparison with Manufacturer Data for HC Coupons ............................... 156

Table 5.16 Comparison with Manufacturer Data for HG Coupons.............................. 156

Table 5.17 Comparison with Manufacturer Data for HH Coupons.............................. 156

Table 5.18 Comparison with Manufacturer Data for HL Coupons .............................. 157

Table 5.19 Comparison of Ultimate Tensile Strains................................................... 157

Table 5.20 Manufacturer Data for Compressive Properties of FRP Materials............... 158

Table 5.21 Manufacturer Data for Ultimate Compressive Strains of HL ...................... 158

Table 5.22 Comparison of Ultimate Compressive Strains......................................... 159

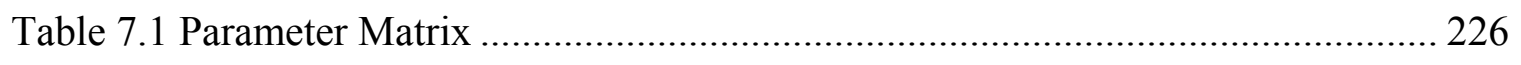




\section{LIST OF FIGURES}

Figure 3.1 Sonotubes and Filament-Wound FRP Tube ................................................. 48

Figure 3.2 Preparation of Carbon FRP Tube in the Laboratory ....................................... 48

Figure 3.3 Cured Laboratory-Made FRP Tubes: (a) GFRP Tube for Specimen G, (b) CFRP Tube for Specimen SC, and (c) CFRP Tube for Specimen LC and Hybrid CFRP/GFRP Tube for Specimen $\mathrm{H}$. 48

Figure 3.4 Column Reinforcement of Specimen RC Embedded into the Footing ........... 49

Figure 3.5 Column Reinforcement of Specimen LC ................................................... 49

Figure 3.6 Column Reinforcement Details for Specimen RC and CFFT Specimens....... 50

Figure 3.7 Embedment of FRP Tube and Column Reinforcement into the Footing of

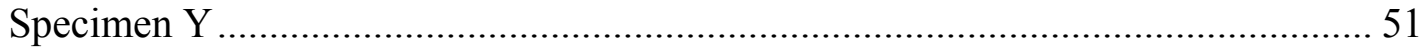

Figure 3.8 Overall Embedment into the Column Heads and Footings of Specimens G, Y

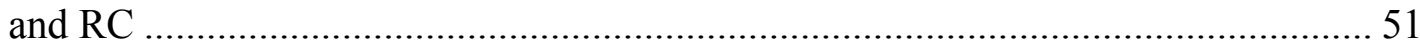

Figure 3.9 Formworks of Specimens H and SC ………....................................... 52

Figure 3.10 Template and Formwork for Specimen LC ............................................... 52

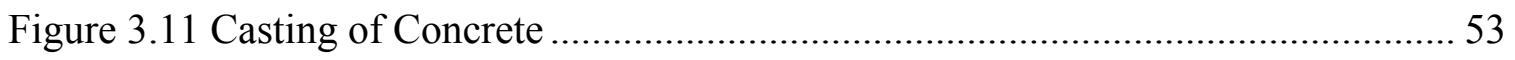

Figure 3.12 Specimens H and SC Right after Concrete Casting ………….................... 53

Figure 3.13 Five Short Column Specimens after De-Molding .......................................... 54

Figure 3.14 Specimen LC and Pedestal after De-Molding ............................................. 54

Figure 3.15 Small Pockets of Concrete Void along the Top of Specimen RC................. 55

Figure 3.16 Epoxy Injection Port............................................................................. 55

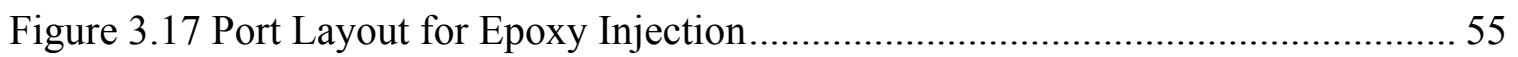

Figure 3.18 Epoxy Injection Process ..................................................................... 56

Figure 3.19 Specimen after Epoxy Injection ............................................................. 56

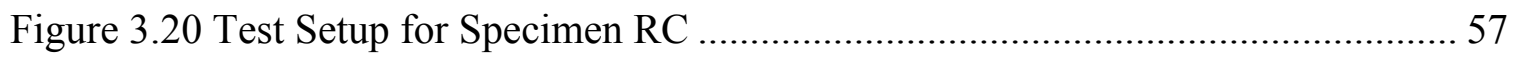

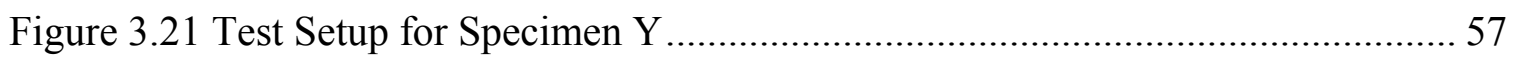

Figure 3.22 Test Setup for Specimen G.............................................................. 58

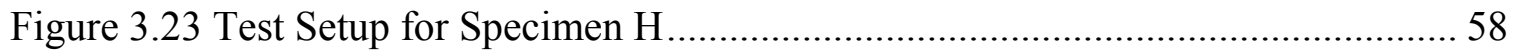

Figure 3.24 Test Setup for Specimen SC ................................................................. 59

Figure 3.25 Test Setup for Specimen LC................................................................. 59

Figure 3.26 Post-Tensioning of Specimen G to Simulate Axial Force.............................. 60

Figure 3.27 Instrumentation Plan: (a) Short Specimens and (b) Specimen LC................ 61 


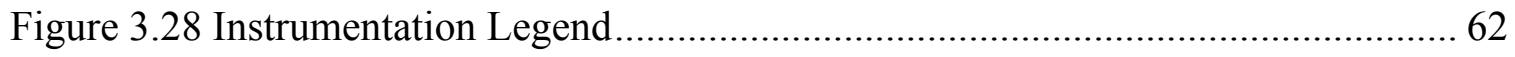

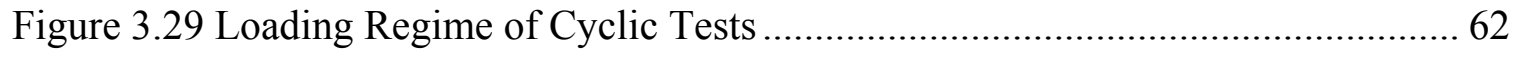

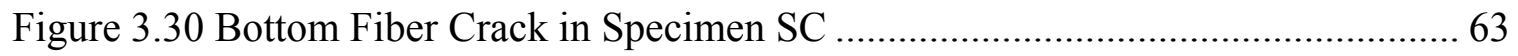

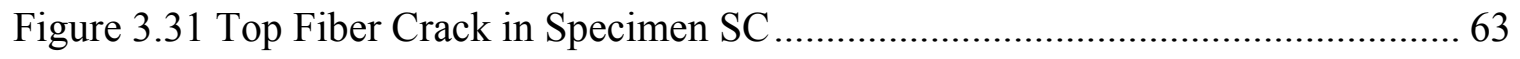

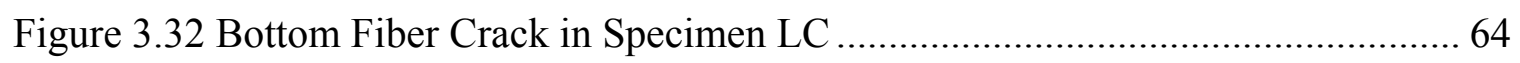

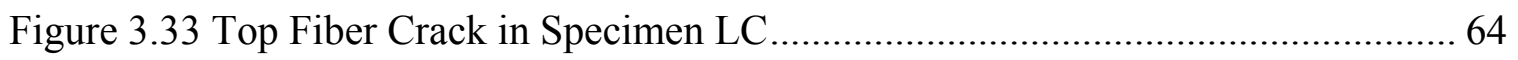

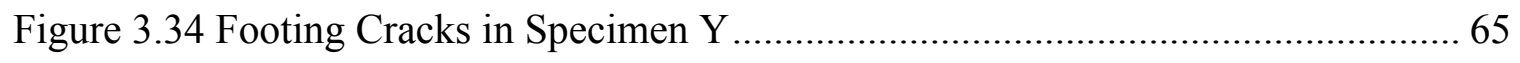

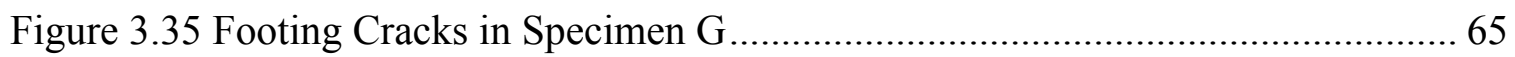

Figure 3.36 Concrete Spalling in Footing of Specimen H........................................ 66

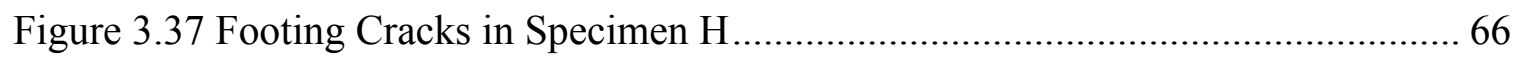

Figure 3.38 Separation between FRP Tube and RC Footing in Specimen Y .................. 67

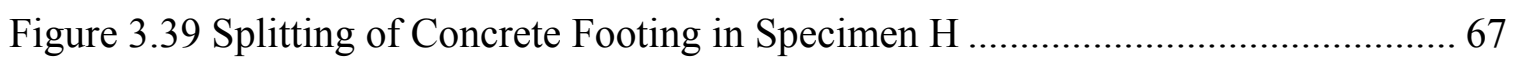

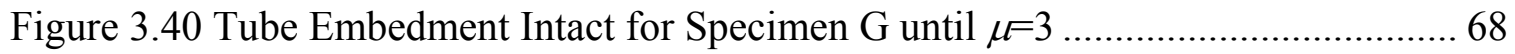

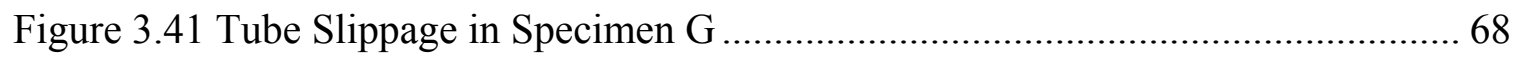

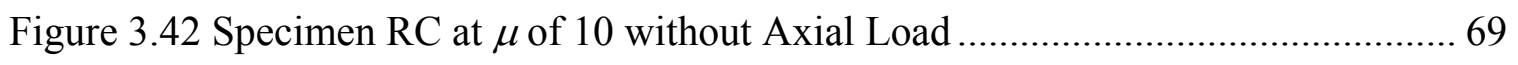

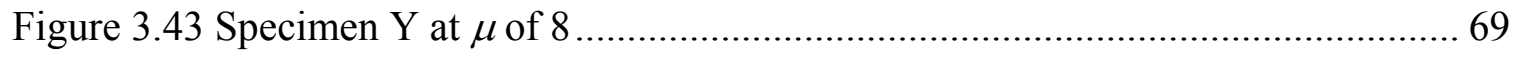

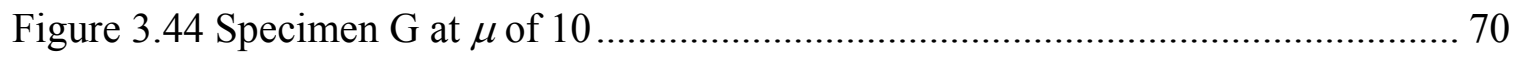

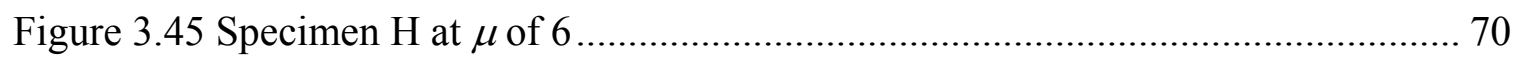

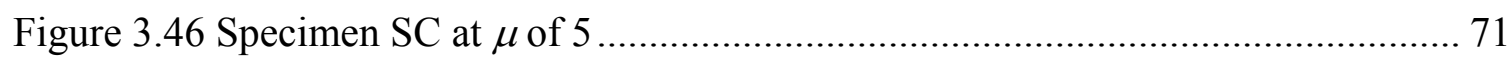

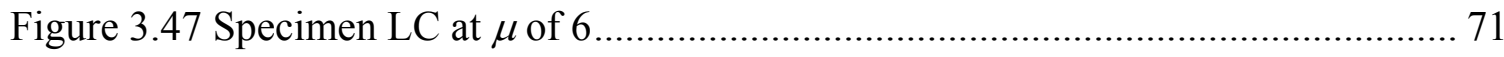

Figure 3.48 Axial Load Fluctuations for Specimen LC ............................................ 72

Figure 3.49 Hysteretic Normalized Moment - Deflection Response of Specimen RC... 72

Figure 3.50 Hysteretic Normalized Moment - Deflection Response of Specimen Y ..... 73

Figure 3.51 Hysteretic Normalized Moment - Deflection Response of Specimen G ...... 73

Figure 3.52 Hysteretic Normalized Moment - Deflection Response of Specimen H ...... 74

Figure 3.53 Hysteretic Normalized Moment - Deflection Response of Specimen SC ... 74

Figure 3.54 Hysteretic Normalized Moment - Deflection Response of Specimen LC .... 75

Figure 3.55 Normalized Moment - Drift Ratio Envelope Curves of All Specimens ....... 75

Figure 3.56 Normalized Cumulative Dissipated Energy versus Drift Ratio ................... 76

Figure 3.57 Longitudinal Rebar Strain Profile of Specimen Y During Push .................. 76

Figure 3.58 Longitudinal Rebar Strain Profile of Specimen G During Push .................. 77 
Figure 3.59 Longitudinal Rebar Strain Profile of Specimen H During Pull................... 77

Figure 3.60 Longitudinal Rebar Strain Profile of Specimen SC During Pull................. 78

Figure 3.61 Longitudinal Rebar Strain Profile of Specimen LC During Pull ................. 78

Figure 3.62 Plastic Hinge Length versus Normalized Moments ................................. 79

Figure 3.63 Deflected Shapes of Specimen RC at Various Ductility Levels .................. 79

Figure 3.64 Deflected Shapes of Specimen Y at Various Ductility Levels..................... 80

Figure 3.65 Deflected Shapes of Specimen G at Various Ductility Levels.................... 80

Figure 3.66 Deflected Shapes of Specimen H at Various Ductility Levels..................... 81

Figure 3.67 Deflected Shapes of Specimen SC at Various Ductility Levels.................. 81

Figure 3.68 Deflected Shapes of Specimen LC at Various Ductility Levels................... 82

Figure 3.69 Normalized Moment - Curvature Responses......................................... 82

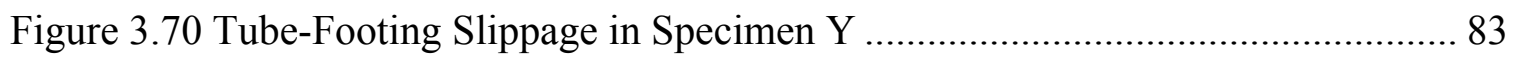

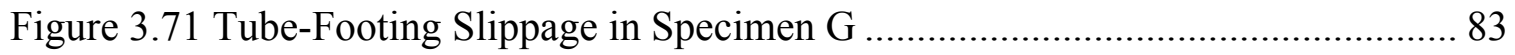

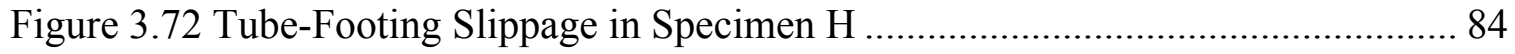

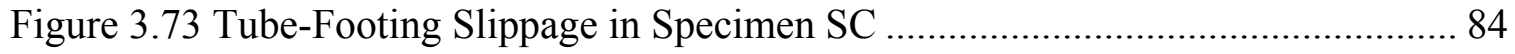

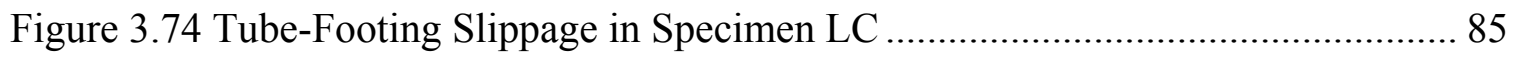

Figure 3.75 Comparison of Tube-Footing Slippages on Top for Specimens SC, H, Y, and

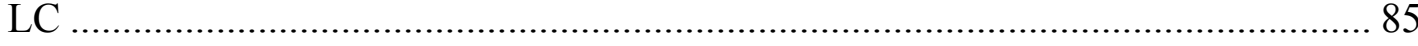

Figure 3.76 Comparison of Tube-Footing Net Slippages on Top for Specimens SC, H, Y,

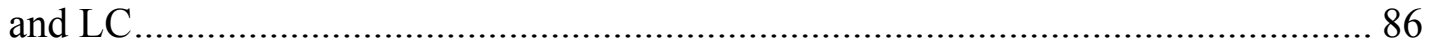

Figure 3.77 Average Absolute Residual Drift Ratios of CFFT Specimens at Zero Loads86

Figure 3.78 Percentage of Total Residual Normalized Moment at Zero Deflection to Total Maximum Normalized Moment at Each Ductility Factor for CFFT Specimens

Figure 4.1 Monotonic Test Setup for Specimen RC ................................................ 109

Figure 4.2 Monotonic Test Setup for Specimen Y ................................................. 109

Figure 4.3 Monotonic Test Setup for Specimen G ................................................... 110

Figure 4.4 Monotonic Test set-up for Specimen H................................................ 110

Figure 4.5 Monotonic Test set-up for Specimen SC .................................................. 111

Figure 4.6 Monotonic Test set-up for Specimen LC ................................................ 111

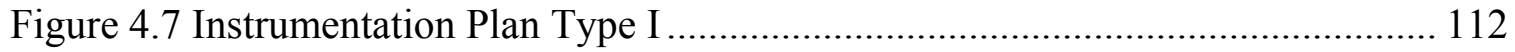

Figure 4.8 Instrumentation Plan Type II (for Specimens RC and G) ......................... 112

Figure 4.9 Instrumentation List for Monotonic Tests .............................................. 113 
Figure 4.10 Flexural Cracks of Specimen RC at Mid-Span ..... 113

Figure 4.11 Shear Cracks of Specimen RC in Shear-Flexural Region Close to Column Head..... 114

Figure 4.12 East View of Final Cracking Pattern Close to Footing in Specimen RC ... 114 Figure 4.13 West View of Final Cracking Pattern Close to Footing in Specimen RC... 115

Figure 4.14 Crushing of Specimen $\mathrm{Y}$ at the Top (East View) ....................................... 115

Figure 4.15 Crushing of Specimen Y at the Top (West View)...................................... 116

Figure 4.16 Cracking Pattern of Specimen G (East View) ............................................. 116

Figure 4.17 Cracking Pattern of Specimen G (West View)........................................... 117

Figure 4.18 Close up View of Specimen G (West View)............................................ 117

Figure 4.19 Overall View of Specimen G (West View) ............................................... 118

Figure 4.20 Direct Loading on Specimen H Using Neoprene Pads ............................... 118

Figure 4.21 Crumpling Crack in Specimen $\mathrm{H}$ at the Top (East View).......................... 119

Figure 4.22 Crumpling Crack in Specimen $\mathrm{H}$ at the Top (West View)......................... 119

Figure 4.23 Close up of Crumpling Crack at the Top of Specimen H............................ 120

Figure 4.24 Flexural Crack in Specimen SC (West View) .......................................... 120

Figure 4.25 Crumpling Crack in Specimen SC (West View) ........................................ 121

Figure 4.26 Flexural Crack in Specimen LC (East View) .............................................. 121

Figure 4.27 Flexural Crack Extended to Mid-Span in Specimen LC (West View) ....... 122

Figure 4.28 Top Crumpling Crack in Specimen LC (East View).................................. 122

Figure 4.29 Top Crumpling Crack in Specimen LC (West View) .................................. 123

Figure 4.30 Final Crack Pattern in Specimen LC (East View)...................................... 123

Figure 4.31 Final Unzipping Crack in Specimen LC (West View)............................... 124

Figure 4.32 Normalized Mid-Span Moment - Deflection Response of Specimen RC .. 124

Figure 4.33 Normalized Mid-Span Moment - Deflection Response of Specimen Y ... 125

Figure 4.34 Normalized Mid-Span Moment - Deflection Response of Specimen G ... 125

Figure 4.35 Normalized Mid-Span Moment - Deflection Response of Specimen H ... 126

Figure 4.36 Normalized Mid-Span Moment - Deflection Response of Specimen SC .. 126

Figure 4.37 Normalized Mid-Span Moment - Deflection Response of Specimen LC .. 127

Figure 4.38 Normalized Mid-Span Moment - Deflection Responses of All Specimens 127

Figure 4.39 Normalized Cumulative Dissipated Energy - Deflection Responses ......... 128

Figure 4.40 Normalized Initial Stiffness versus Stiffness Ratio (FRP/Concrete) .......... 128 
Figure 4.41 CFFT Ductility versus FRP Ultimate Tensile Strain............................... 129

Figure 4.42 Normalized Mid-Span Moment - Strain Response of Specimen RC ........ 129

Figure 4.43 Normalized Mid-Span Moment - Strain Response of Specimen Y ........... 130

Figure 4.44 Normalized Mid-Span Moment - Strain Response of Specimen G........... 130

Figure 4.45 Normalized Mid-Span Moment - Strain Response of Specimen H........... 131

Figure 4.46 Normalized Mid-Span Moment - Strain Response of Specimen SC......... 131

Figure 4.47 Normalized Mid-Span Moment - Strain Response of Specimen LC......... 132

Figure 4.48 Normalized Mid-Span Moment - Strain Responses of All Specimens ...... 132

Figure 4.49 Normalized Moment - Curvature Responses........................................ 133

Figure 4.50 Maximum Normalized Moments versus Reinforcement Strength Indices . 134

Figure 4.51 Normalized Shear Forces versus FRP Hoop Strength Index..................... 134

Figure 5.1 Typical Coupon Test Setup ................................................................. 160

Figure 5.2 Coupon Instrumentation and Data Acquisition System ............................ 160

Figure 5.3 Failure Mode of CH-I-1: LGM........................................................... 161

Figure 5.4 Failure Mode of CH-I-2: LWV ................................................................. 161

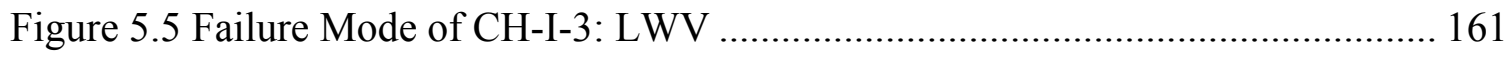

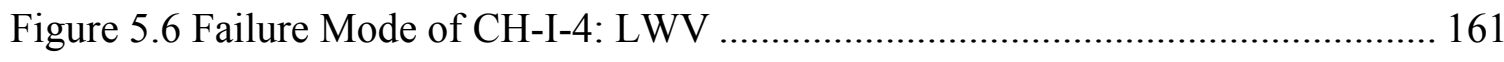

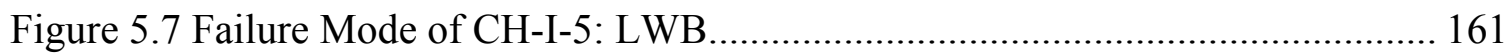

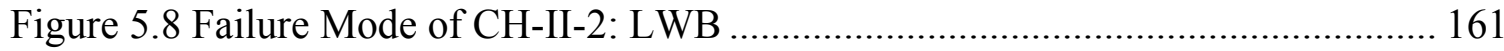

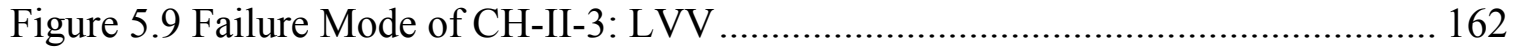

Figure 5.10 Failure Mode of CH-II-4: LVV ........................................................ 162

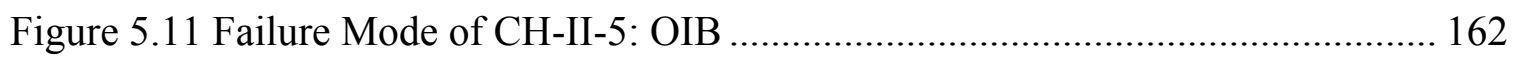

Figure 5.12 Failure Mode of CH-II-6: LWT ......................................................... 162

Figure 5.13 Failure Mode of CH-II-7: LGM ...................................................... 162

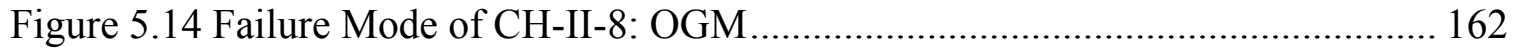

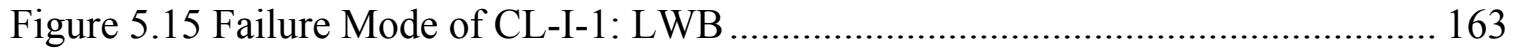

Figure 5.16 Failure Mode of CL-I-2: LAB ....................................................... 163

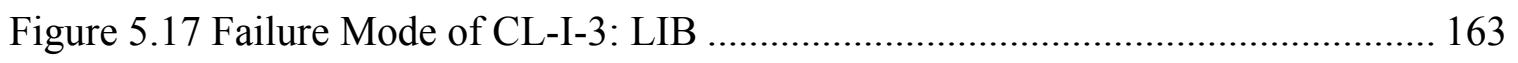

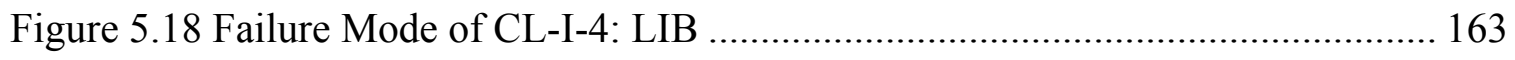

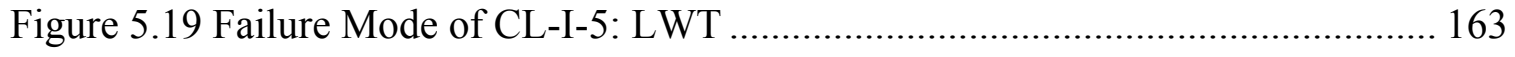

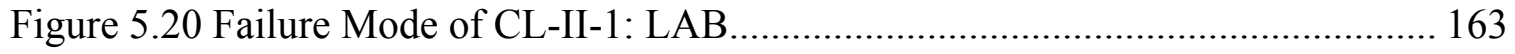

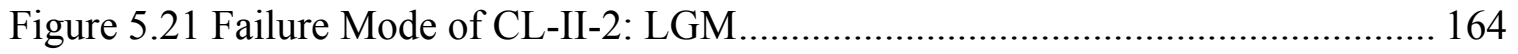


Figure 5.22 Failure Mode of CL-II-3: LAB ............................................................ 164

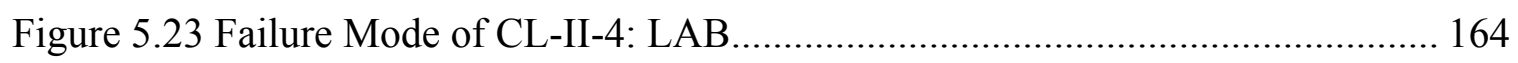

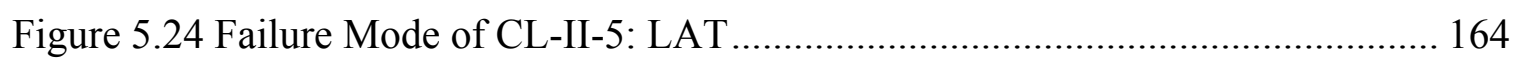

Figure 5.25 Failure Mode of GH-I-1: LGM ............................................................. 164

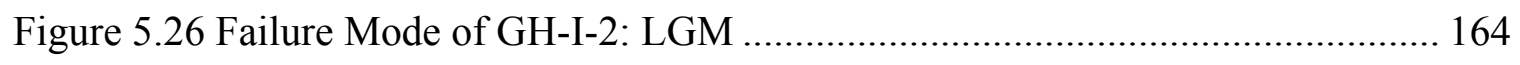

Figure 5.27 Failure Mode of GH-I-3: OWT ............................................................ 165

Figure 5.28 Failure Mode of GH-III-1: LGM............................................................ 165

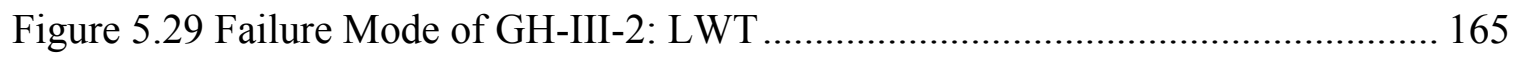

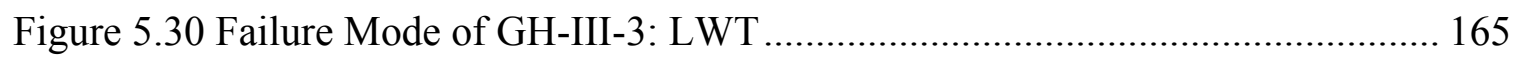

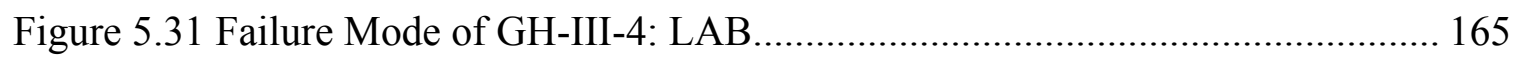

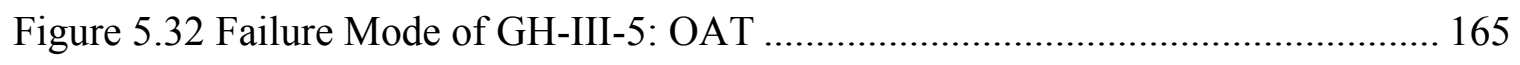

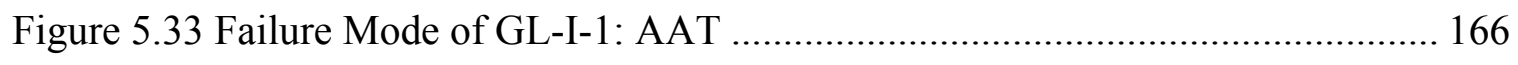

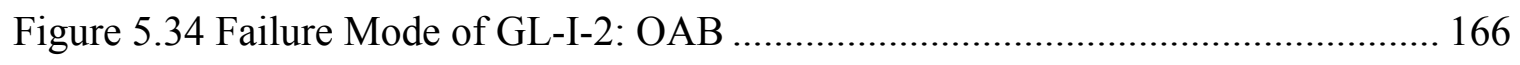

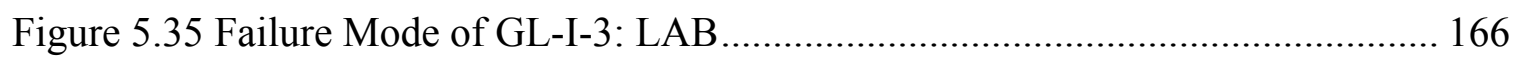

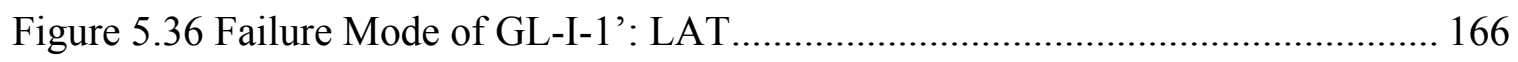

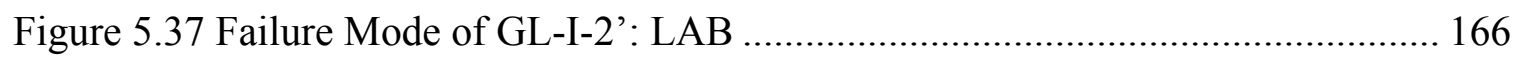

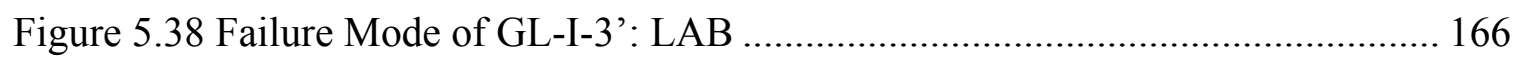

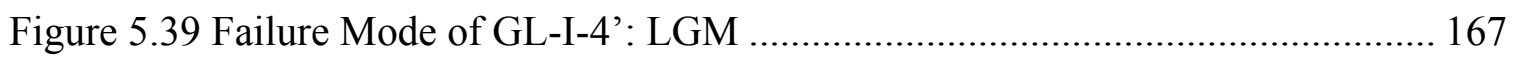

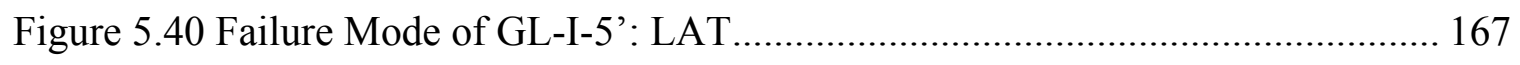

Figure 5.41 Failure Mode of GL-III-1: LGM ……………......................................... 167

Figure 5.42 Failure Mode of GL-III-2: LGM …………............................................ 167

Figure 5.43 Failure Mode of GL-III-3: LIT ............................................................. 167

Figure 5.44 Failure Mode of GL-III-1': LGM............................................................ 167

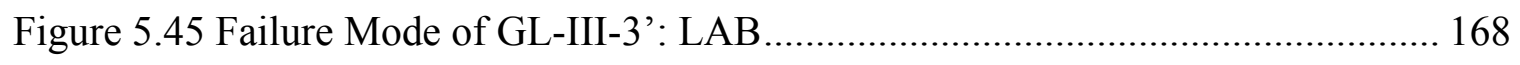

Figure 5.46 Failure Mode of GL-III-5': LAB ……………........................................ 168

Figure 5.47 Failure Mode of HC-I-1: LGM........................................................... 168

Figure 5.48 Failure Mode of HC-I-2: SGM........................................................... 168

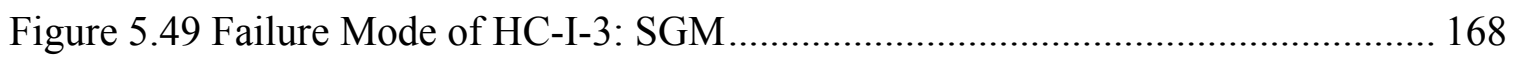

Figure 5.50 Failure Mode of HC-I-4: SGM........................................................... 168

Figure 5.51 Failure Mode of HC-I-5: SGM............................................................ 169

Figure 5.52 Failure Mode of HG-I-1: SGM............................................................ 169

Figure 5.53 Failure Mode of HG-I-2: SGM.............................................................. 169 
Figure 5.54 Failure Mode of HG-I-3: SGM............................................................. 169

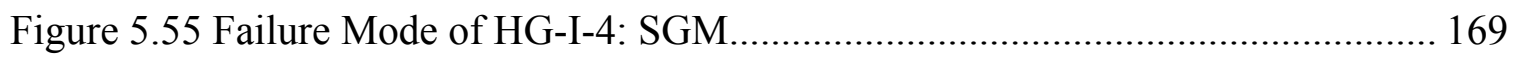

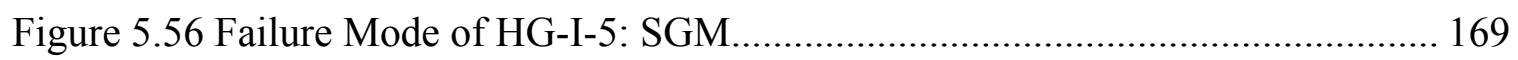

Figure 5.57 Failure Mode of HH-V-1: LAT ……………...................................... 170

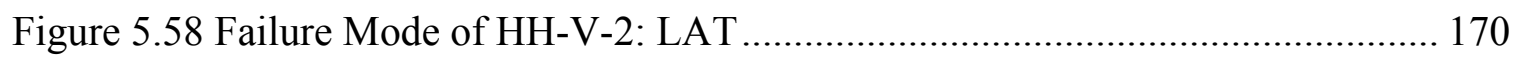

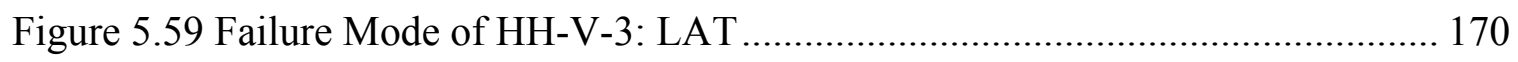

Figure 5.60 Failure Mode of HH-V-4: LGM........................................................ 170

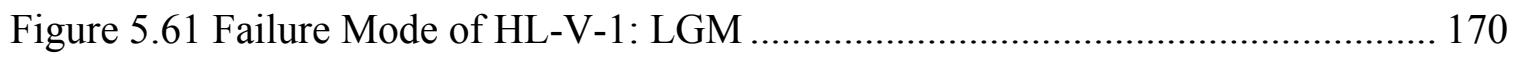

Figure 5.62 Failure Mode of HL-V-2: LWB ....................................................... 170

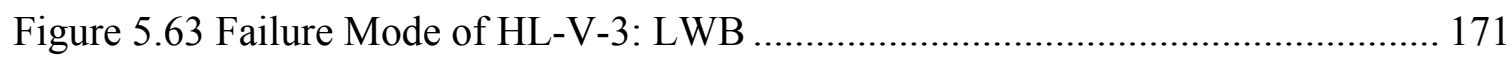

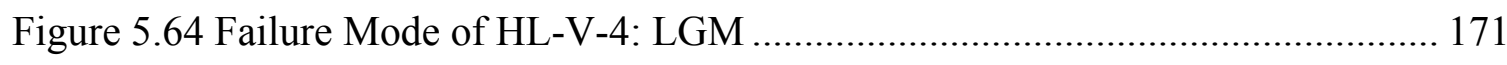

Figure 5.65 Tensile Stress-Strain Responses of CH Coupons........................................ 171

Figure 5.66 Tensile Stress-Strain Responses of CL Coupons ......................................... 172

Figure 5.67 Tensile Stress-Strain Responses of GH Coupons....................................... 172

Figure 5.68 Tensile Stress-Strain Responses of GL Coupons ......................................... 173

Figure 5.69 Tensile Stress-Strain Responses of HH Coupons......................................... 173

Figure 5.70 Tensile Stress-Strain Responses of HL Coupons ........................................ 174

Figure 6.1 Block Diagram of Ultrasonic Equipment ................................................. 184

Figure 6.2 Two B225 Pulse and Receiver Transducers............................................... 184

Figure 6.3 Test Set-up and Instrumentation.......................................................... 185

Figure 6.4 Velocity Measurements in the B, L, R and T Directions for Each Specimen 188 Figure 6.5 Velocity Measurements in the H, LR, RL and V Directions for Each Specimen 191

Figure 6.6 Average Velocity Measurements in the Two Direction Groups for Each Specimen 194

Figure 6.7 Velocity Measurements in the L, R and V Directions for Each Specimen... 197 Figure 6.8 Velocity Measurements in the B, H and T Directions for Each Specimen ... 200 Figure 6.9 Velocity Measurements in the B, L, R and T Directions for All Specimens 203 Figure 6.10 Velocity Measurements in the H, LR, RL and V Directions for All Specimens 206

Figure 6.11 Average Velocity Measurements in Various Directions for All Specimens207 Figure 6.12 Average Velocity Measurements versus Strength Index.............................. 207 Figure 6.13 Average Velocity Measurements versus FRP Rupture Strain..................... 208 
Figure 7.1 Typical Hysteretic Stress-Strain Curve of Concrete Model 227

Figure 7.2 Stress-Strain Relationship of MMFX and Grade 60 Steel (Sumpter et al. 2009)

Figure 7.3 Typical Hysteretic Stress-Strain Response of Steel Reinforcement............. 228

Figure 7.4 Typical Hysteretic Stress-Strain Response of FRP Tube for Column Y...... 228

Figure 7.5 Analytical Model for CFFT and RC Columns ........................................... 229

Figure 7.6 Illustration of the Extended Equivalent Section Concept........................... 230

Figure 7.7 Transformation from Moment-Curvature Response to Stress-Strain Input .. 231

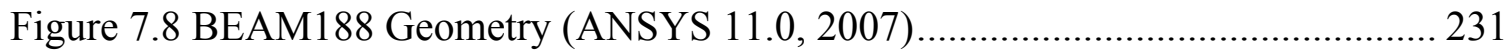

Figure 7.9 Geometry of I-Shape Cross Section (ANSYS 11.0, 2007) ......................... 232

Figure 7.10 Geometry of MASS21 Element (ANSYS 11.0, 2007) ............................. 232

Figure 7.11 Nonlinear Plastic Material Model with Multilinear Kinematic Hardening

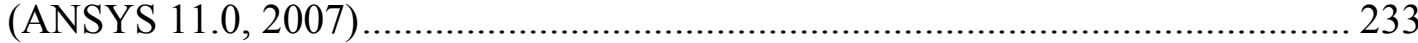

Figure 7.12 Simplified Column Model for ANSYS .............................................. 233

Figure 7.13 Moment-Deflection Hysteretic Simulation of Specimen RC ..................... 234

Figure 7.14 Moment-Deflection Hysteretic Simulation of Specimen Y ...................... 234

Figure 7.15 Moment-Deflection Hysteretic Simulation of Specimen G ...................... 235

Figure 7.16 Moment-Deflection Hysteretic Simulation of Specimen H ..................... 235

Figure 7.17 Moment-Deflection Hysteretic Simulation of Specimen SC .................... 236

Figure 7.18 Moment-Deflection Hysteretic Simulation of Specimen LC .................... 236

Figure 7.19 Moment-Deflection Push-Over Simulation of Specimen RC ................... 237

Figure 7.20 Moment-Deflection Push-Over Simulation of Specimen Y ...................... 237

Figure 7.21 Moment-Deflection Push-Over Simulation of Specimen G..................... 238

Figure 7.22 Moment-Deflection Push-Over Simulation of Specimen H...................... 238

Figure 7.23 Moment-Deflection Push-Over Simulation of Specimen SC.................... 239

Figure 7.24 Moment-Deflection Push-Over Simulation of Specimen LC ................... 239

Figure 7.25 Monotonic Flexural Simulation of Specimen RC by OpenSees ................ 240

Figure 7.26 Monotonic Flexural Simulation of Specimen Y by OpenSees................... 240

Figure 7.27 Monotonic Flexural Simulation of Specimen G by OpenSees................... 241

Figure 7.28 Monotonic Flexural Simulation of Specimen H by OpenSees................... 241

Figure 7.29 Monotonic Flexural Simulation of Specimen SC by OpenSees................. 242

Figure 7.30 Monotonic Flexural Simulation of Specimen LC by OpenSees ................ 242 
Figure 7.31 Effect of Steel Reinforcement on Hysteretic Response of Column Y ....... 243

Figure 7.32 Effect of $L / D_{o}$ Ratio on Hysteretic Response of Column Y ....................... 243

Figure 7.33 Effect of FRP Tube Thickness on Hysteretic Response of Column Y....... 244

Figure 7.34 Effect of Steel Reinforcement on Response Envelope of Column Y......... 244

Figure 7.35 Effect of $L / D_{o}$ Ratio on Response Envelope of Column Y ....................... 245

Figure 7.36 Effect of FRP Tube Thickness on Response Envelope of Column Y ........ 245

Figure 7.37 Effect of Steel Reinforcement on Normalized Cumulative Dissipated Energy

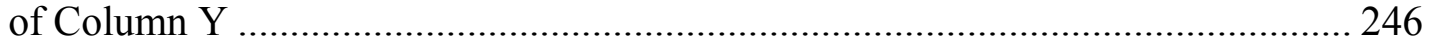

Figure 7.38 Effect of $L / D_{o}$ Ratio on Normalized Cumulative Dissipated Energy of Column Y 246

Figure 7.39 Effect of FRP Tube Thickness on Normalized Cumulative Dissipated Energy of Column Y 247

Figure 7.40 Effect of Steel Reinforcement on Hysteretic Response of Column G ........ 247

Figure 7.41 Effect of $L / D_{o}$ Ratio on Hysteretic Response of Column G...................... 248

Figure 7.42 Effect of FRP Tube Thickness on Hysteretic Response of Column G....... 248

Figure 7.43 Effect of Steel Reinforcement on Response Envelope of Column G......... 249

Figure 7.44 Effect of $L / D_{o}$ Ratio on Response Envelope of Column G ....................... 249

Figure 7.45 Effect of FRP Tube Thickness on Response Envelope of Column G........ 250

Figure 7.46 Effect of Steel Reinforcement on Normalized Cumulative Dissipated Energy

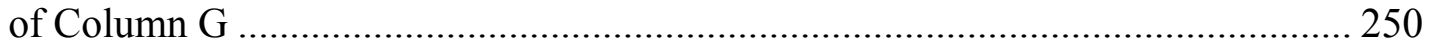

Figure 7.47 Effect of $L / D_{o}$ Ratio on Normalized Cumulative Dissipated Energy of Column G

Figure 7.48 Effect of FRP Tube Thickness on Normalized Cumulative Dissipated Energy of Column $\mathrm{G}$ 251

Figure 7.49 Effect of Steel Reinforcement on Hysteretic Response of Column H ....... 252

Figure 7.50 Effect of $L / D_{o}$ Ratio on Hysteretic Response of Column H...................... 252

Figure 7.51 Effect of FRP Tube Thickness on Hysteretic Response of Column H....... 253

Figure 7.52 Effect of Steel Reinforcement on Response Envelope of Column H......... 253

Figure 7.53 Effect of $L / D_{o}$ Ratio on Response Envelope of Column H ....................... 254

Figure 7.54 Effect of FRP Tube Thickness on Response Envelope of Column H........ 254

Figure 7.55 Effect of Steel Reinforcement on Normalized Cumulative Dissipated Energy of Column $\mathrm{H}$ 255

Figure 7.56 Effect of $L / D_{o}$ Ratio on Normalized Cumulative Dissipated Energy of Column $\mathrm{H}$ 255 
Figure 7.57 Effect of FRP Tube Thickness on Normalized Cumulative Dissipated Energy

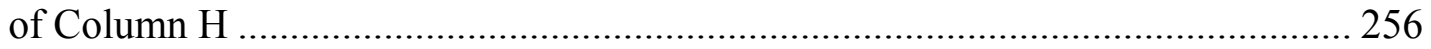

Figure 7.58 Effect of Steel Reinforcement on Hysteretic Response of Column C......... 256

Figure 7.59 Effect of $L / D_{o}$ Ratio on Hysteretic Response of Column C ........................ 257

Figure 7.60 Effect of FRP Tube Thickness on Hysteretic Response of Column C........ 257

Figure 7.61 Effect of Steel Reinforcement on Response Envelope of Column C.......... 258

Figure 7.62 Effect of $L / D_{o}$ Ratio on Response Envelope of Column C ......................... 258

Figure 7.63 Effect of FRP Tube Thickness on Response Envelope of Column C ......... 259

Figure 7.64 Effect of Steel Reinforcement on Normalized Cumulative Dissipated Energy

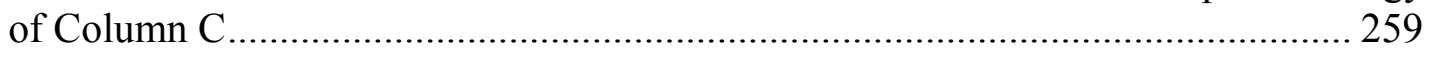

Figure 7.65 Effect of $L / D_{o}$ Ratio on Normalized Cumulative Dissipated Energy of Column C 260

Figure 7.66 Effect of FRP Tube Thickness on Normalized Cumulative Dissipated Energy

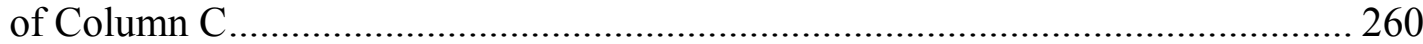

Figure 7.67 Effect of Steel Reinforcement Strength Index on Maximum Total Normalized

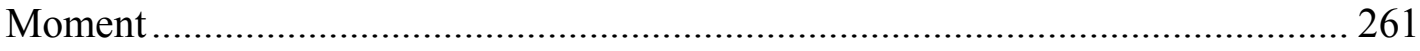

Figure 7.68 Effect of $L / D_{o}$ Ratio on Maximum Total Normalized Moment .................. 261

Figure 7.69 Effect of FRP Strength Index on Maximum Total Normalized Moment.... 262

Figure 7.70 Effect of Steel Reinforcement Strength Index on Maximum Drift Ratio ... 262

Figure 7.71 Effect of $L / D_{o}$ Ratio on Maximum Drift Ratio............................................. 263

Figure 7.72 Effect of FRP Strength Index on Maximum Drift Ratio ............................ 263

Figure 7.73 Effect of Steel Reinforcement Strength Index on Maximum Normalized Cumulative Dissipated Energy …………………………...................................... 264

Figure 7.74 Effect of $L / D_{o}$ Ratio on Maximum Normalized Cumulative Dissipated

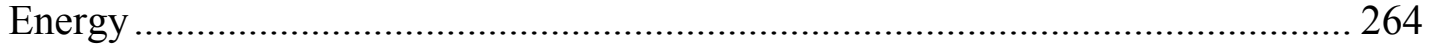

Figure 7.75 Effect of FRP Strength Index on Maximum Normalized Cumulative Dissipated Energy ……………………........................................................ 265

Figure 7.76 Effect of Total Reinforcement Index on Maximum Total Normalized Moment of Column Y ................................................................................... 265

Figure 7.77 Effect of Total Reinforcement Index on Maximum Total Normalized Moment of Column G.................................................................................. 266

Figure 7.78 Effect of Total Reinforcement Index on Maximum Total Normalized Moment of Column H....................................................................................... 266

Figure 7.79 Effect of Total Reinforcement Index on Maximum Total Normalized Moment of Column C ..................................................................................... 267 
Figure 7.80 Total Reinforcement Index versus Maximum Total Normalized Moment. 267

Figure 7.81 Tabas Earthquake Ground Acceleration Time History ............................ 268

Figure 7.82 Sylmar Earthquake Ground Acceleration Time History ........................... 268

Figure 7.83 Llollelo Earthquake Ground Acceleration Time History .......................... 269

Figure 7.84 Column Base Shear Force Response Time Histories of Columns Y and G for

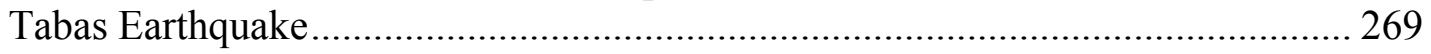

Figure 7.85 Column Base Shear Force Response Time Histories of Columns G and H for

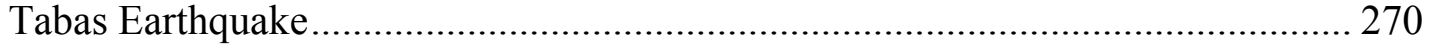

Figure 7.86 Column Base Shear Force Response Time Histories of Columns Y and C for Tabas Earthquake.................................................................................... 270

Figure 7.87 Column Base Shear Force Response Time Histories of All Columns for

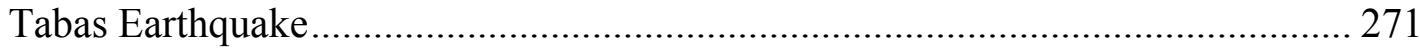

Figure 7.88 Column Displacement Response Time Histories of Columns Y and G for

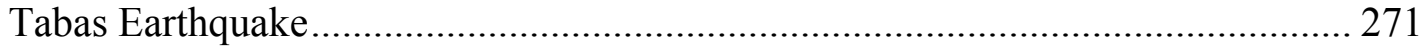

Figure 7.89 Column Displacement Response Time Histories of Columns $\mathrm{G}$ and $\mathrm{H}$ for

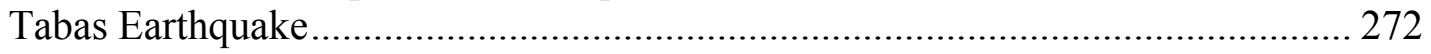

Figure 7.90 Column Displacement Response Time Histories of Columns Y and C for

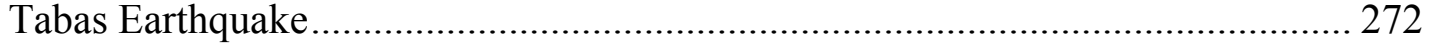

Figure 7.91 Column Displacement Response Time Histories of All Columns for Tabas Earthquake 273

Figure 7.92 Column Base Shear Force Response Time Histories of Columns Y and G for Sylmar Earthquake. 273

Figure 7.93 Column Base Shear Force Response Time Histories of Columns G, H, and C

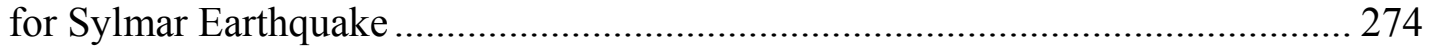

Figure 7.94 Column Base Shear Force Response Time Histories of All Columns for Sylmar Earthquake. 274

Figure 7.95 Column Displacement Response Time Histories of Columns Y and G for Sylmar Earthquake. 275

Figure 7.96 Column Displacement Response Time Histories of Columns G, H, and C for Sylmar Earthquake..... 275

Figure 7.97 Column Displacement Response Time Histories of All Columns for Sylmar Earthquake 276

Figure 7.98 Column Base Shear Force Response Time Histories of Columns Y and G for Llollelo Earthquake. 276

Figure 7.99 Column Base Shear Force Response Time Histories of Columns G and H for Llollelo Earthquake. 277 
Figure 7.100 Column Base Shear Force Response Time Histories of Columns Y and C for Llollelo Earthquake... 277

Figure 7.101 Column Base Shear Force Response Time Histories of All Columns for Llollelo Earthquake. 278

Figure 7.102 Column Displacement Response Time Histories of Columns Y and G for Llollelo Earthquake. 278

Figure 7.103 Column Displacement Response Time Histories of Columns G and H for Llollelo Earthquake. 279

Figure 7.104 Column Displacement Response Time Histories of Columns Y and C for Llollelo Earthquake. 279

Figure 7.105 Column Displacement Response Time Histories of All Columns for Llollelo Earthquake 280

Figure 7.106 Column Base Shear Force Response Time Histories of Column Y for All Earthquakes 280

Figure 7.107 Column Base Shear Force Response Time Histories of Column G for All Earthquakes 281

Figure 7.108 Column Base Shear Force Response Time Histories of Column H for All Earthquakes. 281

Figure 7.109 Column Base Shear Force Response Time Histories of Column C for All Earthquakes.................................................................................................. 282

Figure 7.110 Column Displacement Response Time Histories of Column Y for All Earthquakes.... 282

Figure 7.111 Column Displacement Response Time Histories of Column G for All Earthquakes. 283

Figure 7.112 Column Displacement Response Time Histories of Column $\mathrm{H}$ for All Earthquakes 283

Figure 7.113 Column Displacement Response Time Histories of Column C for All Earthquakes. 284 


\section{CHAPTER 1 INTRODUCTION}

\subsection{RESEARCH BACKGROUND}

Since their early use in defense industry in the 1940's, applications of fiber reinforced polymer (FRP) composites have been extended to other industries, including aerospace, marine, automobiles, electrical transmission, oil and gas, and most recently, civil infrastructure. Rehabilitation of existing bridges constitutes the largest usage of FRP in infrastructure, while concrete-filled FRP tube (CFFT) may be the most promising application of FRP in new bridge construction.

The concept of CFFT was in fact an extension of concrete-filled steel tube (CFST). The merits of CFST lie in the full section confinement for concrete core provided by the steel tube and that, in return, concrete core prevents buckling of the tube. This enhances stiffness, strength, ductility and stability of the system. However, high modulus of elasticity of steel may cause its premature buckling, since a large portion of axial loads is sustained by the tube. Moreover, due to a higher Poisson's ratio of steel relative to concrete at the early stages of loading, the initial separation of the two materials may delay the activation of confinement mechanism. Finally and most obviously, maintenance of steel tube against corrosion in harsh environments could be expensive (Mirmiran et al. 1997a).

These problems may be eliminated by replacing steel with FRP composites. CFFT features better corrosion resistance with higher strength-to-weight and stiffness-to-weight ratios than conventional reinforced concrete $(\mathrm{RC})$ columns. As a stay-in-place formwork and protective jacket for concrete, FRP tube helps speed up the construction, eliminates 
the installation and removal of traditional formwork, and reduces maintenance requirements for steel protection by extending the service life of the column. Moreover, FRP tube provides better confinement of concrete core, and enhances its ductility. In seismic regions, if designed properly, concrete core can remain contained within the tube throughout the ground shake, which is essential in surviving a large earthquake.

In recent years, the American Concrete Institute (ACI) Committee 440 has published design guidelines for internal FRP reinforcement (440.1R-06), externally bonded FRP reinforcement for strengthening (440.2R-08), prestressed FRP reinforcement (440.4R-04), and test methods for FRP products (440.3R-04). However, no guideline exists for structurally integrated stay-in-place FRP formwork. The principal reason lies in the limited experimental database in this field, which makes it difficult to develop design and construction guidelines and specifications for the proposed structural system.

\subsection{PROBLEM STATEMENT}

Significant advances have been made during the last decade in the field of CFFTs. However, there still remain several issues, among which, seismic performance of hybrid FRP-concrete columns deserves further consideration. Similar approach could be taken for blast and other man-made hazards.

Previous studies have demonstrated both feasibility and advantages of CFFT for seismic applications at the member level (Shao et al. 2005b) and the connection level (Zhu et al. 2006a). Despite better understanding of cyclic behavior of CFFTs, engineers may still hesitate in applying CFFTs for life safety purposes. Since FRP materials enhance design optimization through controlling of FRP laminate architecture, it may be 
questioned as to which FRP composite is the most appropriate for CFFTs in seismic prone regions. In particular, the following two issues must be addressed:

Issue 1: In choosing the proper fiber, some studies consider the fact that carbon FRP (CFRP) possesses a higher strength than glass FRP (GFRP), while others prefer GFRP for its better flexibility, which may translate into higher ductility. It has also been suggested that a hybrid lay-up with CFRP in the axial direction and GFRP in the hoop direction may combine the advantages of both materials. Thus, the question is which FRP lay-up provides the best seismic performance for CFFT columns.

Issue 2: Earlier beam-column static tests showed that it would be better to design FRP-concrete as an over-reinforced section for its lower deflection (Mirmiran et al. 2000b). However, recent cyclic tests at the member level (Shao et al. 2005b) indicate a brittle failure for over-reinforced members, and a ductile failure for under-reinforced members. More recent cyclic tests at the connection level (Zhu et al. 2006a) did not consider the issue of FRP reinforcement ratio or index. Hence, the question is what FRP reinforcement ratio or index provides the optimum performance for CFFT columns in seismic regions.

Shao and Mirmiran (2005) carried out four-point bending tests of six CFFT specimens as simple-span beam-columns under constant axial loading and pseudo-static reverse cyclic lateral loading. The tests focused on the cyclic behavior influenced by pure flexure and axial load in the critical section within the constant moment region. Zhu et al. (2006a) tested three CFFT and one RC cantilever columns under constant axial loading and pseudo-static reverse cyclic lateral loading. The tests revealed cyclic behavior at the column base under the influences of both shear and flexure. The shear span-to-depth 
ratios of the specimens for the above two test series were 3.3 and 7.5 , respectively. Hence, it is imperative to further compare the combined shear and moment effects on CFFTs with short and long shear spans, as identified in the following issue:

Issue 3: The question is how different CFFT columns perform with short and long shear spans under combined moment and shear effects.

Another major question for engineers is the concern about non-ductile shear failure of short CFFT bridge substructures. A recent study by Ahmad et al. (2008a) reported that even with a shear span-to-depth ratio of 0.9 , deep CFFT specimens would not fail in shear. Those specimens, however, were neither reinforced with mild steel nor were they equipped with end restraints that would arrest slippage of FRP tube. On the other hand, Fam and Cole (2007) reported shear failure in the form of diagonal tension in both FRP tube and concrete core when testing CFFT beams with steel reinforcement under three-point bending at a shear span-to-depth ratio of 1.0. This directs us to the following issue:

Issue 4: The question is how to design CFFT columns to avoid non-ductile shear failure.

Once the above four issues are addressed, it is indispensable for a direct comparison of the proposed system with conventional RC system at structural level, if the proposed system is going to be viable for bridge applications in earthquake-prone zones, and this relates to the following two issues:

Issue 5: Although CFFT pier frames have been tested by Zhu et al. (2004) under gravity loads, pushover or cyclic tests on such bents have never been carried out before. 
The design implications at the connections as well as the pier cap beam have not been addressed either.

Issue 6: To date, a holistic system-wide performance assessment of CFFT bridge substructure has not been done, except for an analytical simulation (Zhu et al. 2006c). Unless a shake table study on multi-span bridge with such substructure is made, systemwide performance under ground acceleration may not be as clear and convincing for bridge designers.

The first four issues will shape this dissertation, and the last two issues would be addressed by other members of the research team, who study FRP-concrete pier columns, FRP-concrete pier frames and shake table test ands on large-scale bridge model. This study is part of a multi-university research cooperation funded by National Science Foundation (NSF) Network for Earthquake Engineering Simulation Research (NEESR) program, which is led by University of Nevada at Reno, and includes Florida International University (FIU), University of California at Berkeley, University of California at San Diego, and Stanford University.

\subsection{RESEARCH OBJECTIVES}

To address the above stated issues, the following objectives are established for this proposed experimental and analytical study:

1) To compare seismic behavior of CFFT columns with different FRP lay-ups using glass and carbon fibers through large-scale cyclic tests;

2) To develop rational for optimization of FRP reinforcement ratio for seismic design of CFFT columns; 
3) To compare seismic behavior of CFFT columns with short and long shear spans under combined moment and shear effects; and

4) To compare the flexural and shear behavior of CFFT columns with conventional RC columns.

\subsection{RESEARCH APPORACHES}

\subsubsection{Experimental Studies}

The substructure prototypes of a highway bridge were $1 / 4$ scaled down as cantilever CFFT columns with two different shear spans. Four different types of FRP tubes were used as the stay-in-place structural formwork for the beam-column specimens. A reinforced concrete $(\mathrm{RC})$ control specimen was also considered as a reference. Cyclic tests were carried out first to evaluate seismic performance of CFFT and RC specimens at column base with different FRP architecture and shear spans. Monotonic flexural tests of these same specimens were further conducted in three or four-point bending to investigate the shear and flexural behavior of the proposed system. Tensile coupon tests were also performed on FRP laminates to obtain their material properties.

Performance measures included: strength, energy dissipation, initial stiffness, ductility, pinching, plastic hinge length and residual deflection. Shear span-to-depth ratios of the follow-up monotonic tests were maintained between 1.0 to 1.6 for short beams and about 2.5 for the long beam.

Between the two sets of cyclic and monotonic flexural tests, all tested specimens were also evaluated using an ultrasonic pulse velocity system to assess the state of internal concrete core. 


\subsubsection{Analytical Studies}

Analytical tools for hysteretic modeling of CFFT columns were developed to trace the push-over and hysteretic moment-curvature and load-deflection of a cantilever CFFT or RC column subjected to a constant axial loading and a reverse cyclic lateral loading. Analysis included ANSYS, a general purpose finite element program, and OpenSees (Open System for Earthquake Engineering Simulation); the latter has been developed by UC Berkeley. The results from these two analytical methods were compared.

After the analytical models were validated against test data, a comprehensive parametric study was carried out for FRP reinforcement index of different FRP laminate architectures, shear span-to-depth ratio, and reinforcement index of both mild and microcomposite multistructural formable (MMFX) steel, in order to develop rational for an optimized total reinforcement index (FRP and Steel). The responses of typical CFFT columns to three representative earthquake records are also investigated.

\subsection{DISSERTATION STRUCTURE}

This dissertation consists of eight chapters. Chapter 1, this chapter, discusses research background, problem statement, research objectives, research approaches and structure of the dissertation. A synthesized literature review of CFFT members under axial compression, axial-flexural and cyclic loading, with an overview of CFFT, is presented in Chapter 2. Chapters 3 and 4 describe cyclic and monotonic flexural tests, respectively, while Chapters 5 and 6 introduce the coupon tests and nondestructive damage evaluation, respectively. Chapter 7 depicts analytical modeling, parametric study 
and transient analysis. Finally, Chapter 8 provides a summary and conclusion for the entire research and recommendations for future work in this field. 


\section{CHAPTER 2 LITERATURE REVIEW}

\subsection{OVERVIEW OF CFFT}

Concrete-filled fiber reinforced polymer (FRP) tubes (CFFTs) were initially proposed as alternative to conventional reinforced concrete (RC) bridge substructure in corrosive environments of Florida (Mirmiran and Shahawy 1995). Systematic studies have since demonstrated the feasibility and merits of CFFTs with or without internal mild steel reinforcement. Behavior of CFFTs has been investigated under different loading conditions; including uniaxial compression (Mirmiran et al. 1997a, Fam et al. 2001a), axial-flexural (Mirmiran et al. 1999a, 2000b; Fam et al. 2002), deep beam shear (Ahmad et al. 2008a), reverse cyclic (Shao et al. 2005b, Zhu et al. 2006a) and fatigue loading (Ahmad et al. 2008b, Helmi et al. 2006, 2008), as well as long-term creep and shrinkage (Naguib et al. 2002), transient loading of impact (Zheng 2007), and other conditions such as freeze and thaw (Fam et al. 2008a).

Variety of parameters have been considered for CFFTs, in terms of internal steel or FRP reinforcement ratio (or index), internal FRP or steel tubes, partial filling of concrete, fiber architecture, shear span, slenderness ratio, shape and bond effect, level of axial load, prestressing (or lack thereof), concrete compressive strength, and type of connection (Cole et al. 2006; Fam et al. 2001a, 2001b, 2002, 2003b, 2007; Mandal et al. 2005, 2006; Mirmiran et al. 1998b, 1999a, 2000b, 2001a; Shao et al. 2005a, 2005b; Zhu et al. 2005, 2006a, 2006b). Field experiments and applications of CFFTs as bridge girders (Seible et al. 1999), and piers and piles (Fam et al. 2003, Mirmiran and Shahawy 2003) have also established their construction feasibility quite convincingly. Limited studies on 
acoustic emission (Mirmiran et al. 1999b, 2000c) and ultrasonic pulse velocity (Mirmiran et al. 2001b) for damage assessment have confirmed their potential for structural health monitoring of CFFT columns.

\subsection{AXIAL COMPRESSION BEHAVIOR OF CFFT}

The load-carrying mechanism of CFFT is not much different from a spirally reinforced concrete column or a CFST. As axial deformation increases, concrete tends to dilate laterally and presses onto its confining device. Subsequently, the confining device restrains the expansion of concrete core, thereby delaying its cracking and eventual failure. While the lateral confining system remains in hoop tension, concrete core undergoes a triaxial-state of stress, which is known to increase its strength and ductility. The eventual failure is generally triggered by rupture of the confining device, especially in continuous sleeves such as those in CFFT and CFST. However, confining pressure in CFFT is variable, and is a function of the interaction between the expanding concrete core and the FRP tube with its linear characteristics (i.e., passive confinement), which is different from steel-confined concrete, where the confining pressure is stable once the steel yields (Mirmiran et al. 1997b).

Earlier studies of CFFT were initially directed to developing a new confinement

model from uniaxial compression tests of FRP-encased concrete cylinders, finding that available confinement models for conventional reinforced concrete columns overestimate the strength of FRP-encased concrete, mainly because they ignore the stiffness of the restraining mechanism (Mirmiran et al. 1997a, 1997b; Samaan et al. 1998). The new 
models were then expanded to consider the shape, length and bond effects (Mirmiran et al. 1998b).

Studies on uniaxial compression behavior of CFFT were extended by Fam et al. New parameters were introduced for central holes with or without an inner GFRP tube, laminate structure and interface roughness to simulate practical applications and loading conditions (Fam et al. 2001a). A parametric study indicated that increasing the central hole size would reduce the confinement effect, while increasing the stiffness of the tube would improve the confinement, and finally, direct loading of the FRP tube would significantly reduce the confinement (Fam et al. 2001b).

For FRP tubes to be utilized as piles driven under impact loading, potential instability and dynamic buckling may pose serious problems. Hence, filament-wound Eglass fiber tubes were tested in uniaxial compression to study their slenderness limit. A new equation was proposed for the slenderness limit of hybrid columns based on a maximum of 5\% strength reduction (Mirmiran et al. 2001a). Armed with the acquired knowledge, field experiments on the performance of composite tubes under pile driving impact were conducted, which proved feasibility of the system for bridge substructure (Mirmiran et al. 2002). Field application of CFFT as bridge piles was then reported as precast piles for Route 40 Bridge in Virginia (Fam et al. 2003a).

Zhu et al. (2005) continued axial compression studies on CFFT including the effect of size, end load-bearing conditions, and internal steel or FRP reinforcement of CFFT columns. Meanwhile, Mandal et al. (2005) studied influence of concrete strength on confinement effectiveness for both concrete-filled FRP tubes and FRP-wrapped 
concrete cylinders. For high strength concrete, it was reported that enhancement in strength is very limited, with hardly any improvement in ductility.

Fewer studies were conducted for rectangular CFFT axial compression members than for circular CFFT columns because of less effective confinement, apart from an early research (Mirmiran et al. 1998b). Most recently, however, Ozbakkaloglu et al. (2008a) reported experimental studies on the influence of critical confinement parameters on the confinement effectiveness of square and rectangular FRP tubes. Moreover, a new type of rectangular FRP tube with internal FRP cross-ties or with internal FRP panel was reported to improve the inherently low confinement effectiveness of rectangular tubes (Ozbakkaloglu et al. 2008b).

\subsection{CONSTITUTIVE MODELING OF CFFT}

Different analytical models have been developed to predict the stress-strain response of confined concrete using FRP tubes. Some models are based on dilation relationship of confined concrete (Samaan et al. 1998, Davol et al. 2001), modified Ahmad and Shah's model (Saafi et al. 1999) or modified Mander's model (Mander et al. 1988) using different relationships between lateral and axial strains (Spoelstra et al. 1999, Fam et al. 2001b). Naguib et al. (2002) showed the significance of strain rate on the level of confinement, which could potentially affect the comparison of various confinement tests. Several researchers have used plasticity models such as Drucker-Prager in finite element analysis to predict the behavior of FRP-confined concrete (Mirmiran et al. 2000a). Published comparative studies and surveys of some of the confinement models can be found in Lam et al. (2002), De Lorenzis et al. (2003), and Teng et al. (2004). 


\subsection{AXIAL-FLEXURAL BEHAVIOR OF CFFT}

Mirmiran et al. (1997-2002) investigated the static beam-column behavior for both short and slender columns with custom-made interior shear ribs to reduce the slippage between the tube and the core. Strength enhancement was confirmed, and the failure of CFFT was noted as ductile with much advance warning (Mirmiran et al. 1998a, 1999a). Investigations were then turned to off-the-shelf products considering the costeffectiveness issue, still without conventional reinforcement inside the tubes. Mirmiran et al. (2000b) showed the feasibility of CFFT as an alternative to prestressed concrete. The detailed failure modes of specimens from the latter two studies are discussed below.

Mirmiran et al. (1999a) tested a total of five $178 \times 178 \times 1,320 \mathrm{~mm}(7 \times 7 \times 52 \mathrm{in}$. $)$ rectangular specimens at various combinations of axial and transverse loads to develop a full moment-thrust interaction diagram for hybrid FRP-concrete columns. Specimen B with pure bending developed a major tension crack of FRP tube at peak load. Specimens $\mathrm{BC} 1$ and $\mathrm{BC} 2$ with axial loads developed tension cracks at about $75 \%$ and $85 \%$ of the peak lateral loads, respectively. The cracks gradually increased in intensity and depth, resulting in a tension and compression failure, respectively. Specimen BC3 with the highest axial load failed in compression as the tube cracked at about $90 \%$ of the peak lateral load.

Mirmiran et al. (2000b) performed beam-column tests on a total of sixteen $2.75 \mathrm{~m}$ (108 in.) long specimens demonstrating the feasibility of off-the-shelf FRP products. Type I specimens as over-reinforced members failed in compression with crumpling and wrinkling of the tube near the mid-span region, and in some cases, longitudinal split rupture of the tube near the support. Type II specimens as under-reinforced members 
generally failed by tube fracture along its main winding angle. At lower levels of axial load, failure of Type II specimens was generally controlled by tension, while under larger axial loads, concrete crushed in compression.

Other studies were conducted by Davol et al. (2001), including four-point bending tests of two large-scale carbon FRP shells with $343 \mathrm{~mm}$ (13.5 in.) inside diameter filled with concrete without any axial load. Both specimens failed in local buckling on the compression side of the CFRP shell.

Pure flexural and axial-flexural loading tests have also been conducted by Fam et al. (2002-2008). Experimental evidence indicated an insignificant effect of concrete confinement on flexural strength; however, ductility was improved (Fam et al. 2002). Later research findings showed that the interaction diagrams were significantly affected by both the laminate structure and reinforcement ratio of the FRP tube. The contribution of confinement to the overall axial strength of CFFT seemed to be significant only for thin-walled tubes (Fam et al. 2003b). Following the studies on circular concrete-filled FRP tubes, the behavior of rectangular filament-wound GFRP tubes was explored (Fam et al. 2005a, 2005b). The detailed failure modes of specimens from the two studies by Fam and his co-workers are discussed below.

A total of twenty beams were tested in four-point bending by Fam et al. (2002). The hollow filament-wound GFRP tube, beam 2(a), failed by crushing of the tube in compression near the loading point after considerable ovalization, while the concretefilled tube, beam 2(b), failed by tensile rupture of the fibers. The hollow pultruded tube, beam 3(a), failed by local crushing and lateral splitting of the tube at the loading point, while the concrete-filled tube, beam 3(b), failed in horizontal shear by splitting of the 
tube due to the lack of strength in the hoop direction. Beams $4-8$ as well as beams 10(I and II) also failure by tensile rupture of the fibers. Beam 9 is the only one that had compression failure of the tube by cracking of the matrix and buckling of fibers due to the absence of fibers in the hoop direction to confine the main fibers oriented at $\pm 30^{\circ}$. Beams 11(I and II)-13(I and II) all failed by tensile rupture of the fibers in the $\pm 34^{\circ}$ direction.

Test results of concrete-filled FRP tubes subjected to combined axial compressive loads and bending moments were reported by Fam et al. (2003b). The experimental program included ten specimens subjected to eccentric axial loads, two (2) specimens under concentric axial loads, and two (2) others in pure bending. Specimens B1-I and B1II failed by rupture of the fibers on the tension side within the constant moment region in a similar fashion to the eccentrically loaded columns that failed in tension. Specimens BC1-I, BC2-I, BC3-I, BC1-II, and BC2-II all failed in tension by rupture of the fibers, similar to Specimens B1-I and B1-II; while Specimens BC5-I, BC3-II, BC4-II, and BC5II failed in compression by crushing of the fibers on the compression side. Specimen BC4-I had a balanced failure including rupture of fibers on the tension side, almost simultaneously with crushing of the fibers on the compression side.

None of the above studies included conventional mild steel reinforcement in CFFT, until recent studies on cyclic behavior of CFFT showed moderate amount of mild steel reinforcement in CFFT would significantly improve ductility (Shao et al. 2005b).

Recently, the effects of shear span length and internal reinforcement on strength of rectangular and circular CFFT beams were investigated (Cole et al. 2006, Fam et al. 2007). Fam et al. also studied prestressed CFFT beams (2006). Most recently, a spun-cast 
manufacturing method for CFFT was introduced (Fam et al. 2008b), as discussed further below.

Cole et al. (2006) reported flexural tests of seven specimens reinforced with either steel, GFRP, or CFRP rebars of various sizes. It was shown that beams with mild steel rebars were quite superior to those with FRP rebars, which lacked ductility. In FRPreinforced CFFTs, FRP rebars failed almost simultaneously with the FRP tube. It was also shown that laminate structure of the tube affected the behavior, only after yielding of the steel bars. Steel reinforcement ratio significantly affected stiffness and strength of the specimens, whereas concrete compressive strength had an insignificant effect on the overall performance.

Fam et al. (2007) studied bending and shear behavior of GFRP tubes versus conventional steel spiral reinforcement in CFFTs. In particular, two of the specimens were prestressed. It was reported that unlike spiral reinforcement, GFRP tubes confined larger concrete areas, and also contributed as longitudinal reinforcement, leading to increases in flexural and shear strengths, by up to $113 \%$ and $69 \%$, respectively. Furthermore, a unique observation that had not been reported in the literature before for concrete-filled FRP tubes was that one of the specimens had a shear-bond failure through diagonal tension. The shear failure took place through both the concrete core and GFRP tube.

Most recently, a new type of hybrid FRP-concrete-steel member was proposed consisting of an inner steel tube, an outer FRP tube, and a concrete infill between the two tubes (Teng et al. 2007). A series of four-point bending tests were conducted on specimens with a hybrid section in which the inner steel tube was shifted towards the 
tension side to demonstrate the application of the hybrid section in a beam. These beams were found to show a very ductile behavior. The results also showed that the GFRP tube in such beams enhances the structural behavior by providing both confinements to the concrete infill and additional shear resistance. However, significant slippage between the concrete infill and the two tubes, particularly the steel tube, and associated load fluctuations were also reported (Yu et al. 2006).

\subsection{CYCLIC BEHAVIOR OF CFFT}

Seible et al. (1996) were the first to explore the cyclic behavior of CFFT with or without internal mild steel starter bars, and with or without embedment in the footing. They concluded that FRP alone would not be feasible for use in seismic regions, and that internal steel reinforcement would be necessary to develop plastic hinge in a column or pile.

In China, Fan et al. (2000) and Zhuo et al. (2001) studied the seismic performance of RC columns confined by glass or carbon FRP tubes (GFRP or CFRP) as cantilever columns under both pseudo-static cyclic loading and shake table ground motion. Test results indicated that the FRP tube did not increase column strength, but greatly enhanced its hysteretic response up to a displacement ductility of 10. Taking advantage of the offaxis behavior of FRP, Yuan et al. (2002) proposed concrete-filled GFRP tube with $\pm 45^{\circ}$ fiber orientation and without any internal steel reinforcement. They reported that the FRP tube enhanced the strength of concrete by 2.5 times. Coupon tests of FRP tube itself also indicated a bilinear response with a distinct yield point. In Japan, Yamakawa et al. (2001) 
reported similar observations on the seismic performance of square RC columns that were confined with aramid FRP (AFRP) tubes.

In the US, Shao et al. (2005b) conducted cyclic tests on six CFFT specimens as simple-span beam-columns under constant axial loading and quasi-static reverse lateral loading in four-point bending. Three of the tubes were made using centrifuge (spin) casting with $12.7 \mathrm{~mm}(0.5 \mathrm{in}$.) thickness and the majority of the fibers in the longitudinal direction, whereas the other three were filament wound with $5 \mathrm{~mm}(0.2$ in.) thickness and $\pm 55^{\circ}$ fiber orientation. One specimen for each type of tube had no internal reinforcement, whereas the other two incorporated approximately $1.7 \%$ and $2.5 \%$ steel reinforcement ratios, respectively. The two types of tubes represented two different failure modes; a brittle compression failure for the thick tubes with the majority of the fibers in the longitudinal direction, and a ductile tension failure for the thin tubes with off-axis fibers. The study showed that CFFT could be designed with ductility behavior comparable to that of RC members. Significant ductility could stem from the fiber architecture and inter-laminar shear in the FRP tube. Moderate amount of internal steel reinforcement in the range of $1-2 \%$ would further improve the cyclic behavior of CFFT, especially in specimens with under-reinforced tubes.

In addition to the six beam-column tests, a total of 24 FRP-confined concrete stub specimens were tested in uniaxial compression under different levels of loading and unloading, with different fiber type, wrap thickness, and loading patterns. Based on a regression analysis of test results, a constitutive model was developed that included cyclic rules for loading and unloading, plastic strains, and stiffness and strength degradations (Shao et al. 2006). 
Shao et al. (2004 and 2005a) developed a two-dimensional three-noded combined element along with constitutive models for cyclic loading of FRP and concrete. A study was carried out to evaluate the effect of CFFT parameters on its hysteretic response, and to compare the response with reinforced concrete (RC) and concrete-filled steel tubes (CFST). The study showed the feasibility of designing CFFT columns with comparable hysteretic performance to RC columns. However, hysteretic response of CFFT columns could not measure up to their CFST counterparts, unless their superior durability was considered in the selection process (Shao et al. 2004, 2005a).

Most recently, Zhu et al. (2006a) investigated construction feasibility and seismic performance of structural joints for CFFT as bridge substructure. Based on the common practices of the precast industry and previous research on CFFT, the test matrix included a control RC column and three CFFT columns made of the same concrete and FRP tube including a cast-in-place CFFT column with embedded starter bars, a precast CFFT column with grouted starter bars, and a precast CFFT column with unbonded posttensioned rods. All proposed joints proved feasible in construction, and showed robust performance under cyclic loading. The CFFT columns, with FRP tube secured properly in the footing, exhibited significant improvement over traditional RC columns in terms of both ultimate strength and ductility.

Modeling of CFFT either as cast-in-place reinforced or precast post-tensioned column was carried out by Zhu et al. (2006b), who verified both cyclic tests by Shao et al. (2005b) and Zhu et al. (2006a). Moreover, seismic performances of CFFT versus RC columns were compared under three different ground acceleration records. The study showed that internal steel reinforcement and a minimum thickness of FRP tube were 
necessary to provide adequate ductility and system integrity in seismic applications. A bridge case study was also conducted to simulate the holistic behavior of the proposed system. They showed that since FRP had a lower rupture strain than steel spiral and because of its linear elastic response, CFFT section showed less ductility than RC section. However, at the member level, CFFT column distinctly outperformed its RC counterpart with almost twice the base shear capacity and over three times the lateral drift capacity. Earthquake simulation showed that CFFT substructure suffered moderate damage, while maintaining structural integrity, as compared to the RC substructure with severe and irreparable damages (Zhu et al. 2006c).

Ozbakkaloglu et al. $(2006,2007)$ investigated seismic behavior of circular and square columns with either high-strength concrete (HSC) or normal-strength concrete (NSC) confined by FRP tubes. The results indicated that inelastic deformability of HSC and NSC columns could be improved significantly by using FRP tubes, beyond the performance level usually expected of comparable columns confined with conventional steel reinforcement. The results further indicated that the confinement effectiveness of square columns was significantly affected by the corner radius of the tubes. Additionally, the confinement efficiency could be improved with the use of FRP cross-ties introduced in the study.

The present study extends the earlier work in several areas, including (a) effect of fiber type and architecture on seismic behavior of CFFT, (b) optimization of FRP tube, (c) effect of shear span on seismic response of CFFT, and (d) combined effect of shear and flexural loading on the cyclic response of CFFT. 


\section{CHAPTER 3 CYCLIC TEST}

\subsection{TEST MATRIX AND SPECIMEN PREPARATION}

\subsubsection{Test Matrix}

Test matrix included one control RC and five CFFT columns with different FRP tubes as stay-in-place structural formwork, as shown in Table 3.1. Except for the long column with CFRP tube (Specimen LC) that had a 2,210 mm (87 in.) length, all other specimens had the same length of $1,295 \mathrm{~mm}$ (51 in.). The specimens were cast in two batches with 28-day concrete compressive strengths of 44.8 and $33.1 \mathrm{MPa}$ (6.5 and 4.8 ksi), as shown in Table 3.1.

\subsubsection{Specimen Preparation}

\subsubsection{Preparation of FRP Tubes}

The formwork for Specimen RC was a $310 \mathrm{~mm}$ (12.2 in.) diameter sonotube, while CFFT columns used FRP tubes as the stay-in-place structural formwork. Specimen Y had an off-the-shelf FRP tube made by filament winding of 17 layers of $\pm 55^{\circ}$ E-glass fibers and epoxy resin, with an inside diameter of $312 \mathrm{~mm}$ (12.3 in.) and a wall thickness of $6 \mathrm{~mm}$ (0.22 in.). Figure 3.1 shows the filament-wound FRP tube for Specimen Y and the sonotubes.

The other four FRP tubes were made in the laboratory by wrapping resinimpregnated FRP fabrics around sonotubes of the same diameter as that used for Specimen RC. Sikadur 300 epoxy made by Sika Corporation of Lyndhurst, NJ, was used as the resin for all FRP tubes made in the lab. The sonotubes were first cut longitudinally 
and were then taped back tightly to make a stiff formwork for FRP wrapping, while allowing easy removal of the sonotubes after curing of FRP tube. The sonotube was then covered with a layer of wax paper, so that the FRP tubes could be easily detached from the sonotubes later. Figure 3.2 illustrates the preparation of one carbon FRP tube.

Specimen G was made of three layers of bi-directional $\left(0^{\circ} / 90^{\circ}\right)$ GFRP sheets, while Specimens SC and LC were both made of two layers of bi-directional $\left(0^{\circ} / 90^{\circ}\right)$ CFRP sheets. The bi-directional glass and carbon fabrics were P3W-GE041 and P3WC1059, respectively, from 3TEX, Inc. of Cary, NC. Specimen H was made of two layers of unidirectional CFRP sheets in the longitudinal direction alternately wrapped with three layers of unidirectional GFRP sheets in the hoop direction. The unidirectional carbon and glass fiber sheets were SikaWrap Hex 103C and SikaWrap Hex 100G, respectively, made by Sika Corp. The four laboratory-made FRP tubes consisted of $152 \mathrm{~mm}$ (6 in.) overlaps of fabrics in the hoop direction and $305 \mathrm{~mm}$ (12 in.) overlap in the longitudinal direction. Table 3.2 lists the properties of FRP tubes from manufacturer data for Specimen Y, or from coupon tests following ASTM D 3039 (2006) for other specimens, as will be discussed in Chapter 5. Figure 3.3 (a) through (c) show the cured FRP tubes.

\subsubsection{Specimen Reinforcement}

All six columns had the same longitudinal mild steel reinforcement of sixteen 9.5 mm (No. 3) steel bars of Grade $414 \mathrm{MPa}$ along their entire lengths, with $610 \mathrm{~mm}$ (24 in.) and $305 \mathrm{~mm}$ (12 in.) embedment into the footing and column head, respectively. The reinforcement ratio was $1.5 \%$ for Specimen RC, $1.4 \%$ for Specimens Y, SC and LC, and $1.3 \%$ for Specimens G and H. Specimen RC also included a $5.3 \mathrm{~mm}(0.21$ in.) diameter 
steel wire spiral reinforcement of Grade $414 \mathrm{MPa}$ with $279 \mathrm{~mm}$ (11 in.) outside diameter at a pitch of $32 \mathrm{~mm}$ (1.25 in.). The CFFT specimens had no transverse steel reinforcement, except for very few hoops of $5.3 \mathrm{~mm}$ diameter steel wires placed with an outside diameter of $279 \mathrm{~mm}$ (11 in.) and a spacing of $305 \mathrm{~mm}$ (12 in.) only to hold the longitudinal steel cage together during casting of concrete. A clear cover of $12.7 \mathrm{~mm}(0.5$ in.) was maintained for steel bars in all specimens. Figure 3.4 shows the column reinforcement of Specimen RC embedded into the footing. Figure 3.5 shows the column reinforcement for Specimen LC. Figure 3.6 shows the reinforcement details for the RC and CFFT columns.

\subsubsection{Column-Footing and Column-Head Connections}

The footings of all six specimens had the same dimensions and internal steel reinforcement. Similarly, the column heads of all six specimens had the same dimensions and internal reinforcement. The FRP tubes were all embedded $305 \mathrm{~mm}$ (12 in.) and 152 mm (6 in.), or approximately $1 D_{o}$ and $0.5 D_{o}$, respectively, into the footings and column heads, where $D_{o}$ is the outside diameter of the FRP tubes. A few small holes and slots were cut out from the embedded portions of FRP tubes to facilitate the reinforcement and PVC ducts in the footings and column heads. Figure 3.7 shows the embedment of FRP tube and column reinforcement into the footing of Specimen Y. Figure 3.8 shows the overall embedment into the heads and footings of Specimens $\mathrm{Y}, \mathrm{G}$ and RC for the first concrete batch. 


\subsubsection{Formwork and Concrete Casting}

Reinforcement and formwork for footings and column heads followed a horizontal testing plan. Figure 3.9 shows the formworks for Specimens SC and H. A pedestal was designed to accommodate the height of the reaction frame with the actuator, and to also span over the tie-down pattern in the strong floor. To facilitate application of axial loads on the columns, PVC ducts with $44 \mathrm{~mm}$ (1.75 in.) outside diameter were embedded into the footings and column heads on each side of the columns. PVC ducts were also placed at tie-down locations in the footings and the column heads. Special templates were developed to ensure that the holes set in the footings would fit the tiedown pattern of the strong floor, and that the holes in the column heads would fit the actuator. Figure 3.10 shows the template and the formwork for Specimen LC.

In light of the horizontal testing configuration, the ready-mix concrete was ordered with a slump of $254 \mathrm{~mm}$ (10 in.), equivalent of a pump mix, to ensure proper placement of concrete throughout the length of the columns. Concrete was cast in two batches on August 18, 2006 and September 1, 2006. Both batches had good workability. As stated earlier, the 28-day compressive strengths for the two batches were measured as 44.8 $\mathrm{MPa}(6.5 \mathrm{ksi})$ and $33.1 \mathrm{MPa}(4.8 \mathrm{ksi})$, respectively, while the target strength for the two batches was $34.5 \mathrm{MPa}(5 \mathrm{ksi})$. Figure 3.11 shows the casting of concrete. After casting concrete, the specimens were covered by plastic sheets, and were cured by watering each day for seven days in the normal room temperature at $21^{\circ} \mathrm{C}\left(70^{\circ} \mathrm{F}\right)$. Figure 3.12 shows Specimens $\mathrm{H}$ and SC right after concrete casting. De-molding of the specimens took place after one week from casting of concrete. Figure 3.13 shows the five 
short column specimens after de-molding, while Figure 3.14 shows Specimen LC and the pedestal after de-molding.

\subsubsection{Epoxy Injection}

After removal of the sonotube from Specimen RC, some pockets of concrete void between the sonotube and the top of RC section were observed (Figure 3.15), which were deemed of no significance for RC column. This was a result of horizontal casting plan. Using a coin tapping procedure, it was verified that similar pockets of voids existed between FRP tubes and the top of concrete section in the CFFT columns. This was expected to potentially affect structural integrity of CFFT and cause local buckling of the tubes. Therefore, epoxy injection was used for the CFFT columns, as described below.

The process of epoxy injection in this project followed a standard industry practice of epoxy injection for concrete repair. Sikadur 35 (Hi-Mod LV LPL) from Sika Corporation was used as the epoxy resin. Table 3.3 lists the mechanical properties of Sikadur 35, the injection epoxy, as well as Sikadur 300, the resin for the laboratory-made FRP tubes. Other major components included ports (Figure 3.16), caps, a nozzle and a caulking gun. First, a series of $3 \mathrm{~mm}$ (1/8 in.) diameter holes were drilled on top of CFFT sections at $152 \mathrm{~mm}$ (6 in.) spacing along the column length. Then, the ports were mounted and sealed onto the holes (Figure 3.17). The epoxy was then injected into the CFFT columns through the ports one by one from one end to the other. The process of moving forward was to seal the injecting port with a cap and continue onward to the next uncapped port as long as epoxy flew out of the next uncapped port. The ports were knocked off after three days to allow for curing of epoxy. Figure 3.18 shows the epoxy 
injection process and Figure 3.19 shows one of the specimens after epoxy injection with the ports capped.

\subsection{TEST SETUP AND INSTRUMENTATION}

\subsubsection{Test Setup}

Each specimen was placed on top of the pedestal, through which its footing was tied down to the strong floor using eight threaded rods. Another four threaded rods tied the footing with the pedestal in the middle. All threaded rods were hand-tightened to a tie-down force of about $44.5 \mathrm{kN}$ (10 kips), as measured by a load cell. A 1,045 kN (235 kips) capacity hydraulic actuator hung from a steel reaction frame was attached to the specimen using four threaded rods through the column head.

To simulate the gravity load on the columns, the specimens were externally posttensioned to $89 \mathrm{kN}$ (20 kips), corresponding to approximately $0.03 f_{c}{ }^{\prime} A_{g}$, where $f_{c}$ ' is the unconfined compressive strength of concrete core, and $A_{g}$ is the gross cross sectional area of the column. Using two $25.4 \mathrm{~mm}$ (1 in.) threaded rods through the column head and the footing, post-tensioning was carried out with two inter-connected hydraulic jacks controlled by a single hand pump. The axial load was maintained during the testing using a pressure relief valve. All threaded rods were $25.4 \mathrm{~mm}$ (1 in.) diameter Grade B-7 with yield strength of $724 \mathrm{MPa}(105 \mathrm{ksi})$. Figure 3.20 through Figure 3.25 show the test set-up for the six specimens. Figure 3.26 shows the post-tensioning of the specimens to simulate axial force. 


\subsubsection{Instrumentation}

Each specimen was instrumented with six string potentiometers, four linear potentiometers, four $\Omega$ gauges, twelve strain gauges and two load cells. In addition, load and displacement output from the actuator controller was monitored using a high-speed data acquisition system, for a total of 30 simultaneous readings at a frequency of $1 \mathrm{~Hz}$.

Two $305 \mathrm{~mm}$ (12 in.) range string potentiometers were attached to the bottom and the west side of the column head to monitor its displacements. Three $152 \mathrm{~mm}$ (6 in.) string potentiometers were placed at quarter points along the column to measure deflections relative to mid-height of the section on its west side. One additional string pot was set at quarter span on the east side of the section near column head to compare the displacements of the two sides, and to detect any potential to regional deformation.

Slippage of FRP tube from column footing and column head at both top and bottom of the section were monitored using four $38 \mathrm{~mm}$ (1.5 in.) range potentiometers. Each column was also instrumented with two pairs of $50 \mathrm{~mm}$ ( 2 in.) $\Omega$ gauges mounted at the column base as well as at the first quarter point from the footing along the column on both top and bottom in the loading plane to measure strain profiles at different sections. The CFFT columns were additionally instrumented with twelve $20 \mathrm{~mm}(0.79 \mathrm{in}$.) long surface mounted strain gauges (PFL-30-11-5L of Tokyo Sokki Kenkyujo Co., Ltd.); three pairs at quarter spans on both top and bottom surfaces of the column in the loading plane, and two pairs within the first quarter span of the column near the footing. Two additional strain gauges were attached in the hoop direction on opposite sides of the column next to the footing in the loading plane. 
One load cell was placed in line with each of the two hydraulic jacks to monitor any fluctuation in axial load during the test. After it was verified that the axial forces in the two jacks were quite similar and stable in subsequent tests, one of the two load cells was placed in line with one of the anchoring rods to monitor the tie-down forces for Specimens SC and H, for safety reasons. Figure 3.27 (a) and (b) show the instrumentation plans for short specimens and the long specimen, respectively, with the legend and instrumentation list shown in Figure 3.28.

\subsection{TEST PROCEDURE AND OBSERVATIONS}

\subsubsection{Test Procedure}

Each specimen was first subjected to the external post-tensioning force to simulate the dead load on the structure. Subsequently, a reverse cyclic load was applied in displacement control in a number of incremental steps. Column drift was applied in terms of displacement ductility $\mu$, defined as the ratio of the imposed displacement to a reference displacement. The reference displacement corresponded to the first yielding of the internal steel reinforcement in the control RC column, which was calculated to be $12.7 \mathrm{~mm}(0.5 \mathrm{in}$.$) for the short specimens and 25.4 \mathrm{~mm}(1 \mathrm{in}$.) for the long specimen, based on a nonlinear sectional analysis using Response-2000 (http://www.ecf.utoronto.ca/ bentz/home.shtml) and a member-level push-over simulation using OpenSees 2.0 (http://opensees.berkeley.edu/).

At each level of ductility, two full cycles of reverse lateral loading were applied. The loading rate was kept constant at $0.2 \mathrm{~mm} / \mathrm{s}(0.5 \mathrm{in} . / \mathrm{min})$. Figure 3.29 depicts the cyclic loading regime, where Push and Pull stand for actuator forcing the specimen 
downward (negative) and upward (positive), respectively. All specimens were tested up to $\mu=6$, except for Specimen SC which failed at $\mu=5$. Afterwards, the axial loading was released for safety reasons; and some of the specimens were loaded monotonically up to a higher displacement ductility factor at the same loading rate as that used for cyclic loading, but only in one direction, push or pull.

\subsubsection{Test Observations}

\subsubsection{Observed Cracks in FRP Tubes}

In Specimens SC and LC, the FRP tubes cracked in flexure with a loud sound as well as a noticeable sudden load drop. However, the cracks were only limited to one at the top and one at the bottom at the column base and the specimens still had considerable residual capacity after FRP cracking. On the other hand, Specimens Y, G and H remained intact without any noticeable matrix cracking. This remained the case even during subsequent monotonic testing for Specimens $\mathrm{Y}$ and $\mathrm{G}$ beyond ductility factor $\mu$ of 6 .

In Specimen SC, top and bottom fibers cracked in tension at the first and second cycles, respectively, of ductility factor of 3 . During loading cycles at $\mu$ of 4 , the bottom crack extended to the mid-height of the section, as shown in Figure 3.30. The top cracks, however, were much smaller, as shown in Figure 3.31. In Specimen LC, a sudden cracking sound was first heard while being pushed down at $\mu$ of 2 , followed by another cracking sound while being pulled up at the first peak of $\mu$ of 3 . The top fiber cracks could only be discerned at $\mu$ of 4 , and the bottom fiber cracks were later noticed at $\mu$ of 5 . The cracks, however, were limited to the outer layer of the tube, and did not expose concrete until $\mu$ of 6 . While being pulled back, the cracked fibers crushed in compression. 
However, the bottom inner layer of FRP did not crack until the end of the test. Figure 3.32 and Figure 3.33 show bottom and top fiber cracks in Specimen LC, respectively.

\subsubsection{Observed Cracks in Footings}

The footing of Specimen RC exhibited no cracks throughout the test proving that the footing design was adequate for reinforced concrete members. Nonetheless, footings of all five CFFT columns extensively cracked during the tests. One or two cracks first appeared at the top and bottom at $\mu$ of 2 . The cracks then gradually formed a radial pattern around the edges of CFFT columns at later stages of loading. The footings for five CFFT columns may be differentiated into two groups: Specimens Y, G and H, in which the FRP tubes did not show any cracking; and Specimens SC and LC, in both of which FRP tubes cracked.

Cracks in footings of Specimens $\mathrm{Y}$ and $\mathrm{G}$ developed and progressively grew quite evenly during the tests, corresponding to a smooth hysteretic response seen in these columns. Figure 3.34 and Figure 3.35 show the footing cracks in Specimens $Y$ and G, respectively. In the footing of Specimen $\mathrm{H}$, a chunk of concrete split from the footing adjacent to the FRP tube, which fell off at $\mu$ of 5 (Figure 3.36). Figure 3.37 shows the footing cracks in Specimen $\mathrm{H}$.

The footing in Specimen SC stopped cracking after $\mu$ of 3, after both layers of FRP tube had cracked at top and bottom, and the load had dropped. On the other hand, the footing in Specimen LC continued to crack until $\mu$ of 5 , since the inside layer of FRP tube had not completely cracked, as discussed earlier. Cracking of FRP tubes in Specimens LC and SC generally resulted in less cracking in the footing, as well as less 
slippage for the FRP tube, as compared with the other three CFFT specimens, as will be discussed later in this chapter.

Generally, the footings provided adequate anchorage for the CFFT columns with the given tube embedment. The cracks in the footings did not affect the structural behavior of the CFFT columns, but may have limited their potential capacity, especially in Specimens G, Y, and H. Therefore, design of connections must be taken into detailed consideration for structurally integrated stay-in-place FRP formwork.

\subsubsection{Observed Tube-Footing Separation and FRP Tube Slippage}

A slight separation between the tube and the footing was developed in Specimen $\mathrm{Y}$ during the test, as shown in Figure 3.38. The separation mostly recovered with the return of the specimen to its original position at the end of each loading cycle. Despite its limited slippage and separation from the footing, the embedded tube effectively participated as a structural component and as longitudinal reinforcement for concrete, and not simply as a confining device. This was also verified for Specimen $\mathrm{H}$, where a chunk of concrete spalled off from the footing adjacent to the tube, as shown in Figure 3.39.

For Specimen G, the separation was quite noticeable at different stages along the test. Figure 3.40 shows the original tube-footing joint until $\mu$ of 3 , while Figure 3.41 shows the tube slippage relative to the footing, which could be clearly identified from the original marks on the tube.

The separation between FRP tube and RC footing, which was typically visible only at higher displacements, did not cause any disturbance in the load transfer 
mechanism between the column and the footing, since no sign of stress relief in the FRP tube was evident from strain measurements, as will be discussed later in this chapter.

\subsubsection{Observed Failure Modes}

Despite its initial inadvertent and rapid pre-loading beyond the yielding stage, Specimen RC demonstrated cracking and failure mode typical of conventional reinforced concrete columns. The spiral steel appeared intact after removal of the spalled concrete. Figure 3.42 shows Specimen $\mathrm{RC}$ at $\mu$ of 10 after removing axial loads for safety reasons. In Specimens SC and LC, the FRP tubes cracked in the hoop direction with a loud sound as well as a noticeable sudden load drop. However, cracks were only limited to one at the top and one at the bottom at the column base, and the specimens still showed considerable residual strength after FRP cracking. On the other hand, Specimens Y, G and $\mathrm{H}$ remained intact without any noticeable matrix cracking. This remained the case even during subsequent monotonic testing for Specimens $\mathrm{Y}$ and $\mathrm{G}$ up to $\mu=8$ and 10 , respectively. Figure 3.43 through Figure 3.47 capture the images of the different CFFT specimens at their respective maximum displacements.

\subsection{TEST RESULTS AND DISCUSSIONS}

\subsubsection{Stability of Axial Load}

Given the inter-dependence of axial load and lateral displacement, the axial force was monitored throughout the tests. The axial load slightly fluctuated during the cyclic loading. However, the post-tensioning mechanism was used to effectively control this fluctuation during the experiments. The control included a single handle pressure relief 
valve to reduce the axial force, and the hand pump to increase it, as needed. Figure 3.48 shows a typical axial load fluctuation during the test of Specimen LC, with the readings of the two load cells, one for each threaded rod; and the total axial force. The standard deviation for this experiment was less than $2.56 \%$, confirming the stability of axial force.

Table 3.4 lists the mean and standard deviation of the axial force in all specimens. The statistical variables are based on the sum of the two load cell readings in Specimens $\mathrm{RC}, \mathrm{Y}, \mathrm{G}$, and LC, and the output from one load cell reading in the tests of Specimens $\mathrm{H}$ and SC. The average of the means of the six tests is $90.03 \mathrm{kN}$ (20.24 kips), which is only $1.01 \%$ from the target value of $88.96 \mathrm{kN}$ (20 kips). The average standard deviation is $2.54 \mathrm{kN}(0.57 \mathrm{kips})$, or $2.85 \%$ of the target axial load. The statistical data confirms the high accuracy of the applied axial load in these tests.

\subsubsection{Hysteretic Response}

Figure 3.49 through Figure 3.54 show the normalized moment - deflection hysteretic responses of all specimens. Moments are normalized to remove the effects of different concrete compressive strengths and core diameters, as $M / f^{\prime}{ }_{c} D^{3}$, where $M$ is the moment at the column base; and $D$ is concrete core diameter or the internal diameter of the FRP tube. The total moment term includes both the primary (lateral) and the secondary $(P-\Delta)$ effects. The deflection is shown both as the column head displacement $\Delta$ and the drift ratio $\Delta L$, where $L$ is the shear span. The hysteretic loops in the figures are marked for each ductility factor $\mu$.

Specimen RC was inadvertently and rapidly pre-loaded in push well beyond its yielding stage, and thus showed a damaged hysteretic response in that direction. However, 
its response in the pull direction correlated favorably with the OpenSees analytical simulation as will be discussed in Chapter 7. Thus, the experimental data in pull direction will be considered as a valid reference for the CFFT specimens. Specimen RC had a slight load drop at $\mu$ of 5 in pull direction.

The most significant feature of Specimen $\mathrm{Y}$ was that its flexural strength continued to increase throughout the cyclic test in both directions, and at a higher rate than Specimen G, the other GFRP specimen. The hysteretic response of Specimen G showed that its flexural strength continued to increase until $\mu=4$, after which it kept almost constant. Specimen H experienced $10-11 \%$ load drops at $\mu=3$ in both directions. No FRP cracks were detected during the test; although the load drop clearly indicated the development of such cracks. The hysteretic response of Specimen SC showed that its flexural strength dropped by $13 \%$ at $\mu=4$, after the tube cracked. The load drop was not as significant on the push side, since cracks on top of the tube were not as extensive as those in the bottom. In Specimen LC, load drops were also associated with cracking of FRP tube; however, the overall capacity did not decrease.

\subsubsection{Response Envelope}

Figure 3.55 compares the normalized moment - drift ratio envelope curves for all specimens. The data is calculated based on the maximum/minimum normalized moments and the drift ratio of the first cycle for each level of ductility displacement. A quantitative comparison of the performance measures for different specimens is also presented in Table 3.5. Only data in pull direction is presented for Specimen RC with an assumed loading start from zero. 
It is clearly shown that all CFFT specimens had higher flexural strength than Specimen RC. Specimen H demonstrated the highest flexural strength and initial stiffness, whereas Specimens Y and G exhibited better ductility. Specimen LC did not exhibit a symmetric response in the push and pull directions. However, the average absolute total maximum normalized moments of both directions for Specimens SC and LC were almost identical, as expected from the identical fiber architecture of the two FRP tubes.

\subsubsection{Energy Dissipation}

Figure 3.56 shows the normalized cumulative dissipated energy of all specimens versus their drift ratio in the pull direction. The energy is calculated based on the maximum normalized moment and drift ratio of the first cycle for each level of ductility displacement. It is clear that all CFFT specimens had higher energy dissipation than Specimen RC. Moreover, at the same drift ratio, Specimen H distinguishes itself with the highest cumulative energy and dissipation rate, i.e., slope of the curve. Specimen G, the second highest curve, performed better than Specimen Y, the other fiberglass tube, in terms of both dissipated energy and dissipation rate. Higher performance of Specimen LC is due to its longer flexural span, rather than its sectional curvature.

\subsubsection{Performance Measures of Stiffness, Ductility and Pinching}

Table 3.6 compares performance measures of stiffness, ductility and pinching for CFFT specimens. The normalized initial stiffness of all specimens is based on the initial elastic slopes of the hysteretic normalized moment - drift ratio responses. The R2, coefficient of determination, was derived from the linear regression analysis of the slope 
in the elastic range. Clearly, Specimen $\mathrm{H}$ had the highest normalized initial stiffness, followed by Specimen SC and the two fiberglass Specimens Y and G. Lower stiffness of Specimen LC is due to its longer shear span.

Ductility of a structural member is defined as its ability to sustain inelastic deformation prior to failure, without substantial loss of strength. A yield-based ductility index is defined as the ultimate deflection over its corresponding yield value. The yield deflection is defined as that of an equivalent elasto-plastic system with the same elastic stiffness and ultimate load as those of the real system. Table 3.6 lists the ductility of all specimens based on their drift ratios. The yield drift ratio was obtained using the ultimate normalized moment divided by the normalized initial stiffness. Except for Specimen Y, the data was obtained in the push direction. It is clear that fiberglass specimens had higher ductility than carbon and hybrid CFFTs. Specimen LC showed higher ductility than Specimen SC, because of its longer shear span.

Table 3.6 also lists pinching factors for all CFFT specimens. Pinching factor is defined as the ratio of the width of the hysteretic loop at its widest point to that at the origin. It is noted that fiberglass and hybrid lay-up may lead to higher pinching effect than those with carbon tubes.

\subsubsection{Load-Strain Response and Plastic Hinge Length}

Figure 3.57 through Figure 3.61 show strain profiles for the steel bars along individual CFFT specimens during the push cycles at different ductility factors. The readings are marked as SG and $\Omega$ for the type of gauge, and Top and Bottom for the bar/gauge location. The figure also depicts the plastic hinge length based on the 0.002 
yielding strain of mild steel. Table 3.7 lists the plastic hinge lengths $\left(L_{p}\right)$ for all CFFT specimens, which were calculated as percentages of each column length $\left(L_{c}\right)$ and also compared with outside diameters $\left(D_{o}\right)$ of each column. Figure 3.62 shows the plastic hinge lengths $\left(L_{p}\right)$ as a fraction of column length $\left(L_{c}\right)$ or outside diameters $\left(D_{o}\right)$ of each column. The plastic hinge lengths were from the maximum values of Table 3.7 for all short CFFT specimens. The graphs are plotted as a function of the absolute average of maximum normalized moment from both directions. For Specimen RC, only data from the bottom strain gauge in the pull direction was used.

All CFFTs exhibited longer plastic hinge than Specimen RC, validating the findings of earlier studies (Zhu et al. 2006a\&b). Specimen $\mathrm{H}$ had the least plastic hinge length among the four short CFFT specimens, perhaps due to its higher flexural strength, as will be discussed later. Since Specimen LC required larger deflection to initiate steel yielding, it had a shorter plastic hinge zone than the short CFFTs. Figure 3.62 also shows the plastic hinge length to be inversely proportional to the flexural strength.

\subsubsection{Deflected Shapes and Normalized Moment - Curvature Responses}

Figure 3.63 through Figure 3.68 show the deflected shapes of all specimens at various ductility levels. In each figure, deflections and drift ratios are shown relative to the distance from the footing for the entire range of displacement ductility $\mu$. The deflected shapes of all CFFT columns are generally linear even at highest levels of displacement ductility, primarily because of limited number of measurements taken along the length of the columns. 
Figure 3.69 compares the normalized moment - curvature responses of all specimens from cyclic tests, except for Specimen RC, which was obtained from the OpenSees push-over analysis as presented later in Chapter 7. Specimens H and RC had the highest and lowest capacities, respectively, at each curvature. It should be noted that the maximum curvatures for CFFTs do not constitute failure, but rather the last available strain gauge data.

\subsubsection{Tube-Footing Slippage}

Readings from the top and bottom potentiometers at the column-head joints confirmed that there was no slippage between the tube and the column head in any of the CFFT specimens. Figure 3.70 through Figure 3.74 show normalized moment - slippage of Specimens $\mathrm{Y}$ and $\mathrm{H}$ at column base, where Top/Bottom denotes location of potentiometer, and Compression/Tension indicates the state of strain.

In Specimen G (Figure 3.71), due to the potentiometer malfunction, slippage was not recorded when potentiometers were in tension and was only partially recorded when potentiometers were in compression. Therefore, only data for $\mu$ of 5 and 6 could be recovered for the top potentiometer, and for $\mu$ of $2-10$ for the bottom potentiometer. In Specimen H (Figure 3.72), a chunk of concrete in the footing spalled off adjacent to the tube, as discussed earlier (Figure 3.39), again leading to a gap in subsequent slippage data in the figure. In Specimens SC (Figure 3.67) and LC (Figure 3.68), the potentiometers placed at the bottom of FRP tube and RC footing suddenly fell down after cracking of the tube, and therefore, no data was recorded after $\mu$ of 3 . 
From the figures, it is apparent that at each level of ductility factor, the slippage in the second cycle was larger than that in the first cycle under the same column head displacement. It is also noted that the slippage was larger in tension than that in compression, except for Specimen SC, where the top potentiometer on the compression side showed larger slippage than that in tension. This may be attributed to cracks in the FRP tube. Generally, this is consistent with overall responses of strain profiles where tensile strains were larger than compressive strains along the same section.

Figure 3.75 compares the tube-footing slippage on the top for Specimens SC, H, Y, and LC. Specimen Y seemingly has the largest slippage amongst the CFFT columns, perhaps because of its smooth surface. However, the slippage is not significantly different among the various CFFTs. Figure 3.76 shows the tube-footing net slippage on the top for Specimens SC, H, Y, and LC, eliminating the elongation or shortening component from the center of potentiometer to the footing edge. The figure shows the same pattern as that of Figure 3.75, confirming the insignificant effect of the straining component on the overall slippage.

\subsubsection{Residual Deflections and Residual Loads}

Figure 3.77 compares the average absolute residual drift ratios at zero loading in both directions of push and pull for CFFT specimens at each ductility factor. It is noted that fiberglass specimens (i.e., $\mathrm{Y}$ and $\mathrm{G}$ ) exhibited the smallest residual drift, an important feature in seismic application when considering possible repair. Specimens made with carbon fibers (i.e., LC and SC), on the other hand, had largest residual drift. The residual drift for Specimen $\mathrm{H}$ lies in between the two groups. 
Figure 3.78 compares the percentages of total residual normalized moment at zero deflection relative to total maximum normalized moment at each ductility factor for CFFT Specimens. In this figure, it is observed that the trend at higher level of ductility factor is quite similar to that in Figure 3.77, with Specimen $\mathrm{H}$ in between the fiberglass and carbon tubes.

\subsubsection{Combined Shear and Flexural Effects of CFFT Columns}

Specimens SC and LC were similar in all respects, except for their shear span-todepth ratios of 4.61 and 7.57, respectively. Although Specimen LC had higher deformation capacity than Specimen SC, they had identical flexural failure modes with very similar flexural strength. Zhuo et al. (2005) reported that fiberglass CFFTs fail in flexure under both cyclic and shake table tests, even at a shear span-to-depth ratio of 2.5, whereas RC control specimens would exhibit shear-flexural failure. Therefore, it may be concluded that under combined shear and flexural effects with shear span-to-depth ratios typical of bridge substructure, flexure remains the dominant mode of failure for CFFT columns, if properly designed.

\subsection{CONCLUSIONS}

To investigate the seismic performance of CFFT columns as bridge substructure, cyclic tests were conducted on five CFFT specimens and one control RC specimen. The five CFFTs had different fiber type and architecture and shear span-to-depth ratios. Performance measures included: strength, energy dissipation, initial stiffness, ductility, pinching, plastic hinge length and residual deflection. The following conclusions may be drawn from this experimental study: 
1. The footings in all CFFTs exhibited significant cracking, contrary to the footing in Specimen RC, which experienced no cracking. Only specimens with carbon FRP cracked, while specimens with glass or hybrid FRP did not show any visible cracks throughout cyclic tests.

2. All CFFTs showed higher flexural strength and energy dissipation than the RC column. Hybrid lay-up led to the highest flexural strength, initial stiffness and energy dissipation.

3. Specimens with GFRP tubes exhibited higher ductility than those with carbon and hybrid tubes. Meanwhile, fiberglass and hybrid lay-up may lead to higher pinching effect than those with carbon tubes.

4. All CFFT specimens developed a longer plastic hinge zone than Specimen RC. Moreover, the plastic hinge length was inversely proportional to the flexural strength.

5. Slippage was larger in tension than in compression, similar to the sectional strain response. Specimen Y had the largest slippage amongst all specimens because of its smooth surface. However, slippage was not significantly different among the various CFFT specimens.

6. GFRP specimens exhibited the smallest residual deflections and loads, an important feature in seismic applications when considering possible repair. CFRP tubes led to the largest residual deflections and loads, while hybrid lay-up lied in between the two groups. 
7. Under combined shear and flexural effects with shear span-to-depth ratios of typical bridge substructures, it is expected that CFFT columns will have flexure dominant failure. 
Table 3.1 Test Matrix

\begin{tabular}{|c|c|c|c|c|c|c|c|c|c|}
\hline Specimen & $\begin{array}{l}\text { Column } \\
\text { Length } \\
\text { mm (in.) }\end{array}$ & $\begin{array}{c}\text { Shear Span } \\
\text { in Cyclic } \\
\text { Test } \\
\text { mm (in.) } \\
\end{array}$ & $\begin{array}{c}\text { Concrete } \\
\text { Core } \\
\text { Diameter } \\
\text { mm (in.) }\end{array}$ & $\begin{array}{c}\text { Tube } \\
\text { Thickness } \\
\text { mm (in.) }\end{array}$ & $\begin{array}{l}\text { Column } \\
\text { Outside } \\
\text { Diameter } \\
\text { mm (in.) }\end{array}$ & $\begin{array}{l}\text { Con- } \\
\text { crete } \\
\text { Batch }\end{array}$ & $\begin{array}{l}f_{c}^{\prime}{ }^{\prime} \\
\mathrm{MPa} \\
\text { (ksi) }\end{array}$ & Longitudinal FRP & Transverse FRP \\
\hline $\mathrm{RC}$ & \multirow{5}{*}{$1,295(51)$} & \multirow{5}{*}{$1,524(60)$} & N/A & N/A & $\begin{array}{c}309.9 \\
(12.20) \\
\end{array}$ & \multirow{3}{*}{1} & \multirow{3}{*}{$\begin{array}{l}44.8 \\
(6.5)\end{array}$} & \multicolumn{2}{|c|}{ None } \\
\hline Y & & & $\begin{array}{c}311.86 \\
(12.278) \\
\end{array}$ & $\begin{array}{c}5.5 \\
(0.2160) \\
\end{array}$ & $\begin{array}{c}322.8 \\
(12.71) \\
\end{array}$ & & & \multicolumn{2}{|c|}{17 Layers of $\pm 55^{\circ}$ E-Glass } \\
\hline G & & & \multirow{4}{*}{$\begin{array}{c}317.50 \\
(12.5)\end{array}$} & $\begin{array}{c}7.3 \\
(0.2878) \\
\end{array}$ & $\begin{array}{c}332.1 \\
(13.0756) \\
\end{array}$ & & & \multicolumn{2}{|c|}{3 Layers of Bi-Directional E-Glass } \\
\hline $\mathrm{H}$ & & & & $\begin{array}{c}6.7 \\
(0.2635) \\
\end{array}$ & $\begin{array}{c}330.9 \\
(13.0270)\end{array}$ & \multirow{3}{*}{2} & \multirow{3}{*}{$\begin{array}{l}33.1 \\
(4.8)\end{array}$} & $\begin{array}{c}2 \text { Layers of Uni- } \\
\text { Directional Carbon }\end{array}$ & $\begin{array}{c}3 \text { Layers of Uni- } \\
\text { Directional E-Glass }\end{array}$ \\
\hline $\mathrm{SC}$ & & & & 2.2 & 322.0 & & & \multirow{2}{*}{\multicolumn{2}{|c|}{2 Layers of Bi-Directional Carbon }} \\
\hline LC & $2,210(87)$ & $2,438(96)$ & & $(0.0884)$ & (12.6767) & & & & \\
\hline
\end{tabular}

Table 3.2 Properties of FRP Tube or Laminates

\begin{tabular}{|c|c|c|c|c|c|c|c|c|}
\hline Specimen & $\begin{array}{l}\text { Manufacturer } \\
\text { Product Number }\end{array}$ & Data Source & $\begin{array}{c}\text { Tensile } \\
\text { Strength } \\
\text { MPa (ksi) } \\
\end{array}$ & $\begin{array}{c}\text { Tensile } \\
\text { Modulus } \\
\text { GPa (msi) } \\
\end{array}$ & $\begin{array}{c}\text { Hoop } \\
\text { Strength } \\
\text { MPa (ksi) } \\
\end{array}$ & $\begin{array}{c}\text { Hoop } \\
\text { Modulus } \\
\text { GPa (msi) } \\
\end{array}$ & $\begin{array}{c}\text { Flexural } \\
\text { Strength } \\
\mathrm{MPa}(\mathrm{ksi}) \\
\end{array}$ & $\begin{array}{c}\text { Flexural } \\
\text { Modulus } \\
\text { GPa (msi) } \\
\end{array}$ \\
\hline Y & $\begin{array}{l}\text { Smith Fiberglass / } \\
\text { Red Thread II Pipe }\end{array}$ & Manufacturer & $\begin{array}{c}71.0 \\
(10.3)\end{array}$ & $\begin{array}{l}12.55 \\
(1.82)\end{array}$ & $\begin{array}{l}234.4 \\
(34.0)\end{array}$ & N/A & $\begin{array}{l}158.6 \\
(23.0)\end{array}$ & $\begin{array}{l}15.03 \\
(2.18)\end{array}$ \\
\hline G & $\begin{array}{c}\text { 3TEX / } \\
\text { P3W-GE041 }\end{array}$ & \multirow{3}{*}{$\begin{array}{c}\text { Coupon Tests } \\
\text { Based on } \\
\text { ASTM D } \\
3039\end{array}$} & $\begin{array}{l}193.7 \\
(28.1)\end{array}$ & $\begin{array}{l}15.9 \\
(2.3)\end{array}$ & $\begin{array}{l}208.2 \\
(30.2)\end{array}$ & $\begin{array}{l}15.9 \\
(2.3)\end{array}$ & \multirow{3}{*}{\multicolumn{2}{|c|}{ N/A }} \\
\hline $\mathrm{H}$ & $\begin{array}{c}\text { Sika Corp. / } \\
\text { Hex 103C / 100G }\end{array}$ & & $\begin{array}{l}249.6 \\
(36.2)\end{array}$ & $\begin{array}{l}33.8 \\
(4.9)\end{array}$ & $\begin{array}{l}268.9 \\
(39.0)\end{array}$ & $\begin{array}{l}17.2 \\
(2.5)\end{array}$ & & \\
\hline $\mathrm{SC}, \mathrm{LC}$ & $\begin{array}{c}\text { 3TEX / } \\
\text { P3W-C1059 }\end{array}$ & & $\begin{array}{l}117.9 \\
(17.1)\end{array}$ & $\begin{array}{l}17.9 \\
(2.6)\end{array}$ & $\begin{array}{l}364.1 \\
(52.8)\end{array}$ & $\begin{array}{l}35.9 \\
(5.2)\end{array}$ & & \\
\hline
\end{tabular}


Table 3.3 Properties of Sikadur 35 and Sikadur 300

\begin{tabular}{|c|c|c|c|c|c|c|c|c|}
\hline Product & Usage & $\begin{array}{c}\text { Tensile } \\
\text { Strength } \\
\text { MPa (ksi) }\end{array}$ & $\begin{array}{c}\text { Tensile } \\
\text { Modulus } \\
\text { GPa (msi) }\end{array}$ & $\begin{array}{c}\text { Tensile } \\
\text { Elongation at } \\
\text { Break }\end{array}$ & $\begin{array}{c}\text { Compressive } \\
\text { Strength } \\
\text { MPa (ksi) }\end{array}$ & $\begin{array}{c}\text { Compressive } \\
\text { Modulus } \\
\text { GPa (msi) }\end{array}$ & $\begin{array}{c}\text { Flexural } \\
\text { Strength } \\
\text { MPa (ksi) }\end{array}$ & $\begin{array}{c}\text { Flexural } \\
\text { Modulus } \\
\text { GPa (msi) }\end{array}$ \\
\hline Sikadur 35 & $\begin{array}{c}\text { Epoxy } \\
\text { Injection }\end{array}$ & $\begin{array}{l}51.8 \\
(7.5)\end{array}$ & N/A & $4.8 \%$ & $\begin{array}{c}81.3 \\
(11.8)\end{array}$ & $\begin{array}{l}1.86 \\
(0.27)\end{array}$ & $\mathrm{N} / \mathrm{A}$ & N/A \\
\hline Sikadur 300 & $\begin{array}{l}\text { Impregnating } \\
\text { Resin }\end{array}$ & $\begin{array}{l}55.0 \\
(8.0)\end{array}$ & $\begin{array}{c}1.72 \\
(0.25)\end{array}$ & $3.0 \%$ & $\mathrm{~N} / \mathrm{A}$ & N/A & $\begin{array}{c}79.0 \\
(11.5)\end{array}$ & $\begin{array}{c}3.45 \\
(0.50)\end{array}$ \\
\hline
\end{tabular}

Table 3.4 Statistical Variables for the Applied Axial Forces

\begin{tabular}{|c|c|c|c|c|c|}
\hline Specimen & $\begin{array}{c}\text { Load Cell } \\
\text { Readings }\end{array}$ & $\begin{array}{c}\text { Mean } \\
\mathrm{kN}(\mathrm{kips})\end{array}$ & $\begin{array}{c}\text { Deviation of } \\
\text { Mean from } \\
\text { Target* (\%) }\end{array}$ & $\begin{array}{c}\text { Standard } \\
\text { Deviation } \\
\mathrm{kN} \text { (kips) }\end{array}$ & $\begin{array}{c}\text { Standard } \\
\text { Deviation / } \\
\text { Target* (\%) }\end{array}$ \\
\hline $\mathrm{RC}$ & 2 & $\begin{array}{c}88.78 \\
(19.96)\end{array}$ & $-0.2 \%$ & $\begin{array}{c}3.74 \\
(0.84)\end{array}$ & $4.20 \%$ \\
\hline $\mathrm{Y}$ & 2 & $\begin{array}{c}90.43 \\
(20.33)\end{array}$ & $1.65 \%$ & $\begin{array}{c}2.15 \\
(0.48)\end{array}$ & $2.42 \%$ \\
\hline $\mathrm{G}$ & 2 & $\begin{array}{c}89.85 \\
(20.20)\end{array}$ & $1.00 \%$ & $\begin{array}{c}2.51 \\
(0.57)\end{array}$ & $2.83 \%$ \\
\hline $\mathrm{H}$ & 1 & $\begin{array}{c}90.43 \\
(20.33)\end{array}$ & $1.65 \%$ & $\begin{array}{c}1.70 \\
(0.38)\end{array}$ & $1.91 \%$ \\
\hline $\mathrm{SC}$ & 1 & $\begin{array}{c}90.38 \\
(20.32)\end{array}$ & $1.60 \%$ & $\begin{array}{c}2.78 \\
(0.63)\end{array}$ & $3.13 \%$ \\
\hline $\mathrm{LC}$ & 2 & $\begin{array}{c}90.16 \\
(20.27)\end{array}$ & $1.35 \%$ & $\begin{array}{c}2.24 \\
(0.50)\end{array}$ & $2.52 \%$ \\
\hline \multicolumn{2}{|c|}{ Average } & $\begin{array}{c}90.03 \\
(20.24)\end{array}$ & $1.01 \%$ & $\begin{array}{c}2.54 \\
(0.57)\end{array}$ & $2.85 \%$ \\
\hline
\end{tabular}

* Target axial load $=88.96 \mathrm{kN}$ (20 kips) 
Table 3.5 Comparison of System Performance Measures

\begin{tabular}{|c|c|c|c|c|c|c|c|}
\hline Items & Unit & $\begin{array}{c}\text { Specimen } \\
\text { RC }\end{array}$ & $\begin{array}{c}\text { Specimen } \\
\mathrm{Y}\end{array}$ & $\begin{array}{c}\text { Specimen } \\
\mathrm{G}\end{array}$ & $\begin{array}{c}\text { Specimen } \\
\mathrm{H}\end{array}$ & $\begin{array}{c}\text { Specimen } \\
\mathrm{SC}\end{array}$ & $\begin{array}{c}\text { Specimen } \\
\text { LC }\end{array}$ \\
\hline $\begin{array}{c}\text { Maximum } \\
\text { Normalized } \\
\text { Moment in } \\
\text { Pull }\end{array}$ & - & 0.0834 & 0.0996 & 0.1195 & 0.1457 & 0.1002 & 0.1214 \\
\hline $\begin{array}{c}\text { Maximum } \\
\text { Normalized } \\
\text { Moment in } \\
\text { Push }\end{array}$ & - & - & -0.0861 & -0.0896 & -0.1289 & -0.0806 & -0.0680 \\
\hline $\begin{array}{c}\text { Average } \\
\text { Absolute } \\
\text { Maximum } \\
\text { Normalized } \\
\text { Moments }\end{array}$ & - & 0.0834 & 0.0928 & 0.1046 & 0.1373 & 0.0904 & 0.0947 \\
\hline $\begin{array}{l}\text { Maximum } \\
\text { Deflection in } \\
\text { Pull }\end{array}$ & $\begin{array}{l}\mathrm{mm} \\
\text { (in.) }\end{array}$ & $\begin{array}{l}78.94 \\
(3.11)\end{array}$ & $\begin{array}{l}100.80 \\
(3.97)\end{array}$ & $\begin{array}{l}74.86 \\
(2.95)\end{array}$ & $\begin{array}{l}73.37 \\
(2.89)\end{array}$ & $\begin{array}{l}61.92 \\
(2.44)\end{array}$ & $\begin{array}{l}152.52 \\
(6.00)\end{array}$ \\
\hline $\begin{array}{l}\text { Maximum } \\
\text { Deflection in } \\
\text { Push }\end{array}$ & $\begin{array}{l}\mathrm{mm} \\
\text { (in.) }\end{array}$ & - & $\begin{array}{l}-72.82 \\
(-2.87)\end{array}$ & $\begin{array}{c}-123.75 \\
(-4.87) \\
\end{array}$ & $\begin{array}{l}-73.77 \\
(-2.90)\end{array}$ & $\begin{array}{l}-60.84 \\
(-2.40)\end{array}$ & $\begin{array}{l}-148.91 \\
(-5.86)\end{array}$ \\
\hline $\begin{array}{l}\text { Maximum } \\
\text { Drift Ratio in } \\
\text { Pull }\end{array}$ & $\%$ & 5.18 & 6.61 & 4.91 & 4.81 & 4.06 & 6.26 \\
\hline $\begin{array}{l}\text { Maximum } \\
\text { Drift Ratio in } \\
\text { Push }\end{array}$ & $\%$ & - & -4.78 & -8.12 & -4.84 & -3.99 & -6.11 \\
\hline Damage Level & - & $\begin{array}{c}\text { Severe } \\
\text { Damage }\end{array}$ & \multicolumn{3}{|c|}{ No Visible Damage } & \multicolumn{2}{|c|}{ Minor Damage } \\
\hline Failure Mode & - & $\begin{array}{l}\text { Concrete } \\
\text { Spalling }\end{array}$ & \multicolumn{3}{|c|}{ No Visible FRP Cracking } & \multicolumn{2}{|c|}{$\begin{array}{c}\text { Flexural Cracking of } \\
\text { FRP Tubes }\end{array}$} \\
\hline
\end{tabular}

Note: positive data were obtained from pull direction and negative data were obtained from push direction. 
Table 3.6 Performance Measures of Stiffness, Ductility and Pinching of CFFT Specimens

\begin{tabular}{|c|c|c|c|c|c|}
\hline Specimen & $\mathrm{Y}$ & $\mathrm{G}$ & $\mathrm{H}$ & $\mathrm{SC}$ & $\mathrm{LC}$ \\
\hline $\begin{array}{c}\text { Normalized } \\
\text { Initial Stiffness }\end{array}$ & 0.065 & 0.060 & 0.096 & 0.073 & 0.055 \\
\hline$R^{2}$ & 0.840 & 0.920 & 0.878 & 0.854 & 0.903 \\
\hline $\begin{array}{c}\text { Normalized } \\
\text { Ultimate } \\
\text { Moment* }\end{array}$ & 0.100 & -0.090 & -0.129 & -0.081 & -0.068 \\
\hline $\begin{array}{c}\text { Yield Drift } \\
\text { Ratio* } \\
(\%)\end{array}$ & 1.530 & -1.491 & -1.343 & -1.103 & -1.232 \\
\hline $\begin{array}{c}\text { Ultimate Drift } \\
\text { Ratio* } \\
(\%)\end{array}$ & 6.614 & -8.120 & -4.841 & -3.992 & -6.107 \\
\hline $\begin{array}{c}\text { Ductility } \\
\text { Pinching Factor }\end{array}$ & 2.50 & 2.00 & 2.20 & 1.63 & 1.89 \\
\hline
\end{tabular}

* Positive and negative data represent pull and push directions, respectively. 
Table 3.7 Comparison of Plastic Hinge Lengths

\begin{tabular}{|c|c|c|c|c|c|}
\hline \multirow{3}{*}{\multicolumn{2}{|c|}{ Specimen }} & \multicolumn{4}{|c|}{ Plastic Hinge Length } \\
\hline & & \multicolumn{2}{|c|}{ Push } & \multicolumn{2}{|c|}{ Pull } \\
\hline & & \multirow{2}{*}{$\begin{array}{c}\text { Top Tensile } \\
\text { Region }\end{array}$} & \multirow{2}{*}{$\begin{array}{c}\begin{array}{c}\text { Bottom } \\
\text { Compressive } \\
\text { Region }\end{array} \\
-\end{array}$} & \multirow{2}{*}{$\begin{array}{c}\text { Top Compressive } \\
\text { Region }\end{array}$} & \multirow{2}{*}{$\begin{array}{c}\begin{array}{c}\text { Bottom Tensile } \\
\text { Region }\end{array} \\
22 \%\end{array}$} \\
\hline & $L_{p} / L_{c}$ & & & & \\
\hline & $L_{p} / D_{o}$ & - & - & - & 0.92 \\
\hline \multirow{2}{*}{$\mathrm{Y}$} & $L_{p} / L_{c}$ & $53 \%$ & $23 \%$ & $23 \%$ & $49 \%$ \\
\hline & $L_{p} / D_{o}$ & 2.13 & 0.92 & 0.92 & 1.97 \\
\hline \multirow{2}{*}{$\mathrm{G}$} & $L_{p} / L_{c}$ & $54 \%$ & $21 \%$ & $29 \%$ & $32 \%$ \\
\hline & $L_{p} / D_{o}$ & 2.11 & 0.82 & 1.13 & 1.25 \\
\hline \multirow{2}{*}{$\mathrm{H}$} & $L_{p} / L_{c}$ & $28 \%$ & $13 \%$ & $17 \%$ & $21 \%$ \\
\hline & $L_{p} / D_{o}$ & 1.10 & 0.51 & 0.67 & 0.82 \\
\hline \multirow{2}{*}{$\mathrm{SC}$} & $L_{p} / L_{c}$ & $30 \%$ & $20 \%$ & $16 \%$ & $57 \%$ \\
\hline & $L_{p} / D_{o}$ & 1.21 & 0.80 & 0.64 & 2.29 \\
\hline \multirow{2}{*}{$\mathrm{LC}$} & $L_{p} / L_{c}$ & $8 \%$ & $3 \%$ & $17 \%$ & - \\
\hline & $L_{p} / D_{o}$ & 0.55 & 0.21 & 1.17 & - \\
\hline
\end{tabular}




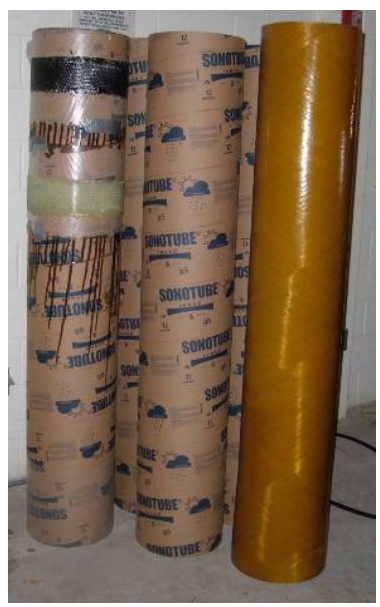

Figure 3.1 Sonotubes and FilamentWound FRP Tube

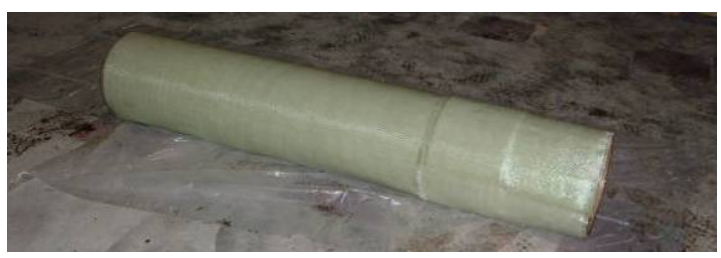

(a)

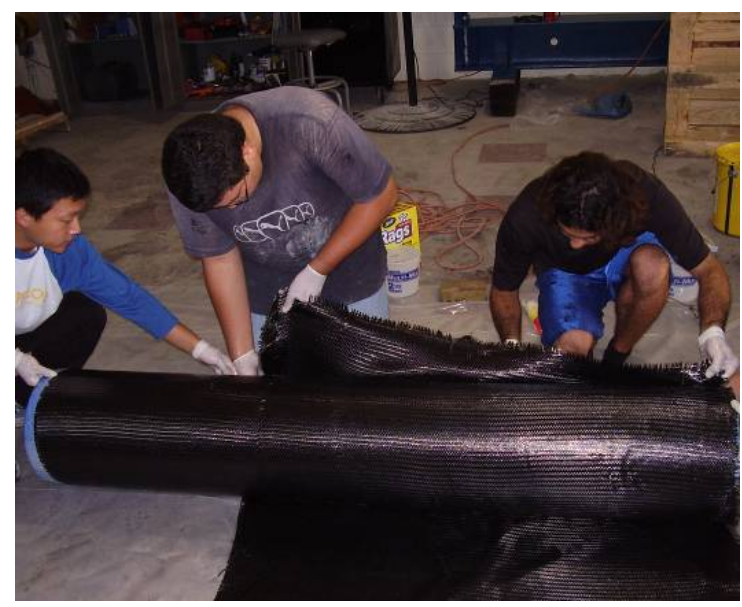

Figure 3.2 Preparation of Carbon FRP Tube in the Laboratory

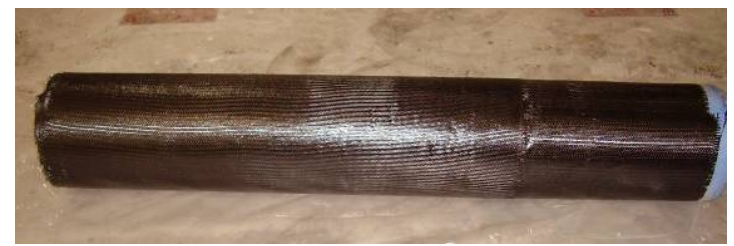

(b)

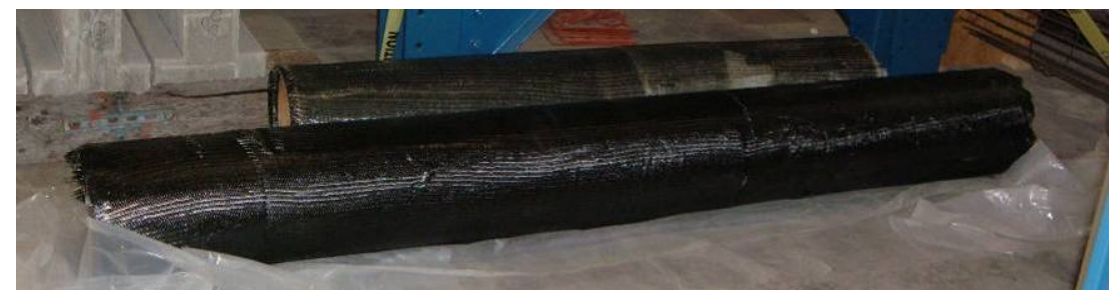

(c)

Figure 3.3 Cured Laboratory-Made FRP Tubes: (a) GFRP Tube for Specimen G, (b) CFRP Tube for Specimen SC, and (c) CFRP Tube for Specimen LC and Hybrid CFRP/GFRP Tube for Specimen H 


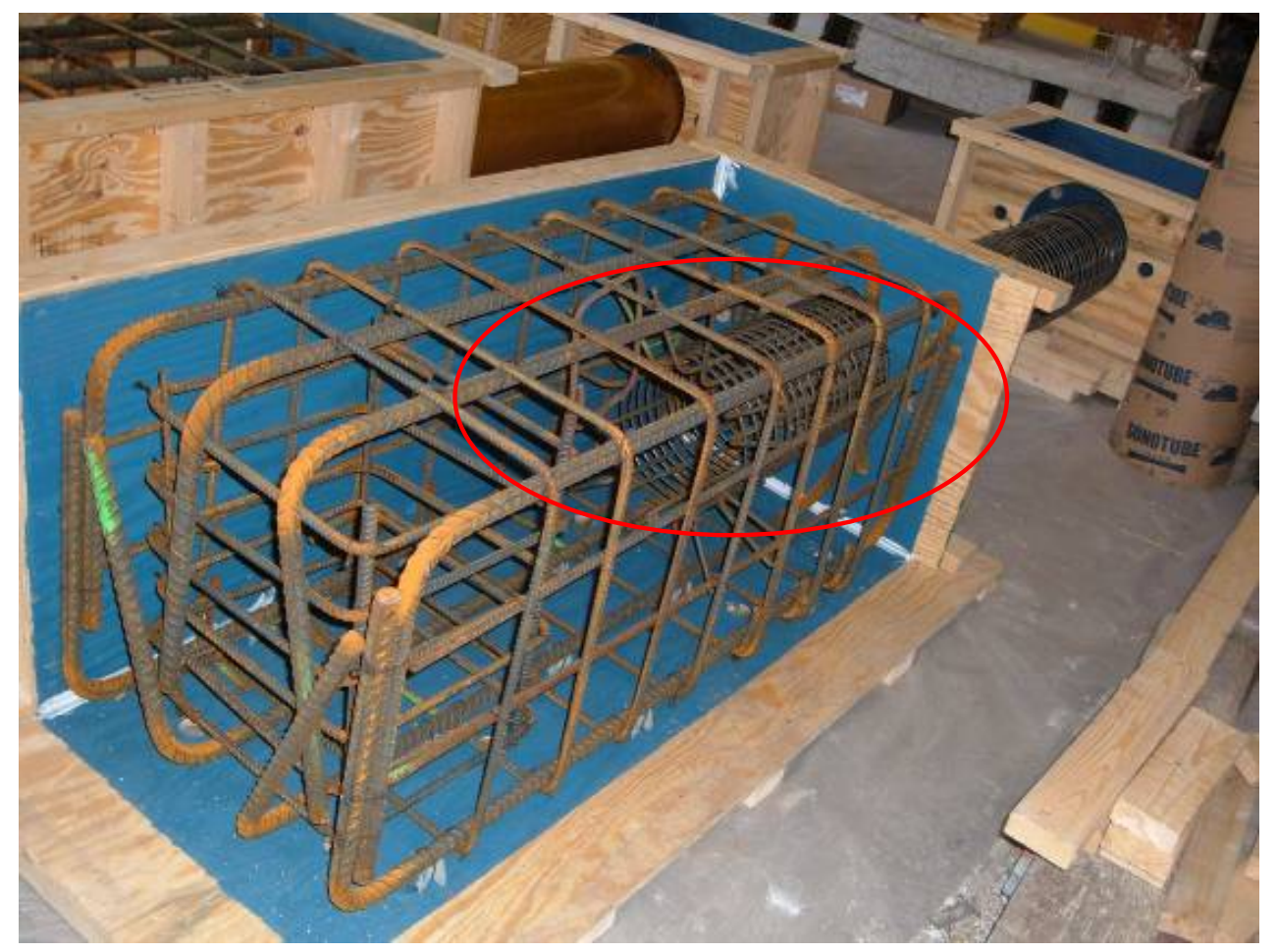

Figure 3.4 Column Reinforcement of Specimen RC Embedded into the Footing

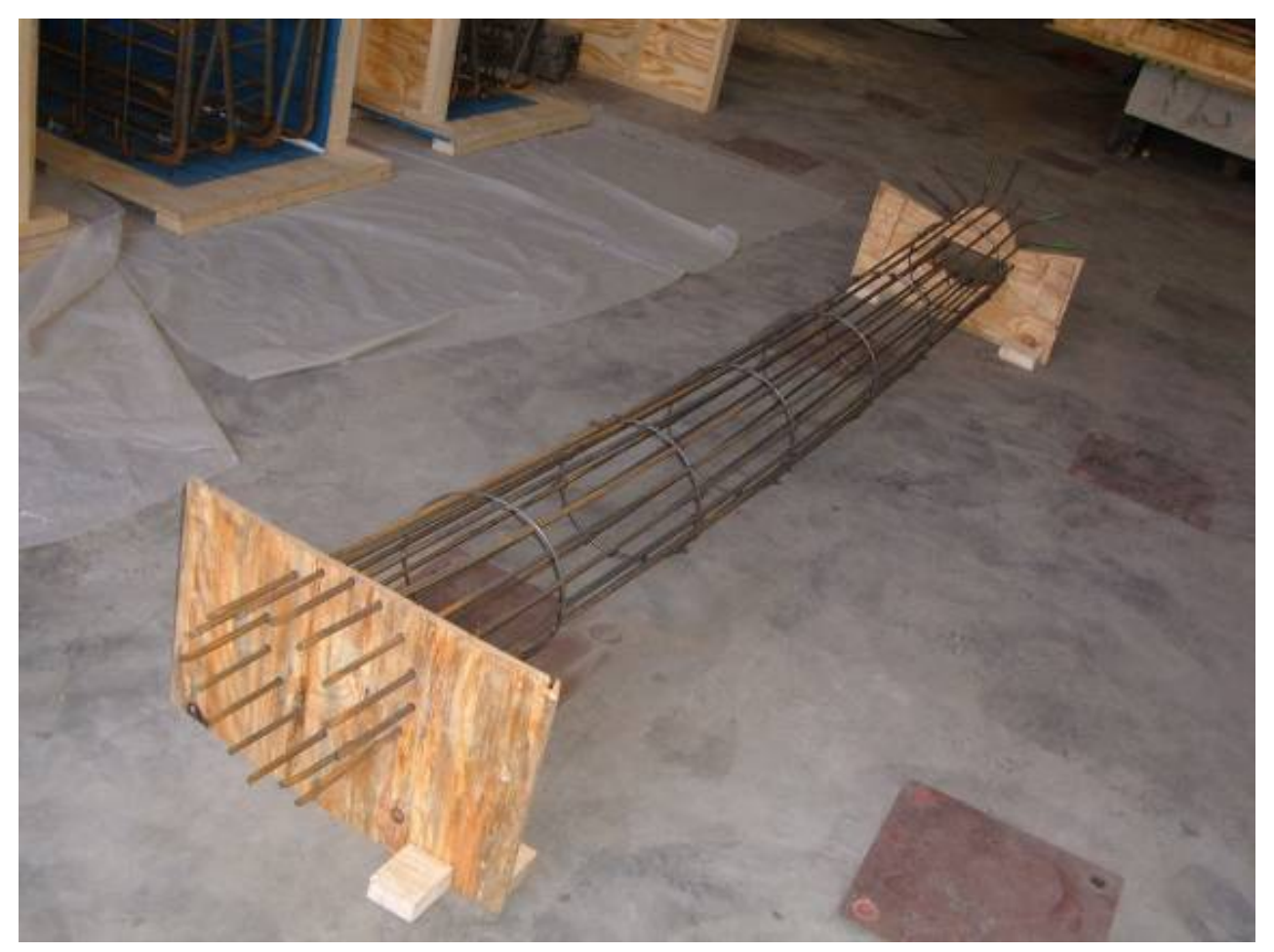

Figure 3.5 Column Reinforcement of Specimen LC 

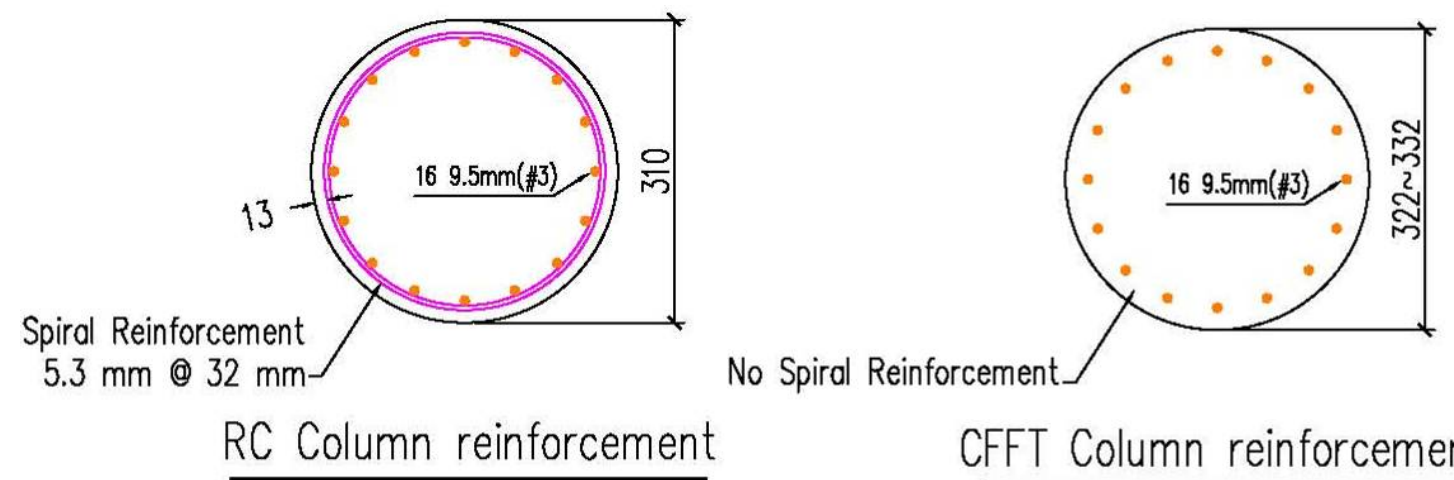

CFFT Column reinforcement
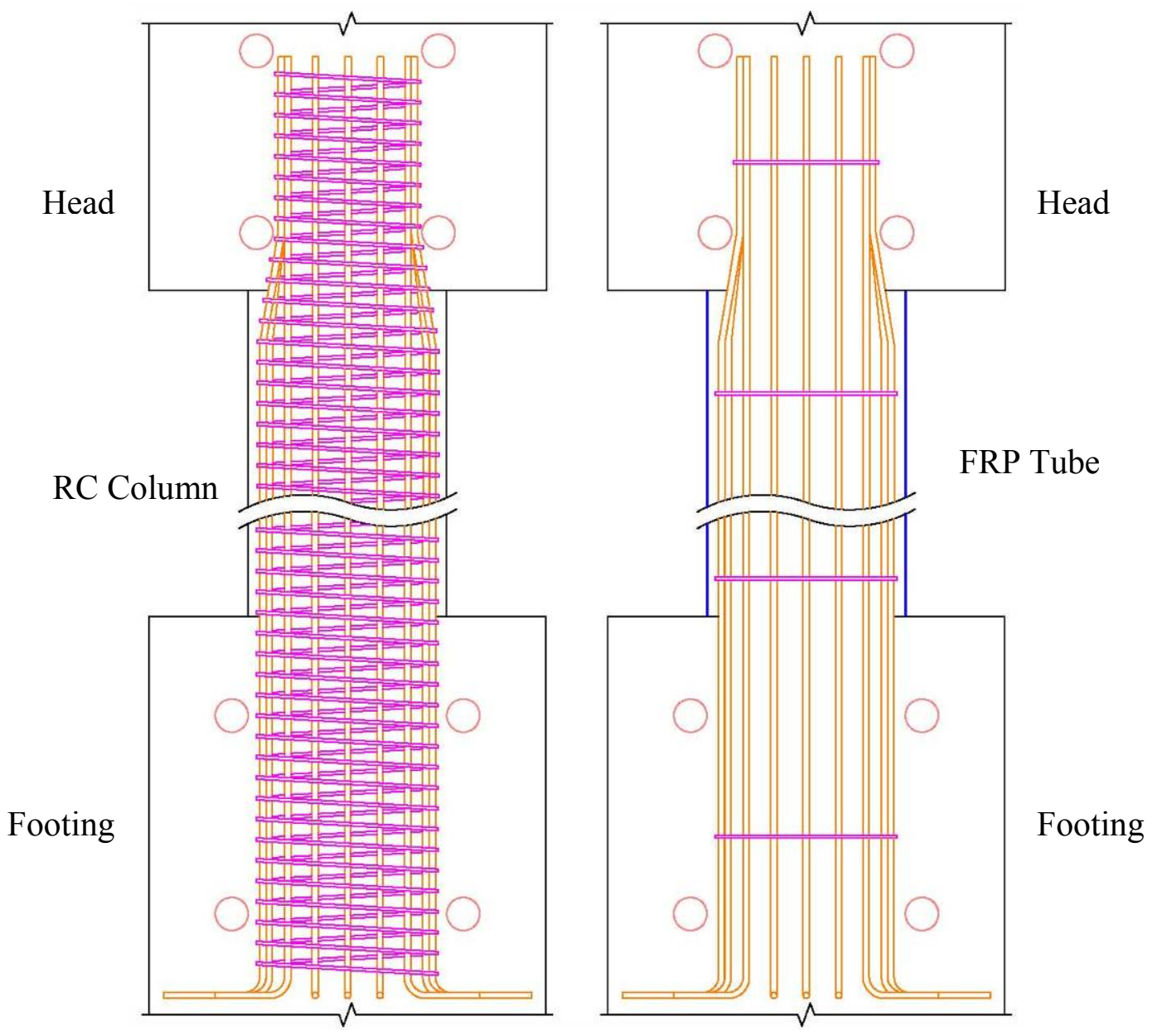

Figure 3.6 Column Reinforcement Details for Specimen RC and CFFT Specimens 


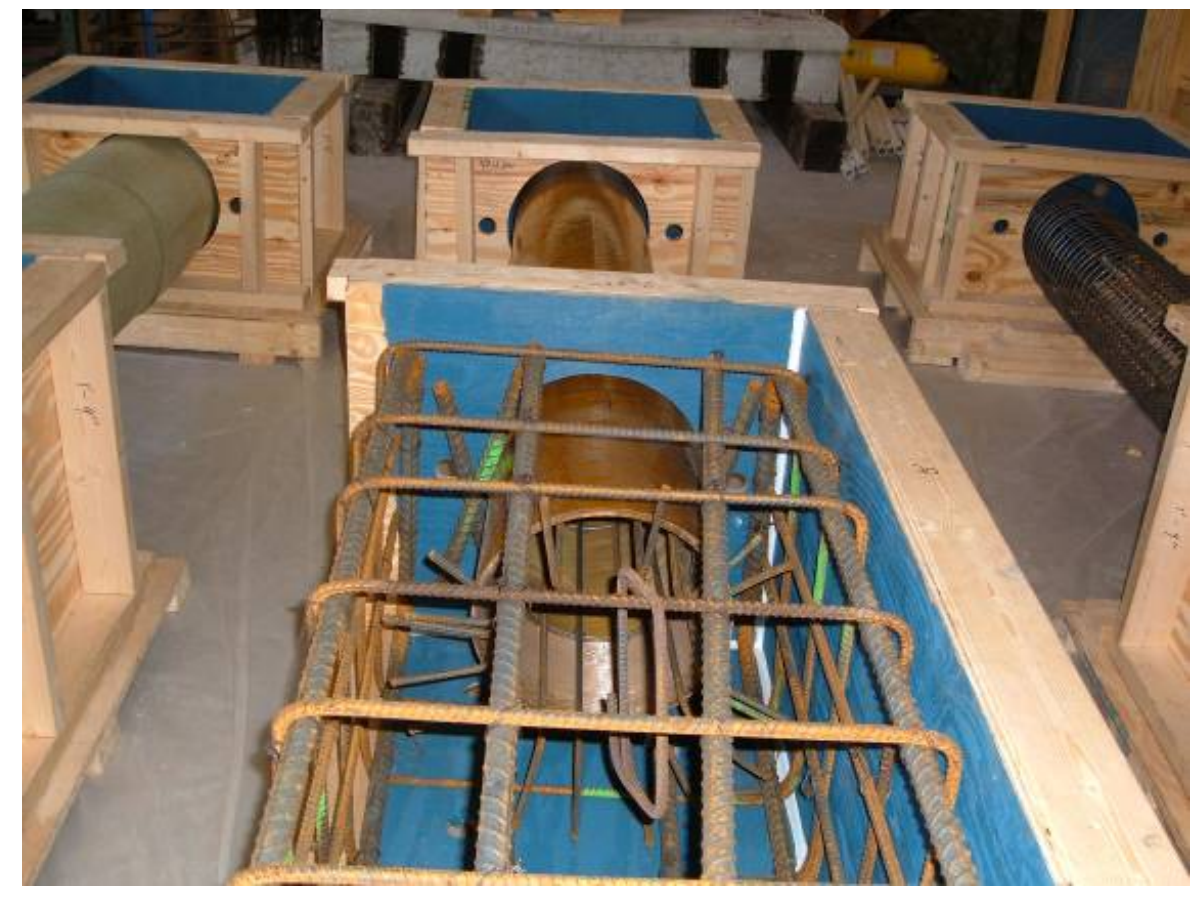

Figure 3.7 Embedment of FRP Tube and Column Reinforcement into the Footing of Specimen Y

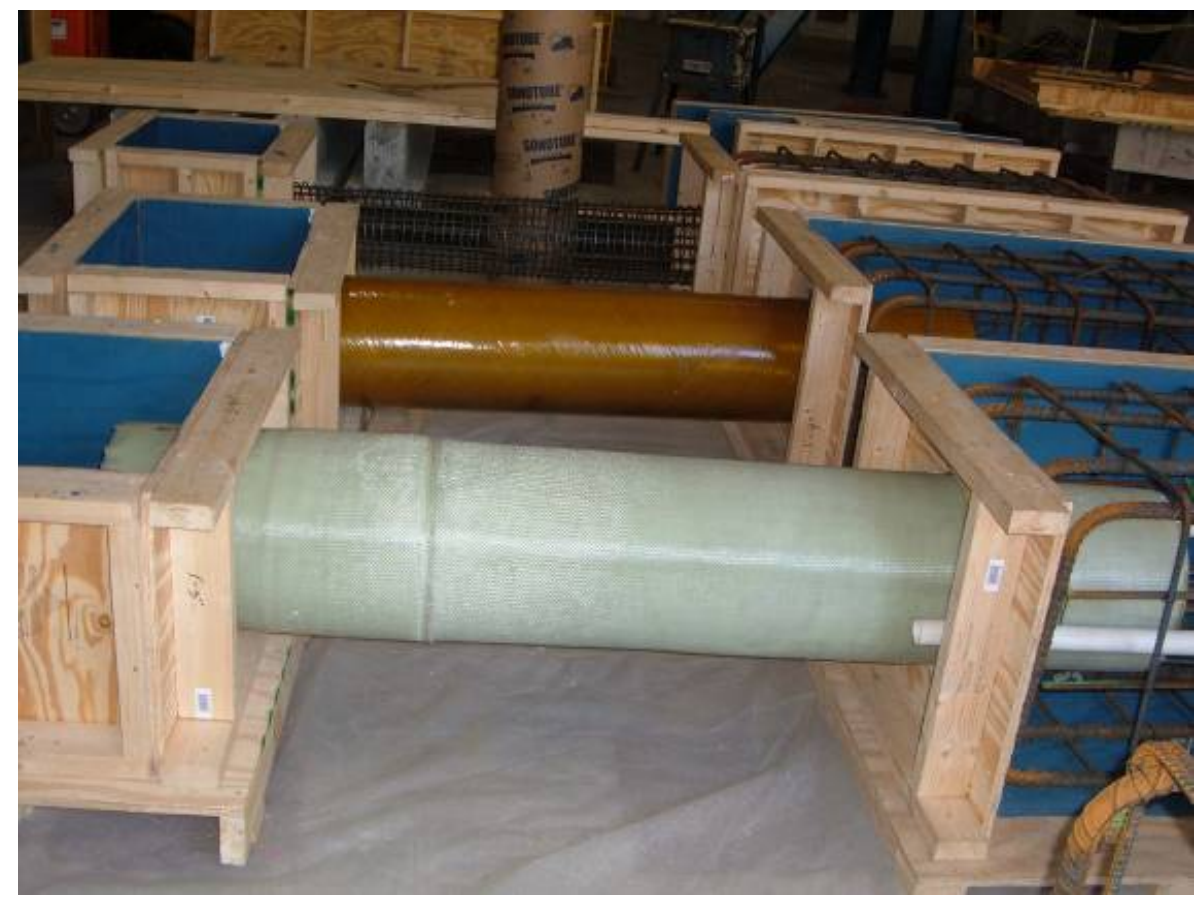

Figure 3.8 Overall Embedment into the Column Heads and Footings of Specimens G, $\mathrm{Y}$ and $\mathrm{RC}$ 


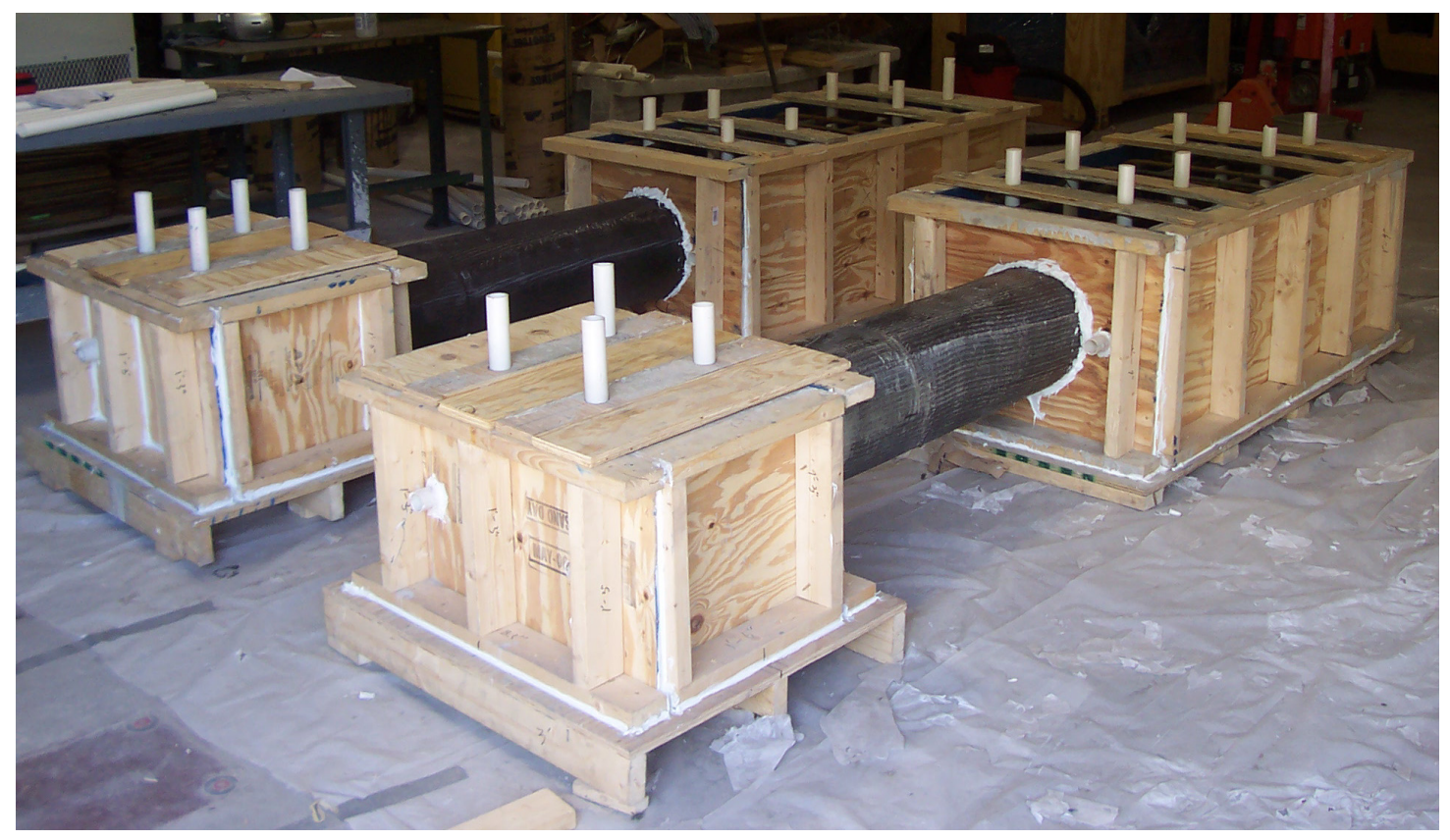

Figure 3.9 Formworks of Specimens H and SC

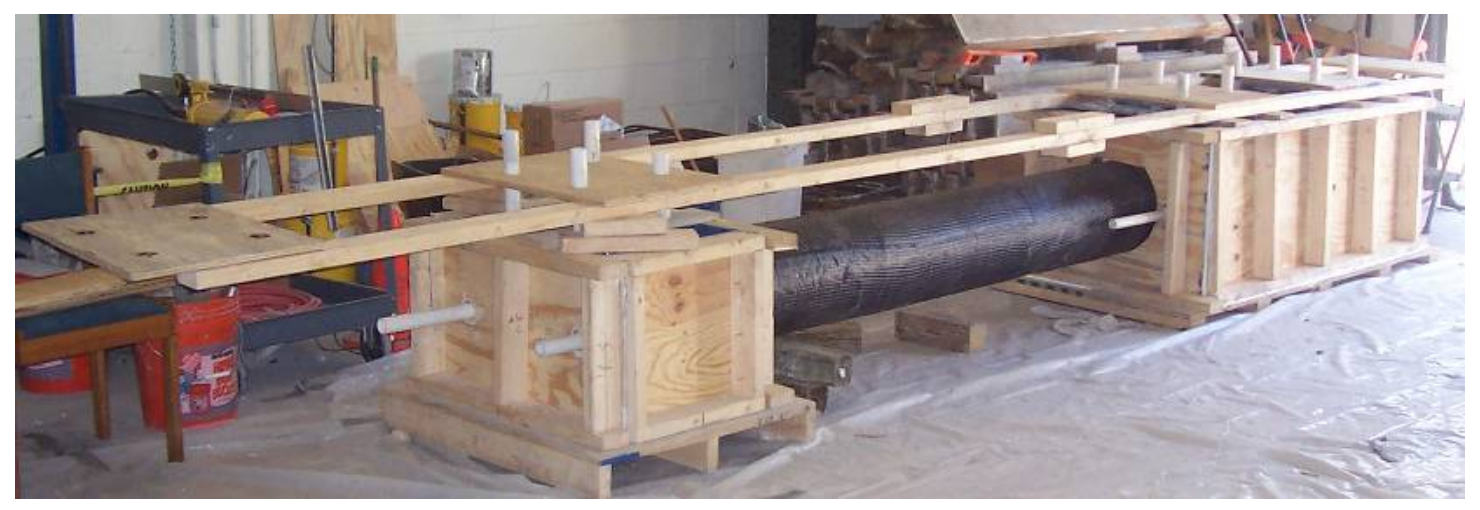

Figure 3.10 Template and Formwork for Specimen LC 


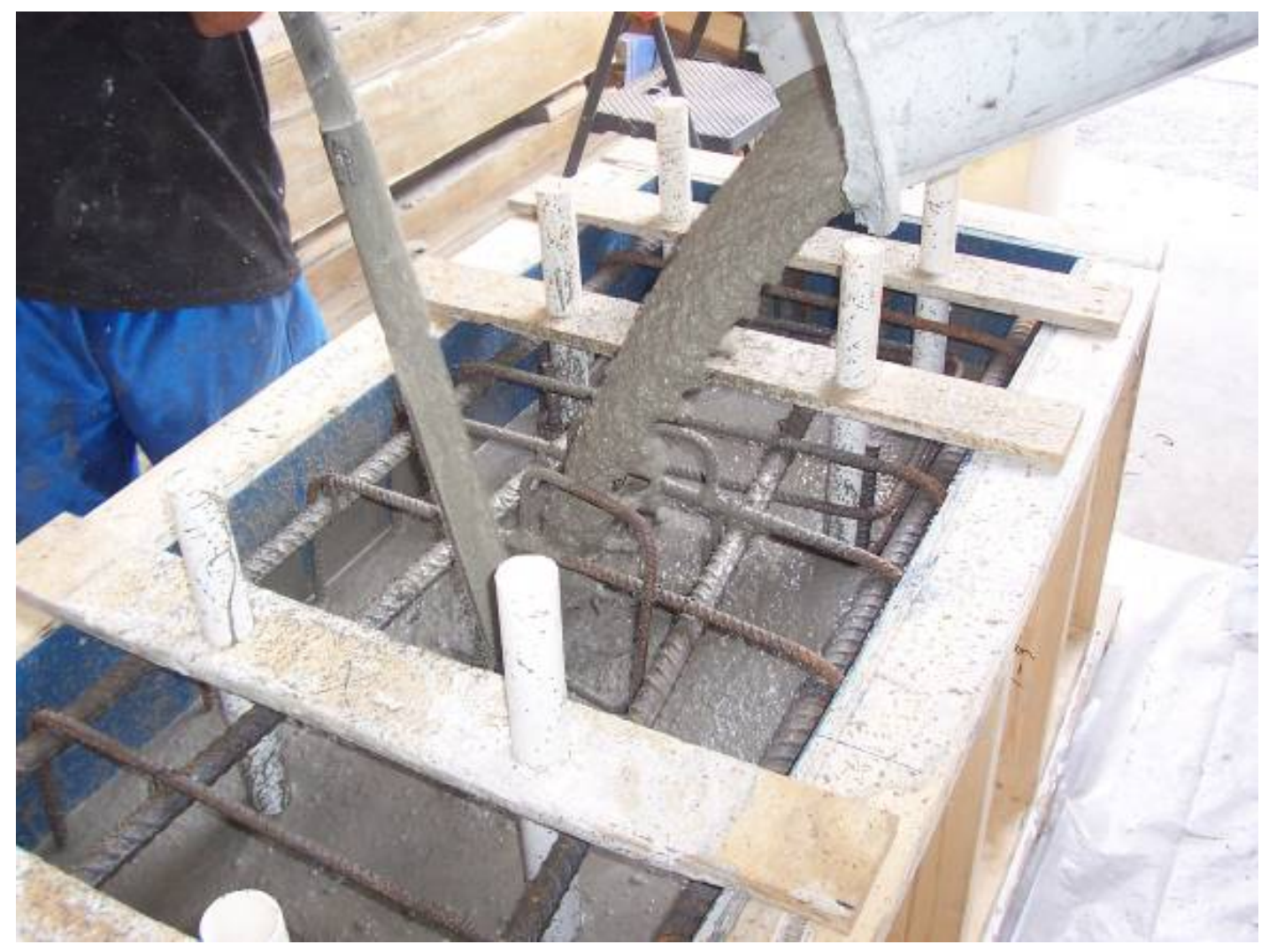

Figure 3.11 Casting of Concrete

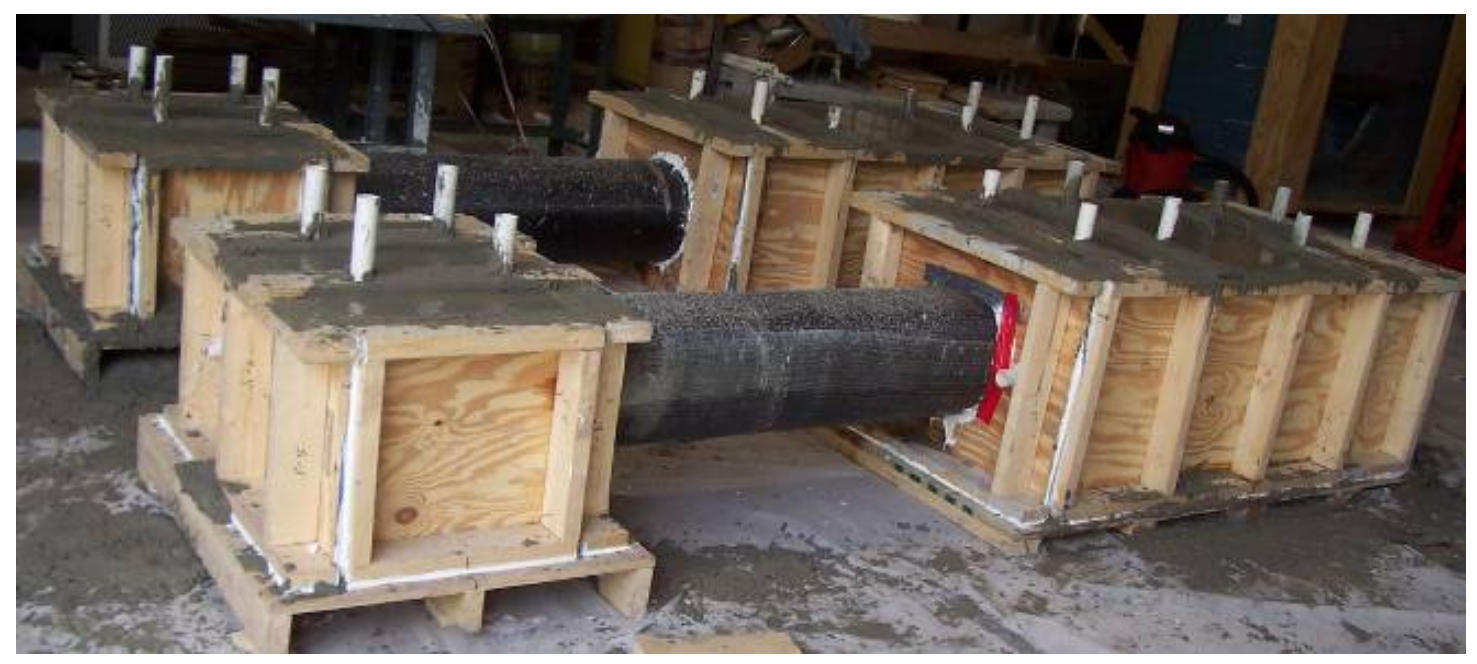

Figure 3.12 Specimens H and SC Right after Concrete Casting 


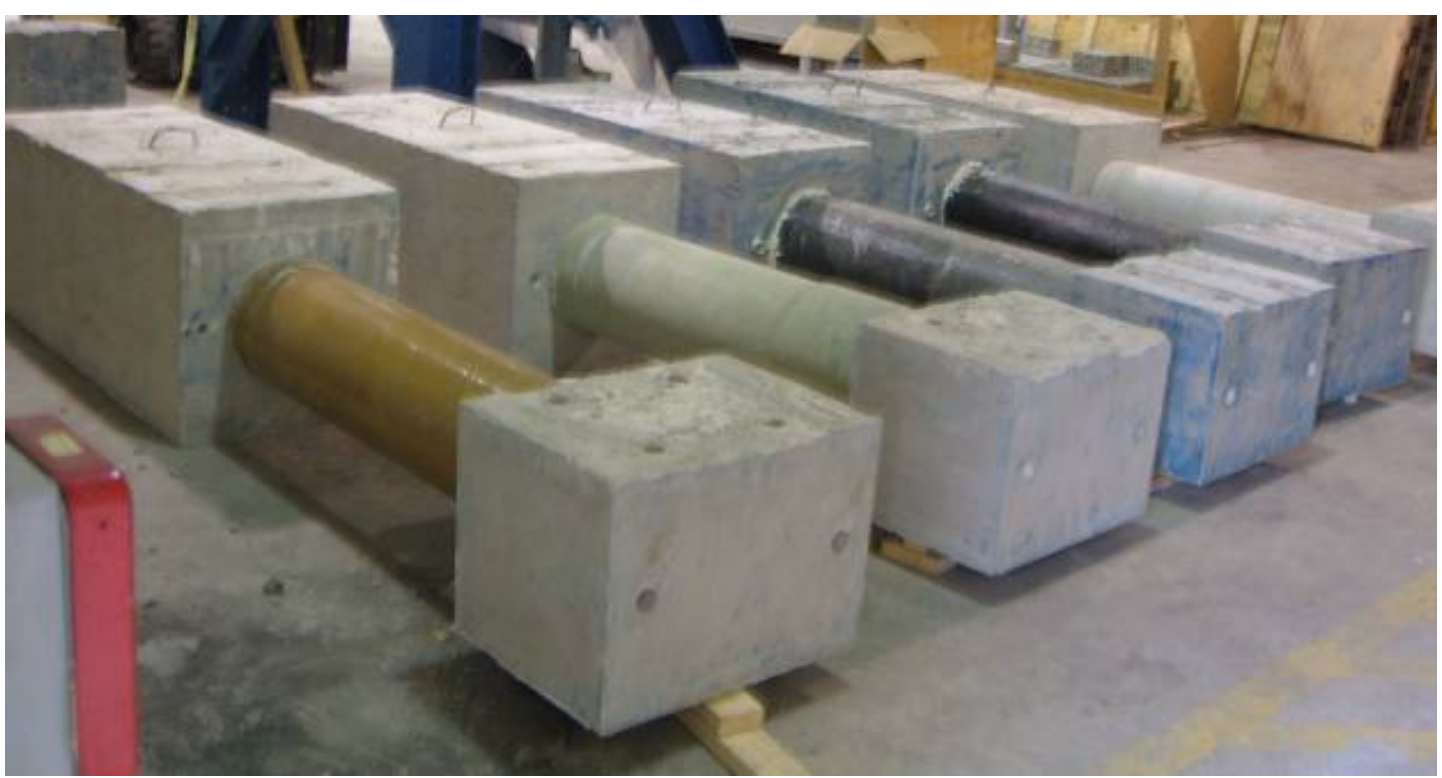

Figure 3.13 Five Short Column Specimens after De-Molding

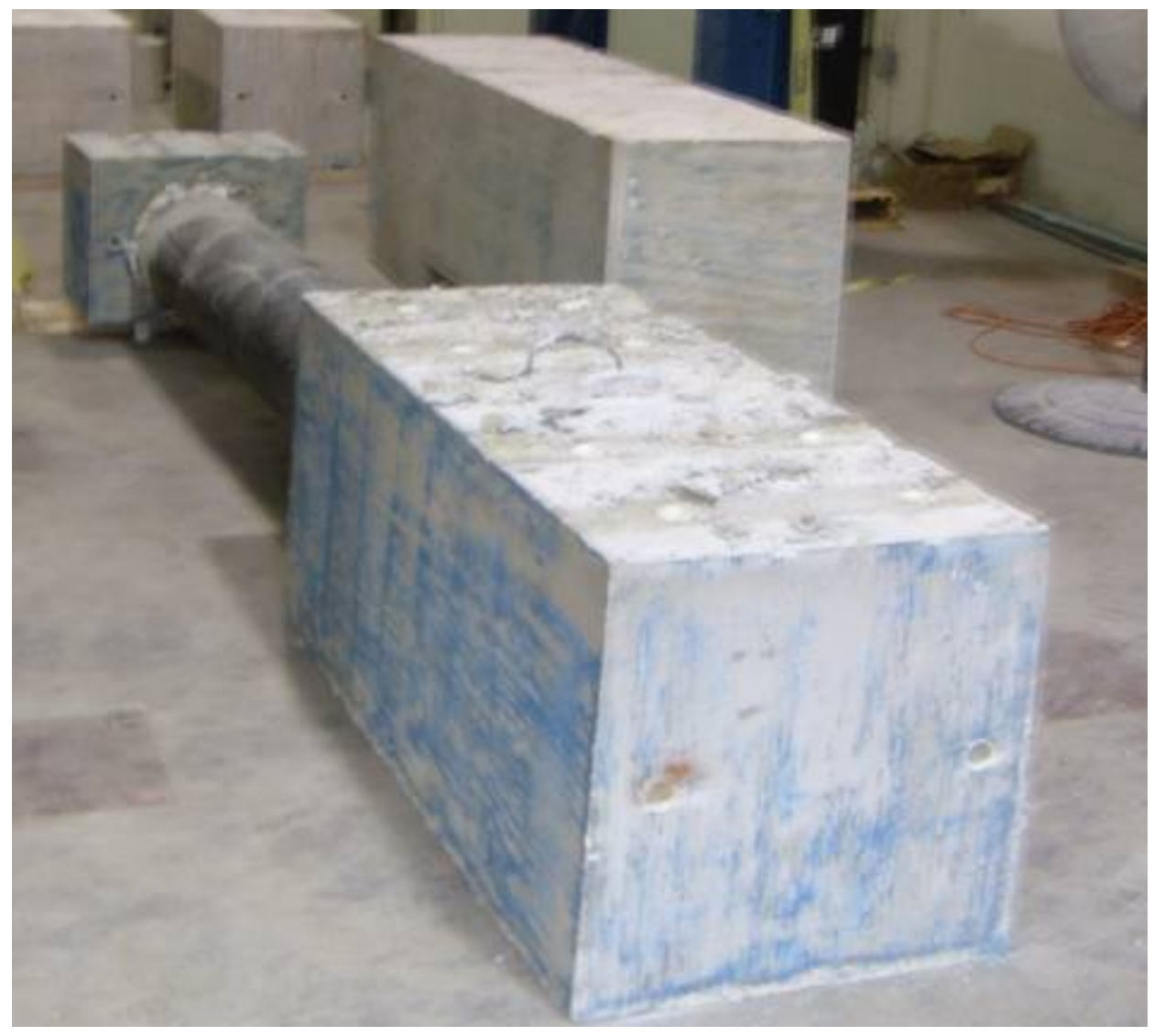

Figure 3.14 Specimen LC and Pedestal after De-Molding 


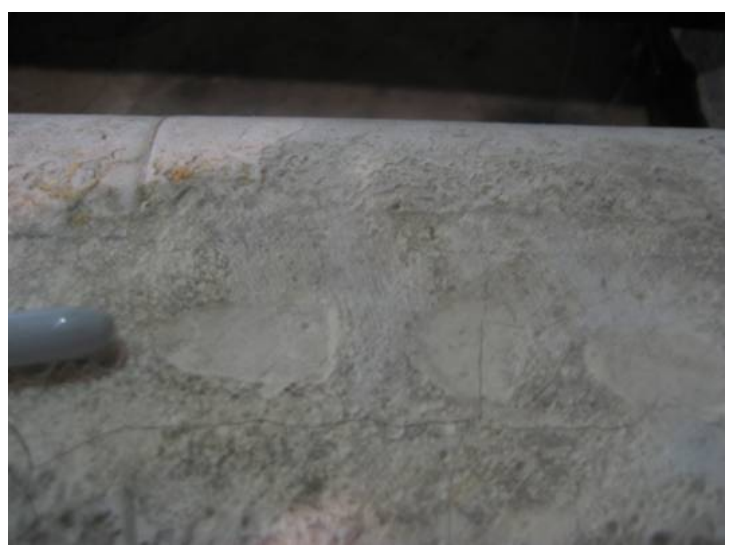

Figure 3.15 Small Pockets of Concrete Void along the Top of Specimen RC

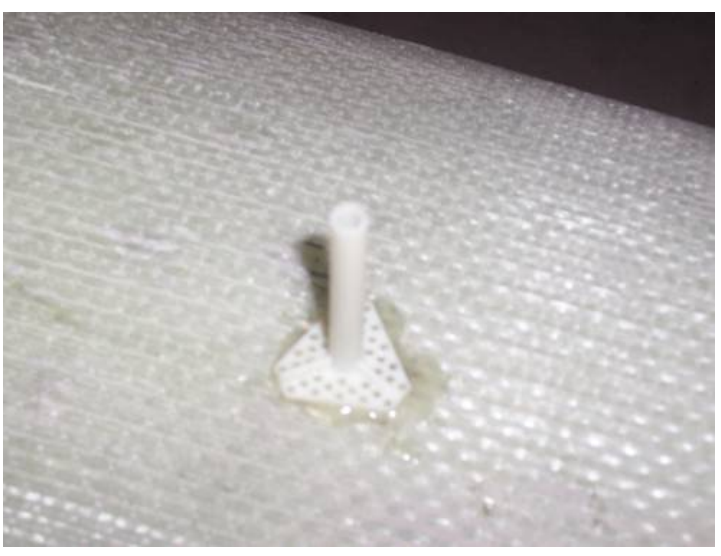

Figure 3.16 Epoxy Injection Port

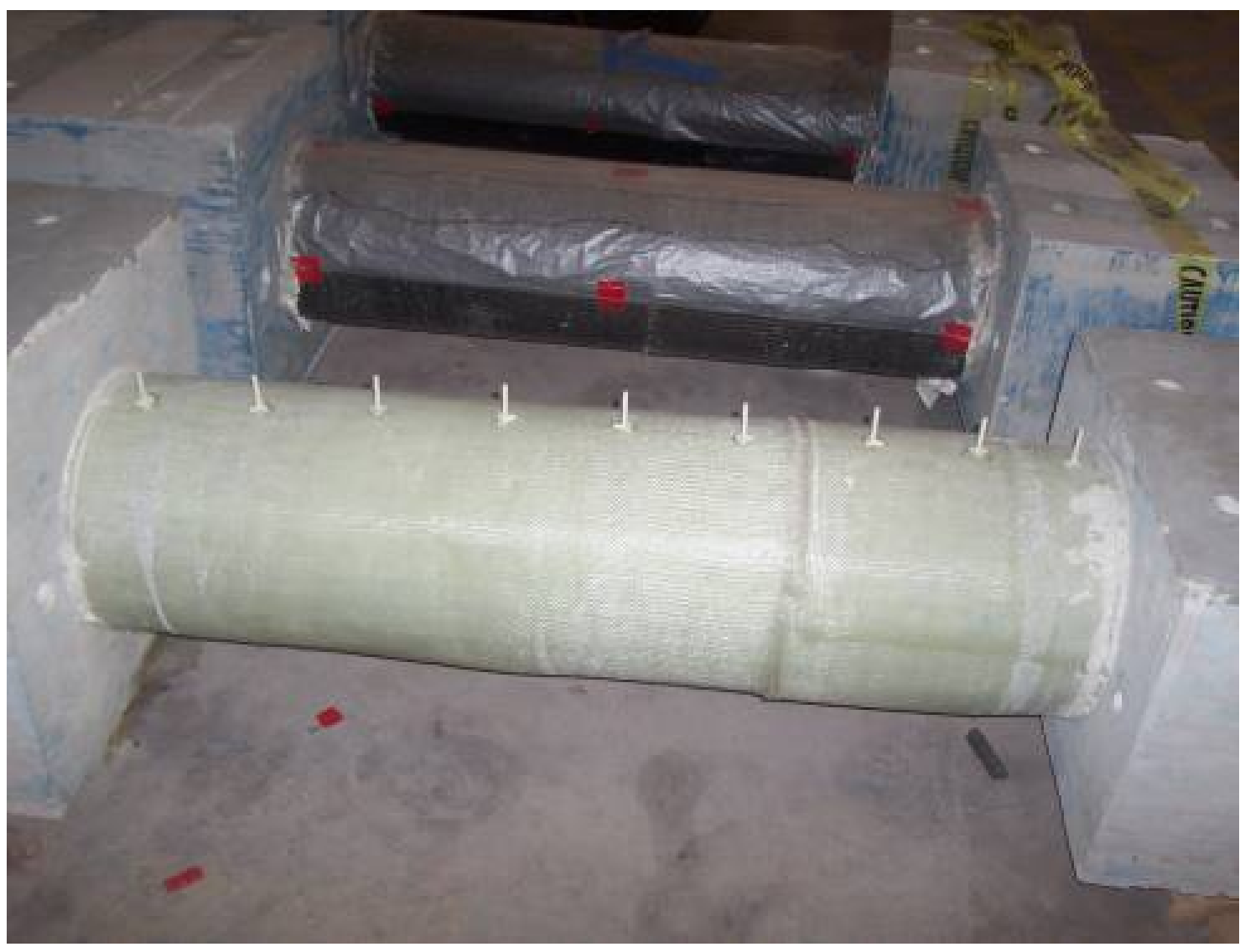

Figure 3.17 Port Layout for Epoxy Injection 


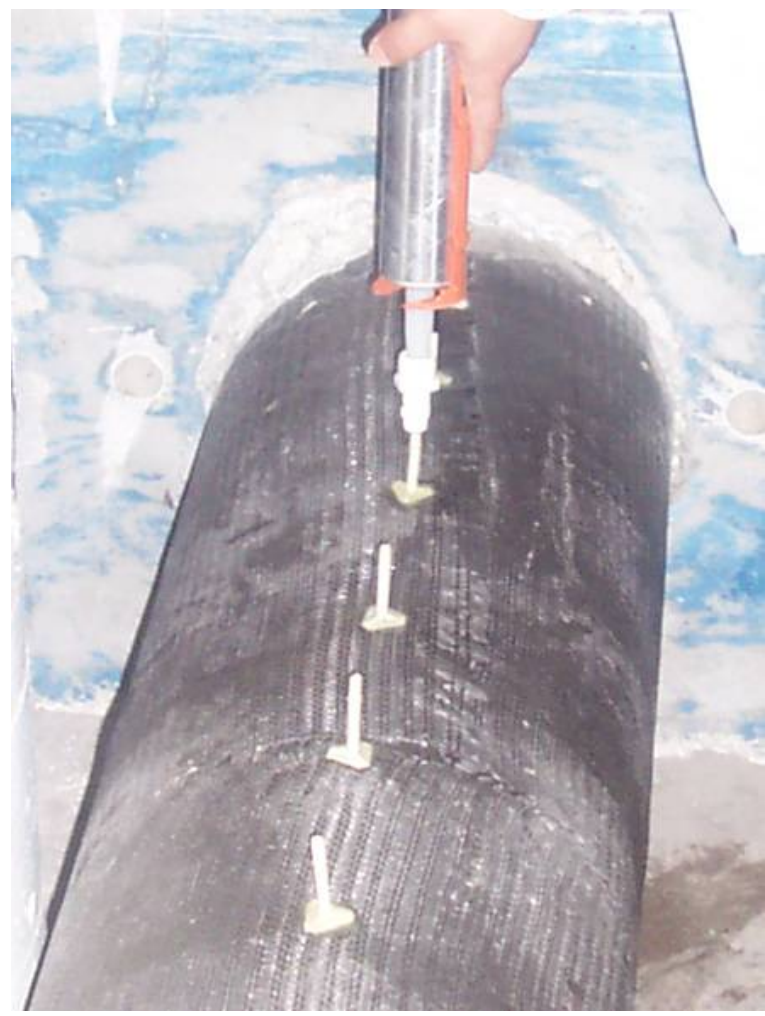

Figure 3.18 Epoxy Injection Process

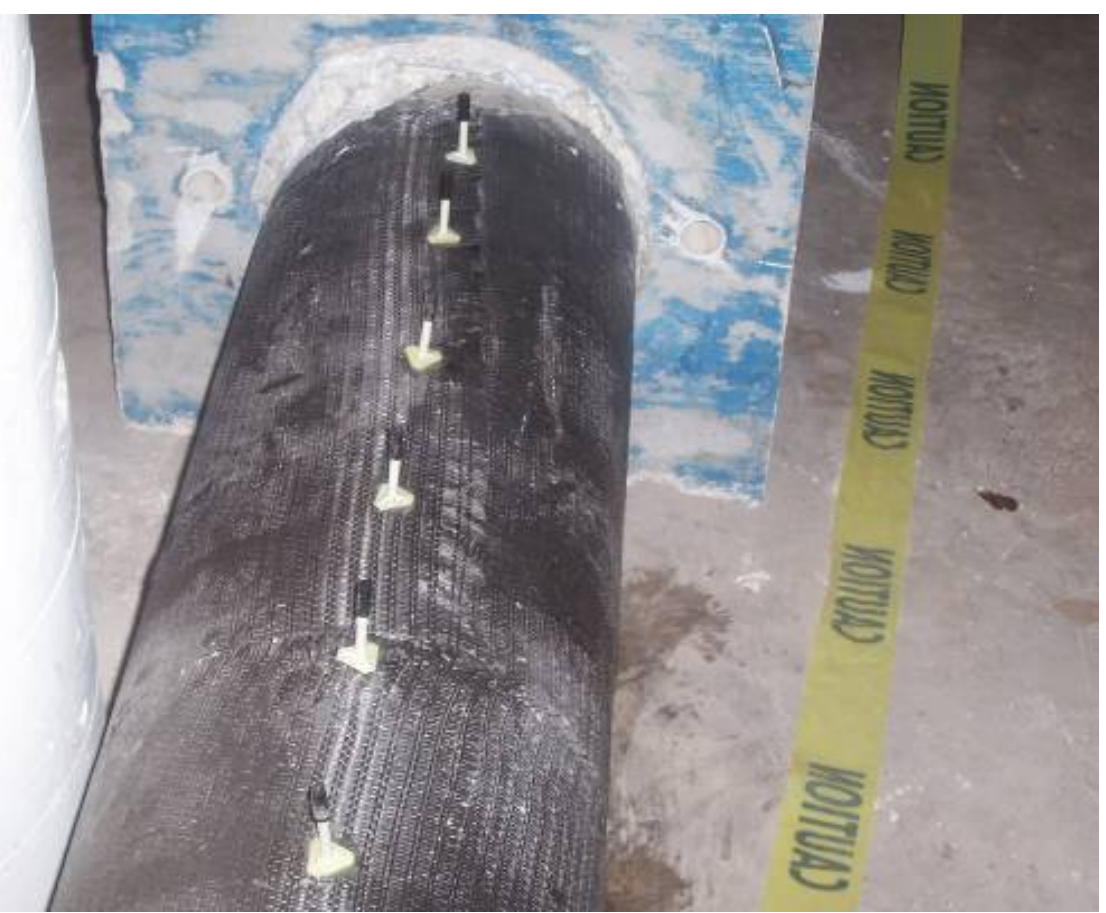

Figure 3.19 Specimen after Epoxy Injection 


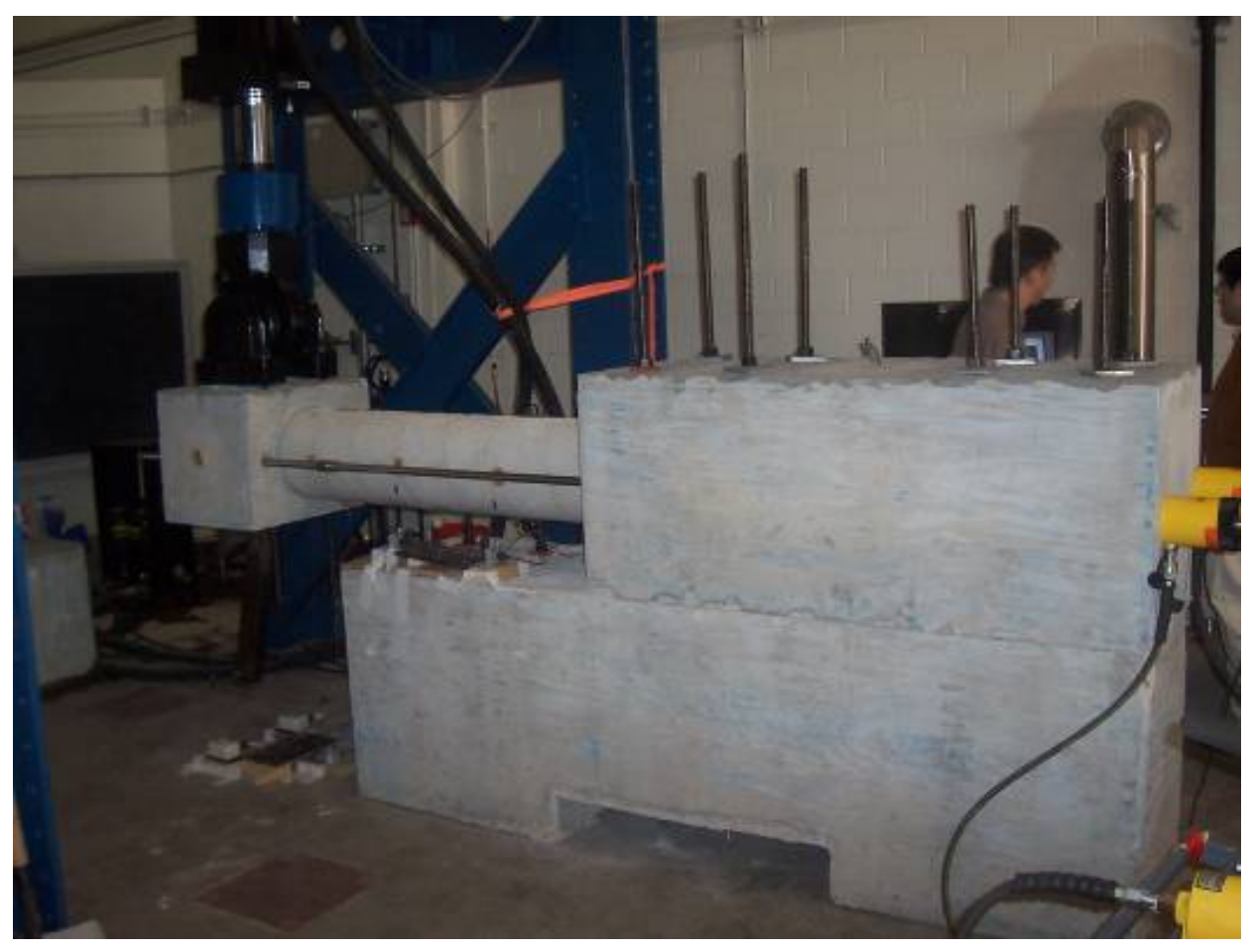

Figure 3.20 Test Setup for Specimen RC

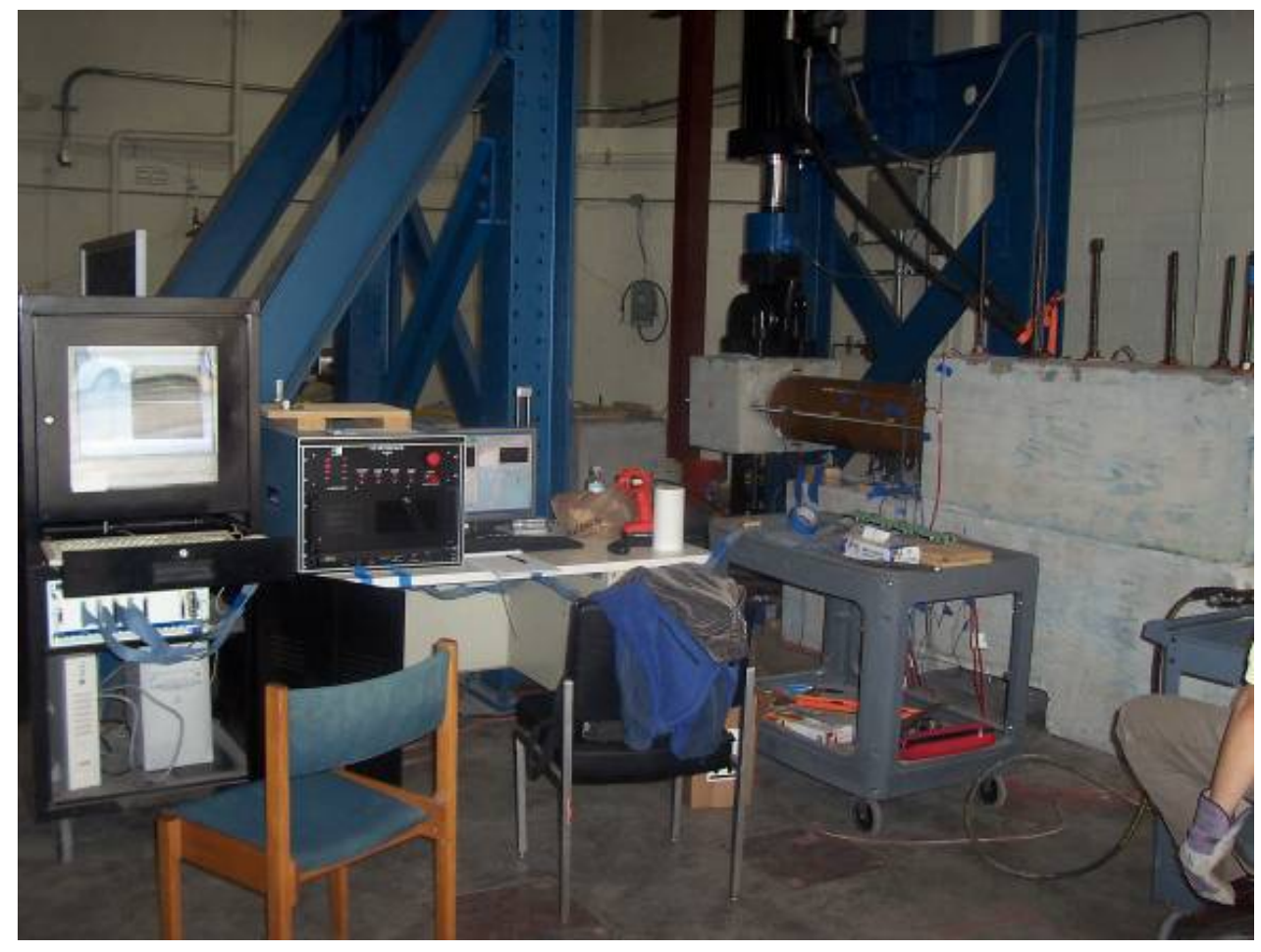

Figure 3.21 Test Setup for Specimen Y 


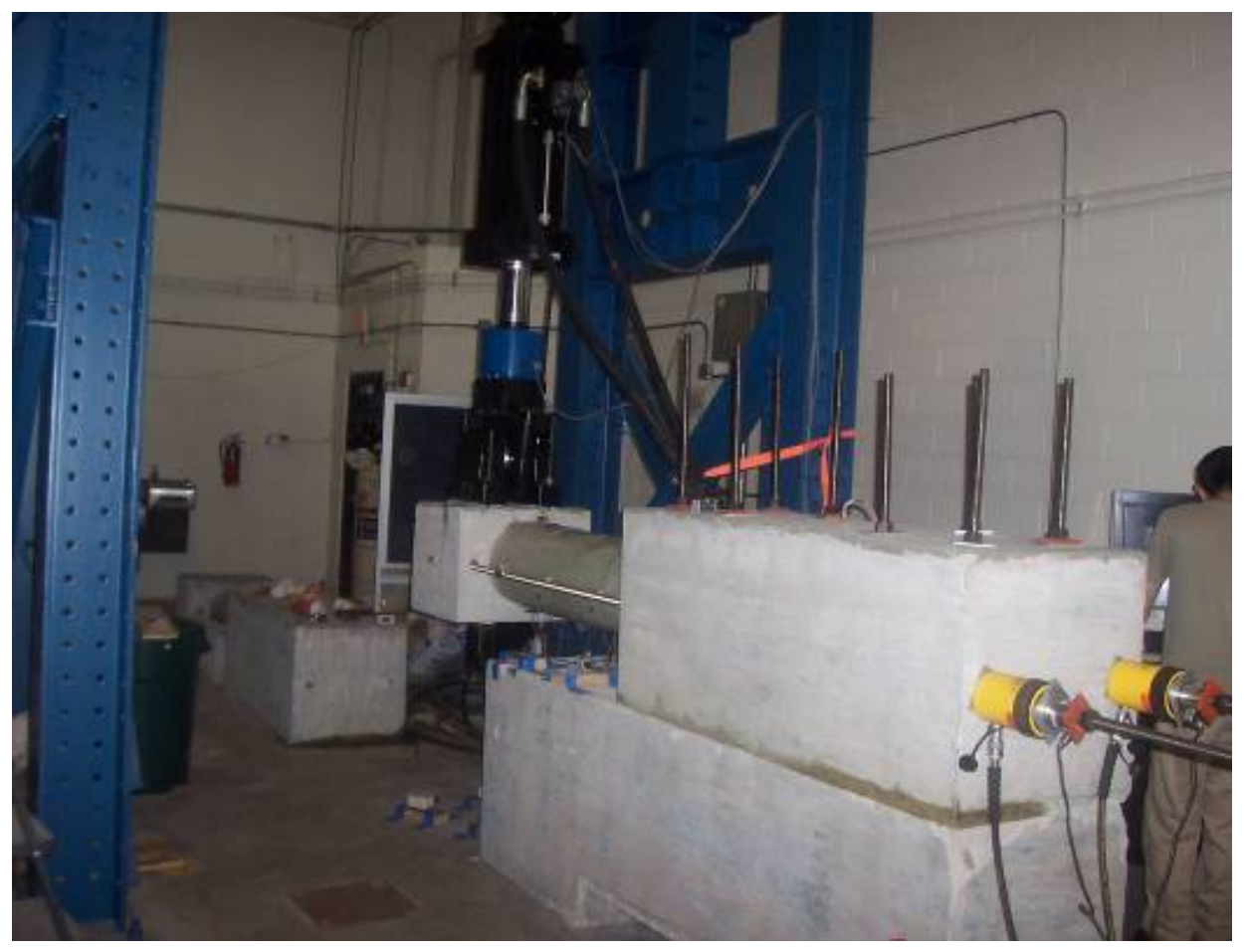

Figure 3.22 Test Setup for Specimen G

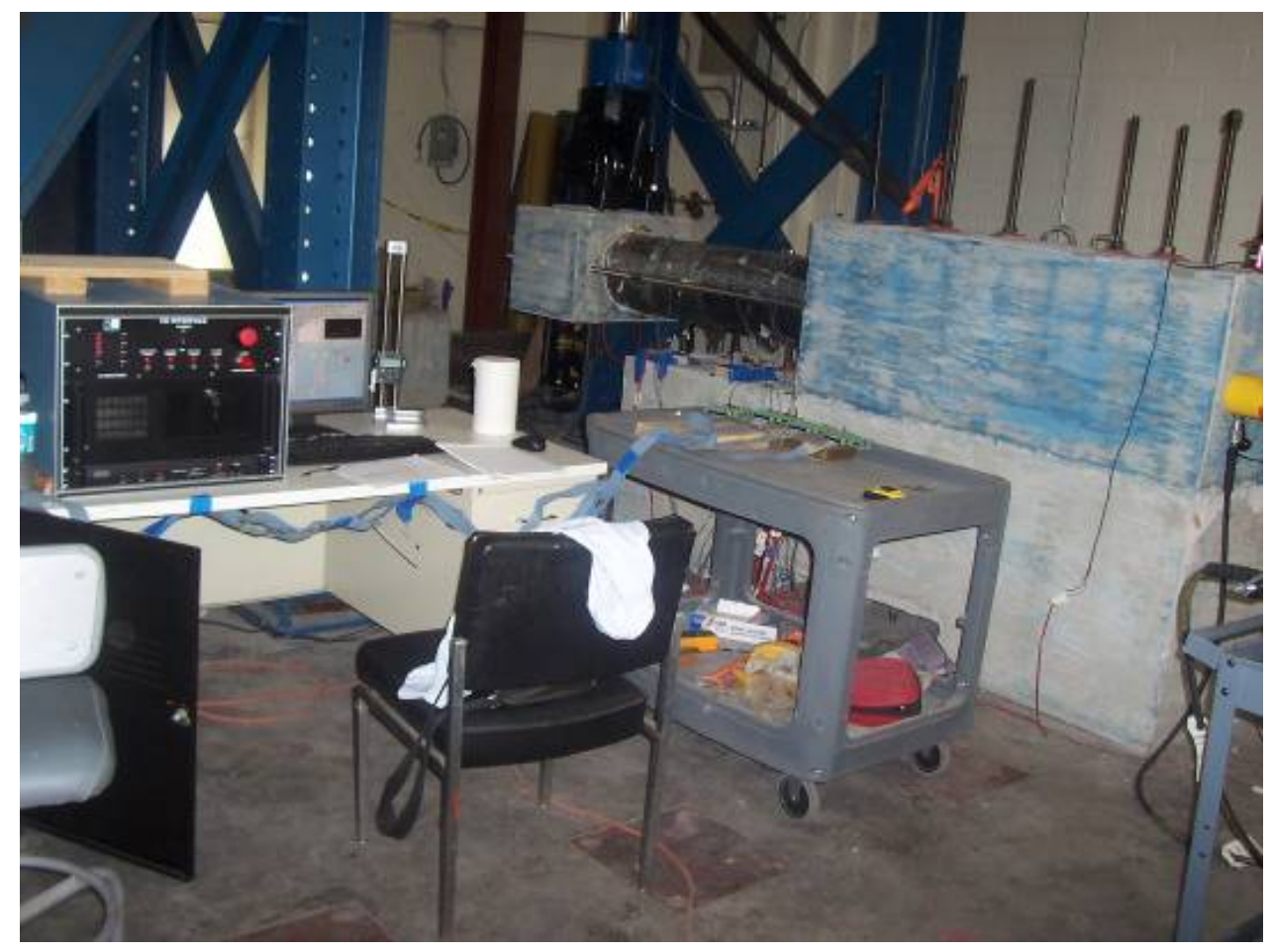

Figure 3.23 Test Setup for Specimen $\mathrm{H}$ 


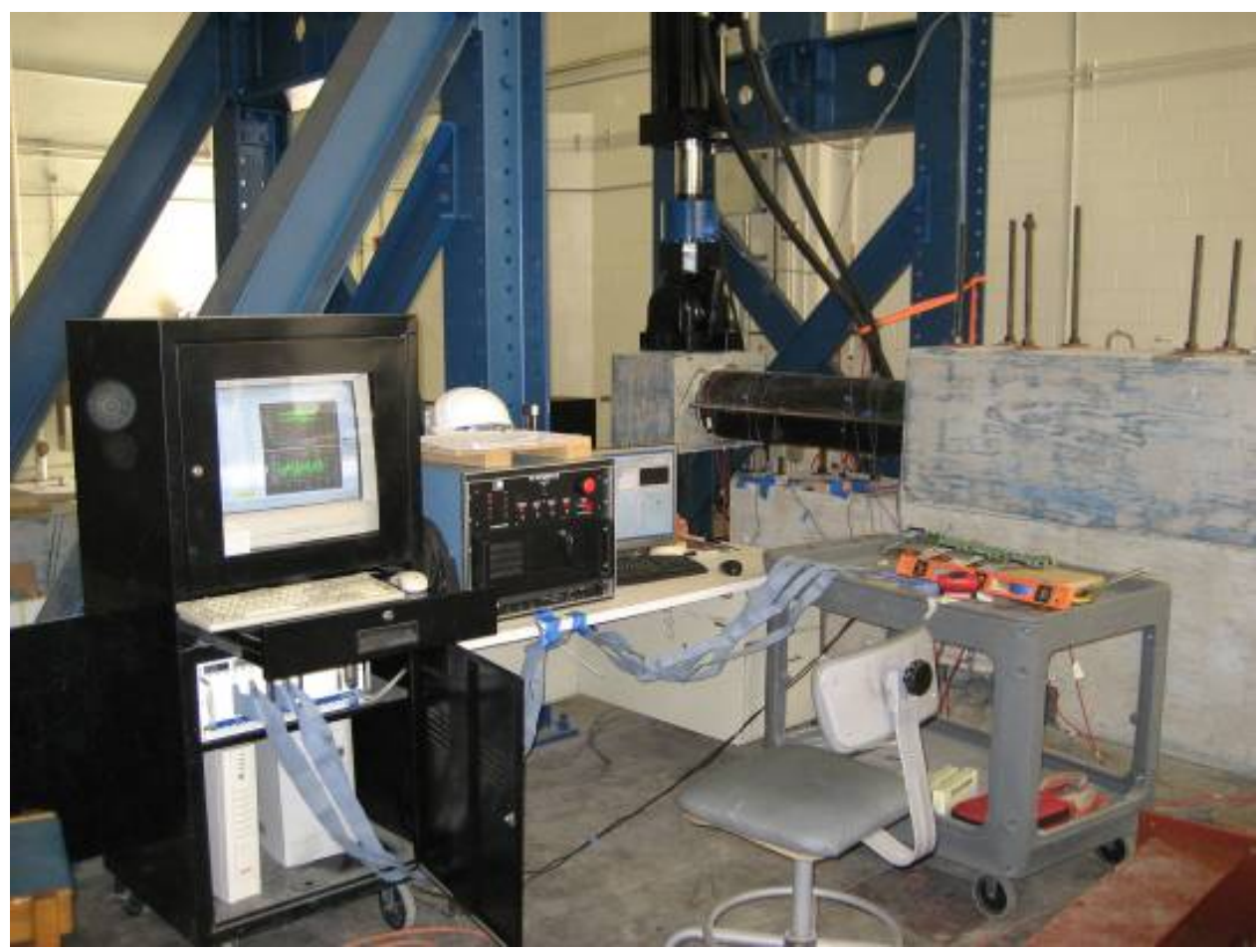

Figure 3.24 Test Setup for Specimen SC

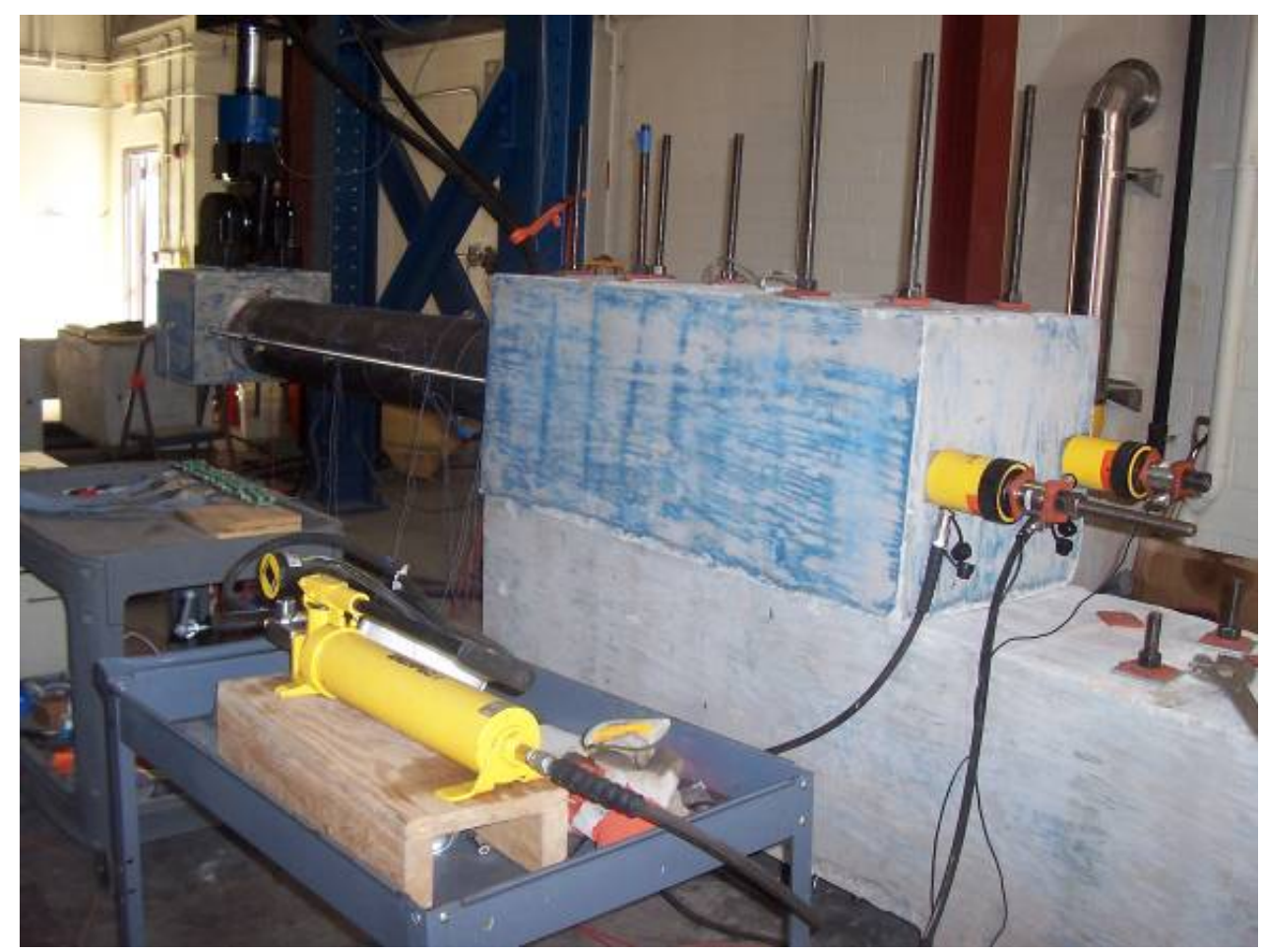

Figure 3.25 Test Setup for Specimen LC 


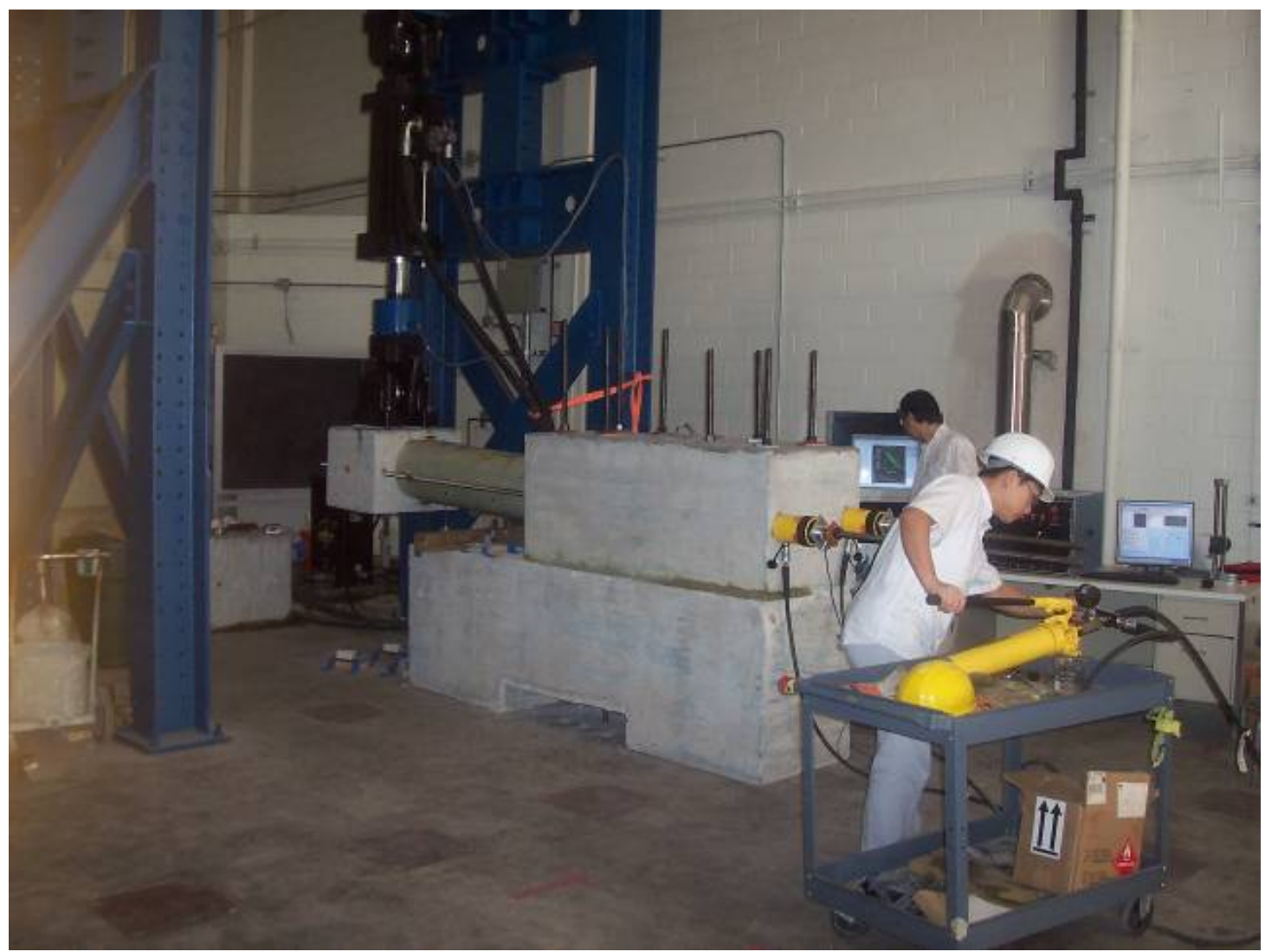

Figure 3.26 Post-Tensioning of Specimen G to Simulate Axial Force

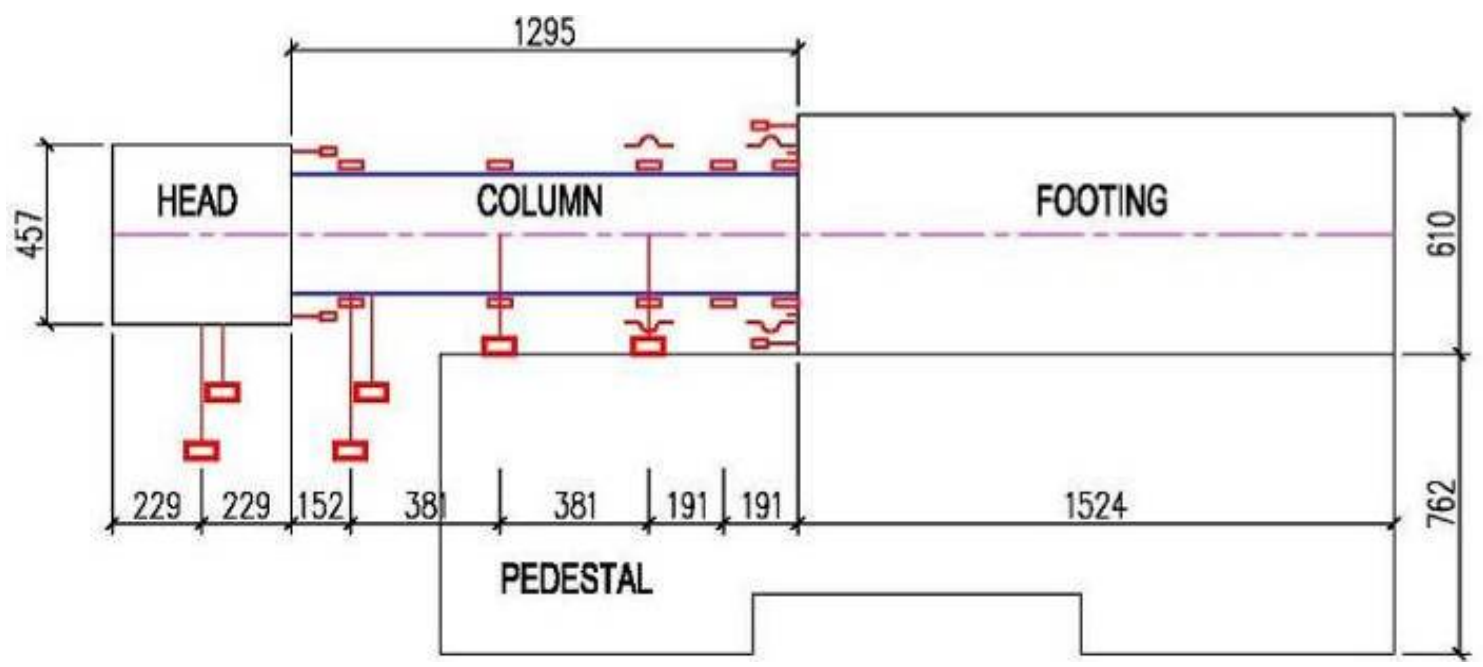

(a) 


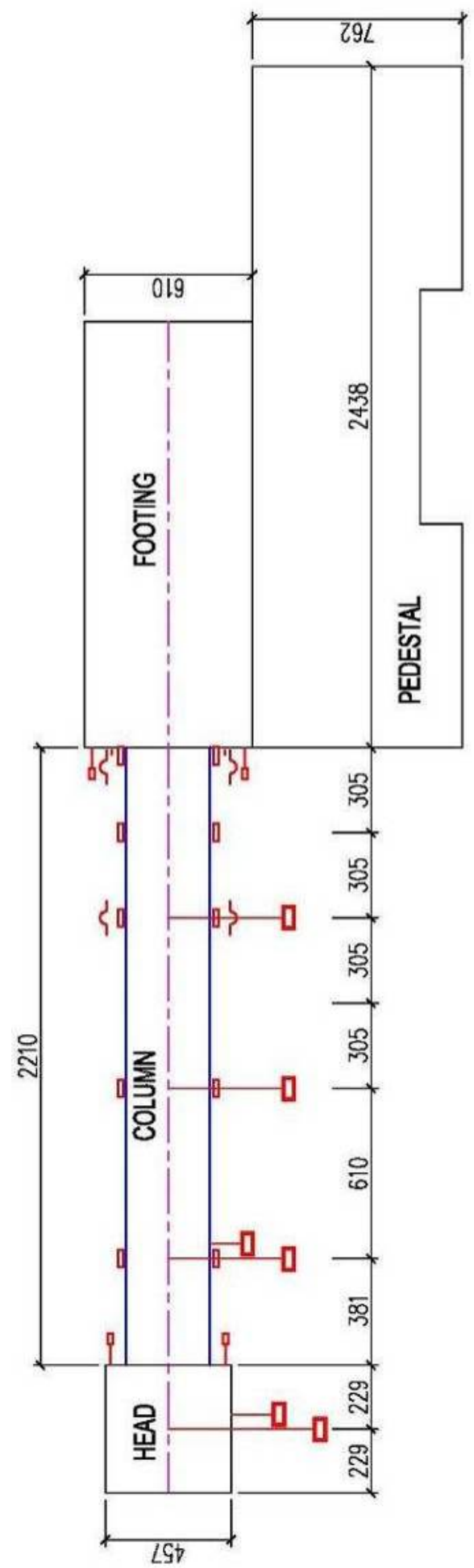

(b)

Figure 3.27 Instrumentation Plan: (a) Short Specimens and (b) Specimen LC 


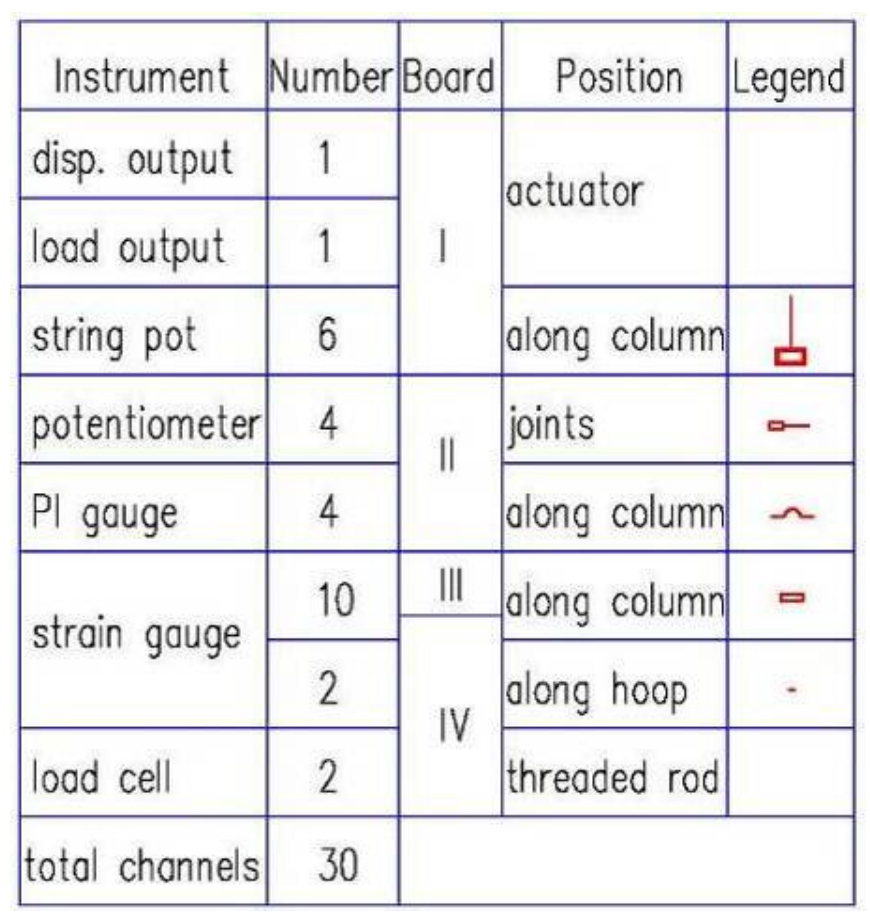

Figure 3.28 Instrumentation Legend

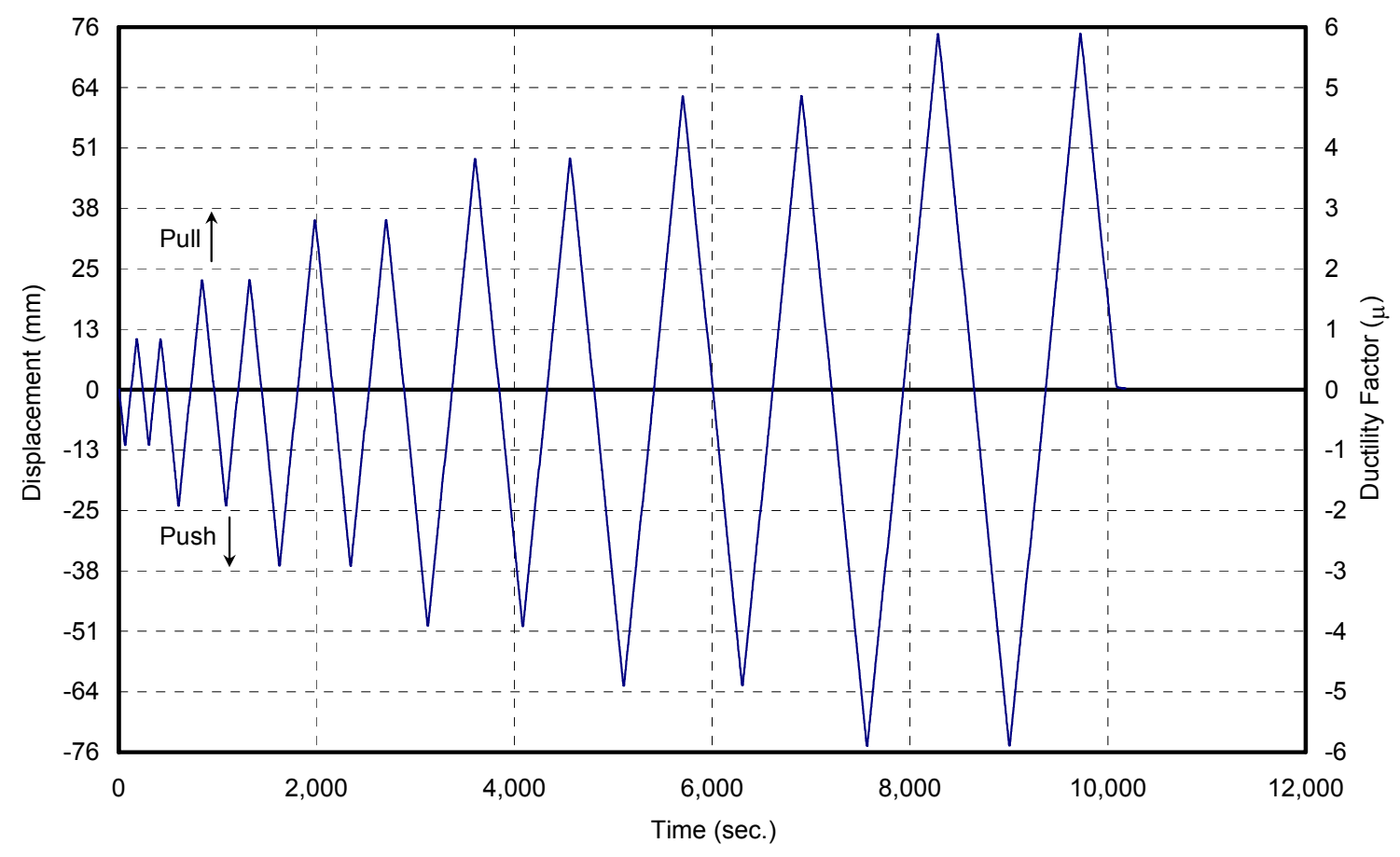

Figure 3.29 Loading Regime of Cyclic Tests 


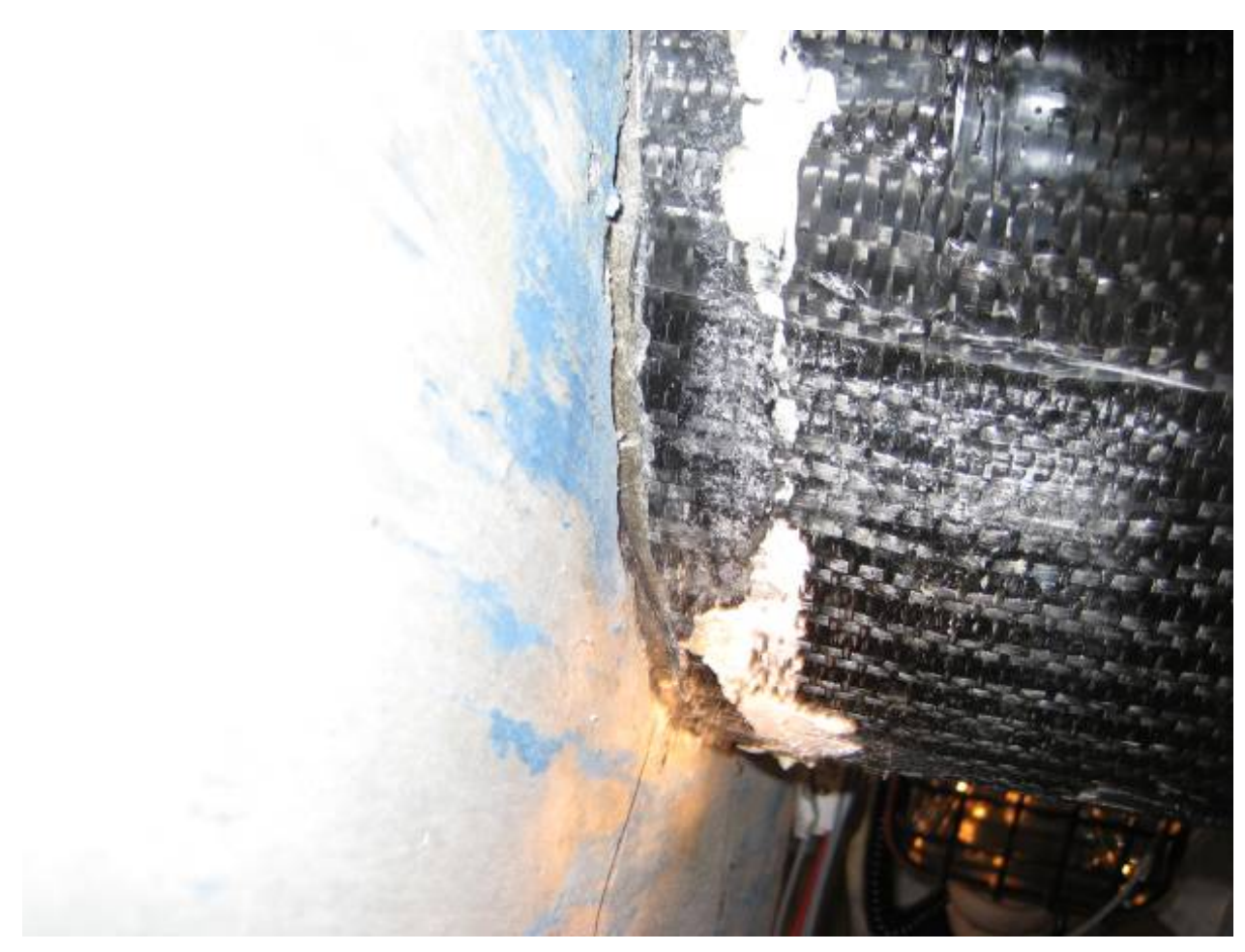

Figure 3.30 Bottom Fiber Crack in Specimen SC

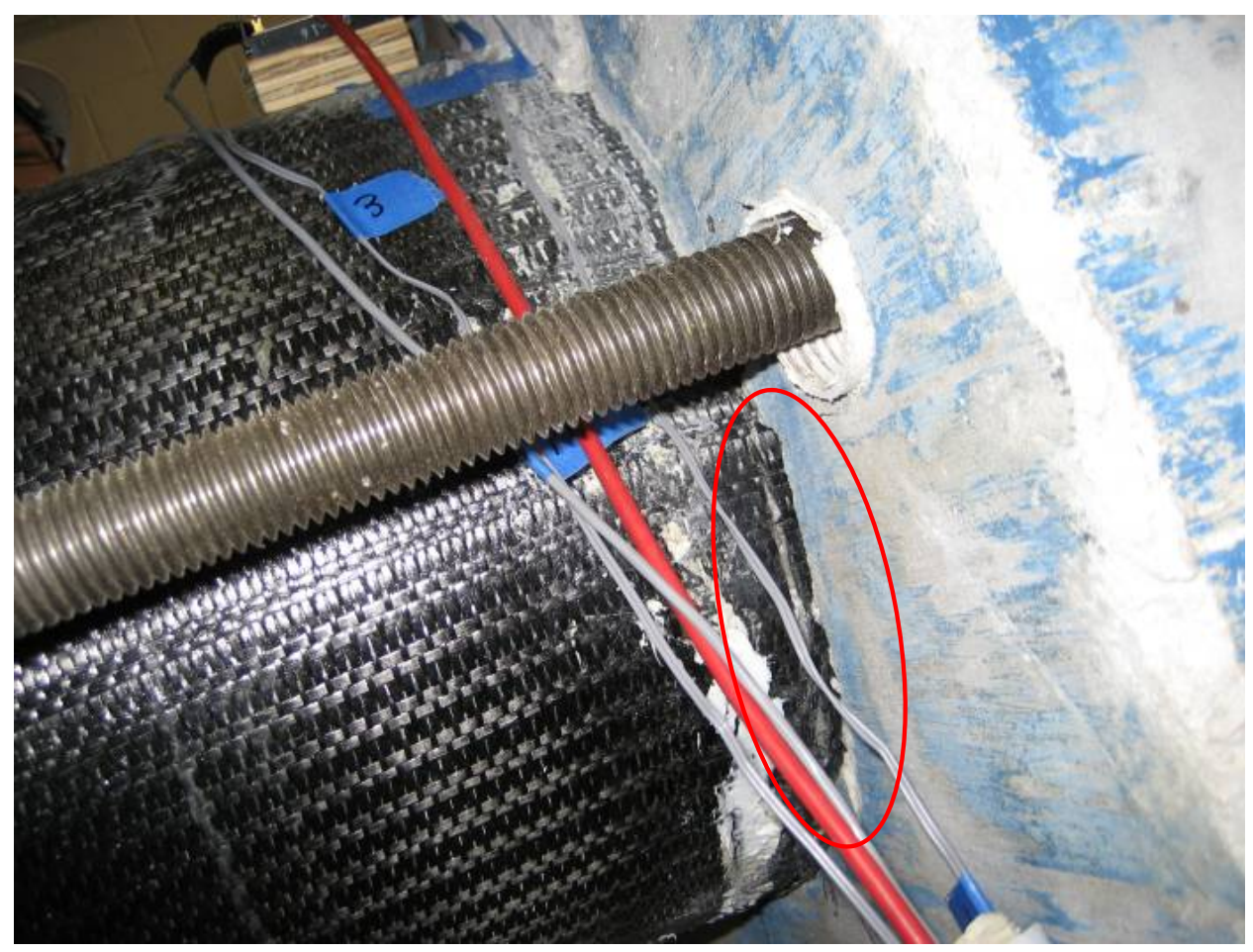

Figure 3.31 Top Fiber Crack in Specimen SC 


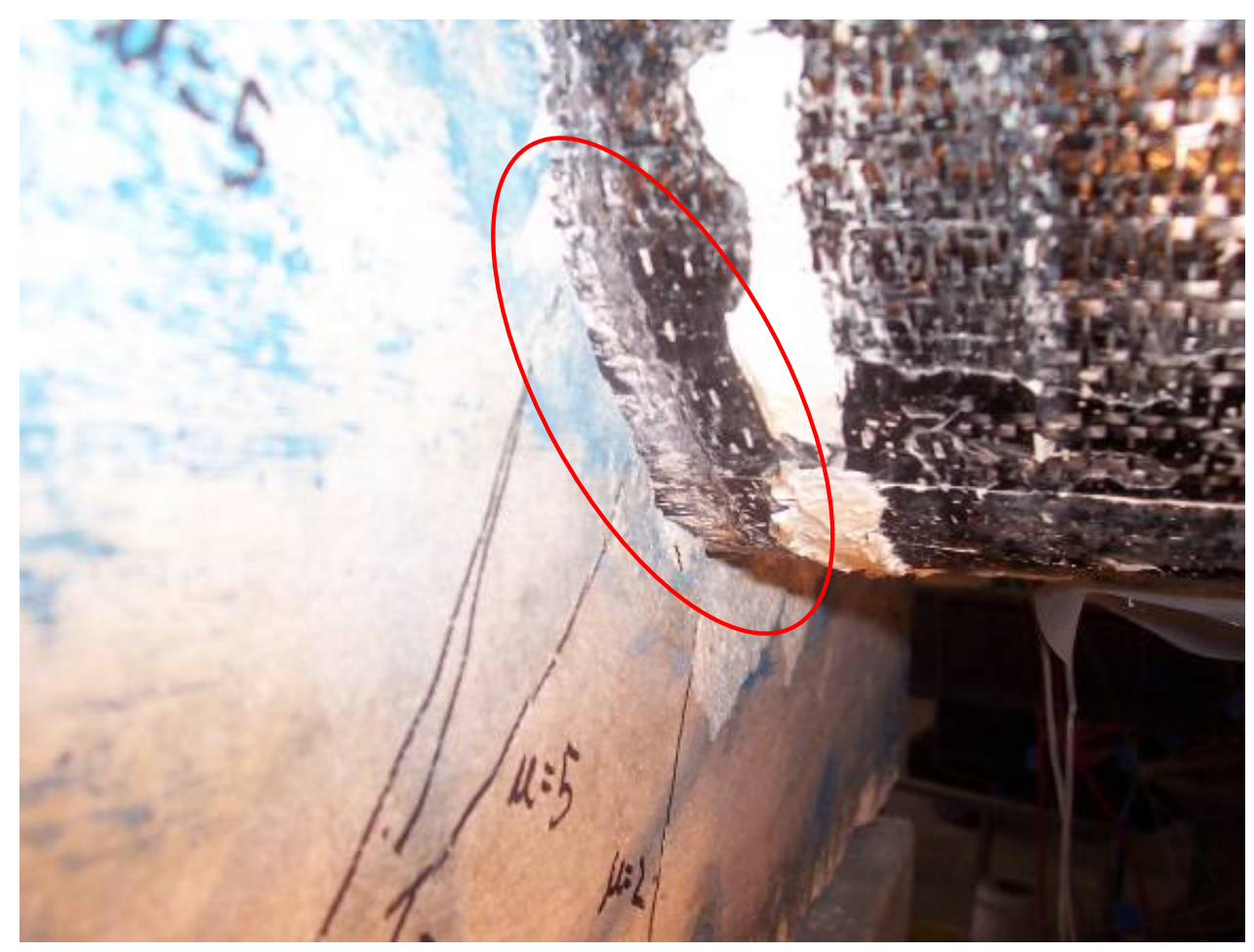

Figure 3.32 Bottom Fiber Crack in Specimen LC

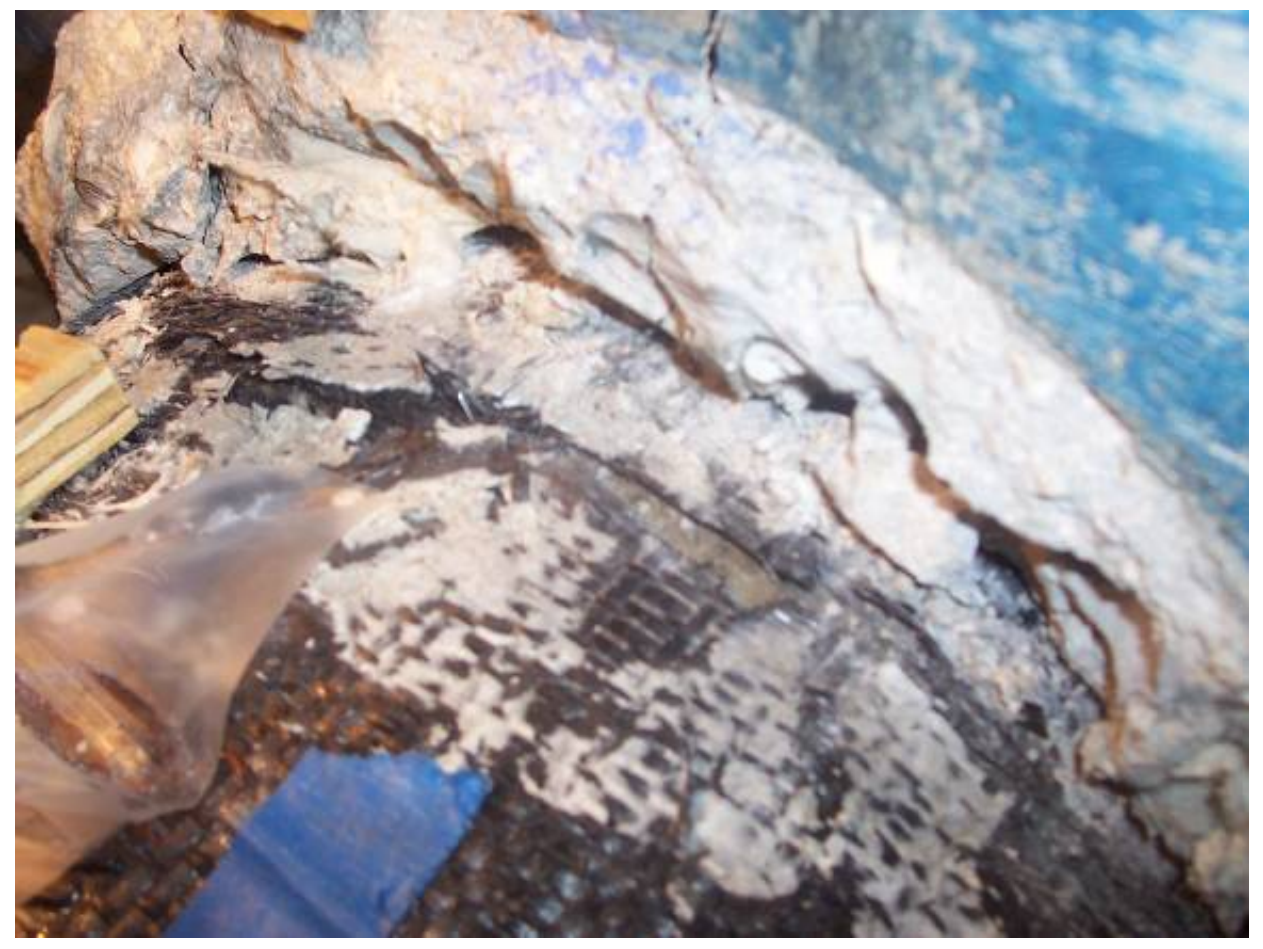

Figure 3.33 Top Fiber Crack in Specimen LC 


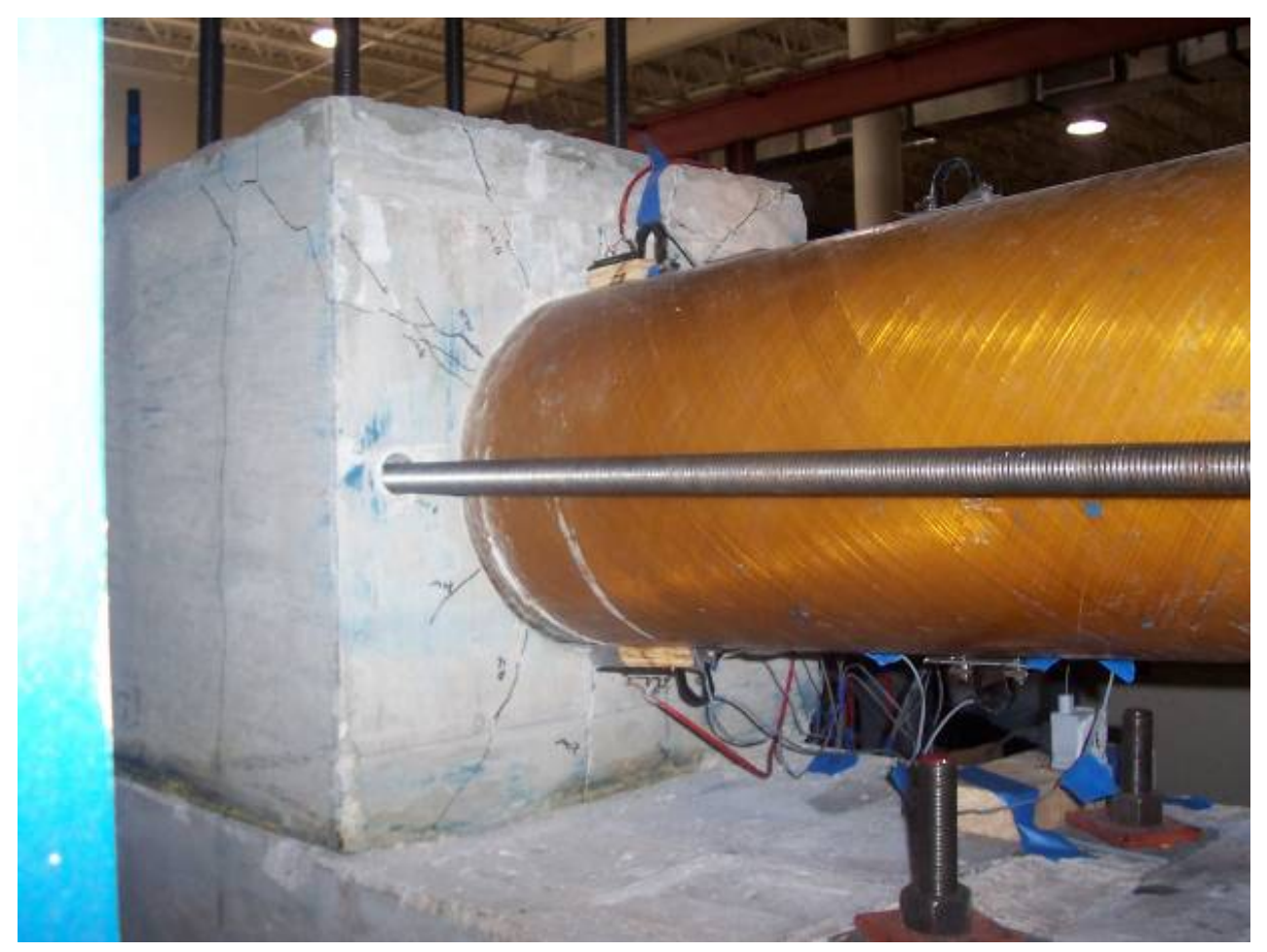

Figure 3.34 Footing Cracks in Specimen Y

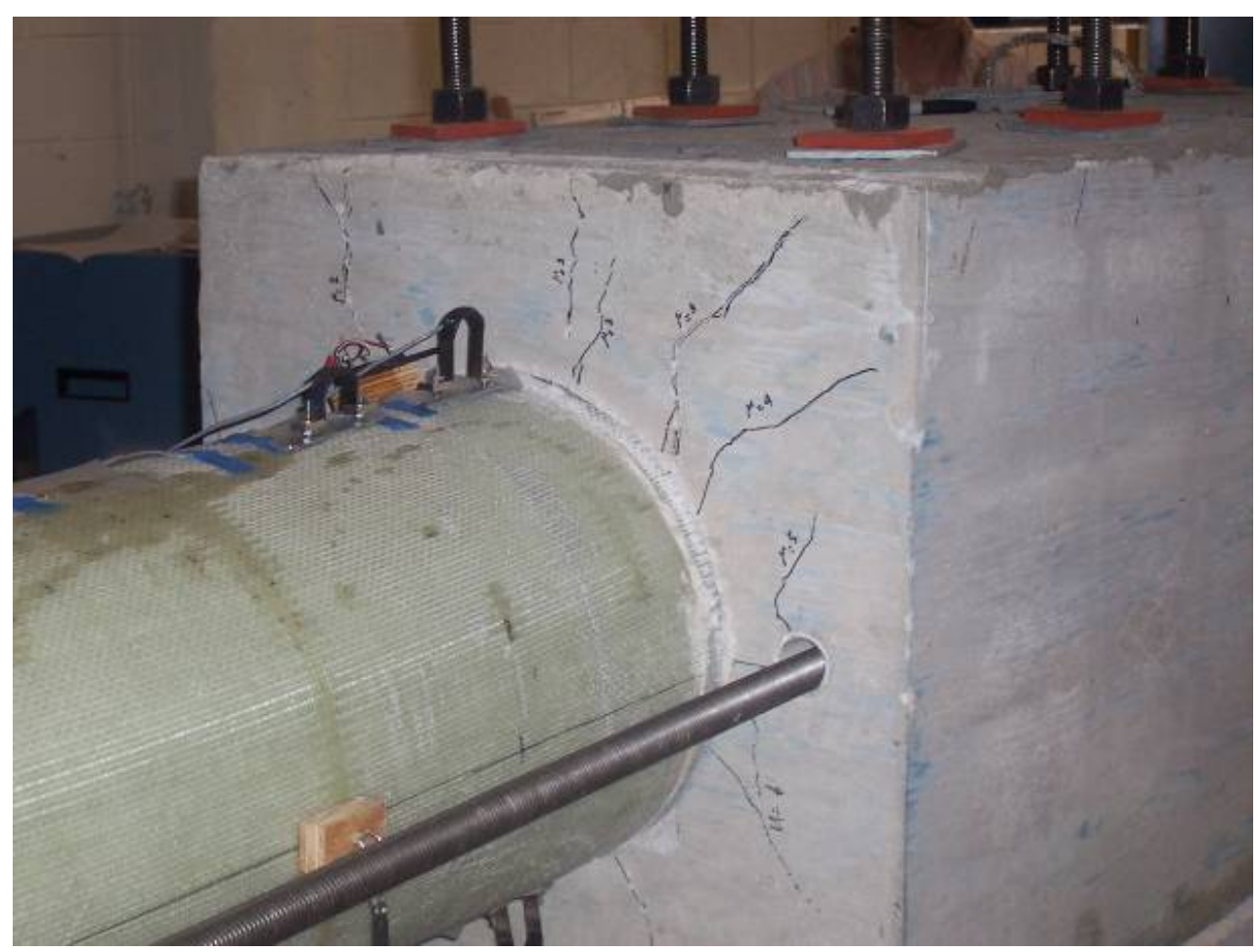

Figure 3.35 Footing Cracks in Specimen G 


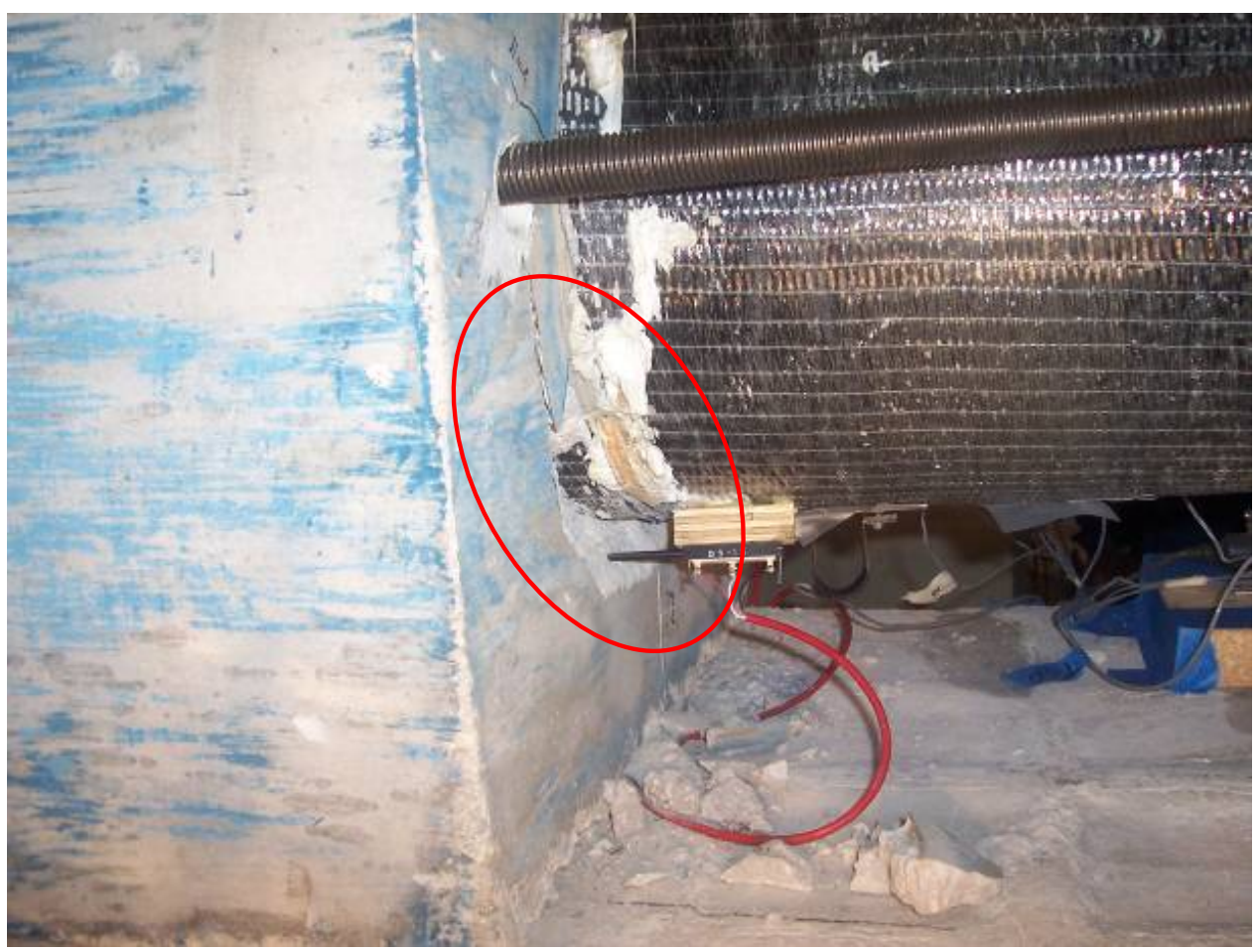

Figure 3.36 Concrete Spalling in Footing of Specimen H

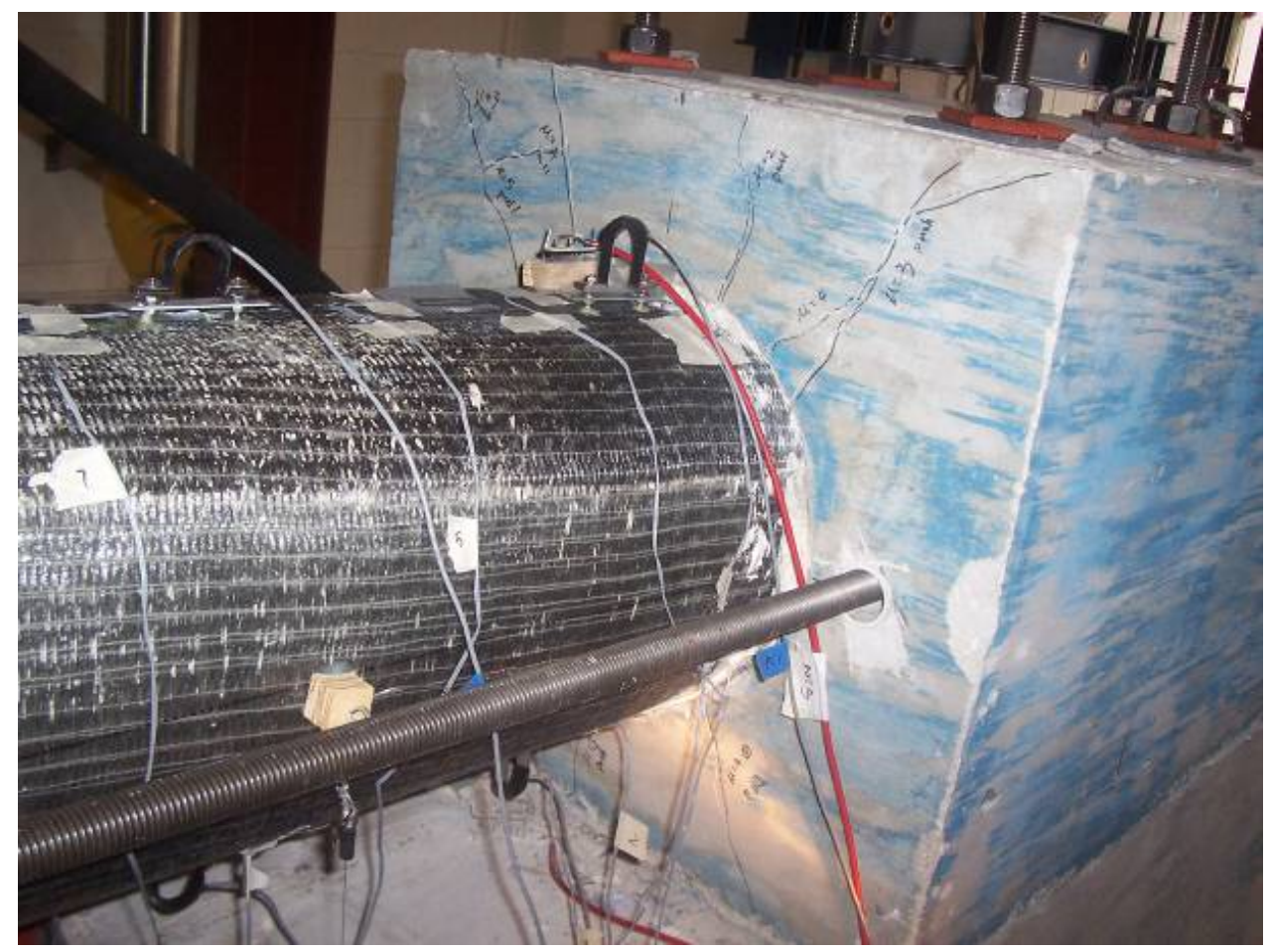

Figure 3.37 Footing Cracks in Specimen H 


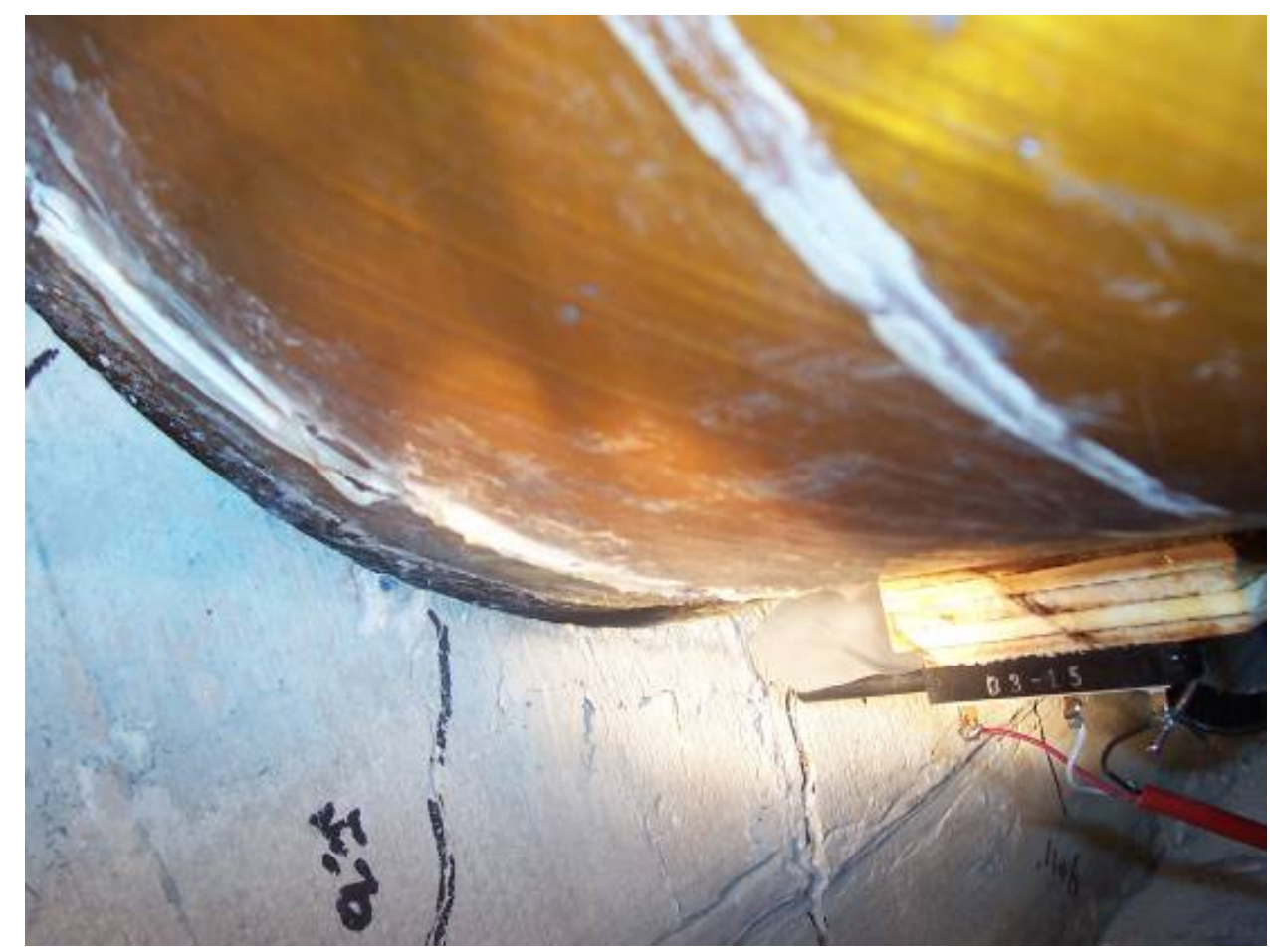

Figure 3.38 Separation between FRP Tube and RC Footing in Specimen Y

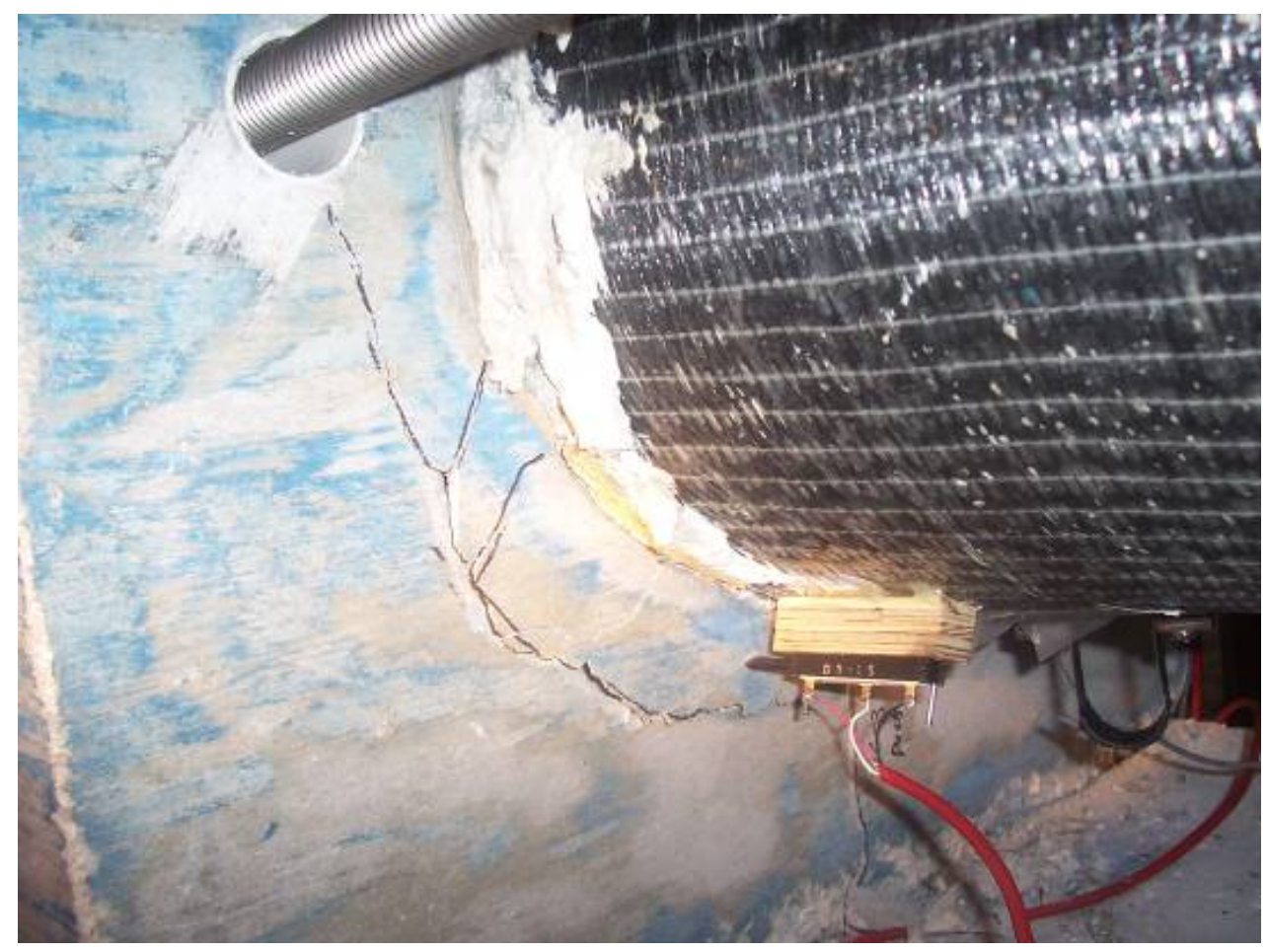

Figure 3.39 Splitting of Concrete Footing in Specimen H 


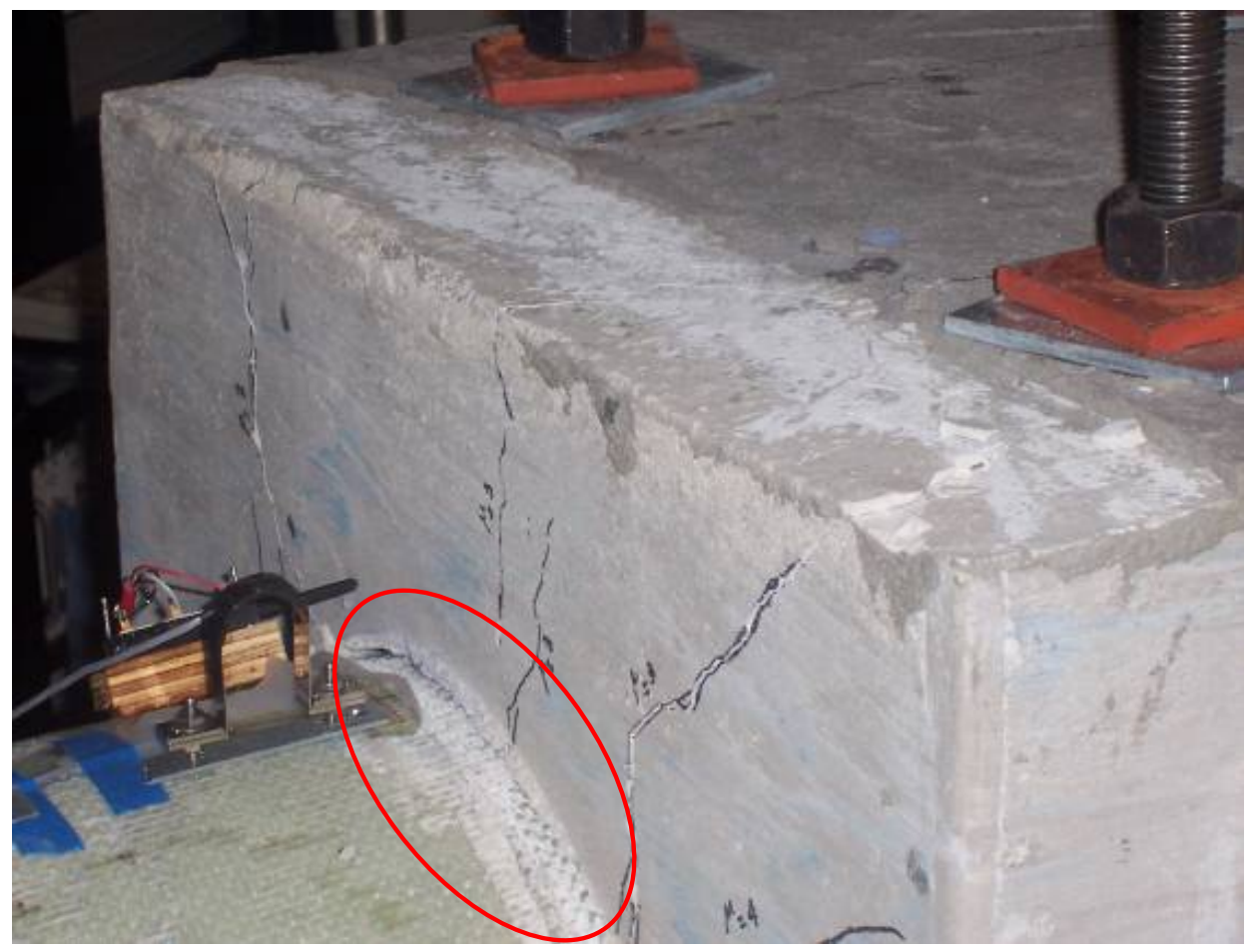

Figure 3.40 Tube Embedment Intact for Specimen $\mathrm{G}$ until $\mu=3$

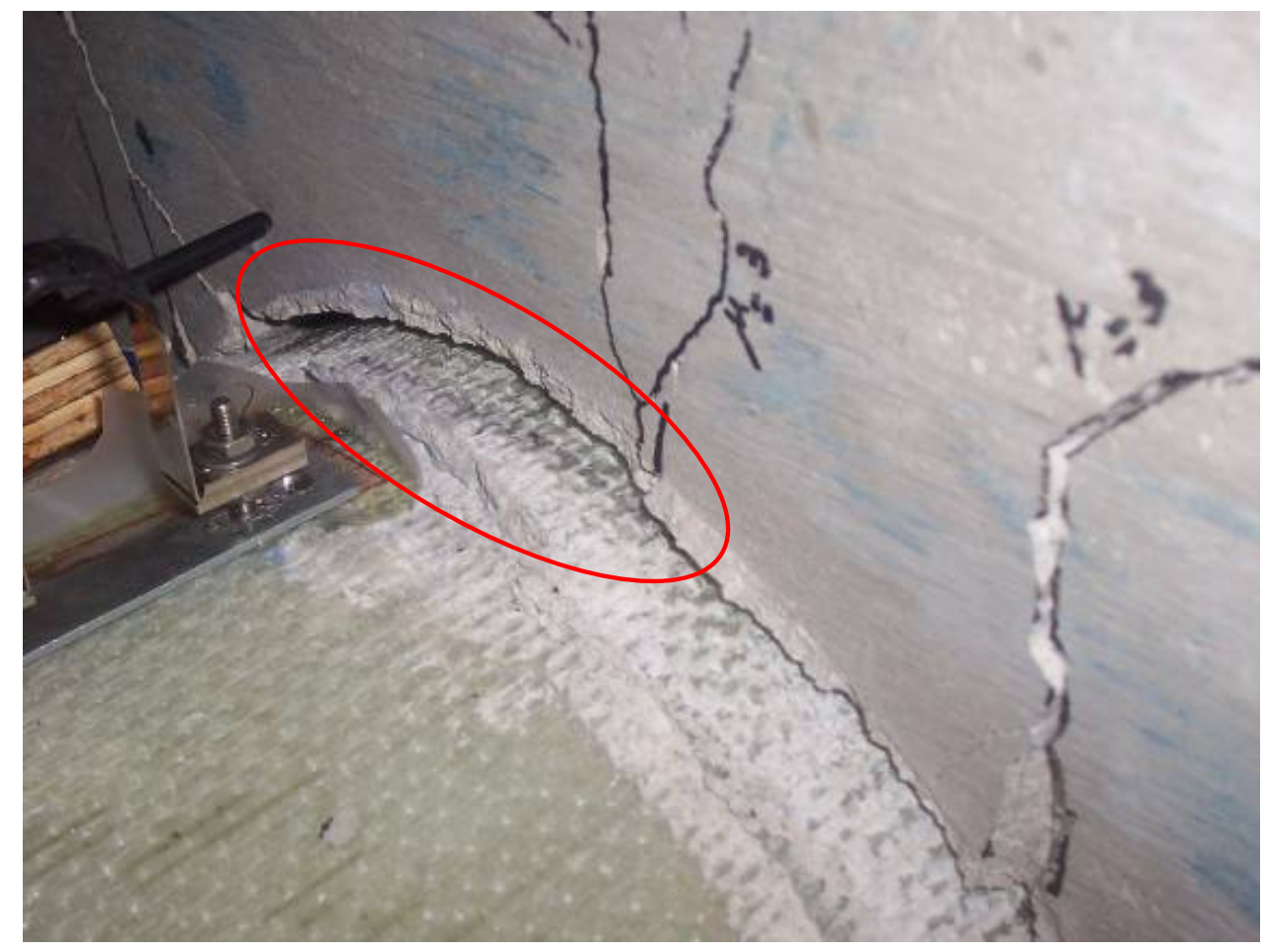

Figure 3.41 Tube Slippage in Specimen G 


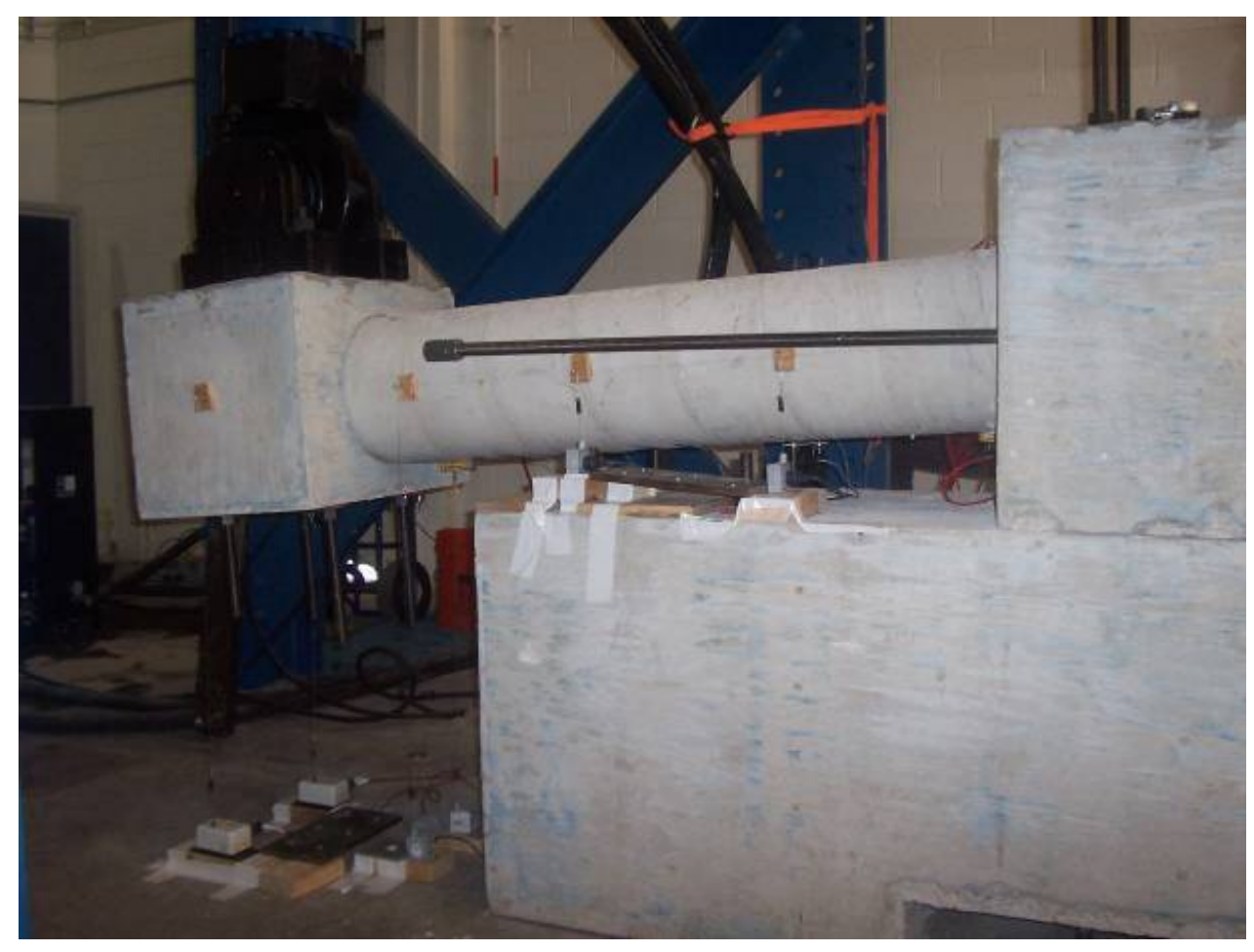

Figure 3.42 Specimen RC at $\mu$ of 10 without Axial Load

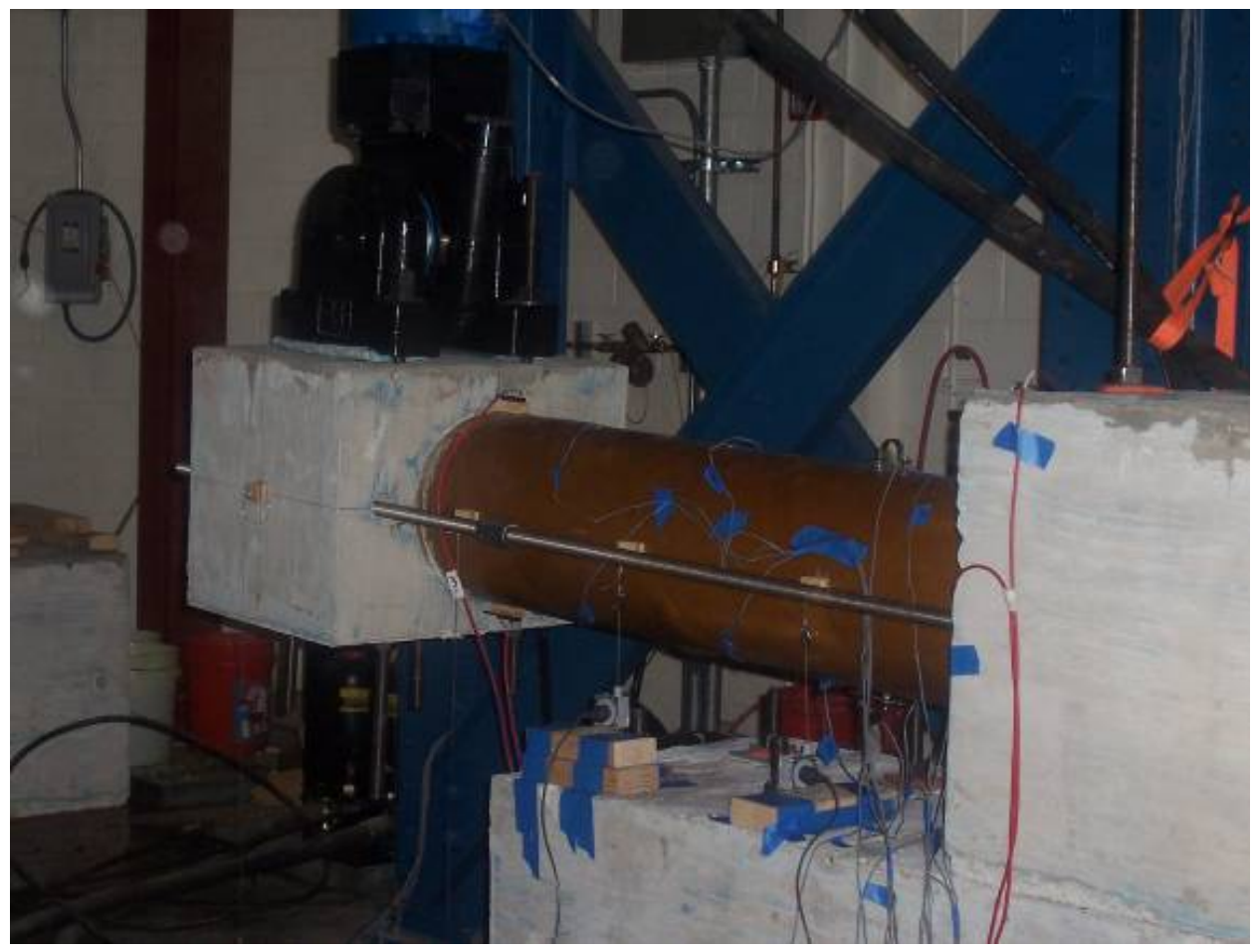

Figure 3.43 Specimen $\mathrm{Y}$ at $\mu$ of 8 


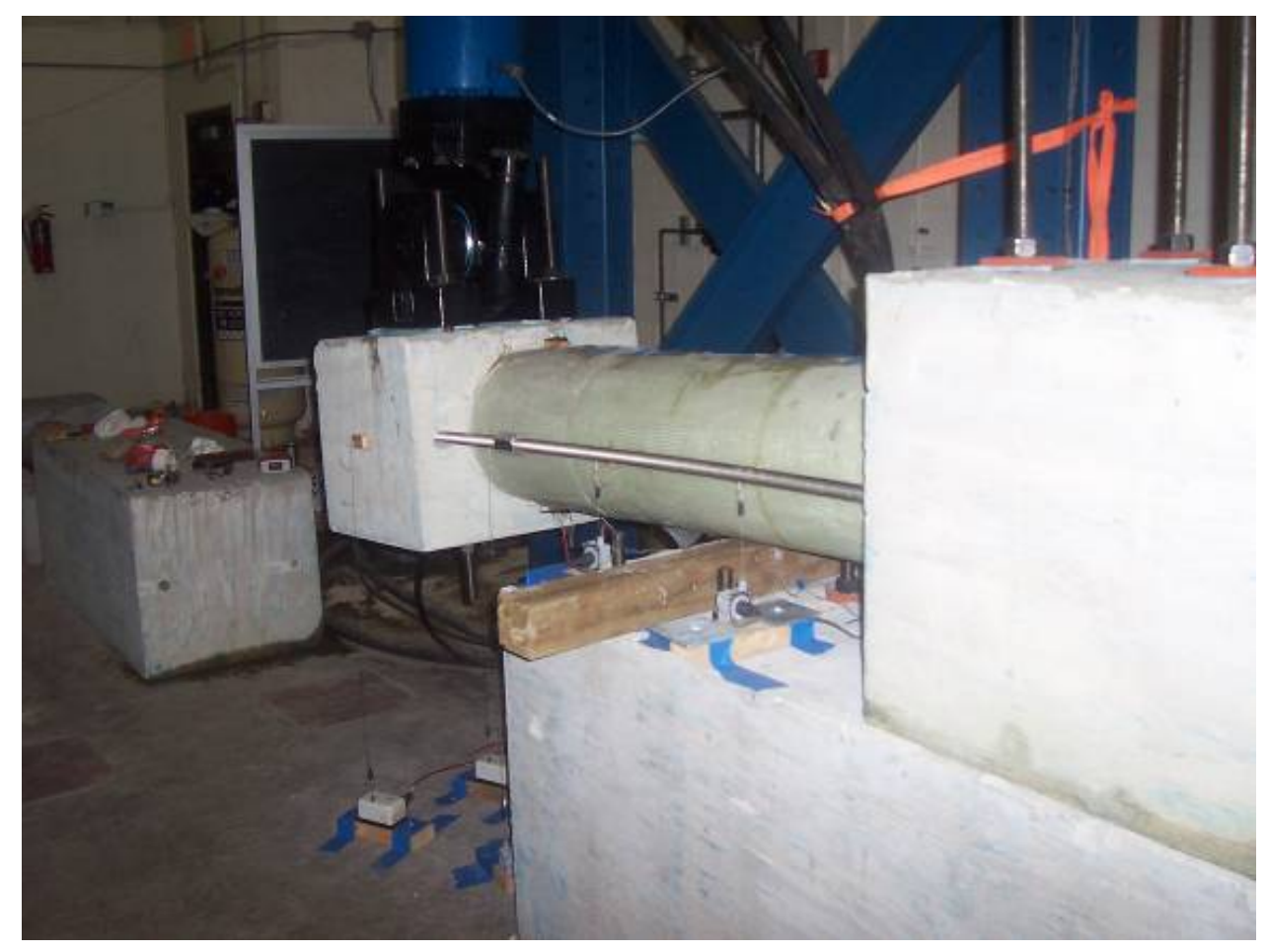

Figure 3.44 Specimen $\mathrm{G}$ at $\mu$ of 10

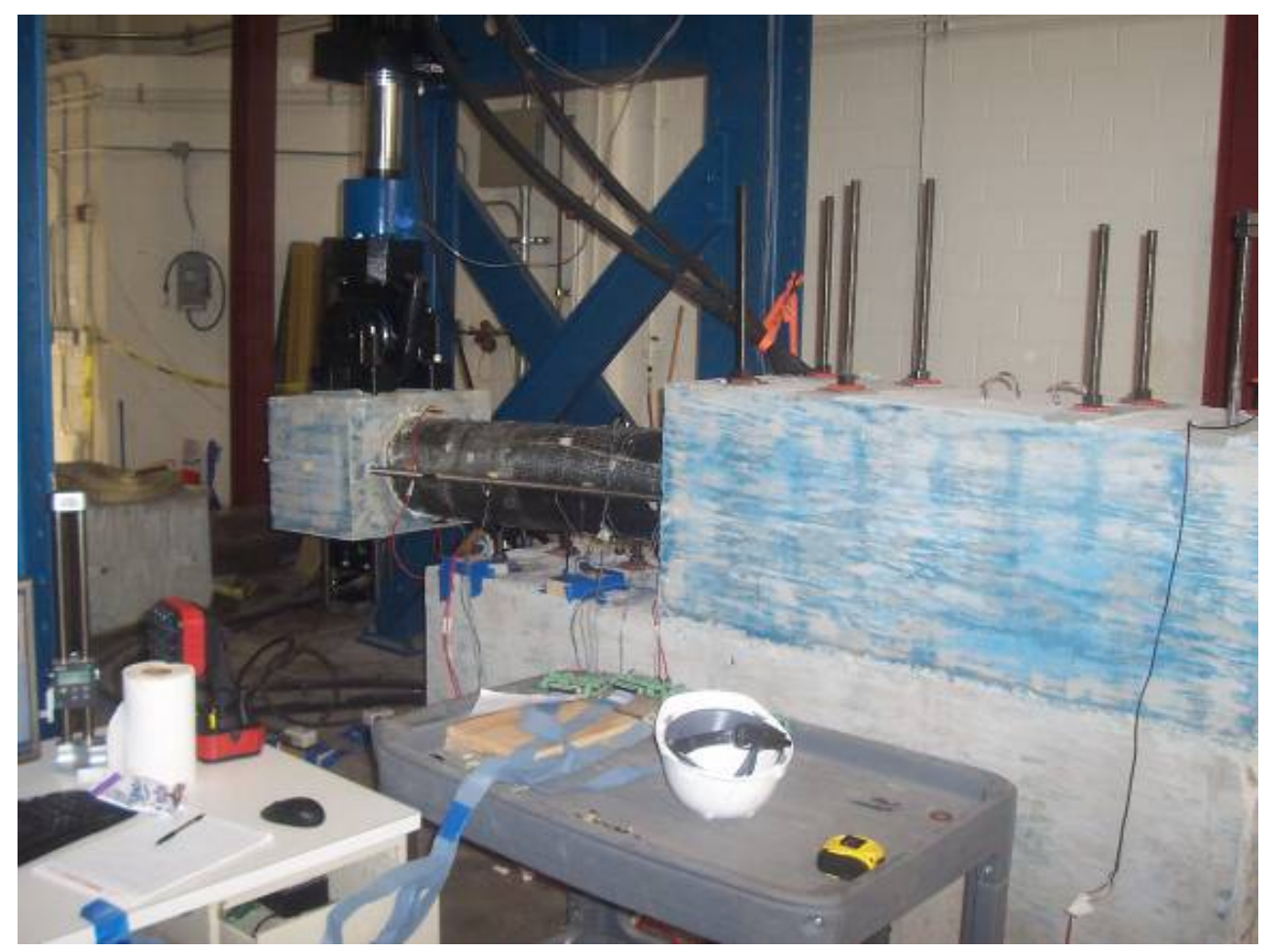

Figure 3.45 Specimen $H$ at $\mu$ of 6 


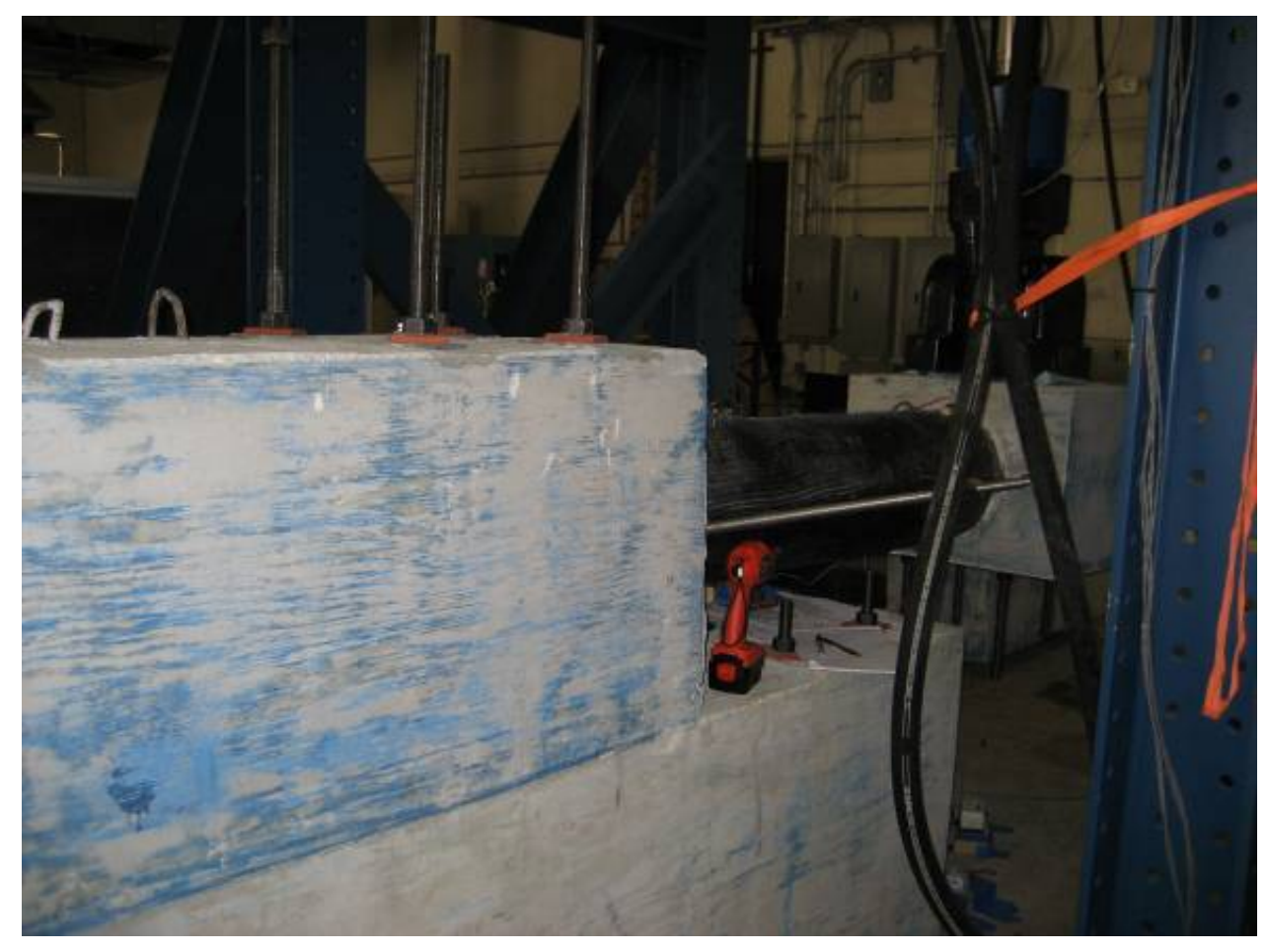

Figure 3.46 Specimen SC at $\mu$ of 5

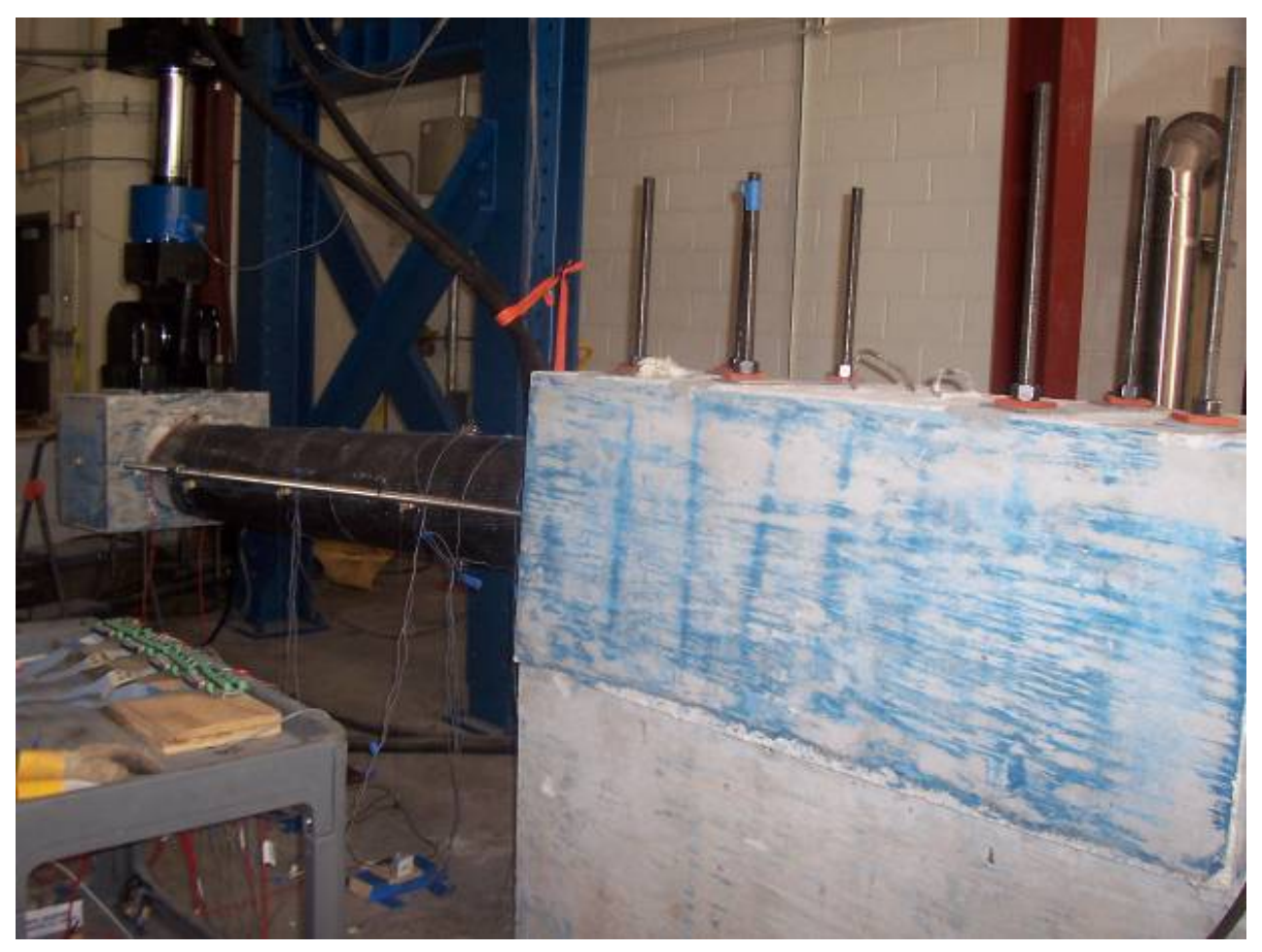

Figure 3.47 Specimen LC at $\mu$ of 6 


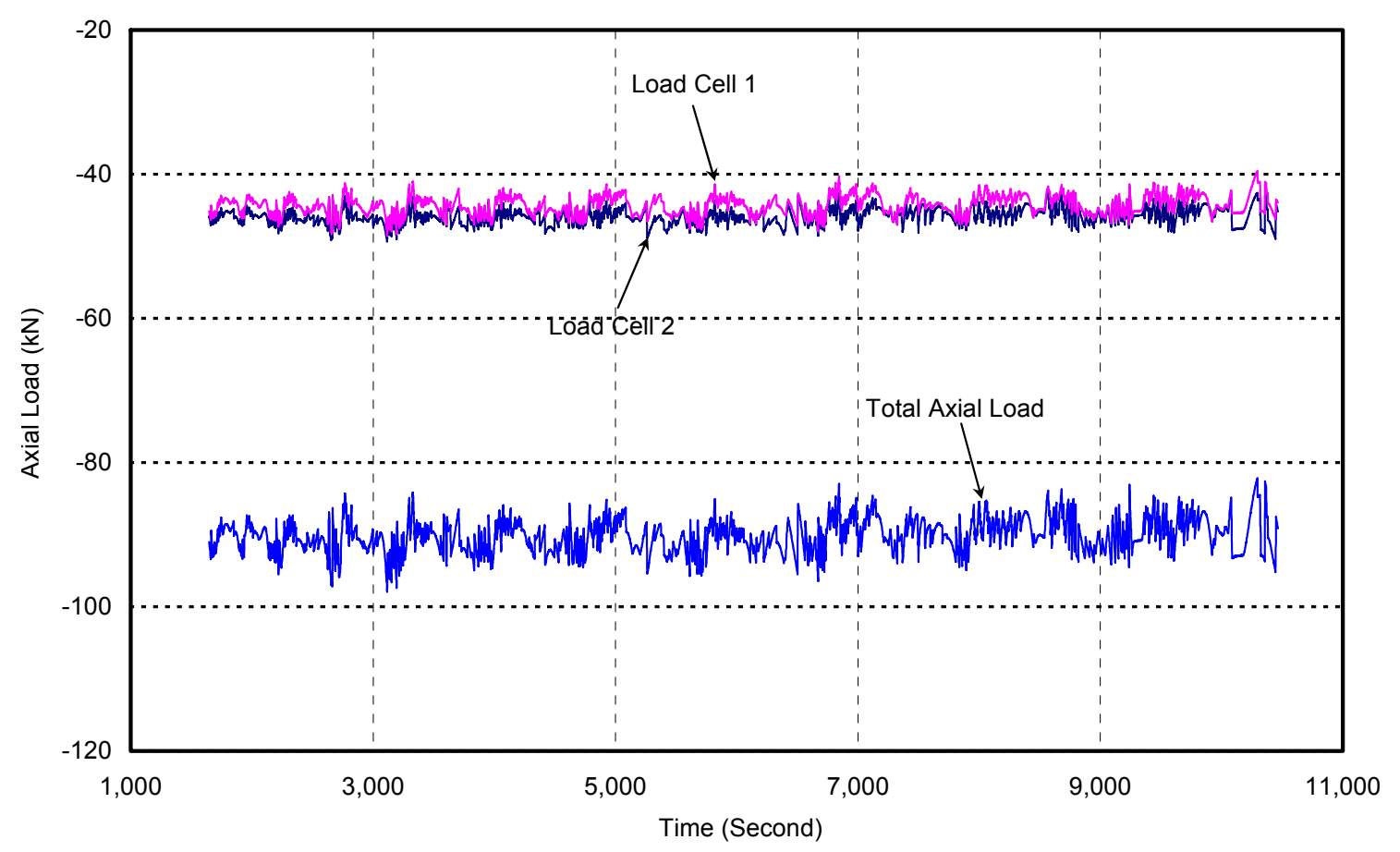

Figure 3.48 Axial Load Fluctuations for Specimen LC

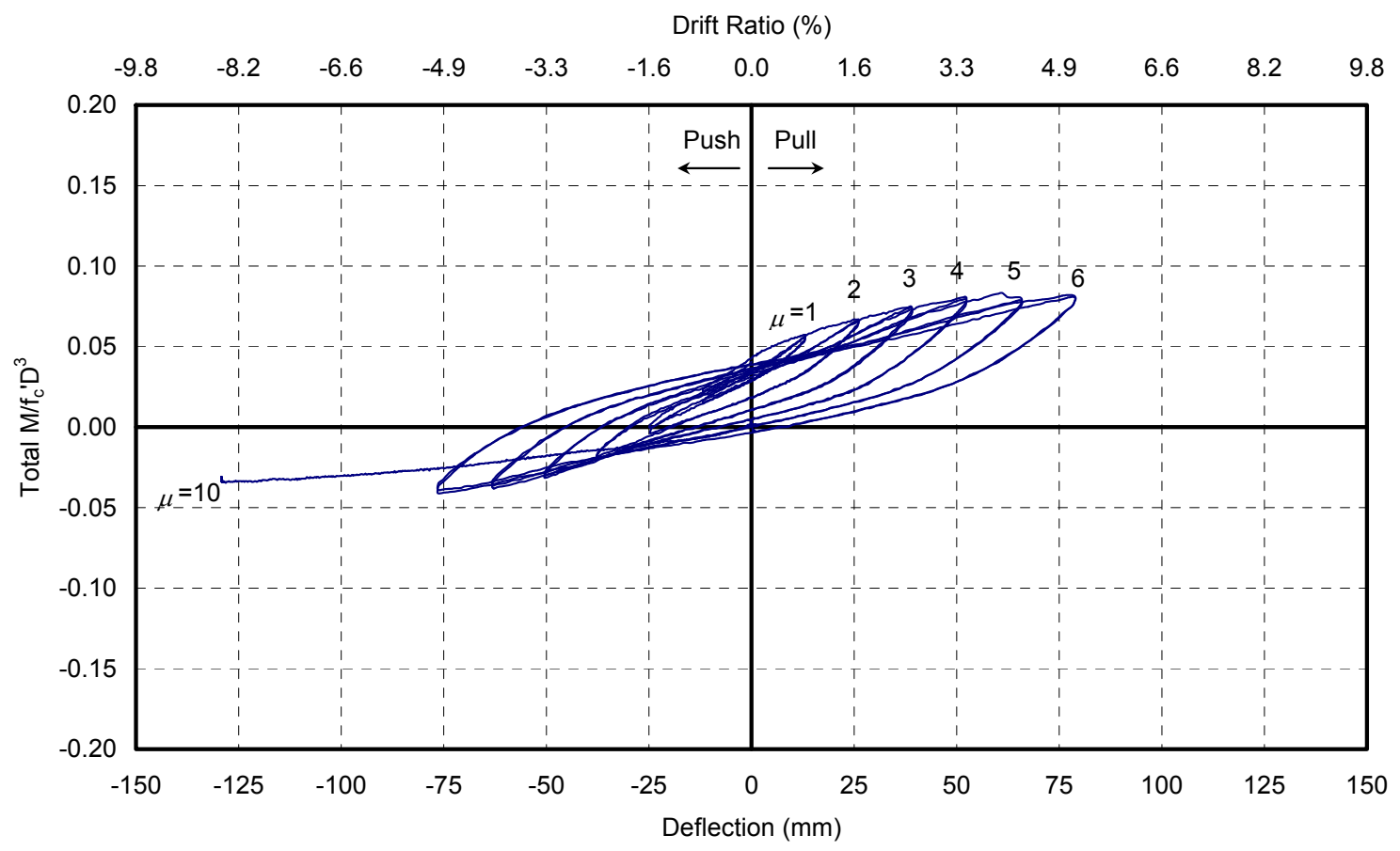

Figure 3.49 Hysteretic Normalized Moment - Deflection Response of Specimen RC 


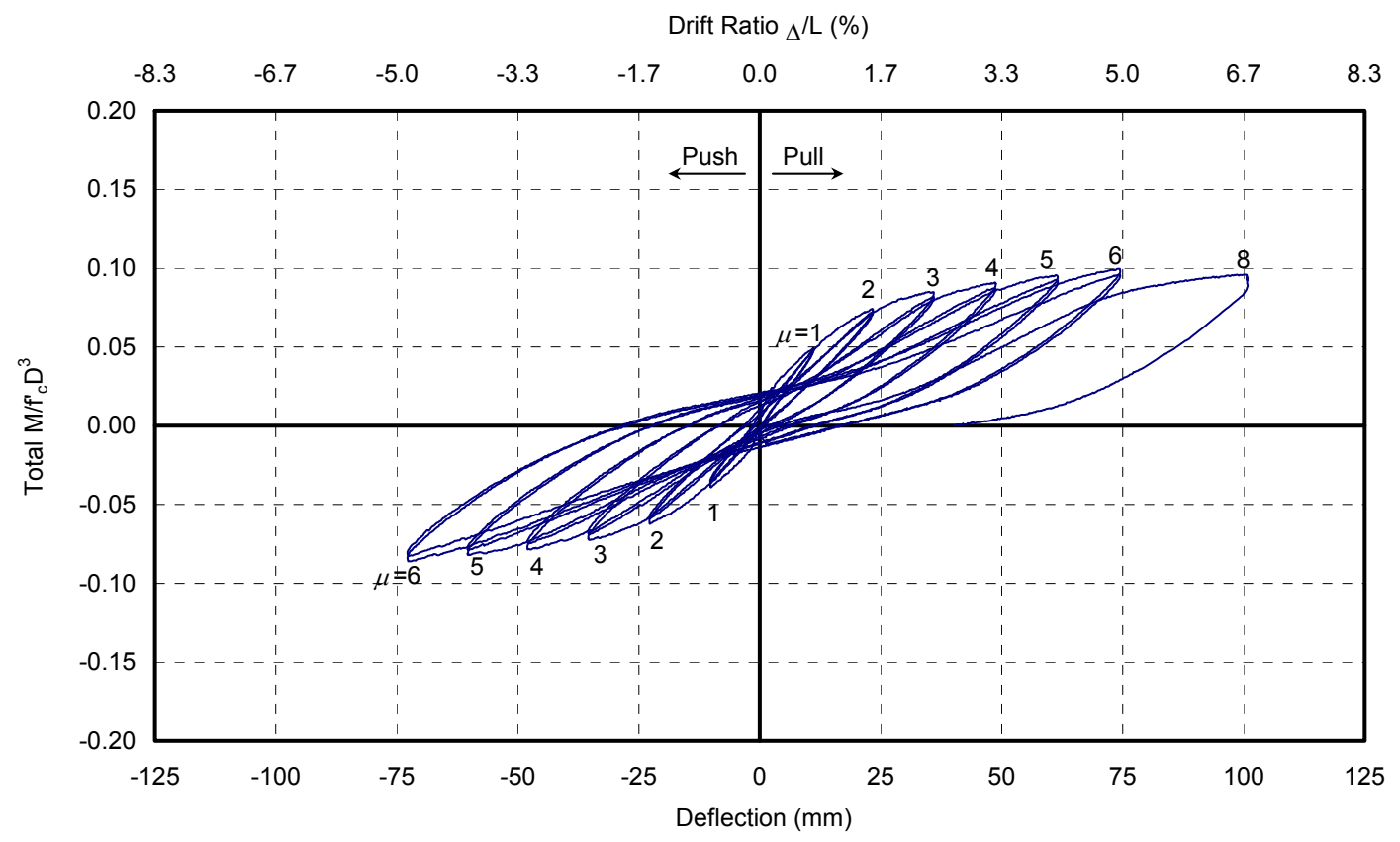

Figure 3.50 Hysteretic Normalized Moment - Deflection Response of Specimen Y

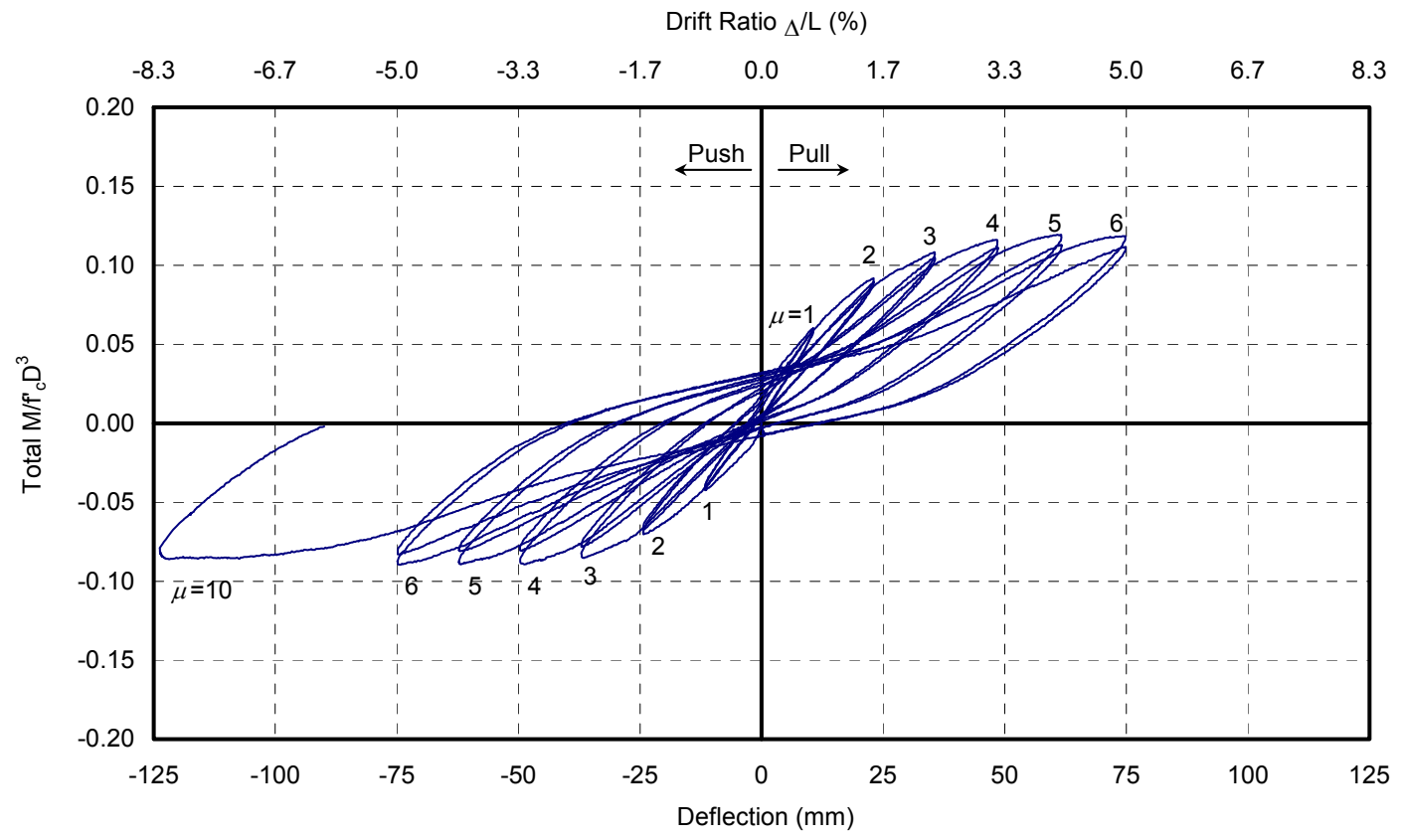

Figure 3.51 Hysteretic Normalized Moment - Deflection Response of Specimen G 


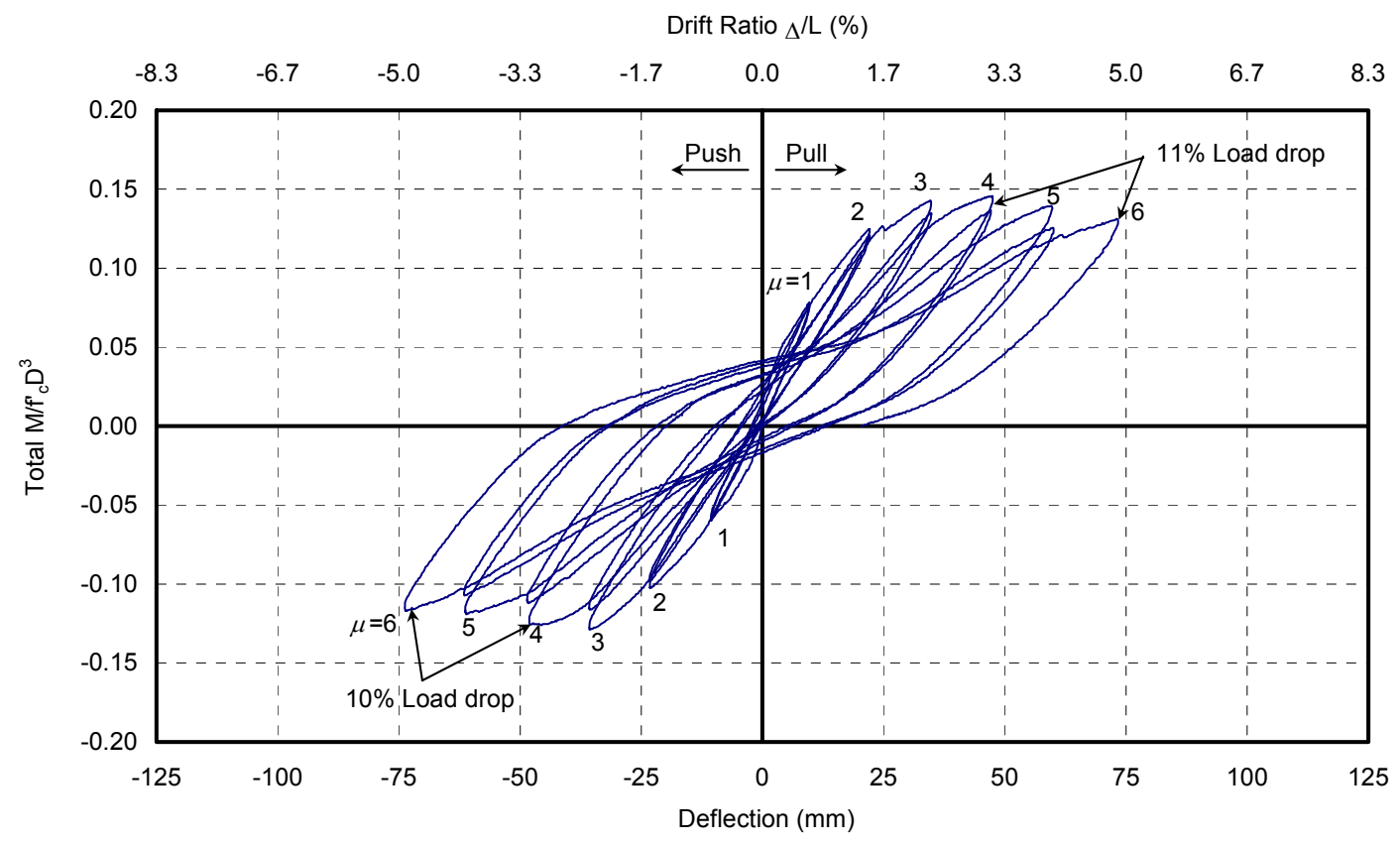

Figure 3.52 Hysteretic Normalized Moment - Deflection Response of Specimen H

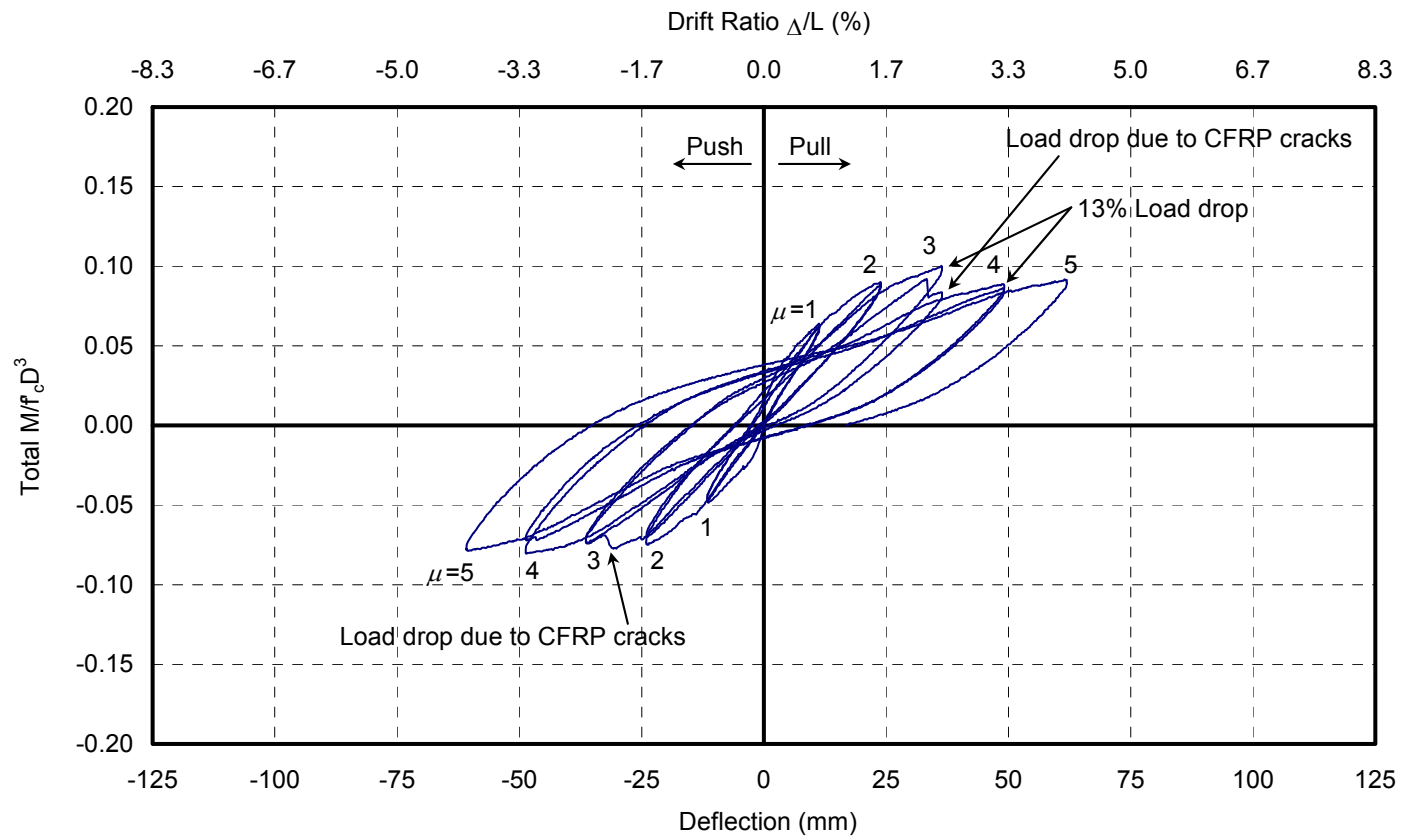

Figure 3.53 Hysteretic Normalized Moment - Deflection Response of Specimen SC 


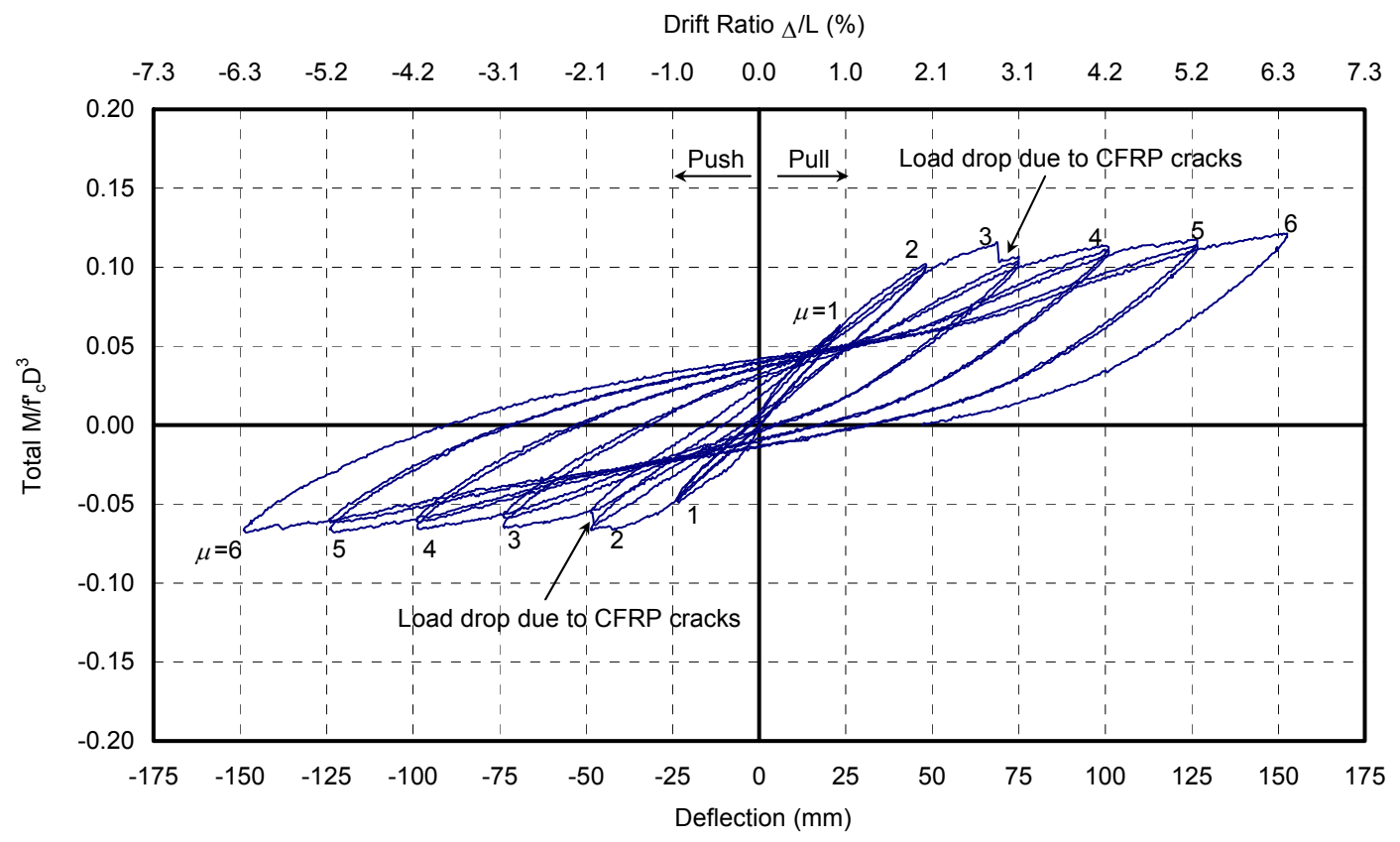

Figure 3.54 Hysteretic Normalized Moment - Deflection Response of Specimen LC

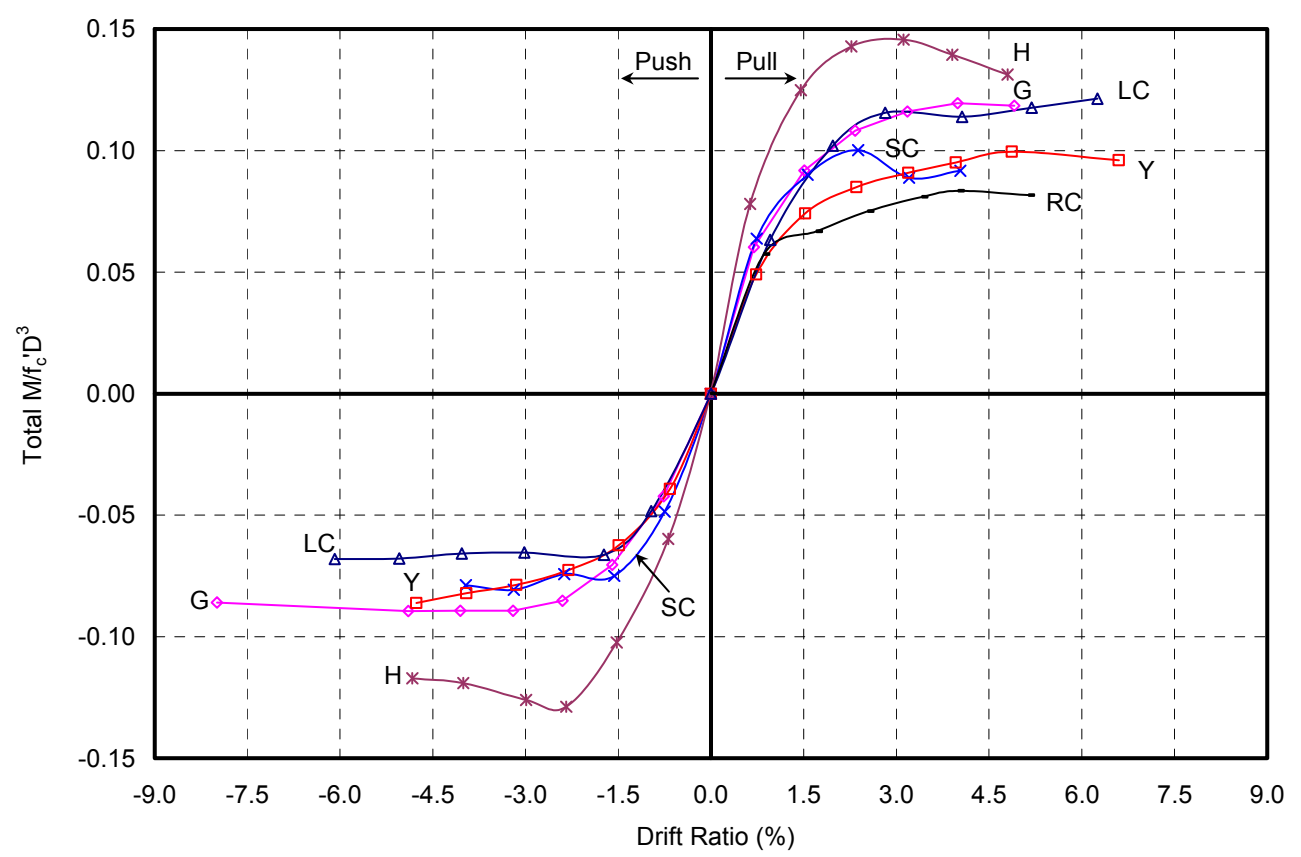

Figure 3.55 Normalized Moment - Drift Ratio Envelope Curves of All Specimens 


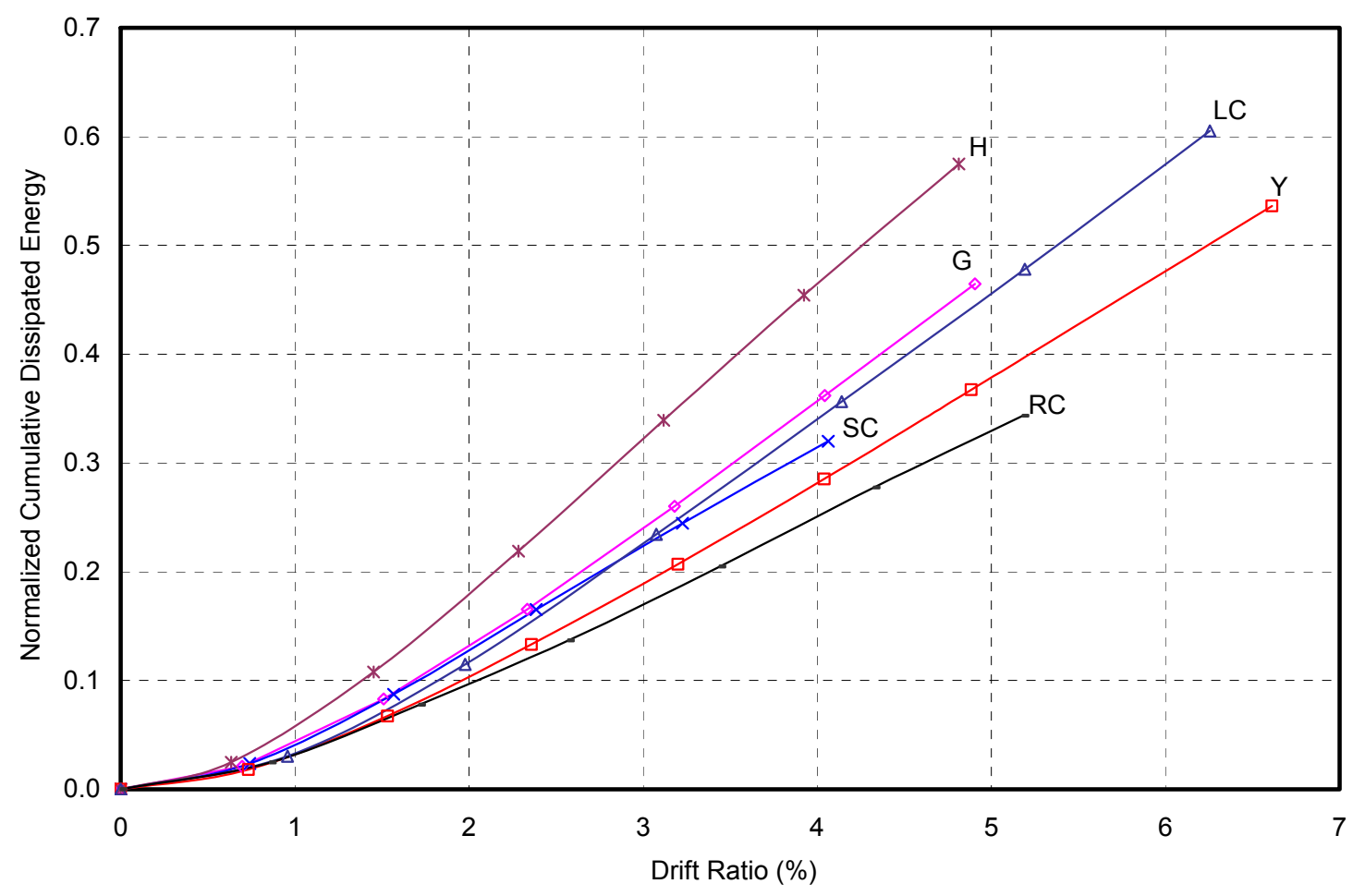

Figure 3.56 Normalized Cumulative Dissipated Energy versus Drift Ratio

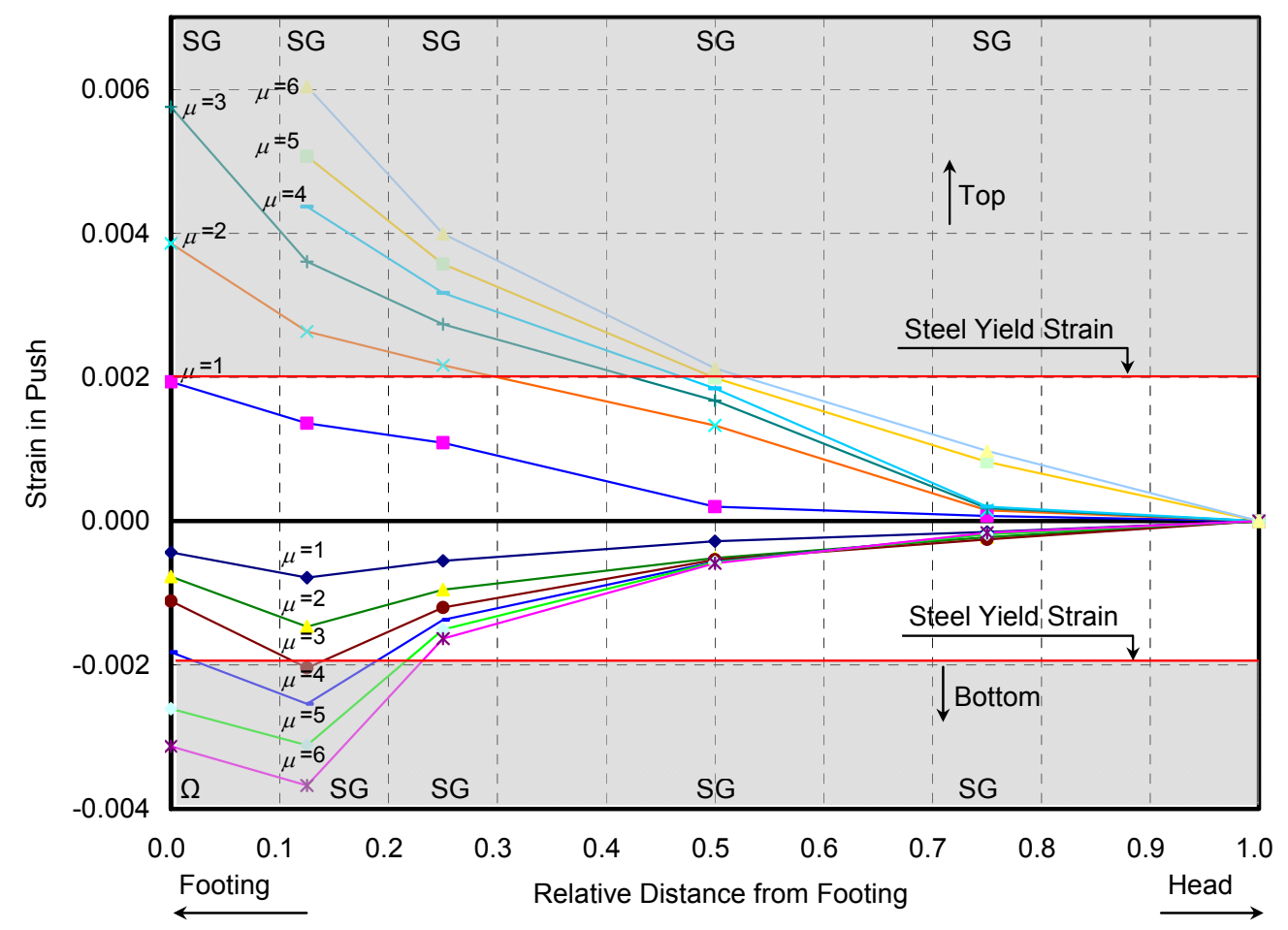

Figure 3.57 Longitudinal Rebar Strain Profile of Specimen Y During Push 


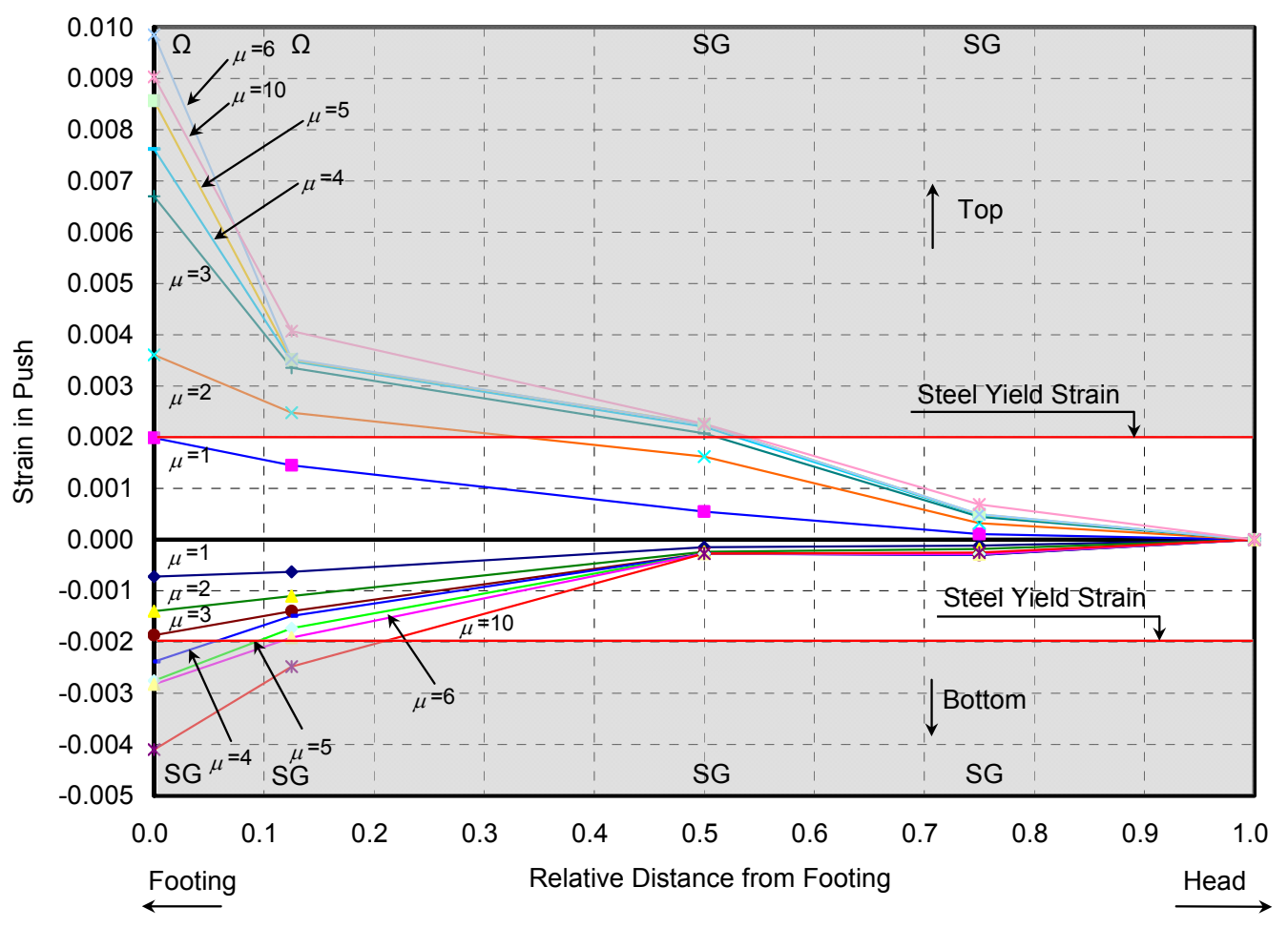

Figure 3.58 Longitudinal Rebar Strain Profile of Specimen G During Push

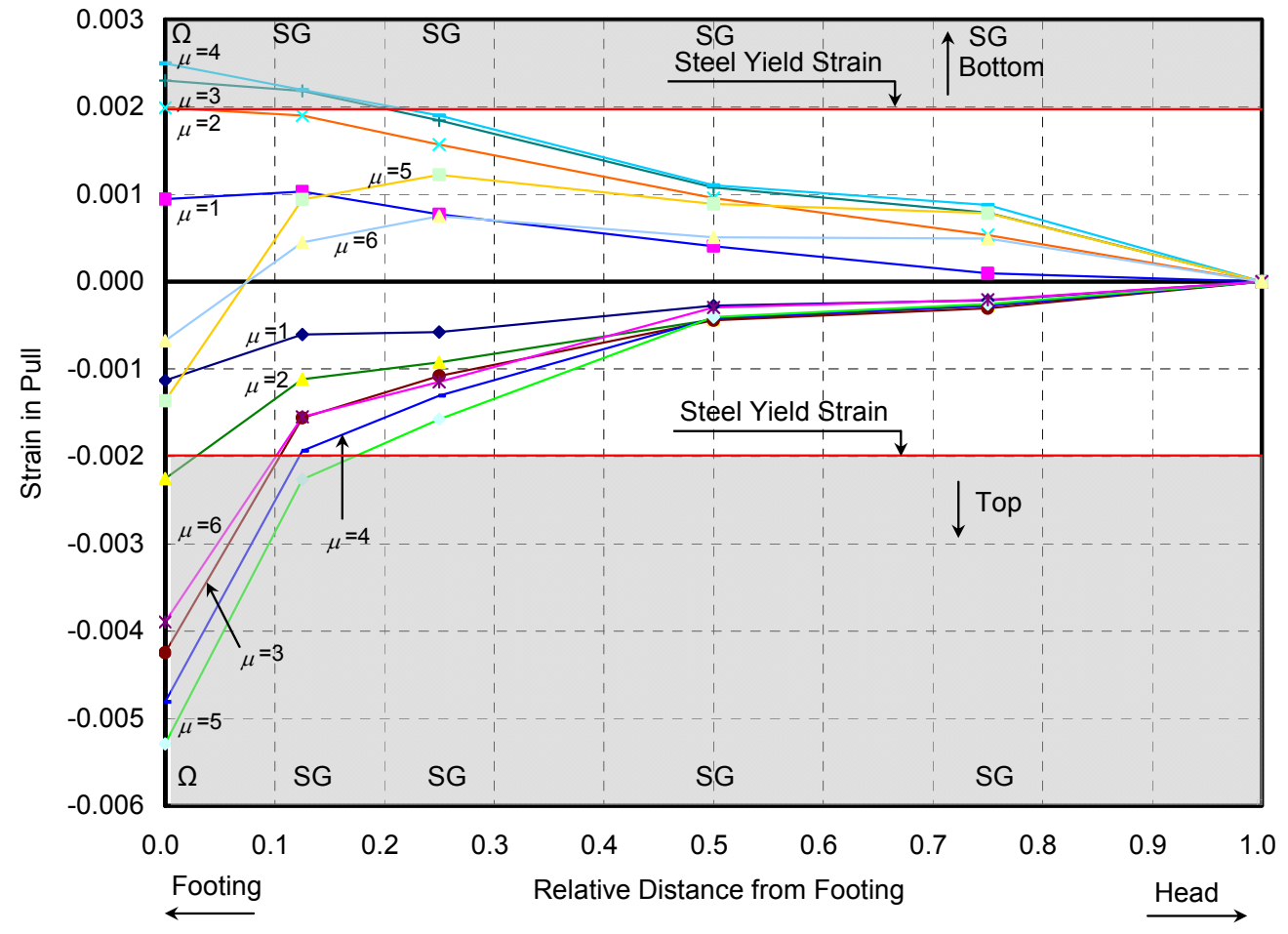

Figure 3.59 Longitudinal Rebar Strain Profile of Specimen H During Pull 


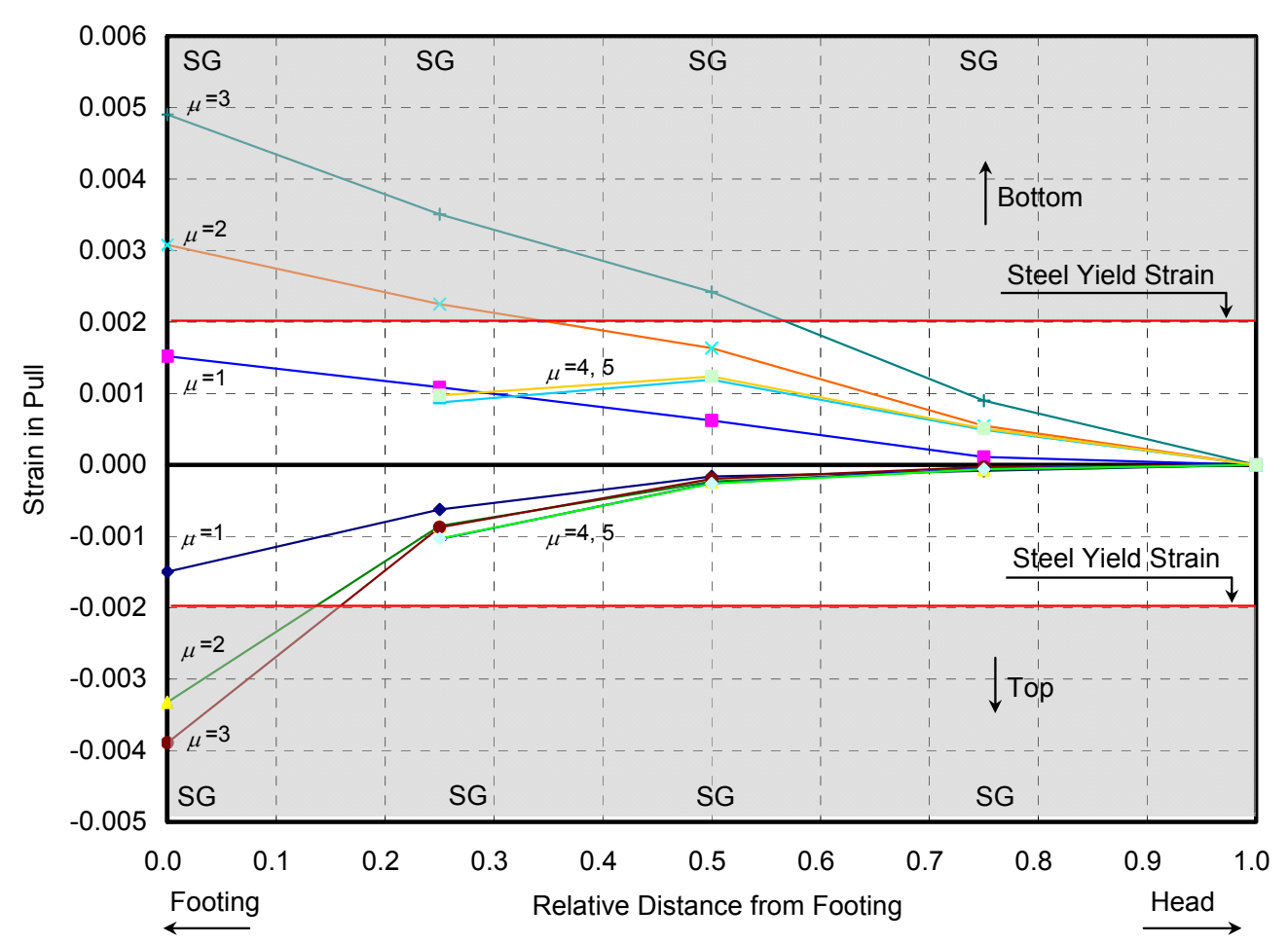

Figure 3.60 Longitudinal Rebar Strain Profile of Specimen SC During Pull

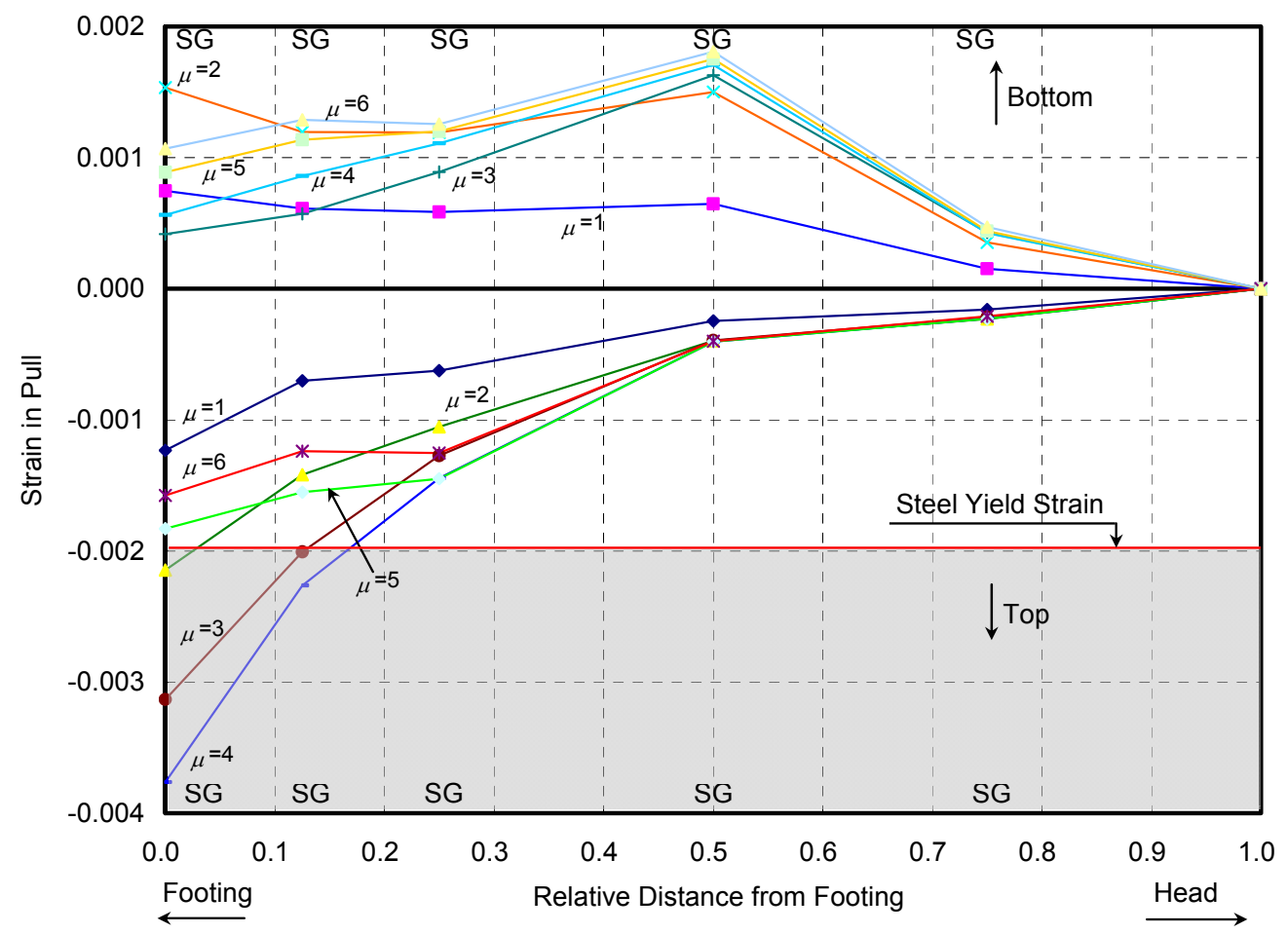

Figure 3.61 Longitudinal Rebar Strain Profile of Specimen LC During Pull 


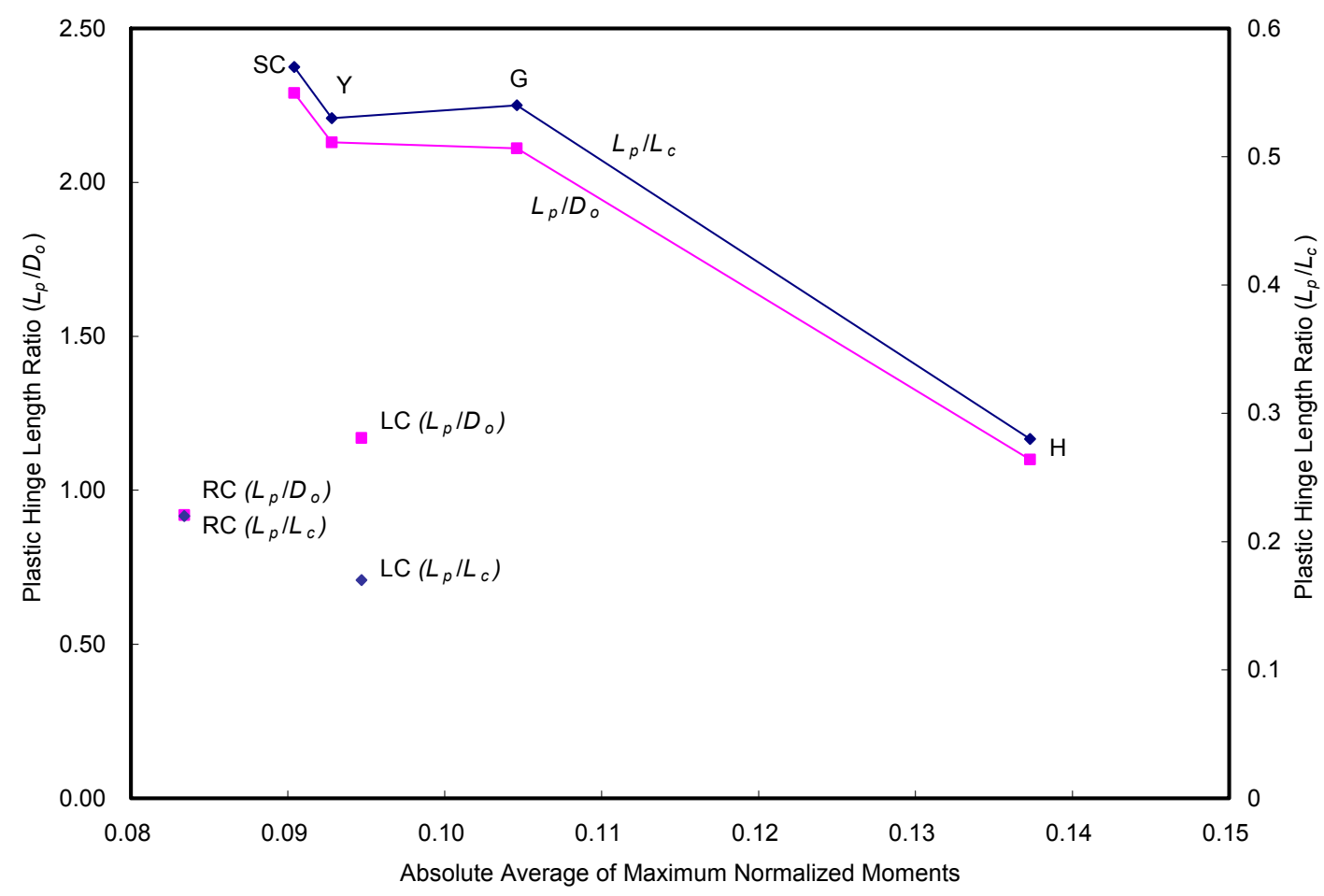

Figure 3.62 Plastic Hinge Length versus Normalized Moments

Spatial Distribution of Displacement along Column Height of Specimen RC

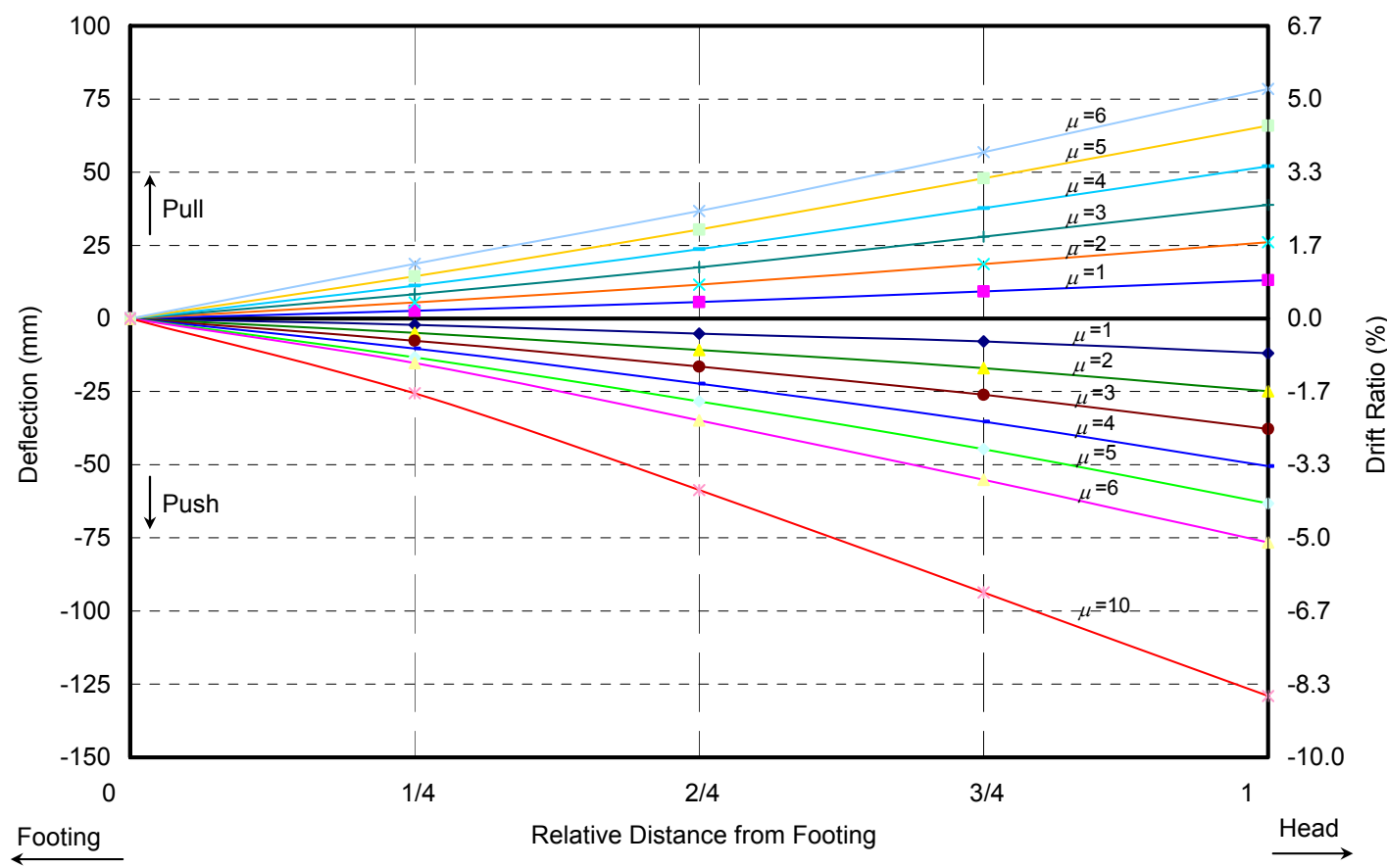

Figure 3.63 Deflected Shapes of Specimen RC at Various Ductility Levels 


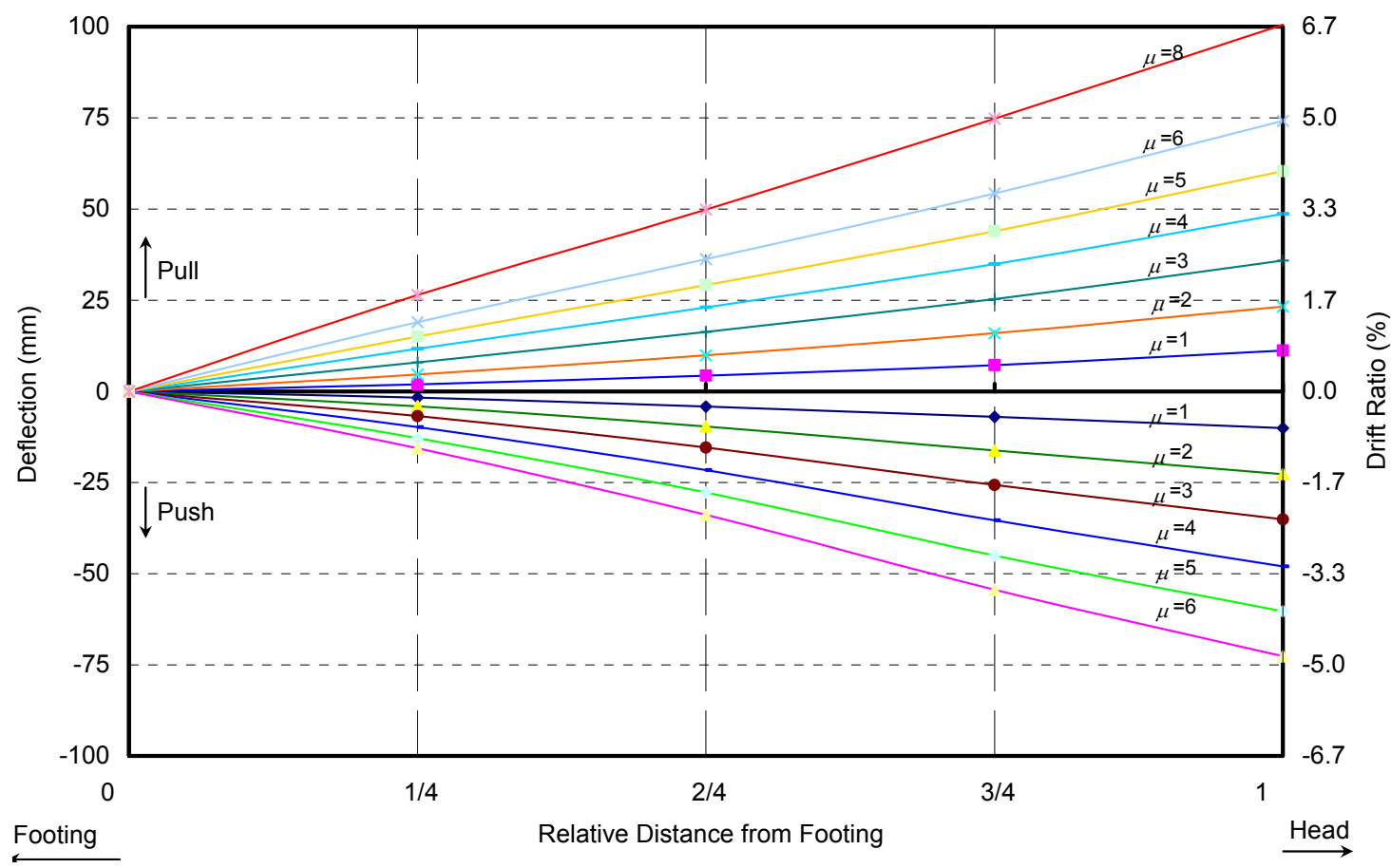

Figure 3.64 Deflected Shapes of Specimen Y at Various Ductility Levels

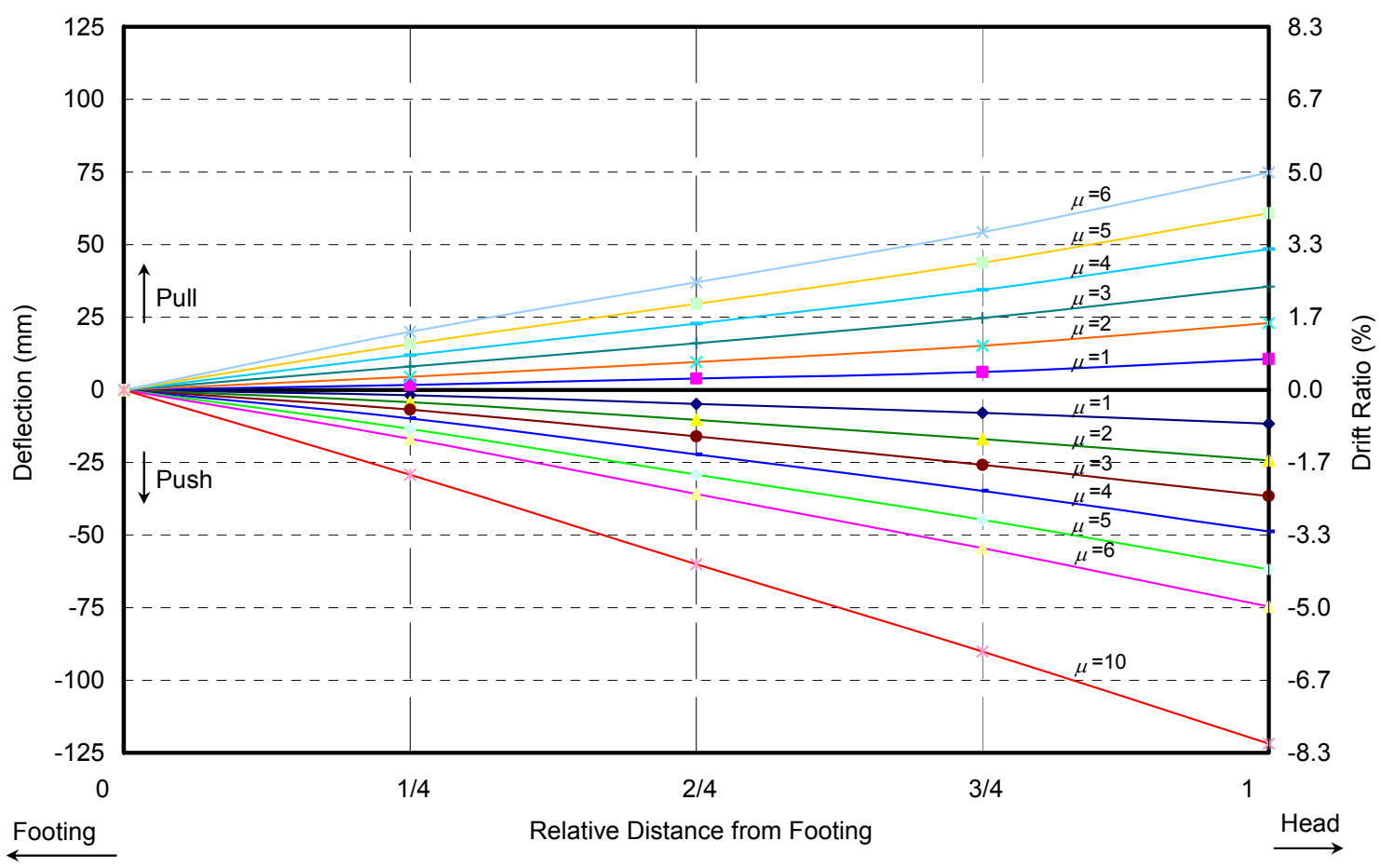

Figure 3.65 Deflected Shapes of Specimen G at Various Ductility Levels 


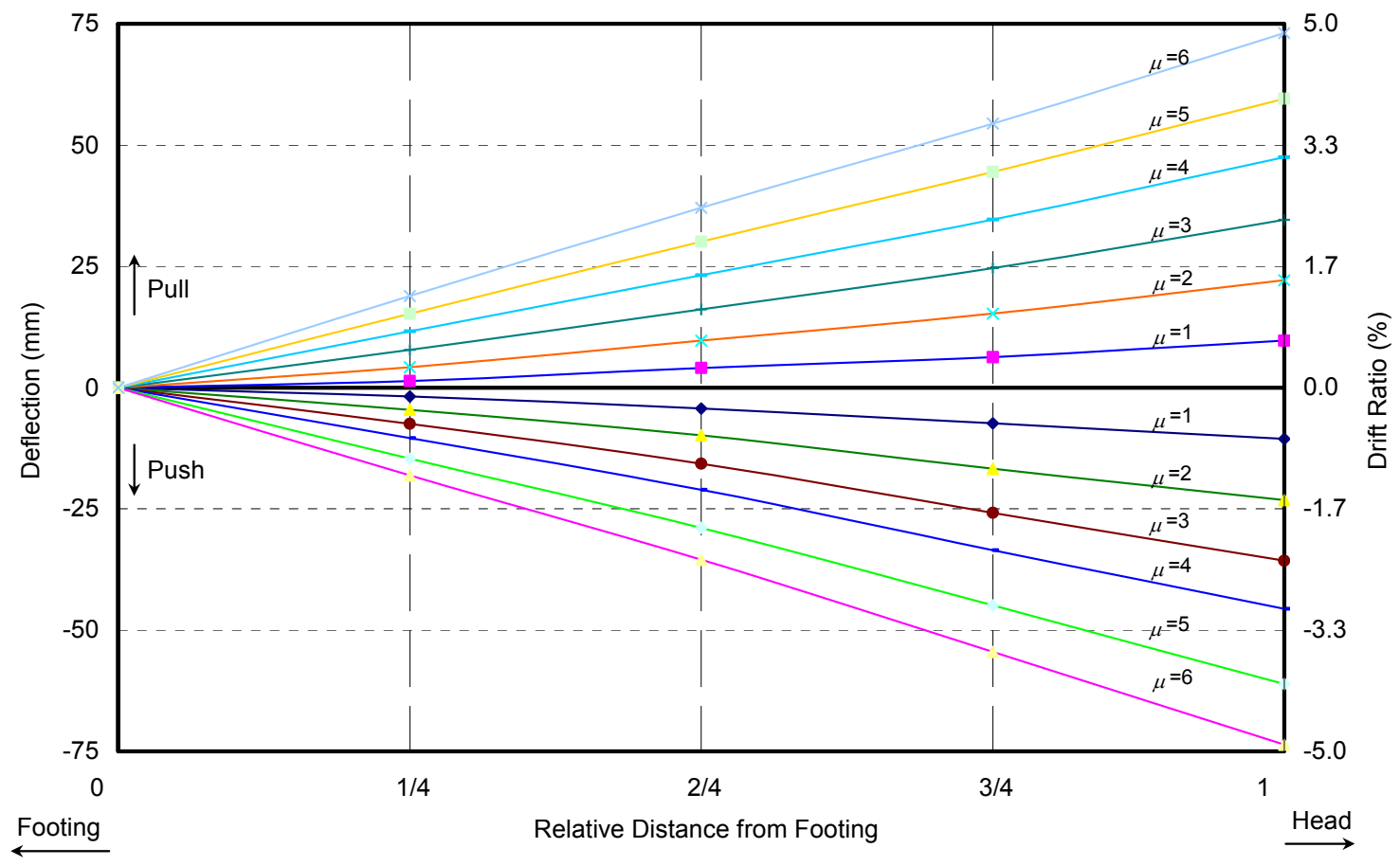

Figure 3.66 Deflected Shapes of Specimen H at Various Ductility Levels

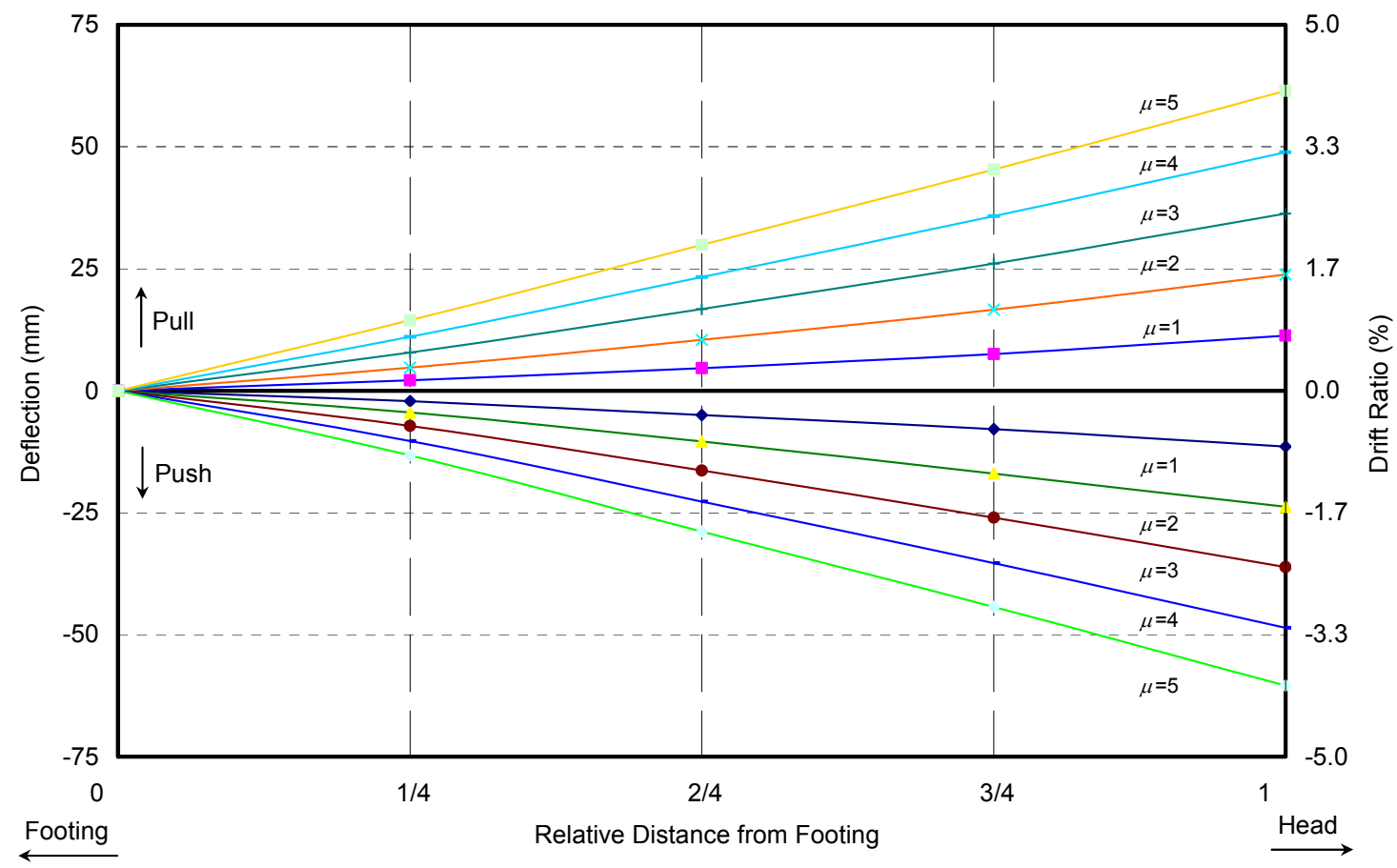

Figure 3.67 Deflected Shapes of Specimen SC at Various Ductility Levels 


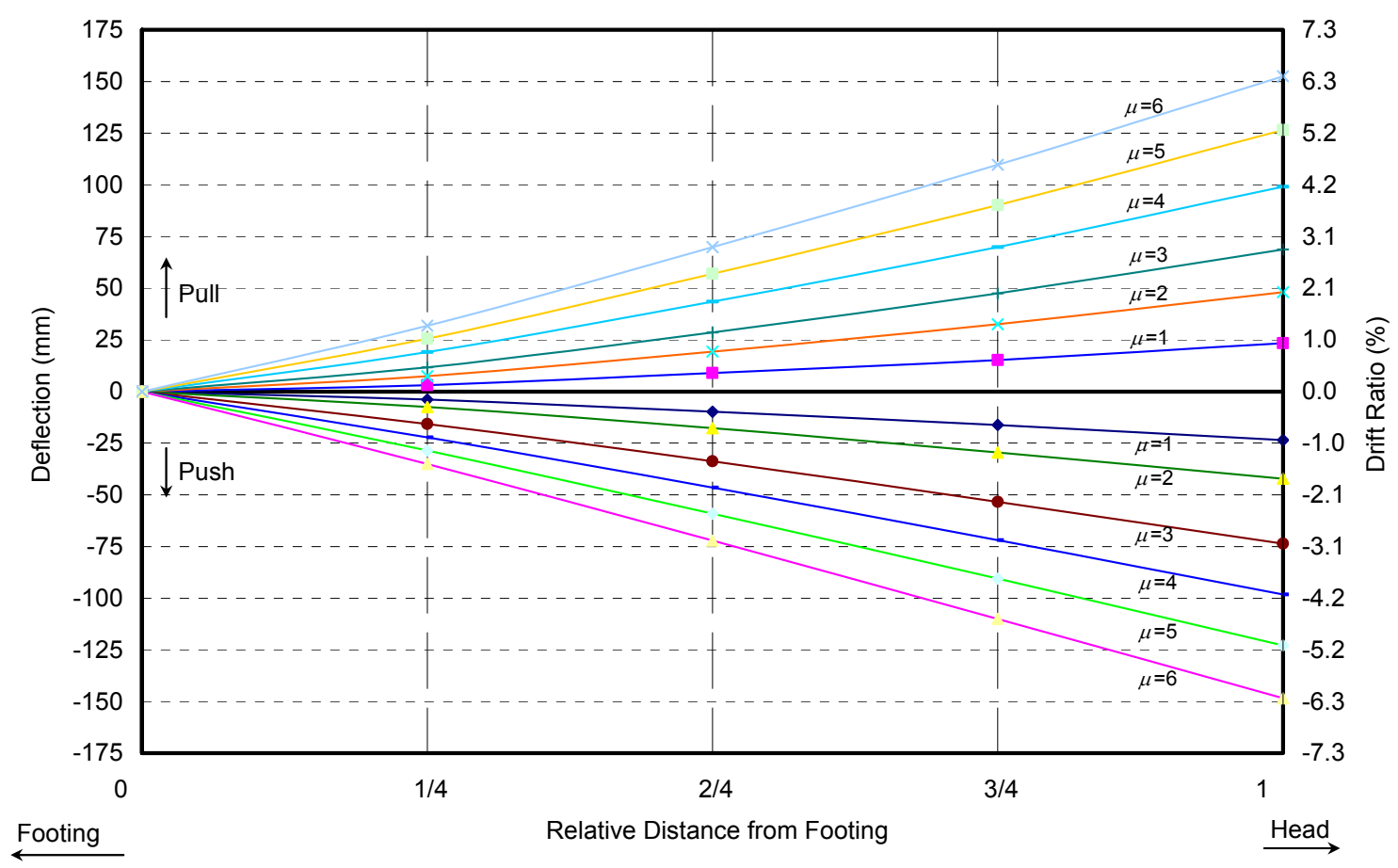

Figure 3.68 Deflected Shapes of Specimen LC at Various Ductility Levels

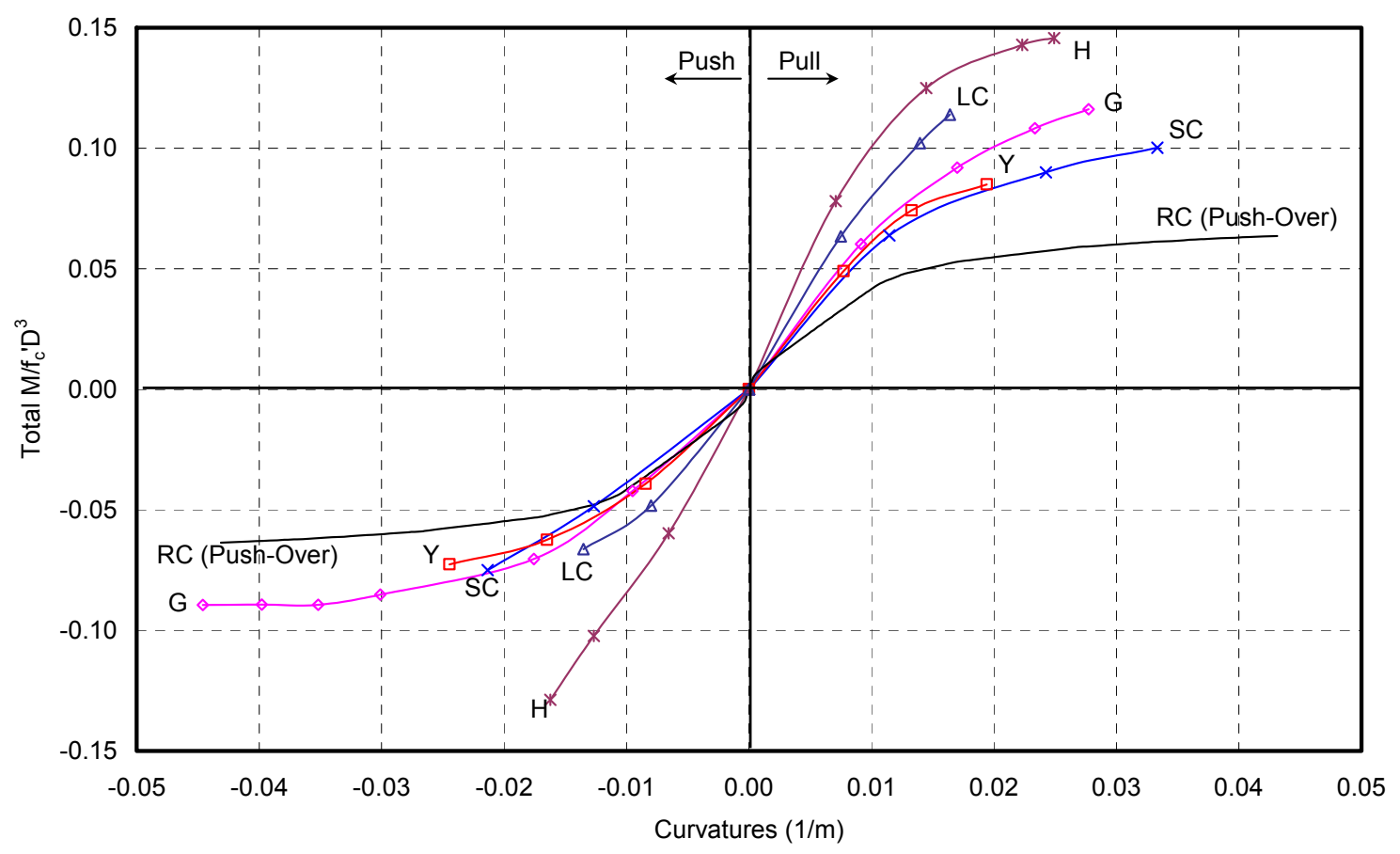

Figure 3.69 Normalized Moment - Curvature Responses 


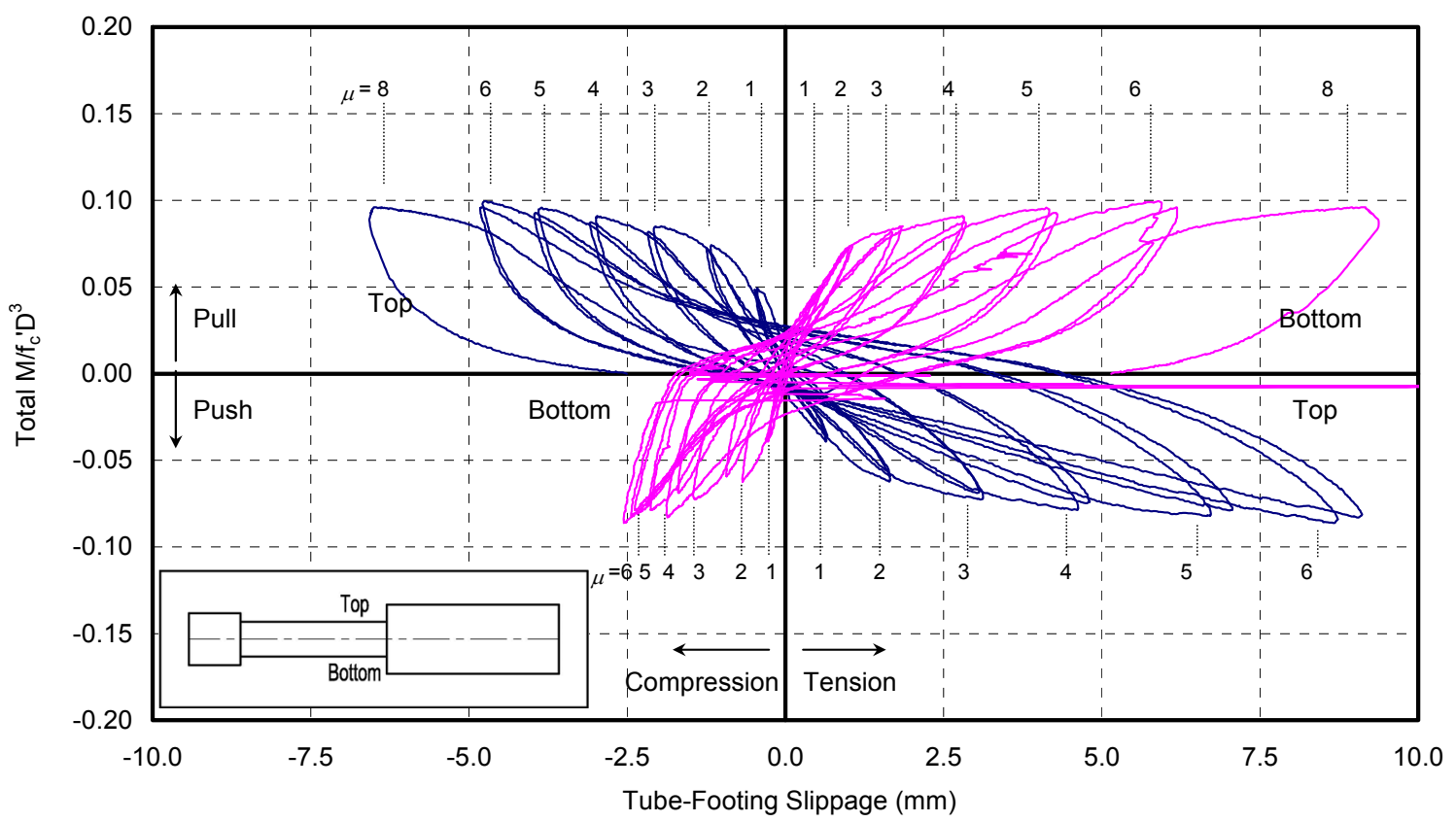

Figure 3.70 Tube-Footing Slippage in Specimen Y

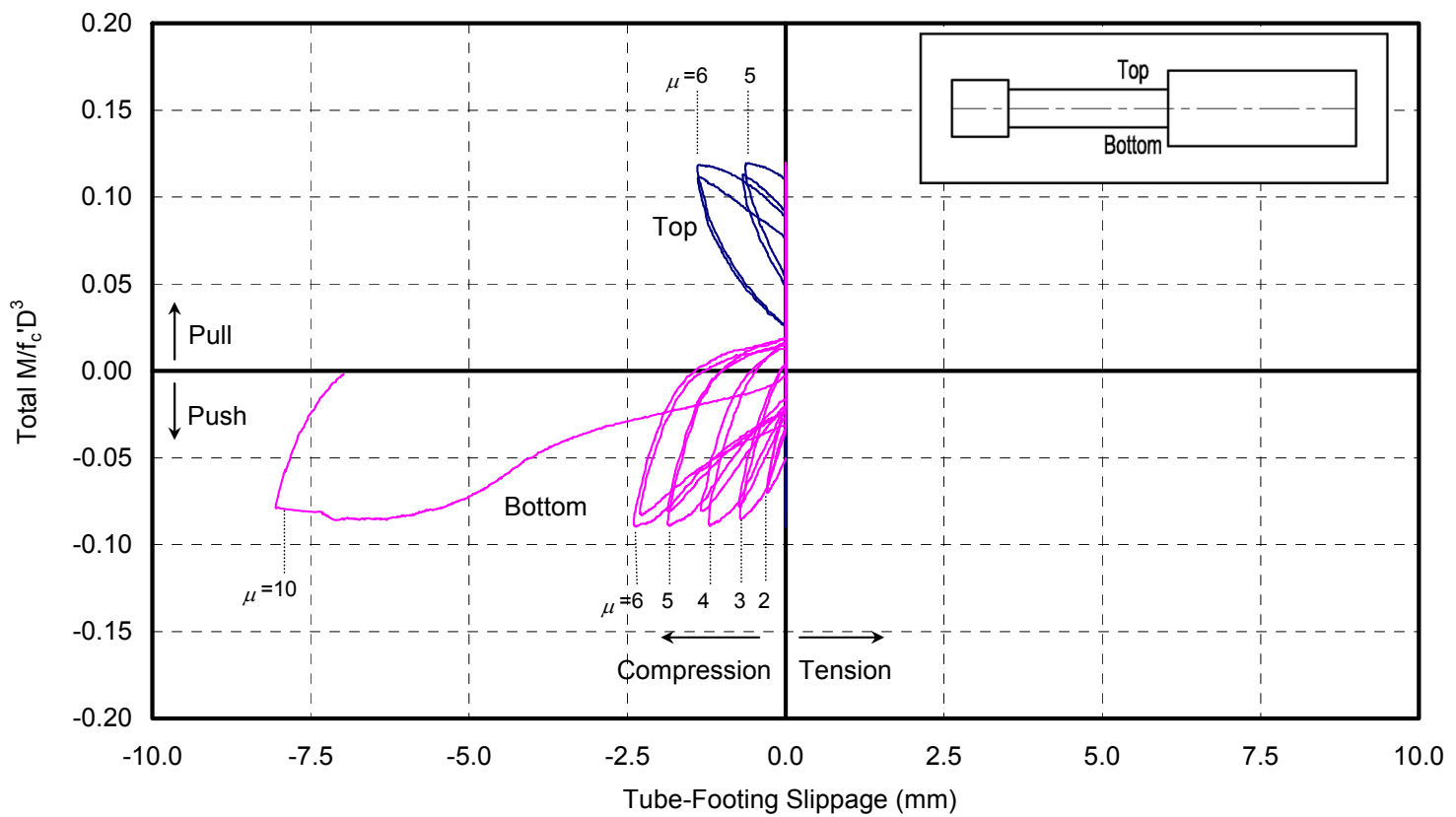

Figure 3.71 Tube-Footing Slippage in Specimen G 


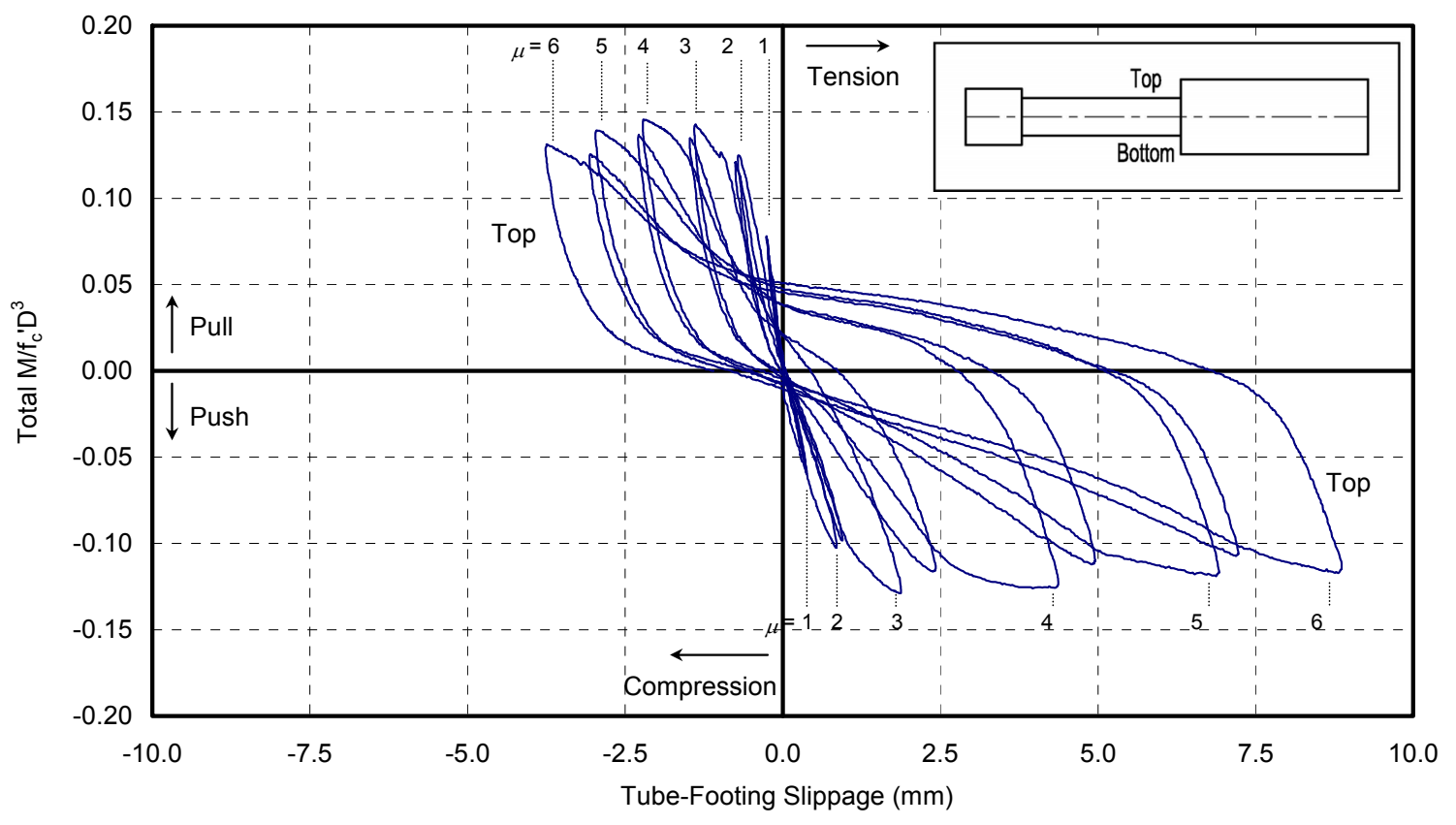

Figure 3.72 Tube-Footing Slippage in Specimen H

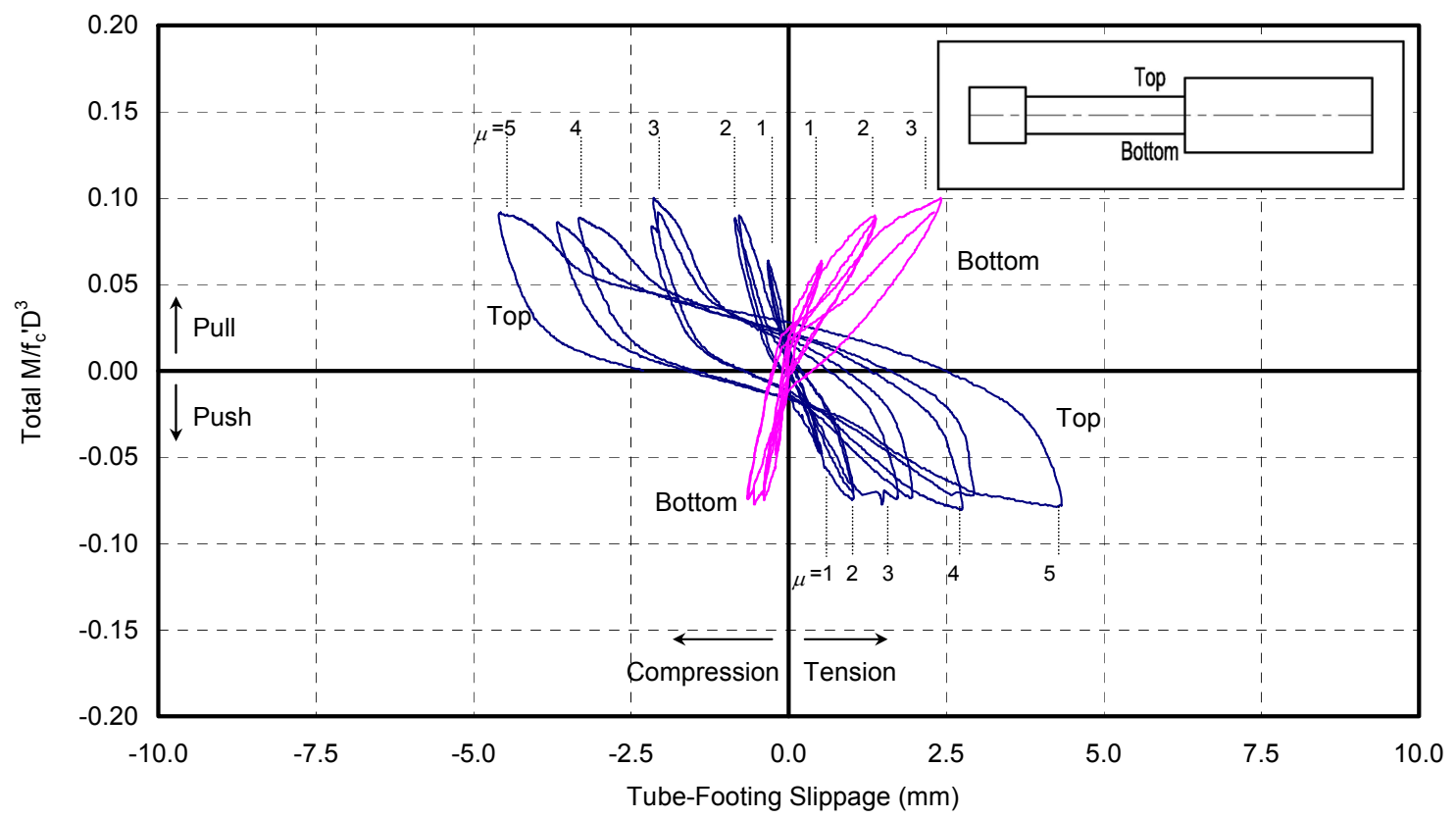

Figure 3.73 Tube-Footing Slippage in Specimen SC 


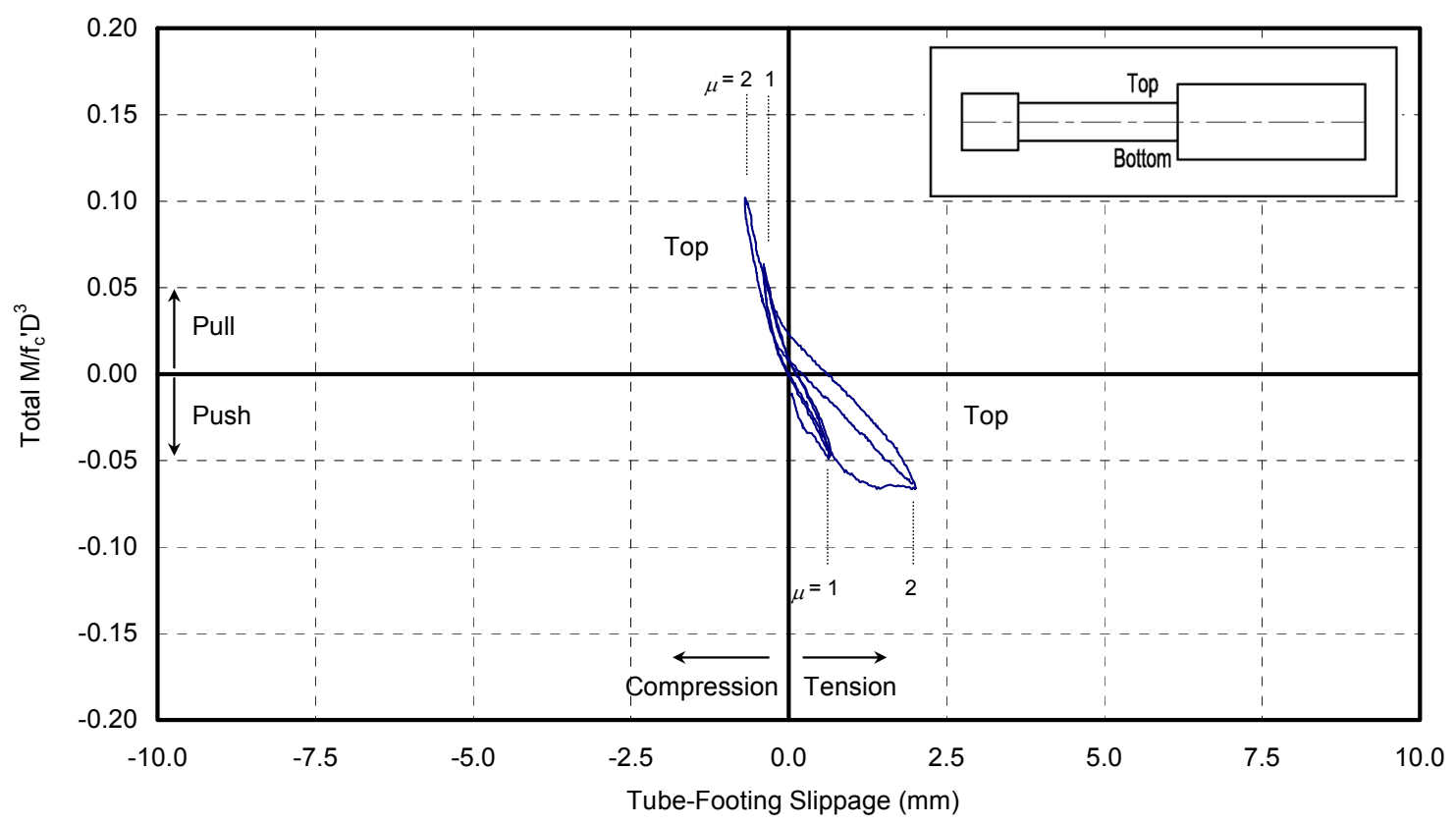

Figure 3.74 Tube-Footing Slippage in Specimen LC

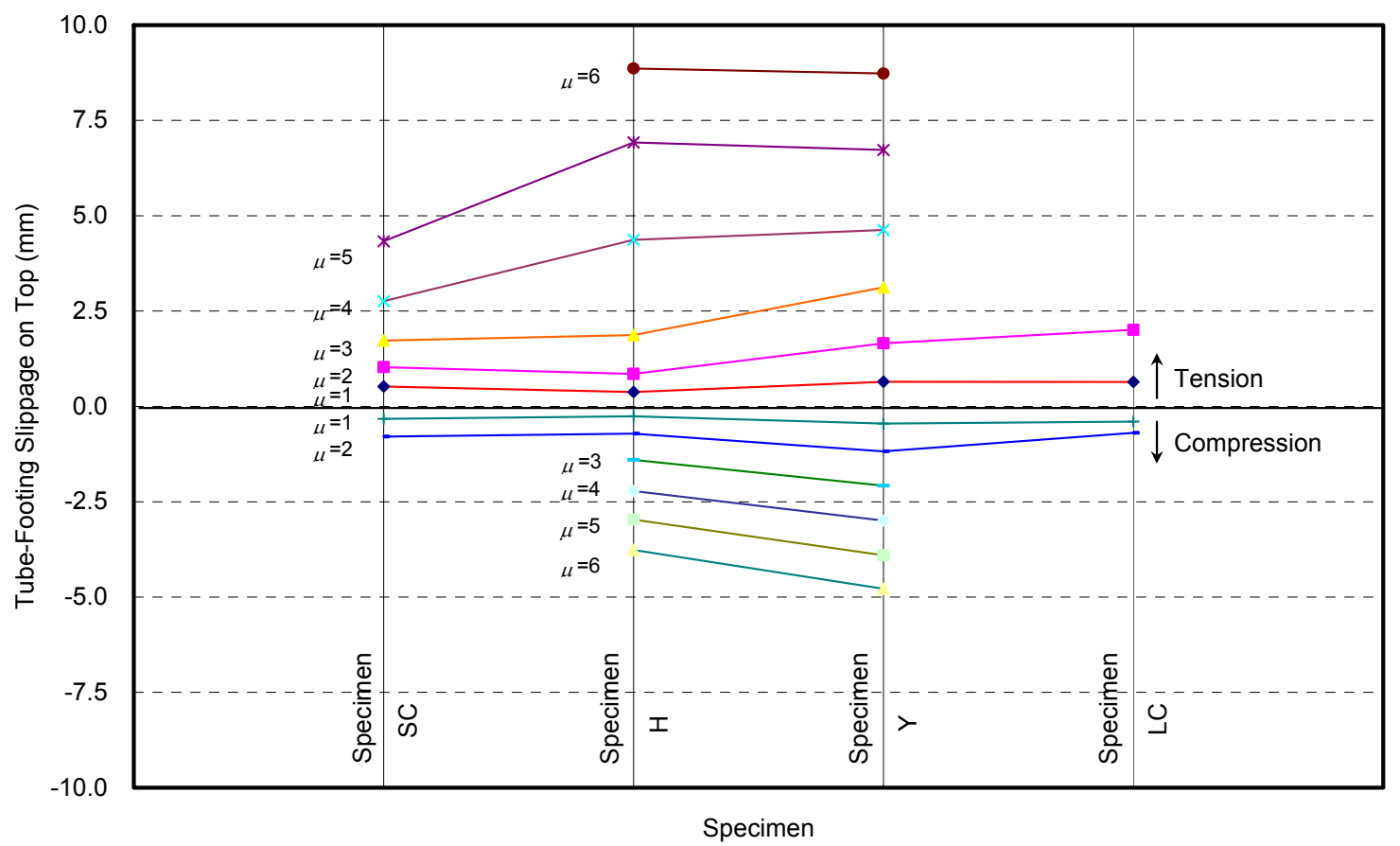

Figure 3.75 Comparison of Tube-Footing Slippages on Top for Specimens SC, H, Y, and LC 


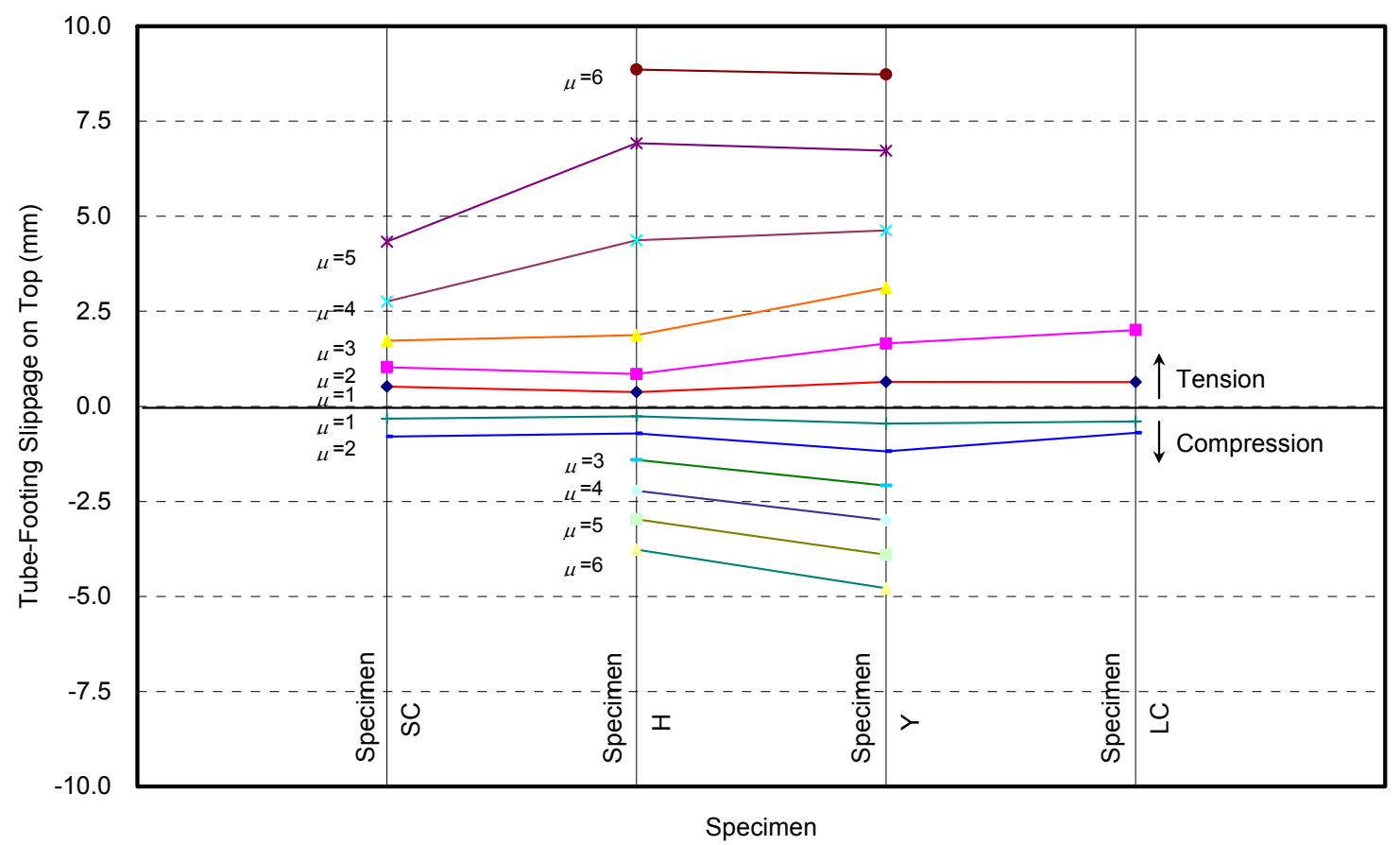

Figure 3.76 Comparison of Tube-Footing Net Slippages on Top for Specimens SC, H, $\mathrm{Y}$, and LC

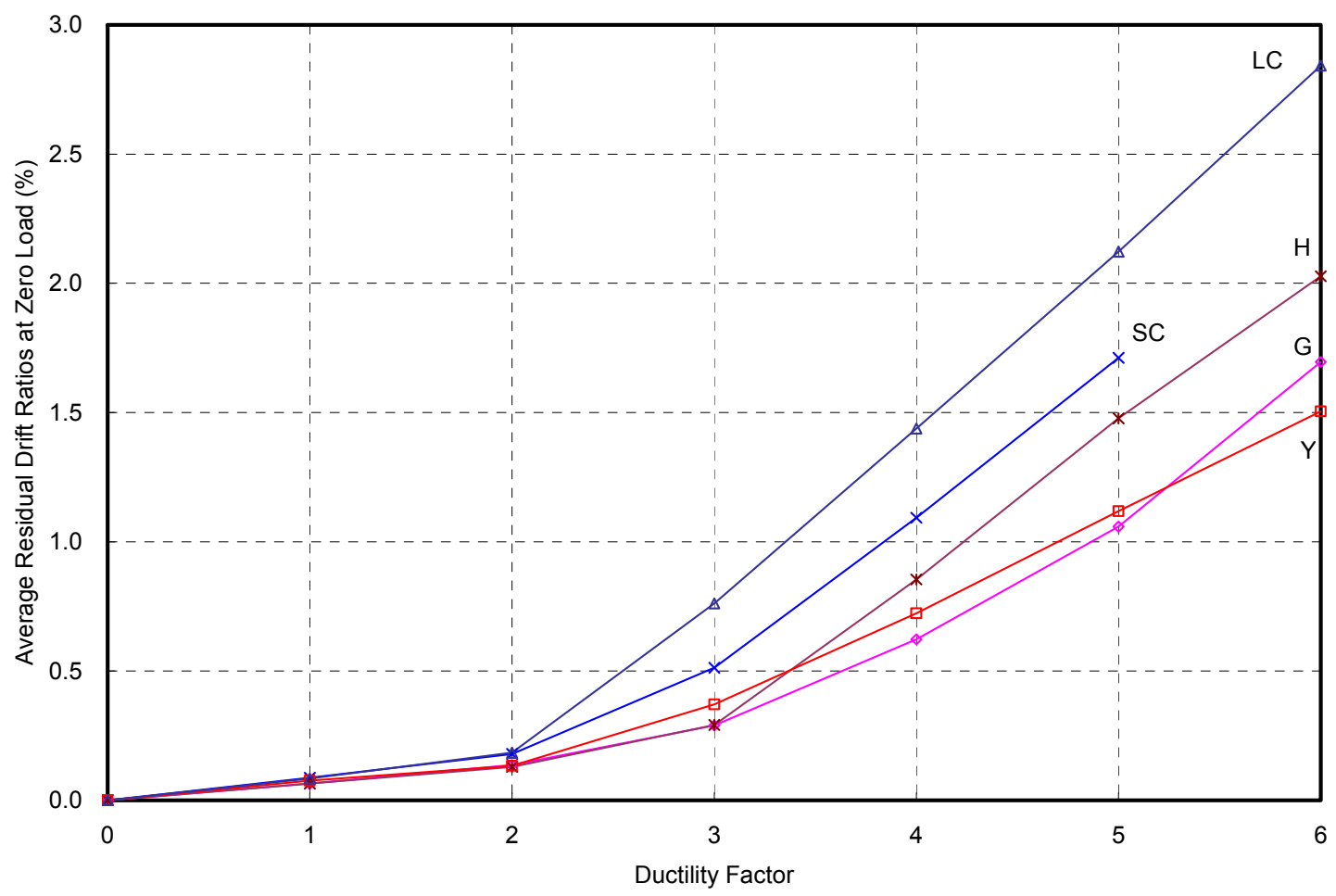

Figure 3.77 Average Absolute Residual Drift Ratios of CFFT Specimens at Zero Loads 


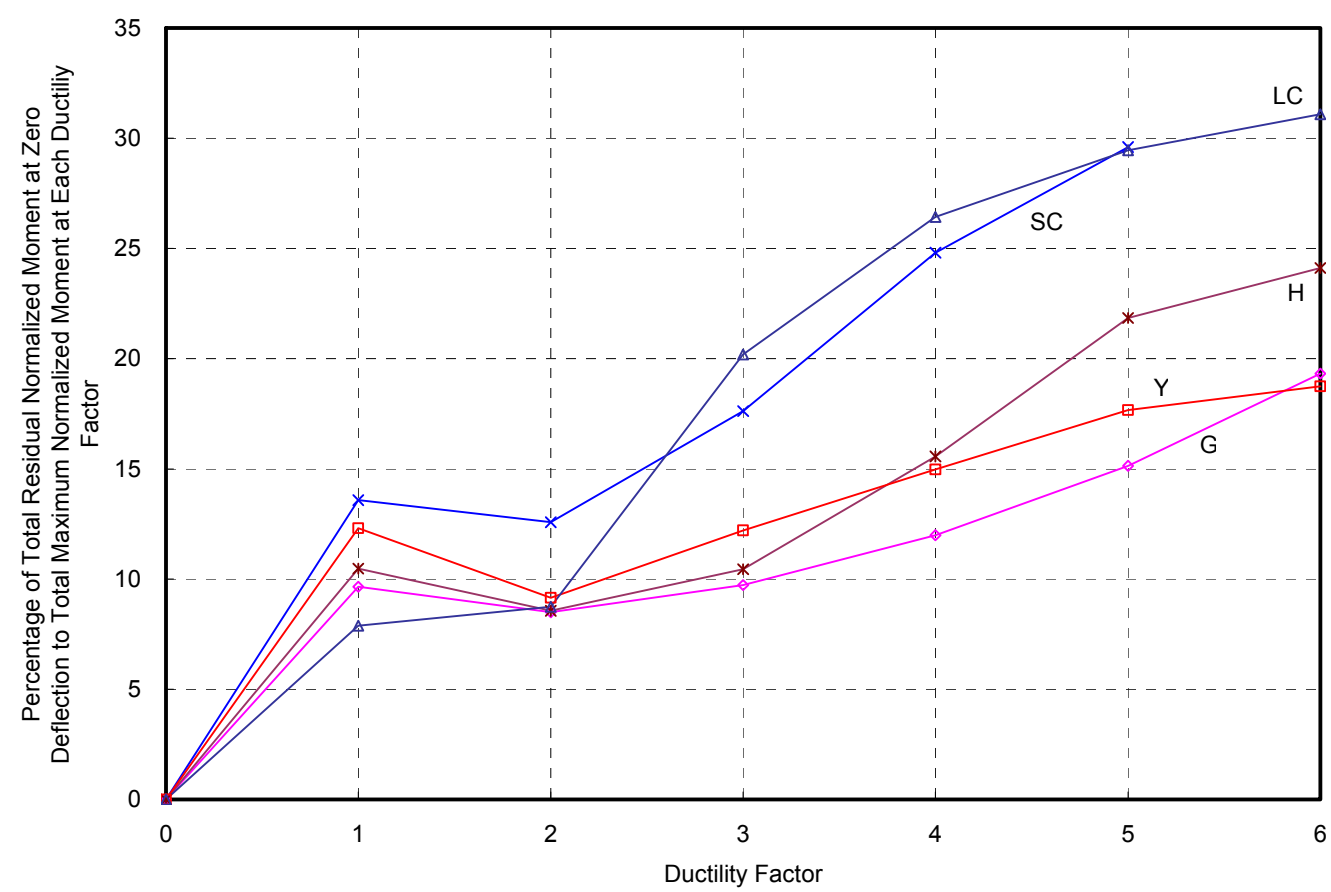

Figure 3.78 Percentage of Total Residual Normalized Moment at Zero Deflection to Total Maximum Normalized Moment at Each Ductility Factor for CFFT Specimens 


\section{CHAPTER 4 MONOTONIC FLEXURAL TEST}

\subsection{INTRODUCTION}

Because cyclic tests aimed at investigating the behavior of column-footing connections, the specimens made with glass FRP tubes neither showed any visible crack, nor did they reach their ultimate capacity. Even carbon FRP tubes showed visible cracks only at column base. Therefore, a series of follow-up four-point monotonic bending tests of these specimens was carried out to shed further light on their flexural strength.

\subsection{SPECIMEN CONDITIONS}

After the cyclic tests, Specimens Y, G and H had remained intact without any visible matrix crack, while Specimens LC and SC showed visible cracks in the FRP tubes. Nonetheless, the cracks were limited to the column base. Specimen RC suffered severe damage at column-footing connection region, with concrete spalling off, but no fracture of spiral or longitudinal steel. Moreover, no crack was detected in the mid-span in any of the columns after cyclic tests.

All specimens had residual displacements after cyclic tests. Specimens H, SC and LC had very small downward residual displacements in the range of 3-4 mm (0.10-0.15 in., $0.2 \%$ of respective column lengths) at column heads, while Specimen $\mathrm{Y}$ had an upward residual displacement of $28 \mathrm{~mm}$ (1.10 in., $2 \%$ of column length) at column head. In these cases, the bending test setups were not influenced by the residual displacements. On the other hand, Specimens $\mathrm{G}$ and RC had downward residual displacements of 90 and $129 \mathrm{~mm}$ (3.54 and 5.09 in., 7\% and 10\% of respective column lengths) at column heads, respectively. Therefore, a different instrumentation plan was developed for these two 
specimens. Table 4.1 shows the specimen conditions after cyclic tests. Types I and II instrumentation plans will be described in Section 4.3.2.

\subsection{TEST SETUP AND INSTRUMENTATION}

\subsubsection{Test Setup}

The specimens were placed on two concrete pedestals with the head and footing acting as supports, resting on neoprene pads. The clear span in monotonic tests was 2,210 mm (87 in.) for Specimen LC and 1,295 mm (51 in.) for all other short specimens.

A $1,045 \mathrm{kN}$ (235 kips) capacity hydraulic actuator hung from a steel reaction frame was used to apply the load on the specimens with two steel saddles as loading points, and a steel spreader plate that was attached to the actuator using threaded rods. Neoprene pads were also placed at loading points. Specimen H was loaded without the steel saddles, because top of the beam was not as round as the other specimens. No axial load was applied to any of the specimens. Figure 4.1 through Figure 4.6 show the test setups for the six specimens. Different loading patterns were used based on the specimen condition after previous cyclic tests. Table 4.2 shows the detailed loading patterns for each specimen.

\subsubsection{Instrumentation}

Each specimen was instrumented with six string potentiometers, two strain gauges and two inclinometers. In addition, the load and displacement outputs from the actuator controller were monitored using a high-speed data acquisition system, for a total of twelve readings at a frequency of $1 \mathrm{~Hz}$. 
Two of the $152 \mathrm{~mm}$ (6 in.) range string potentiometers were attached at both ends of each specimen to monitor support displacements. Three similar string potentiometers were placed at quarter spans to measure deflections at mid-height of the section on one side. For Specimens Y, H, SC and LC, an additional string potentiometer was set at midspan on the opposite side of the section to compare the displacements on the two sides. This instrumentation plan for string potentiometers is denoted as Type I in Table 4.1. For Specimens RC and G, there were large downward residual displacements after cyclic tests, which made it difficult to support the column heads. Hence, the additional string potentiometer was placed at the far end of the column head to monitor its total rigid body movement. This instrumentation plan is denoted as Type II in Table 4.1. Each specimen was also instrumented with two $20 \mathrm{~mm}(0.8 \mathrm{in}$.) strain gauges (PFL-30-11-5L of Tokyo Sokki Kenkyujo Co., Ltd.) at the top and bottom at mid-span. Two inclinometers were placed to monitor the end rotations. Figure 4.7 shows Type I instrumentation plan, whereas Figure 4.8 shows Type II instrumentation plan. Figure 4.9 includes the instrumentation list for the monotonic tests.

\subsection{TEST PROCEDURE AND OBSERVATIONS}

\subsubsection{Test Procedure}

Each specimen was subjected to a monotonic load applied in displacement control at a rate of $0.02 \mathrm{~mm} / \mathrm{s}(0.05 \mathrm{in}$. $/ \mathrm{min})$. At times, loading was temporarily stopped to monitor crack growth. 


\subsubsection{Test Observations}

\subsubsection{Specimen $R C$}

Specimen RC was loaded in four-point bending with the loading center exactly at its mid-span. The first small cracking sound was heard at about $36 \%$ of the peak load with a tensile strain of 0.0022 at mid-span. Following flexural cracks, shear cracks developed within the shear span. The specimen eventually failed near the footing support mainly due to the severe damage from the cyclic test. Figure 4.10 and Figure 4.11 show the flexural cracks at mid-span and the cracks in the shear-flexural region, respectively. Figure 4.12 and Figure 4.13 show the final cracking pattern near the column footing.

\subsubsection{Specimen $Y$}

Specimen Y was loaded in three-point bending with slightly offset loading. The first small cracking sound was heard at about $78 \%$ of the peak load with a compressive strain of 0.0073 and a tensile strain of 0.0025 both at mid-span. A sudden FRP crushing burst occurred at the peak load near one of the loading points. Figure 4.14 and Figure 4.15 show the bursting cracks at the top from the east and west sides of the section, respectively. The burst in the FRP tube split the matrix into powders, while several pieces on the surface of FRP spalled off.

\subsubsection{Specimen $G$}

Specimen G was loaded in four-point bending with the loading center $13 \mathrm{~mm}$ off the mid-span toward the column head. The first small cracking sound was heard at about $66 \%$ of the peak load with the tensile strain of 0.00475 at mid-span. After the test, two 
crumpling cracks were found near the loading points. The cracking patterns are shown in Figure 4.16 and Figure 4.17. Figure 4.18 and Figure 4.19 show the close up and overall views of the specimen, respectively.

\subsubsection{Specimen $H$}

Specimen H was loaded in four-point bending with the loading center $38 \mathrm{~mm}(1.5$ in.) off the mid-span toward the column head. Figure 4.20 shows the direct loading of Specimen H using neoprene pads without steel saddles. The first small cracking sound was heard without any load drop at about $67 \%$ of the peak load with the compressive and tensile strains at the mid-span both at about 0.0025 . At about $83 \%$ of the peak load, another cracking noise was heard and a slight load drop was noticed. Upon removal of neoprene pads, two crumpling cracks were noticed near the loading points, as shown in Figure 4.21 and Figure 4.22. Figure 4.23 provides a close up of the cracks at the top of the specimen.

\subsubsection{Specimen $S C$}

Specimen SC was loaded in four-point bending with the loading center $38 \mathrm{~mm}$ (1.5 in.) off the mid-span toward the column head. The first cracking sound was heard at about $80 \%$ of the peak load with the tensile strain of 0.0047 at mid-span. The load continued to increase with cracking sounds heard throughout the test. The FRP tube ruptured, with the only flexural crack formed at the peak load exactly at mid-span with a loud bursting sound (Figure 4.24). The load dropped $80 \%$ immediately after the peak load. The only crumpling crack was then noticed at the top near the mid-span. Figure 4.25 captures both the flexural crack at the bottom and the crumpling crack at the top. 


\subsubsection{Specimen $L C$}

Specimen LC was loaded in four-point bending centered exactly at its mid span. The FRP tube ruptured with only a single flexural crack forming within the shear span at the peak load accompanied by a loud sound and a significant load drop. The crack may be attributed to the FRP sheet wrinkling during the tube fabrication, as shown in Figure 4.26. After the peak load, the crack extended to the mid-span, as shown in Figure 4.27. Approaching the end of the test, the crack extended to the top in the form of crushing or crumpling, as shown in Figure 4.28 through Figure 4.31.

\subsection{TEST RESULTS AND DISCUSSIONS}

\subsubsection{Moment and Shear at Peak Loads}

As reported in Section 4.3.1, flexural loading pattern was different for each specimen due to their different conditions after cyclic tests. Since mid-span displacements were monitored for all specimens, it is necessary to compare mid-span moments for cross referencing. Also for comparison with cyclic tests results, maximum moments of each specimen must be derived. Hence, a structural engineering software RISA-2D 8.1 was applied for structural analysis purposes, the results of which were validated with hand calculation. The negative overhang moments generated by the two end blocks (head and footing) were also considered in the calculation, however. Beam self-weight was not accounted for. The two point loads were entered as distributed loads each with $100 \mathrm{~mm}$ (4 in.) width. The maximum values of shear and moment at peak load along each specimen, as well as mid-span moment, are all recorded in Table 4.3. 


\subsubsection{Normalized Moment-Deflection Responses}

Figure 4.32 through Figure 4.37 show the normalized moment-deflection responses. The deflection is shown both as the mid-span displacement $\Delta$ and the normalized displacement $\Delta L$, where $L$ is the clear span.

For specimens with instrumentation Type I (Specimens Y, H, SC and LC), the mid-span deflections were calculated as the average of mid-span displacements of two string potentiometers minus the average of the two end support displacements. As described in Section 4.3.2, specimens with instrumentation Type II (Specimens RC and G) had two potentiometers monitoring the total rigid body movement of the column head due to the large residual displacements after cyclic tests. Results of the column head displacements showed that the supports for both specimens were quite efficient, and that the clear spans were maintained well at the inner edge of the column head. Hence, the displacement calculations followed the same procedure as that of specimens with Type I instrumentation.

All CFFT specimens showed bi-linear behavior with transition zones at about $65 \%$ of the respective peak loads for Specimens H, SC and LC; and about $50 \%$ of the peak load for Specimen Y. Specimen RC was severely damaged during the cyclic test, and thus it did not show any yielding plateau. Specimen Y exhibited a significant strain hardening behavior, while Specimen G showed a distinct yielding plateau. For Specimen LC (Figure 4.37), the first major load drop was associated with the flexural crack, followed by a series of slight load drops, corresponding to the development of flexural 
cracks at mid-span, as described in Section 4.4.2.6. The overall load capacity, however, generally did not decrease until the end of the test.

Figure 4.38 shows the mid-span normalized moment and deflection responses for

all specimens. Specimens LC and SC followed the same general response until cracking. When compared with Specimens SC and LC, Specimen Y had a similar bilinear response, somewhat different from the envelope curves of the cyclic tests. Specimen G showed the largest yielding moment and deflection capacity among all short CFFT specimens. Specimen H showed the largest flexural strength, albeit only $3 \%$ higher than that of Specimen G.

\subsubsection{Maximum Normalized Moment}

Table 4.3 compares the maximum moments from cyclic and monotonic tests for all specimens. Specimen RC was severely damaged in the cyclic tests, while all CFFT specimens had larger monotonic flexural capacity, indicating that only a fraction of their strengths were utilized in the cyclic tests. Specimen Y had the highest reserved strength among all CFFT specimens. In the table, " $T$ " and " $\mathrm{C}$ " denote tension and crumpling compression cracks, respectively. It was noticed that cracks in the monotonic tests were not necessarily near the maximum moment sections. Moreover, for Specimens RC, G, H, SC and LC, the mid-span moments are only within $2.5 \%$ of the maximum moments at peak loads. For Specimen Y, the difference is about $10 \%$.

\subsubsection{Energy Dissipation}

Figure 4.39 shows the normalized cumulative dissipated energy versus their normalized mid-span deflection in monotonic tests. Comparing with the total normalized 
cumulative dissipated energy versus their drift ratio responses in cyclic tests (Figure 3.57), it is clear that in both figures, Specimens $\mathrm{H}$ distinguishes itself with the highest cumulative dissipated energy at the same drift ratio. Specimen G, the second highest curve, performed better than Specimen Y, the other fiberglass tube, both in terms of dissipated energy and dissipation rate. Corresponding to their similar behaviors of loaddeflection responses, Specimens LC, SC and $\mathrm{Y}$ also had similar energy dissipation trends expect at larger deflections in monotonic tests, where Specimen Y showed better energy dissipation than Specimen LC.

\subsubsection{Normalized Initial Stiffness}

Table 4.4 compares the normalized initial stiffness of CFFT specimens from monotonic and cyclic tests, based on the initial elastic slopes of normalized moment deflection response curves. The $R^{2}$, coefficient of determination, was derived from the linear regression analysis in the elastic region. The ratios between the two test sets as well as theoretical elastic stiffness ratios are also listed. Moreover, the theoretical ratios are shown as percentages over the experimental ratios, which may indicate the potential damage of each CFFT specimen after cyclic tests. It is noted that all short CFFT specimens (Y, G, H and SC) had a stiffness loss of about 33\%, whereas the stiffness loss in Specimen LC was only $8 \%$. Figure 4.40 shows the relationship of normalized initial stiffness with FRP/concrete stiffness ratio for both cyclic and monotonic tests of short CFFT specimens. Specimen H had higher normalized initial stiffness primarily due to its higher FRP/concrete stiffness ratio. 


\subsubsection{Ductility}

Table 4.5 compares the ductility of CFFT specimens from monotonic and cyclic tests, along with their respective calculation steps. In monotonic tests, Specimen LC had the highest ductility since the test carried on after a major crack, and maintained a substantial capacity. Ductility of Specimen H is in between specimens with GFRP tubes (Specimens G and Y) and CFRP tube (Specimen SC). In cyclic tests, the actual ductility values for Specimens $Y$ and $G$ are expected to be higher than those listed, because neither specimen failed in the cyclic tests.

Figure 4.41 shows the relationship between ductility and the longitudinal FRP tensile strains for short CFFT specimens from both cyclic and monotonic tests. It is evident that ductility has a strong linear and somewhat similar correlation with rupture strain of FRP tube in both sets of tests.

\subsubsection{Normalized Moment-Strain Responses}

Figure 4.42 through Figure 4.47 show the normalized mid-span moment - FRP strain responses for each specimen. The mid-span strain readings were from the top and bottom gauges mounted on the FRP tubes or on the surface of the RC beam, with negative readings indicating compression. Figure 4.48 shows the normalized mid-span moment - FRP strain responses for all specimens. All specimens demonstrated a bi-linear response, with the two fiberglass specimens ( $\mathrm{Y}$ and $\mathrm{G}$ ) having similar initial slope and transition zone. The second slope of Specimen G, however, was larger than that of Specimen Y. Specimen H had almost the same initial slope as those of Specimens SC and LC. Specimen Y reached the highest compressive strain, while Specimen G developed 
the highest tensile strain. It is also evident that load-strain responses generally followed the same pattern as the load-deflection responses in all specimens.

The strains in the transition zones of Specimens SC and LC were almost identical, with 0.003 in tension and 0.0015 in compression. Moreover, final compressive strains for both specimens were similar at around 0.0042 . In general, tensile strain was larger than compressive strain, which explains why both specimens had tension failures. For Specimen $Y$, however, the compressive strains were larger than tensile strains, leading to its compressive burst failure.

\subsubsection{Normalized Moment-Curvature Responses}

Figure 4.49 shows normalized mid-span moment - curvature responses for all specimens from the monotonic tests, except for Specimen G, which instead features the envelope of its cyclic test results at column base in the push direction (Shi 2009), shown in dashed lines. Cyclic test results of Specimen $\mathrm{Y}$ in the push direction are also shown in dashed lines. The two data sets of Specimen Y were quite similar, thus confirming the validity of comparing cyclic tests results of Specimen $G$ with the monotonic test data from the others. Specimen $\mathrm{H}$ showed the highest flexural strength at the same curvature level because of its high stiffness, while the other four CFFT specimens demonstrated similar sectional curvature responses.

\subsubsection{Normalized Moment and Reinforcement Index Relationship}

Table 4.6 lists the strength and stiffness indices for FRP and mild steel reinforcement, using both confined and unconfined concrete compressive strengths, along 
with the maximum normalized moments and shear forces from monotonic tests. FRP strength indices based on the unconfined and confined concrete compressive strengths, respectively, are defined as:

$$
\omega=\rho f_{u} / f^{\prime}{ }_{c}
$$

$$
\omega_{c}=\rho f_{u} / f_{c u}^{\prime}
$$

where $f_{u}$ is ultimate tensile strength of FRP, $f_{c u}^{\prime}$ is compressive strength of confined concrete, and FRP reinforcement ratio, $\rho$, is defined as:

$$
\rho=4 t / D_{o}
$$

where $t$ is the FRP tube thickness and $D_{o}$ is the outside diameter of the specimen. FRP stiffness index is defined as:

$$
\omega^{\prime}=\rho E_{F R P} / E_{c}
$$

where $E_{F R P}$ and $E_{c}$ are moduli of elasticity of FRP and concrete, respectively.

Mild steel strength indices based on unconfined concrete compressive strength $\left(\varpi_{s}\right)$ and confined concrete compressive strength $\left(\varpi_{c s}\right)$, may be derived from Equations (1) and (2), respectively, should ultimate strength of steel be used for $f_{u}$. Compressive strength for confined concrete core, $f_{c u}^{\prime}$, is calculated based on Samaan (1998) model for FRP-confined concrete and Kent-Park model, as modified by Scott (1982) for spiral steel-confined concrete. 
Figure 4.50 (a) and (b) show the relationship of normalized moment with strength indices of CFFT specimens using the unconfined and confined concrete compressive strengths, respectively. The normalized moment increases with the reinforcement index based on the unconfined concrete compressive strength. There seems to be an optimum reinforcement index for achieving the design moment. On the other hand, for confined strength of concrete, there is a descending branch between Specimens $\mathrm{Y}, \mathrm{G}$ and $\mathrm{H}$ at higher reinforcement indices. This further indicates the existence of an optimum reinforcement index without over-confining the concrete.

\subsubsection{Influence of Shear Span Ratio and Reinforcement Index on Flexural and Shear Behavior}

Specimens Y, G, H and SC were tested with short shear span-to-depth ratios in the range of 1.0 to 1.6 , whereas Specimen LC was tested at a ratio of 2.5. Specimens LC and SC exhibited identical tension failures, while Specimens Y, G and H all experienced local buckling failure. None of the specimens failed in shear. Moreover, since tubeconcrete slippage in these specimens was prevented with both ends embedded in concrete blocks and with additional dowel steel, the results fully extend and validate the findings of an earlier study by Ahmad et al. (2008a).

In a previous study, however, Fam et al. (2007) indicated that a diagonal tension failure may occur for a CFFT beam with internal steel reinforcement. Their Specimen B6 had a total reinforcement (FRP and mild steel) index of 0.86 with a shear span-to-depth ratio of 1.0. On the other hand, one of the CFFT short and deep beams tested by Ahmad et al. (2008a), Specimen S-5, also had a shear span-to-depth ratio of 1.0 and a high FRP 
reinforcement index of 1.97 . Although the specimen was loaded up to only $80 \%$ of its predicted capacity due to the limitation of the test frame, some diagonal shear cracks were developed in concrete core. Nonetheless, the high FRP reinforcement assisted shear capacity of Specimen S-5 in the study by Ahmad et al. (2008a).

Table 4.7 compares the reinforcement index and normalized moment and shear force of Specimens SC and H with those of Beams B6 (Fam et al. 2007) and S-5 (Ahmad et al. 2008a). It is noted that Specimens B6 and $\mathrm{H}$ were highly comparable in all their properties except for the longitudinal FRP stiffness indices. Although the longitudinal FRP and mild steel configurations were different, the total reinforcement indices were highly close to each other leading to very similar flexural strengths. The ultimate shear capacity of Specimen B6, however, was substantially larger than that of Specimen H. This was attributed not only to the relatively higher hoop strength index of Specimen B6, but also to its shorter shear span-to-depth ratio. Figure 4.51 captures the above discussion, relating the normalized shear forces with the hoop strength indices of five CFFT specimens of present study and Specimen B6 from Fam et al. (2007) with their respective failure modes.

Specimens SC and B6 had almost the same shear span-to-depth ratio of 1.0, but failed in flexure and shear, respectively. This may be attributed to the fact that Specimen SC had more transverse FRP than Specimen B6, when comparing the ratio of hoop over longitudinal strength indices. Therefore, one may consider an optimal balanced design between flexural and shear FRP reinforcement to avoid a non-ductile shear failure, without over-confining the section in the hoop direction. 


\subsection{CONCLUSIONS}

A series of monotonic bending tests were conducted on the one $\mathrm{RC}$ and five CFFT specimens that were previously subjected to reverse cyclic tests. Following conclusions may be drawn from this study:

1. Specimens SC and LC both experienced flexural failures by FRP rupture in tension and crumpling in compression. Specimens $\mathrm{Y}, \mathrm{G}$ and $\mathrm{H}$ all had FRP local buckling failure. Specimen Y exhibited an FRP burst crushing, while FRP tubes in Specimens $\mathrm{G}$ and $\mathrm{H}$ had crumpling cracks.

2. CFFT specimens all showed a bi-linear response. Of the two fiberglass specimens, Specimen Y with filament-wound FRP tube exhibited a rather significant strain hardening behavior, whereas Specimen G with hand lay-up FRP tube had a distinct yielding plateau.

3. Specimen $\mathrm{H}$ with its hybrid glass/carbon lay-up demonstrated the highest flexural strength mainly because of its high reinforcement index. It also had the highest initial stiffness due to its high $\mathrm{FRP} /$ concrete stiffness ratio.

4. At the same drift ratio, Specimen $\mathrm{H}$ was considered as the best in both terms of energy dissipation.

5. Specimens with glassfiber tubes ( $\mathrm{Y}$ and $\mathrm{G})$ exhibited the highest ductility due to higher flexibility of GFRP composites. Furthermore, ductility of CFFTs had a strong correlation with the rupture strain of FRP.

6. Specimen $\mathrm{H}$ showed the highest flexural strength at the same curvature level because of its high stiffness, while the other four CFFT specimens demonstrated about the same level of moment-curvature responses. 
7. Flexural strength increases with the reinforcement index based on unconfined concrete compressive strength, but depicts a descending branch when considering the confined concrete compressive strength. Hence, one can optimize reinforcement index for achieving a design moment without over-confining in the hoop direction.

8. With proper FRP architecture, shear failure is not expected to be critical for CFFT specimens at short shear span-to-depth ratios as low as 1.0, with or without steel reinforcement and end restraints. 
Table 4.1 Specimen Conditions after Cyclic Tests

\begin{tabular}{|c|c|c|c|c|c|}
\hline Specimen & $\begin{array}{l}\text { Column Base } \\
\text { Condition after } \\
\text { Cyclic Tests }\end{array}$ & $\begin{array}{c}\text { Footing } \\
\text { Condition after } \\
\text { Cyclic Tests }\end{array}$ & $\begin{array}{c}\text { Column } \\
\text { Condition at } \\
\text { Mid-Span after } \\
\text { Cyclic Tests }\end{array}$ & $\begin{array}{c}\text { Residual } \\
\text { Displacement } \\
\text { after Cyclic } \\
\text { Tests * } \\
\text { mm (in.) }\end{array}$ & $\begin{array}{c}\text { Instrumentation } \\
\text { Plan Type of } \\
\text { Monotonic } \\
\text { Tests } \\
\end{array}$ \\
\hline $\mathrm{RC}$ & $\begin{array}{c}\text { Concrete } \\
\text { Cracks at } \\
\text { Column Base } \\
\end{array}$ & $\begin{array}{l}\text { No Visible } \\
\text { Cracks }\end{array}$ & \multirow{6}{*}{ Intact } & $-129(-5.09)$ & II \\
\hline $\mathrm{Y}$ & \multirow{3}{*}{$\begin{array}{l}\text { No Visible } \\
\text { Cracks }\end{array}$} & \multirow{5}{*}{$\begin{array}{l}\text { Extensive } \\
\text { Concrete } \\
\text { Cracks }\end{array}$} & & $28(1.10)$ & I \\
\hline G & & & & $-90(-3.54)$ & II \\
\hline $\mathrm{H}$ & & & & $-3(-0.11)$ & \multirow{3}{*}{ I } \\
\hline $\mathrm{SC}$ & $\begin{array}{l}\text { FRP Cracks at } \\
\text { Column Base }\end{array}$ & & & $-3(-0.10)$ & \\
\hline LC & $\begin{array}{c}\text { (One at Top } \\
\text { and One at } \\
\text { Bottom) }\end{array}$ & & & $-4(-0.15)$ & \\
\hline
\end{tabular}

* Negative signs indicate downward displacements.

Table 4.2 Loading Patterns for Test Specimens

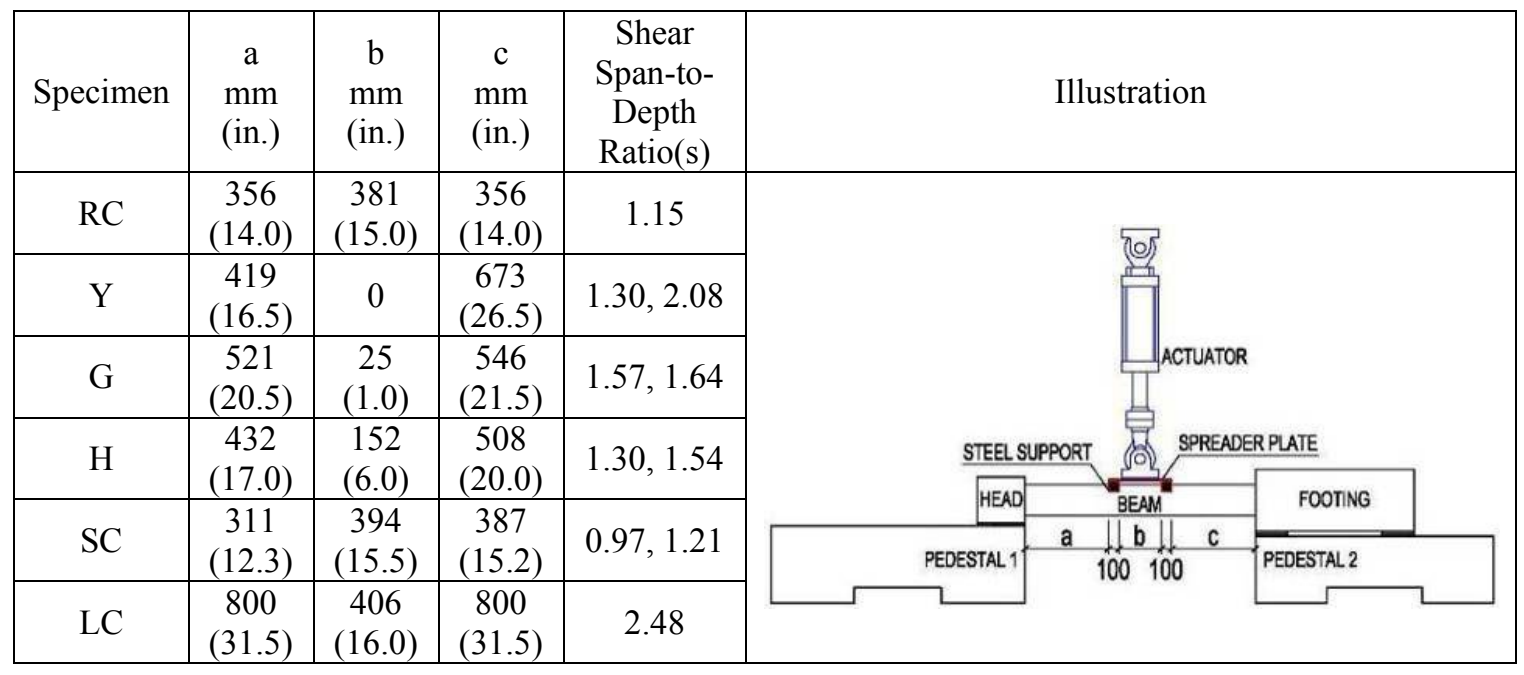


Table 4.3 Comparison of Monotonic and Cyclic Tests Moments

\begin{tabular}{|c|c|c|c|c|c|c|c|}
\hline Test Sets & Specimen & $\mathrm{RC}$ & $\mathrm{Y}$ & $\mathrm{G}$ & $\mathrm{H}$ & $\mathrm{SC}$ & $\mathrm{LC}$ \\
\hline \multirow{3}{*}{ Cyclic } & $\begin{array}{l}\text { Maximum } \\
\text { Normalized } \\
\text { Moment (Pull) }\end{array}$ & 0.0834 & 0.0996 & 0.1195 & 0.1457 & 0.1002 & 0.1214 \\
\hline & $\begin{array}{c}\text { Maximum } \\
\text { Normalized } \\
\text { Moment (Push) }\end{array}$ & $\begin{array}{c}0.0413 \\
\text { Damaged }\end{array}$ & 0.0861 & 0.0896 & 0.1289 & 0.0806 & 0.0680 \\
\hline & $\begin{array}{l}\text { Average } \\
\text { Normalized } \\
\text { Moment } \\
\end{array}$ & $0.0834^{*}$ & 0.0929 & 0.1046 & 0.1373 & 0.0904 & 0.0947 \\
\hline \multirow{4}{*}{ Monotonic } & $\begin{array}{l}\text { Maximum } \\
\text { Normalized } \\
\text { Moment } \\
\end{array}$ & $\begin{array}{c}0.0441 \\
\text { Damaged }\end{array}$ & 0.1443 & 0.1497 & 0.1543 & 0.1011 & 0.0990 \\
\hline & $\begin{array}{l}\text { Distance from } \\
\text { Head Support } \\
\text { mm (in.) }\end{array}$ & $\begin{array}{c}459 \\
(18.06)\end{array}$ & $\begin{array}{c}540 \\
(21.25)\end{array}$ & $\begin{array}{c}648 \\
(25.50)\end{array}$ & $\begin{array}{c}688 \\
(27.10)\end{array}$ & $\begin{array}{c}810 \\
(31.88)\end{array}$ & $\begin{array}{c}898 \\
(35.34)\end{array}$ \\
\hline & $\begin{array}{c}\text { Cracks } \\
\text { Measured from } \\
\text { Column Head } \\
\text { mm (in.) }\end{array}$ & $\begin{array}{l}\text { Multiple } \\
\text { Location }\end{array}$ & $\begin{array}{c}699 \sim 737 \\
(27.5 \sim \\
29.0) \\
{[C]^{* * *}}\end{array}$ & $\begin{array}{c}483 \\
(19.0) \\
{[\mathrm{C}]} \\
660 \\
(26.0) \\
{[\mathrm{C}]} \\
\end{array}$ & $\begin{array}{c}597 \\
(23.5) \\
{[C]} \\
699 \\
(27.5) \\
{[C]} \\
\end{array}$ & $\begin{array}{c}648 \\
(25.5) \\
{[\mathrm{T}]^{* *}} \\
483 \\
(19.0) \\
{[\mathrm{C}]}\end{array}$ & $\begin{array}{c}1,626 \\
(64.0) \\
{[\mathrm{T}]} \\
1,092 \\
(43.0) \\
{[\mathrm{C}]} \\
\end{array}$ \\
\hline & $\begin{array}{c}\text { Mid-Span } \\
\text { Normalized } \\
\text { Moment } \\
\text { (Percentage of } \\
\text { Maximum } \\
\text { Normalized } \\
\text { Monotonic } \\
\text { Moment) }\end{array}$ & $\begin{array}{c}0.0431 \\
(97.73 \%)\end{array}$ & $\begin{array}{c}0.1301 \\
(90.16 \%)\end{array}$ & $\begin{array}{c}0.1497 \\
(100 \%)\end{array}$ & $\begin{array}{c}0.1539 \\
(99.74 \%)\end{array}$ & $\begin{array}{c}0.0997 \\
(98.62 \%)\end{array}$ & $\begin{array}{c}0.0981 \\
(99.09 \%)\end{array}$ \\
\hline \multicolumn{2}{|c|}{$\begin{array}{c}\text { Ratio of Maximum Normalized } \\
\text { Moments } \\
\text { (Cyclic / Monotonic) }\end{array}$} & $141 \%$ & $64 \%$ & $70 \%$ & $89 \%$ & $89 \%$ & $96 \%$ \\
\hline
\end{tabular}

* Data is only accounted for the pull direction, due to initial damage from unintended overload in the push direction.

** T: Tension Cracks

*** C: Crumpling Cracks 
Table 4.4 Comparison of Normalized Initial Stiffness from Monotonic and Cyclic Tests

\begin{tabular}{|c|c|c|c|c|c|c|}
\hline Test Sets & Specimen & $\mathrm{Y}$ & $\mathrm{G}$ & $\mathrm{H}$ & $\mathrm{SC}$ & $\mathrm{LC}$ \\
\hline \multirow{2}{*}{ Cyclic } & $\begin{array}{c}\text { Normalized } \\
\text { Initial Stiffness }\end{array}$ & 0.0651 & 0.0601 & 0.0960 & 0.0731 & 0.0552 \\
\cline { 2 - 7 } & $R^{2}$ & 0.8399 & 0.9203 & 0.8783 & 0.8544 & 0.9030 \\
\hline Monotonic & $\begin{array}{c}\text { Normalized } \\
\text { Initial Stiffness }\end{array}$ & 0.1646 & 0.1680 & 0.2663 & 0.1808 & 0.1923 \\
\cline { 2 - 7 } & $R^{2}$ & 0.9989 & 0.9989 & 0.9996 & 0.9975 & 0.9856 \\
\hline $\begin{array}{c}\text { Normalized Initial Stiffness } \\
\text { Ratio } \\
\text { (Cyclic / Monotonic) }\end{array}$ & 0.3955 & 0.3577 & 0.3605 & 0.4043 & 0.2871 \\
\hline $\begin{array}{c}\text { Theoretical Elastic Stiffness } \\
\text { Ratio } \\
\text { (Cyclic / Monotonic) }\end{array}$ & 0.2418 & 0.2310 & 0.2428 & 0.2493 & 0.2641 \\
\hline $\begin{array}{c}\text { Theoretical Stiffness Ratio / } \\
\text { Experimental Stiffness Ratio } \\
\text { (\%) }\end{array}$ & $61.1 \%$ & $64.6 \%$ & $67.4 \%$ & $61.7 \%$ & $92.0 \%$ \\
\hline
\end{tabular}

Table 4.5 Comparison of Ductility of CFFT Specimens from Monotonic and Cyclic Tests

\begin{tabular}{|c|c|c|c|c|c|c|c|}
\hline Test Sets & Item & Specimen & $\mathrm{Y}$ & $\mathrm{G}$ & $\mathrm{H}$ & $\mathrm{SC}$ & LC \\
\hline \multirow{5}{*}{ Cyclic } & (a) & $\begin{array}{c}\text { Normalized } \\
\text { Maximum Moment }\end{array}$ & 0.0996 & -0.0896 & -0.1289 & -0.0806 & -0.0680 \\
\hline & (b) & $\begin{array}{c}\text { Normalized Initial } \\
\text { Stiffness }\end{array}$ & 0.0651 & 0.0601 & 0.0960 & 0.0731 & 0.0552 \\
\hline & $\begin{array}{c}(\mathrm{c})= \\
(\mathrm{a}) /(\mathrm{b})\end{array}$ & $\begin{array}{c}\text { Yield Deflection } \\
\text { Ratio }\end{array}$ & 1.5300 & -1.4908 & -1.3427 & -1.1026 & -1.2319 \\
\hline & (d) & $\begin{array}{c}\text { Maximum } \\
\text { Deflection Ratio }\end{array}$ & 6.6140 & -8.1203 & -4.8409 & -3.9920 & -6.1070 \\
\hline & $\begin{array}{c}(\mathrm{e})= \\
(\mathrm{d}) /(\mathrm{c})\end{array}$ & Ductility & 4.32 & 5.45 & 3.61 & 3.62 & 4.96 \\
\hline \multirow{5}{*}{ Monotonic } & (f) & $\begin{array}{c}\text { Normalized } \\
\text { Maximum Moment }\end{array}$ & 0.1443 & 0.1497 & 0.1539 & 0.0997 & 0.0981 \\
\hline & (g) & $\begin{array}{c}\text { Normalized Initial } \\
\text { Stiffness }\end{array}$ & 0.1646 & 0.1680 & 0.2663 & 0.1808 & 0.1923 \\
\hline & $\begin{array}{c}(\mathrm{h})= \\
(\mathrm{f}) /(\mathrm{g})\end{array}$ & $\begin{array}{c}\text { Yield Deflection } \\
\text { Ratio } \\
\end{array}$ & 0.8767 & 0.8911 & 0.5779 & 0.5514 & 0.5101 \\
\hline & (i) & $\begin{array}{c}\text { Maximum } \\
\text { Deflection Ratio } \\
\end{array}$ & 2.6353 & 2.8715 & 1.2601 & 1.0163 & 2.3684 \\
\hline & $\begin{array}{c}(\mathrm{j})= \\
(\mathrm{i}) /(\mathrm{h})\end{array}$ & Ductility & 3.01 & 3.22 & 2.18 & 1.84 & 4.64 \\
\hline $\begin{array}{l}\text { Cyclic/ } \\
\text { Monotonic }\end{array}$ & $\begin{array}{c}(\mathrm{k})= \\
(\mathrm{e}) /(\mathrm{j})\end{array}$ & $\begin{array}{c}\text { Ductility Ratio } \\
\text { (Cyclic/ } \\
\text { Monotonic) }\end{array}$ & 1.44 & 1.69 & 1.66 & 1.93 & 1.07 \\
\hline
\end{tabular}

Note: Positive and negative data represent pull and push directions, respectively. 
Table 4.6 FRP and Steel Strength and Stiffness Indices with Maximum Normalized Moments and Shear Forces

\begin{tabular}{|c|c|c|c|c|c|c|c|c|c|}
\hline \multirow[b]{2}{*}{ Specimen } & \multirow[b]{2}{*}{$f_{c u}^{\prime} / f_{c}^{\prime}$} & \multicolumn{2}{|c|}{$\begin{array}{c}\text { FRP Strength Indices } \\
\varpi\left(\varpi_{c}\right)\end{array}$} & \multicolumn{2}{|c|}{$\begin{array}{l}\text { FRP Stiffness Indices } \\
\qquad \varpi^{\prime}\end{array}$} & \multicolumn{2}{|c|}{$\begin{array}{c}\text { Steel Strength Indices } \\
\varpi_{s}\left(\varpi_{c s}\right)\end{array}$} & \multirow{2}{*}{$\begin{array}{c}\text { Maximum } \\
\text { Normalized } \\
\text { Moment } \\
M / f^{\prime}{ }_{c} D^{3} \\
\left(M / f^{\prime}{ }_{c u} D^{3}\right)\end{array}$} & \multirow{2}{*}{$\begin{array}{c}\text { Maximum } \\
\text { Normalized } \\
\text { Shear } \\
V / f^{\prime}{ }_{c} D^{2}\end{array}$} \\
\hline & & Longitudinal & Hoop & Longitudinal & Hoop & Longitudinal & Hoop & & \\
\hline $\mathrm{RC}$ & 1.09 & - & - & - & - & $\begin{array}{c}0.2085 \\
(0.1919)\end{array}$ & $\begin{array}{c}0.1081 \\
(0.0990)\end{array}$ & $\begin{array}{c}0.0834 \\
(0.0764)\end{array}$ & 0.0375 \\
\hline Y & 1.59 & $\begin{array}{l}0.2405^{*} \\
(0.1513)\end{array}$ & $\begin{array}{c}0.3556 \\
(0.2237)\end{array}$ & $0.0351 * *$ & N/A & $\begin{array}{c}0.1921 \\
(0.1208)\end{array}$ & \multirow{5}{*}{0} & $\begin{array}{c}0.1443 \\
(0.0908)\end{array}$ & 0.0880 \\
\hline G & 1.66 & $\begin{array}{c}0.3813 \\
(0.2304)\end{array}$ & $\begin{array}{c}0.4088 \\
(0.2470)\end{array}$ & 0.0471 & 0.0475 & $\begin{array}{c}0.1815 \\
(0.1097)\end{array}$ & & $\begin{array}{c}0.1497 \\
(0.0905)\end{array}$ & 0.0762 \\
\hline $\mathrm{H}$ & 2.00 & $\begin{array}{c}0.6097 \\
(0.3052) \\
\end{array}$ & $\begin{array}{c}0.6579 \\
(0.3294) \\
\end{array}$ & 0.1004 & 0.0512 & $\begin{array}{c}0.2476 \\
(0.1240) \\
\end{array}$ & & $\begin{array}{c}0.1543 \\
(0.0773) \\
\end{array}$ & 0.0925 \\
\hline $\mathrm{SC}$ & \multirow{2}{*}{1.57} & \multirow{2}{*}{$\begin{array}{c}0.0993 \\
(0.0631)\end{array}$} & \multirow{2}{*}{$\begin{array}{c}0.3066 \\
(0.1948)\end{array}$} & \multirow{2}{*}{0.0185} & \multirow{2}{*}{0.0367} & \multirow{2}{*}{$\begin{array}{c}0.2615 \\
(0.1661)\end{array}$} & & $\begin{array}{c}0.1011 \\
(0.0642)\end{array}$ & 0.0834 \\
\hline $\mathrm{LC}$ & & & & & & & & $\begin{array}{c}0.0990 \\
(0.0629)\end{array}$ & 0.0386 \\
\hline
\end{tabular}

* Using flexure strength and modulus instead of tensile strength and modulus because of the specific fiber architecture. 
Table 4.7 Comparison of Reinforcement Indices and Normalized Moments of Specimens H and SC with Beams B6* and S-5**

\begin{tabular}{|c|c|c|c|c|c|c|c|c|c|}
\hline $\begin{array}{l}\text { Specimen } \\
\text { (Shear } \\
\text { Span-to- } \\
\text { Depth }\end{array}$ & $\begin{array}{c}\text { FRP } \\
\text { Strength } \\
\text { Indices } \\
\varpi\end{array}$ & & $\begin{array}{c}\text { FRP } \\
\text { Stiffness } \\
\text { Indices } \\
\varpi^{\prime}\end{array}$ & & $\begin{array}{c}\text { Steel } \\
\text { Strength } \\
\text { Indices } \\
\varpi_{s}\end{array}$ & $\begin{array}{c}\text { Total } \\
\text { Strength } \\
\text { Indices } \\
\varpi+\varpi_{s}\end{array}$ & & \multirow[t]{2}{*}{$\begin{array}{l}\text { Maximum } \\
\text { Normalized } \\
\text { Moment } \\
M / f^{\prime}{ }_{c} D^{3}\end{array}$} & \multirow[t]{2}{*}{$\begin{array}{c}\text { Maximum } \\
\text { Normalized } \\
\text { Shear } \\
V / f^{\prime}{ }_{c} D^{2}\end{array}$} \\
\hline Ratios) & Longitudinal & Hoop & Longitudinal & Hoop & Longitudinal & Longitudinal & Hoop & & \\
\hline $\begin{array}{c}\mathrm{SC} \\
(0.97,1.21) \\
\end{array}$ & 0.0993 & 0.3066 & 0.0185 & 0.0367 & 0.2615 & 0.3608 & 0.3066 & 0.1011 & 0.0834 \\
\hline $\begin{array}{c}\mathrm{H} \\
(1.30,1.54)\end{array}$ & 0.6097 & 0.6579 & 0.1004 & 0.0512 & 0.2476 & 0.8573 & 0.6579 & 0.1543 & 0.0925 \\
\hline $\begin{array}{l}\text { B6* } \\
(1.0)\end{array}$ & 0.3027 & 0.6789 & 0.0275 & 0.0453 & 0.5584 & 0.8611 & 0.6789 & 0.1547 & 0.1540 \\
\hline $\begin{array}{c}\text { S-5** } \\
(1.0)\end{array}$ & 1.9700 & N/A & 0.1273 & N/A & 0 & 1.9700 & N/A & $0.2230 * * *$ & $0.3917^{* * *}$ \\
\hline
\end{tabular}




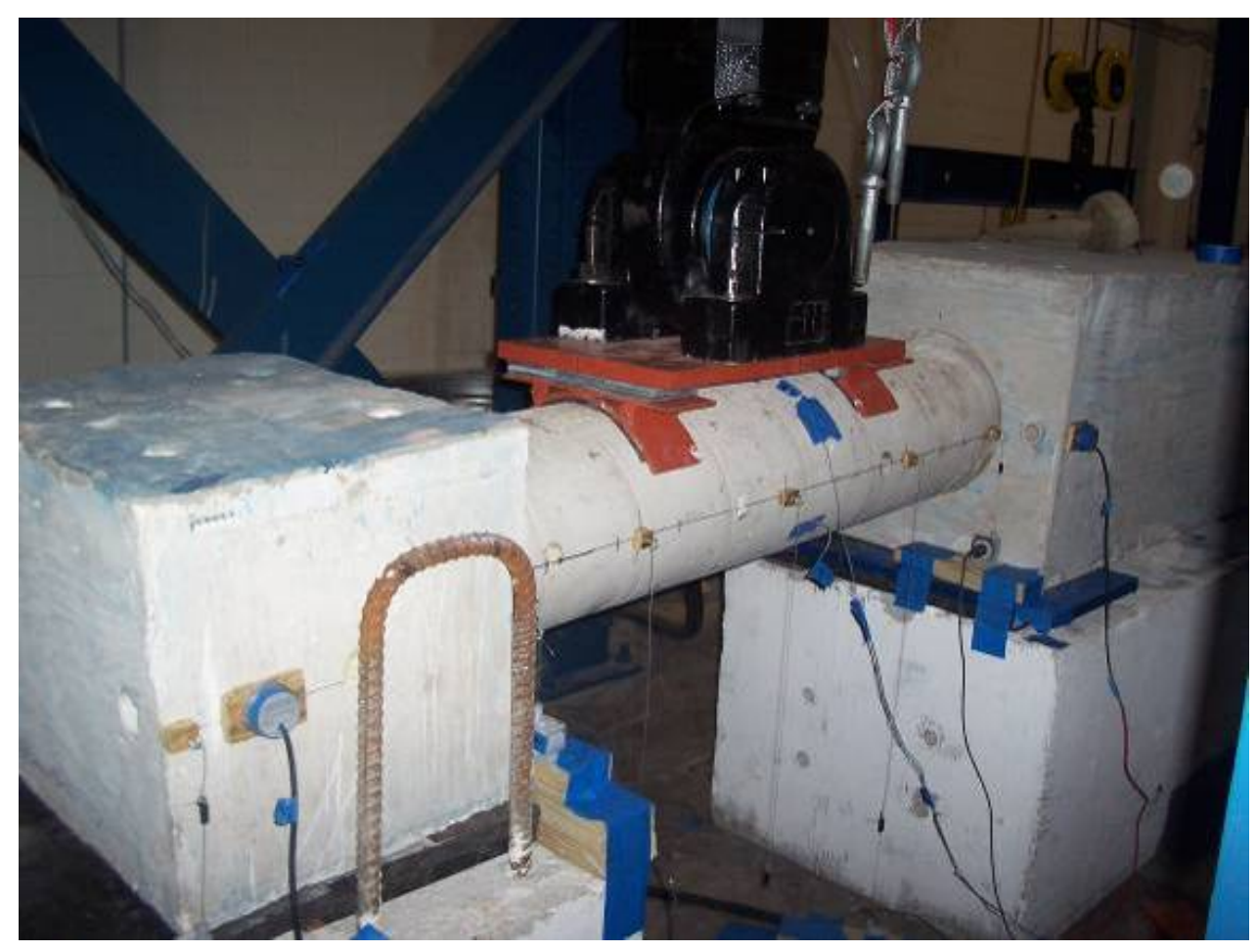

Figure 4.1 Monotonic Test Setup for Specimen RC

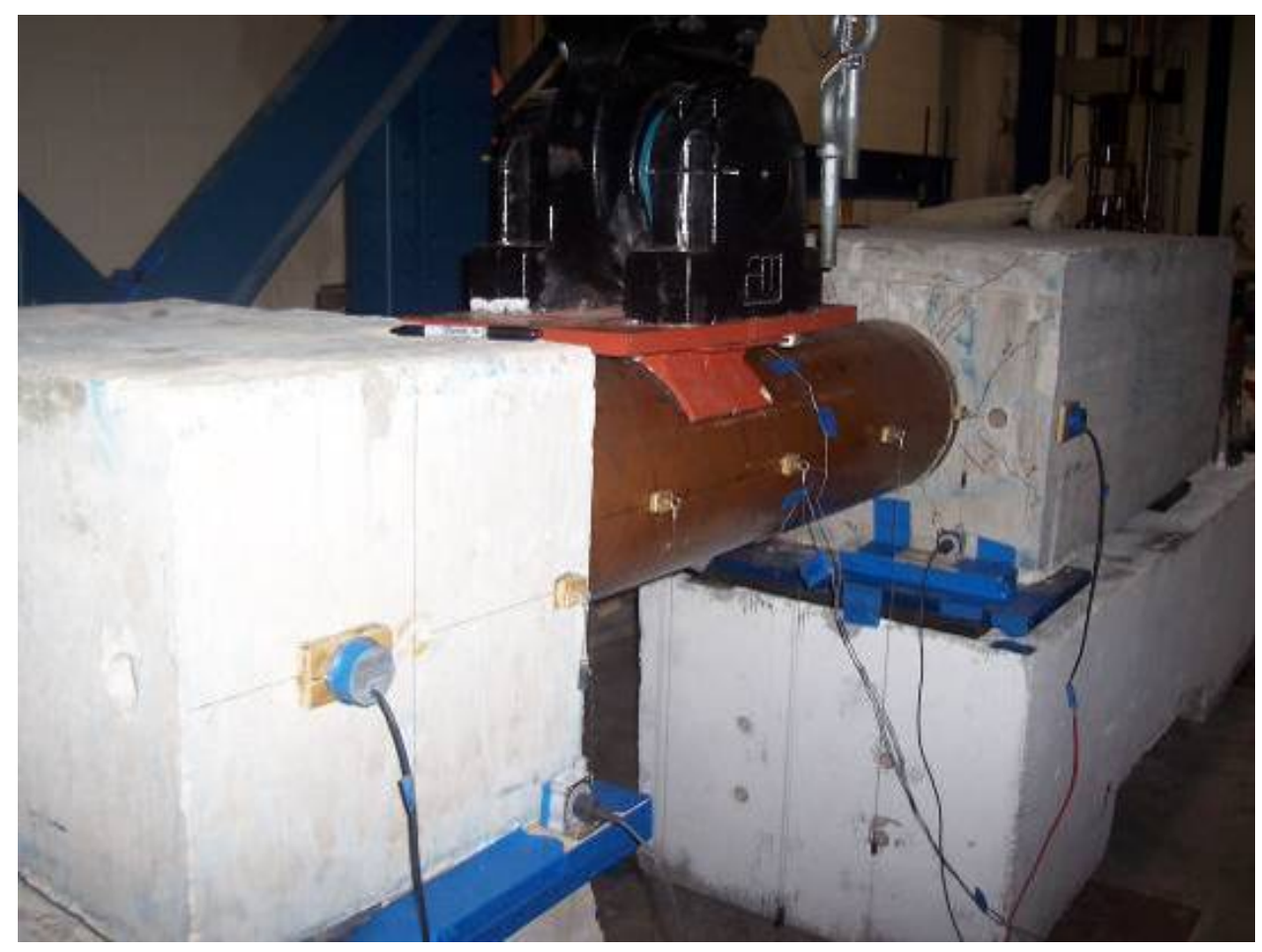

Figure 4.2 Monotonic Test Setup for Specimen Y 


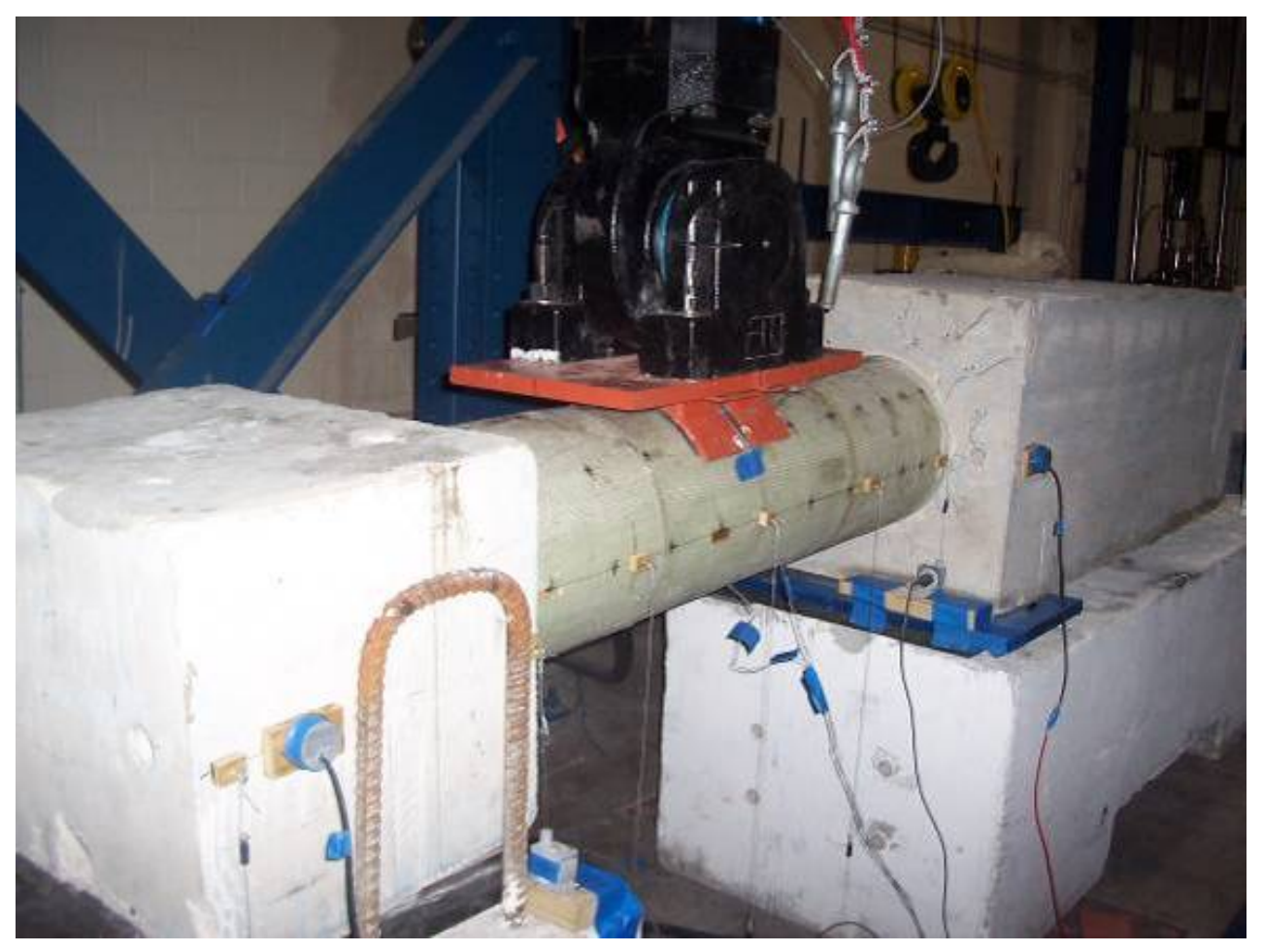

Figure 4.3 Monotonic Test Setup for Specimen G

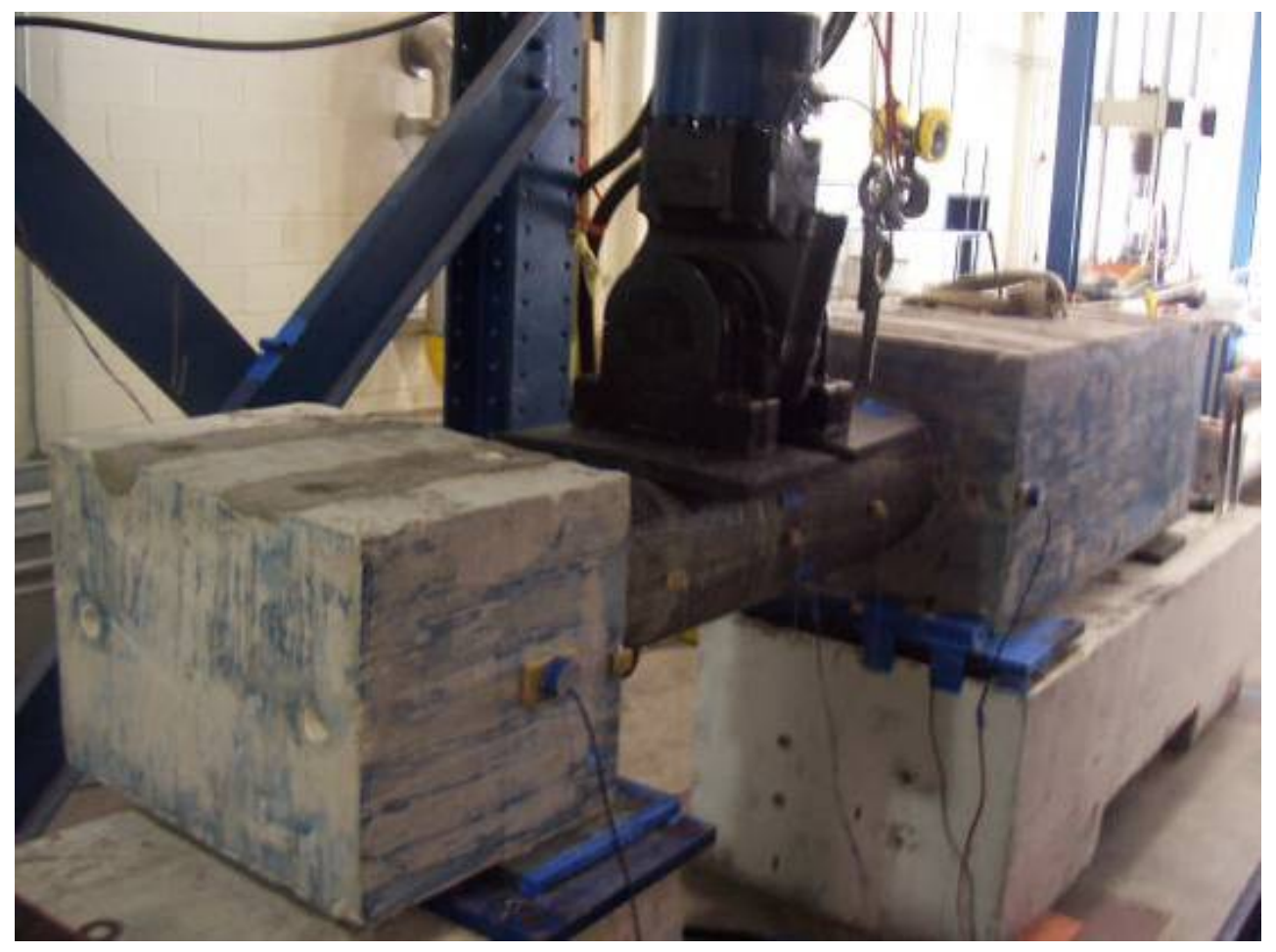

Figure 4.4 Monotonic Test set-up for Specimen H 


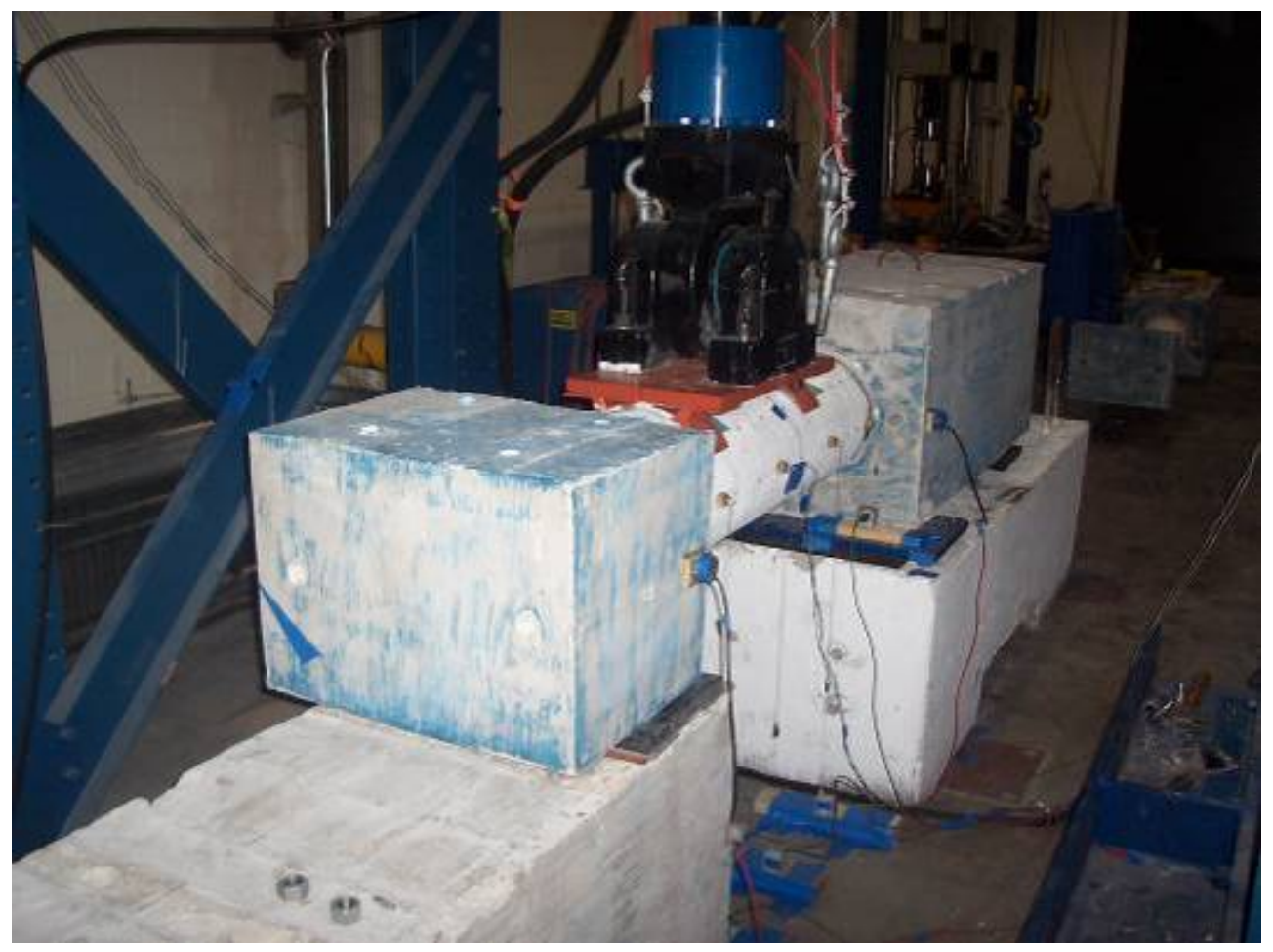

Figure 4.5 Monotonic Test set-up for Specimen SC

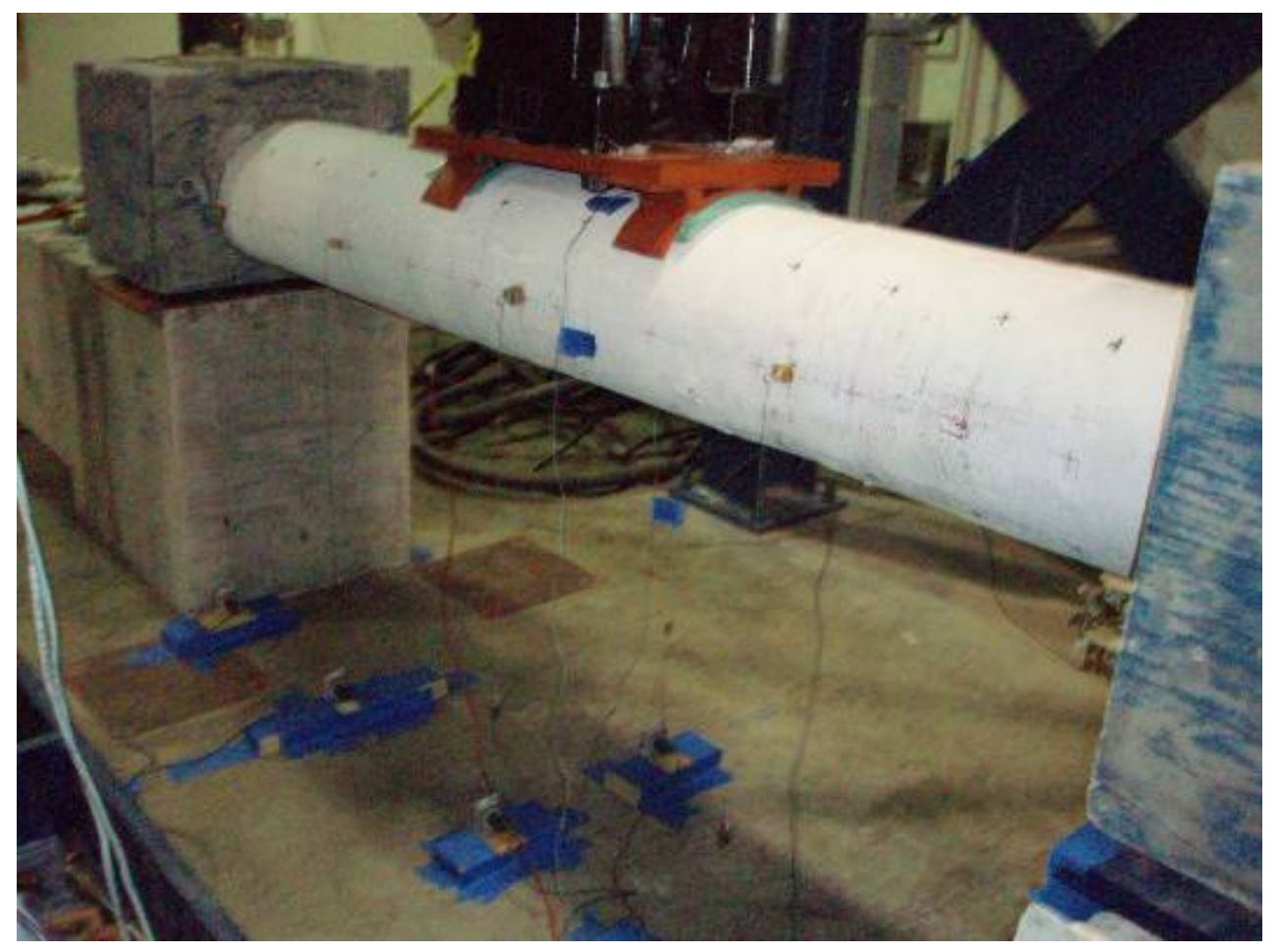

Figure 4.6 Monotonic Test set-up for Specimen LC 


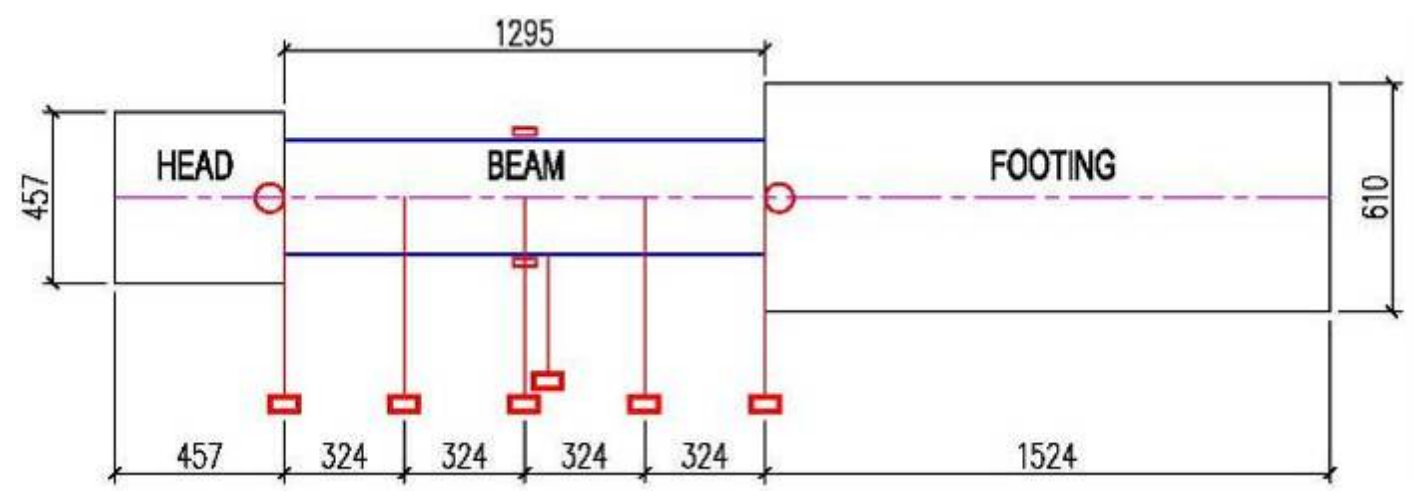

(a) Specimens Y, H, and SC

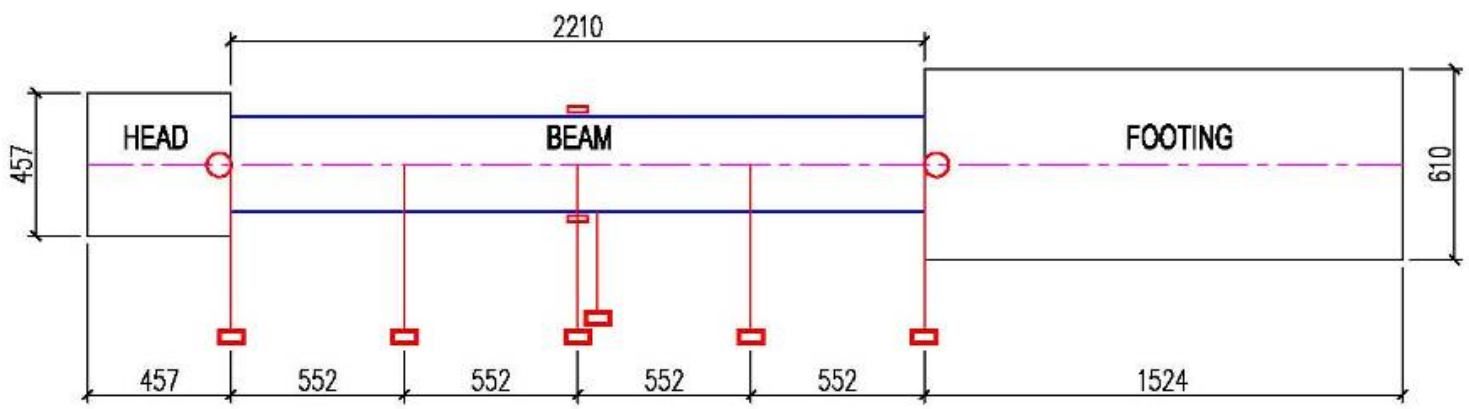

(b) Specimen LC

Figure 4.7 Instrumentation Plan Type I

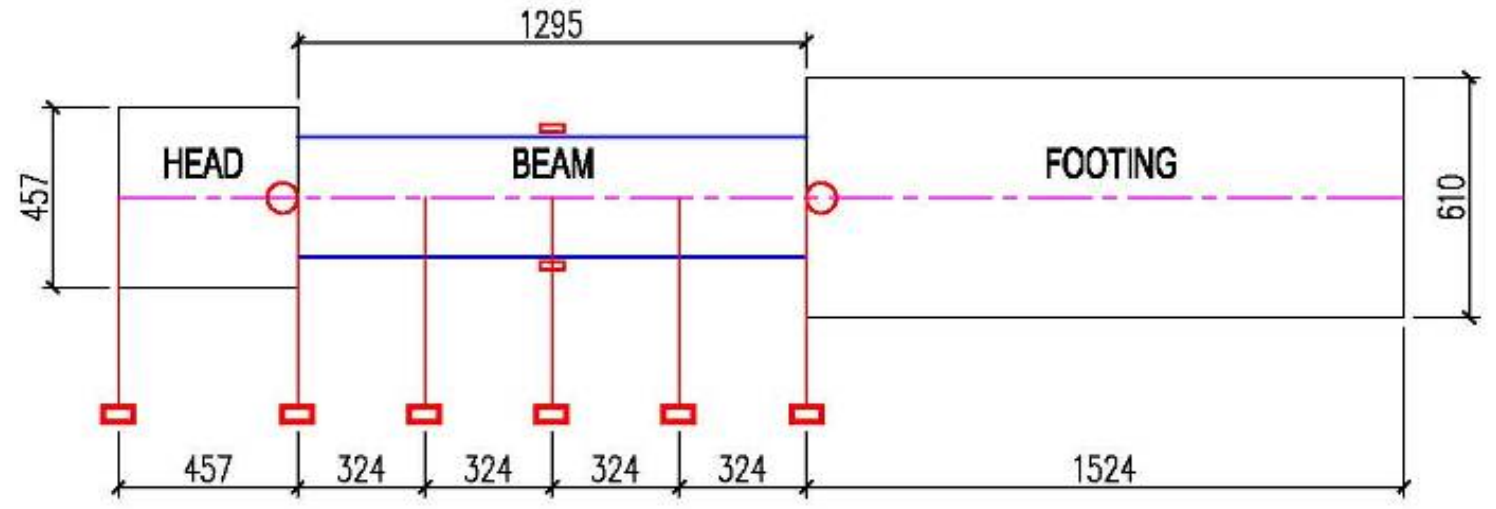

Figure 4.8 Instrumentation Plan Type II (for Specimens RC and G) 


\begin{tabular}{|l|c|c|l|l|}
\hline Instrument & Number & Channel & Position & Legend \\
\hline disp. output & 1 & 24 & actuator & \\
\hline load output & 1 & 25 & & \\
\hline string pot & 6 & $16 \sim 21$ & quarter points & 口 \\
\hline strain gauge & 2 & $0 \sim 1$ & mid points & 口 \\
\hline inclinometer & 2 & $26 \sim 27$ & support ends & 0 \\
\hline total channels & 12 & & & \\
\hline
\end{tabular}

Figure 4.9 Instrumentation List for Monotonic Tests

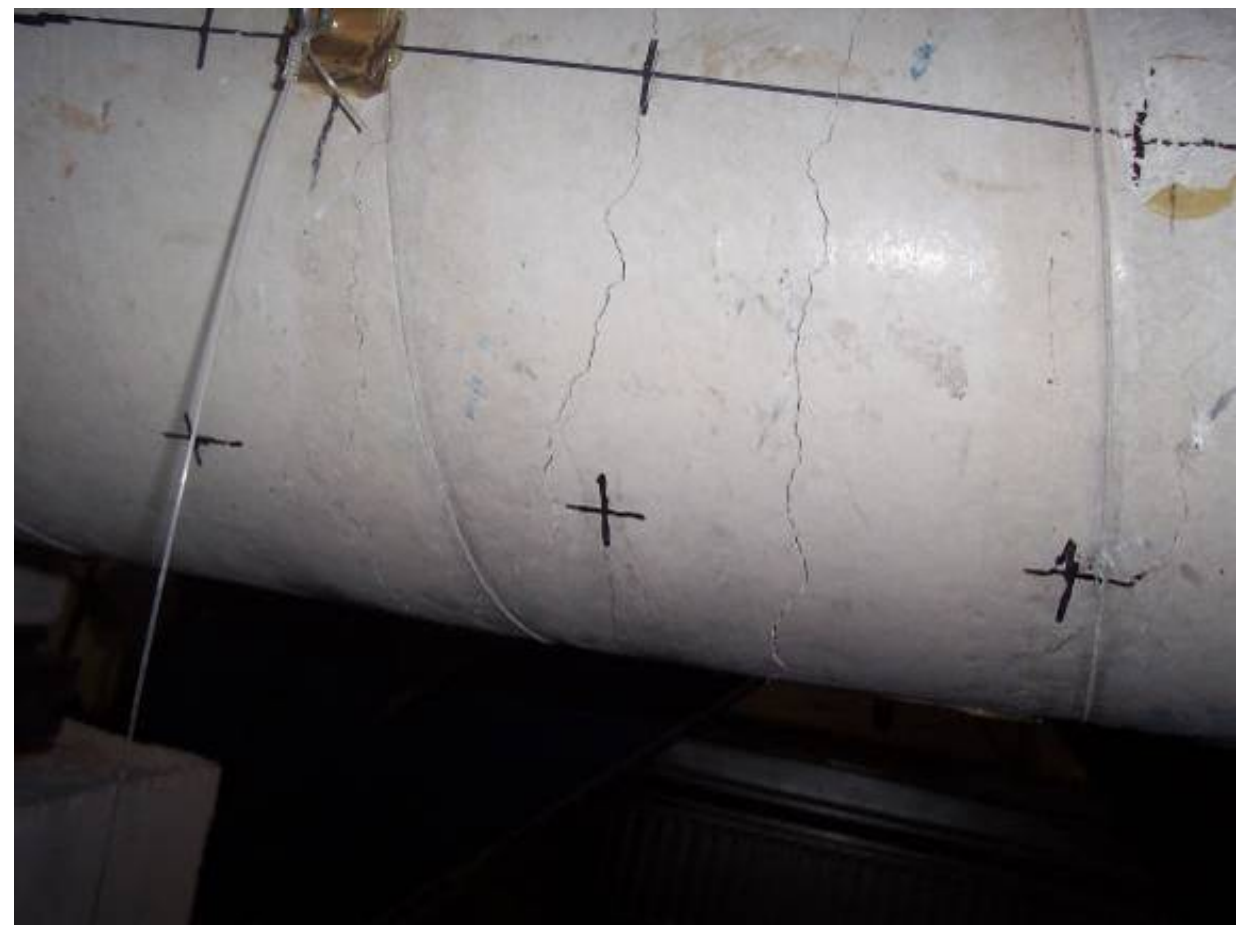

Figure 4.10 Flexural Cracks of Specimen RC at Mid-Span 


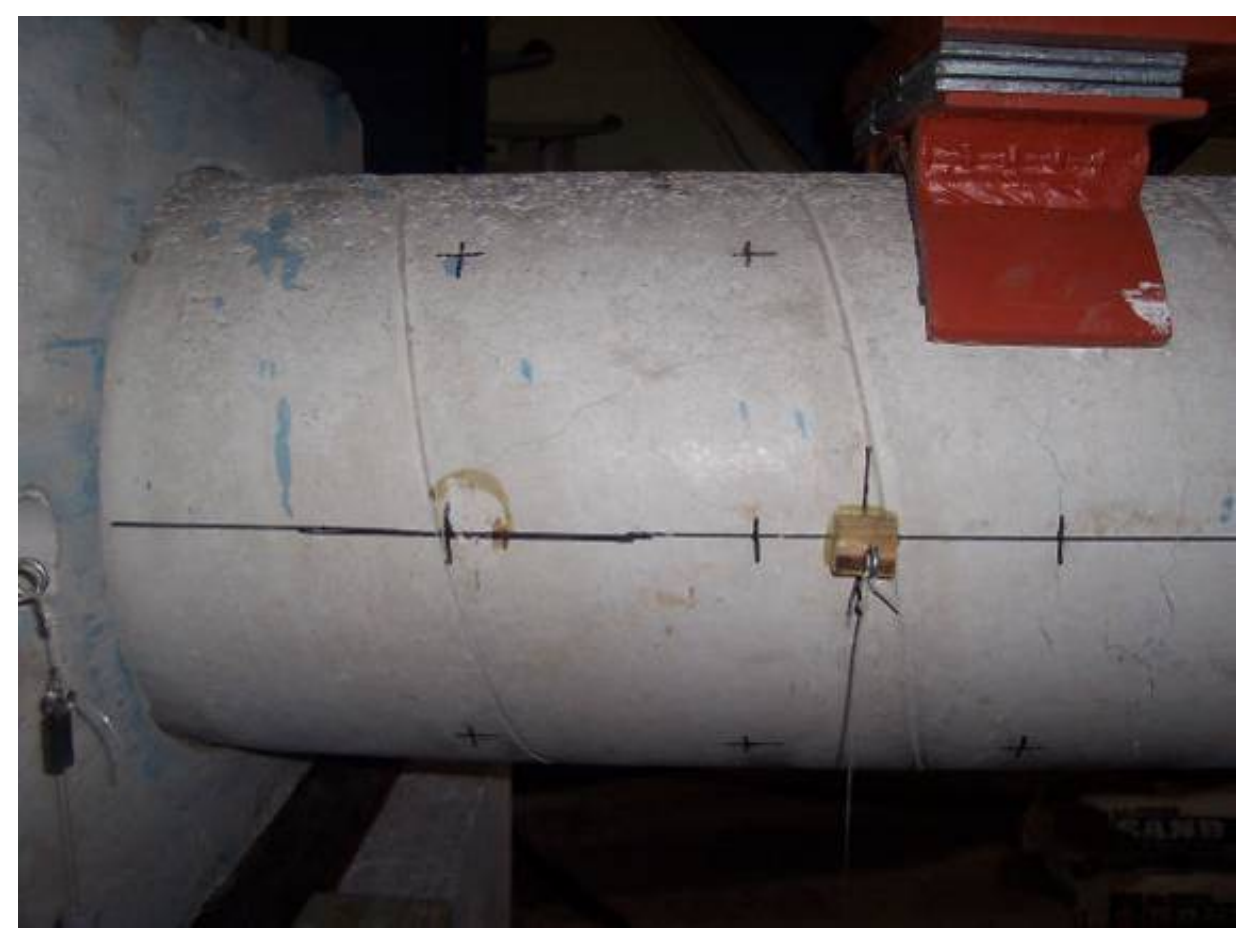

Figure 4.11 Shear Cracks of Specimen RC in Shear-Flexural Region Close to Column Head

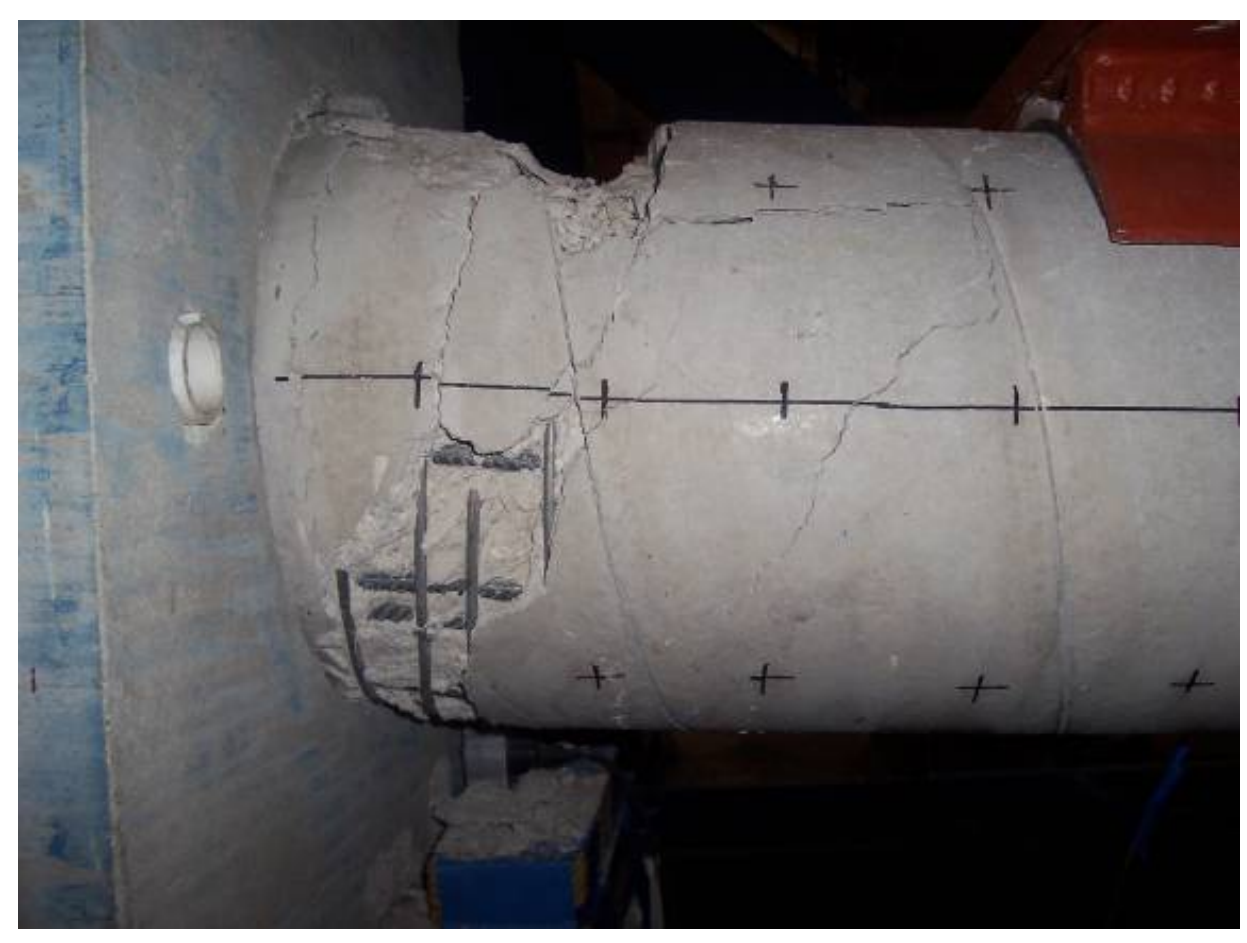

Figure 4.12 East View of Final Cracking Pattern Close to Footing in Specimen RC 


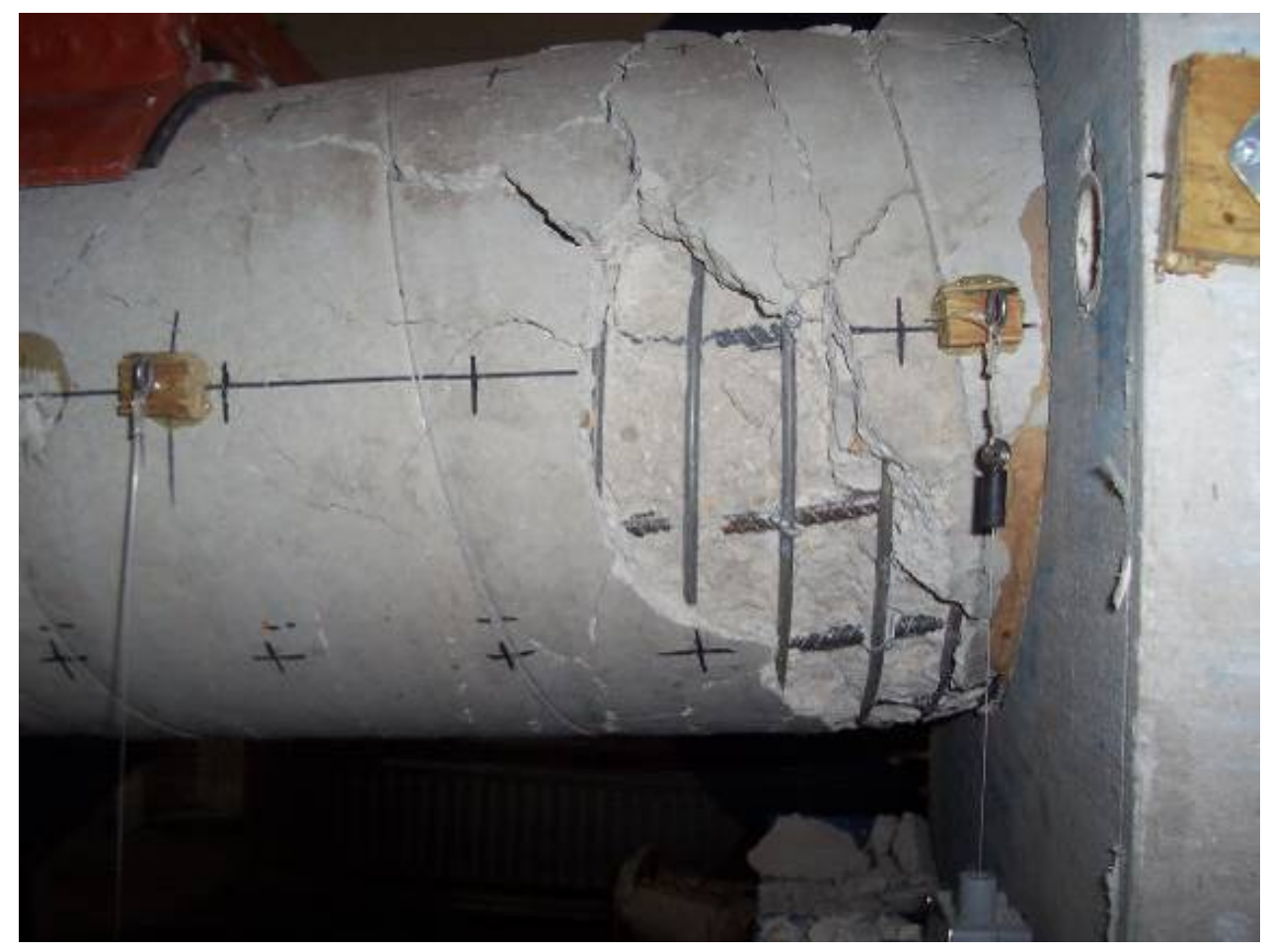

Figure 4.13 West View of Final Cracking Pattern Close to Footing in Specimen RC

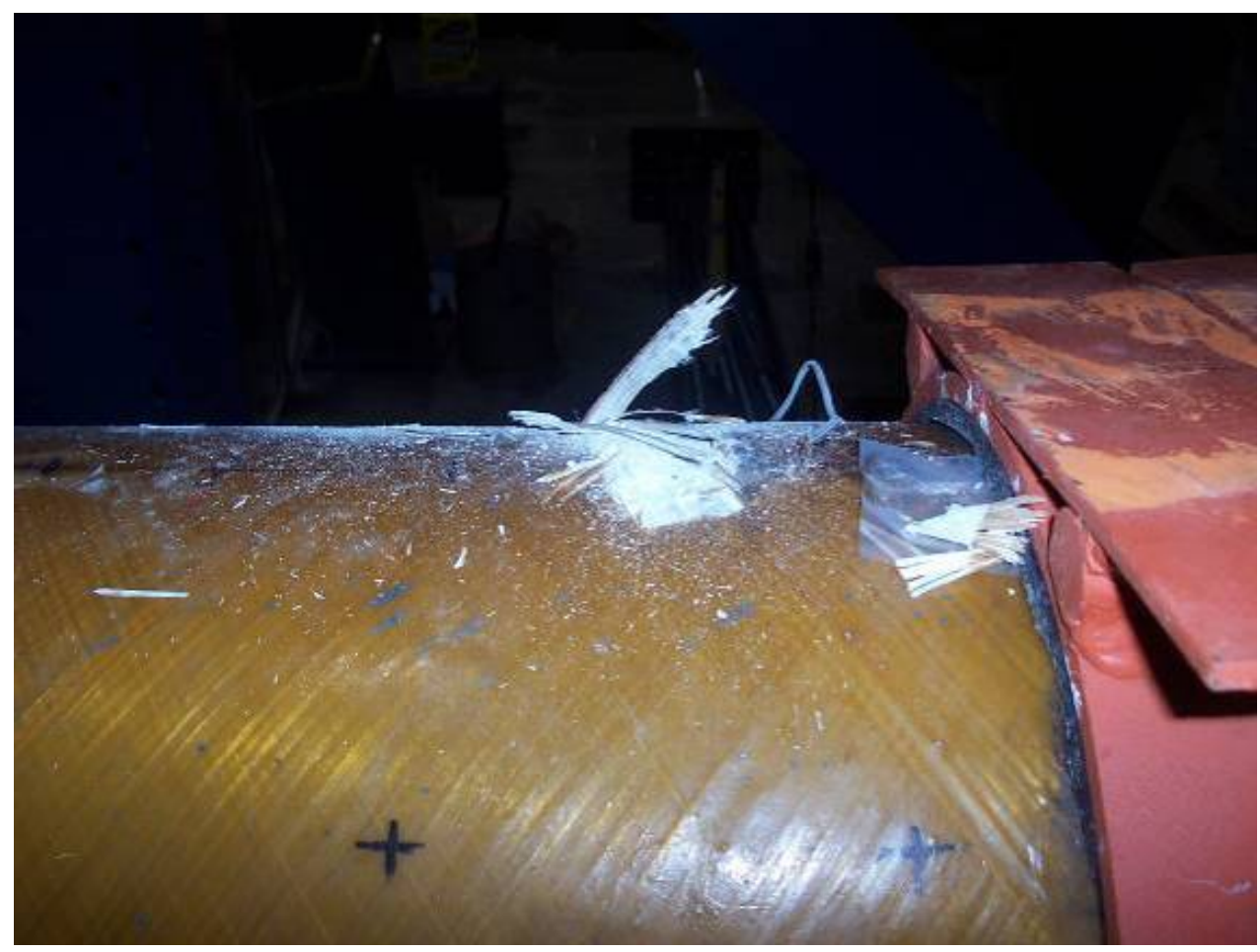

Figure 4.14 Crushing of Specimen Y at the Top (East View) 


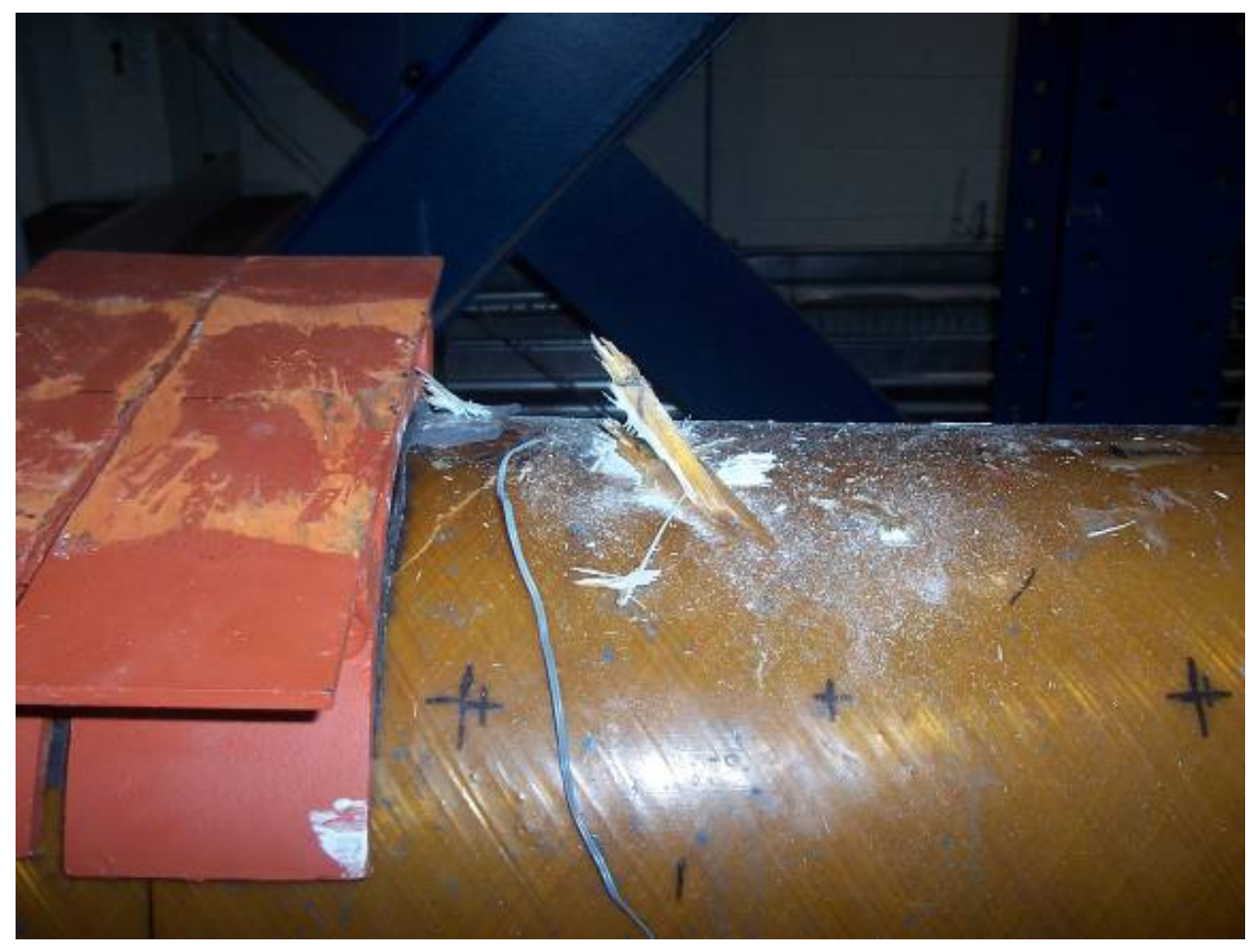

Figure 4.15 Crushing of Specimen Y at the Top (West View)

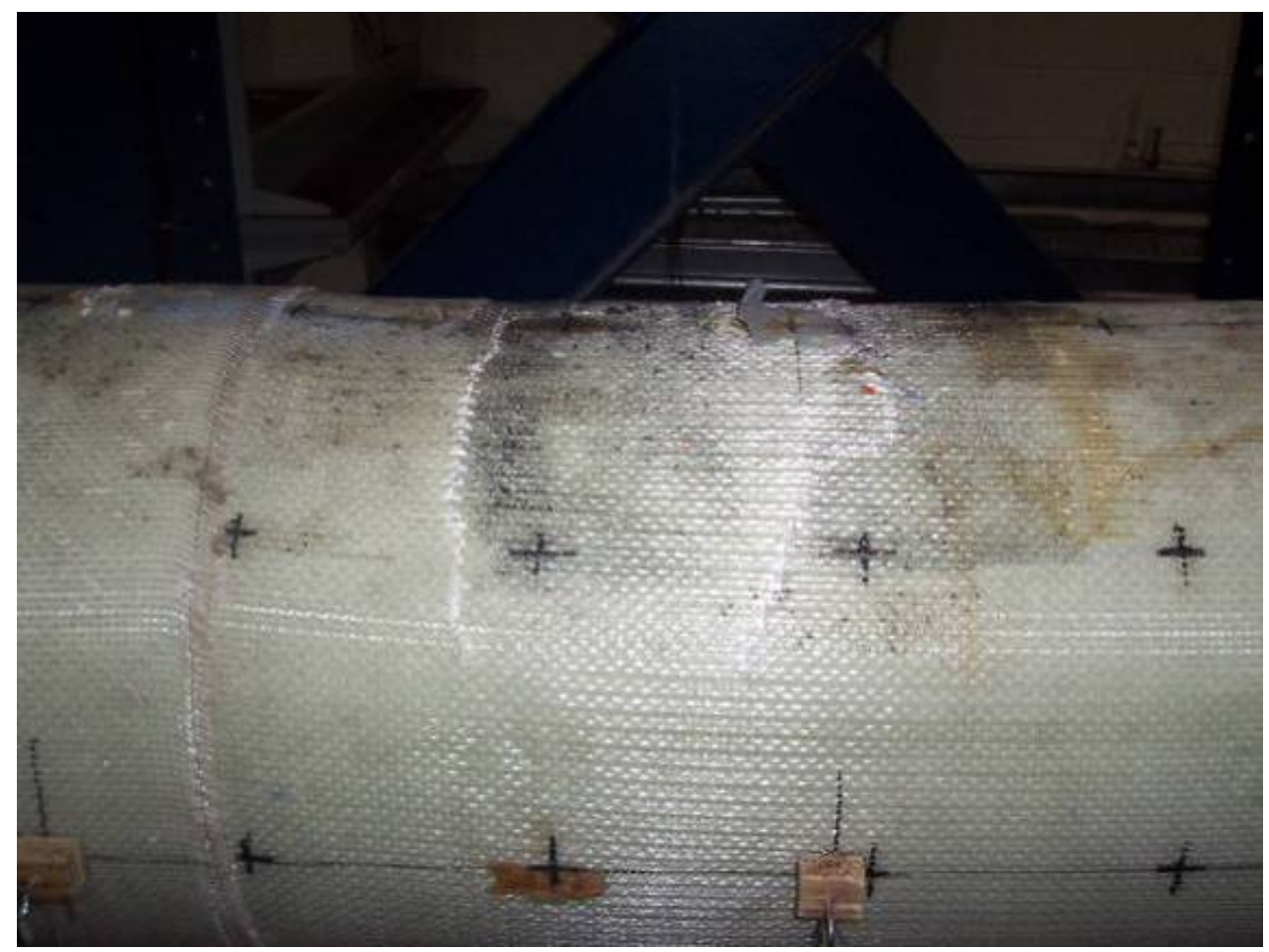

Figure 4.16 Cracking Pattern of Specimen G (East View) 


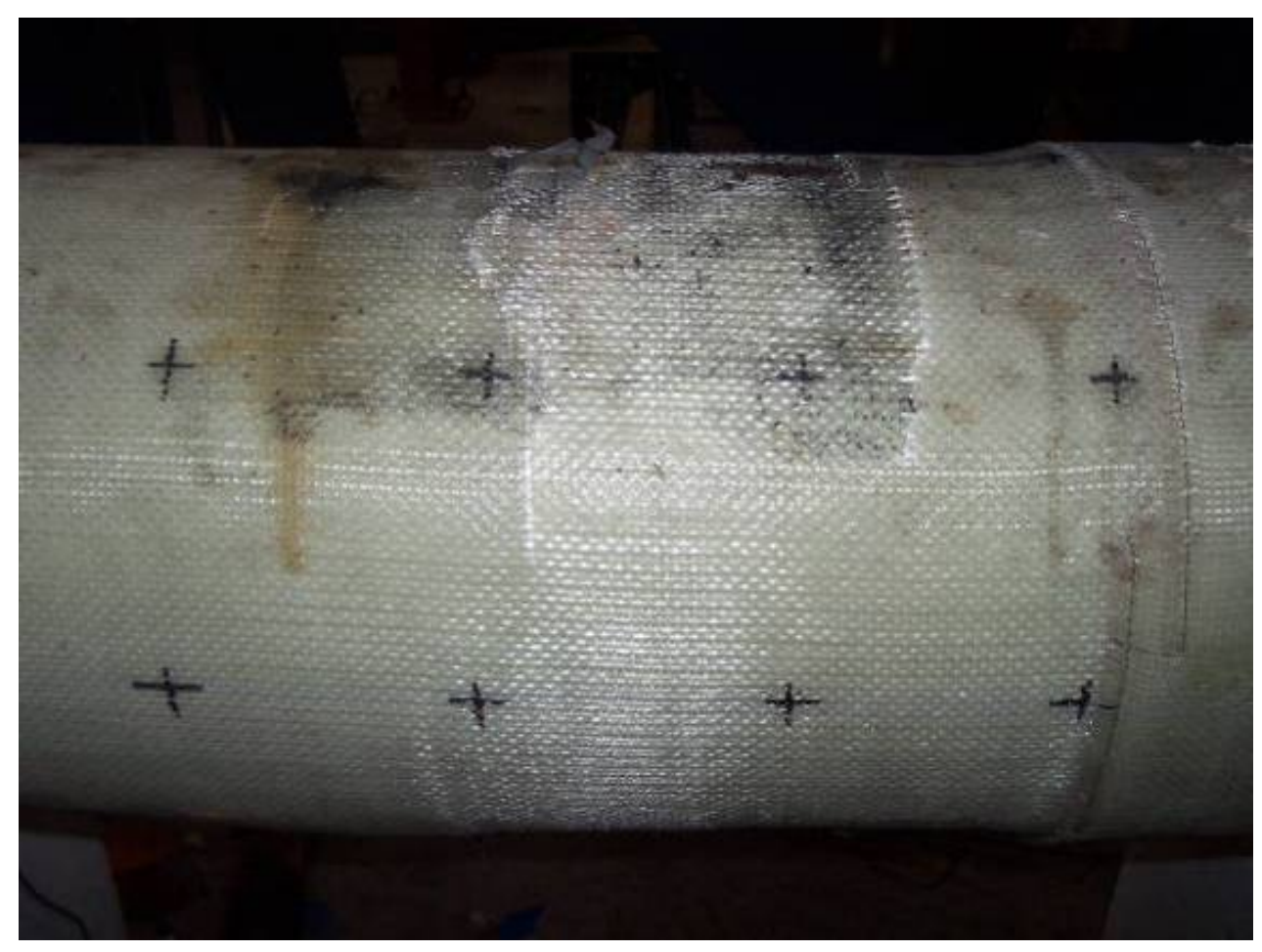

Figure 4.17 Cracking Pattern of Specimen G (West View)

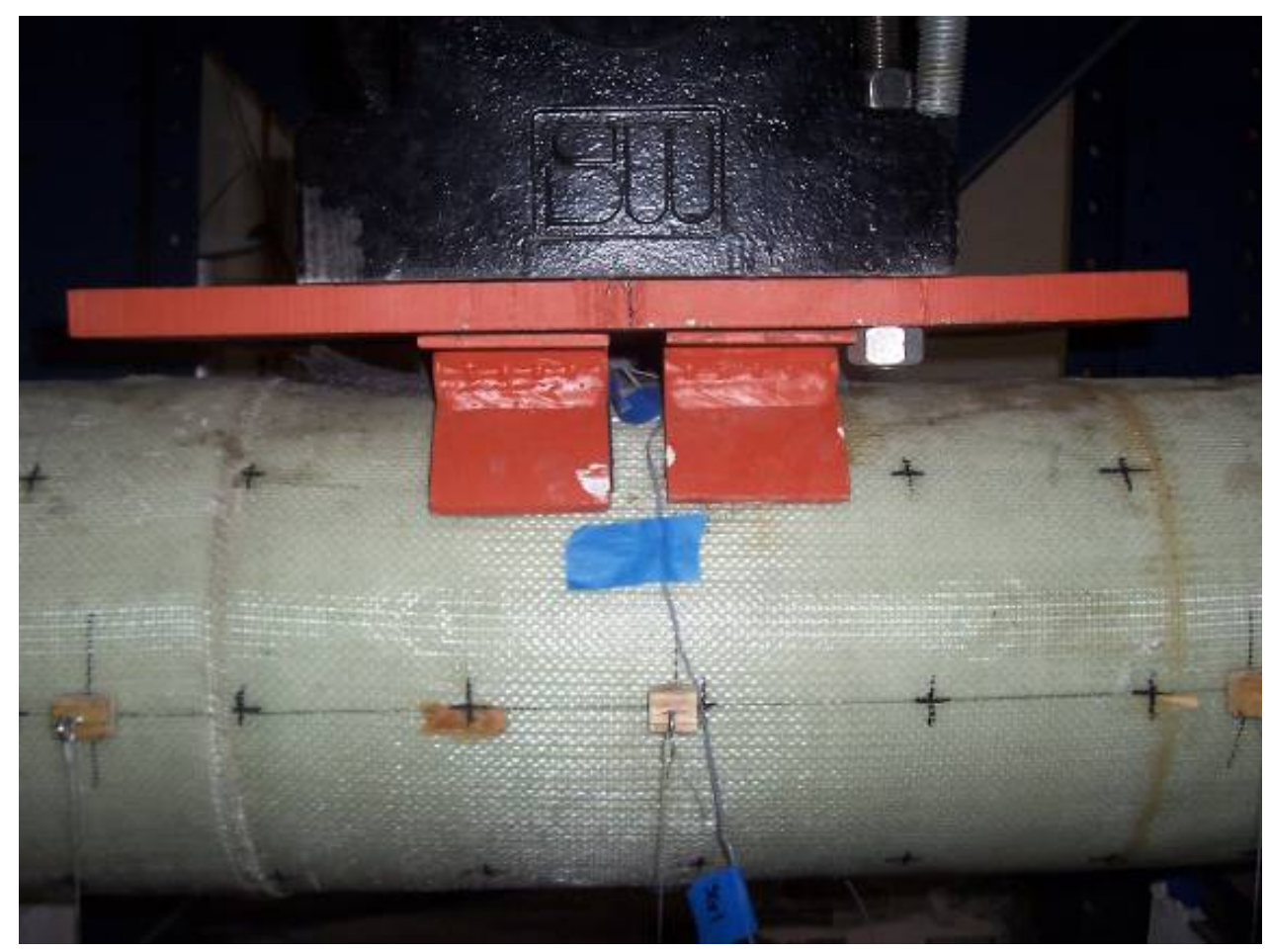

Figure 4.18 Close up View of Specimen G (West View) 


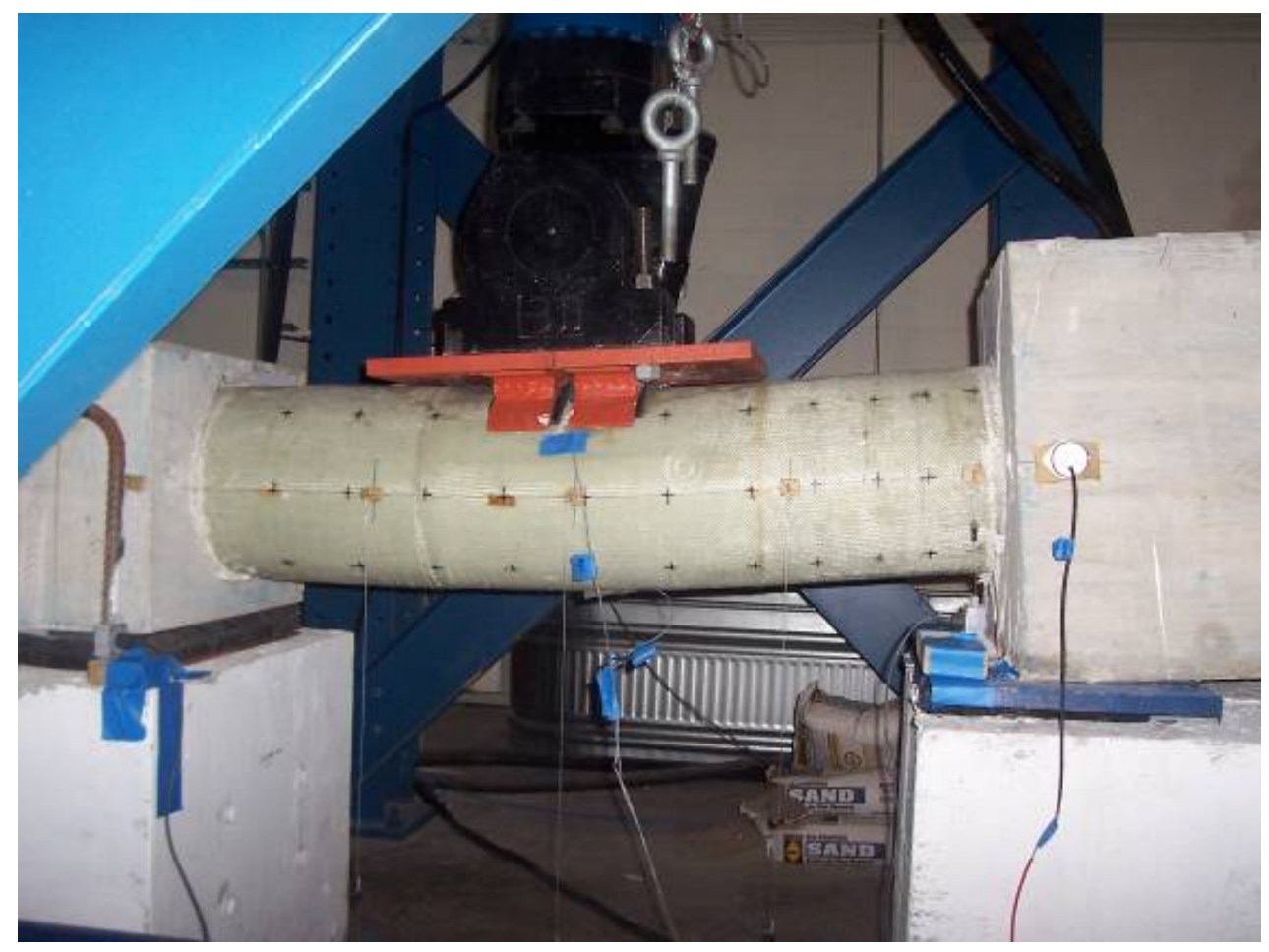

Figure 4.19 Overall View of Specimen G (West View)

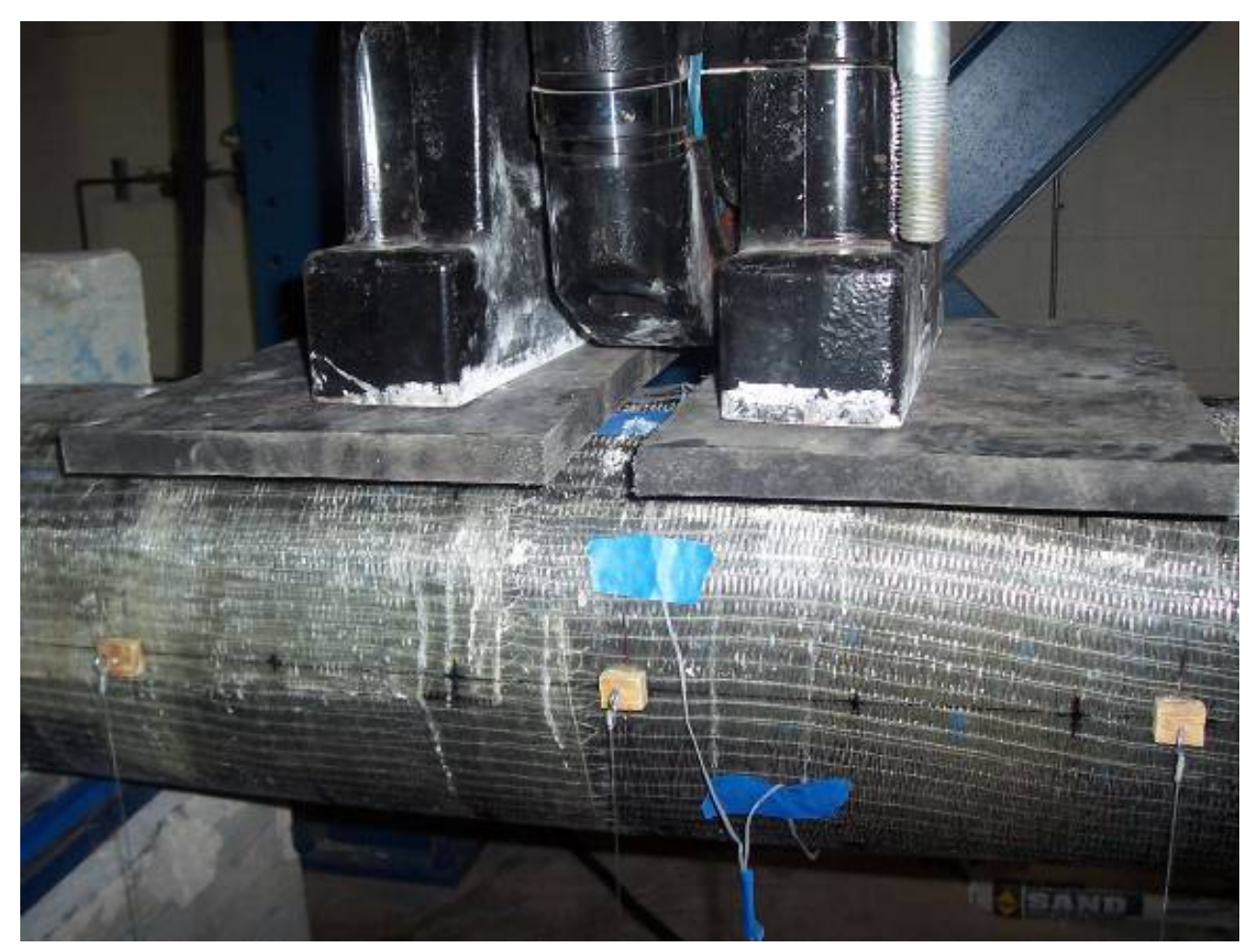

Figure 4.20 Direct Loading on Specimen H Using Neoprene Pads 


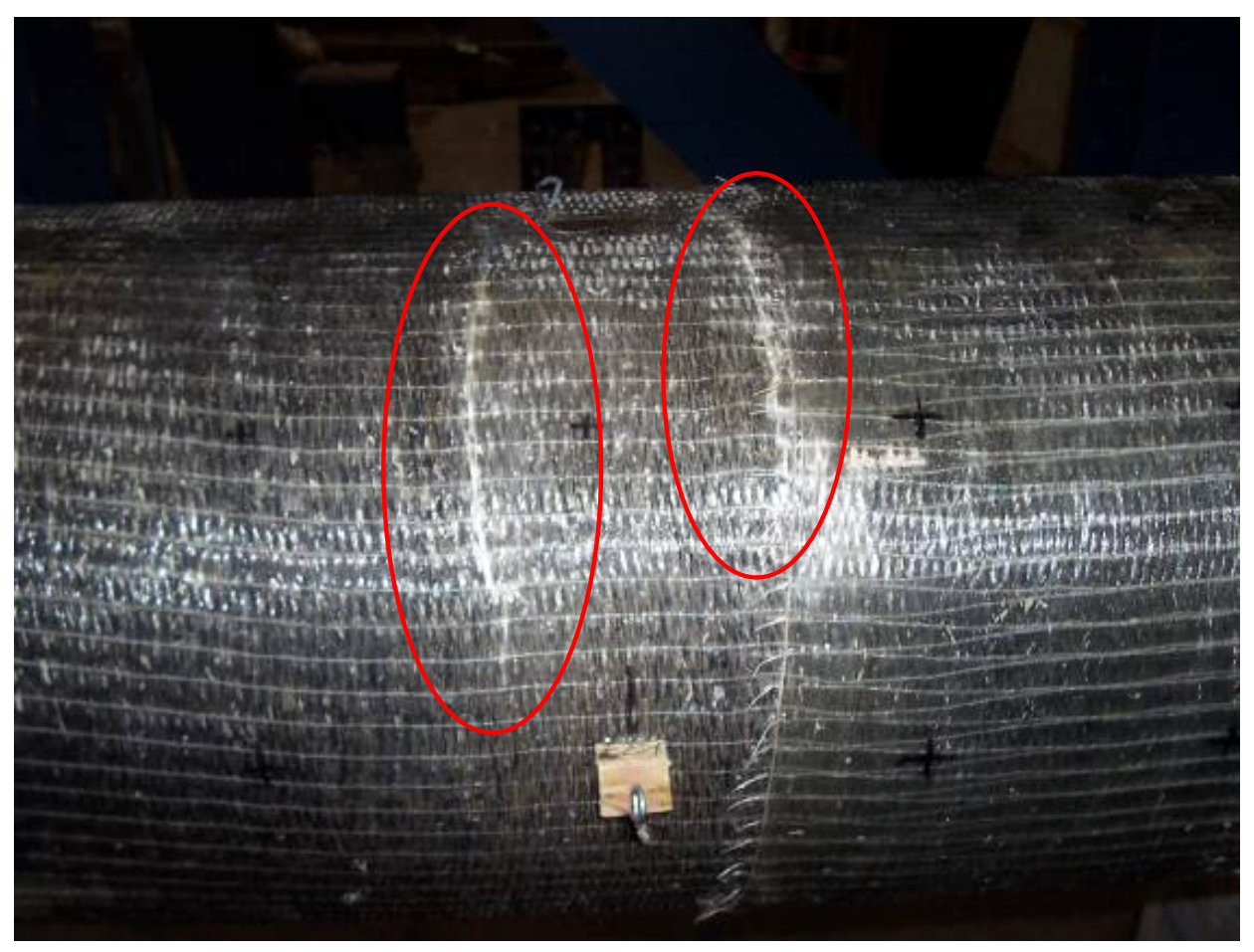

Figure 4.21 Crumpling Crack in Specimen $\mathrm{H}$ at the Top (East View)

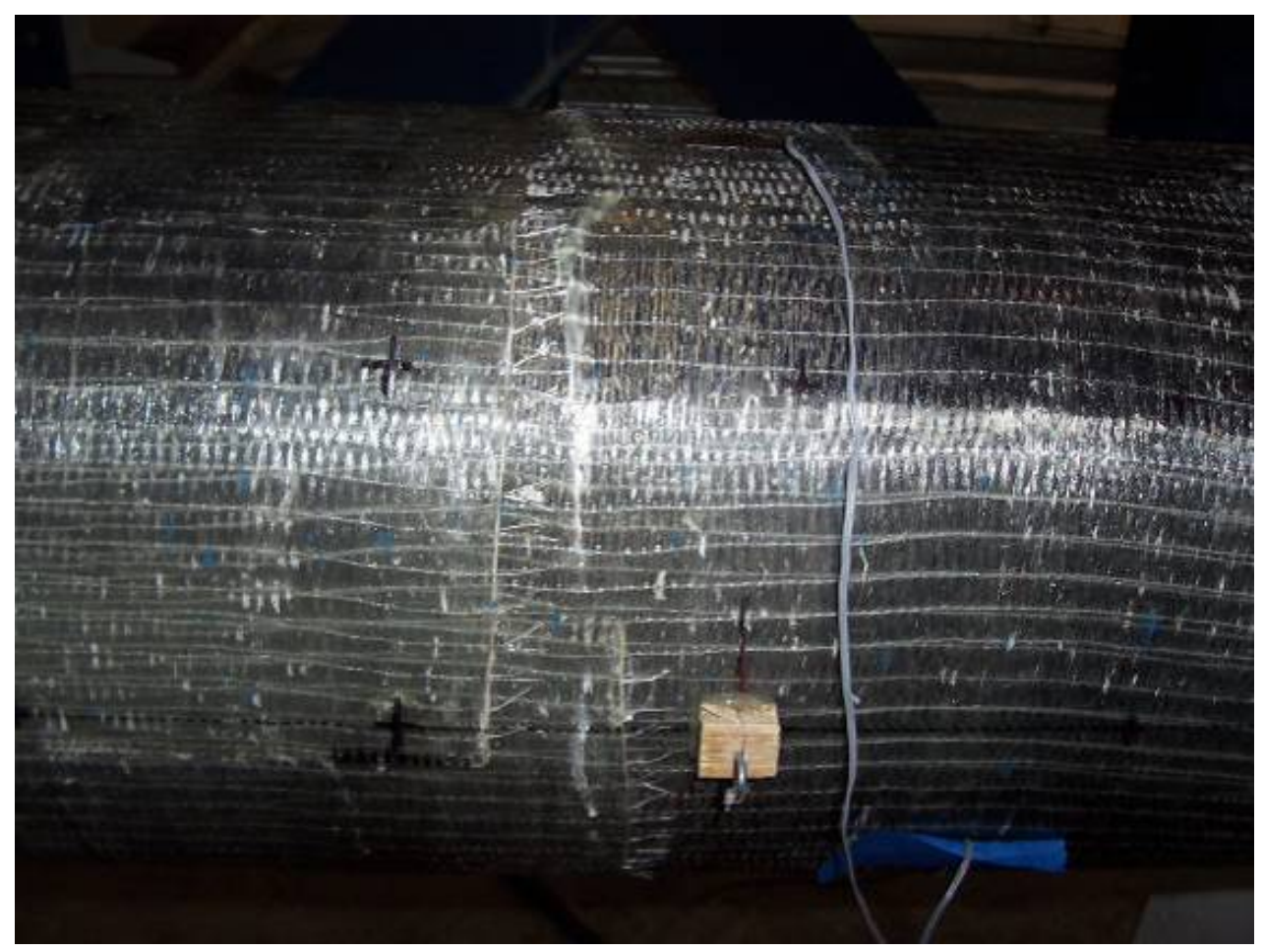

Figure 4.22 Crumpling Crack in Specimen $\mathrm{H}$ at the Top (West View) 


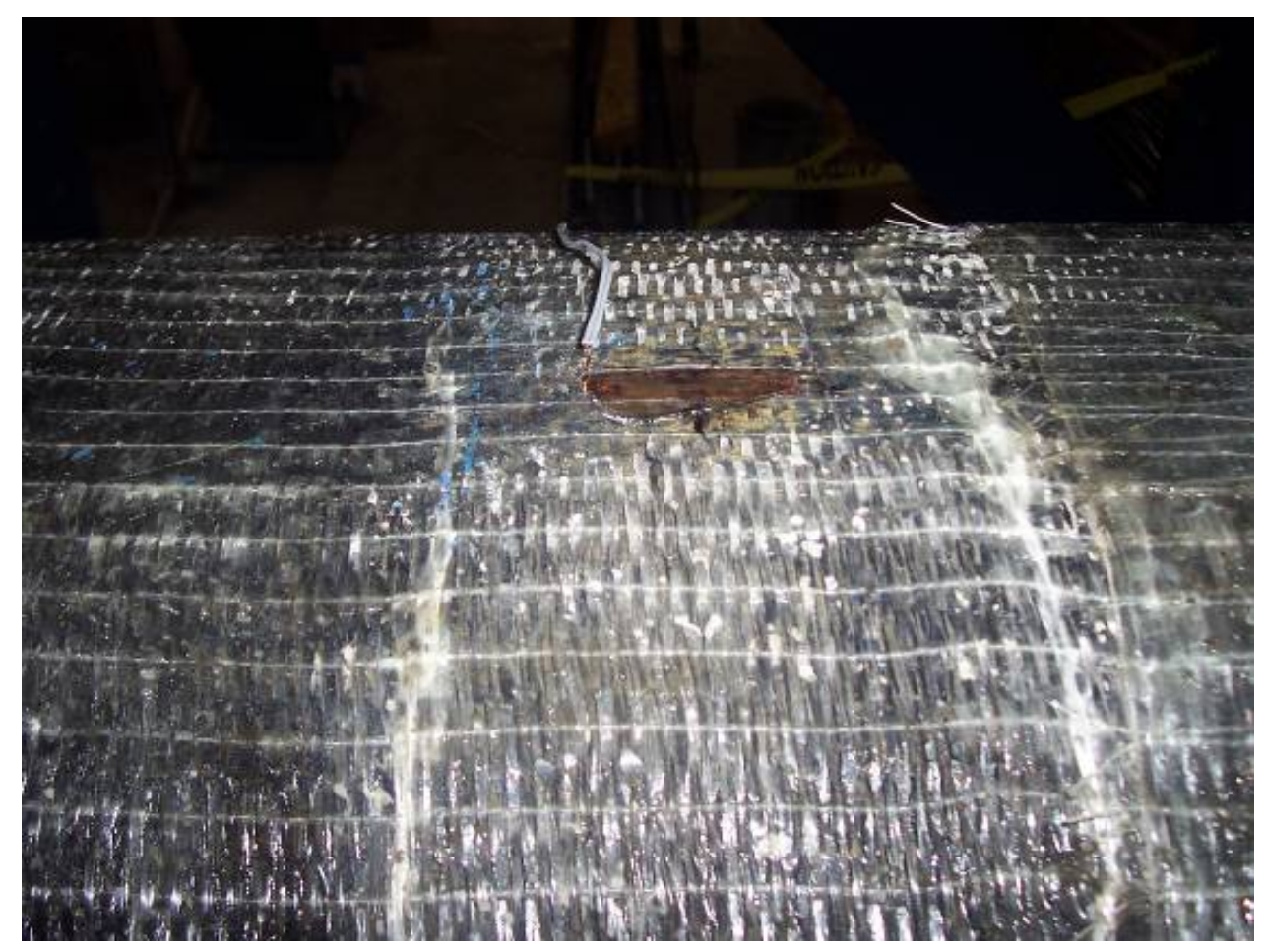

Figure 4.23 Close up of Crumpling Crack at the Top of Specimen H

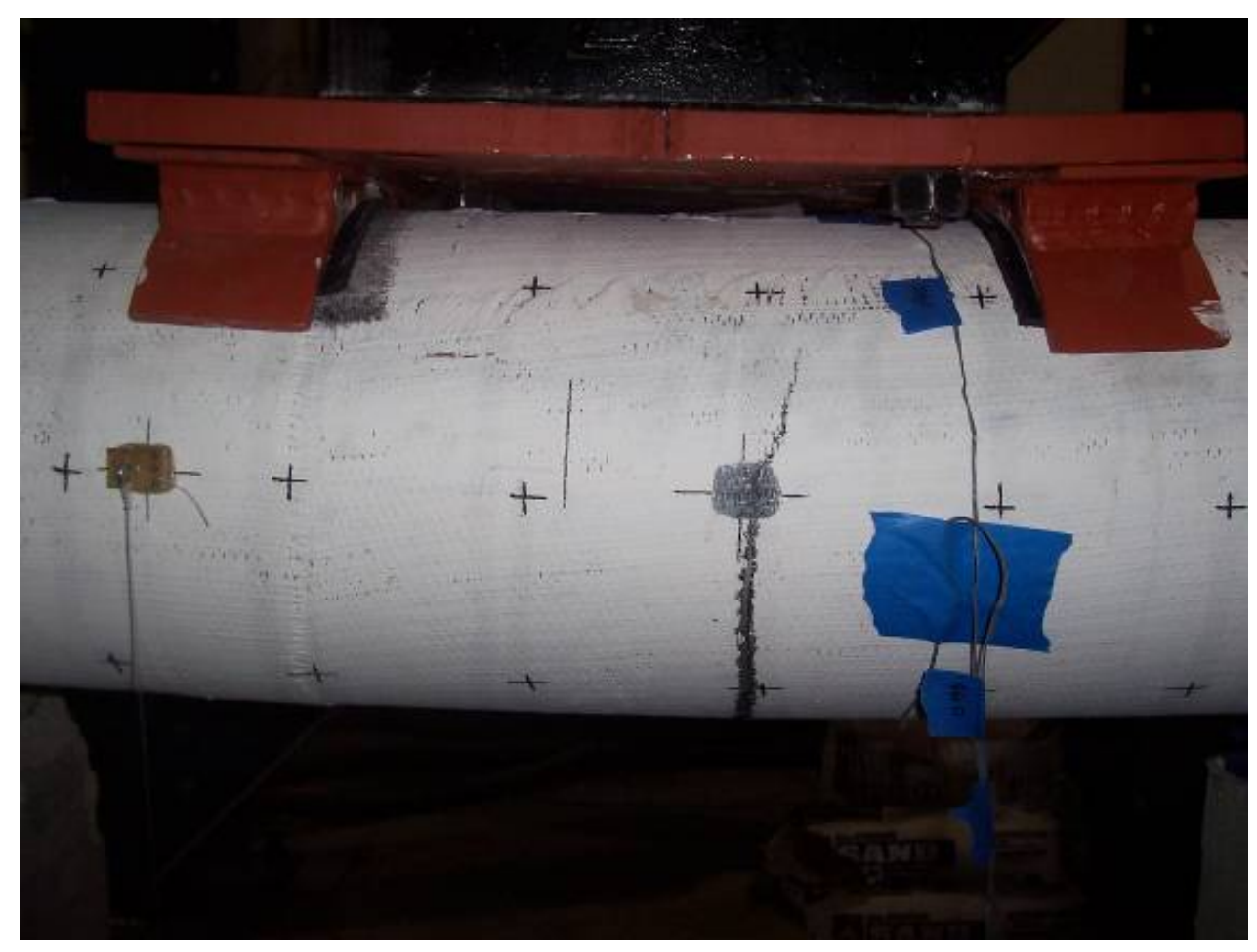

Figure 4.24 Flexural Crack in Specimen SC (West View) 


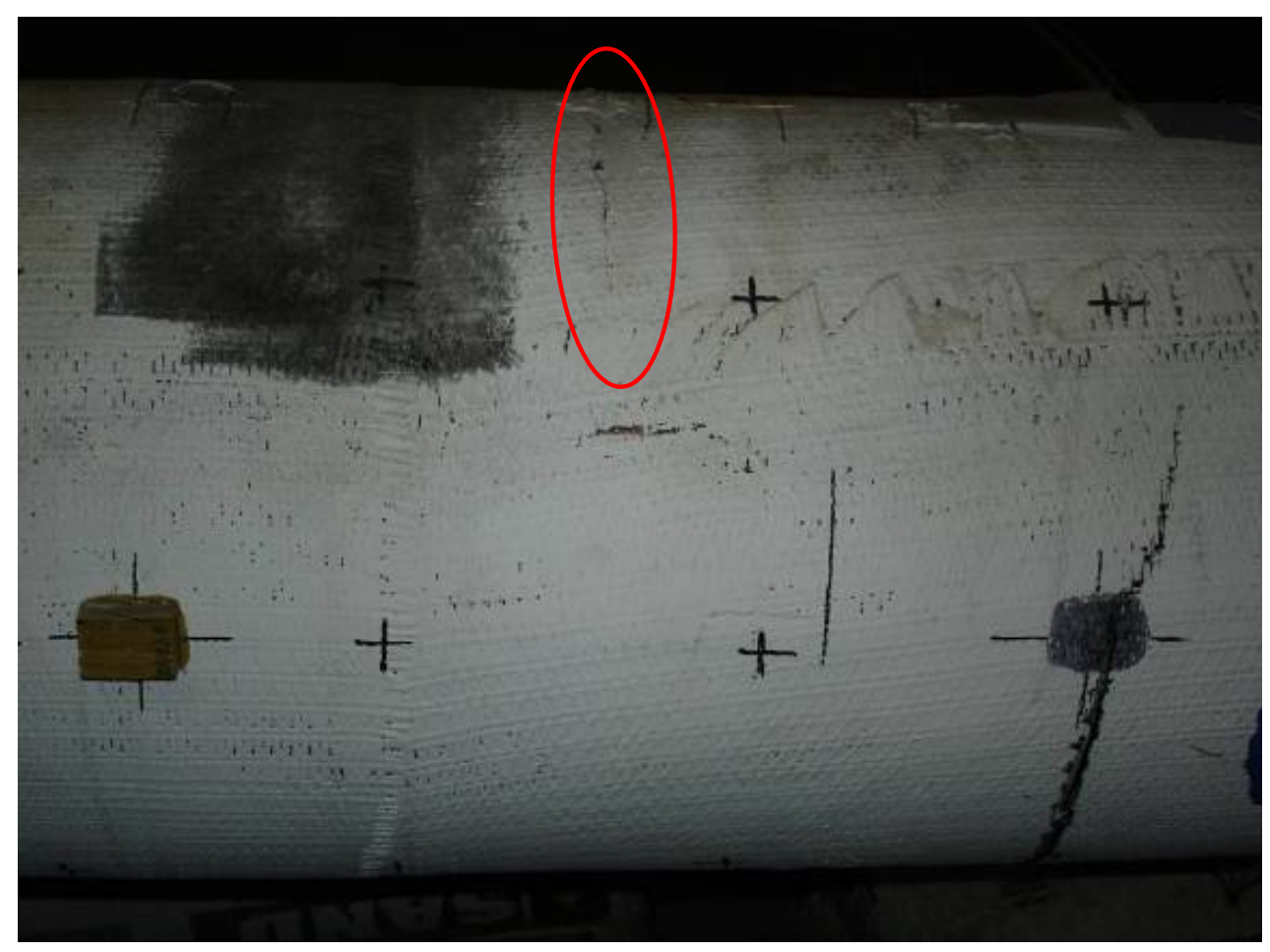

Figure 4.25 Crumpling Crack in Specimen SC (West View)

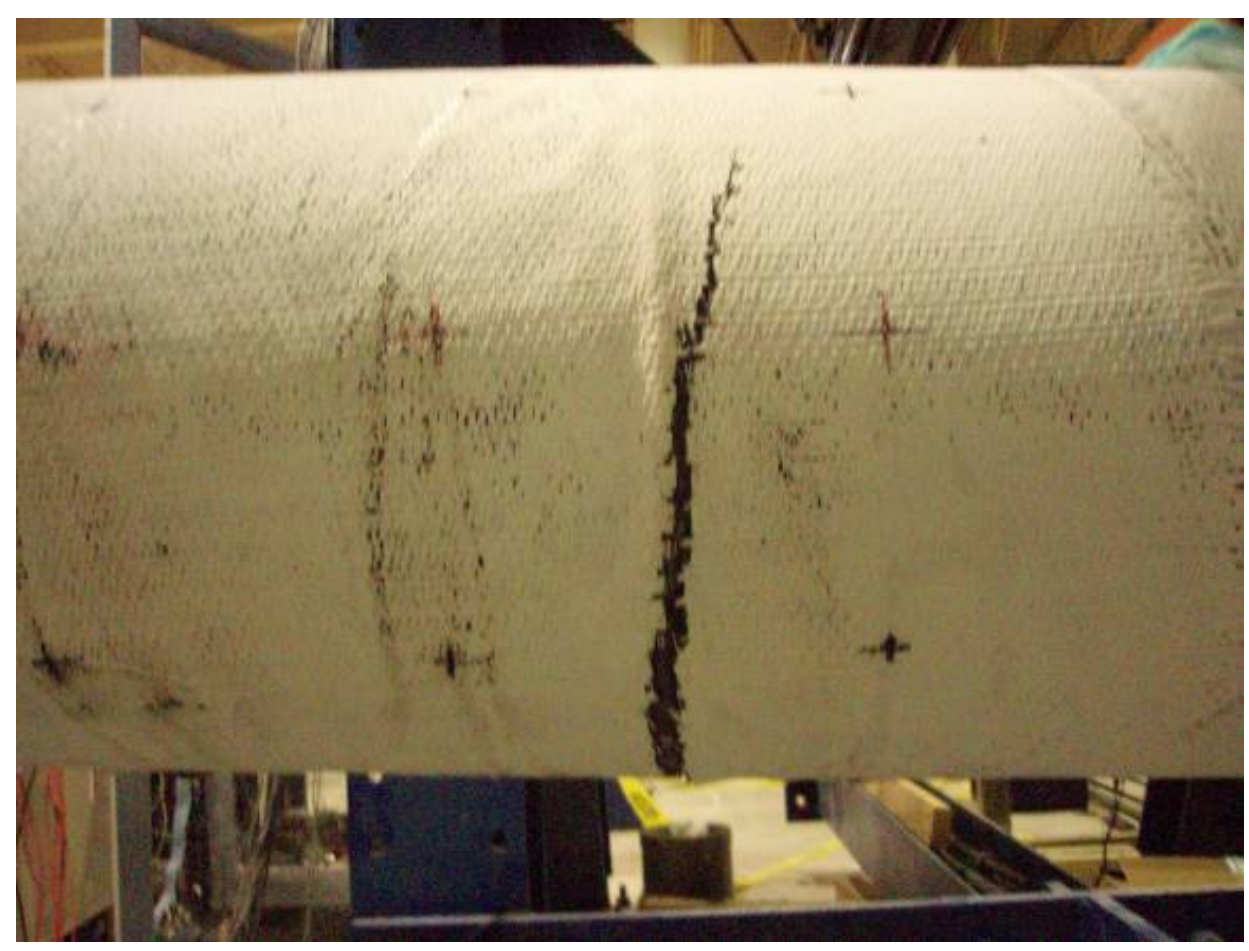

Figure 4.26 Flexural Crack in Specimen LC (East View) 


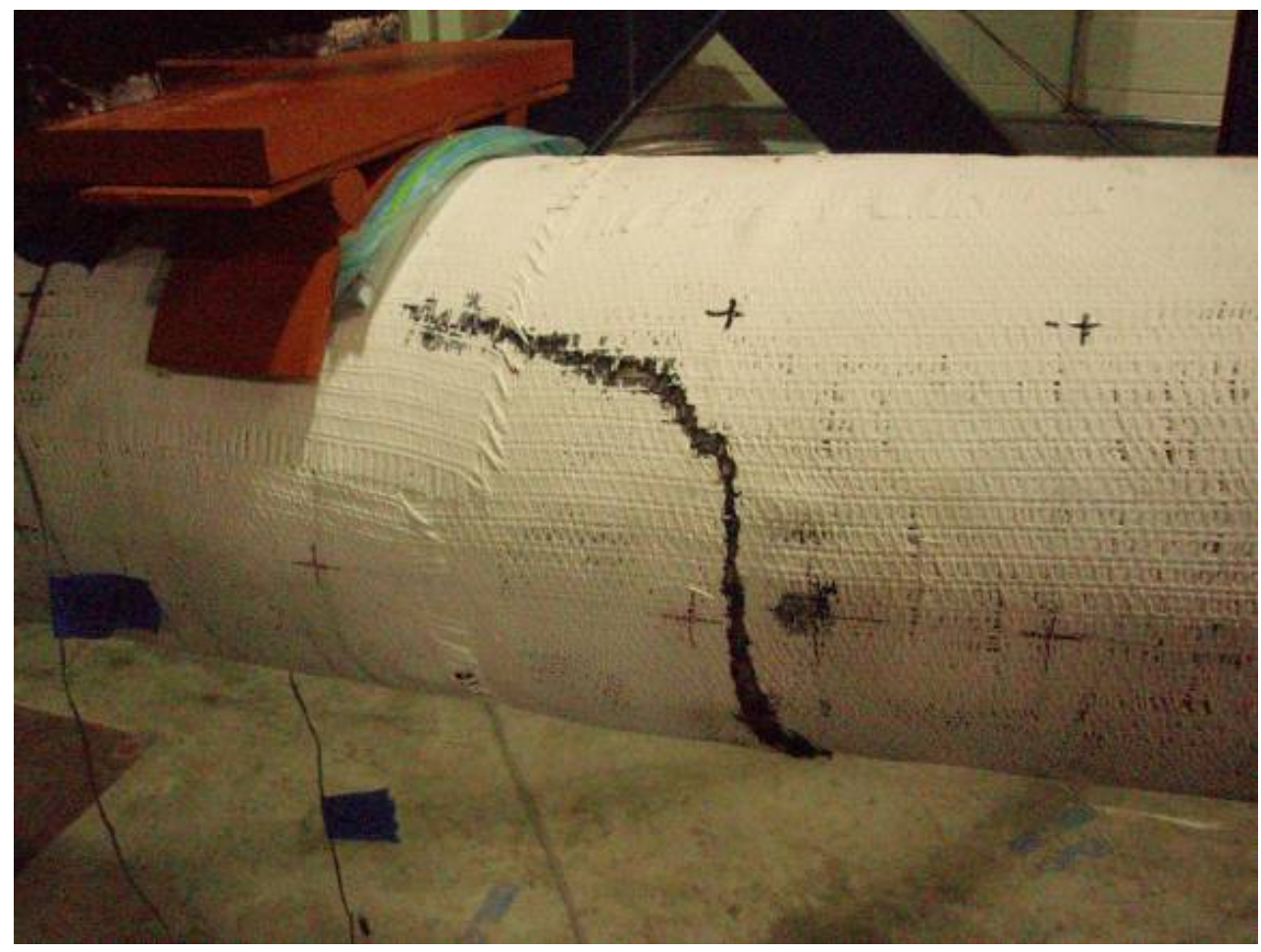

Figure 4.27 Flexural Crack Extended to Mid-Span in Specimen LC (West View)

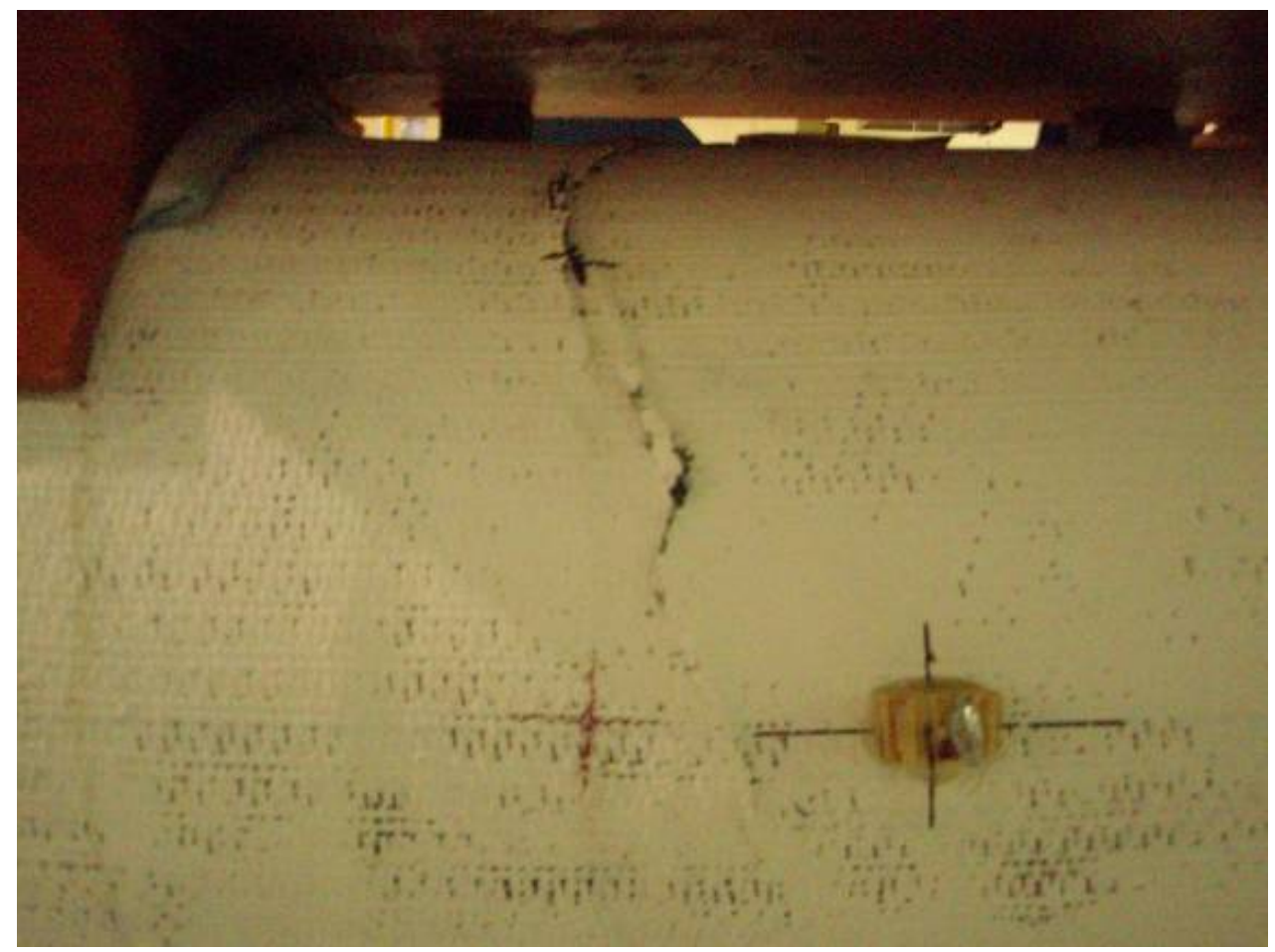

Figure 4.28 Top Crumpling Crack in Specimen LC (East View) 


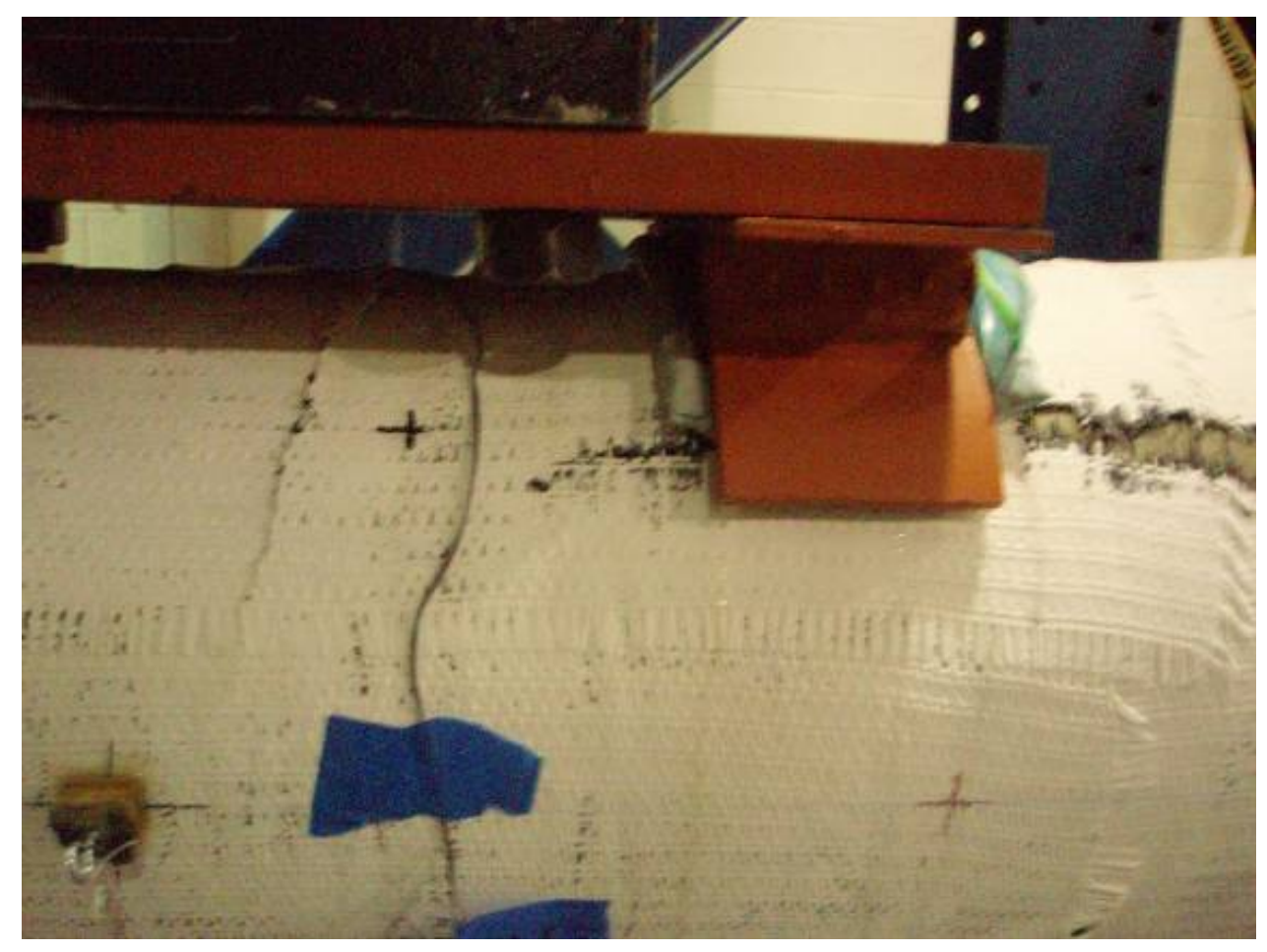

Figure 4.29 Top Crumpling Crack in Specimen LC (West View)

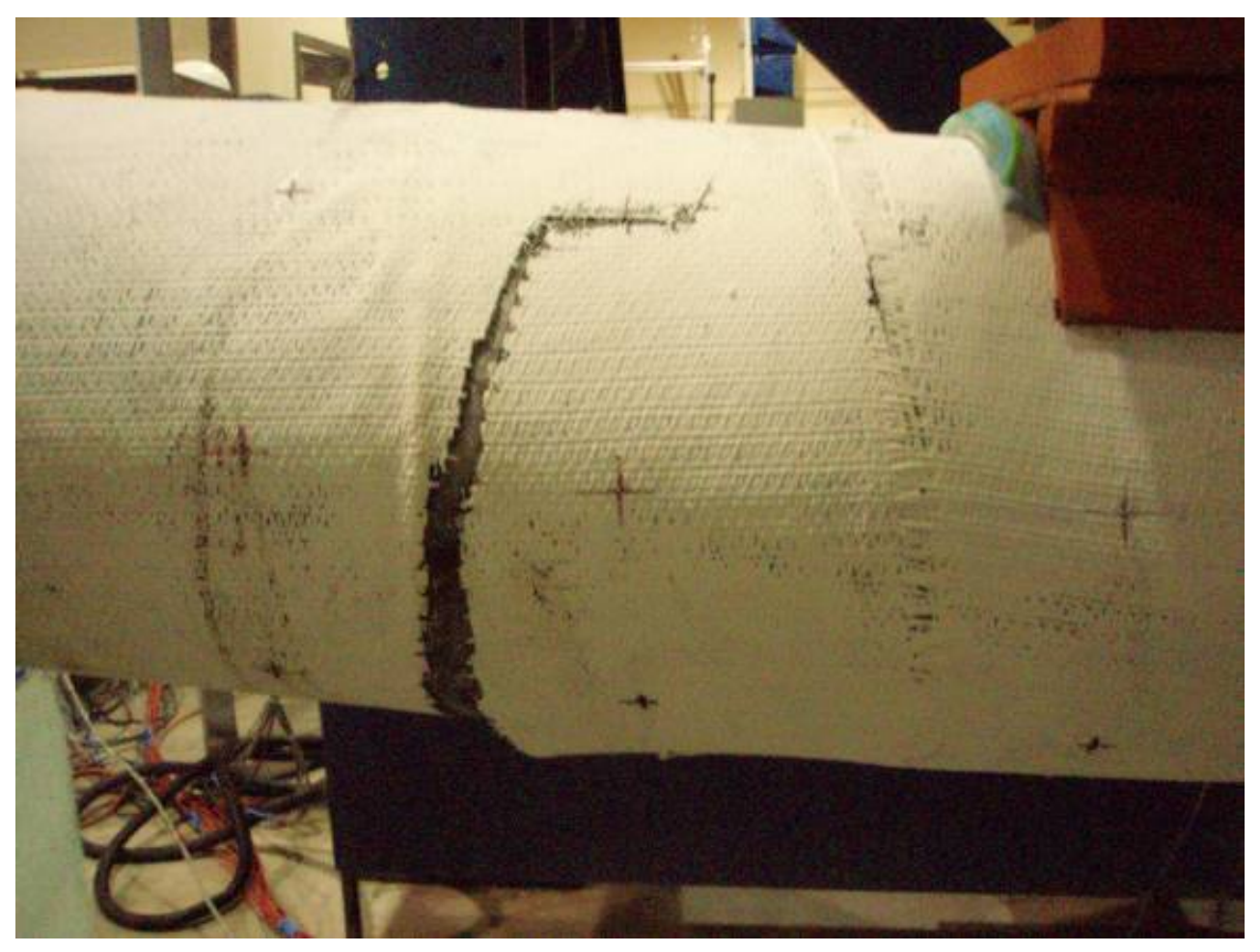

Figure 4.30 Final Crack Pattern in Specimen LC (East View) 


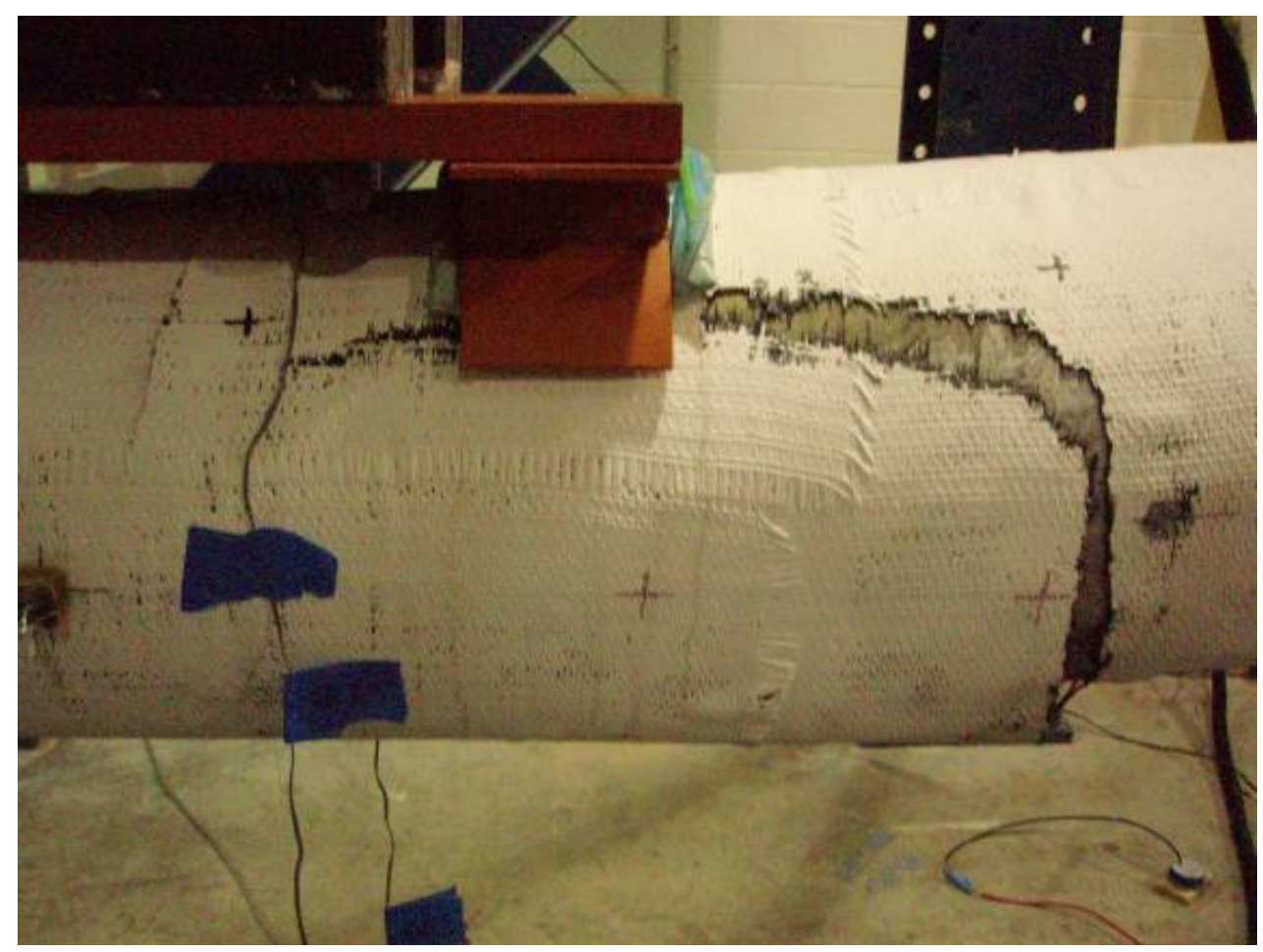

Figure 4.31 Final Unzipping Crack in Specimen LC (West View)

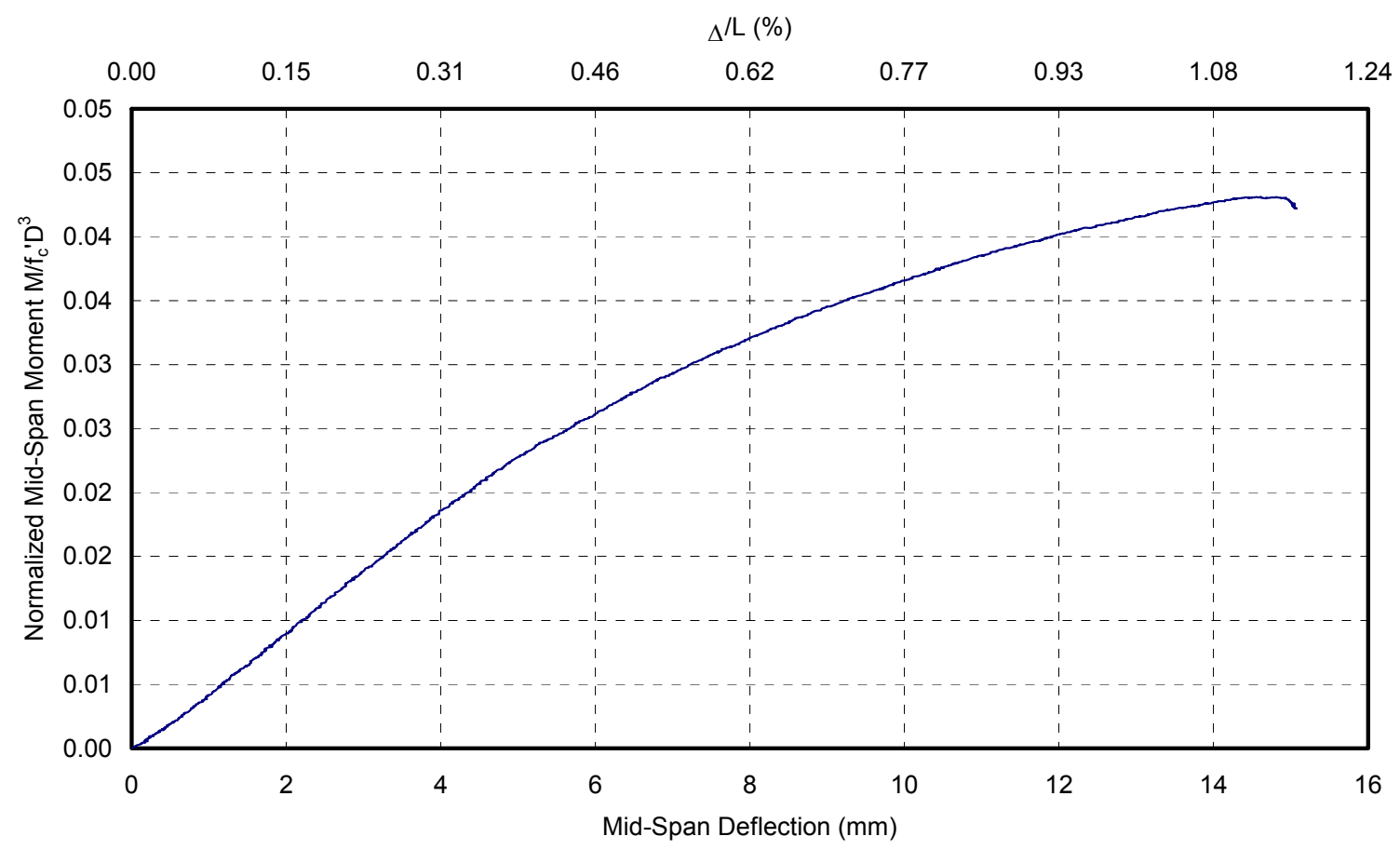

Figure 4.32 Normalized Mid-Span Moment - Deflection Response of Specimen RC 


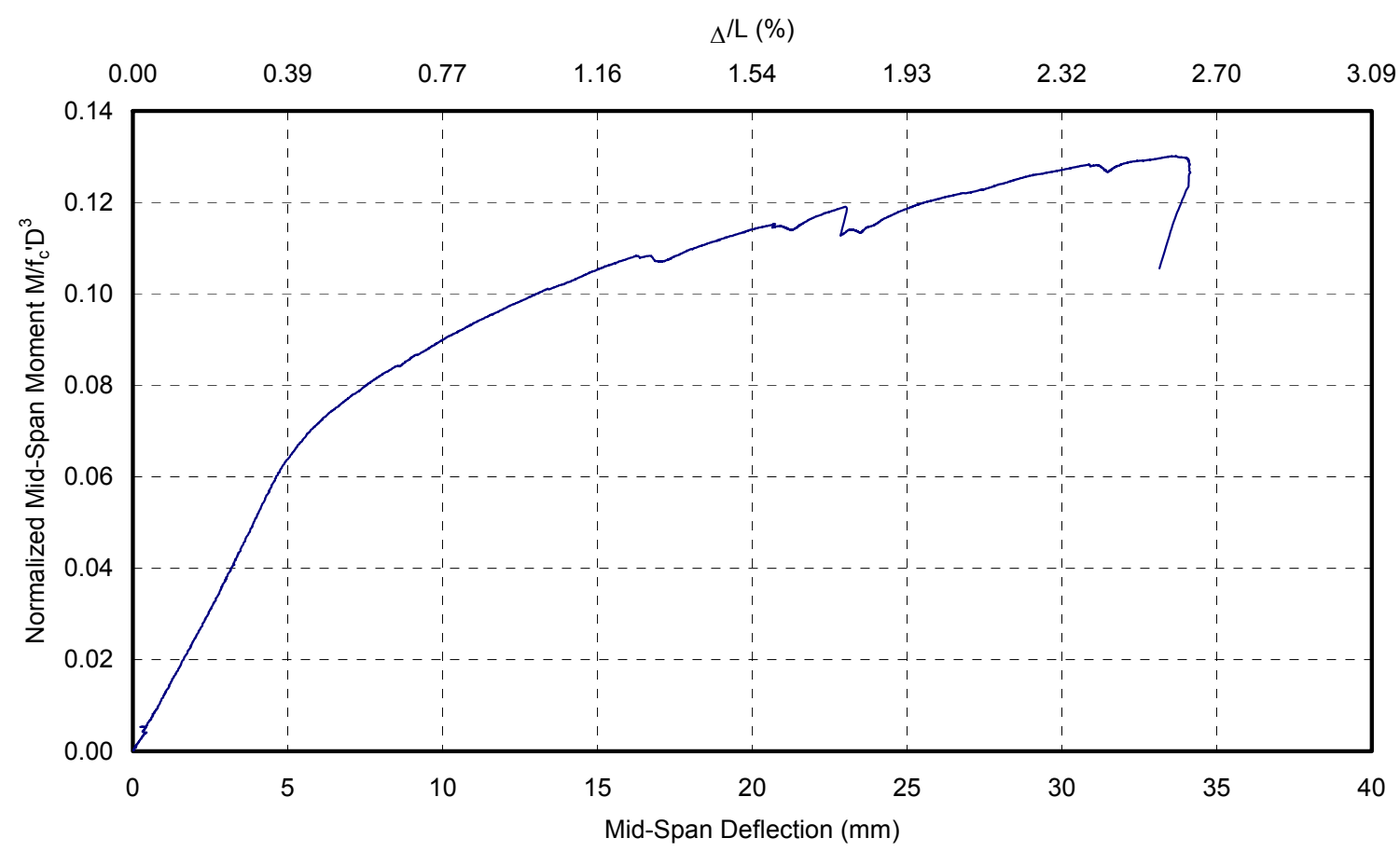

Figure 4.33 Normalized Mid-Span Moment - Deflection Response of Specimen Y

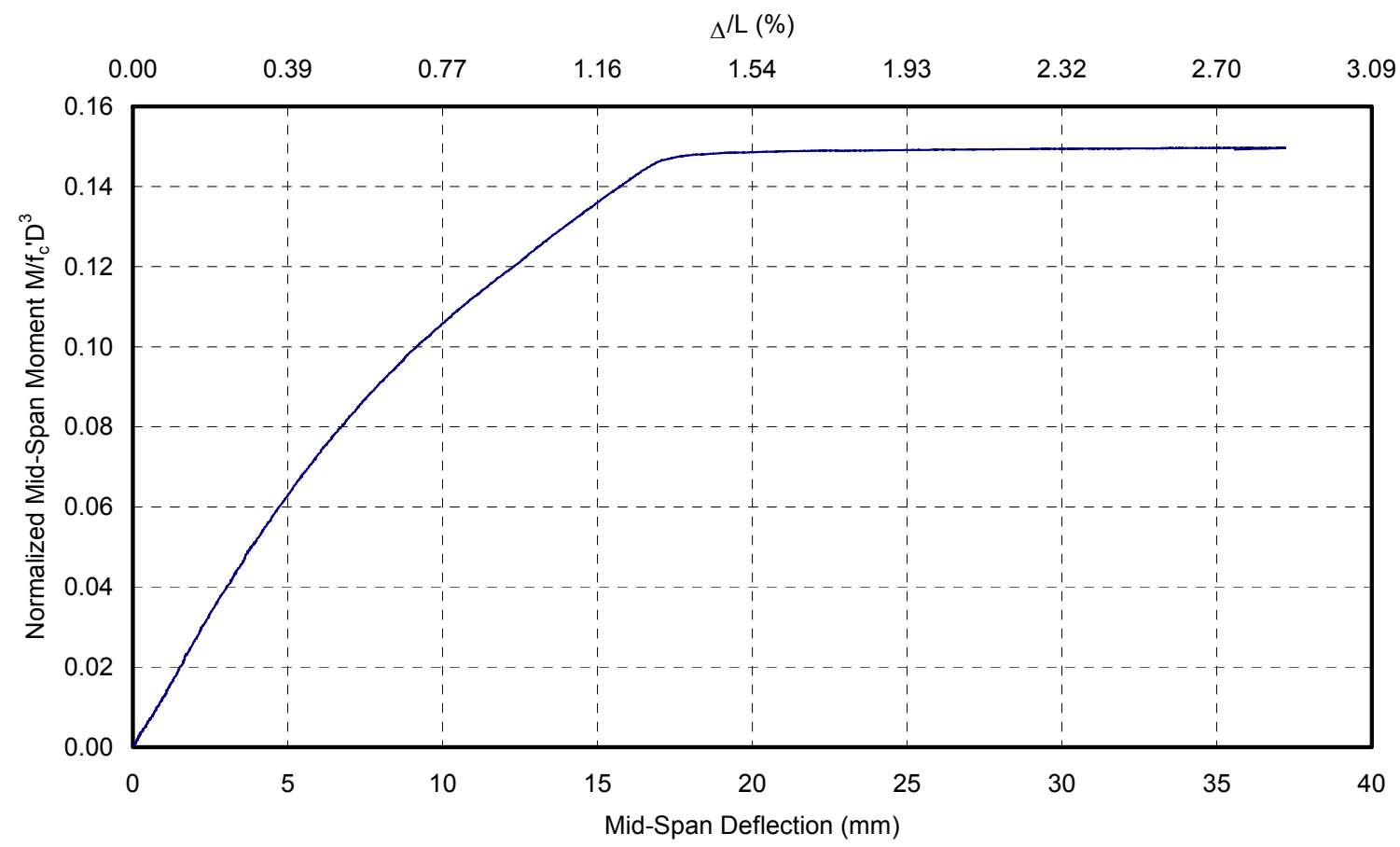

Figure 4.34 Normalized Mid-Span Moment - Deflection Response of Specimen G 


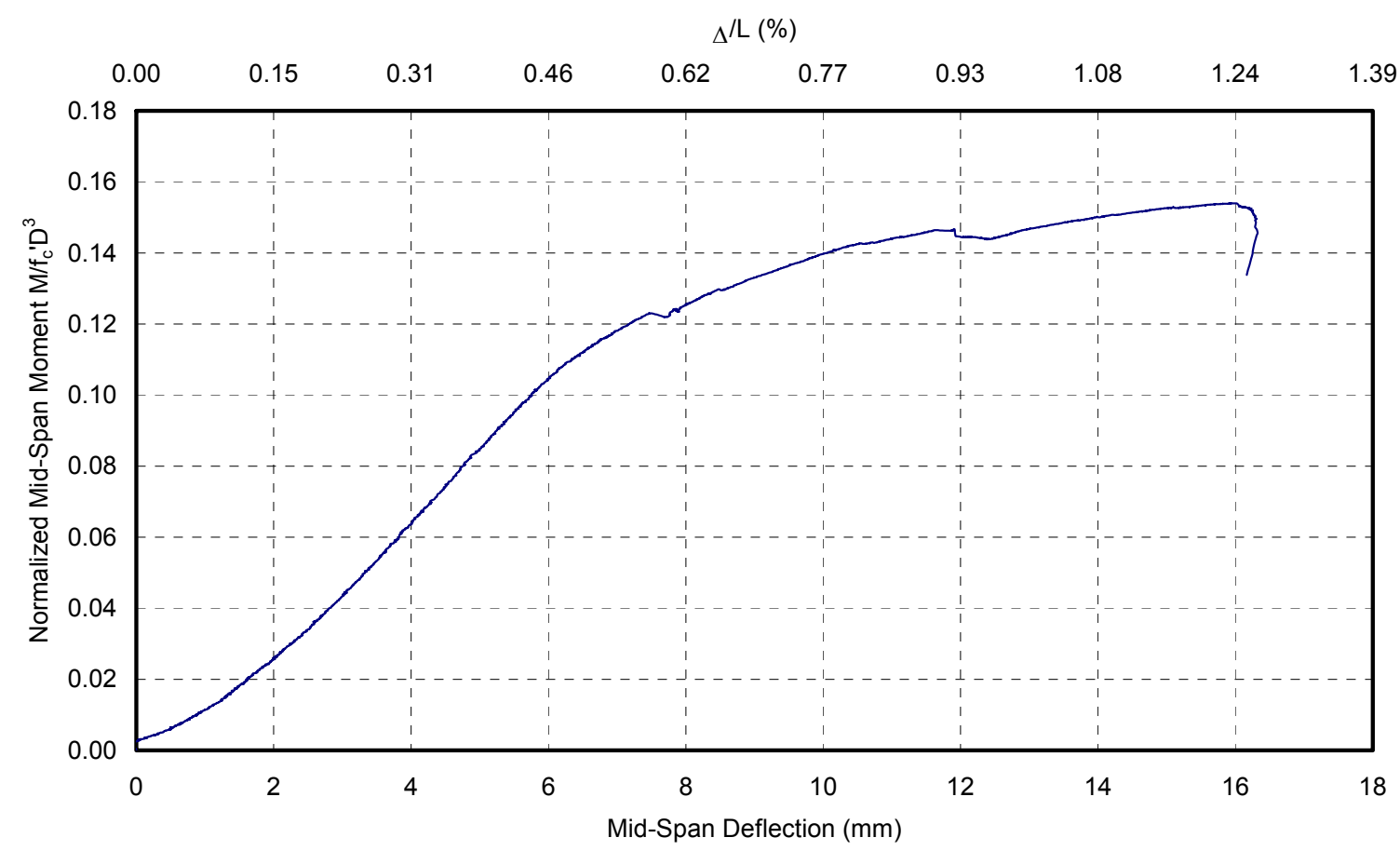

Figure 4.35 Normalized Mid-Span Moment - Deflection Response of Specimen H

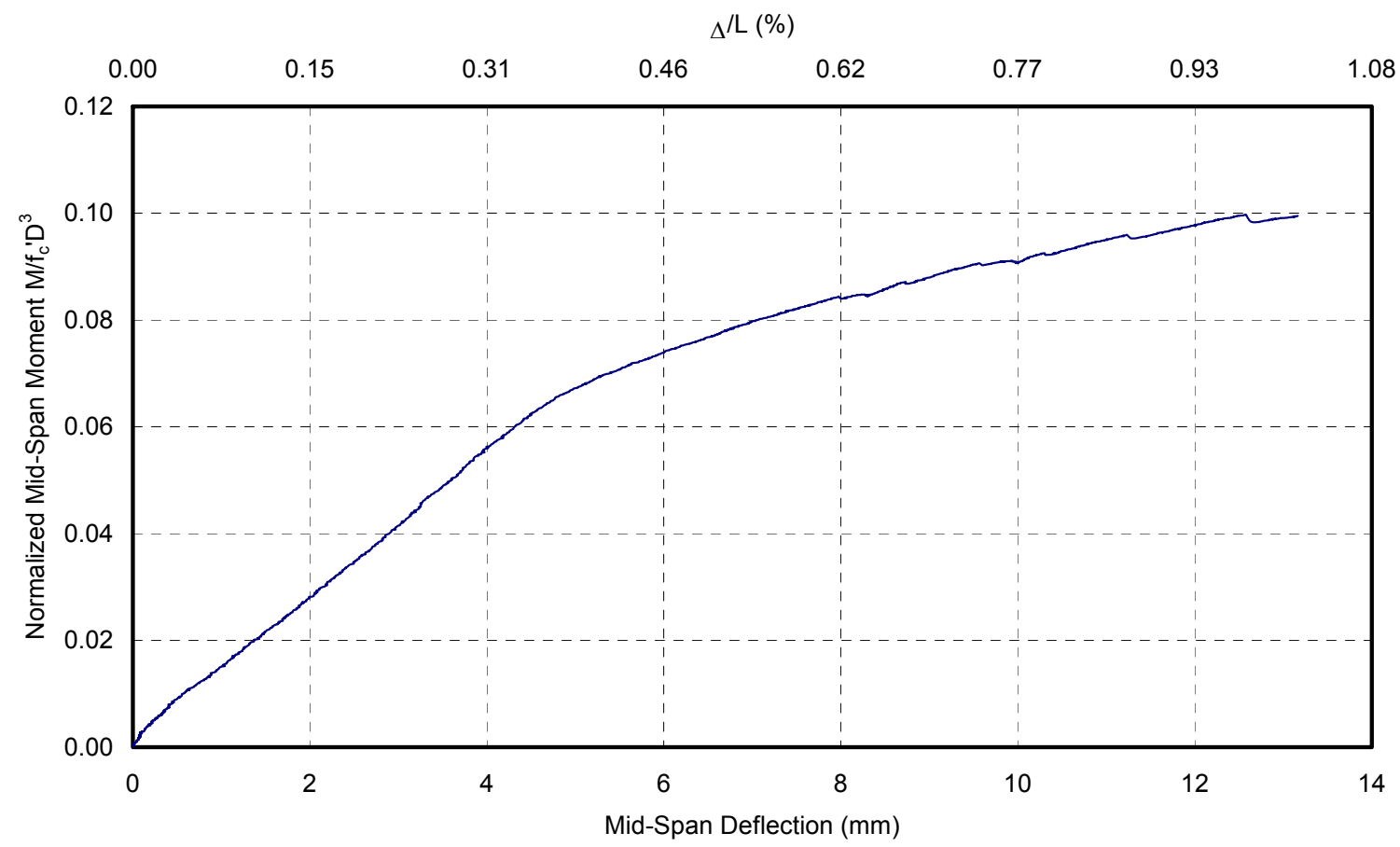

Figure 4.36 Normalized Mid-Span Moment - Deflection Response of Specimen SC 


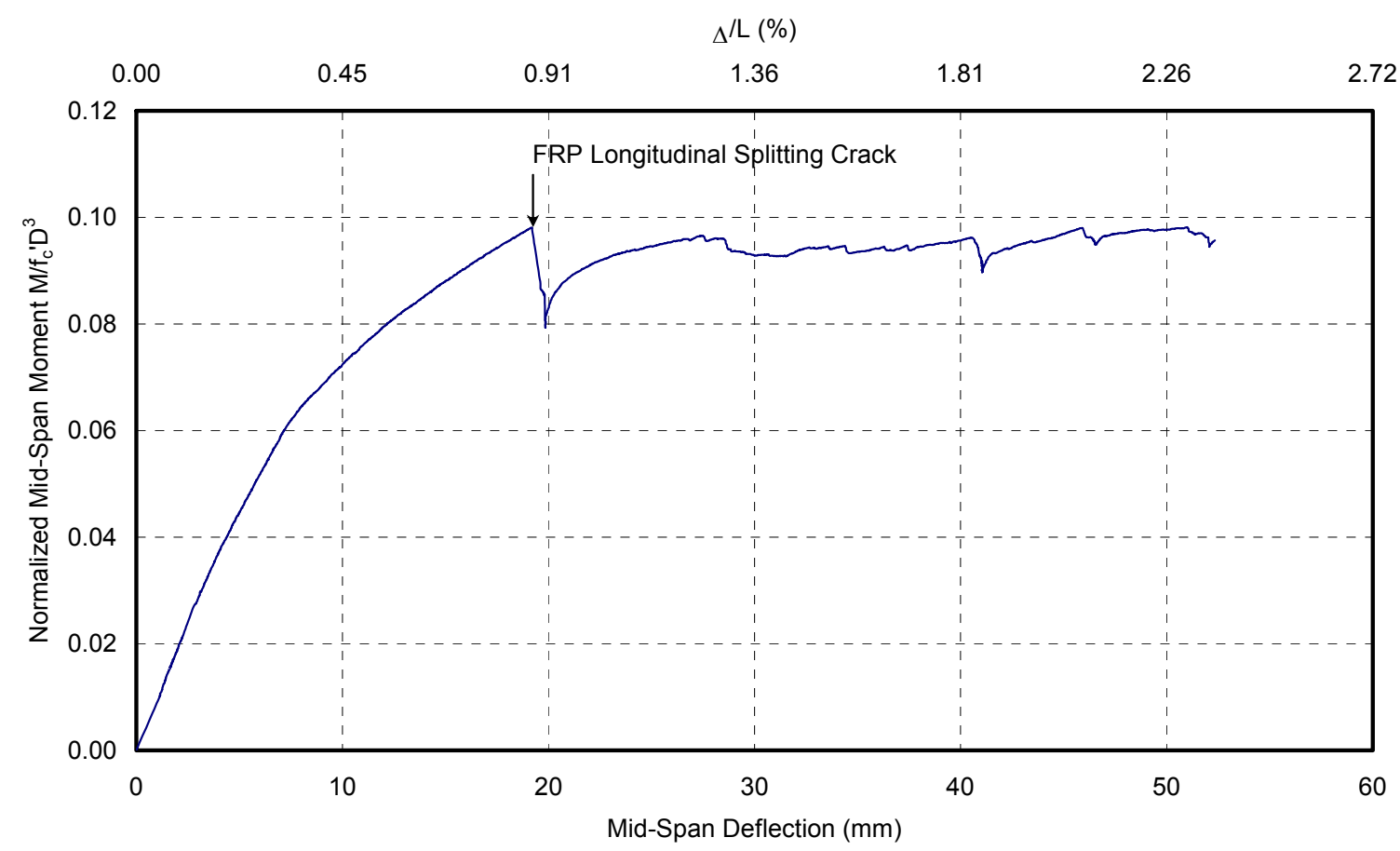

Figure 4.37 Normalized Mid-Span Moment - Deflection Response of Specimen LC

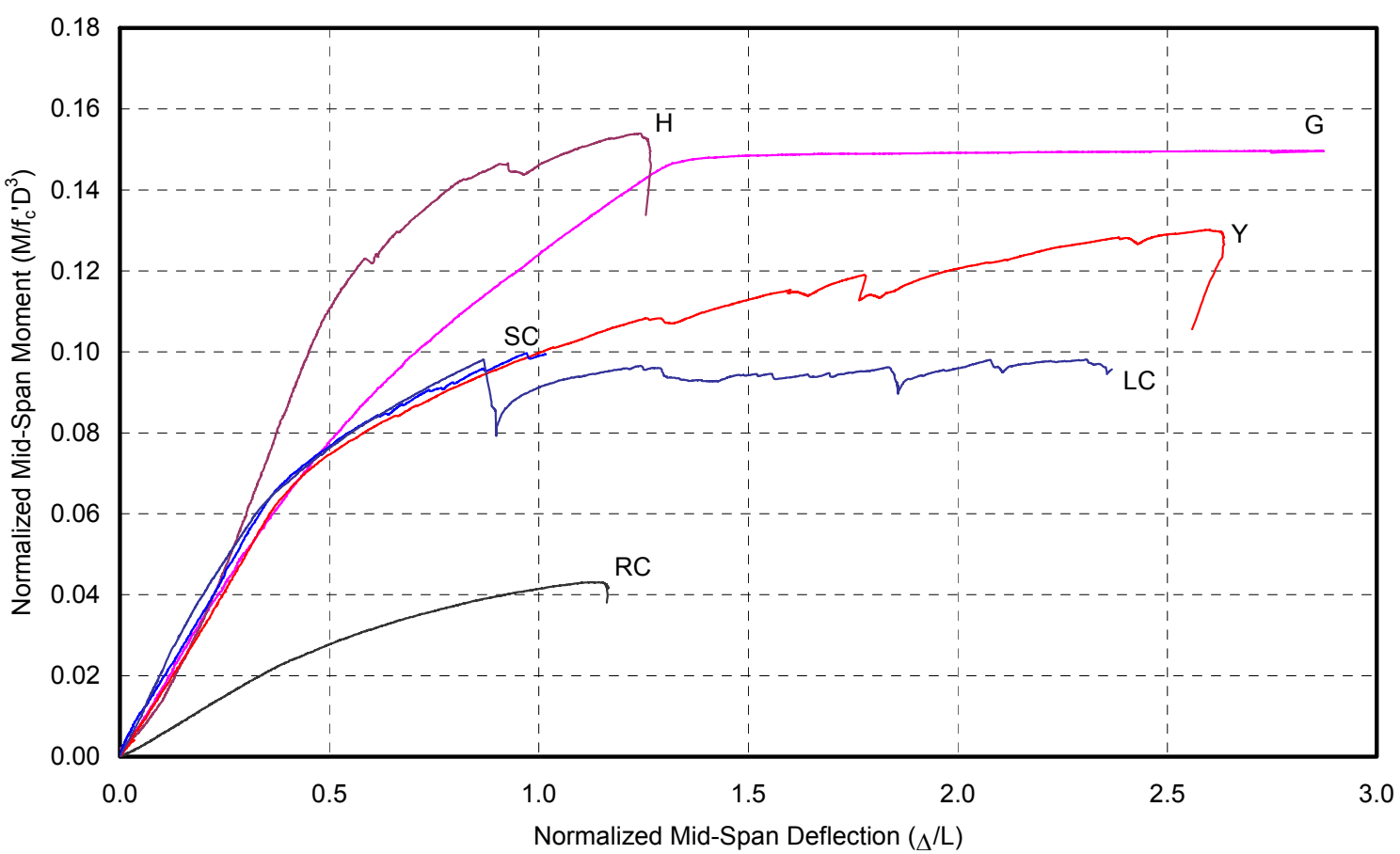

Figure 4.38 Normalized Mid-Span Moment - Deflection Responses of All Specimens 


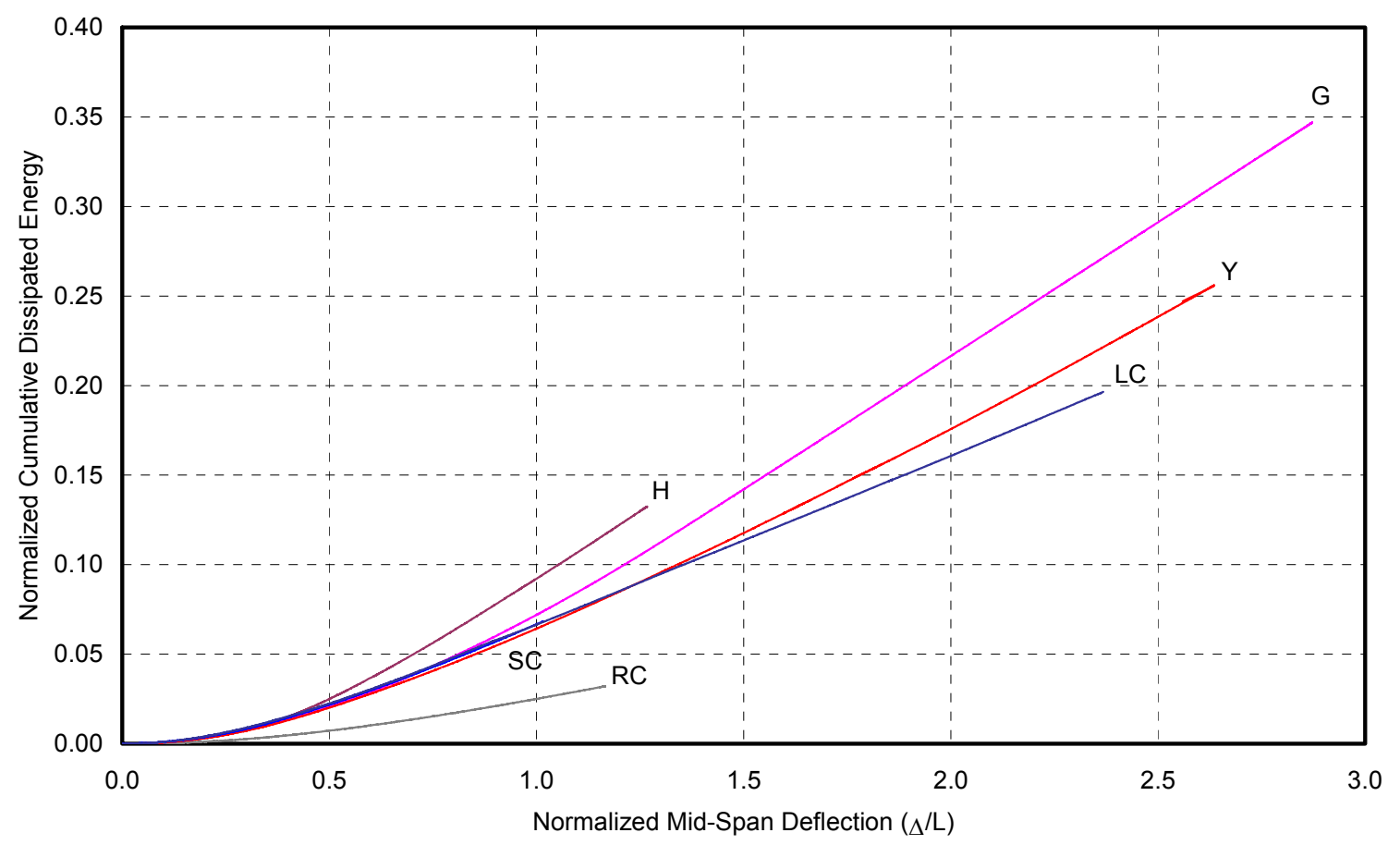

Figure 4.39 Normalized Cumulative Dissipated Energy - Deflection Responses

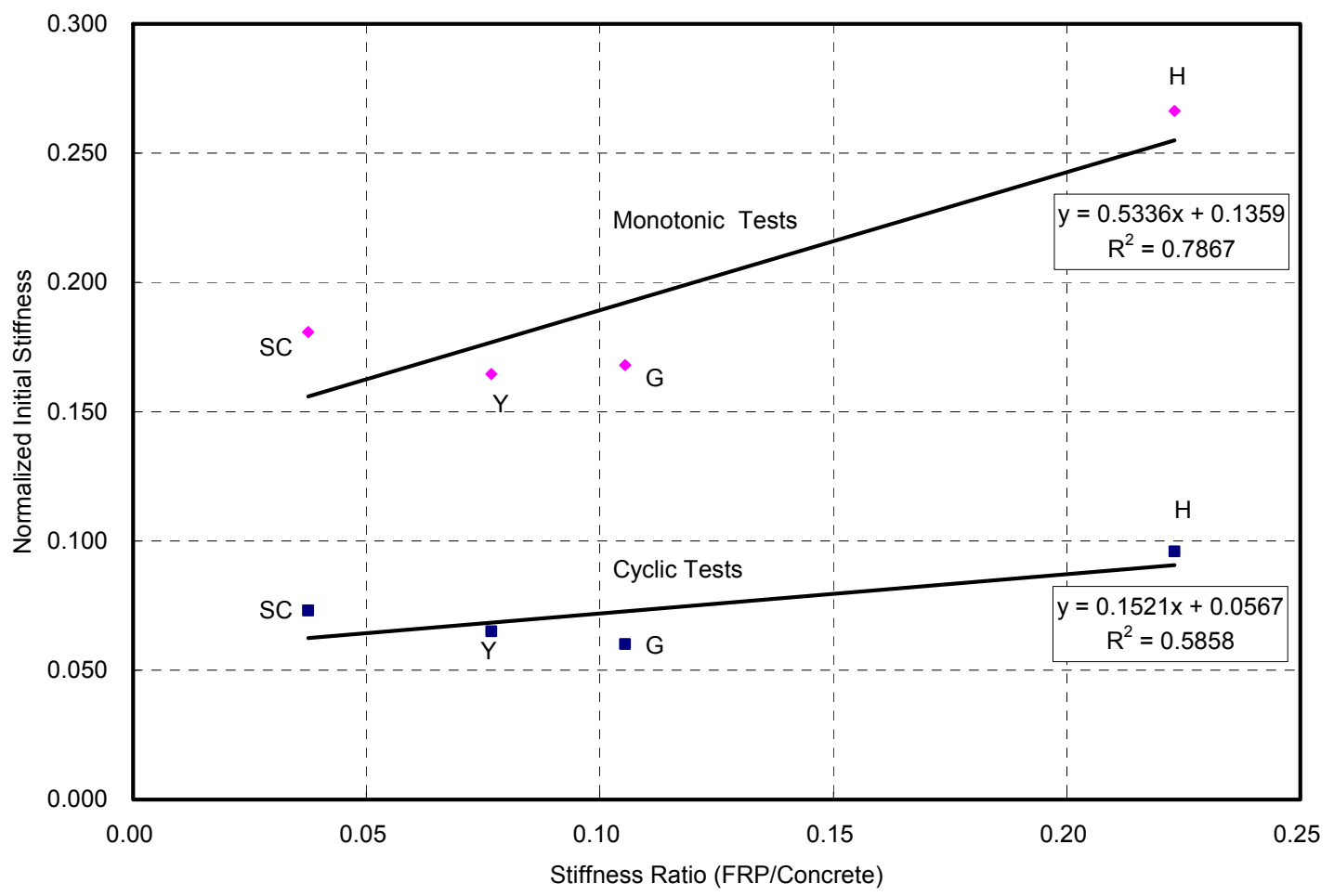

Figure 4.40 Normalized Initial Stiffness versus Stiffness Ratio (FRP/Concrete) 


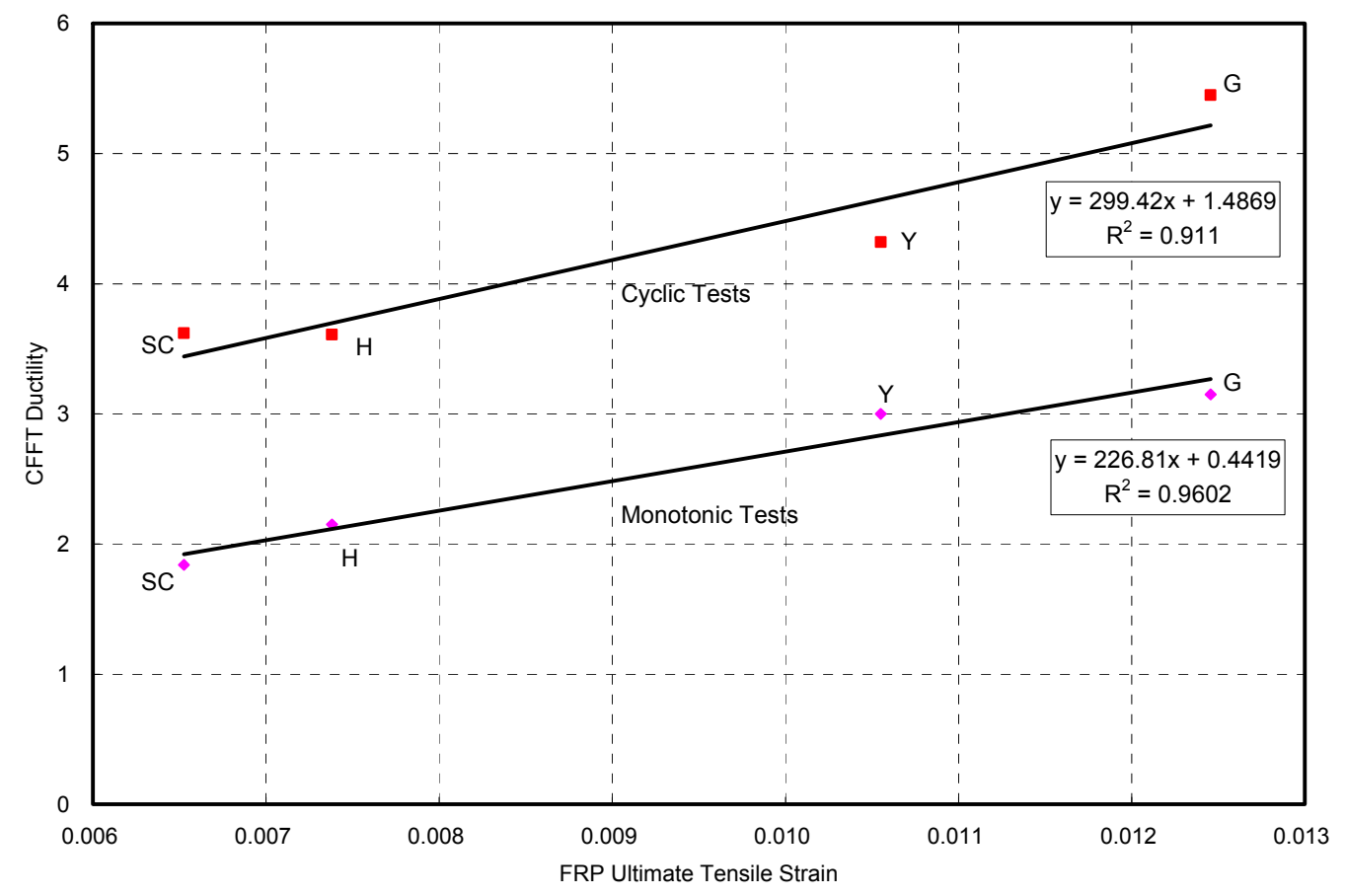

Figure 4.41 CFFT Ductility versus FRP Ultimate Tensile Strain

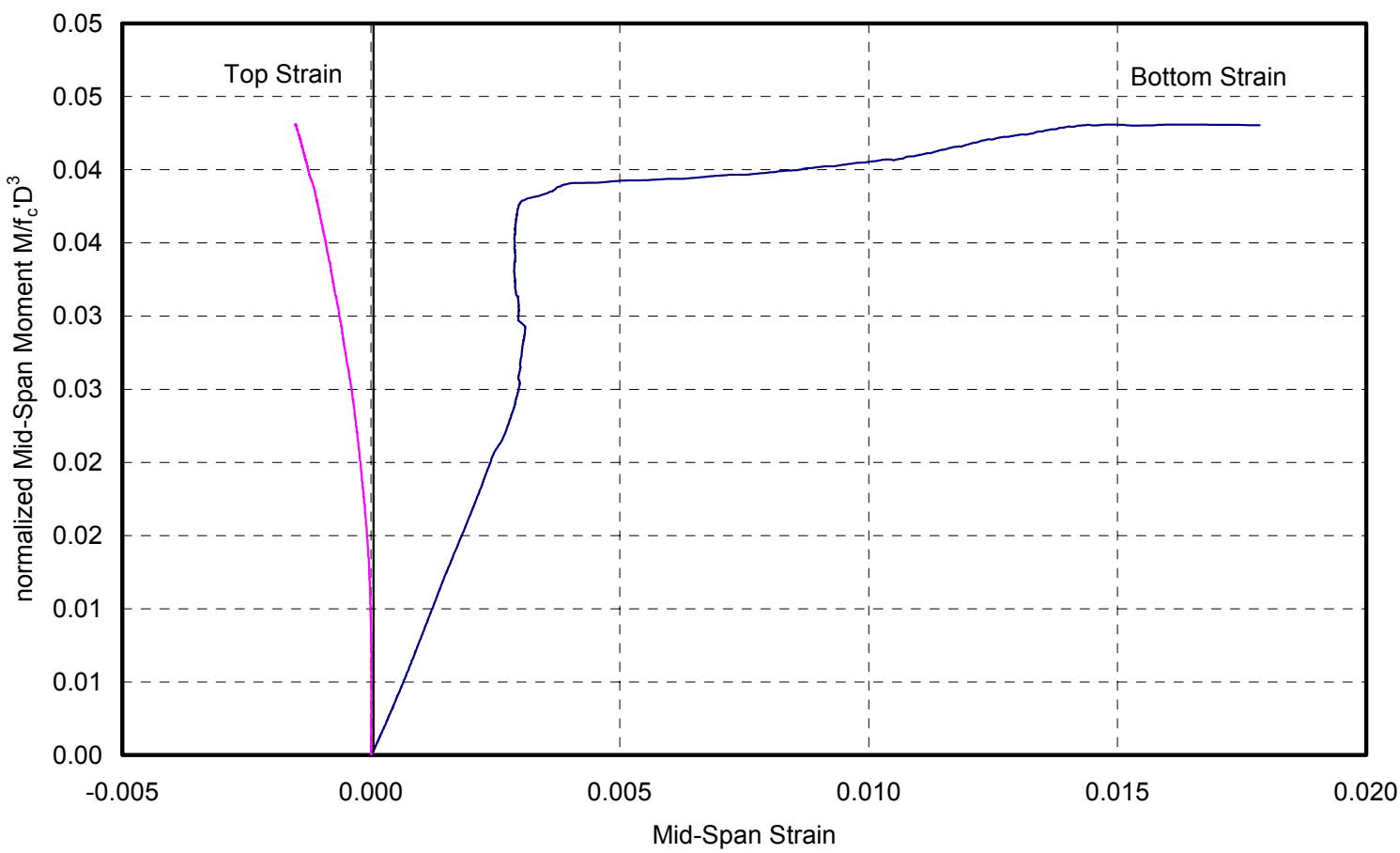

Figure 4.42 Normalized Mid-Span Moment - Strain Response of Specimen RC 


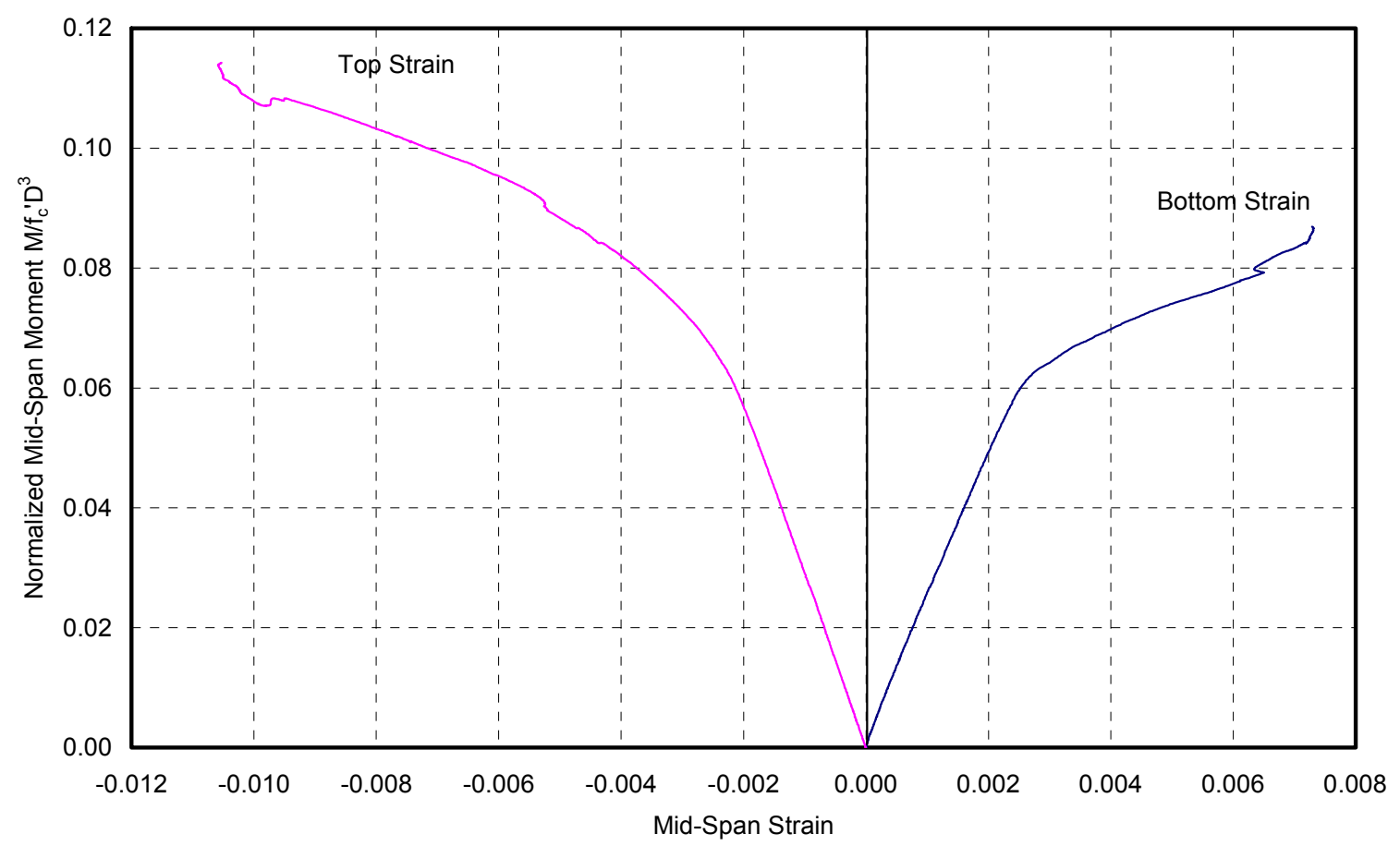

Figure 4.43 Normalized Mid-Span Moment - Strain Response of Specimen Y

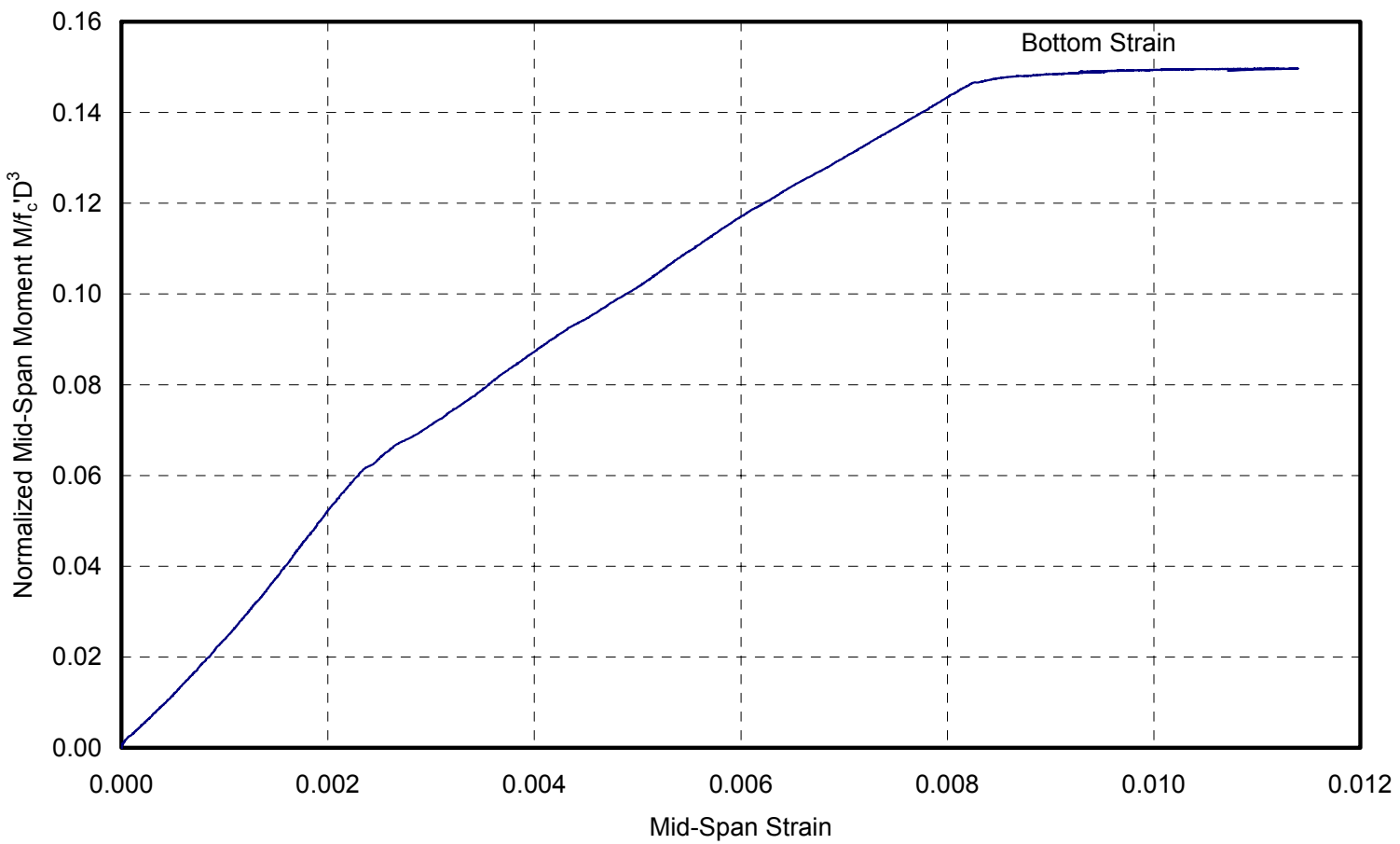

Figure 4.44 Normalized Mid-Span Moment - Strain Response of Specimen G 


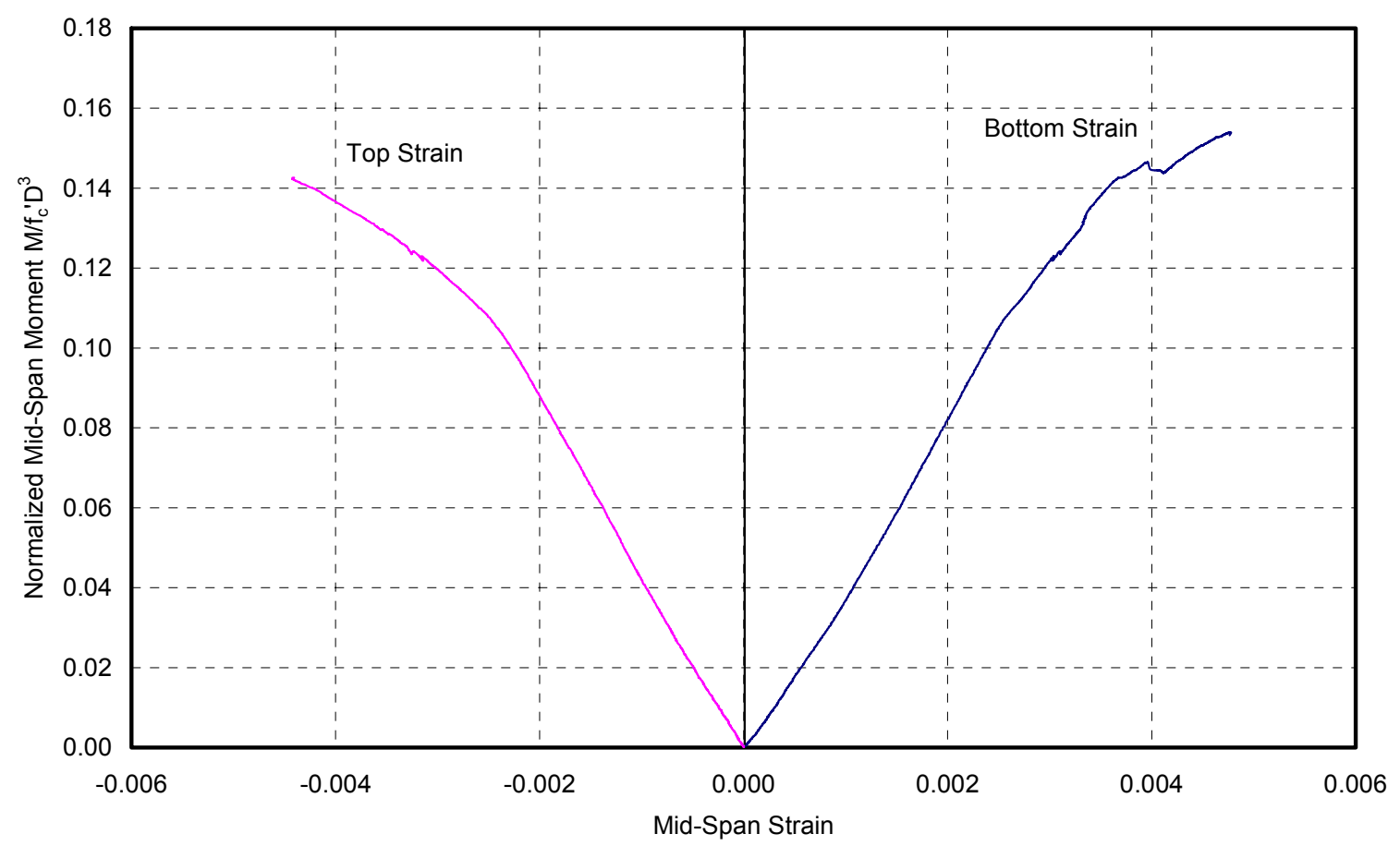

Figure 4.45 Normalized Mid-Span Moment - Strain Response of Specimen H

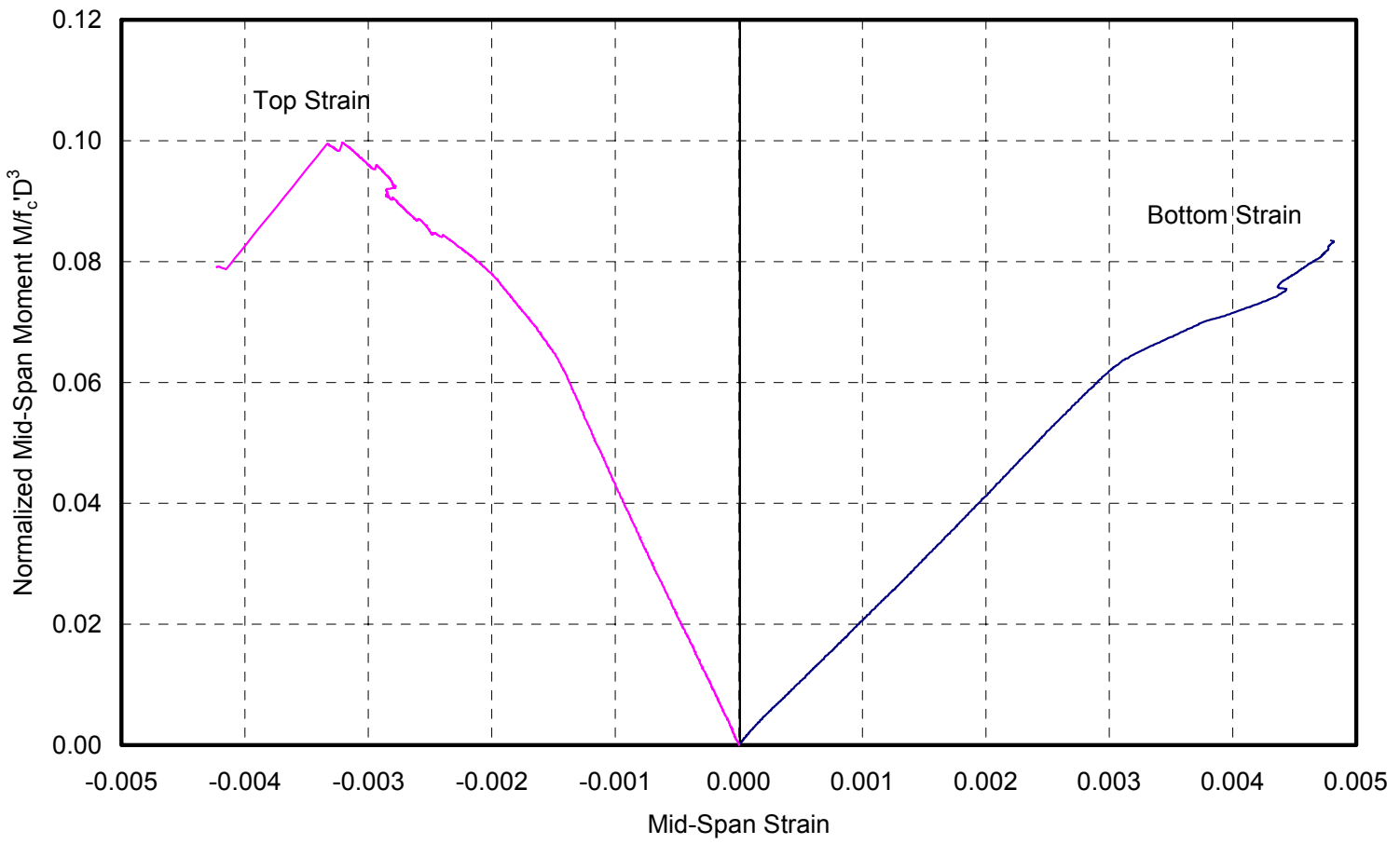

Figure 4.46 Normalized Mid-Span Moment - Strain Response of Specimen SC 


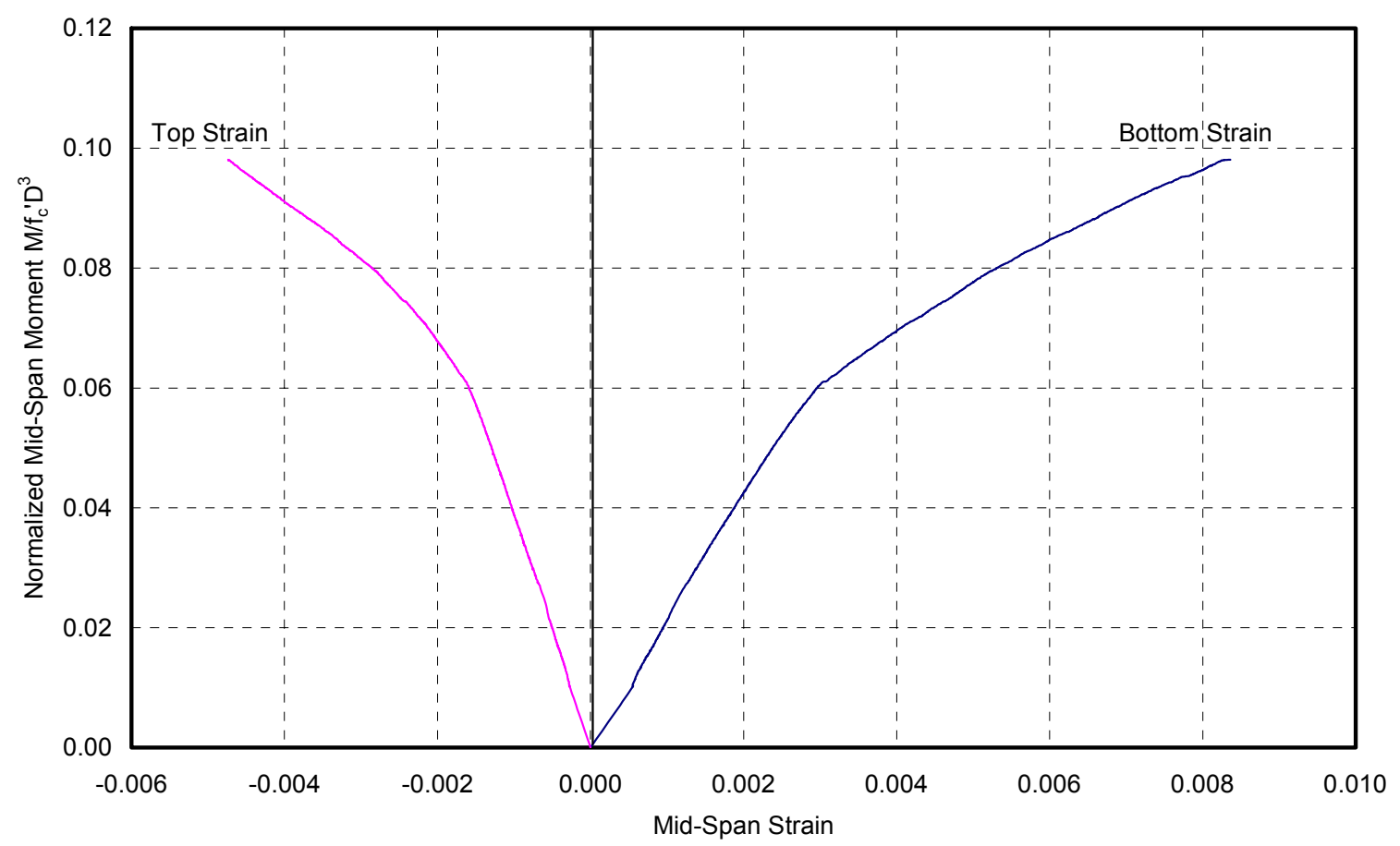

Figure 4.47 Normalized Mid-Span Moment - Strain Response of Specimen LC

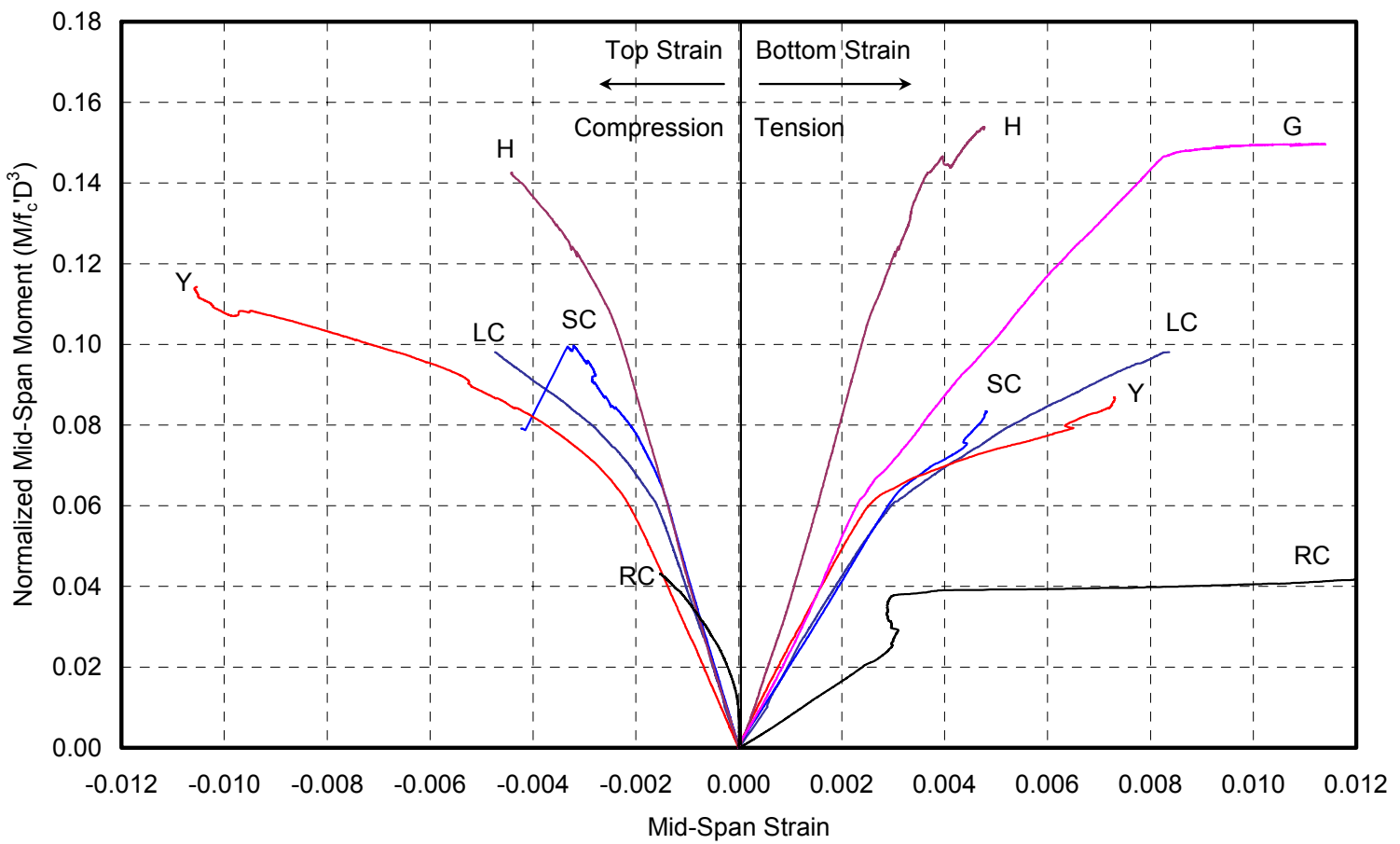

Figure 4.48 Normalized Mid-Span Moment - Strain Responses of All Specimens 


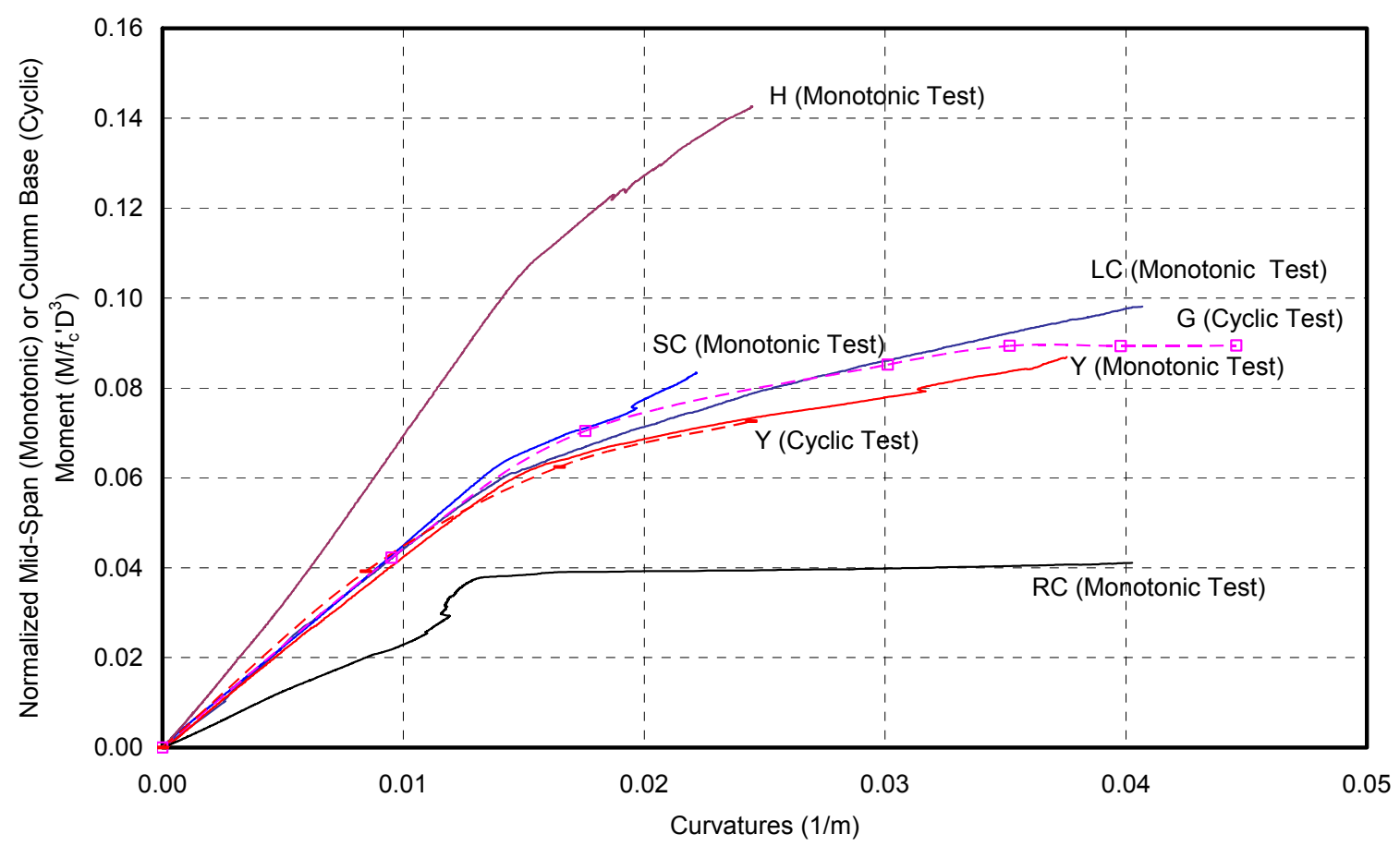

Figure 4.49 Normalized Moment - Curvature Responses

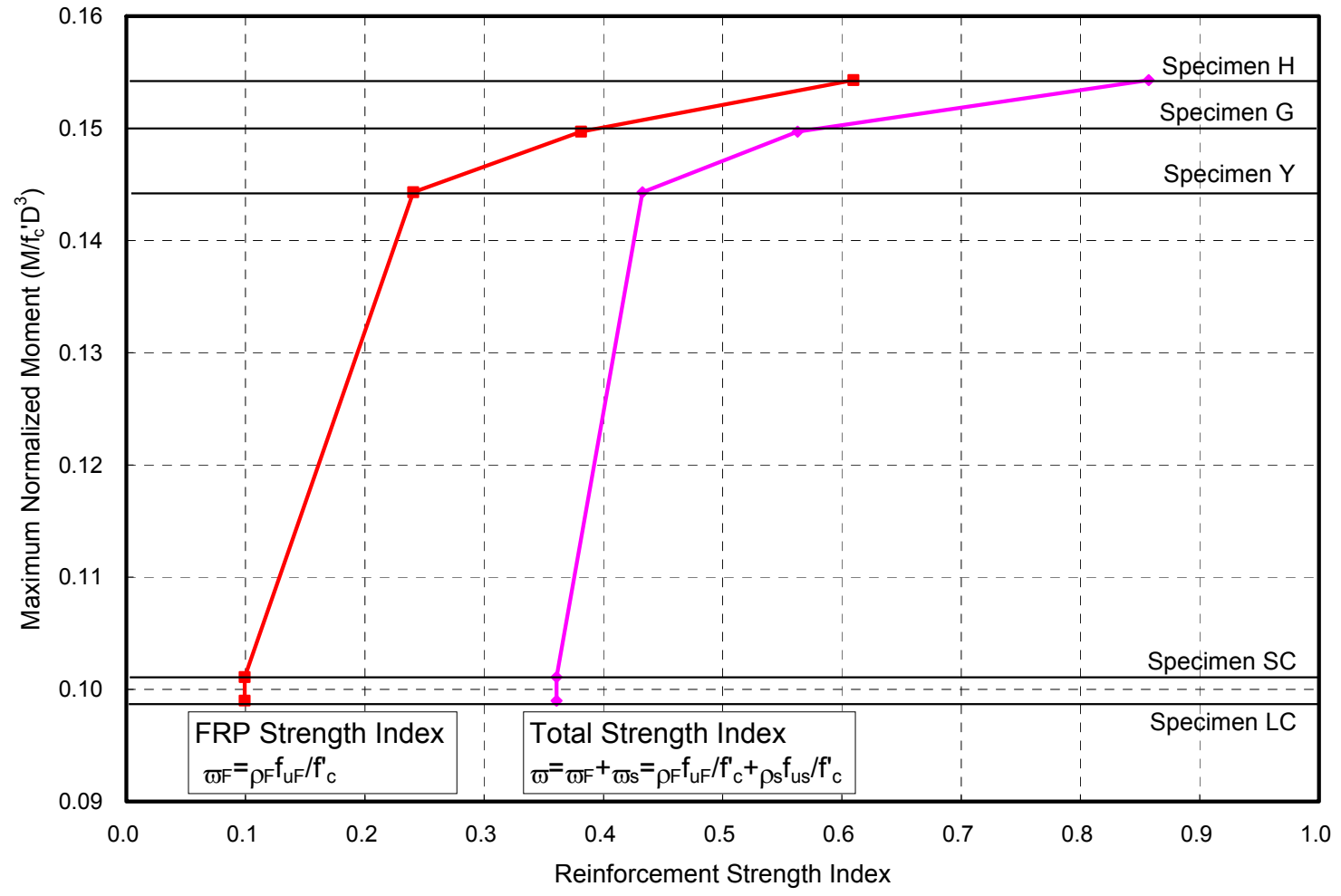

(a) Based on Unconfined Concrete Compressive Strength 


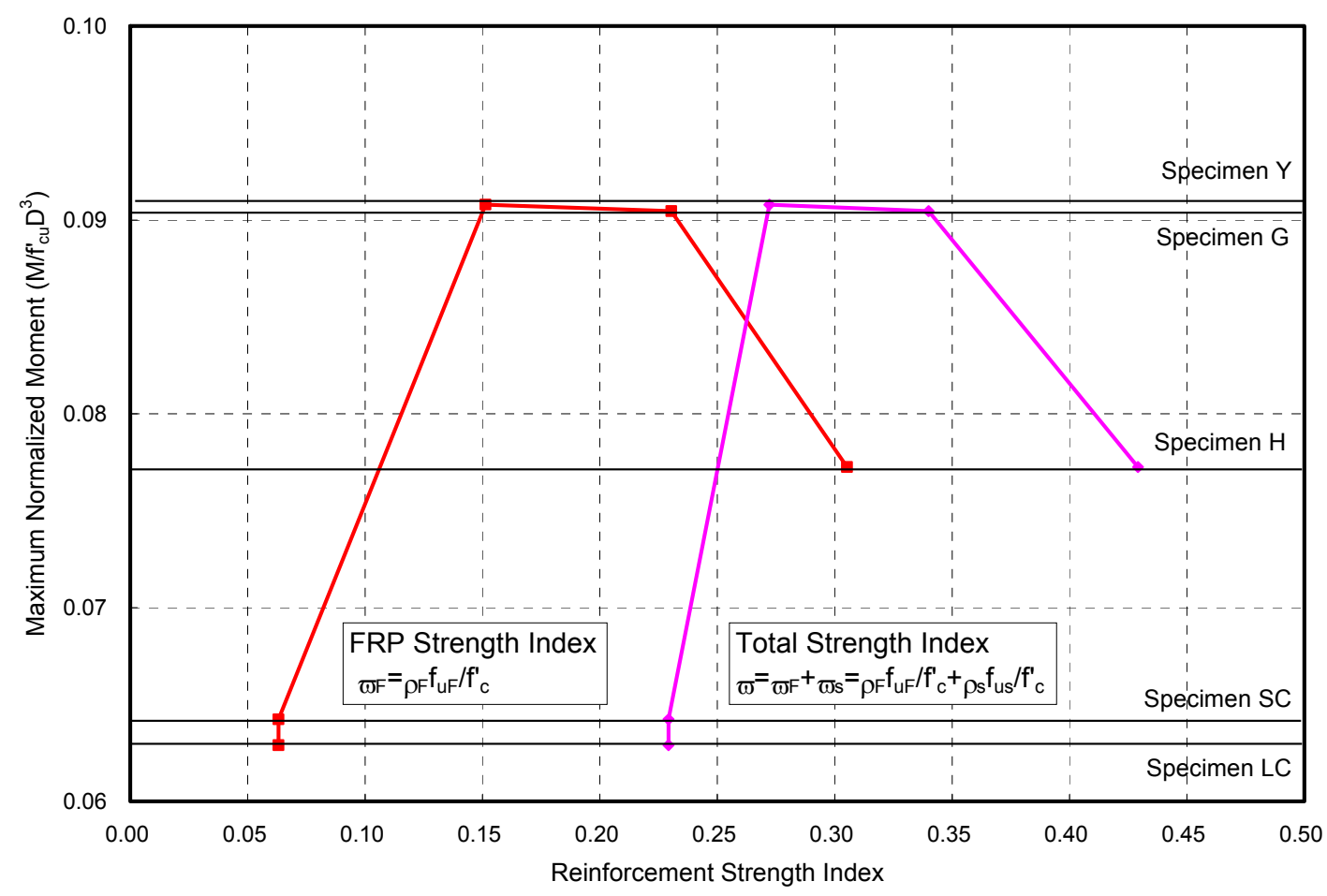

(b) Based on Confined Concrete Compressive Strength

Figure 4.50 Maximum Normalized Moments versus Reinforcement Strength Indices

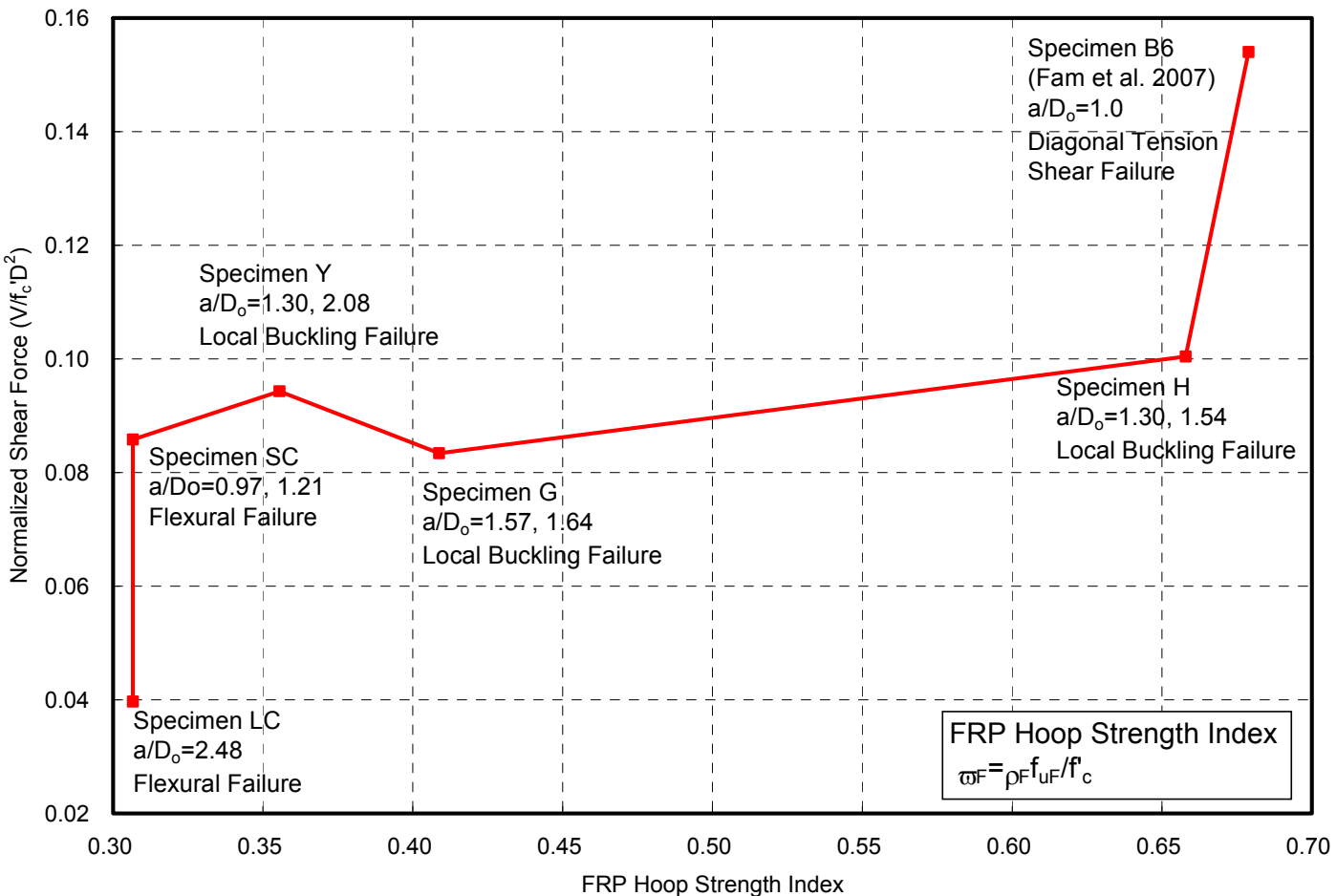

Figure 4.51 Normalized Shear Forces versus FRP Hoop Strength Index 


\section{CHAPTER 5 COUPON TEST}

\subsection{TEST MATRIX AND SPECIMEN PREPARATION}

\subsubsection{Test Matrix}

A total of sixty-five coupons were prepared for tension tests, as shown in Table 5.1. The first character in specimen name denotes the FRP material: "C" for carbon, "G" for glass and " $\mathrm{H}$ " for hybrid layups using both carbon and glass. The second character

stands for the fiber direction: " $\mathrm{H}$ " for hoop, " $\mathrm{L}$ " for longitudinal, "C" for $0^{\circ}$ carbon and "G" for $0^{\circ}$ glass. The last character indicates ply numbers in Roman numerals.

Fiber architecture in all cases was maintained according to the forming patterns of FRP tubes, where in $\mathrm{C}$ and $\mathrm{G}$ coupons, hoop direction along the specimen was the warp direction in FRP sheet, and the longitudinal direction the fillet direction. In all cases, both single-ply and multi-ply coupons were tested. Some of the coupons were mounted with strain gauges to obtain stress-strain response curves.

According to ASTM Standard D 3039 (2006), five coupons were prepared for each set of tests. In some cases, up to eight specimens were prepared to achieve statistically sound data. HL and HH coupons each were tested with four samples in good correlation, while single-ply GH coupons were tested with three specimens in close agreement.

Manufacturer data for the FRP composites used in Specimen Y was detailed and reliable, especially because the material had been applied in several earlier projects of the research group and was previously compared against laboratory coupon tests. Hence, the tests did not include any coupons for Specimen Y. Manufacturer data for P3W-GE041, 
SikaWrapHex 103C and SikaWrapHex 100G were also available for comparison with coupon tests. Manufacturer data was not available for P3W-C1059.

\subsubsection{Specimen Preparation}

All coupons were $50 \mathrm{~mm}$ ( 2 in.) wide and $305 \mathrm{~mm}$ (12 in.) long to provide an adequate gripping length at each end. The preparation of coupons followed the same fabrication procedure as that used for FRP tubes. The single-ply FRP coupons were cut from the sheets and impregnated with Sikadur 300 epoxy resin. Multi-ply FRP coupons were then stacked accordingly using single-ply coupons. The coupons were cured in room temperature of $25^{\circ} \mathrm{C}\left(77^{\circ} \mathrm{F}\right)$ for at least 72 hours. No gripping tabs were prepared for the coupons, since initial trials were performed successfully without any such tabs.

\subsection{TEST SETUP AND INSTRUMENTATION}

\subsubsection{Test Setup}

Tests were performed using Super "L" Universal Testing Machine (Model 602) of Tinius Olsen Testing Machine Co., Inc. The cured coupons were placed between the two serrated grips of the testing machine leaving $152 \mathrm{~mm}(6 \mathrm{in}$.) of gauge length in the middle. A folded strip of medium grade emery cloth was also placed on both sides of the coupons within the grip jaws to provide a non-slip surface on the specimen without any jaw serration damage. Figure 5.1 shows a typical coupon test setup.

\subsubsection{Instrumentation}

The load from the testing machine was accurately calibrated. A PFL-30-11-5L strain gauge made by Tokyo Sokki Kenkyujo Co., Ltd. was mounted in the middle of the 
gauge length to monitor the strain behavior of the coupons, as indicated in the last column of Table 5.1. The data was recorded using Vishay 6000 high-speed data acquisition system at a frequency of $1 \mathrm{~Hz}$. Figure 5.2 shows the instrumentation setup.

\subsection{TEST PROCEDURE AND OBSERVATIONS}

\subsubsection{Test Procedure}

Coupon tests were conducted following ASTM standard D 3039 (2006). The load was applied in displacement control at a rate of $2 \mathrm{~mm} / \mathrm{min}(0.05 \mathrm{in} . / \mathrm{min})$. Width and thickness of each coupon were obtained as average of three different measurements within the gauge length, and used for stress calculations.

\subsubsection{Test Observations}

Table 5.2 lists failure modes, using the standard codes for tensile test, as described by ASTM D 3039.

For the thirteen $\mathrm{CH}$ coupons, the first three out of five single-ply coupons (CH-I-1 to $\mathrm{CH}-\mathrm{I}-3)$ and the first five out of eight two-ply coupons (CH-II-1 to $\mathrm{CH}-\mathrm{II}-5)$ were mounted with strain gauges. Figure 5.3 through Figure 5.14 show the failure modes for all $\mathrm{CH}$ coupons, except for $\mathrm{CH}-\mathrm{II}-1$, which was not counted in the stress-strain response calculation because of its premature failure. The other coupons all had brittle lateral (or highly close to lateral) failures with a sudden rupture noise, albeit at different locations. Out of the twelve failures, three were at gauge $(\mathrm{G})$, seven within one width from grips (W), one at grip (A) and another inside grips (I). Hence, from the failure mode point of 
view, the results were acceptable. The difference between the single-ply and two-ply coupons was of no significance.

For the ten CL coupons, only the five two-ply coupons (CL-II-1 to CL-II-5) were instrumented with strain gauges. Figure 5.15 through Figure 5.24 show the failure modes for all $\mathrm{CL}$ coupons. The failure modes were quite identical to $\mathrm{CH}$ coupons, with all lateral ruptures. Out of the ten lateral failures, one was at gauge $(\mathrm{G})$, two within one width from grips (W), five at grips (A), and another two inside grips (I). Although 70\% failures were at or inside grips, the stress-strain results were quite stable, as will be discussed in Section 5.4.1.

Out of the eight GH coupons, all three single-ply coupons (GH-I-1 to GH-I-3) and the first three three-ply coupons (GH-III-1 to GH-III-3) were instrumented with strain gauges. Figure 5.25 through Figure 5.32 show the failure modes for all GH coupons. Six failures were brittle lateral rupture, and the other two included partial damage at grips. Three were at gauge $(\mathrm{G})$, three within one width from grips (W), and the last two at grips (A).

For the sixteen GL coupons, the first three out of eight single-ply coupons (GL-I1 to GL-I-3) and all the eight three-ply coupons (GL-III-1 to GL-III-8) were instrumented with strain gauges. Figure 5.33 through Figure 5.46 show all failure modes for GL coupons, except for GL-III-2' and GL-III-4'. Fourteen coupons had lateral failures and the other two were damaged in angle at grips. Four failures were at gauge (G), ten at grip (A), and the last two inside the grips (I). The failure modes were not any different from the GH coupons. 
All five $\mathrm{HC}$ and five $\mathrm{HG}$ coupons were tested without any strain gauge, because abundant manufacturer data was available. The only objective of these coupon tests was to compare the ultimate strength with the manufacturer data. Figure 5.47 through Figure 5.51 show the failure modes for all $\mathrm{HC}$ coupons, and Figure 5.52 through Figure 5.56 for all HG coupons. Apart from HC-I-1 that showed lateral rupture, all other coupons had longitudinal splitting failure (S). The splitting failure of $\mathrm{HC}$ coupons was explosive (HCI-5, for example), while HG coupons retained a certain level of integrity after failure, mainly because the lateral yarns held the debris. Figure 5.61 through Figure 5.64 show failure modes for all $\mathrm{HH}$ coupons, and Figure 5.57 through Figure 5.60 for all $\mathrm{HL}$ coupons. All failures were lateral rupture, with one at gauge (G) and three at grips (A) for HH coupons, and two at gauge (G) and two within one width from grips (W) for HL coupons.

\subsection{TEST RESULTS AND DISCUSSIONS}

\subsubsection{Stress-Strain Behavior}

Table 5.3 lists the maximum stress and strain values, and Figure 5.65 shows stress-strain responses for $\mathrm{CH}$ coupons. The modulus of elasticity $E$ in the table was obtained from linear regression analysis of the stress-strain response. The average of the multi-ply thickness of coupons was also obtained for comparison with the manufacturer data. For single-ply $\mathrm{CH}$ coupons, the ultimate strength of $\mathrm{CH}-\mathrm{I}-4$ and $\mathrm{CH}-\mathrm{I}-5$ were very close to the average data. However, $\mathrm{CH}-\mathrm{II}-6$ and $\mathrm{CH}-\mathrm{II}-8$ did not conform to the average data due to their premature failure. It is clear that irrespective of the fiber architecture, the stress-strain response is always linear elastic until rupture. 
Table 5.4 lists the maximum stress and strain values, and Figure 5.66 shows the stress-strain responses for CL coupons. It is clear that the value of modulus of elasticity is quite consistent for all coupons. Moreover, the ultimate strengths of one-ply and two-ply coupons are quite similar.

Table 5.5 lists the maximum stress and strain values, and Figure 5.67 shows the stress-strain responses for GH coupons. The average modulus of elasticity is quite close, as shown in the figure. However, the ultimate strengths and strains were not as consistent.

Table 5.6 lists the maximum stress and strain values, and Figure 5.68 shows stress-strain responses for GL coupons. Since GL-I-1 and GL-III-1 through GL-III-3 all had premature failure, those data were not included in the calculation of averages.

Table 5.7 and Table 5.8 lists the maximum stress and strain values for $\mathrm{HC}$ and HG coupons, respectively. Since none of them included strain gauges, modulus of elasticity and ultimate strains were not monitored for their coupons. The ultimate strength of $\mathrm{HC}$ coupons was highly close to the average, while variation was slightly higher for HG coupons.

Table 5.9 lists the maximum stress and strain values, and Figure 5.69 shows the stress-strain responses for $\mathrm{HH}$ coupons. The data for $\mathrm{HH}-\mathrm{V}-4$ deviated from the average for both the modulus of elasticity and the ultimate strain. However, the ultimate strength was very close to the average. This phenomenon was quite similar to some of the other FRP coupons. Hence, it is of more interest to compare the ultimate strength and modulus of elasticity with the manufacturer data. Also, it is noticed that the first three data sets are quite close to each other. 
Table 5.10 lists the maximum stress and strain values, and Figure 5.70 shows the stress-strain responses for HL coupons. This set of data was statistically more dispersed, as compared with the other FRP coupons. The HL-V-4 stood out with the largest ultimate strain and the smallest modulus of elasticity.

\subsubsection{Comparison of Mechanical Properties with Manufacturer Data}

\subsubsection{Manufacturer Data}

Table 5.11 lists manufacturer data of products associated with Specimens Y, G, and $\mathrm{H}$, respectively, as well as their associated coupons. Fiber direction indicates the orientation from FRP sheet or tube for each specific coupon. For Specimen Y, the nominal wall thickness is comprised of 17 layers of $\pm 55^{\circ}$ E-Glass FRP composites. For Specimens $\mathrm{G}$ and $\mathrm{H}$, the thickness provided is for one ply only.

It should be noted that the mechanical properties of glass FRP composite reported by 3 TEX are based on Hydrex 100 resin, which is different from Sikadur 300 used in this study.

Table 5.12 compares the mechanical properties of Hydrex 100 and Sikadur 300. The former resin is vinyl ester with stronger properties than the latter, which is made of epoxy. Both materials, however, are tested using the same method (ASTM Standard D 638).

\subsubsection{GH and GL Coupons}

The left half of Table 5.13 shows the comparison between manufacturer data and GH coupon tests. Since coupons for these two sources had different thicknesses, and 
were made of different resins, the manufacturer data needs to be adjusted for these two factors to be comparable with coupon test results, as shown in the right half of the table.

Adjustment factor, $K_{l}$, accounts for the influence of thickness on the ultimate strength. Adjustment factor, $K_{2}$, accounts for the resin influence on both the ultimate strength and the modulus of elasticity. In other words, modulus of elasticity does not change with the thickness, whereas strength of resin does influence the strength of FRP composite. Factor $K_{2}$ is the product of square roots of two ratios of both moduli of elasticity and ultimate strengths of the two resins. Ultimate strain was finally estimated by the two adjusted results of modulus of elasticity and ultimate strength for the manufacturer data.

The comparisons show that coupon test results were $11.90 \%$ larger than the adjusted manufacturer data for the modulus of elasticity. For the ultimate strength, they were only $0.28 \%$ off. Finally, ultimate strain of the coupon tests was $12.63 \%$ less than the respective manufacturer data.

Table 5.14 shows the comparison of manufacturer data with GL coupon tests. It also shows the adjustment factor calculations in the same fashion as those described for GH coupons. The comparison shows that coupon test results were $6.49 \%$ larger than the adjusted manufacturer data for the modulus of elasticity, but $9.77 \%$ lower for the ultimate strength and $17.39 \%$ lower for the ultimate strain.

In general, it is evident that the bi-directional GFRP sheet has identical mechanical properties in both directions. The coupon test results on modulus of elasticity and ultimate strength were quite reliable, as compared with the adjusted manufacturer 
data. There were moderate differences for the ultimate strains, which will be discussed in Section 5.4.3.

\subsubsection{HC and HG Coupons}

Table 5.15 and Table 5.16 compare data for HC and HG coupons, respectively. Since the same resin was used for both coupon tests and the manufacturer data, only thickness difference was considered for all $\mathrm{H}$ coupons. The comparisons show that $\mathrm{HC}$ and $\mathrm{HG}$ coupon tests were as close as within $1.01 \%$ and $3.20 \%$, respectively, from the adjusted manufacturer data for ultimate strengths. This also provides strong confidence in direct application of the manufacturer data for modulus of elasticity.

\subsubsection{HH and HL Coupons}

Table 5.17 and Table 5.18 compare data for HH and HL coupons. HH coupons comprised of three layers of $0^{\circ}$ GFRP and two layers of $90^{\circ}$ CFRP sheets, while $\mathrm{HL}$ coupons comprised of two layers of $0^{\circ}$ CFRP and three layers of $90^{\circ}$ GFRP sheets, as reflected in each adjustment calculation.

When compared with the adjusted manufacturer data, the modulus of elasticity and the ultimate strength were $2.25 \%$ and $9.89 \%$ lower for the HH coupons, respectively. The HL coupons had a $4.98 \%$ higher modulus of elasticity and a $5.55 \%$ lower ultimate strength than the manufacturer data. The test results of ultimate strains for $\mathrm{HH}$ coupons were estimated by the ratio of ultimate strength over modulus of elasticity, and the difference with the estimated manufacturer data was $7.47 \%$. The ultimate strain for HL coupons was $8.40 \%$ less than the estimated manufacturer data. Generally, the modulus of elasticity was within $5 \%$ and the ultimate strength was within $10 \%$ of the manufacturer 
data for $\mathrm{HH}$ and HL series, making this series quite comparable with the manufacture data.

\subsubsection{Comparison with Large-Scale Specimens}

Table 5.19 lists the ultimate tensile strains for the cyclic, monotonic and coupon tests as well as the manufacturer data. The notes for cyclic tests also identify the location of strain gauges within the cross section (i.e., top or bottom), location along the column ("0 Height" or " $1 / 8$ Height" from the footing along the column) and the time stamp during cyclic tests in terms of ductility factor $\mu$. The remarks for monotonic tests indicate whether the ultimate strain readings were at or before failure.

The data for Specimen Y was not comparable, since cyclic test reading was not at the maximum moment region and the strain reading of the monotonic test dropped before failure. Specimen G almost achieved the ultimate tensile strain in both cyclic and monotonic tests, although it did not experience rupture failure in either test. For Specimen $\mathrm{H}$, flexure test data was recorded at failure, but cyclic test data could not be

considered because it was not from the maximum moment region. Nonetheless, it achieved $58.5 \%$ of the manufacturer reported ultimate tensile strain for monotonic test. Finally, for both Specimens SC and LC, the ultimate tensile strains were quite reasonable, when compared with coupon test results, indicating that the two specimens both had flexural rupture failures in both cyclic and monotonic tests.

Table 5.20 lists available compressive properties from the manufacturer data according to ASTM Standard D 695 (2002). Table 5.21 shows the calculation procedure for ultimate compressive strain in HL coupons following the procedure used for tensile 
property. The compressive strengths of $90^{\circ}$ direction for uni-directional CFRP and GFRP composites were considered as zero in the calculation of HL coupons. These two tables facilitate the comparison of ultimate compressive strains as summarized in Table 5.22.

For Specimen Y, monotonic test achieved $40.5 \%$ of the manufacturer reported ultimate compressive strain before the compressive burst failure, although this value of 0.0106 was highly significant when comparing with other specimens. Specimen G did not yield any comparable information because of strain gauge malfunction at top of the section, and due to unavailability of manufacturer data. Specimen $\mathrm{H}$ achieved $51.8 \%$ of the manufacturer reported ultimate compressive strain before failure. Considering almost the same level of achieved ultimate tensile strain at failure, it may be concluded that Specimen $\mathrm{H}$ experienced local bucking failure rather than compressive failure. Finally, for Specimens H, SC and LC, the achieved ultimate compressive strains were all at the same level of around 0.0045 , leading to the conclusion that the three specimens had the same local buckling failure in compressive regions of the sections. This may be attributed to the fact that the longitudinal fibers for all three specimens were carbon.

\subsection{CONCLUSIONS}

A series of tension coupon tests were conducted to verify the mechanical properties of different FRP tubes. The results were compared with available manufacturer data and with the results of both monotonic and cyclic tests. Compressive mechanical properties from manufacturer data were also compared with both monotonic and cyclic test results. Following conclusions could be drawn from this study: 
1. All FRP coupons exhibited a linear elastic stress-strain response. Most failures were lateral brittle ruptures for bi-directional coupons, and longitudinal splitting failure for uni-directional coupons. No significant difference in strength was noted between single-ply and multi-ply coupons.

2. The coupon test results were very close to the available manufacturer data when adjusted by strength and thickness factors, leading to strong confidence in the validity of the coupon tests.

3. Comparisons of ultimate strains achieved in monotonic tests with available manufacturer data confirmed that Specimens H, G, LC, and SC all had local buckling failure.

4. Comparisons of ultimate tensile strains of the three test sets (cyclic, monotonic, and coupon tests) showed that Specimen G almost achieved the ultimate tensile strength in both cyclic and monotonic tests, although it did not experience rupture failure in both tests.

5. For both Specimens SC and LC, the ultimate tensile strains from both cyclic and monotonic tests were quite reasonable when compared with coupon test results, indicating that the two specimens both had flexural rupture failures in both cyclic and monotonic tests. 
Table 5.1 Test Matrix of Coupon Specimens

\begin{tabular}{|c|c|c|c|c|c|c|c|}
\hline $\begin{array}{l}\text { Specimen } \\
\text { Name }\end{array}$ & Manufacturer & Direction & Material & $\begin{array}{c}\text { Fiber } \\
\text { Architecture }\end{array}$ & $\begin{array}{l}\text { Number } \\
\text { of Plies }\end{array}$ & $\begin{array}{l}\text { Number of } \\
\text { Specimens }\end{array}$ & $\begin{array}{c}\text { No. of } \\
\text { Specimens } \\
\text { with Strain } \\
\text { Gauges }\end{array}$ \\
\hline CH-I & \multirow{8}{*}{ 3TEX Inc. } & \multirow{8}{*}{$\begin{array}{c}\text { Bi- } \\
\text { Directional }\end{array}$} & \multirow{4}{*}{ P3W-C1059 } & \multirow{2}{*}{$\begin{array}{l}\text { Hoop } \\
\text { (Warp) }\end{array}$} & $\mathrm{I}$ & 5 & 3 \\
\hline CH-II & & & & & II & 8 & 5 \\
\hline CL-I & & & & \multirow{2}{*}{$\begin{array}{l}\text { Longitudinal } \\
\text { (Fillet) }\end{array}$} & $\mathrm{I}$ & 5 & 0 \\
\hline CL-II & & & & & II & 5 & 5 \\
\hline GH-I & & & \multirow{4}{*}{ P3W-GE041 } & \multirow{2}{*}{$\begin{array}{l}\text { Hoop } \\
\text { (Warp) }\end{array}$} & $\mathrm{I}$ & 3 & 3 \\
\hline GH-III & & & & & III & 5 & 3 \\
\hline GL-I & & & & \multirow{2}{*}{$\begin{array}{c}\text { Longitudinal } \\
\text { (Fillet) }\end{array}$} & I & 8 & 3 \\
\hline GL-III & & & & & III & 8 & 8 \\
\hline HC-I & \multirow{4}{*}{ Sika Corp. } & \multirow{2}{*}{$\begin{array}{c}\text { Uni- } \\
\text { Directional }\end{array}$} & $\begin{array}{c}\text { SikaWrapHex } \\
103 \mathrm{C}\end{array}$ & $0^{\circ}$ & \multirow{2}{*}{ I } & 5 & 0 \\
\hline HG-I & & & $\begin{array}{c}\text { SikaWrapHex } \\
100 \mathrm{G}\end{array}$ & $0^{\circ}$ & & 5 & 0 \\
\hline HL-V & & \multirow{2}{*}{$\begin{array}{c}\text { Bi- } \\
\text { Directional }\end{array}$} & \multirow{2}{*}{$\begin{array}{c}\text { Hybrid of } \\
103 \mathrm{C} \text { and } \\
100 \mathrm{G}\end{array}$} & $\begin{array}{l}\mathrm{G} 90 / \mathrm{C} 0 / \mathrm{G} \\
90 / \mathrm{C} 0 / \mathrm{G} 90\end{array}$ & \multirow{2}{*}{ V } & 4 & 4 \\
\hline $\mathrm{HH}-\mathrm{V}$ & & & & $\begin{array}{l}\mathrm{G} 0 / \mathrm{C} 90 / \mathrm{G} \\
0 / \mathrm{C} 90 / \mathrm{G} 0\end{array}$ & & 4 & 4 \\
\hline
\end{tabular}


Table 5.2 Tensile Test Failure Codes (ASTM D 3039)

\begin{tabular}{|c|c|c|c|c|c|}
\hline \multicolumn{2}{|c|}{ First Character } & \multicolumn{2}{c|}{ Second Character } & \multicolumn{2}{c|}{ Third Character } \\
\hline Failure Type & Code & Failure Type & Code & Failure Type & Code \\
\hline Angled & A & Inside grip/tab & I & Bottom & B \\
\hline edge Delamination & D & At grip/tab & A & Top & T \\
\hline Grip/tap & G & $<1$ W from grip/tab & W & Left & L \\
\hline Lateral & L & Gauge & G & Right & R \\
\hline Multi-mode & $\mathrm{M}$ & Multiple areas & M & Middle & M \\
\hline longitudinal Splitting & $\mathrm{S}$ & Various & V & Various & V \\
\hline eXplosive & $\mathrm{X}$ & Unknown & U & Unknown & U \\
\hline Other & $\mathrm{O}$ & & & & \\
\hline
\end{tabular}

Table 5.3 Stress-Strain Data of CH Coupons

\begin{tabular}{|c|c|c|c|c|c|c|c|c|}
\hline $\begin{array}{l}\text { Specimen } \\
\text { Name }\end{array}$ & $\begin{array}{l}\text { Width } \\
\text { mm } \\
\text { (in.) }\end{array}$ & $\begin{array}{c}\text { Thickness } \\
\text { mm } \\
\text { (in.) }\end{array}$ & $\begin{array}{l}\text { Area } \\
\mathrm{mm}^{2} \\
\text { (in. }^{2} \text { ) }\end{array}$ & $\begin{array}{c}E \\
\mathrm{GPa} \\
(\mathrm{Msi})\end{array}$ & $\begin{array}{c}\text { Ultimate } \\
\text { Load } \\
\text { kN (kips) }\end{array}$ & $\begin{array}{l}\text { Ultimate } \\
\text { Strength } \\
\text { MPa (ksi) }\end{array}$ & $\begin{array}{l}\text { Ultimate } \\
\text { Strain }\end{array}$ & $\begin{array}{l}\text { Failure } \\
\text { Mode }\end{array}$ \\
\hline CH-I-1 & $\begin{array}{c}50.9 \\
(2.003)\end{array}$ & $\begin{array}{c}1.1^{*} \\
(0.043)\end{array}$ & $\begin{array}{c}55.6 \\
(0.086)\end{array}$ & $\begin{array}{l}35.2 \\
(5.1)\end{array}$ & $\begin{array}{l}21.4 \\
(4.8)\end{array}$ & $\begin{array}{c}385 \\
(55.8)\end{array}$ & 0.0112 & LGM \\
\hline CH-I-2 & $\begin{array}{c}52.8 \\
(2.079)\end{array}$ & $\begin{array}{c}1.1^{*} \\
(0.044)\end{array}$ & $\begin{array}{c}59.0 \\
(0.092)\end{array}$ & $\begin{array}{l}33.1 \\
(4.8)\end{array}$ & $\begin{array}{l}20.4 \\
(4.6)\end{array}$ & $\begin{array}{c}346 \\
(50.2)\end{array}$ & 0.0108 & LWV \\
\hline CH-I-3 & $\begin{array}{c}49.0 \\
(1.930)\end{array}$ & $\begin{array}{c}1.0^{*} \\
(0.040)\end{array}$ & $\begin{array}{c}49.8 \\
(0.077)\end{array}$ & $\begin{array}{l}34.5 \\
(5.0)\end{array}$ & $\begin{array}{l}19.2 \\
(4.3)\end{array}$ & $\begin{array}{c}385 \\
(55.8)\end{array}$ & 0.0112 & LWV \\
\hline CH-I-4 & $\begin{array}{c}53.8 \\
(2.120)\end{array}$ & $\begin{array}{c}1.1^{*} \\
(0.042)\end{array}$ & $\begin{array}{c}57.4 \\
(0.089)\end{array}$ & \multirow{2}{*}{ N/A } & $\begin{array}{l}20.9 \\
(4.7)\end{array}$ & $\begin{array}{c}363 \\
(52.7)\end{array}$ & \multirow{2}{*}{ N/A } & LWV \\
\hline CH-I-5 & $\begin{array}{c}45.0 \\
(1.770)\end{array}$ & $\begin{array}{c}1.1^{*} \\
(0.042)\end{array}$ & $\begin{array}{c}48.0 \\
(0.074)\end{array}$ & & $\begin{array}{l}17.4 \\
(3.9)\end{array}$ & $\begin{array}{c}364 \\
(52.7)\end{array}$ & & LWB \\
\hline CH-II-2 & $\begin{array}{c}51.6 \\
(2.033)\end{array}$ & $\begin{array}{c}2.0 * * \\
(0.079)\end{array}$ & $\begin{array}{c}103.6 \\
(0.161)\end{array}$ & $\begin{array}{l}38.6 \\
(5.6)\end{array}$ & $\begin{array}{l}37.0 \\
(8.3)\end{array}$ & $\begin{array}{c}357 \\
(51.8)\end{array}$ & 0.0097 & LWB \\
\hline CH-II-3 & $\begin{array}{c}58.1 \\
(2.288)\end{array}$ & $\begin{array}{c}2.1 * * \\
(0.081)\end{array}$ & $\begin{array}{c}119.6 \\
(0.185)\end{array}$ & $\begin{array}{l}36.5 \\
(5.3)\end{array}$ & $\begin{array}{l}42.3 \\
(9.5)\end{array}$ & $\begin{array}{c}353 \\
(51.3)\end{array}$ & 0.0095 & LVV \\
\hline CH-II-4 & $\begin{array}{c}49.8 \\
(1.960)\end{array}$ & $\begin{array}{c}2.2 * * \\
(0.087)\end{array}$ & $\begin{array}{c}110.0 \\
(0.171)\end{array}$ & $\begin{array}{l}33.8 \\
(4.9)\end{array}$ & $\begin{array}{l}39.6 \\
(8.9)\end{array}$ & $\begin{array}{c}360 \\
(52.2)\end{array}$ & 0.0108 & LVV \\
\hline CH-II-5 & $\begin{array}{c}52.5 \\
(2.065)\end{array}$ & $\begin{array}{c}2.1^{* *} \\
(0.081)\end{array}$ & $\begin{array}{c}107.9 \\
(0.167)\end{array}$ & $\begin{array}{l}40.0 \\
(5.8)\end{array}$ & $\begin{array}{l}39.0 \\
(8.8)\end{array}$ & $\begin{array}{c}361 \\
(52.4)\end{array}$ & 0.0090 & OIB \\
\hline CH-II-6 & $\begin{array}{c}56.7 \\
(2.233)\end{array}$ & $\begin{array}{c}2.1 * * \\
(0.082)\end{array}$ & $\begin{array}{c}118.1 \\
(0.183)\end{array}$ & \multirow{3}{*}{ N/A } & $\begin{array}{l}29.8 \\
(6.7)\end{array}$ & $\begin{array}{c}252 \\
(36.6)\end{array}$ & \multirow{3}{*}{ N/A } & LWT \\
\hline CH-II-7 & $\begin{array}{c}57.4 \\
(2.260)\end{array}$ & $\begin{array}{c}2.1^{* *} \\
(0.083)\end{array}$ & $\begin{array}{c}121.0 \\
(0.188)\end{array}$ & & $\begin{array}{l}42.3 \\
(9.5)\end{array}$ & $\begin{array}{c}350 \\
(50.7)\end{array}$ & & LGM \\
\hline CH-II-8 & $\begin{array}{c}58.2 \\
(2.290)\end{array}$ & $\begin{array}{c}2.1 * * \\
(0.083)\end{array}$ & $\begin{array}{c}122.6 \\
(0.190)\end{array}$ & & $\begin{array}{l}36.8 \\
(8.3)\end{array}$ & $\begin{array}{c}300 \\
(43.6)\end{array}$ & & OGM \\
\hline $\begin{array}{c}\text { Average o } \\
\text { Strain }\end{array}$ & $\begin{array}{l}\text { Jata with } \\
\text { quges }\end{array}$ & & & $\begin{array}{l}36.0 \\
(5.2)\end{array}$ & & $\begin{array}{c}364 \\
(52.8)\end{array}$ & 0.0103 & \\
\hline
\end{tabular}


* Average Thickness of One-Ply Coupons: $1.1 \mathrm{~mm}$ (0.042 in.)

** Average Thickness of Two-Ply Coupons: $2.1 \mathrm{~mm}$ (0.083 in.)

Table 5.4 Stress-Strain Data of CL Coupons

\begin{tabular}{|c|c|c|c|c|c|c|c|c|}
\hline $\begin{array}{l}\text { Specimen } \\
\text { Name }\end{array}$ & $\begin{array}{l}\text { Width } \\
\text { mm } \\
\text { (in.) }\end{array}$ & $\begin{array}{c}\text { Thickness } \\
\text { mm } \\
\text { (in.) }\end{array}$ & $\begin{array}{l}\text { Area } \\
\mathrm{mm}^{2} \\
\left(\text { in. }{ }^{2}\right)\end{array}$ & $\begin{array}{c}E \\
\mathrm{GPa} \\
(\mathrm{Msi})\end{array}$ & $\begin{array}{c}\text { Ultimate } \\
\text { Load } \\
\text { kN (kips) }\end{array}$ & $\begin{array}{l}\text { Ultimate } \\
\text { Strength } \\
\text { MPa (ksi) }\end{array}$ & $\begin{array}{l}\text { Ultimate } \\
\text { Strain }\end{array}$ & $\begin{array}{l}\text { Failure } \\
\text { Mode }\end{array}$ \\
\hline CL-I-1 & $\begin{array}{l}40.6 \\
(1.6) \\
\end{array}$ & $\begin{array}{c}1.1^{*} \\
(0.045) \\
\end{array}$ & $\begin{array}{c}46.5 \\
(0.072) \\
\end{array}$ & \multirow{5}{*}{ N/A } & $\begin{array}{c}5.0 \\
(1.1) \\
\end{array}$ & $\begin{array}{c}108 \\
(15.6) \\
\end{array}$ & \multirow{5}{*}{ N/A } & LWB \\
\hline CL-I-2 & $\begin{array}{l}40.6 \\
(1.6)\end{array}$ & $\begin{array}{c}1.1^{*} \\
(0.044)\end{array}$ & $\begin{array}{c}45.4 \\
(0.070)\end{array}$ & & $\begin{array}{c}4.5 \\
(1.0)\end{array}$ & $\begin{array}{c}99 \\
(14.4)\end{array}$ & & LAB \\
\hline CL-I-3 & $\begin{array}{l}45.7 \\
(1.8)\end{array}$ & $\begin{array}{c}1.2^{*} \\
(0.046)\end{array}$ & $\begin{array}{c}53.4 \\
(0.083)\end{array}$ & & $\begin{array}{c}6.7 \\
(6.7)\end{array}$ & $\begin{array}{c}125 \\
(80.8)\end{array}$ & & LIB \\
\hline CL-I-4 & $\begin{array}{l}40.6 \\
(1.6)\end{array}$ & $\begin{array}{c}1.2^{*} \\
(0.046)\end{array}$ & $\begin{array}{c}47.5 \\
(0.074)\end{array}$ & & $\begin{array}{c}5.5 \\
(1.2)\end{array}$ & $\begin{array}{c}116 \\
(16.8)\end{array}$ & & LIB \\
\hline CL-I-5 & $\begin{array}{l}43.2 \\
(1.7)\end{array}$ & $\begin{array}{c}1.1^{*} \\
(0.044)\end{array}$ & $\begin{array}{c}48.3 \\
(0.075)\end{array}$ & & $\begin{array}{c}5.4 \\
(1.2)\end{array}$ & $\begin{array}{c}112 \\
(16.2)\end{array}$ & & LWT \\
\hline CL-II-1 & $\begin{array}{l}43.2 \\
(1.7)\end{array}$ & $\begin{array}{c}2.3 * * \\
(0.090)\end{array}$ & $\begin{array}{c}98.7 \\
(0.153)\end{array}$ & $\begin{array}{l}18.6 \\
(2.7)\end{array}$ & $\begin{array}{l}10.5 \\
(2.4)\end{array}$ & $\begin{array}{c}106 \\
(15.4)\end{array}$ & 0.0057 & LAB \\
\hline CL-II-2 & $\begin{array}{l}45.7 \\
(1.8)\end{array}$ & $\begin{array}{c}2.4^{* *} \\
(0.095) \\
\end{array}$ & $\begin{array}{c}110.3 \\
(0.171)\end{array}$ & $\begin{array}{l}17.9 \\
(2.6)\end{array}$ & $\begin{array}{l}12.8 \\
(2.9) \\
\end{array}$ & $\begin{array}{c}116 \\
(16.8)\end{array}$ & 0.0065 & LGM \\
\hline CL-II-3 & $\begin{array}{l}45.7 \\
(1.8)\end{array}$ & $\begin{array}{c}2.4 * * \\
(0.096) \\
\end{array}$ & $\begin{array}{l}111.5 \\
(0.173)\end{array}$ & $\begin{array}{l}17.9 \\
(2.6)\end{array}$ & $\begin{array}{l}14.4 \\
(3.2) \\
\end{array}$ & $\begin{array}{c}129 \\
(18.8) \\
\end{array}$ & 0.0070 & LAB \\
\hline CL-II-4 & $\begin{array}{l}43.2 \\
(1.7)\end{array}$ & $\begin{array}{c}2.4 * * \\
(0.093)\end{array}$ & $\begin{array}{c}102.0 \\
(0.158)\end{array}$ & $\begin{array}{l}16.5 \\
(2.4)\end{array}$ & $\begin{array}{l}11.8 \\
(2.7)\end{array}$ & $\begin{array}{c}116 \\
(16.8)\end{array}$ & 0.0069 & LAB \\
\hline CL-II-5 & $\begin{array}{l}43.2 \\
(1.7)\end{array}$ & $\begin{array}{c}2.4 * * \\
(0.095)\end{array}$ & $\begin{array}{c}104.2 \\
(0.162)\end{array}$ & $\begin{array}{l}19.3 \\
(2.8)\end{array}$ & $\begin{array}{l}12.8 \\
(2.9)\end{array}$ & $\begin{array}{c}123 \\
(17.8)\end{array}$ & 0.0065 & LAT \\
\hline $\begin{array}{r}\text { Average } \\
\text { with Strai }\end{array}$ & $\begin{array}{l}\text { f Data } \\
\text { Gauges }\end{array}$ & & & $\begin{array}{l}18.1 \\
(2.6) \\
\end{array}$ & & $\begin{array}{c}118 \\
(17.1)\end{array}$ & 0.0065 & \\
\hline
\end{tabular}

* Average Thickness of One-Ply Coupons: $1.1 \mathrm{~mm}(0.045 \mathrm{in}$.)

** Average Thickness of Two-Ply Coupons: 2.4 mm (0.094 in.) 
Table 5.5 Stress-Strain Data of GH Coupons

\begin{tabular}{|c|c|c|c|c|c|c|c|c|}
\hline $\begin{array}{l}\text { Specimen } \\
\text { Name }\end{array}$ & $\begin{array}{l}\text { Width } \\
\text { mm } \\
\text { (in.) }\end{array}$ & $\begin{array}{c}\text { Thickness } \\
\text { mm } \\
\text { (in.) }\end{array}$ & $\begin{array}{l}\text { Area } \\
\mathrm{mm}^{2} \\
\text { (in. }^{2} \text { ) }\end{array}$ & $\begin{array}{c}E \\
\mathrm{GPa} \\
(\mathrm{Msi})\end{array}$ & $\begin{array}{l}\text { Ultimate } \\
\text { Load } \\
\text { kN (kips) }\end{array}$ & $\begin{array}{l}\text { Ultimate } \\
\text { Strength } \\
\text { MPa (ksi) }\end{array}$ & $\begin{array}{l}\text { Ultimate } \\
\text { Strain }\end{array}$ & $\begin{array}{l}\text { Failure } \\
\text { Mode }\end{array}$ \\
\hline GH-I-1 & $\begin{array}{l}53.3 \\
(2.1)\end{array}$ & $\begin{array}{c}2.7^{*} \\
(0.105)\end{array}$ & $\begin{array}{c}142.3 \\
(0.221) \\
\end{array}$ & $\begin{array}{l}17.2 \\
(2.5)\end{array}$ & $\begin{array}{l}33.5 \\
(7.5) \\
\end{array}$ & $\begin{array}{c}235 \\
(34.2)\end{array}$ & 0.0135 & LGM \\
\hline GH-I-2 & $\begin{array}{l}53.3 \\
(2.1) \\
\end{array}$ & $\begin{array}{c}2.8^{*} \\
(0.109) \\
\end{array}$ & $\begin{array}{c}147.7 \\
(0.229) \\
\end{array}$ & $\begin{array}{l}15.2 \\
(2.2) \\
\end{array}$ & $\begin{array}{l}34.7 \\
(7.8) \\
\end{array}$ & $\begin{array}{c}235 \\
(34.1) \\
\end{array}$ & 0.0153 & LGM \\
\hline GH-I-3 & $\begin{array}{l}50.8 \\
(2.0)\end{array}$ & $\begin{array}{c}2.7^{*} \\
(0.105)\end{array}$ & $\begin{array}{c}135.5 \\
(0.210)\end{array}$ & $\begin{array}{l}15.9 \\
(2.3)\end{array}$ & $\begin{array}{l}24.3 \\
(5.5)\end{array}$ & $\begin{array}{c}180 \\
(26.0)\end{array}$ & 0.0111 & OWT \\
\hline GH-III-1 & $\begin{array}{l}52.5 \\
(2.1)\end{array}$ & $\begin{array}{l}7.3^{* *} \\
(0.289)\end{array}$ & $\begin{array}{c}385.0 \\
(0.597)\end{array}$ & $\begin{array}{l}15.9 \\
(2.3)\end{array}$ & $\begin{array}{c}72.9 \\
(16.4)\end{array}$ & $\begin{array}{c}189 \\
(27.5)\end{array}$ & 0.0117 & LGM \\
\hline GH-III-2 & $\begin{array}{l}52.1 \\
(2.1)\end{array}$ & $\begin{array}{c}7.7 * * \\
(0.305) \\
\end{array}$ & $\begin{array}{c}403.4 \\
(0.625) \\
\end{array}$ & $\begin{array}{l}14.5 \\
(2.1) \\
\end{array}$ & $\begin{array}{c}83.3 \\
(18.7) \\
\end{array}$ & $\begin{array}{c}207 \\
(30.0) \\
\end{array}$ & 0.0142 & LWT \\
\hline GH-III-3 & $\begin{array}{l}53.3 \\
(2.1)\end{array}$ & $\begin{array}{c}7.6^{* *} \\
(0.300) \\
\end{array}$ & $\begin{array}{c}406.5 \\
(0.630) \\
\end{array}$ & $\begin{array}{l}15.9 \\
(2.3)\end{array}$ & $\begin{array}{c}82.3 \\
(18.5)\end{array}$ & $\begin{array}{c}202 \\
(29.4)\end{array}$ & 0.0128 & LWT \\
\hline GH-III-4 & $\begin{array}{l}50.8 \\
(2.0)\end{array}$ & $\begin{array}{c}7.1 * * \\
(0.280)\end{array}$ & $\begin{array}{c}361.3 \\
(0.560)\end{array}$ & \multirow{2}{*}{ N/A } & $\begin{array}{c}79.4 \\
(17.9)\end{array}$ & $\begin{array}{c}220 \\
(31.9)\end{array}$ & \multirow{2}{*}{ N/A } & LAB \\
\hline GH-III-5 & $\begin{array}{l}50.8 \\
(2.0)\end{array}$ & $\begin{array}{c}7.2 * * \\
(0.285) \\
\end{array}$ & $\begin{array}{c}367.7 \\
(0.570) \\
\end{array}$ & & $\begin{array}{c}90.3 \\
(20.3) \\
\end{array}$ & $\begin{array}{c}246 \\
(35.6) \\
\end{array}$ & & OAT \\
\hline $\begin{array}{r}\text { Average } \\
\text { with Strai }\end{array}$ & $\begin{array}{l}\text { Data } \\
\text { jauges }\end{array}$ & & & $\begin{array}{l}15.7 \\
(2.3) \\
\end{array}$ & & $\begin{array}{c}208 \\
(30.2)\end{array}$ & 0.0131 & \\
\hline
\end{tabular}

* Average Thickness of One-Ply Coupons: $2.7 \mathrm{~mm}$ (0.106 in.)

** Average Thickness of Three-Ply Coupons: 7.4 mm (0.292 in.) 
Table 5.6 Stress-Strain Data of GL Coupons

\begin{tabular}{|c|c|c|c|c|c|c|c|c|}
\hline $\begin{array}{l}\text { Specimen } \\
\text { Name }\end{array}$ & $\begin{array}{l}\text { Width } \\
\text { mm } \\
\text { (in.) }\end{array}$ & $\begin{array}{c}\text { Thickness } \\
\text { mm } \\
\text { (in.) }\end{array}$ & $\begin{array}{l}\text { Area } \\
\mathrm{mm}^{2} \\
\left(\text { in. }^{2}\right)\end{array}$ & $\begin{array}{c}E \\
\mathrm{GPa} \\
(\mathrm{Msi}) \\
\end{array}$ & $\begin{array}{c}\text { Ultimate } \\
\text { Load } \\
\text { kN (kips) }\end{array}$ & $\begin{array}{c}\text { Ultimate } \\
\text { Strength } \\
\text { MPa (ksi) }\end{array}$ & $\begin{array}{l}\text { Ultimate } \\
\text { Strain }\end{array}$ & $\begin{array}{l}\text { Failure } \\
\text { Mode }\end{array}$ \\
\hline GL-I-1 & $\begin{array}{l}45.7 \\
(1.8) \\
\end{array}$ & $\begin{array}{c}2.8^{*} \\
(0.112)\end{array}$ & $\begin{array}{c}130.1 \\
(0.202)\end{array}$ & $\begin{array}{l}28.3 \\
(4.1) \\
\end{array}$ & $\begin{array}{l}25.0 \\
(5.6) \\
\end{array}$ & $\begin{array}{c}192 \\
(27.9)\end{array}$ & N/A & AAT \\
\hline GL-I-2 & $\begin{array}{l}43.2 \\
(1.7)\end{array}$ & $\begin{array}{c}3.0^{*} \\
(0.119)\end{array}$ & $\begin{array}{c}130.5 \\
(0.202)\end{array}$ & $\begin{array}{l}15.2 \\
(2.2)\end{array}$ & $\begin{array}{l}22.1 \\
(5.0)\end{array}$ & $\begin{array}{c}169 \\
(24.6)\end{array}$ & 0.0109 & $\mathrm{OAB}$ \\
\hline GL-I-3 & $\begin{array}{l}38.1 \\
(1.5)\end{array}$ & $\begin{array}{c}2.7^{*} \\
(0.105)\end{array}$ & $\begin{array}{c}101.6 \\
(0.158)\end{array}$ & $\begin{array}{l}17.2 \\
(2.5) \\
\end{array}$ & $\begin{array}{l}23.2 \\
(5.2) \\
\end{array}$ & $\begin{array}{c}228 \\
(33.1)\end{array}$ & 0.0130 & LAB \\
\hline GL-III-1 & $\begin{array}{l}54.5 \\
(2.1)\end{array}$ & $\begin{array}{l}7.0^{* * *} \\
(0.275)\end{array}$ & $\begin{array}{c}380.6 \\
(0.590)\end{array}$ & $\begin{array}{l}21.4 \\
(3.1)\end{array}$ & $\begin{array}{c}86.1 \\
(19.4)\end{array}$ & $\begin{array}{c}226 \\
(32.8)\end{array}$ & \multirow{8}{*}{ N/A } & LGM \\
\hline GL-III-2 & $\begin{array}{l}50.1 \\
(2.0)\end{array}$ & $\begin{array}{l}7.0^{* * *} \\
(0.275)\end{array}$ & $\begin{array}{c}349.9 \\
(0.542)\end{array}$ & $\begin{array}{l}26.9 \\
(3.9)\end{array}$ & $\begin{array}{c}71.6 \\
(16.1)\end{array}$ & $\begin{array}{c}205 \\
(29.7)\end{array}$ & & LGM \\
\hline GL-III-3 & $\begin{array}{l}46.3 \\
(1.8)\end{array}$ & $\begin{array}{l}7.1^{* *} \\
(0.275)\end{array}$ & $\begin{array}{c}328.0 \\
(0.508)\end{array}$ & $\begin{array}{l}26.2 \\
(3.8)\end{array}$ & $\begin{array}{c}65.8 \\
(14.8)\end{array}$ & $\begin{array}{c}201 \\
(29.1)\end{array}$ & & LIT \\
\hline GL-I-1' & $\begin{array}{l}42.7 \\
(1.7)\end{array}$ & $\begin{array}{c}2.7^{*} \\
(0.105)\end{array}$ & $\begin{array}{c}113.8 \\
(0.176)\end{array}$ & \multirow{5}{*}{ N/A } & $\begin{array}{l}20.9 \\
(4.7)\end{array}$ & $\begin{array}{c}183 \\
(26.6)\end{array}$ & & LAT \\
\hline GL-I-2' & $\begin{array}{l}43.2 \\
(1.7) \\
\end{array}$ & $\begin{array}{c}2.5^{*} \\
(0.100)\end{array}$ & $\begin{array}{c}109.7 \\
(0.170)\end{array}$ & & $\begin{array}{l}20.0 \\
(4.5) \\
\end{array}$ & $\begin{array}{c}182 \\
(26.5)\end{array}$ & & LAB \\
\hline GL-I-3' & $\begin{array}{l}43.7 \\
(1.7)\end{array}$ & $\begin{array}{c}2.7^{*} \\
(0.105)\end{array}$ & $\begin{array}{c}116.5 \\
(0.181)\end{array}$ & & $\begin{array}{l}21.4 \\
(4.8) \\
\end{array}$ & $\begin{array}{c}184 \\
(26.7)\end{array}$ & & LAB \\
\hline GL-I-4' & $\begin{array}{l}43.2 \\
(1.7)\end{array}$ & $\begin{array}{c}2.5^{*} \\
(0.100)\end{array}$ & $\begin{array}{c}109.7 \\
(0.170)\end{array}$ & & $\begin{array}{l}26.7 \\
(6.0)\end{array}$ & $\begin{array}{c}244 \\
(35.4)\end{array}$ & & LGM \\
\hline GL-I-5’ & $\begin{array}{l}43.2 \\
(1.7)\end{array}$ & $\begin{array}{c}2.5^{*} \\
(0.100)\end{array}$ & $\begin{array}{c}109.7 \\
(0.170)\end{array}$ & & $\begin{array}{l}25.4 \\
(5.7)\end{array}$ & $\begin{array}{c}231 \\
(33.5)\end{array}$ & & LAT \\
\hline GL-III-1' & $\begin{array}{l}48.3 \\
(1.9)\end{array}$ & $\begin{array}{c}7.0^{* * *} \\
(0.275)\end{array}$ & $\begin{array}{c}337.1 \\
(0.523)\end{array}$ & $\begin{array}{l}14.5 \\
(2.1)\end{array}$ & $\begin{array}{c}63.1 \\
(14.2)\end{array}$ & $\begin{array}{c}187 \\
(27.2)\end{array}$ & 0.0128 & LGM \\
\hline GL-III-2' & $\begin{array}{l}45.7 \\
(1.8)\end{array}$ & $\begin{array}{c}7.0^{* *} \\
(0.275)\end{array}$ & $\begin{array}{c}319.4 \\
(0.495)\end{array}$ & $\begin{array}{l}15.2 \\
(2.2)\end{array}$ & $\begin{array}{c}58.1 \\
(13.1)\end{array}$ & $\begin{array}{c}182 \\
(26.4)\end{array}$ & 0.0121 & LAT \\
\hline GL-III-3' & $\begin{array}{l}40.6 \\
(1.6)\end{array}$ & $\begin{array}{l}7.6^{* *} \\
(0.300)\end{array}$ & $\begin{array}{c}309.7 \\
(0.480)\end{array}$ & $\begin{array}{l}15.9 \\
(2.3)\end{array}$ & $\begin{array}{c}59.9 \\
(13.5)\end{array}$ & $\begin{array}{c}193 \\
(28.0)\end{array}$ & 0.0118 & LAB \\
\hline GL-III-4' & $\begin{array}{l}43.2 \\
(1.7) \\
\end{array}$ & $\begin{array}{c}7.6^{* *} \\
(0.300) \\
\end{array}$ & $\begin{array}{c}329.0 \\
(0.510) \\
\end{array}$ & $\begin{array}{l}15.9 \\
(2.3) \\
\end{array}$ & $\begin{array}{c}65.9 \\
(14.8) \\
\end{array}$ & $\begin{array}{c}200 \\
(29.1) \\
\end{array}$ & 0.0123 & LIB \\
\hline GL-III-5' & $\begin{array}{l}43.2 \\
(1.7)\end{array}$ & $\begin{array}{c}7.6^{* *} \\
(0.300)\end{array}$ & $\begin{array}{c}329.0 \\
(0.510)\end{array}$ & $\begin{array}{l}15.9 \\
(2.3)\end{array}$ & $\begin{array}{c}65.2 \\
(14.7)\end{array}$ & $\begin{array}{c}198 \\
(28.7)\end{array}$ & 0.0124 & LAB \\
\hline $\begin{array}{r}\text { Average } \\
\text { with Stra }\end{array}$ & $\begin{array}{l}\text { f Data } \\
\text { Gauges }\end{array}$ & & & $\begin{array}{l}15.6 \\
(2.3)\end{array}$ & & $\begin{array}{c}194 \\
(28.1)\end{array}$ & 0.0122 & \\
\hline
\end{tabular}

* Average Thickness of One-Ply Coupons: $2.7 \mathrm{~mm}$ (0.106 in.)

** Average Thickness of Three-Ply Coupons: $7.2 \mathrm{~mm}$ (0.284 in.) 
Table 5.7 Stress-Strain Data of HC Coupons

\begin{tabular}{|c|c|c|c|c|c|c|c|c|}
\hline $\begin{array}{l}\text { Specimen } \\
\text { Name }\end{array}$ & $\begin{array}{l}\text { Width } \\
\text { mm } \\
\text { (in.) }\end{array}$ & $\begin{array}{c}\text { Thickness } \\
\text { mm } \\
\text { (in.) }\end{array}$ & $\begin{array}{l}\text { Area } \\
\mathrm{mm}^{2} \\
\text { (in. }{ }^{2} \text { ) }\end{array}$ & $\begin{array}{c}E \\
\mathrm{GPa} \\
(\mathrm{Msi})\end{array}$ & $\begin{array}{c}\text { Ultimate } \\
\text { Load } \\
\text { kN (kips) }\end{array}$ & $\begin{array}{l}\text { Ultimate } \\
\text { Strength } \\
\text { MPa (ksi) }\end{array}$ & $\begin{array}{l}\text { Ultimate } \\
\text { Strain }\end{array}$ & $\begin{array}{l}\text { Failure } \\
\text { Mode }\end{array}$ \\
\hline HC-I-1 & $\begin{array}{c}51.4 \\
(2.025)\end{array}$ & $\begin{array}{c}1.9 \\
(0.074)\end{array}$ & $\begin{array}{c}96.0 \\
(0.149)\end{array}$ & \multirow{5}{*}{ N/A } & $\begin{array}{c}48.2 \\
(10.8)\end{array}$ & $\begin{array}{c}502 \\
(72.8)\end{array}$ & \multirow{5}{*}{ N/A } & LGM \\
\hline HC-I-2 & $\begin{array}{c}51.3 \\
(2.020)\end{array}$ & $\begin{array}{c}1.7 \\
(0.065) \\
\end{array}$ & $\begin{array}{c}84.7 \\
(0.131) \\
\end{array}$ & & $\begin{array}{l}42.9 \\
(9.7) \\
\end{array}$ & $\begin{array}{c}507 \\
(73.5) \\
\end{array}$ & & \multirow{4}{*}{ SGM } \\
\hline HC-I-3 & $\begin{array}{c}51.7 \\
(2.035) \\
\end{array}$ & $\begin{array}{c}1.7 \\
(0.065) \\
\end{array}$ & $\begin{array}{c}85.3 \\
(0.132) \\
\end{array}$ & & $\begin{array}{l}43.0 \\
(9.7) \\
\end{array}$ & $\begin{array}{c}504 \\
(73.1) \\
\end{array}$ & & \\
\hline HC-I-4 & $\begin{array}{c}54.6 \\
(2.150)\end{array}$ & $\begin{array}{c}1.8 \\
(0.070)\end{array}$ & $\begin{array}{c}97.1 \\
(0.151)\end{array}$ & & $\begin{array}{c}49.2 \\
(11.1)\end{array}$ & $\begin{array}{c}507 \\
(73.6)\end{array}$ & & \\
\hline HC-I-5 & $\begin{array}{c}52.7 \\
(2.075)\end{array}$ & $\begin{array}{c}1.7 \\
(0.065)\end{array}$ & $\begin{array}{c}87.0 \\
(0.135)\end{array}$ & & $\begin{array}{c}44.8 \\
(10.1)\end{array}$ & $\begin{array}{c}515 \\
(74.7)\end{array}$ & & \\
\hline Average & & $\begin{array}{c}1.7 \\
(0.068)\end{array}$ & & & & $\begin{array}{c}507 \\
(73.5) \\
\end{array}$ & & \\
\hline
\end{tabular}

Table 5.8 Stress-Strain Data of HG Coupons

\begin{tabular}{|c|c|c|c|c|c|c|c|c|}
\hline $\begin{array}{l}\text { Specimen } \\
\text { Name }\end{array}$ & $\begin{array}{l}\text { Width } \\
\text { mm } \\
\text { (in.) }\end{array}$ & $\begin{array}{l}\text { Thickness } \\
\text { mm } \\
\text { (in.) }\end{array}$ & $\begin{array}{l}\text { Area } \\
\mathrm{mm}^{2} \\
\text { (in. }{ }^{2} \text { ) }\end{array}$ & $\begin{array}{c}E \\
\mathrm{GPa} \\
(\mathrm{Msi})\end{array}$ & $\begin{array}{l}\text { Ultimate } \\
\text { Load } \\
\text { kN (kips) }\end{array}$ & $\begin{array}{l}\text { Ultimate } \\
\text { Strength } \\
\text { MPa (ksi) }\end{array}$ & $\begin{array}{l}\text { Ultimate } \\
\text { Strain }\end{array}$ & $\begin{array}{l}\text { Failure } \\
\text { Mode }\end{array}$ \\
\hline HG-I-1 & $\begin{array}{c}52.1 \\
(2.051) \\
\end{array}$ & $\begin{array}{c}1.8 \\
(0.073)\end{array}$ & $\begin{array}{c}95.9 \\
(0.149)\end{array}$ & \multirow{5}{*}{ N/A } & $\begin{array}{l}32.4 \\
(7.3)\end{array}$ & $\begin{array}{c}338 \\
(49.0)\end{array}$ & \multirow{5}{*}{ N/A } & \multirow{5}{*}{ SGM } \\
\hline HG-I-2 & $\begin{array}{c}53.3 \\
(2.100)\end{array}$ & $\begin{array}{c}1.8 \\
(0.073)\end{array}$ & $\begin{array}{c}98.2 \\
(0.152)\end{array}$ & & $\begin{array}{l}35.2 \\
(7.9)\end{array}$ & $\begin{array}{c}359 \\
(52.0)\end{array}$ & & \\
\hline HG-I-3 & $\begin{array}{c}49.5 \\
(1.950)\end{array}$ & $\begin{array}{c}1.8 \\
(0.070)\end{array}$ & $\begin{array}{c}88.1 \\
(0.137)\end{array}$ & & $\begin{array}{l}28.0 \\
(6.3)\end{array}$ & $\begin{array}{c}318 \\
(46.2)\end{array}$ & & \\
\hline HG-I-4 & $\begin{array}{c}56.9 \\
(2.238)\end{array}$ & $\begin{array}{c}1.8 \\
(0.070)\end{array}$ & $\begin{array}{c}101.1 \\
(0.157)\end{array}$ & & $\begin{array}{l}32.1 \\
(7.2)\end{array}$ & $\begin{array}{c}317 \\
(46.0)\end{array}$ & & \\
\hline HG-I-5 & $\begin{array}{c}54.2 \\
(2.135)\end{array}$ & $\begin{array}{c}1.8 \\
(0.070)\end{array}$ & $\begin{array}{c}96.4 \\
(0.150)\end{array}$ & & $\begin{array}{l}32.7 \\
(7.4)\end{array}$ & $\begin{array}{c}339 \\
(49.2)\end{array}$ & & \\
\hline Average & & $\begin{array}{c}1.8 \\
(0.071)\end{array}$ & & & & $\begin{array}{c}334 \\
(48.5)\end{array}$ & & \\
\hline
\end{tabular}


Table 5.9 Stress-Strain Data of HH Coupons

\begin{tabular}{|c|c|c|c|c|c|c|c|c|}
\hline $\begin{array}{c}\text { Specimen } \\
\text { Name }\end{array}$ & $\begin{array}{l}\text { Width } \\
\text { mm } \\
\text { (in.) }\end{array}$ & $\begin{array}{c}\text { Thickness } \\
\text { mm } \\
\text { (in.) }\end{array}$ & $\begin{array}{l}\text { Area } \\
\text { mm }^{2} \\
\text { (in. }{ }^{2} \text { ) }\end{array}$ & $\begin{array}{c}E \\
\mathrm{GPa} \\
(\mathrm{Msi}) \\
\end{array}$ & $\begin{array}{l}\text { Ultimate } \\
\text { Load } \\
\text { kN (kips) }\end{array}$ & $\begin{array}{l}\text { Ultimate } \\
\text { Strength } \\
\text { MPa (ksi) }\end{array}$ & $\begin{array}{c}\text { Ultimate } \\
\text { Strain }\end{array}$ & $\begin{array}{c}\text { Failure } \\
\text { Mode }\end{array}$ \\
\hline HH-V-1 & $\begin{array}{c}53.3 \\
(2.100)\end{array}$ & $\begin{array}{c}6.4 \\
(0.250) \\
\end{array}$ & $\begin{array}{c}338.7 \\
(0.525) \\
\end{array}$ & $\begin{array}{l}17.2 \\
(2.5) \\
\end{array}$ & $\begin{array}{c}92.1 \\
(20.7)\end{array}$ & $\begin{array}{c}272 \\
(39.4)\end{array}$ & 0.0102 & \multirow{3}{*}{ LAT } \\
\hline HH-V-2 & $\begin{array}{c}49.5 \\
(1.950) \\
\end{array}$ & $\begin{array}{c}6.4 \\
(0.250) \\
\end{array}$ & $\begin{array}{c}314.5 \\
(0.488) \\
\end{array}$ & $\begin{array}{l}18.6 \\
(2.7) \\
\end{array}$ & $\begin{array}{c}78.3 \\
(17.6) \\
\end{array}$ & $\begin{array}{c}249 \\
(36.1) \\
\end{array}$ & 0.0096 & \\
\hline HH-V-3 & $\begin{array}{c}49.8 \\
(1.960)\end{array}$ & $\begin{array}{c}6.6 \\
(0.260) \\
\end{array}$ & $\begin{array}{c}328.8 \\
(0.510)\end{array}$ & $\begin{array}{l}18.6 \\
(2.7) \\
\end{array}$ & $\begin{array}{c}89.8 \\
(20.2)\end{array}$ & $\begin{array}{c}273 \\
(39.6)\end{array}$ & 0.0101 & \\
\hline HH-V-4 & $\begin{array}{c}51.3 \\
(2.020)\end{array}$ & $\begin{array}{c}6.6 \\
(0.260)\end{array}$ & $\begin{array}{c}338.8 \\
(0.525)\end{array}$ & $\begin{array}{l}14.5 \\
(2.1)\end{array}$ & $\begin{array}{c}95.6 \\
(21.5)\end{array}$ & $\begin{array}{c}282 \\
(40.9)\end{array}$ & 0.0146 & LGM \\
\hline Average & & $\begin{array}{c}6.5 \\
(0.255) \\
\end{array}$ & & $\begin{array}{l}17.2 \\
(2.5) \\
\end{array}$ & & $\begin{array}{c}269 \\
(39.0)\end{array}$ & 0.0111 & \\
\hline
\end{tabular}

Table 5.10 Stress-Strain Data of HL Coupons

\begin{tabular}{|c|c|c|c|c|c|c|c|c|}
\hline $\begin{array}{l}\text { Specimen } \\
\text { Name }\end{array}$ & $\begin{array}{l}\text { Width } \\
\text { mm } \\
\text { (in.) }\end{array}$ & $\begin{array}{c}\text { Thickness } \\
\text { mm } \\
\text { (in.) }\end{array}$ & $\begin{array}{l}\text { Area } \\
\mathrm{mm}^{2} \\
\text { (in. }{ }^{2} \text { ) }\end{array}$ & $\begin{array}{c}E \\
\text { GPa } \\
(\mathrm{Msi}) \\
\end{array}$ & $\begin{array}{c}\text { Ultimate } \\
\text { Load } \\
\text { kN (kips) }\end{array}$ & $\begin{array}{c}\text { Ultimate } \\
\text { Strength } \\
\text { MPa (ksi) }\end{array}$ & $\begin{array}{l}\text { Ultimate } \\
\text { Strain }\end{array}$ & $\begin{array}{l}\text { Failure } \\
\text { Mode }\end{array}$ \\
\hline HL-V-1 & $\begin{array}{c}52.0 \\
(2.047)\end{array}$ & $\begin{array}{c}7.1 \\
(0.278)\end{array}$ & $\begin{array}{c}367.1 \\
(0.569)\end{array}$ & $\begin{array}{l}33.1 \\
(4.8)\end{array}$ & $\begin{array}{c}98.7 \\
(22.2)\end{array}$ & $\begin{array}{c}269 \\
(39.0)\end{array}$ & 0.0079 & LGM \\
\hline HL-V-2 & $\begin{array}{c}53.3 \\
(2.100)\end{array}$ & $\begin{array}{c}6.6 \\
(0.260) \\
\end{array}$ & $\begin{array}{c}352.3 \\
(0.546) \\
\end{array}$ & $\begin{array}{l}37.2 \\
(5.4) \\
\end{array}$ & $\begin{array}{c}80.0 \\
(18.0)\end{array}$ & $\begin{array}{c}227 \\
(32.9) \\
\end{array}$ & 0.0061 & \multirow{2}{*}{ LWB } \\
\hline HL-V-3 & $\begin{array}{c}52.3 \\
(2.060) \\
\end{array}$ & $\begin{array}{c}7.0 \\
(0.275) \\
\end{array}$ & $\begin{array}{c}365.5 \\
(0.567) \\
\end{array}$ & $\begin{array}{l}38.6 \\
(5.6) \\
\end{array}$ & $\begin{array}{c}93.9 \\
(21.1) \\
\end{array}$ & $\begin{array}{c}257 \\
(37.2) \\
\end{array}$ & 0.0068 & \\
\hline HL-V-4 & $\begin{array}{c}51.8 \\
(2.040) \\
\end{array}$ & $\begin{array}{c}7.0 \\
(0.275) \\
\end{array}$ & $\begin{array}{c}361.9 \\
(0.561) \\
\end{array}$ & $\begin{array}{l}26.2 \\
(3.8) \\
\end{array}$ & $\begin{array}{c}88.6 \\
(19.9) \\
\end{array}$ & $\begin{array}{c}245 \\
(35.5) \\
\end{array}$ & 0.0093 & LGM \\
\hline Average & & $\begin{array}{c}6.9 \\
(0.272)\end{array}$ & & $\begin{array}{l}33.8 \\
(4.9)\end{array}$ & & $\begin{array}{c}249 \\
(36.2)\end{array}$ & 0.0075 & \\
\hline
\end{tabular}


Table 5.11 Manufacturer Data for Tensile Properties of FRP Materials

\begin{tabular}{|c|c|c|c|c|c|c|c|c|}
\hline $\begin{array}{c}\text { FRP } \\
\text { Product }\end{array}$ & $\begin{array}{l}\text { Material } \\
\text { Source }\end{array}$ & $\begin{array}{l}\text { Associated } \\
\text { CFFT } \\
\text { Specimen }\end{array}$ & $\begin{array}{c}\text { Associated } \\
\text { Coupons }\end{array}$ & $\begin{array}{c}\text { Fiber } \\
\text { Direction }\end{array}$ & $\begin{array}{l}\text { Modulus } \\
\text { of } \\
\text { Elasticity } \\
\text { GPa } \\
\text { (Msi) }\end{array}$ & $\begin{array}{l}\text { Ultimate } \\
\text { Strength } \\
\mathrm{MPa} \\
(\mathrm{ksi})\end{array}$ & $\begin{array}{l}\text { Nominal } \\
\text { Ply } \\
\text { Thick- } \\
\text { ness } \\
\text { Mm } \\
\text { (in.) }\end{array}$ & $\begin{array}{c}\text { Test } \\
\text { Method }\end{array}$ \\
\hline $\begin{array}{c}\text { Red } \\
\text { Thread II } \\
\text { Pipe }\end{array}$ & $\begin{array}{l}\text { Smith } \\
\text { Fiber- } \\
\text { glass }\end{array}$ & $\begin{array}{c}\text { Specimen } \\
\text { Y }\end{array}$ & N/A & $\begin{array}{c}17 \\
\text { Layers } \\
\text { of } \pm 55^{\circ} \\
\text { E-Glass }\end{array}$ & $\begin{array}{l}15.0 \\
(2.2)\end{array}$ & $\begin{array}{l}159 \\
(23)\end{array}$ & $\begin{array}{c}5.5 \\
(0.216)\end{array}$ & $\begin{array}{l}\text { ASTM } \\
\text { D } 2925\end{array}$ \\
\hline \multirow{2}{*}{$\begin{array}{l}\text { P3W- } \\
\text { GE041 }\end{array}$} & \multirow{2}{*}{$\begin{array}{l}\text { 3TEX, } \\
\text { Inc. }\end{array}$} & \multirow{2}{*}{$\begin{array}{c}\text { Specimen } \\
\text { G }\end{array}$} & GH & Warp & $\begin{array}{l}24.3 \\
(3.5)\end{array}$ & $\begin{array}{l}436 \\
(63)\end{array}$ & \multirow{2}{*}{$\begin{array}{c}2.0 \\
(0.08)\end{array}$} & \multirow{2}{*}{$\begin{array}{l}\text { ASTM } \\
\text { D } 638\end{array}$} \\
\hline & & & GL & Fillet & $\begin{array}{l}25.2 \\
(3.7)\end{array}$ & $\begin{array}{l}436 \\
(63)\end{array}$ & & \\
\hline \multirow{2}{*}{$\begin{array}{c}\text { SikaWrap } \\
\text { Hex } \\
103 \mathrm{C}\end{array}$} & \multirow{4}{*}{$\begin{array}{l}\text { Sika } \\
\text { Corp. }\end{array}$} & \multirow{4}{*}{$\begin{array}{c}\text { Specimen } \\
\mathrm{H}\end{array}$} & $\mathrm{HC}, \mathrm{HL}$ & $0^{\circ}$ & $\begin{array}{c}70.6 \\
(10.2)\end{array}$ & $\begin{array}{c}849 \\
(123)\end{array}$ & \multirow{4}{*}{$\begin{array}{c}1.0 \\
(0.04)\end{array}$} & \multirow{4}{*}{$\begin{array}{l}\text { ASTM } \\
\text { D } 3039\end{array}$} \\
\hline & & & $\mathrm{HH}$ & $90^{\circ}$ & $\begin{array}{c}5.0 \\
(0.7)\end{array}$ & $\begin{array}{c}24 \\
(3.5)\end{array}$ & & \\
\hline \multirow{2}{*}{$\begin{array}{c}\text { SikaWrap } \\
\text { Hex } \\
100 \mathrm{G}\end{array}$} & & & $\mathrm{HG}, \mathrm{HH}$ & $0^{\circ}$ & $\begin{array}{l}26.1 \\
(3.8)\end{array}$ & $\begin{array}{l}612 \\
(89)\end{array}$ & & \\
\hline & & & HL & $90^{\circ}$ & $\begin{array}{c}6.7 \\
(1.0)\end{array}$ & $\begin{array}{c}30 \\
(4.4)\end{array}$ & & \\
\hline
\end{tabular}

Table 5.12 Manufacturer Data for Resins

\begin{tabular}{|c|c|c|c|c|c|c|}
\hline Product & Resin Type & Manufacturer & $\begin{array}{l}\text { Modulus } \\
\text { of } \\
\text { Elasticity } \\
\text { GPa } \\
\text { (Msi) }\end{array}$ & $\begin{array}{c}\text { Ultimate } \\
\text { Strength } \\
\mathrm{MPa} \\
(\mathrm{ksi})\end{array}$ & $\begin{array}{l}\text { Tensile } \\
\text { Elongation } \\
\text { at Break }\end{array}$ & $\begin{array}{c}\text { Test } \\
\text { Method }\end{array}$ \\
\hline Hydrex 100 & Vinyl ester & Reichhold Inc. & $\begin{array}{c}3.6 \\
(0.5) \\
\end{array}$ & $\begin{array}{c}79 \\
(11.5)\end{array}$ & $3.4 \%$ & \multirow{2}{*}{$\begin{array}{r}\text { ASTM } \\
\text { D } 638\end{array}$} \\
\hline Sikadur 300 & Epoxy & Sika Corp. & $\begin{array}{c}1.7 \\
(0.25)\end{array}$ & $\begin{array}{l}55 \\
(8)\end{array}$ & $3.0 \%$ & \\
\hline
\end{tabular}


Table 5.13 Comparison with Manufacturer Data for GH Coupons

\begin{tabular}{|c|c|c|c|c|c|c|c|c|}
\hline Items & $\begin{array}{c}\text { Modulus } \\
\text { of } \\
\text { Elasticity } \\
\text { GPa } \\
\text { (Msi) }\end{array}$ & $\begin{array}{c}\text { Ultimate } \\
\text { Strength } \\
\mathrm{MPa} \\
(\mathrm{ksi})\end{array}$ & $\begin{array}{l}\text { Ultimate } \\
\text { Strain }\end{array}$ & \multicolumn{5}{|c|}{ Adjustment Factors Calculations } \\
\hline $\begin{array}{c}\text { Coupon } \\
\text { Tests Results }\end{array}$ & $\begin{array}{l}15.7 \\
(2.3)\end{array}$ & $\begin{array}{c}208 \\
(30.2)\end{array}$ & 0.0131 & Resource & $\begin{array}{l}\text { Thickness } \\
\text { mm (in.) }\end{array}$ & Resin & $\begin{array}{c}\mathrm{E} \\
\mathrm{GPa} \\
(\mathrm{Msi})\end{array}$ & $\begin{array}{c}\sigma \\
\mathrm{MPa} \\
(\mathrm{ksi})\end{array}$ \\
\hline $\begin{array}{c}\text { Manufacturer } \\
\text { Data }\end{array}$ & $\begin{array}{l}24.3 \\
(3.5)\end{array}$ & $\begin{array}{l}436 \\
(63)\end{array}$ & N/A & $\begin{array}{c}\text { Coupon } \\
\text { Tests }\end{array}$ & $\begin{array}{c}7.4 \\
(0.292)\end{array}$ & $\begin{array}{c}\text { Sikadur } \\
300\end{array}$ & $\begin{array}{c}1.7 \\
(0.25)\end{array}$ & $\begin{array}{l}55 \\
(8)\end{array}$ \\
\hline $\begin{array}{c}\text { Adjusted } \\
\text { Manufacturer } \\
\text { Data }\end{array}$ & $\begin{array}{c}14.1 \\
=24.3 * K_{2} \\
(2.0)\end{array}$ & $\begin{aligned} & 208 \\
= & 436 * K \\
& (30.2)\end{aligned}$ & $\begin{array}{c}0.0147 \\
= \\
0.208 / 14.1\end{array}$ & $\begin{array}{l}\text { Manu- } \\
\text { facturer }\end{array}$ & $\begin{array}{c}6.0=3 * 2.0 \\
(0.24)\end{array}$ & $\begin{array}{l}\text { Hydrex } \\
100\end{array}$ & $\begin{array}{c}3.6 \\
(0.5)\end{array}$ & $\begin{array}{c}79 \\
(11.5)\end{array}$ \\
\hline Difference & $11.90 \%$ & $0.28 \%$ & $-12.63 \%$ & & $\begin{array}{r}K_{I}=6 \\
K_{2}=\sqrt{\frac{1.7}{3.6}} \\
K=K_{1}\end{array}$ & $\begin{array}{l}\begin{array}{l}7.4=0.82 \\
\times \sqrt{\frac{55}{79}}\end{array}= \\
K_{2}=0.47\end{array}$ & & \\
\hline
\end{tabular}

Table 5.14 Comparison with Manufacturer Data for GL Coupons

\begin{tabular}{|c|c|c|c|c|c|c|c|c|}
\hline Items & $\begin{array}{l}\text { Modulus } \\
\text { of } \\
\text { Elasticity }\end{array}$ & $\begin{array}{l}\text { Ultimate } \\
\text { Strength }\end{array}$ & $\begin{array}{l}\text { Ultimate } \\
\text { Strain }\end{array}$ & \multicolumn{5}{|c|}{ Adjustment Factors Calculation } \\
\hline $\begin{array}{c}\text { Coupon } \\
\text { Tests Results }\end{array}$ & $\begin{array}{l}15.6 \\
(2.3)\end{array}$ & $\begin{array}{c}194 \\
(28.1)\end{array}$ & 0.0122 & Resource & $\begin{array}{l}\text { Thickness } \\
\text { mm (in.) }\end{array}$ & Resin & $\begin{array}{c}\mathrm{E} \\
\mathrm{GPa} \\
(\mathrm{Msi})\end{array}$ & $\begin{array}{c}\sigma \\
\mathrm{MPa} \\
(\mathrm{ksi}) \\
\end{array}$ \\
\hline $\begin{array}{c}\text { Manufacturer } \\
\text { Data }\end{array}$ & $\begin{array}{l}25.2 \\
(3.7)\end{array}$ & $\begin{array}{l}436 \\
(63) \\
\end{array}$ & N/A & $\begin{array}{c}\text { Coupon } \\
\text { Tests }\end{array}$ & $\begin{array}{c}7.2 \\
(0.284)\end{array}$ & $\begin{array}{l}\text { Sikadur } \\
300\end{array}$ & $\begin{array}{c}1.7 \\
(0.25)\end{array}$ & $\begin{array}{l}55 \\
(8) \\
\end{array}$ \\
\hline $\begin{array}{c}\text { Adjusted } \\
\text { Manufacturer } \\
\text { Data }\end{array}$ & $\begin{array}{c}14.6 \\
=25.2 * K_{2} \\
(2.1)\end{array}$ & $\begin{array}{c}213 \\
=436 * K \\
(30.9)\end{array}$ & $\begin{array}{c}0.0146 \\
= \\
0.213 / 14.6\end{array}$ & $\begin{array}{l}\text { Manu- } \\
\text { facturer }\end{array}$ & $\begin{array}{c}6.0=3 * 2.0 \\
(0.24)\end{array}$ & $\begin{array}{l}\text { Hydrex } \\
100\end{array}$ & $\begin{array}{c}3.6 \\
(0.5) \\
\end{array}$ & $\begin{array}{c}79 \\
(11.5) \\
\end{array}$ \\
\hline Difference & $6.49 \%$ & $-9.77 \%$ & $-17.39 \%$ & & $\begin{array}{r}K_{l}=6 . \\
K_{2}=\sqrt{\frac{1.7}{3.6}} \\
K=K_{1} *\end{array}$ & $\begin{array}{l}.2=0.83 \\
\sqrt{\frac{55}{79}}= \\
2=0.48\end{array}$ & & \\
\hline
\end{tabular}


Table 5.15 Comparison with Manufacturer Data for HC Coupons

\begin{tabular}{|c|c|c|}
\hline Items & $\begin{array}{l}\text { Thickness } \\
\text { mm (in.) }\end{array}$ & $\begin{array}{l}\text { Ultimate Strength } \\
\mathrm{MPa}(\mathrm{ksi})\end{array}$ \\
\hline Coupon Tests & $\begin{array}{c}1.7 \\
(0.068)\end{array}$ & $\begin{array}{c}507 \\
(73.5)\end{array}$ \\
\hline Manufacturer Data & $\begin{array}{c}1.0 \\
(0.04)\end{array}$ & $\begin{array}{c}849 \\
(123) \\
\end{array}$ \\
\hline Adjustment Factor / Adjusted Data & $0.5908=1.0 / 1.7$ & $\begin{array}{c}502=849 * 0.5908 \\
(72.8)\end{array}$ \\
\hline Difference & N/A & $1.01 \%$ \\
\hline
\end{tabular}

Table 5.16 Comparison with Manufacturer Data for HG Coupons

\begin{tabular}{|c|c|c|}
\hline Items & $\begin{array}{l}\text { Thickness } \\
\text { mm (in.) }\end{array}$ & $\begin{array}{c}\text { Ultimate Strength } \\
\text { MPa (ksi) }\end{array}$ \\
\hline Coupon Tests Results & $\begin{array}{c}1.8 \\
(0.071)\end{array}$ & $\begin{array}{c}334 \\
(48.5)\end{array}$ \\
\hline Manufacturer Data & $\begin{array}{c}1.0 \\
(0.04)\end{array}$ & $\begin{array}{l}612 \\
(89)\end{array}$ \\
\hline Adjustment Factor / Adjusted Data & $0.5634=1.0 / 1.8$ & $\begin{array}{c}345=612 * 0.5634 \\
(50.0)\end{array}$ \\
\hline Difference & N/A & $-3.20 \%$ \\
\hline
\end{tabular}

Table 5.17 Comparison with Manufacturer Data for HH Coupons

\begin{tabular}{|c|c|c|c|c|}
\hline Items & $\begin{array}{l}\text { Thickness } \\
\text { mm (in.) }\end{array}$ & $\begin{array}{l}\text { Modulus of } \\
\text { Elasticity } \\
\text { GPa (Msi) }\end{array}$ & $\begin{array}{l}\text { Ultimate Strength } \\
\text { MPa (ksi) }\end{array}$ & $\begin{array}{l}\text { Ultimate } \\
\text { Strain }\end{array}$ \\
\hline $\begin{array}{c}\text { Coupon Tests } \\
\text { Results }\end{array}$ & $\begin{array}{c}6.5 \\
(0.255)\end{array}$ & $\begin{array}{l}17.2 \\
(2.5)\end{array}$ & $\begin{array}{c}269 \\
(39.0)\end{array}$ & $\begin{aligned} & 0.0156 \\
= & 0.269 / 17.2\end{aligned}$ \\
\hline $\begin{array}{l}\text { SikaWrap Hex } \\
100 \mathrm{G}\left(0^{\circ}\right)\end{array}$ & $\begin{array}{c}1.0 \\
(0.04)\end{array}$ & $\begin{array}{l}26.1 \\
(3.8)\end{array}$ & $\begin{array}{l}612 \\
(89)\end{array}$ & \multirow{3}{*}{ N/A } \\
\hline $\begin{array}{c}\text { SikaWrap Hex } \\
103 \mathrm{C}\left(90^{\circ}\right)\end{array}$ & $\begin{array}{c}1.0 \\
(0.04)\end{array}$ & $\begin{array}{l}5.0 \\
(0.7) \\
\end{array}$ & $\begin{array}{c}24 \\
(3.5) \\
\end{array}$ & \\
\hline HH-V & $\begin{array}{l}5.0=5 * 1.0 \\
(0.20)\end{array}$ & $\begin{array}{c}17.6 \\
=26.1 * 0.6+4.9 * 0.4 \\
(2.55)\end{array}$ & $\begin{array}{c}377 \\
=612 * 0.6+24 * 0.4 \\
(54.7)\end{array}$ & \\
\hline $\begin{array}{l}\text { Adjustment Factor / } \\
\text { Adjusted Data }\end{array}$ & $0.7843=5.0 / 6.5$ & 17.6 & $\begin{aligned} 296= & 377 * 0.7843 \\
& (42.9)\end{aligned}$ & $\begin{aligned} & 0.0168 \\
= & 0.296 / 17.6\end{aligned}$ \\
\hline Difference & N/A & $-2.25 \%$ & $-9.89 \%$ & $-7.47 \%$ \\
\hline
\end{tabular}


Table 5.18 Comparison with Manufacturer Data for HL Coupons

\begin{tabular}{|c|c|c|c|c|}
\hline Items & $\begin{array}{l}\text { Thickness } \\
\text { mm (in.) }\end{array}$ & $\begin{array}{l}\text { Modulus of } \\
\text { Elasticity } \\
\text { GPa (Msi) }\end{array}$ & $\begin{array}{l}\text { Ultimate Strength } \\
\text { MPa (ksi) }\end{array}$ & $\begin{array}{l}\text { Ultimate } \\
\text { Strain }\end{array}$ \\
\hline $\begin{array}{l}\text { Coupon Tests } \\
\text { Results }\end{array}$ & $\begin{array}{c}6.9 \\
(0.272)\end{array}$ & $\begin{array}{l}33.8 \\
(4.9)\end{array}$ & $\begin{array}{c}249 \\
(36.2)\end{array}$ & 0.0075 \\
\hline $\begin{array}{l}\text { SikaWrap Hex } \\
103 \mathrm{C}\left(0^{\circ}\right)\end{array}$ & $\begin{array}{c}1.0 \\
(0.04)\end{array}$ & $\begin{array}{c}70.6 \\
(10.2)\end{array}$ & $\begin{array}{c}849 \\
(123.0)\end{array}$ & \multirow{3}{*}{ N/A } \\
\hline $\begin{array}{c}\text { SikaWrap Hex } \\
\text { 100G }\left(90^{\circ}\right)\end{array}$ & $\begin{array}{c}1.0 \\
(0.04)\end{array}$ & $\begin{array}{c}6.7 \\
(1.0)\end{array}$ & $\begin{array}{c}30 \\
(4.4)\end{array}$ & \\
\hline HL-V & $\begin{array}{l}5.0=5 * 1.0 \\
(0.20)\end{array}$ & $\begin{array}{c}32.2 \\
=70.6 * 0.4+6.7 * 0.6 \\
(4.7)\end{array}$ & $\begin{array}{c}358 \\
=849 * 0.4+30 * 0.6 \\
(51.9)\end{array}$ & \\
\hline $\begin{array}{l}\text { Adjustment Factor } \\
\text { / Adjusted Data }\end{array}$ & $0.7353=1.0 / 6.9$ & $\begin{array}{l}32.2 \\
(4.7)\end{array}$ & $\begin{array}{c}263 \\
=358 * 0.7353 \\
(38.1)\end{array}$ & $\begin{aligned} & 0.0082 \\
= & 0.263 / 32.2\end{aligned}$ \\
\hline Difference & N/A & $4.81 \%$ & $-5.55 \%$ & $-8.40 \%$ \\
\hline
\end{tabular}

Table 5.19 Comparison of Ultimate Tensile Strains

\begin{tabular}{|c|c|c|c|c|c|c|}
\hline \multirow{2}{*}{ Items } & \multicolumn{2}{|c|}{ Cyclic Tests } & \multicolumn{2}{|c|}{ Monotonic Tests } & \multirow{2}{*}{$\begin{array}{l}\text { Coupon } \\
\text { Tests } \\
\text { Strain }\end{array}$} & \multirow{2}{*}{$\begin{array}{c}\text { Manufacturer Dat } \\
\text { Strain }\end{array}$} \\
\hline & Strain & Remarks & Strain & Remarks & & \\
\hline $\begin{array}{l}\text { Specimen Y } \\
\text { (Tension) }\end{array}$ & 0.0070 & $\begin{array}{c}\text { Top } \\
1 / 8 \text { Height } \\
\mu=6\end{array}$ & 0.0073 & $\begin{array}{l}\text { Before } \\
\text { Failure }\end{array}$ & N/A & $0.0106=0.159 / 15$ \\
\hline $\begin{array}{l}\text { Specimen G } \\
\text { (Tension) }\end{array}$ & 0.0112 & $\begin{array}{c}\text { Top } \\
0 \text { Height } \\
\mu=6\end{array}$ & 0.0114 & At Failure & 0.0122 & 0.0146 \\
\hline $\begin{array}{l}\text { Specimen H } \\
\text { (Tension) }\end{array}$ & 0.0032 & $\begin{array}{c}\text { Top } \\
1 / 8 \text { Height } \\
\mu=3\end{array}$ & 0.0048 & At Failure & 0.0075 & 0.0082 \\
\hline $\begin{array}{c}\text { Specimen SC } \\
\text { (Tension) }\end{array}$ & 0.0059 & $\begin{array}{c}\text { Bottom } \\
0 \text { Height } \\
\mu=3\end{array}$ & 0.0048 & $\begin{array}{l}\text { Before } \\
\text { Failure }\end{array}$ & \multirow{2}{*}{0.0065} & \multirow{2}{*}{ N/A } \\
\hline $\begin{array}{l}\text { Specimen LC } \\
\text { (Tension) }\end{array}$ & 0.0030 & $\begin{array}{c}\text { Top } \\
0 \text { Height } \\
\mu=2\end{array}$ & 0.0084 & At Failure & & \\
\hline
\end{tabular}


Table 5.20 Manufacturer Data for Compressive Properties of FRP Materials

\begin{tabular}{|c|c|c|c|c|c|c|c|}
\hline $\begin{array}{c}\text { FRP } \\
\text { Product }\end{array}$ & Source & $\begin{array}{l}\text { Associated } \\
\text { CFFT } \\
\text { Specimen }\end{array}$ & Fiber Direction & $\begin{array}{l}\text { Modulus } \\
\text { of } \\
\text { Elasticity } \\
\text { GPa } \\
\text { (Msi) }\end{array}$ & $\begin{array}{l}\text { Ultimate } \\
\text { Strength } \\
\text { MPa } \\
(\mathrm{ksi})\end{array}$ & $\begin{array}{l}\text { Nominal } \\
\text { Ply } \\
\text { Thickness } \\
\text { mm (in.) }\end{array}$ & $\begin{array}{l}\text { Testing } \\
\text { Method }\end{array}$ \\
\hline $\begin{array}{c}\text { Red } \\
\text { Thread II } \\
\text { Pipe } \\
\end{array}$ & $\begin{array}{c}\text { Smith } \\
\text { Fiberglass }\end{array}$ & $\begin{array}{c}\text { Specimen } \\
\text { Y }\end{array}$ & $\begin{array}{c}17 \text { Layers of } \pm \\
55^{\circ} \text { E-Glass }\end{array}$ & $\begin{array}{c}8.7 \\
(1.3)\end{array}$ & $\begin{array}{c}-228 \\
(-33.1)\end{array}$ & $\begin{array}{c}5.5 \\
(0.216)\end{array}$ & \multirow{5}{*}{$\begin{array}{c}\text { ASTM } \\
\text { D } 695\end{array}$} \\
\hline \multirow{2}{*}{$\begin{array}{l}\text { P3W- } \\
\text { GE041 }\end{array}$} & \multirow{2}{*}{$\begin{array}{l}\text { 3TEX, } \\
\text { Inc. }\end{array}$} & \multirow{2}{*}{$\begin{array}{l}\text { Specimen } \\
\text { G }\end{array}$} & Warp & \multirow{2}{*}{ N/A } & $\begin{array}{c}-399 \\
(-57.9) \\
\end{array}$ & \multirow{2}{*}{$\begin{array}{c}2.0 \\
(0.08)\end{array}$} & \\
\hline & & & Fillet & & $\begin{array}{c}-316 \\
(-45.9) \\
\end{array}$ & & \\
\hline $\begin{array}{l}\mathrm{Hex} \\
103 \mathrm{C} \\
\end{array}$ & \multirow{2}{*}{ Sika Corp. } & \multirow{2}{*}{$\begin{array}{c}\text { Specimen } \\
\mathrm{H}\end{array}$} & $0^{\circ}$ & $\begin{array}{r}67.1 \\
(9.7) \\
\end{array}$ & $\begin{array}{c}-779 \\
(-113.0) \\
\end{array}$ & \multirow{2}{*}{$\begin{array}{c}1.0 \\
(0.04)\end{array}$} & \\
\hline $\begin{array}{c}\mathrm{Hex} \\
100 \mathrm{G}\end{array}$ & & & $0^{\circ}$ & $\begin{array}{l}29.7 \\
(4.3) \\
\end{array}$ & $\begin{array}{c}-597 \\
(-86.6)\end{array}$ & & \\
\hline
\end{tabular}

Table 5.21 Manufacturer Data for Ultimate Compressive Strains of HL

\begin{tabular}{|c|c|c|c|c|}
\hline Items & $\begin{array}{l}\text { Thickness } \\
\text { mm (in.) }\end{array}$ & $\begin{array}{l}\text { Modulus of } \\
\text { Elasticity } \\
\text { GPa (Msi) }\end{array}$ & $\begin{array}{l}\text { Ultimate Strength } \\
\text { MPa (ksi) }\end{array}$ & Ultimate Strain \\
\hline $\begin{array}{c}\text { SikaWrap } \\
\text { Hex 103C } \\
\left(0^{\circ}\right)\end{array}$ & $\begin{array}{c}1.0 \\
(0.04)\end{array}$ & $\begin{array}{l}67.1 \\
(9.7)\end{array}$ & $\begin{array}{c}-779 \\
(-113.0)\end{array}$ & \multirow{2}{*}{ N/A } \\
\hline HL-V & $\begin{array}{c}5.0=5 * 1.0 \\
(0.20)\end{array}$ & $\begin{array}{c}26.8=67.1 * 0.4 \\
(3.9)\end{array}$ & $\begin{array}{c}-312=-779 * 0.4 \\
(-45.2)\end{array}$ & \\
\hline $\begin{array}{c}\text { Adjustment } \\
\text { Factor / } \\
\text { Adjusted Data }\end{array}$ & $0.7353=5.0 / 6.9$ & $\begin{array}{l}26.8 \\
(3.9)\end{array}$ & $\begin{array}{c}-229 \\
=-312 * 0.7353 \\
(-33.2)\end{array}$ & $\begin{aligned} & -0.0085 \\
= & -0.229 / 26.8\end{aligned}$ \\
\hline
\end{tabular}


Table 5.22 Comparison of Ultimate Compressive Strains

\begin{tabular}{|c|c|c|c|c|c|c|}
\hline \multirow{2}{*}{ Items } & \multicolumn{2}{|c|}{ Cyclic Tests } & \multicolumn{2}{|c|}{ Monotonic Tests } & \multirow{2}{*}{$\begin{array}{c}\text { Coupon } \\
\text { Test } \\
\text { Strain }\end{array}$} & \multirow{2}{*}{$\begin{array}{c}\text { Manufacturer } \\
\text { Data Strain }\end{array}$} \\
\hline & Strain & Remarks & Strain & Remarks & & \\
\hline $\begin{array}{c}\text { Specimen Y } \\
\text { (Compression) }\end{array}$ & -0.0046 & $\begin{array}{c}\text { Bottom } \\
\text { 1/8 Height } \\
\mu=6\end{array}$ & -0.0106 & $\begin{array}{l}\text { Before } \\
\text { Failure }\end{array}$ & \multirow{5}{*}{ N/A } & $\begin{array}{c}-0.0262= \\
-0.228 / 8.7\end{array}$ \\
\hline $\begin{array}{c}\text { Specimen G } \\
\text { (Compression) }\end{array}$ & -0.0055 & $\begin{array}{c}\text { Bottom } \\
0 \text { Height } \\
\mu=10\end{array}$ & N/A & N/A & & N/A \\
\hline $\begin{array}{c}\text { Specimen } \mathrm{H} \\
\text { (Compression) }\end{array}$ & -0.0026 & $\begin{array}{c}\text { Top } \\
\text { 1/8 Height } \\
\mu=5\end{array}$ & -0.0044 & $\begin{array}{l}\text { Before } \\
\text { Failure }\end{array}$ & & -0.0085 \\
\hline $\begin{array}{c}\text { Specimen SC } \\
\text { (Compression) }\end{array}$ & -0.0053 & $\begin{array}{c}\text { Top } \\
0 \text { Height } \\
\mu=4\end{array}$ & -0.0042 & $\begin{array}{l}\text { Before } \\
\text { Failure }\end{array}$ & & \multirow{2}{*}{ N/A } \\
\hline $\begin{array}{c}\text { Specimen LC } \\
\text { (Compression) }\end{array}$ & -0.0042 & $\begin{array}{c}\text { Top } \\
0 \text { Height } \\
\mu=4\end{array}$ & -0.0047 & At Failure & & \\
\hline
\end{tabular}




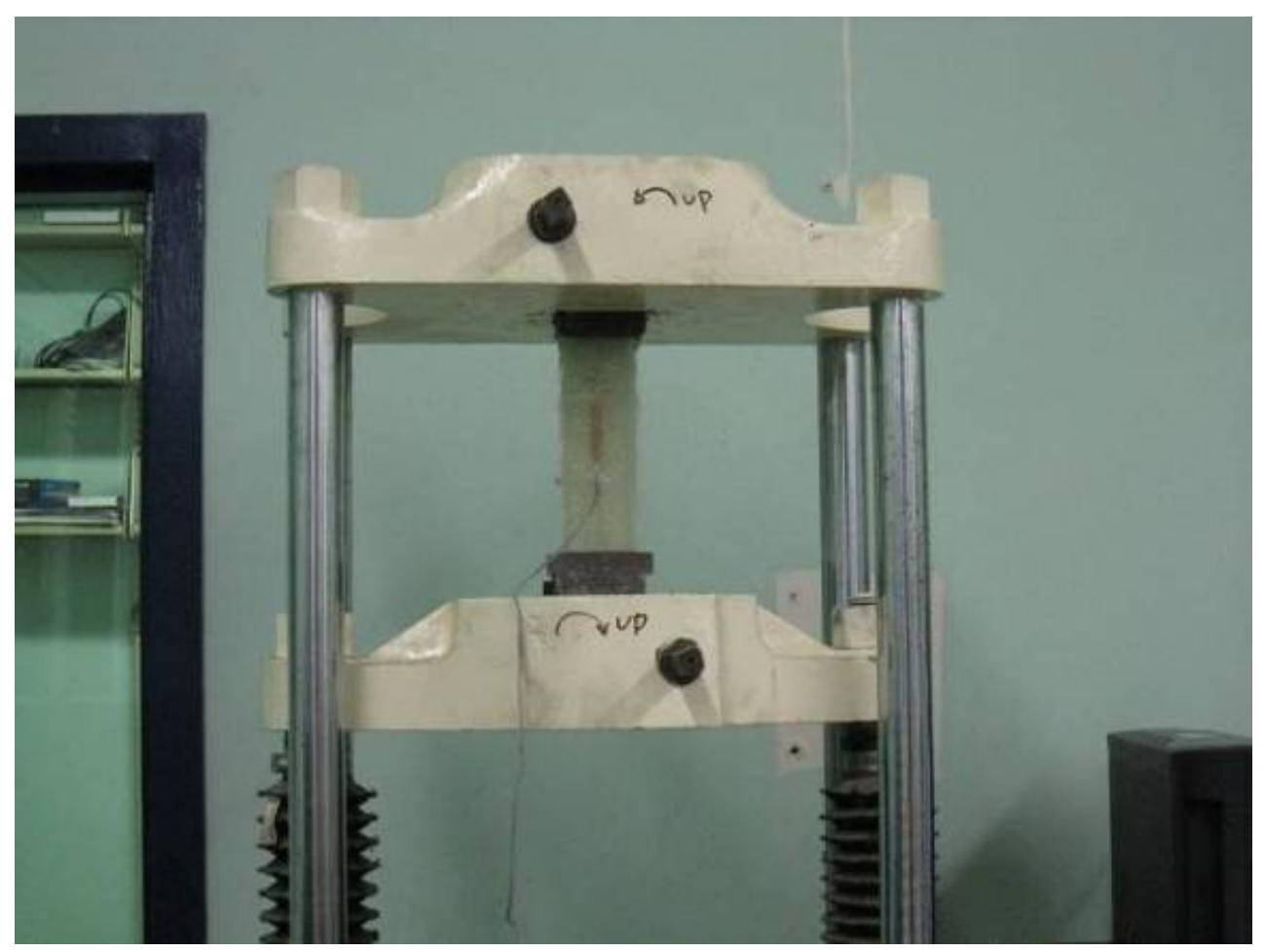

Figure 5.1 Typical Coupon Test Setup

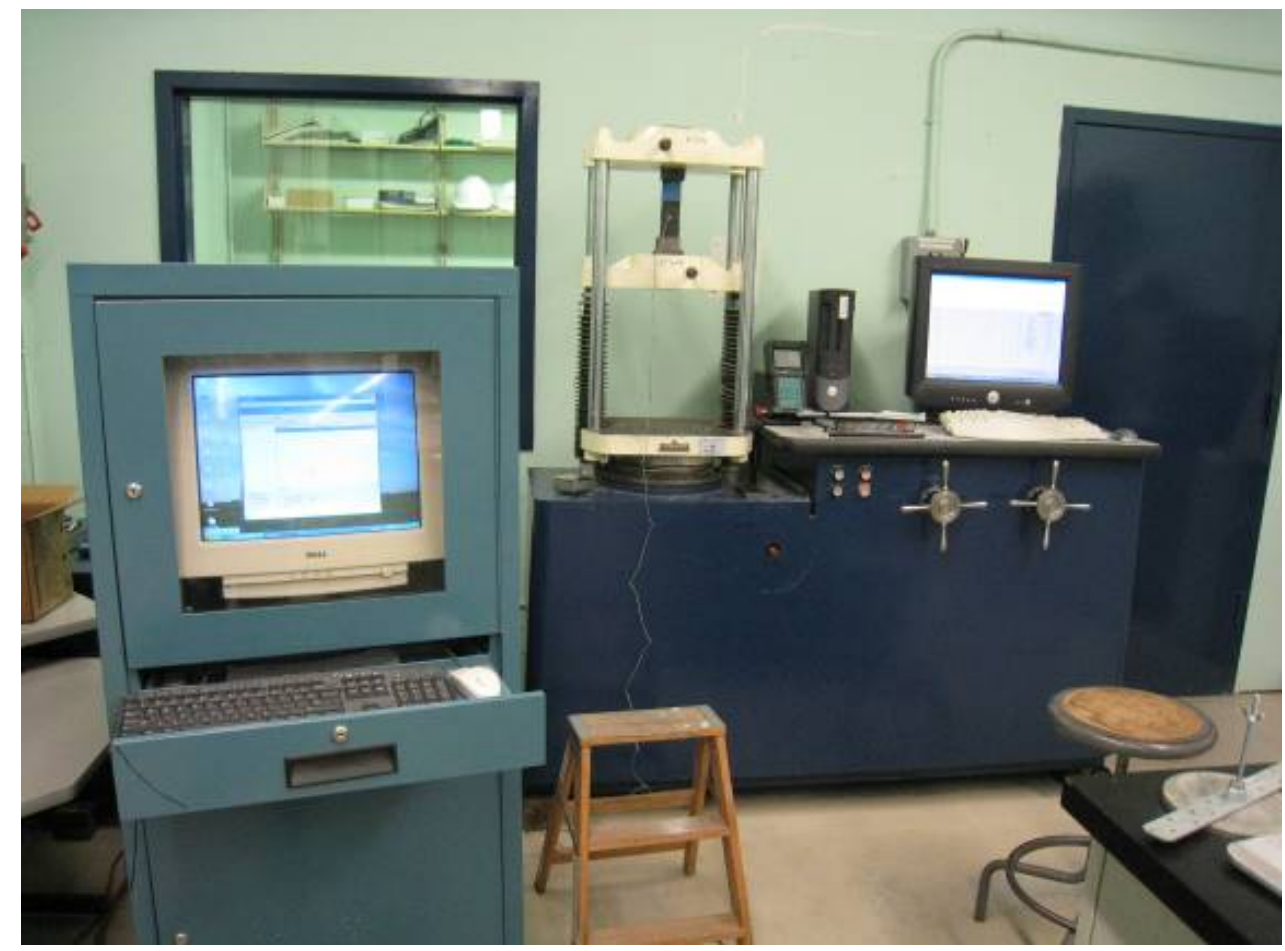

Figure 5.2 Coupon Instrumentation and Data Acquisition System 


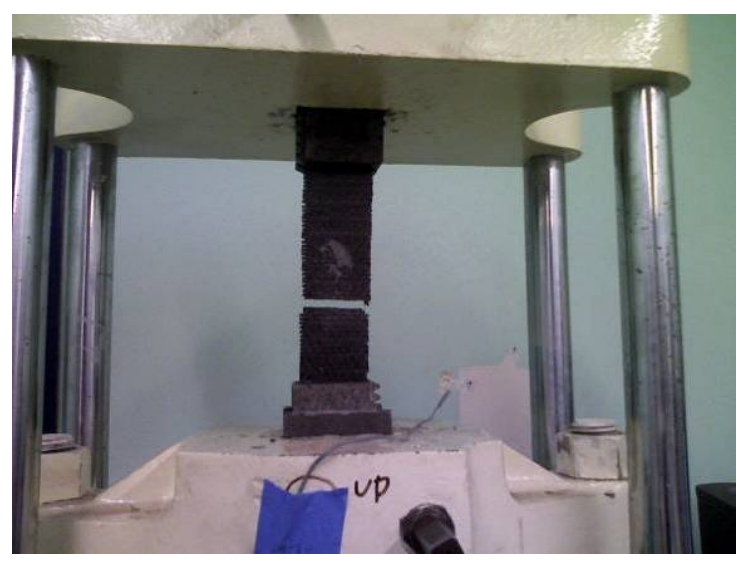

Figure 5.3 Failure Mode of CH-I-1: LGM

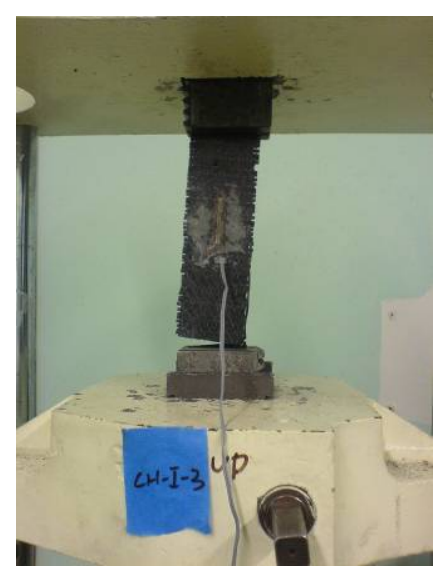

Figure 5.5 Failure Mode of CH-I-3: LWV

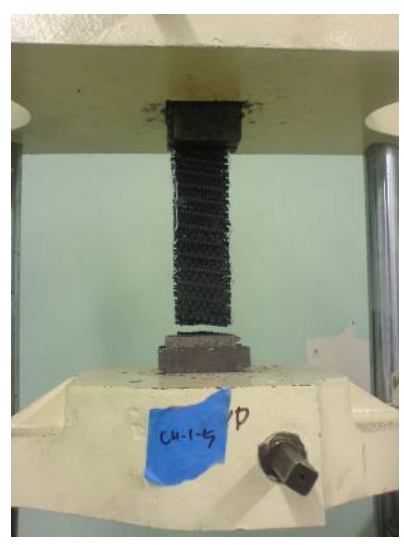

Figure 5.7 Failure Mode of CH-I-5: LWB

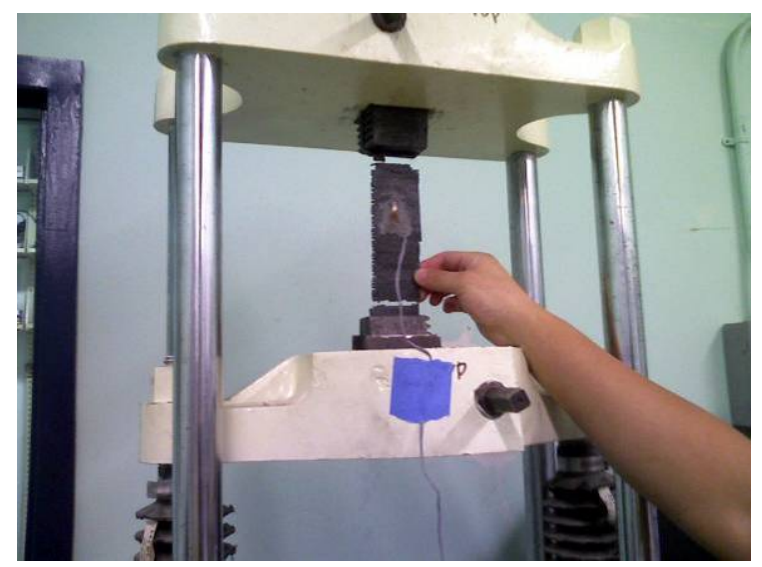

Figure 5.4 Failure Mode of CH-I-2: LWV

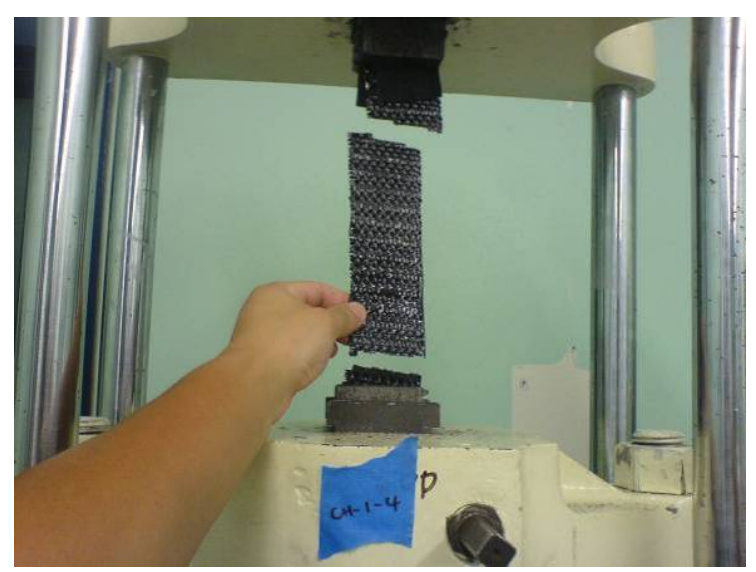

Figure 5.6 Failure Mode of CH-I-4: LWV

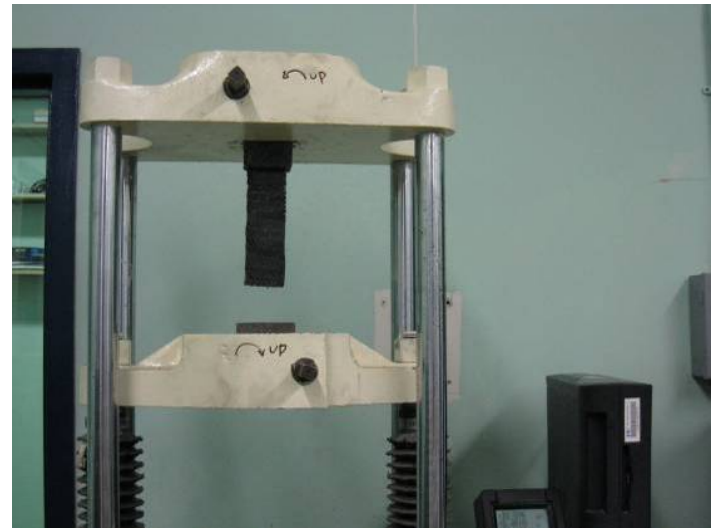

Figure 5.8 Failure Mode of CH-II-2: LWB 


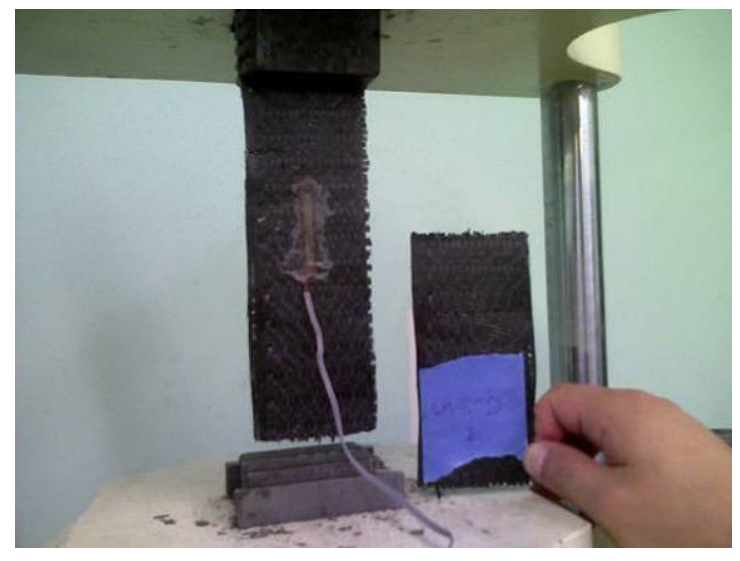

Figure 5.9 Failure Mode of CH-II-3: LVV

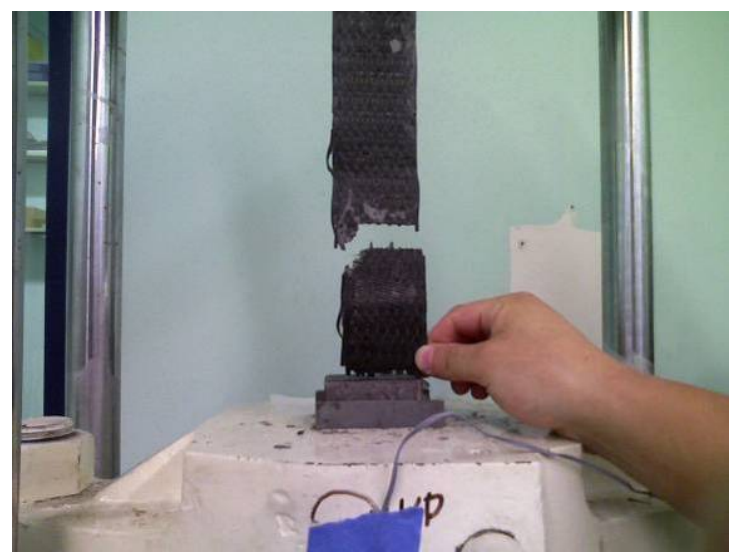

Figure 5.11 Failure Mode of CH-II-5: OIB

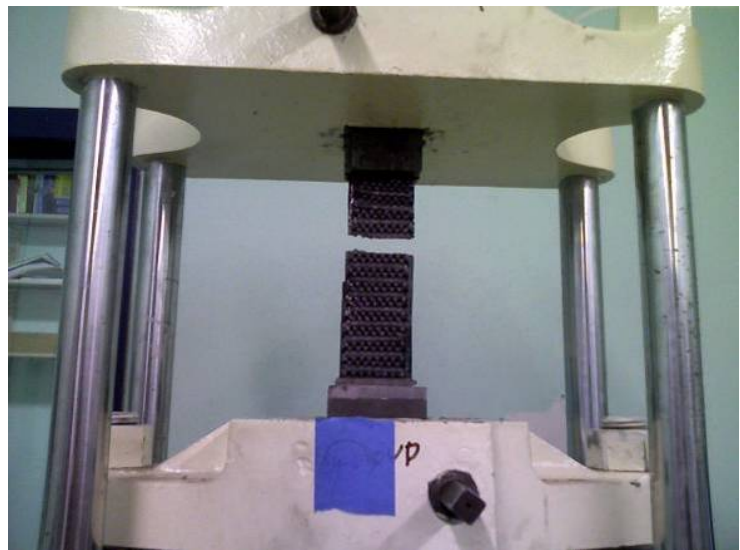

Figure 5.13 Failure Mode of CH-II-7: LGM

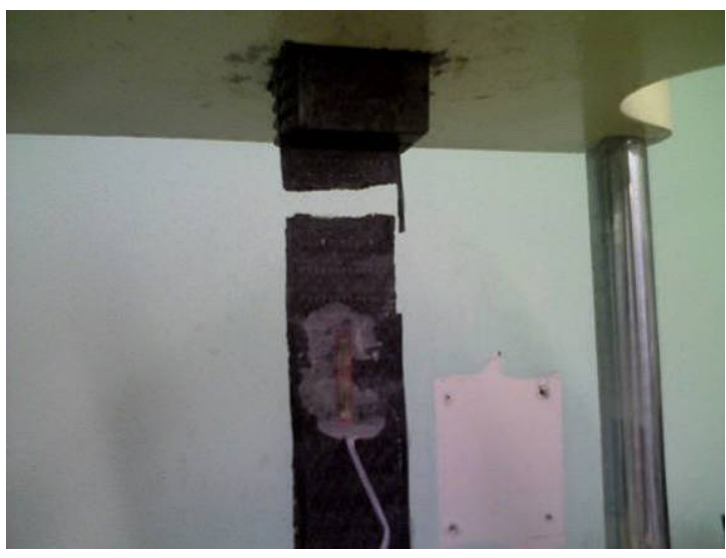

Figure 5.10 Failure Mode of CH-II-4: LVV

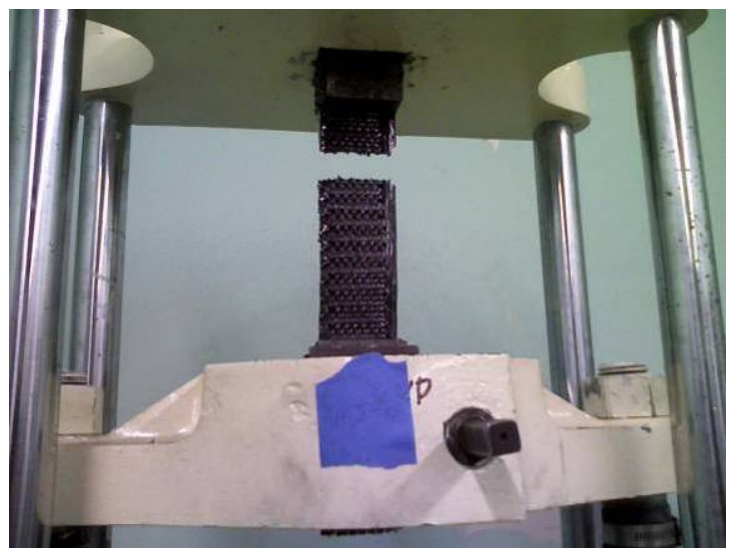

Figure 5.12 Failure Mode of CH-II-6: LWT

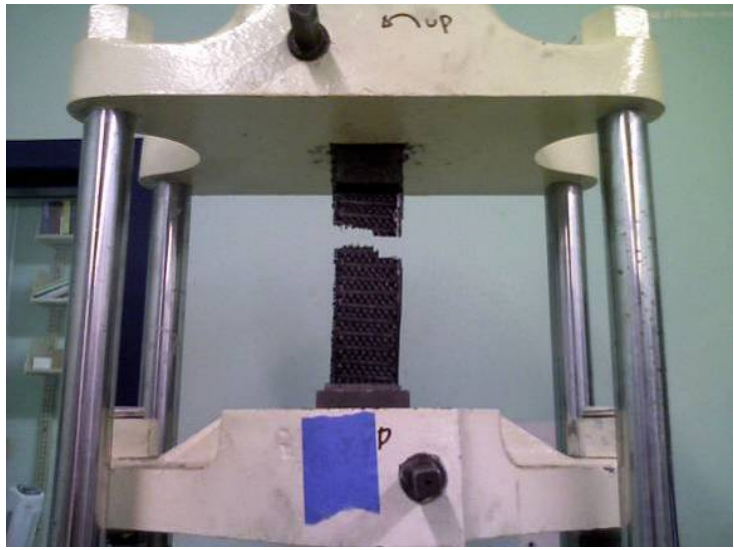

Figure 5.14 Failure Mode of CH-II-8: OGM 


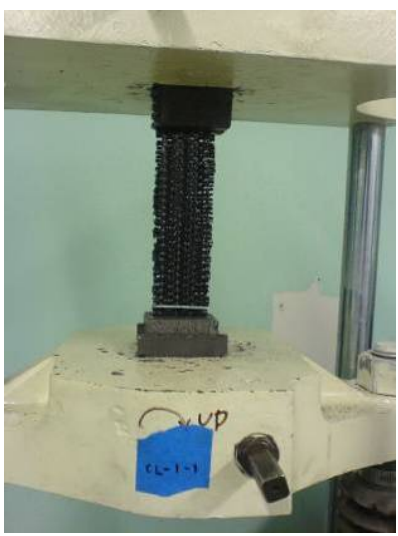

Figure 5.15 Failure Mode of CL-I-1: LWB

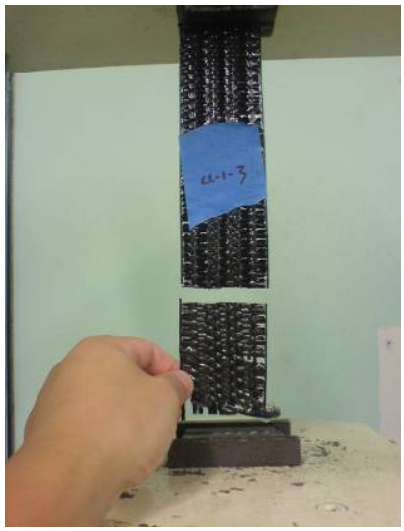

Figure 5.17 Failure Mode of CL-I-3: LIB

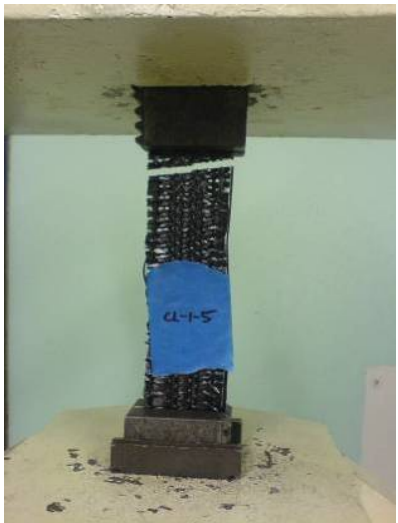

Figure 5.19 Failure Mode of CL-I-5: LWT

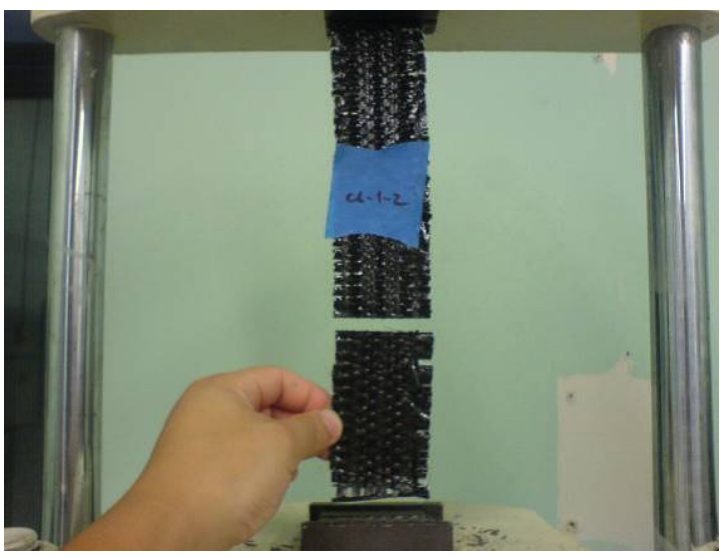

Figure 5.16 Failure Mode of CL-I-2: LAB

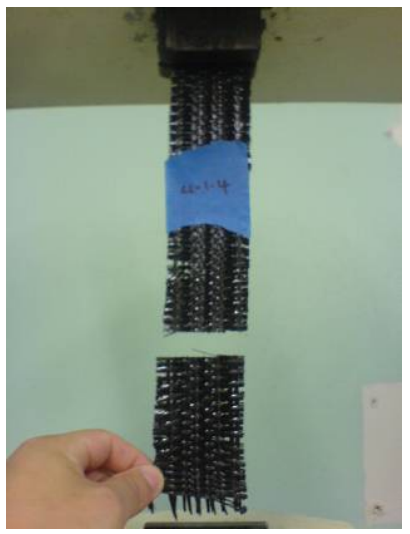

Figure 5.18 Failure Mode of CL-I-4: LIB

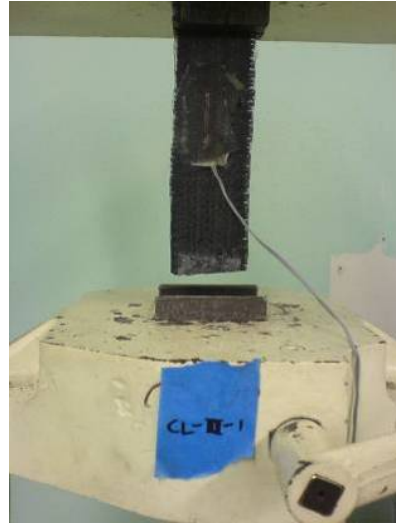

Figure 5.20 Failure Mode of CL-II-1: LAB 

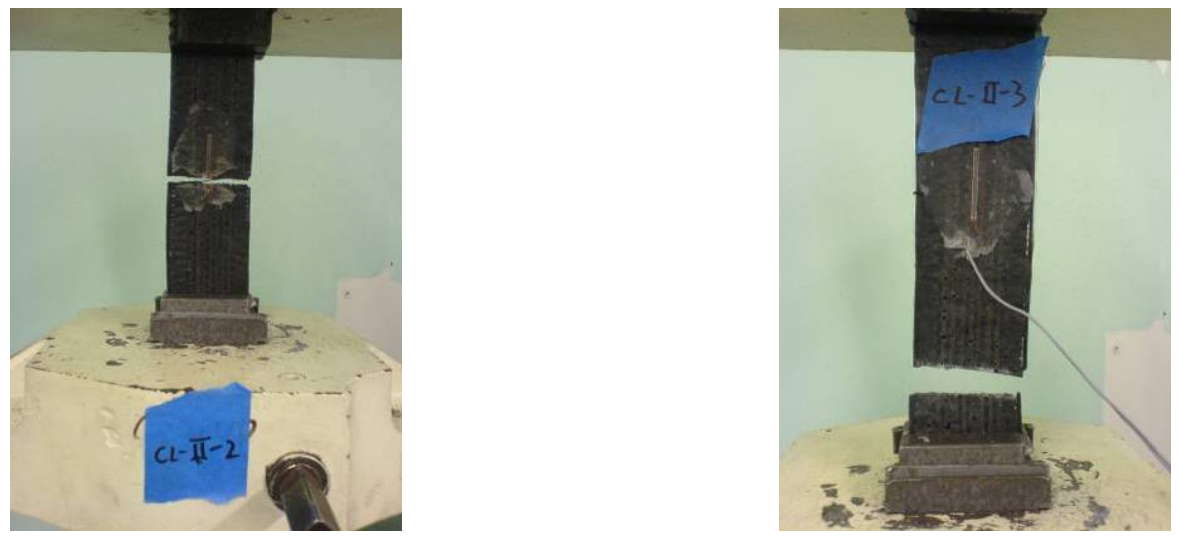

Figure 5.21 Failure Mode of CL-II-2: LGM

Figure 5.22 Failure Mode of CL-II-3: LAB
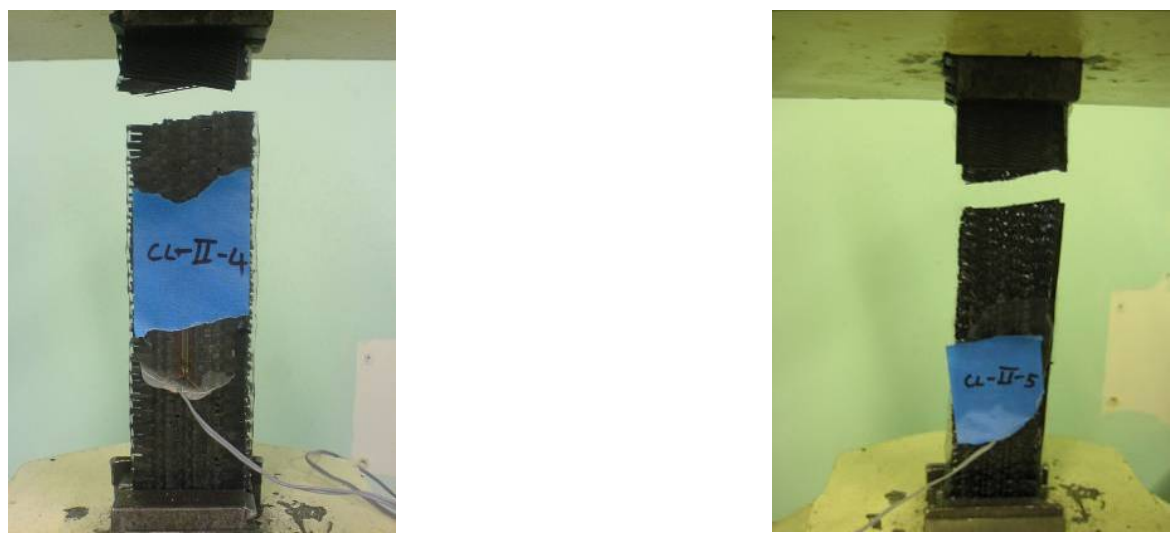

Figure 5.23 Failure Mode of CL-II-4: LAB

Figure 5.24 Failure Mode of CL-II-5: LAT
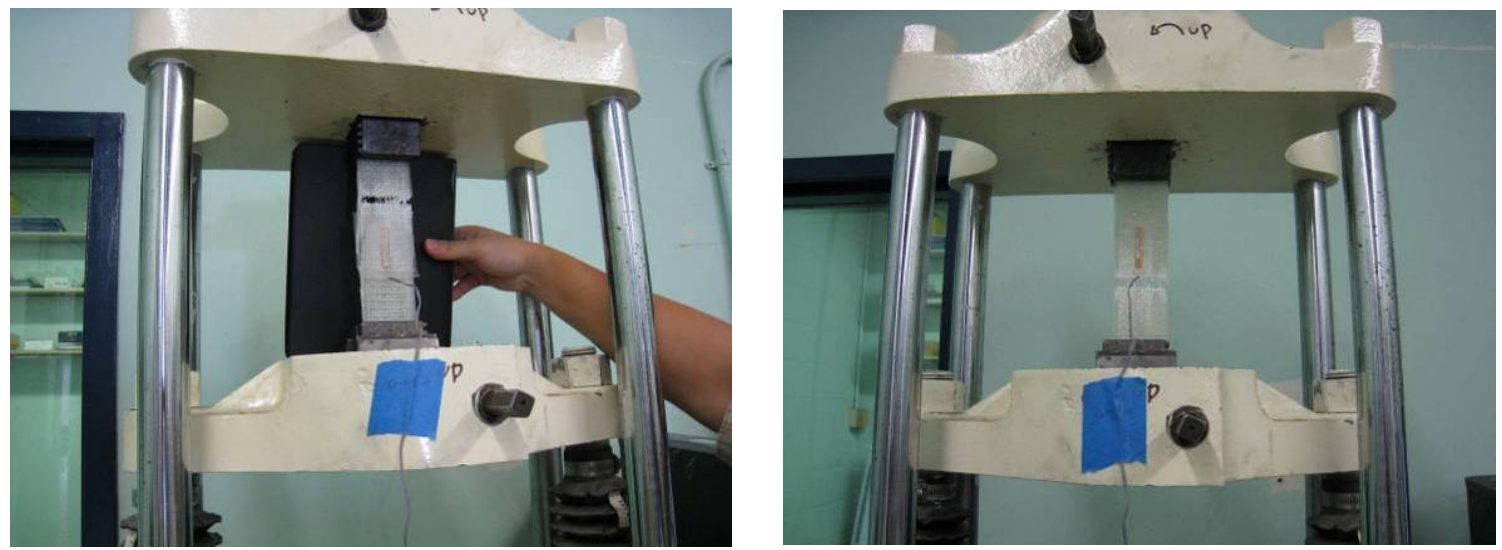

Figure 5.25 Failure Mode of GH-I-1: LGM

Figure 5.26 Failure Mode of GH-I-2: LGM 


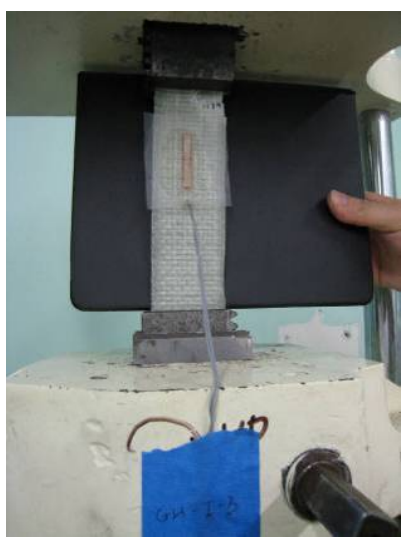

Figure 5.27 Failure Mode of GH-I-3: OWT

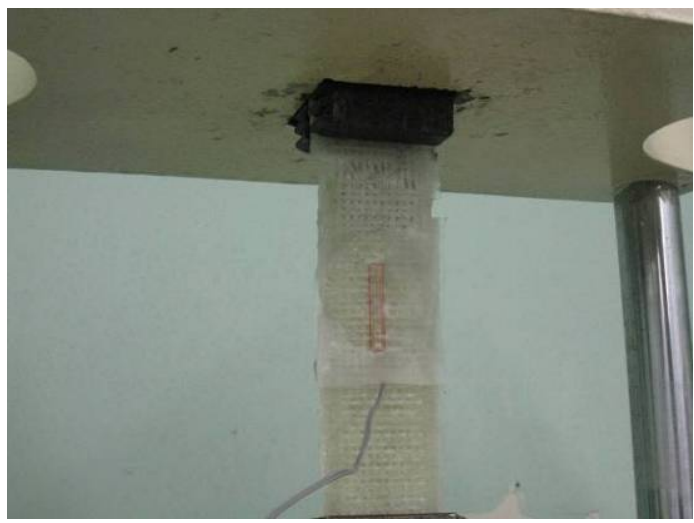

Figure 5.29 Failure Mode of GH-III-2: LWT

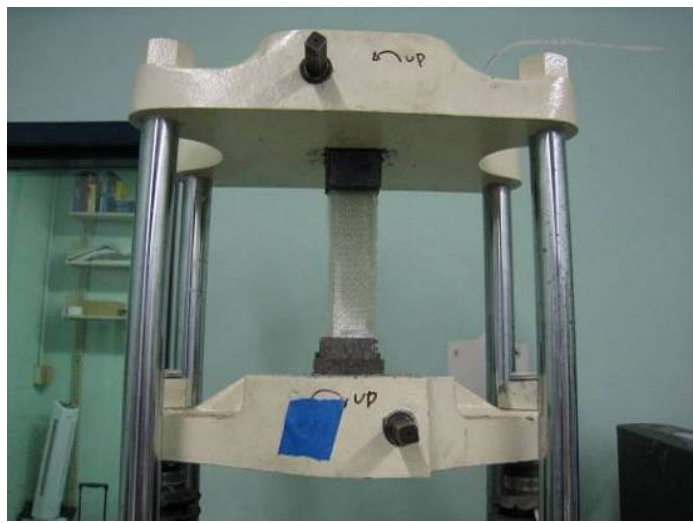

Figure 5.31 Failure Mode of GH-III-4: LAB

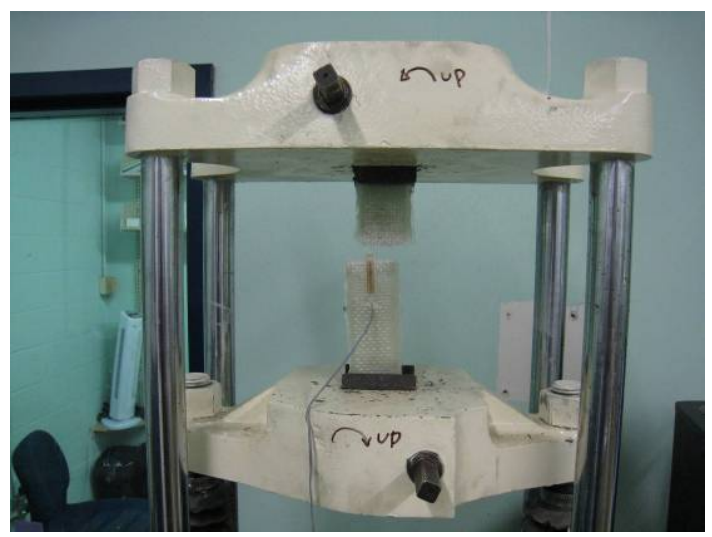

Figure 5.28 Failure Mode of GH-III-1: LGM

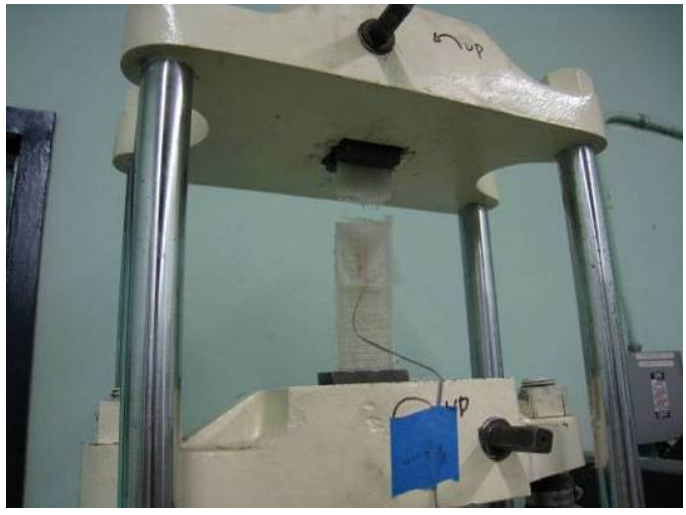

Figure 5.30 Failure Mode of GH-III-3: LWT

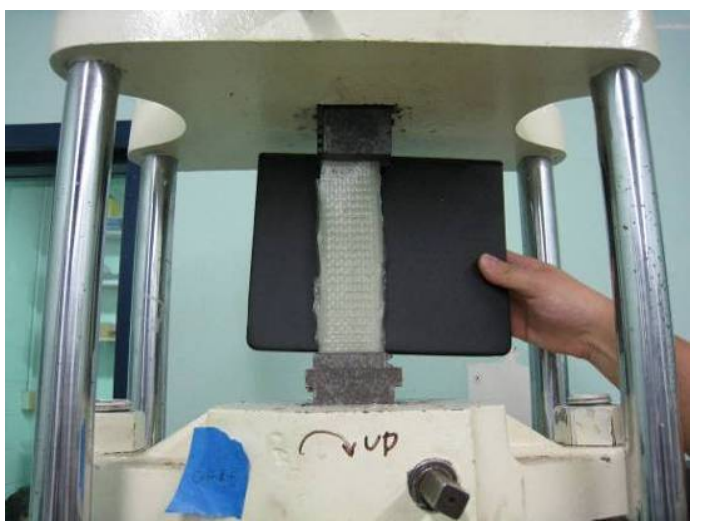

Figure 5.32 Failure Mode of GH-III-5: OAT 


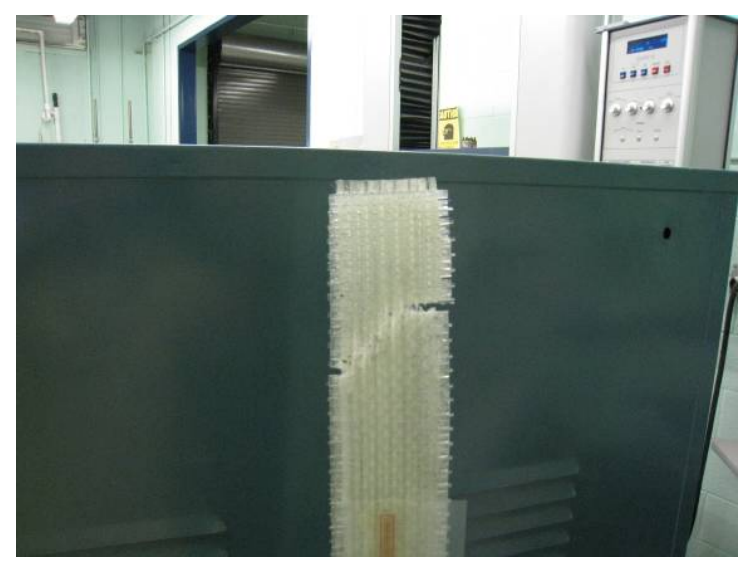

Figure 5.33 Failure Mode of GL-I-1: AAT

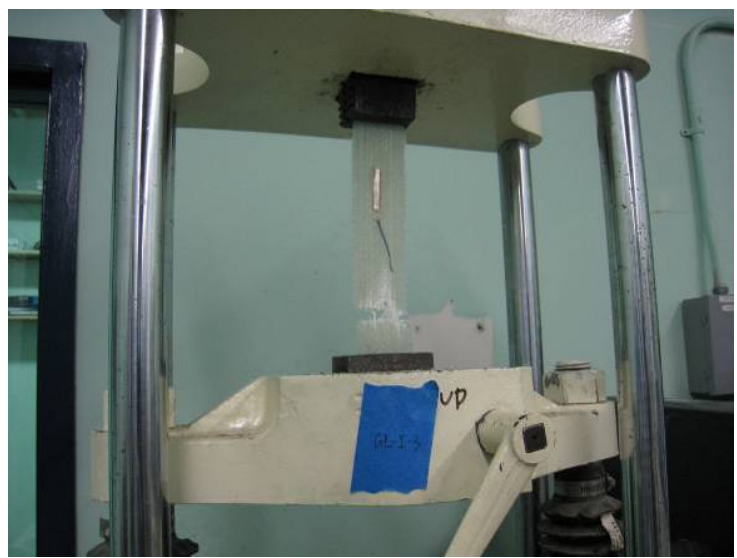

Figure 5.35 Failure Mode of GL-I-3: LAB

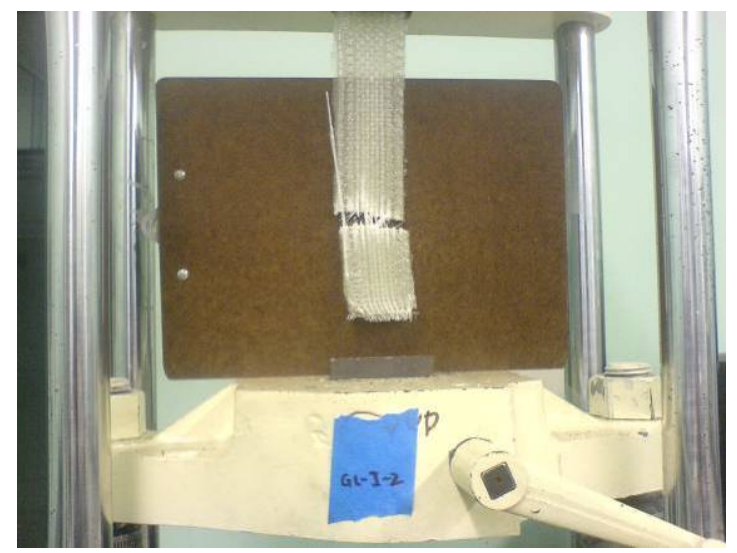

Figure 5.37 Failure Mode of GL-I-2': LAB

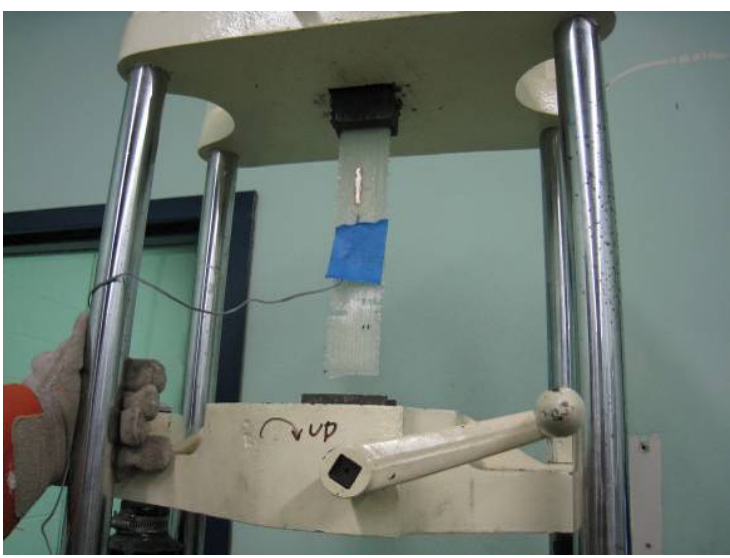

Figure 5.34 Failure Mode of GL-I-2: OAB

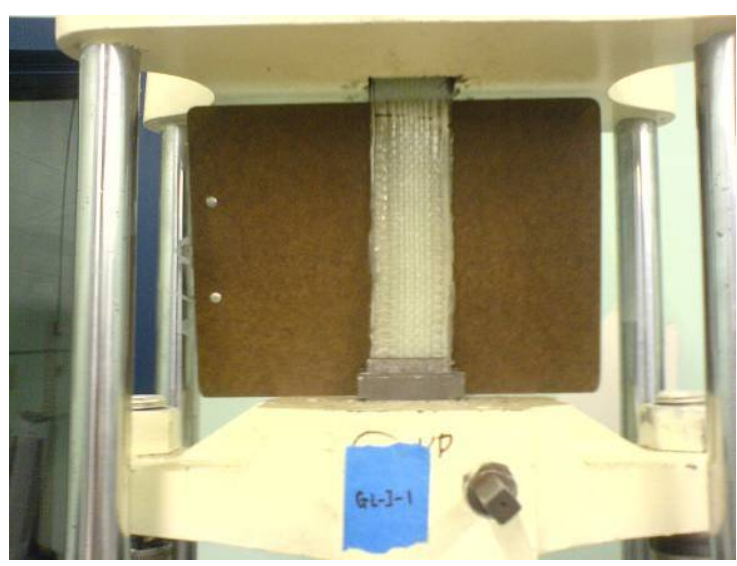

Figure 5.36 Failure Mode of GL-I-1': LAT

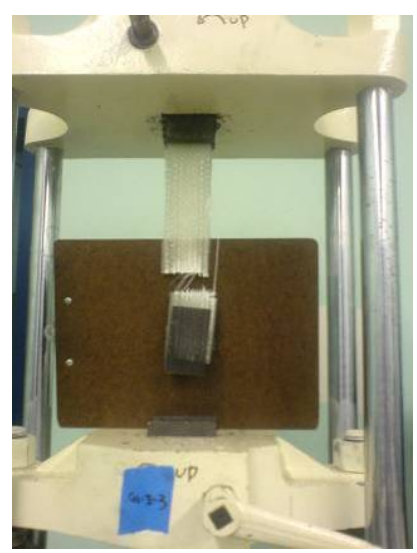

Figure 5.38 Failure Mode of GL-I-3': LAB 


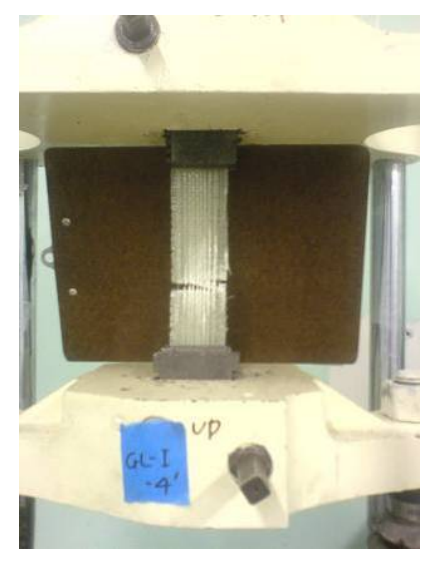

Figure 5.39 Failure Mode of GL-I-4': LGM

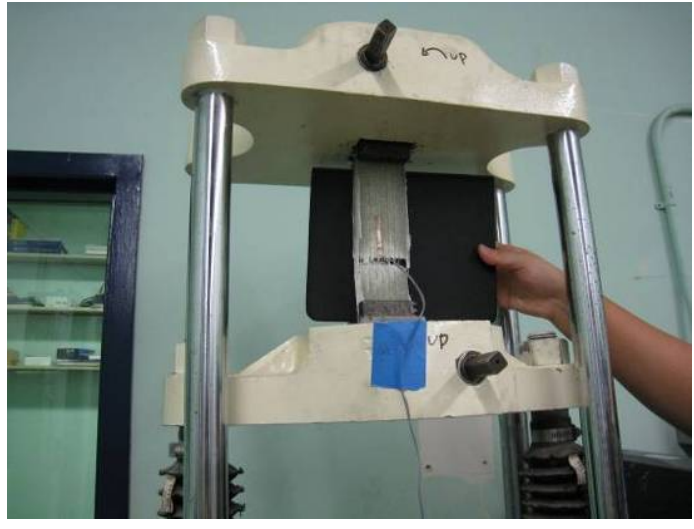

Figure 5.41 Failure Mode of GL-III-1: LGM

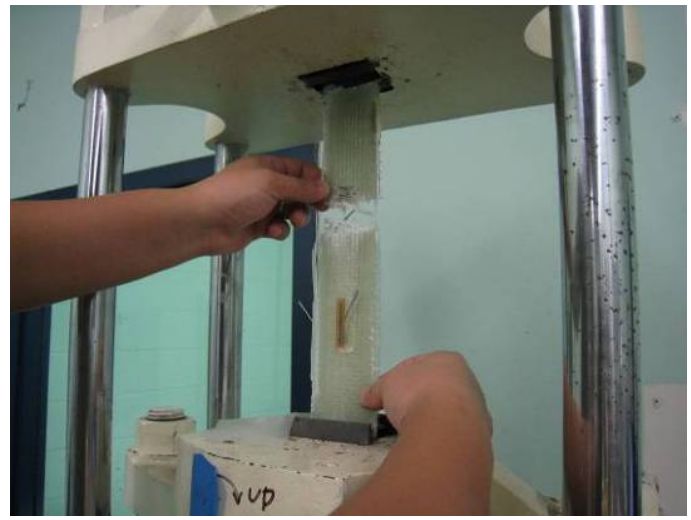

Figure 5.43 Failure Mode of GL-III-3: LIT

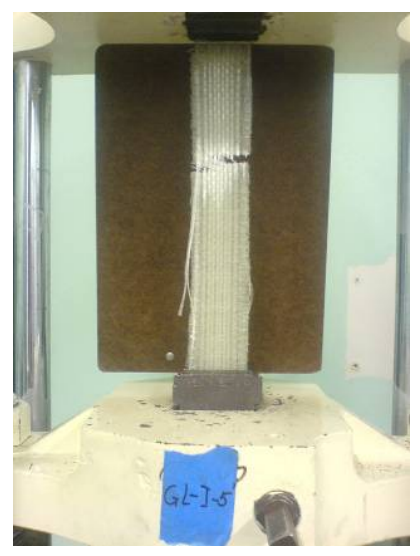

Figure 5.40 Failure Mode of GL-I-5': LAT

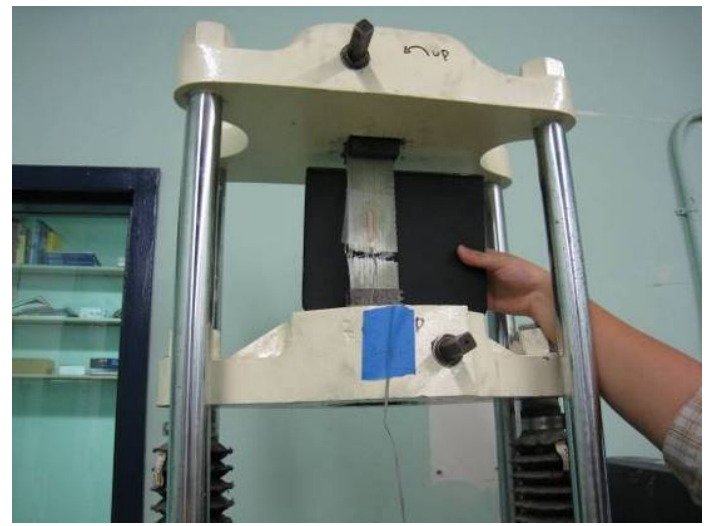

Figure 5.42 Failure Mode of GL-III-2: LGM

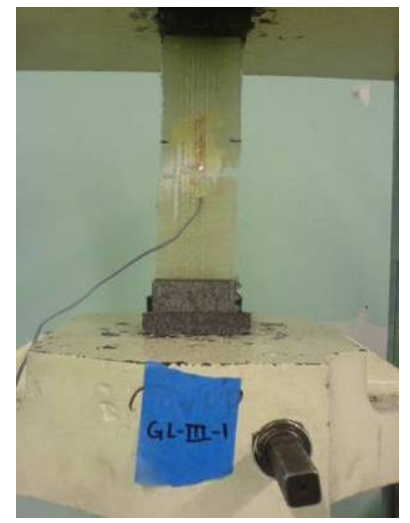

Figure 5.44 Failure Mode of GL-III-1': LGM 


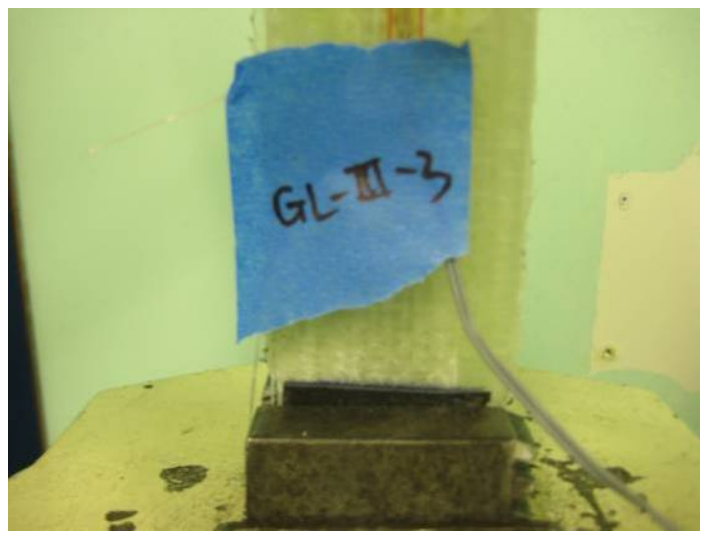

Figure 5.45 Failure Mode of GL-III-3': $\mathrm{LAB}$

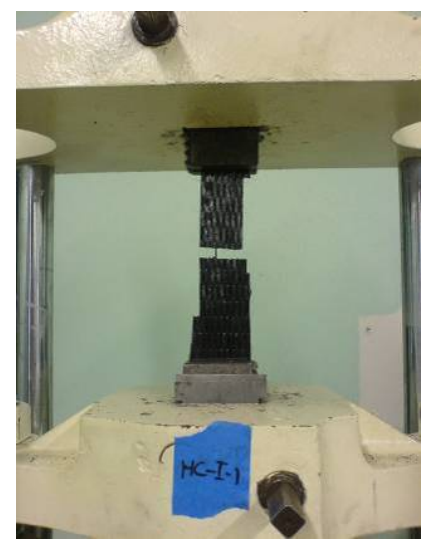

Figure 5.47 Failure Mode of HC-I-1: LGM

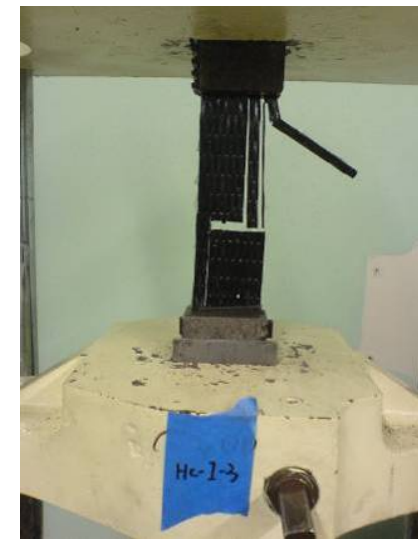

Figure 5.49 Failure Mode of HC-I-3: SGM

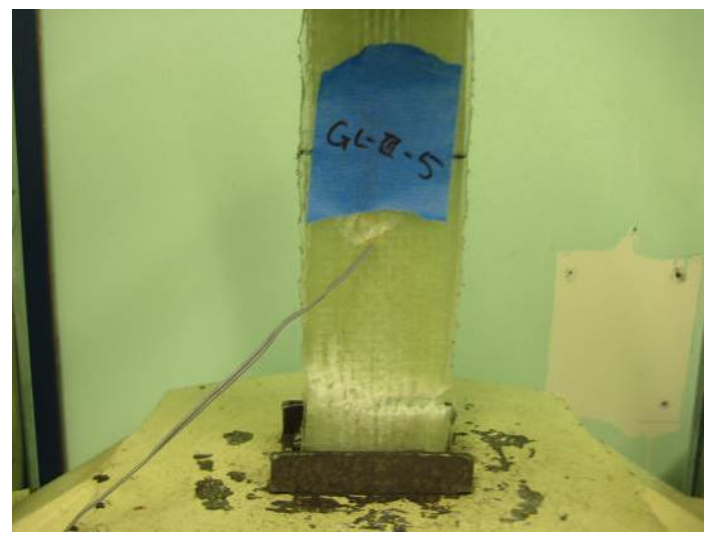

Figure 5.46 Failure Mode of GL-III-5’: $\mathrm{LAB}$

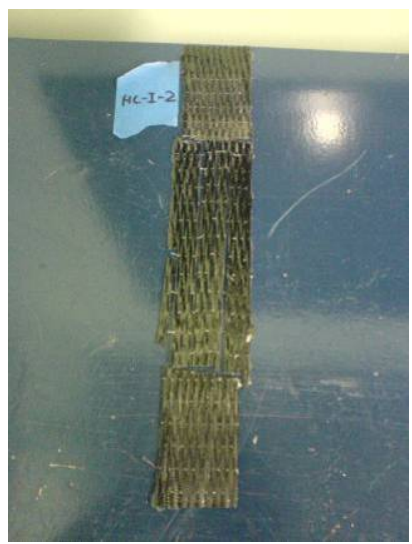

Figure 5.48 Failure Mode of HC-I-2: SGM

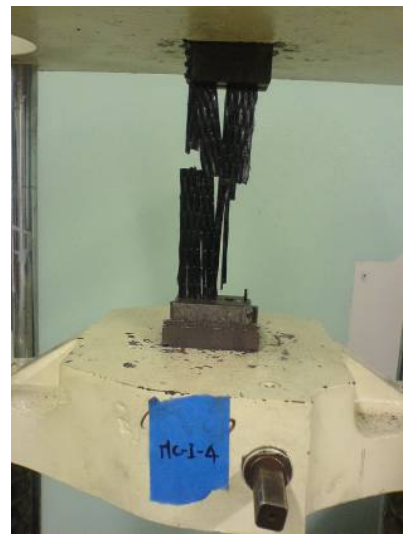

Figure 5.50 Failure Mode of HC-I-4: SGM 


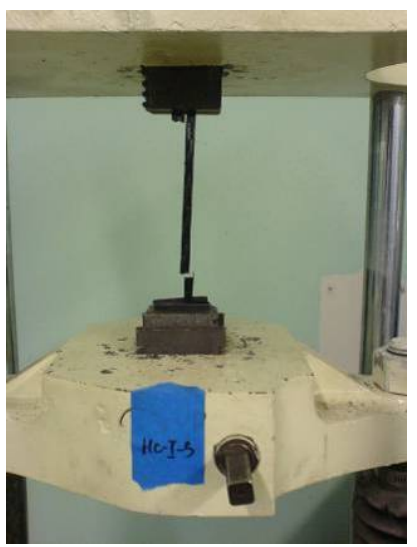

Figure 5.51 Failure Mode of HC-I-5: SGM

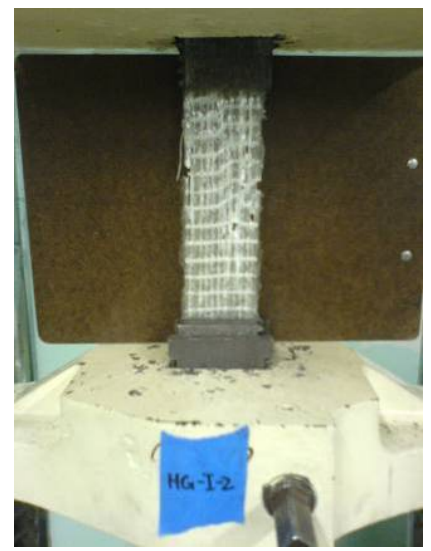

Figure 5.53 Failure Mode of HG-I-2: SGM

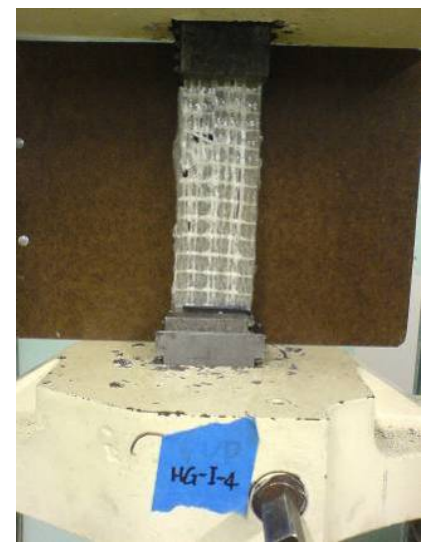

Figure 5.55 Failure Mode of HG-I-4: SGM

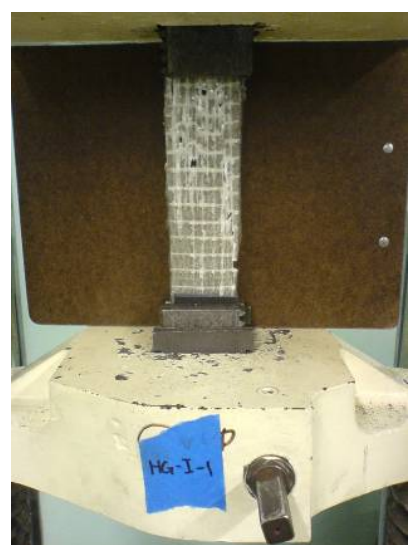

Figure 5.52 Failure Mode of HG-I-1: SGM

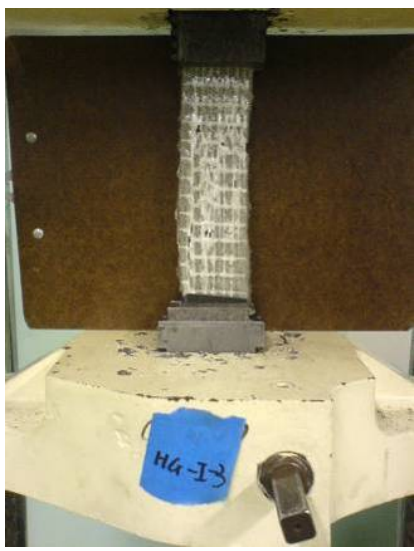

Figure 5.54 Failure Mode of HG-I-3: SGM

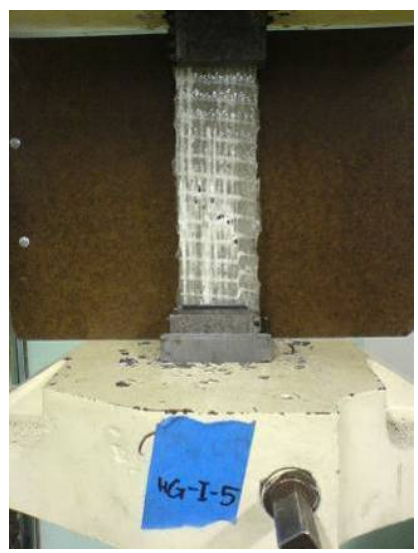

Figure 5.56 Failure Mode of HG-I-5: SGM 


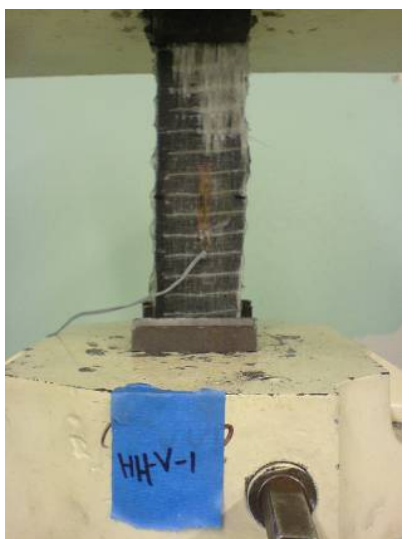

Figure 5.57 Failure Mode of HH-V-1: LAT

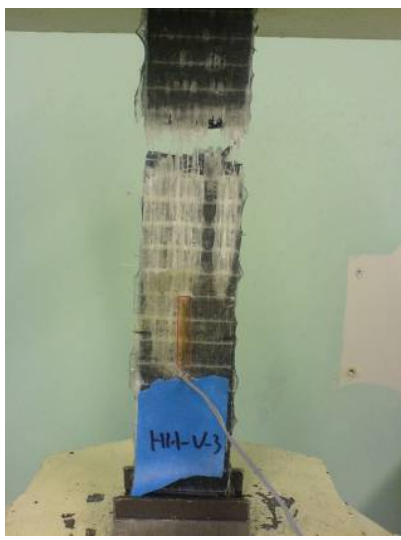

Figure 5.59 Failure Mode of HH-V-3: LAT

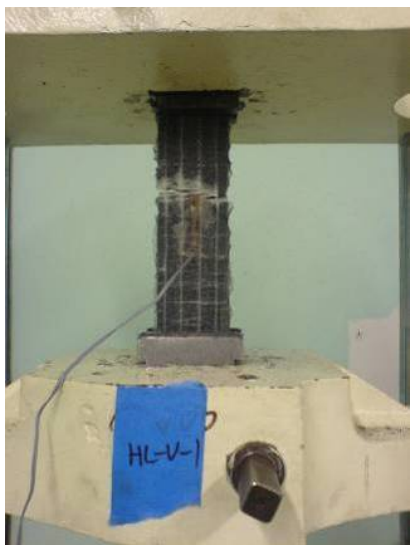

Figure 5.61 Failure Mode of HL-V-1: LGM

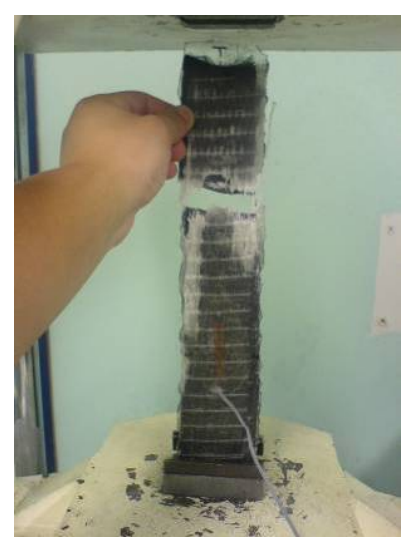

Figure 5.58 Failure Mode of HH-V-2: LAT

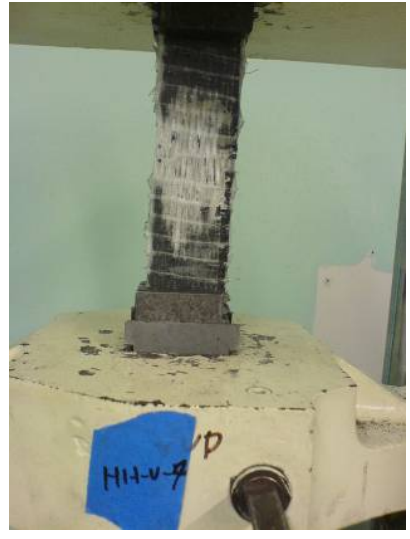

Figure 5.60 Failure Mode of HH-V-4: LGM

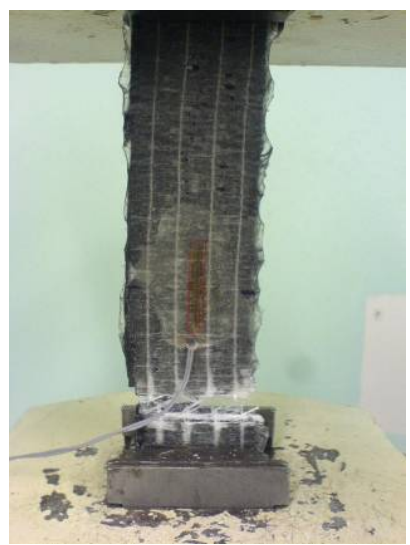

Figure 5.62 Failure Mode of HL-V-2: LWB 


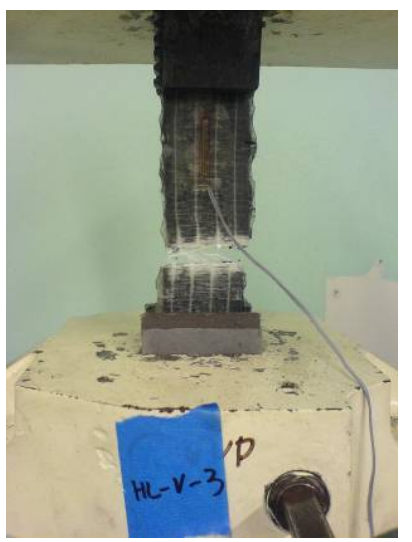

Figure 5.63 Failure Mode of HL-V-3:

LWB

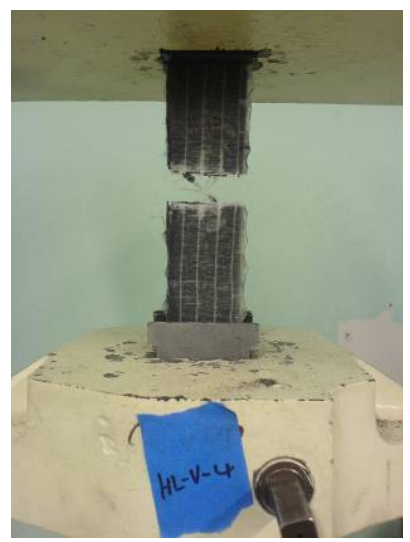

Figure 5.64 Failure Mode of HL-V-4:

LGM

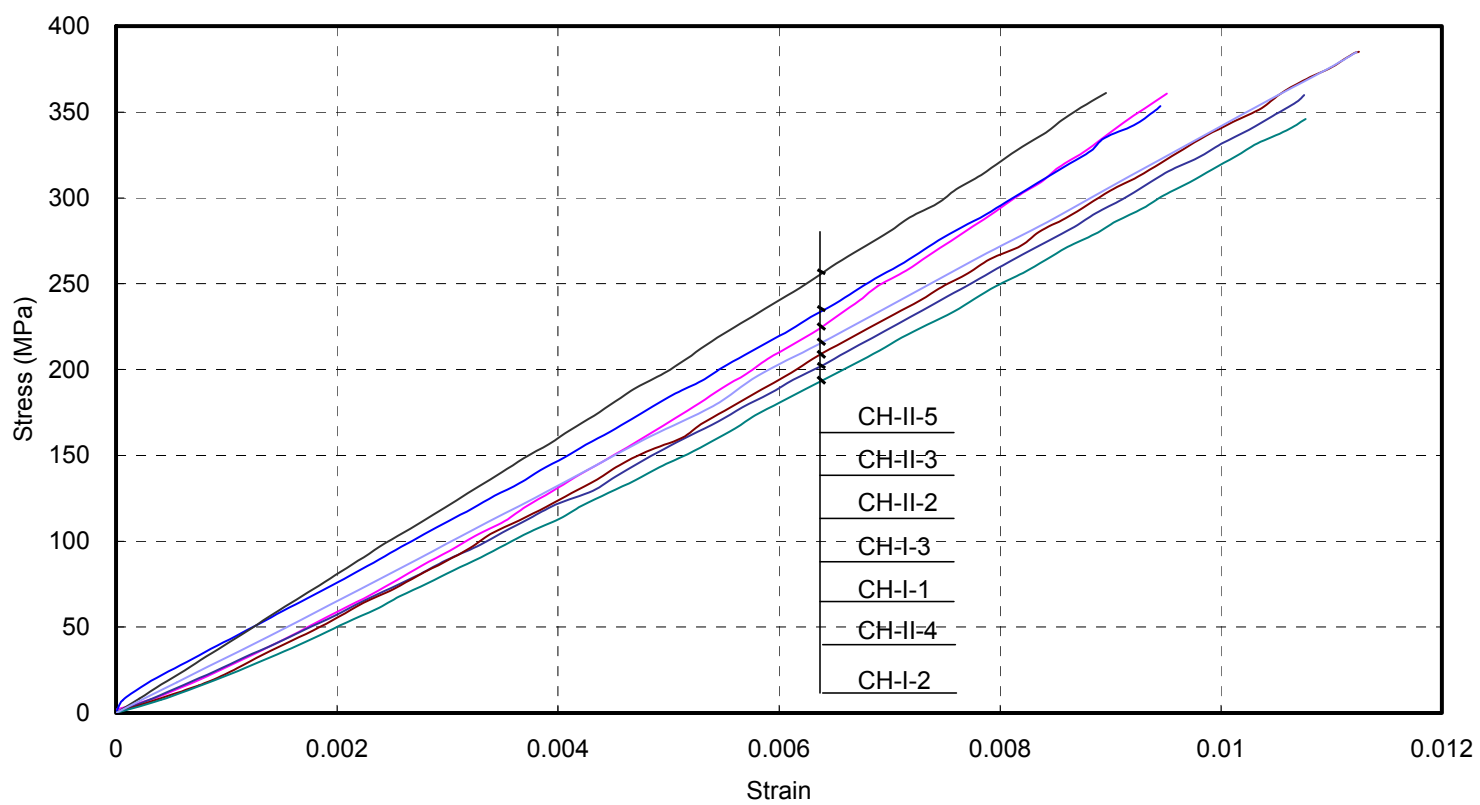

Figure 5.65 Tensile Stress-Strain Responses of CH Coupons 


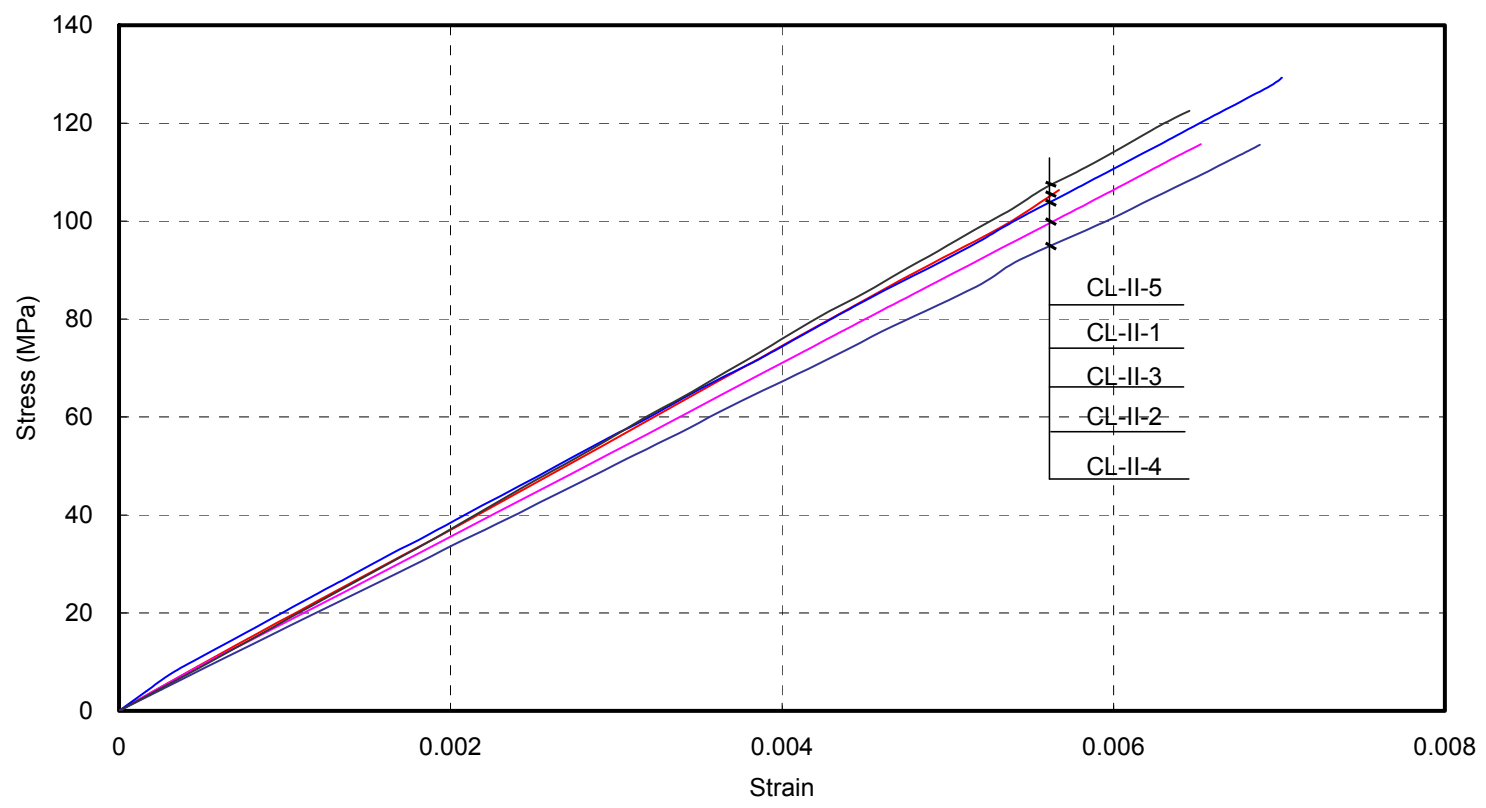

Figure 5.66 Tensile Stress-Strain Responses of CL Coupons

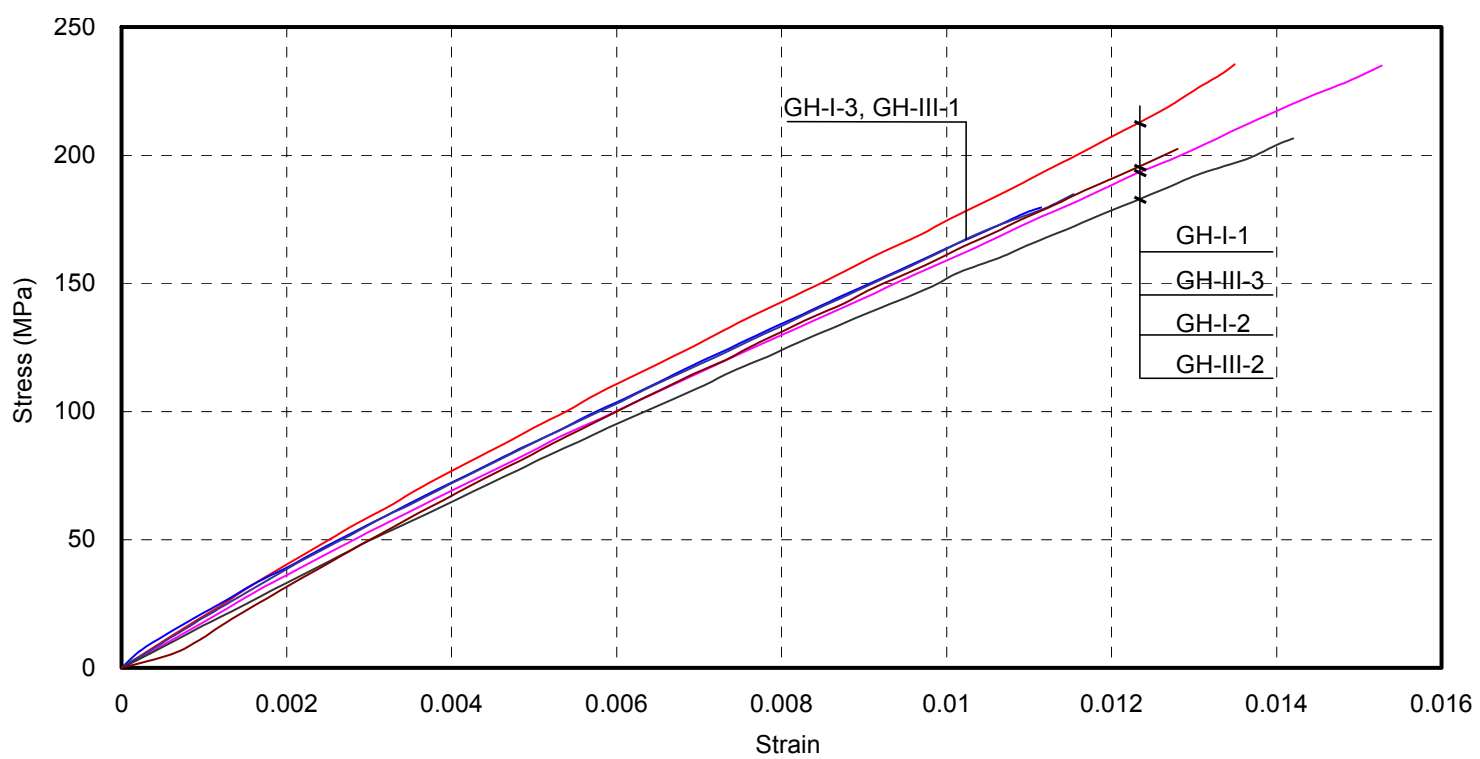

Figure 5.67 Tensile Stress-Strain Responses of GH Coupons 


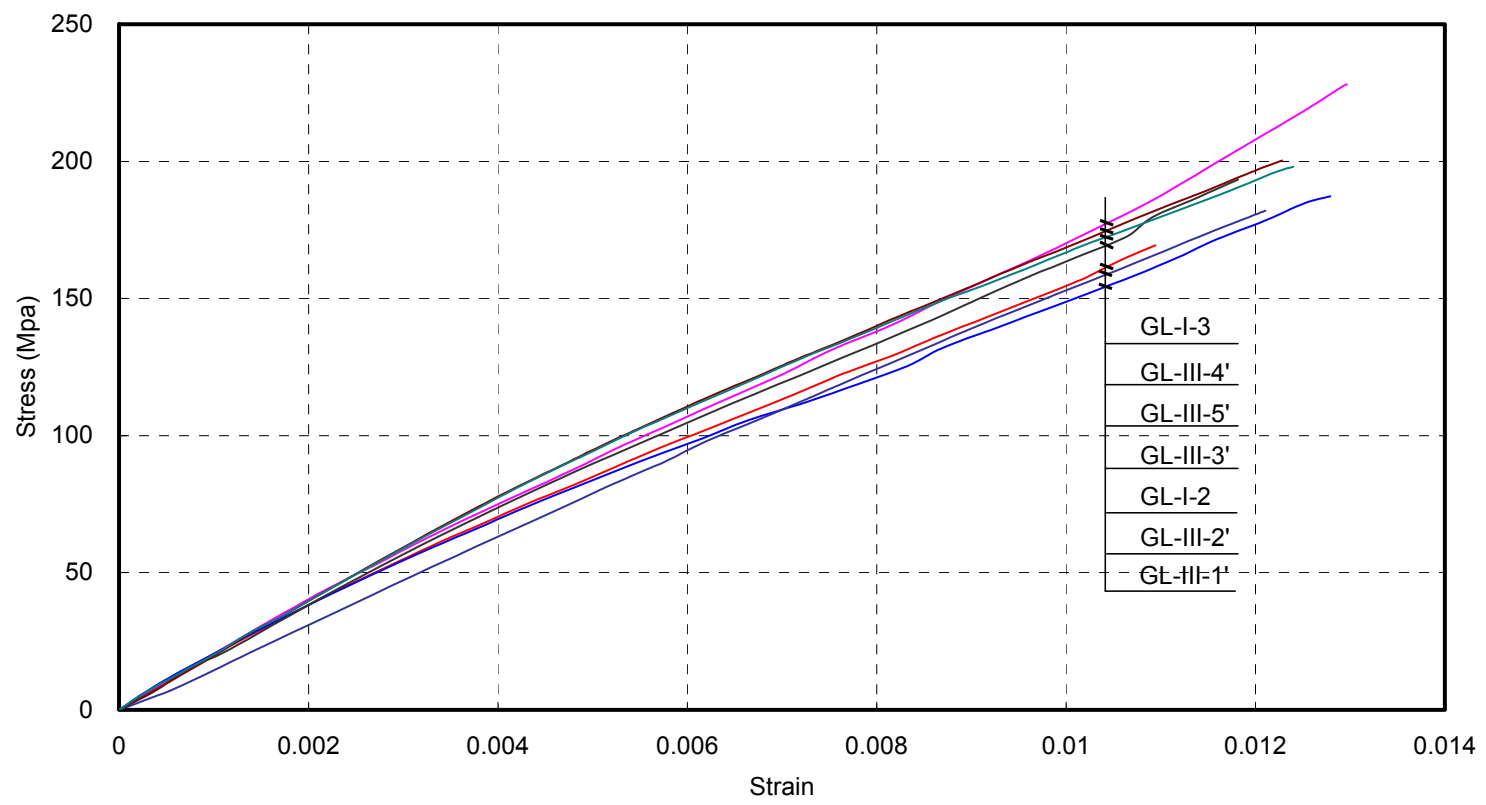

Figure 5.68 Tensile Stress-Strain Responses of GL Coupons

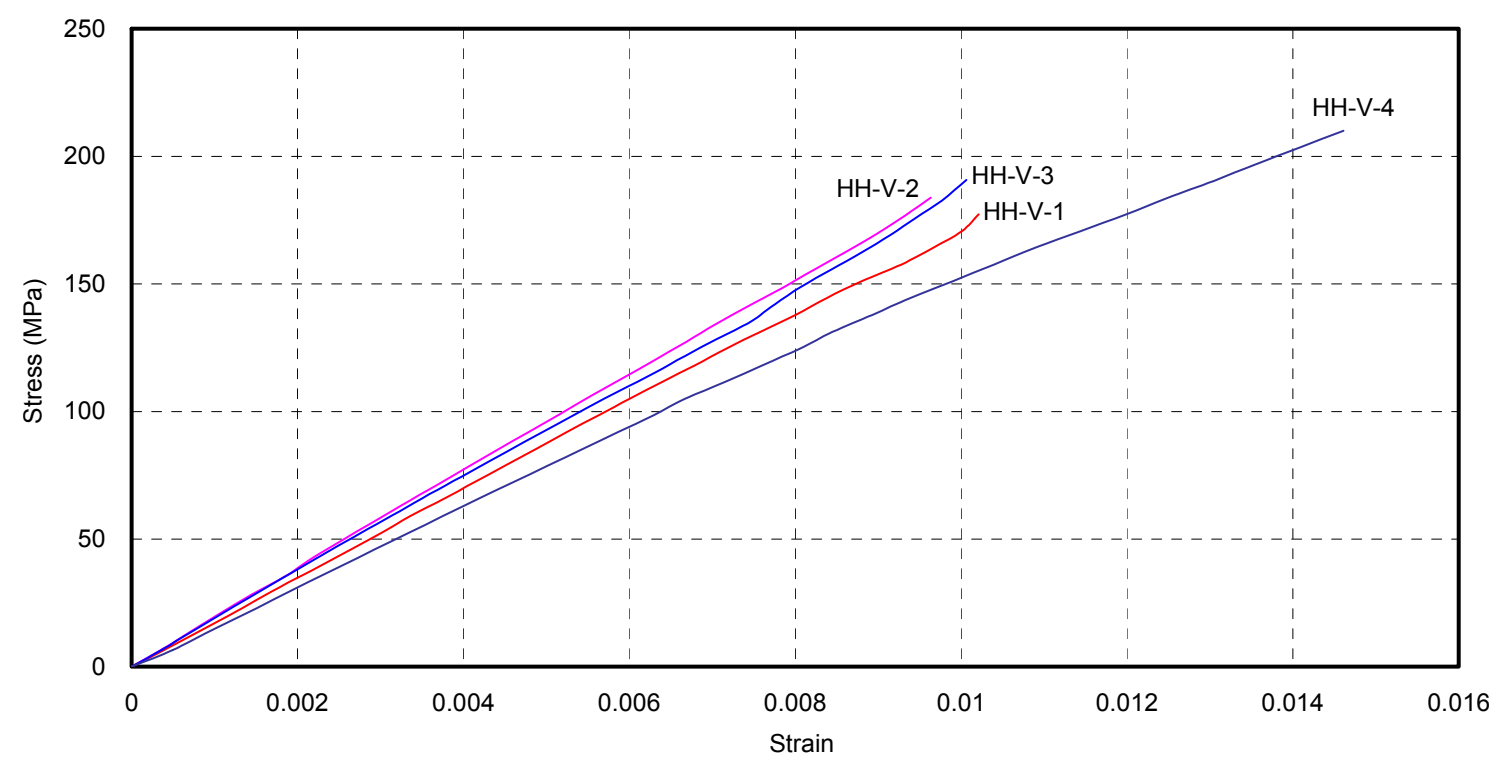

Figure 5.69 Tensile Stress-Strain Responses of HH Coupons 


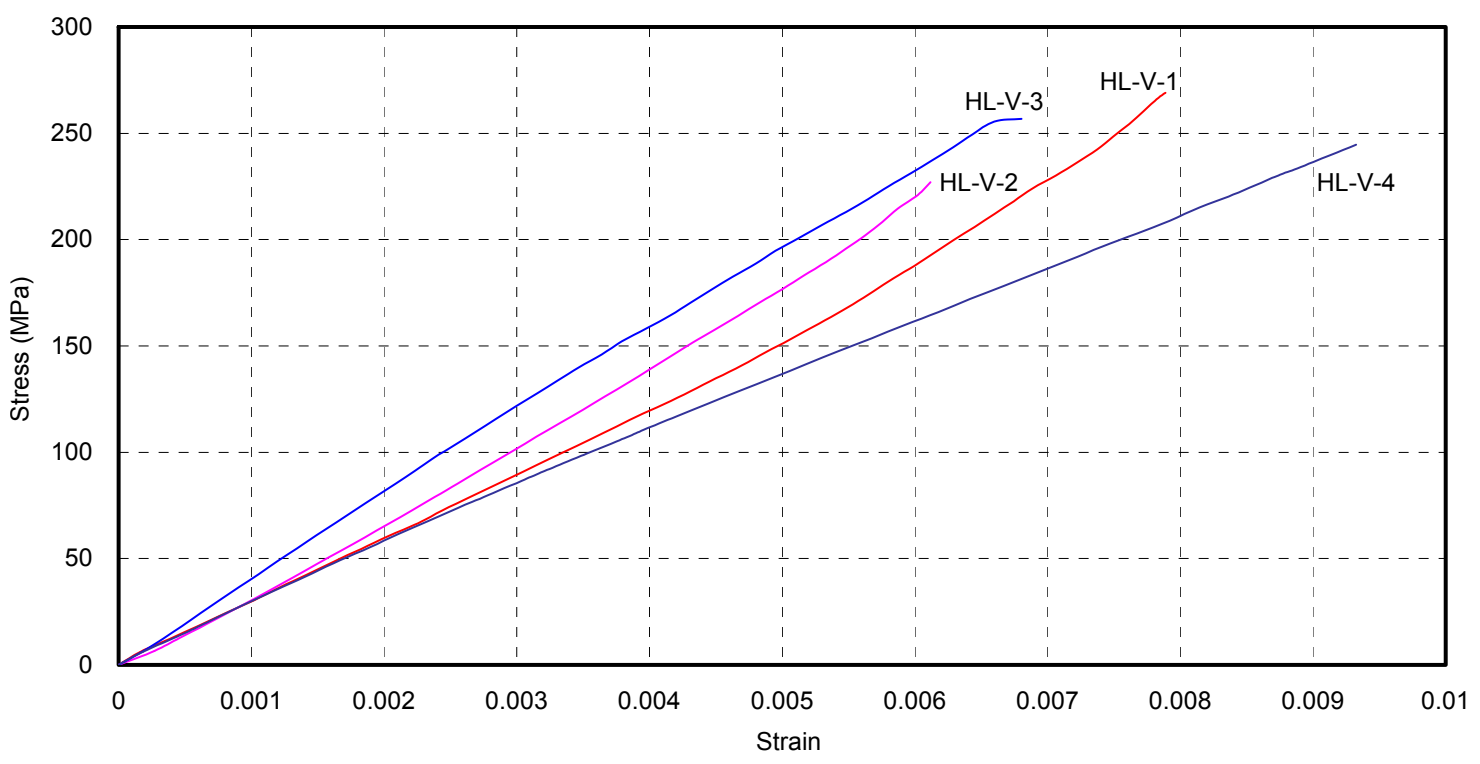

Figure 5.70 Tensile Stress-Strain Responses of HL Coupons 


\section{CHAPTER 6 NONDESTRUCTIVE DAMAGE ASSESSMENT}

\subsection{INTRODUCTION}

After the cyclic tests, none of the specimens with glass or hybrid FRP tubes showed visible cracks on the surface. As discussed in Chapter 4, additional monotonic tests on these specimens were deemed to provide better understanding of their flexural strengths. In order to further investigate the damage level of the specimens, nondestructive damage assessment using ultrasonic pulse velocity was also considered as useful tool prior to the monotonic tests. This chapter presents some of the results using ultrasonic tone bursts to investigate internal damage of previously loaded RC and CFFT specimens.

\subsection{EXPERIMENTAL WORK}

\subsubsection{Test Setup and Instrumentation}

The ultrasonic pulse velocity (UPV) equipment used in this study is a very low frequency (VLF) system developed by Digital Wave Corp of Englewood, CO. The VLF ultrasound extends the penetration capability of conventional ultrasonic testing, and can be used in wood, concrete, composites and rubber. Figure 6.1 shows the block diagram of the test equipment.

The system consists of a synthesized function generator, two broadband transducers, two broadband preamplifiers, one ultrasonic tone-burst amplifier, an 8-bit analog to digital (A/D) board, and laminated plate wave analyzer (LPWA) data acquisition and analysis software. A Stanford Research Systems Model DS345 function 
generator was used to provide input of any pulse waveform of Gaussian modulated cosine, sinusoidal tone burst, swept sine (high or low), single or stepped frequency pulse, and single or multiple pulses at each frequency step. The waveforms could be entered manually or by downloading from the computer through a serial port by the LPWA software. Two broadband B225 transducers were used as pulse and receiver sensors (Figure 6.2), which could transmit signals of any frequency between $1 \mathrm{kHz}$ to $1.5 \mathrm{MHz}$. The $10 \mu \mathrm{V}-10 \mathrm{mV}$ range of output signal from the sensors is enhanced by PA2040 broadband acoustic emission preamplifiers. The UTA 3000 amplifier produces highamplitude tone bursts with a frequency range between $10 \mathrm{kHz}$ and $900 \mathrm{kHz}$ and a total gain of $70 \mathrm{~dB}$. A 10-turn potentiometer knob controls the gain. Combined with Digital Wave's B225 sensor, the UTA 3000 makes it possible to send waves through $400 \mathrm{~mm}$ of concrete. A Sonix STR*825 8-bit A/D board was used to capture the new waveform data, to convert it to a digital signal, and to further allow the signal analyzer to store the waveform data. The waveform was digitized at a frequency of $6.25 \mathrm{MHz}$, resulting in $0.16 \mu \mathrm{s}$ accuracy for travel time measurements, or about $0.25 \%$ error in velocity calculations.

The six specimens after the cyclic tests were first marked for UPV transducer points along their lengths. For the five short specimens (Specimen RC, Y, G, H and SC), eleven sections along column length were identified, whereas in Specimen LC twelve sections were established. At each section along the columns, eight sensing directions were conducted, denoted as $\mathrm{B}, \mathrm{L}, \mathrm{R}, \mathrm{T}, \mathrm{H}, \mathrm{LR}, \mathrm{RL}$ and $\mathrm{V}$, as shown for each figure later described in Section 6.2.3. The sensors were held by hand firmly perpendicular to 
specimen surface with a high viscosity ultrasonic couplant (SLC 70 from GE Inspection Technologies). Figure 6.3 shows the typical test setup and instrumentation.

\subsubsection{Test Procedure and Observations}

A five-cycle tone burst waveform with a $100 \mathrm{kHz}$ frequency was used in this study. The gain was adjusted on the amplifier to yield a clear signal at the receiving end. An initial recording of the signal was made before the start of the test. About 5-10 recordings were made at each testing direction along the eleven or twelve sections on the columns. After the tests, travel time was obtained from recordings of LPWA software. Meanwhile, the section perimeters at each section along columns were measured and the diameters of the column, or travel distances of the waveform, were derived. Finally, travel velocities were compared.

In the severely damaged region of Specimen RC, signals were hardly distinguishable. In the column-footing connection region of Specimens SC and LC, the signals in some directions were very weak due to cracking of FRP. Apart from these cases in which the data was not obtained, all other testing points provided clear signals, albeit with varying strengths.

\subsubsection{Test Results and Discussion}

\subsubsection{Velocities in Different Directions for Each Specimen}

Figure 6.4 (a) through (f) show the velocities in the peripheral B, L, R and T sensing directions for all specimens. Figure 6.5 (a) through (f) show the velocities in the diagonal $\mathrm{H}, \mathrm{LR}, \mathrm{RL}$ and $\mathrm{V}$ sensing directions for all specimens. It is noted that 
measurements in the peripheral directions generally had lower dispersion than those in the diagonal directions. It is also noted that velocity measurements generally did not vary along the columns. This may simply indicate the low resolution of the UPV technique to assess damages in the type of specimen and loading configuration of this study. In few of the specimens and in some directions, the expected trend of lower velocities near the column-footing joint was observed.

In the peripheral directions, the velocity measurements are quite close to each other. This may indicate that generally, damage after the cyclic tests at the top and bottom sections must have not been significant to compare well with the $\mathrm{B}$ and $\mathrm{T}$ directions. The only exceptions lie in the T direction along some parts of the columns in Specimens SC and LC. Variations in some of the measurements through top layer may be attributed to the epoxy injection, although the injection worked rather well for Specimens Y, G and H. It is noteworthy that Specimen Y had least variation of measurements in the peripheral directions along the column.

The velocity measurements in the diagonal directions varied in all specimens, although the differences were least at column bases in Specimens G and H. This may be attributed to full-depth through cracks in concrete core. This was not the case for Specimen $\mathrm{Y}$, where velocity measurement in the $\mathrm{H}$ direction was significantly higher than in the $\mathrm{V}$ direction at column base relative to other sections along the column. This may be attributed to less full-depth through cracks in Specimen Y.

Tensile strains in FRP measured during cyclic tests may help explain why Specimens Y, G and H all had fluctuating velocities, whereas Specimens SC and LC had relatively consistent velocities throughout column lengths. From Table 5.19, maximum 
FRP tensile strains in the cyclic tests for Specimens G, SC and LC were 0.011, 0.006, and 0.003 , respectively. In Specimens $\mathrm{Y}$ and $\mathrm{H}$, maximum strains at column base were not available, but expected to be higher than those measured for Specimens SC and LC. The higher strains are therefore expected to have helped develop more extensive cracks in concrete cores for Specimens Y, G and H, relative to Specimens SC and LC.

Figure 6.6 (a) through (f) show the average velocity measurements in the peripheral and diagonal directions in all specimens. In general, with some exceptions, the velocities in the diagonal directions are lower than those in the peripheral directions. This is consistent with the expected through cracks within concrete core, rather than close to the tubes.

Figure 6.7 (a) through (f) show the velocity measurements at three vertical slices (L, R and V directions) in all specimens. Generally, the velocity measurements in the $\mathrm{V}$ direction were lower than those in the other two slices, as expected. The only exceptions are at few sections in Specimens $\mathrm{H}$ and G. Nonetheless, the measurements in the $\mathrm{V}$ direction at column base were always lower than in the $\mathrm{L}$ and $\mathrm{R}$ directions even for those two specimens. It is also noted that velocities in the $\mathrm{L}$ and $\mathrm{R}$ directions in all specimens were quite close to each other, indicating symmetry in the loading and response.

Figure 6.8 (a) through (f) show the velocity measurements at the three horizontal slices ( $\mathrm{B}, \mathrm{H}$ and $\mathrm{T}$ directions) in all specimens. Average velocities in the $\mathrm{B}$ and $\mathrm{T}$ directions were also plotted as dash lines in the figures. In Specimens SC and LC, the velocity in the $\mathrm{H}$ direction was always lower than the average velocity in the $\mathrm{B}$ and $\mathrm{T}$ directions; similar to what was discussed for Figure 6.6. In Specimens H and Y, velocity in the $\mathrm{H}$ direction was generally lower than the average velocity in the $\mathrm{B}$ and $\mathrm{T}$ 
directions, with a few exceptions near column base region. While in Specimen RC, the velocities were almost at the same level in the undamaged region. In Specimen G, however, the velocity in the $\mathrm{H}$ direction was generally higher than the other two directions, except at or near the column base.

\subsubsection{Velocities in Different Specimens for Specific Sensing Directions}

Figure 6.9 (a) through (f) show velocity measurements at the peripheral B, L, R and $\mathrm{T}$ directions for all specimens. Average velocity measurements in the $\mathrm{L}$ and $\mathrm{R}$ directions as well as average of the four directions are also shown in the figures. Specimens SC and LC had the highest velocity measurements than their other four counterparts. The groups of Specimens $\mathrm{Y}, \mathrm{G}$ and $\mathrm{H}$ had the lowest velocity measurements, while Specimen RC lies in between these two groups in the undamaged part of the column.

Specimen SC had higher velocity measurements than Specimen LC in the B direction and the average of $\mathrm{L}$ and $\mathrm{R}$ directions, perhaps because Specimen $\mathrm{LC}$ developed higher FRP tensile strains than those in Specimen SC. It is also noted that they had almost identical responses at column base, when considering average measurements in the $\mathrm{L}$ and $\mathrm{R}$ directions.

Specimens $\mathrm{Y}, \mathrm{G}$ and $\mathrm{H}$ had almost identical velocity measurements at column base in the $\mathrm{B}$ direction, while showing a slight difference in the $\mathrm{L}, \mathrm{R}$ and $\mathrm{T}$ directions.

Figure 6.10 (a) through (f) velocity measurements in the diagonal H, LR, RL and

$\mathrm{V}$ directions for all specimens. Average velocity measurements in the LR and RL 
directions as well as average of the four directions are also shown in the figures. It generally follows the same trend discussed in Figure 6.9, especially at column base.

Finally, Figure 6.11 shows the average velocity measurements of all directions for all specimens. It is evident that the velocity measurements of Specimen SC were the highest, followed closely by Specimen LC. Specimens Y, G and H all had lower velocities than Specimens SC and LC. Specimen RC lay in between of the two groups except for column base which is severely damaged.

\subsubsection{Relationships of Average Velocity with Strength Index and FRP Rupture Strain}

Figure 6.12 shows the average velocity measurements of CFFT specimens versus their FRP strength indices as well as total strength indices as defined in Chapter 4. Figure 6.13 shows the average velocity measurements of CFFT specimens versus their FRP rupture strains as obtained in Chapter 5. The velocity measurements are averaged along the column lengths from the data in Figure 6.11 for each CFFT specimen. The strength indices are all based on the unconfined concrete compressive strength.

From Figure 6.12, it is clearly shown that average velocity measurements of CFFT specimens decrease along with the increase of their strength indices. This may indicate that the more strength capacity the specimen is, the more damage may develop in the specimen. From Figure 6.13, it is also shown that average velocity measurements of CFFT specimens generally decrease along with the increase of their FRP rupture strain. This may indicate that the more displacement capacity the specimen is, the more damage may develop in the specimen. These two figures clearly show that surface damage such as FRP cracking do not directly correlate with internal damage in concrete core. 
Therefore, Specimens $\mathrm{Y}, \mathrm{G}$ and $\mathrm{H}$ with little or no visible FRP crack contain much more internal cracks than Specimens SC and LC that had developed FRP cracks.

\subsection{CONCLUSIONS}

A series of nondestructive damage evaluation using ultrasonic tone bursts on previously loaded CFFT specimens were carried out. Following conclusions could be drawn based on the study:

1. The velocity measurements generally did not vary along the columns. This may simply indicate the low resolution of the UPV technique to assess damages in the type of specimen and loading configuration of this study.

2. The velocity measurements in the diagonal directions at column bases in Specimens $\mathrm{Y}, \mathrm{G}$ and $\mathrm{H}$ indicate full-depth through cracks in their concrete core, albeit to a lesser extent for Specimen Y.

3. In general, the velocities in the diagonal directions are lower than those in the peripheral directions, as expected.

4. The average velocity measurements of CFFT specimens decrease along with the increase of their strength indices. This may indicate that the more strength capacity the specimen is, the more damage may develop in the specimen.

5. The average velocity measurements of CFFT specimens generally decrease along with the increase of their FRP rupture strain. This may indicate that the more displacement capacity the specimen has, the more damage may develop in the specimen. 
6. It is shown that surface damage such as FRP cracking do not directly correlate with internal damage in concrete core. Therefore, Specimens Y, G and H with little or no visible FRP crack contain much more internal cracks than Specimens SC and LC that had developed FRP cracks. 


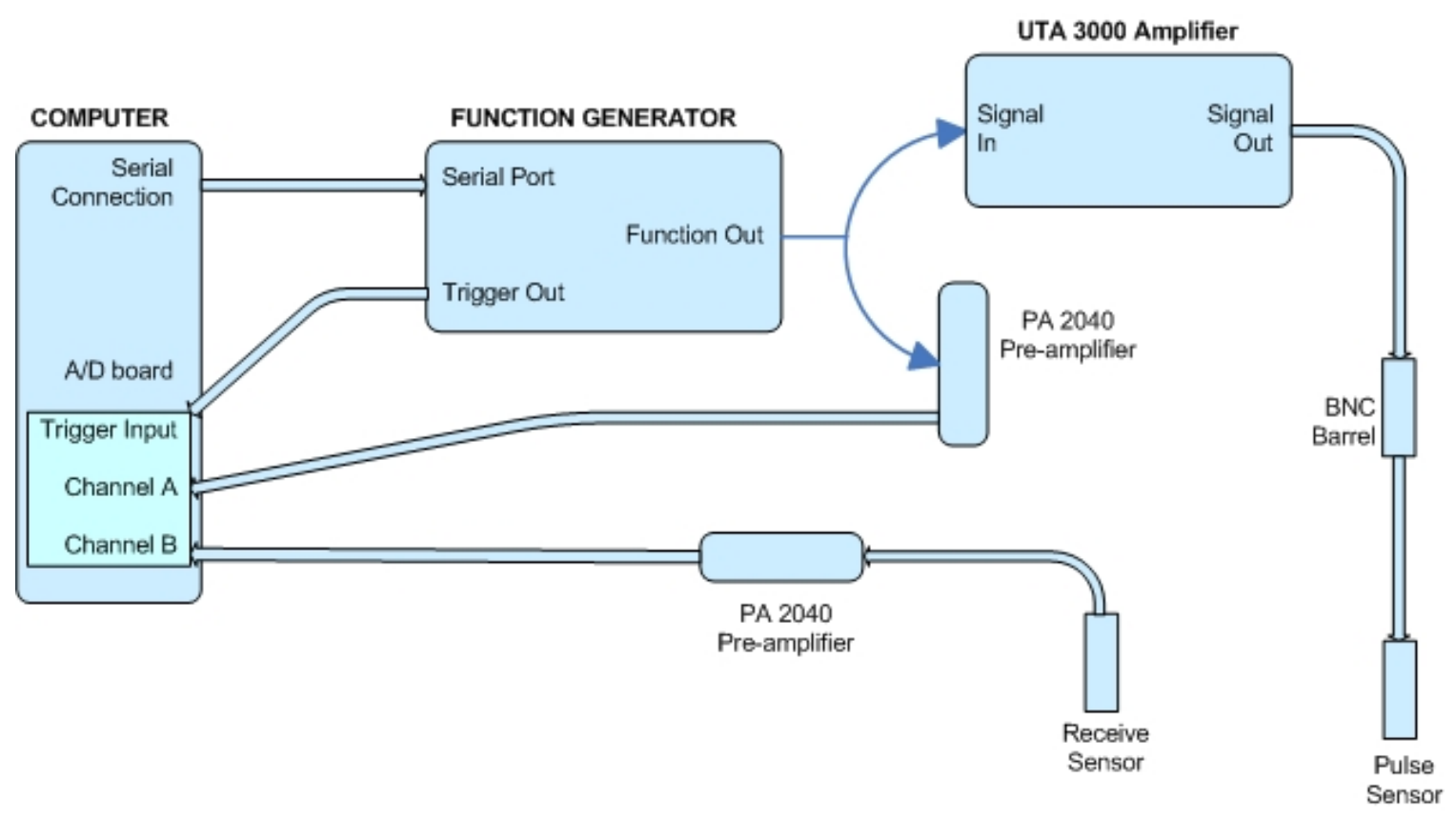

Figure 6.1 Block Diagram of Ultrasonic Equipment

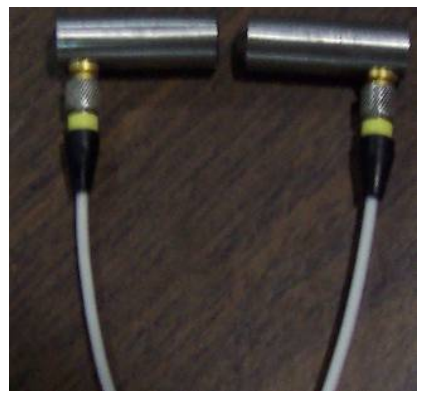

Figure 6.2 Two B225 Pulse and Receiver Transducers 


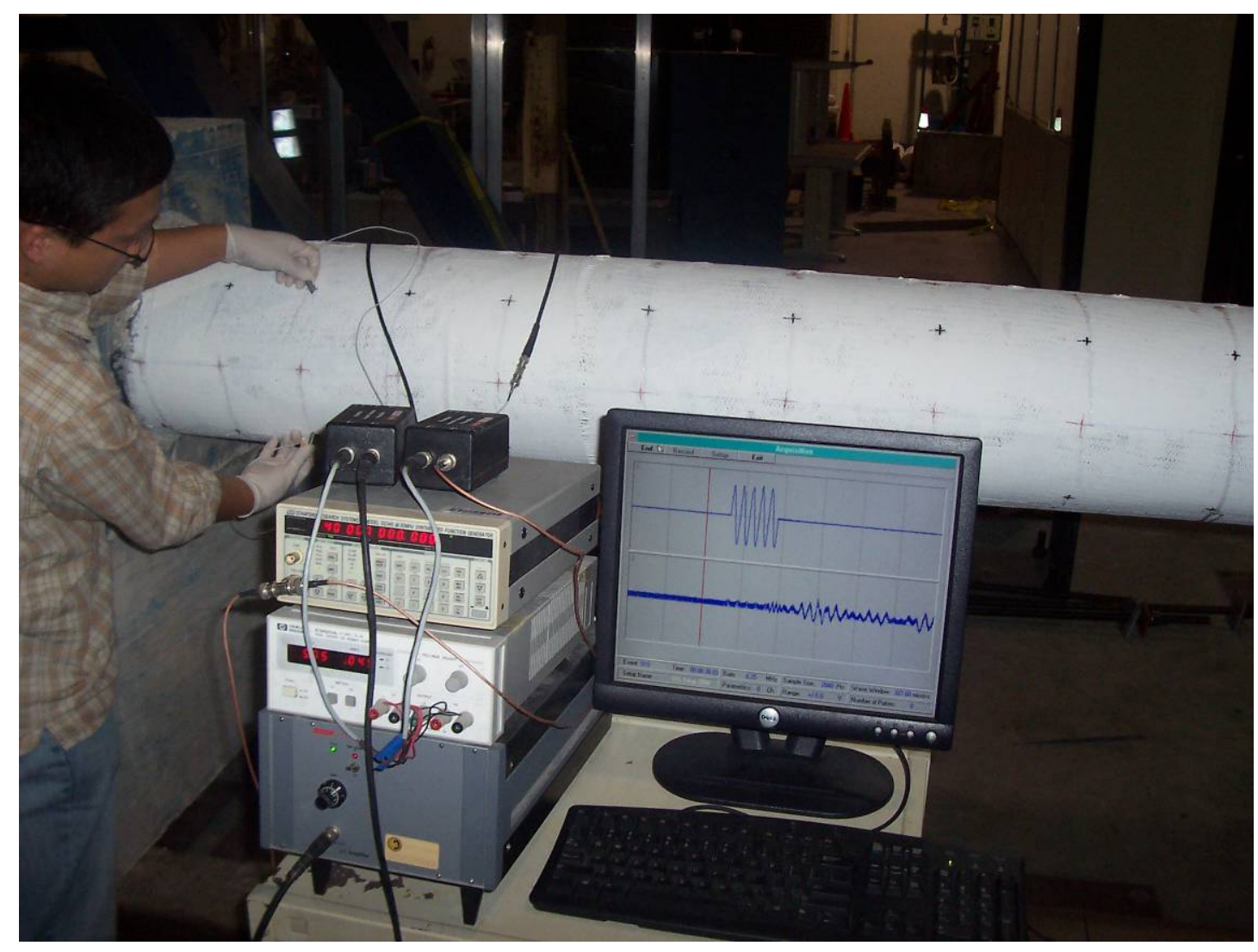

Figure 6.3 Test Set-up and Instrumentation 


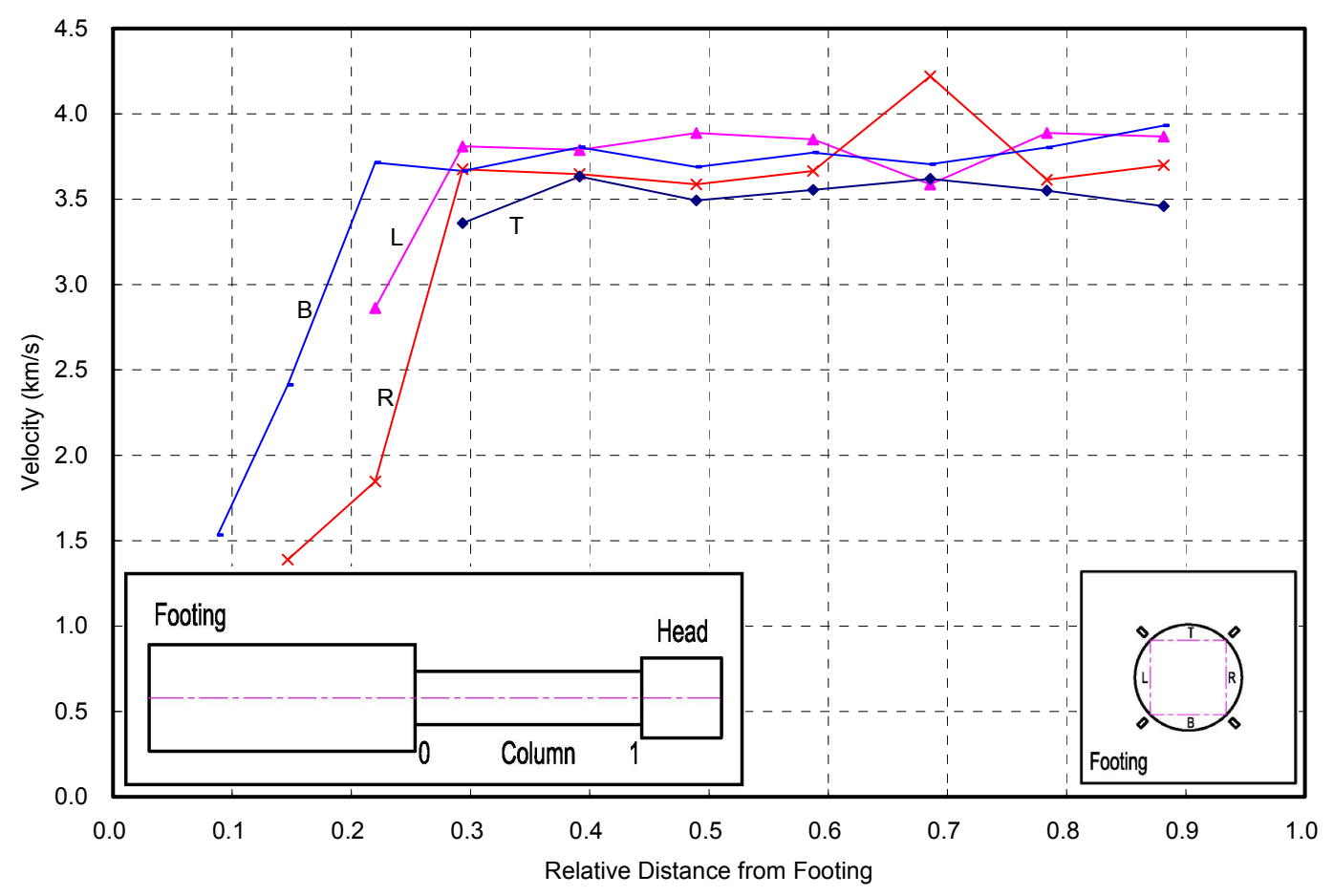

(a) Specimen RC

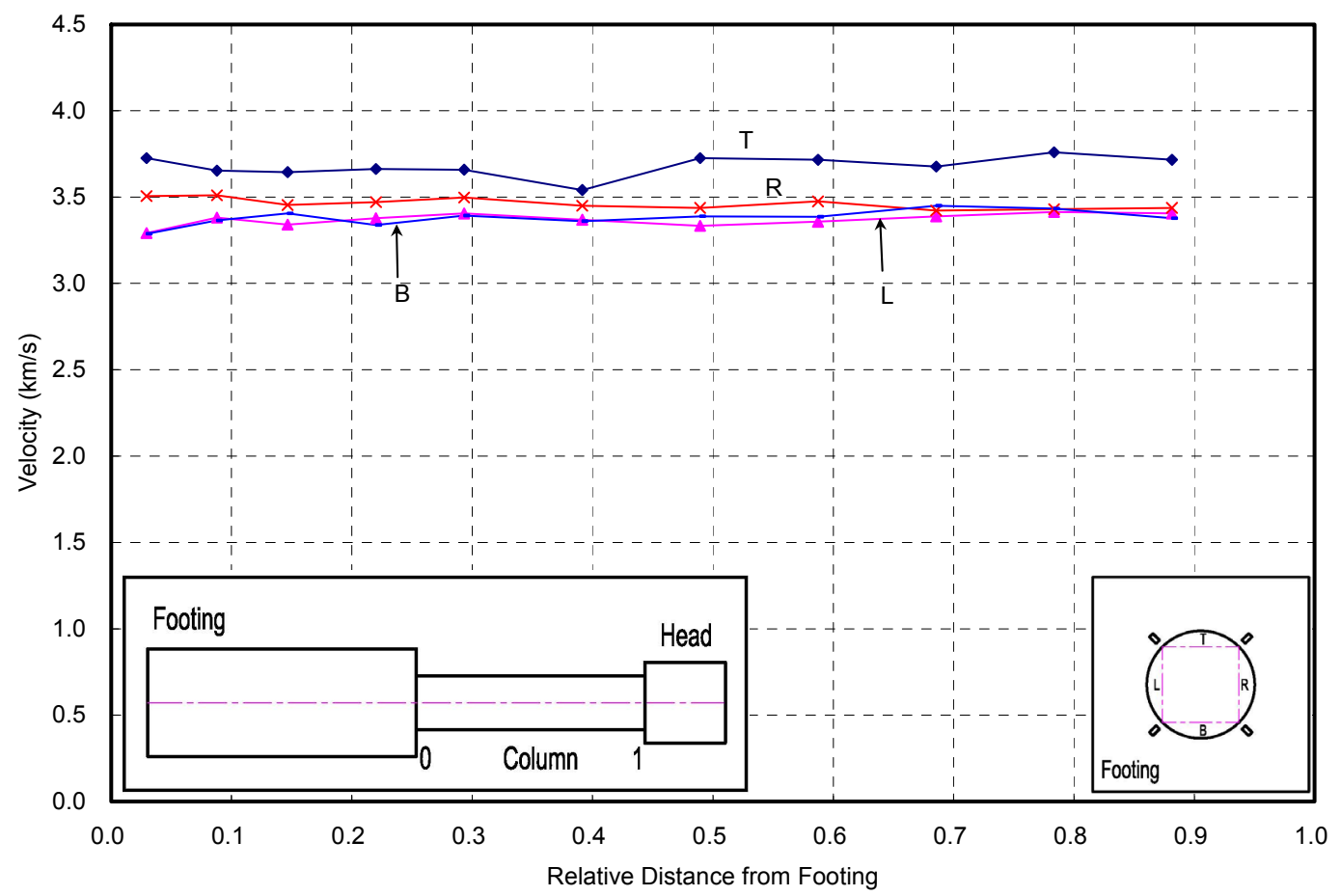

(b) Specimen Y 


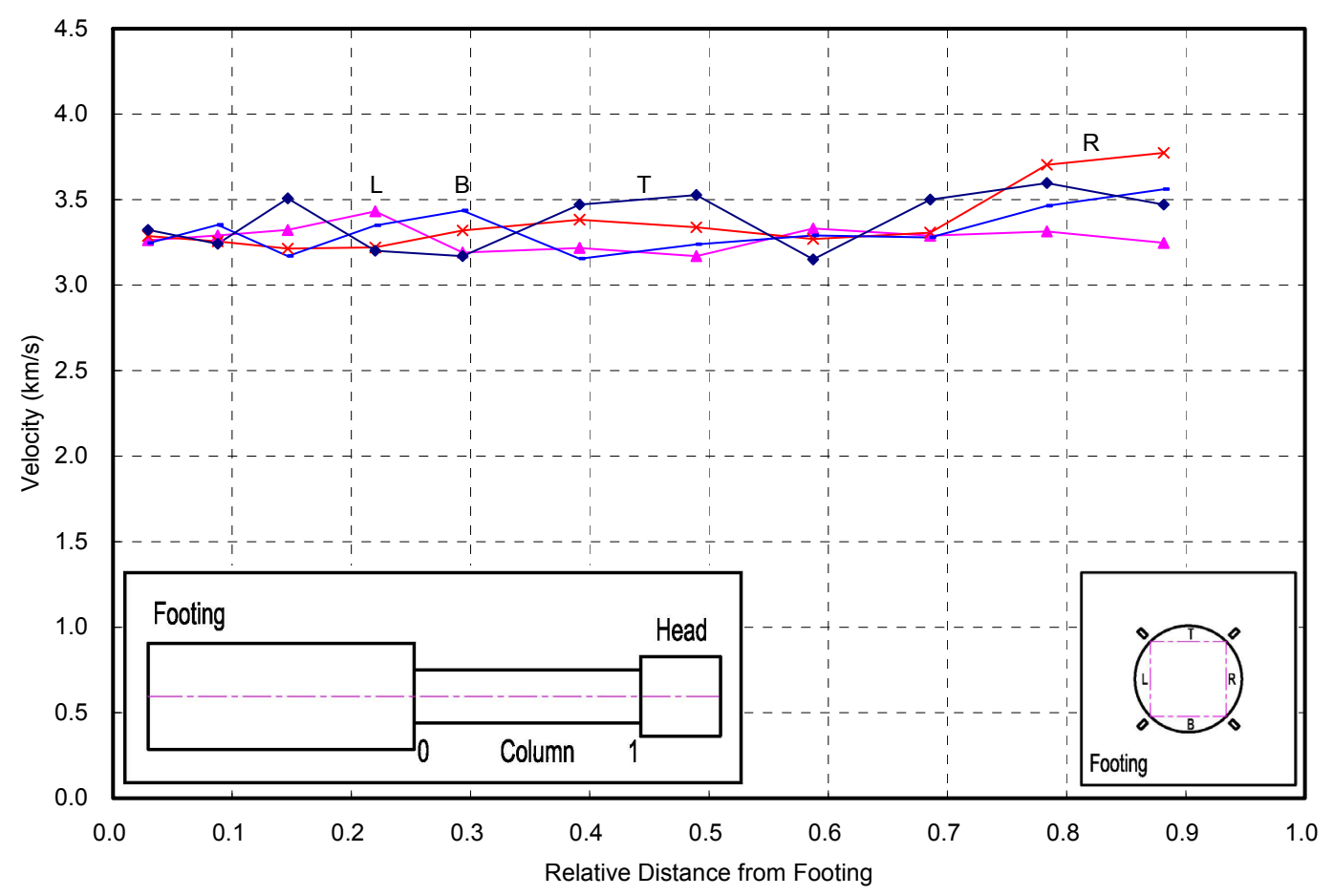

(c) Specimen G

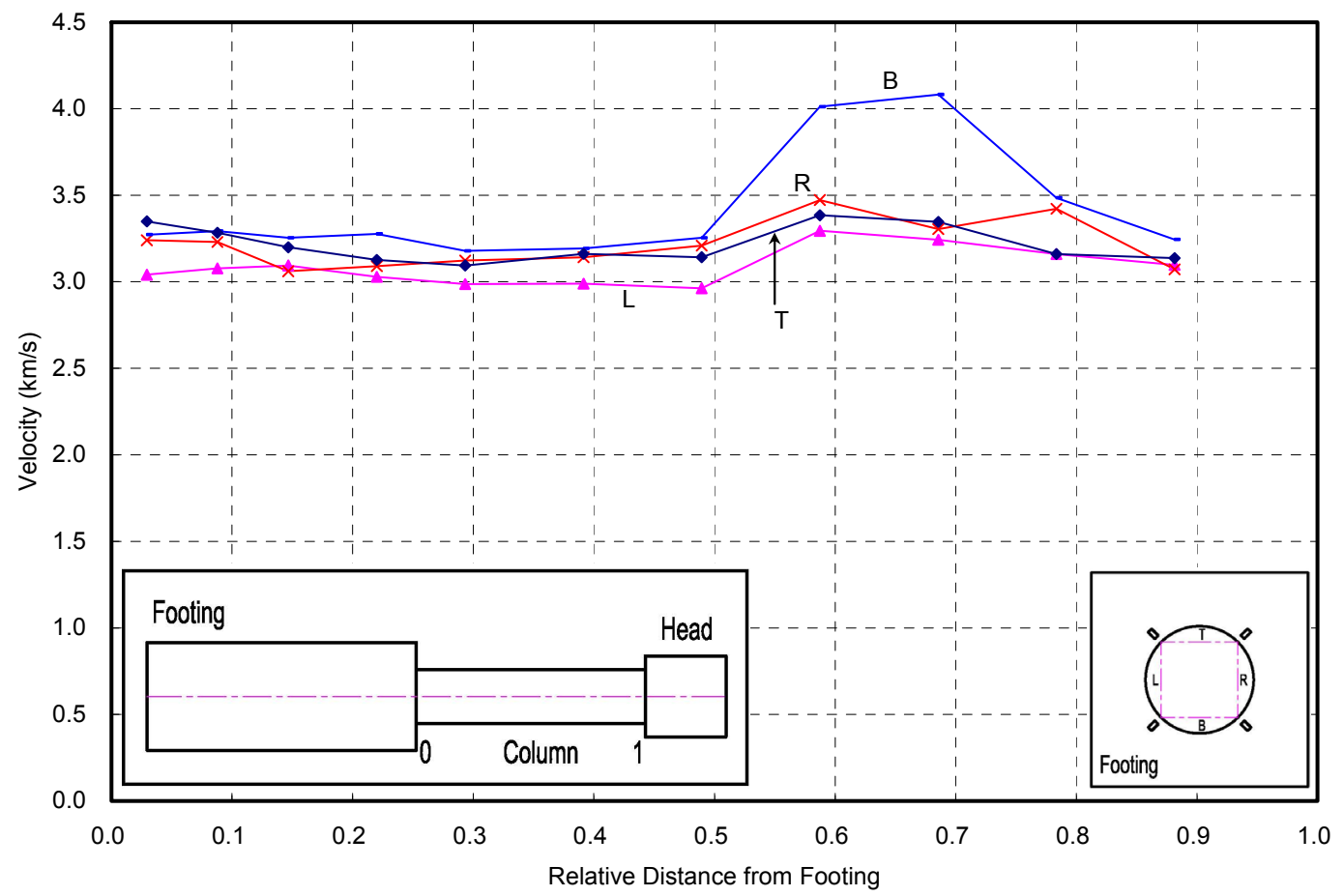

(d) Specimen H 


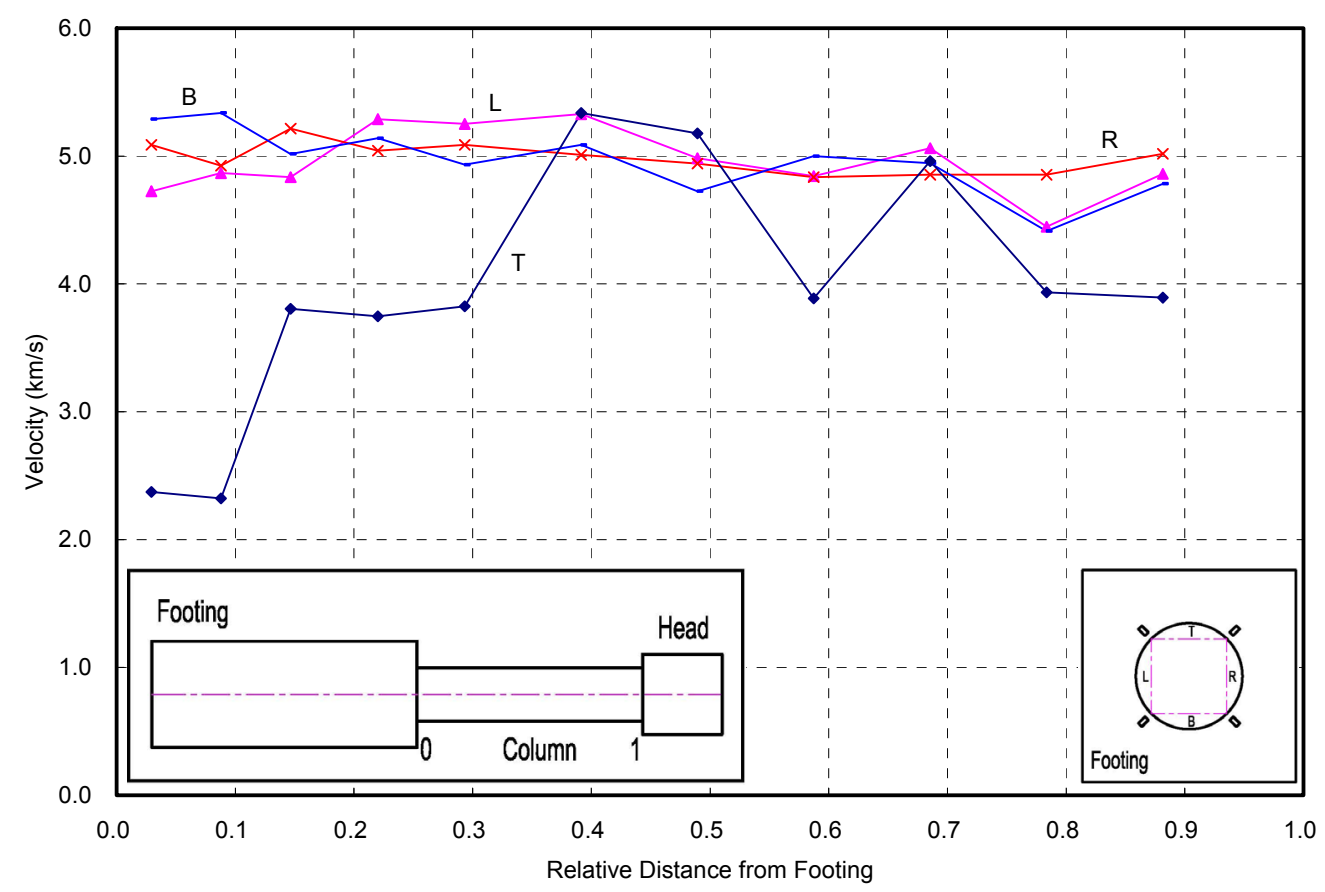

(e) Specimen SC

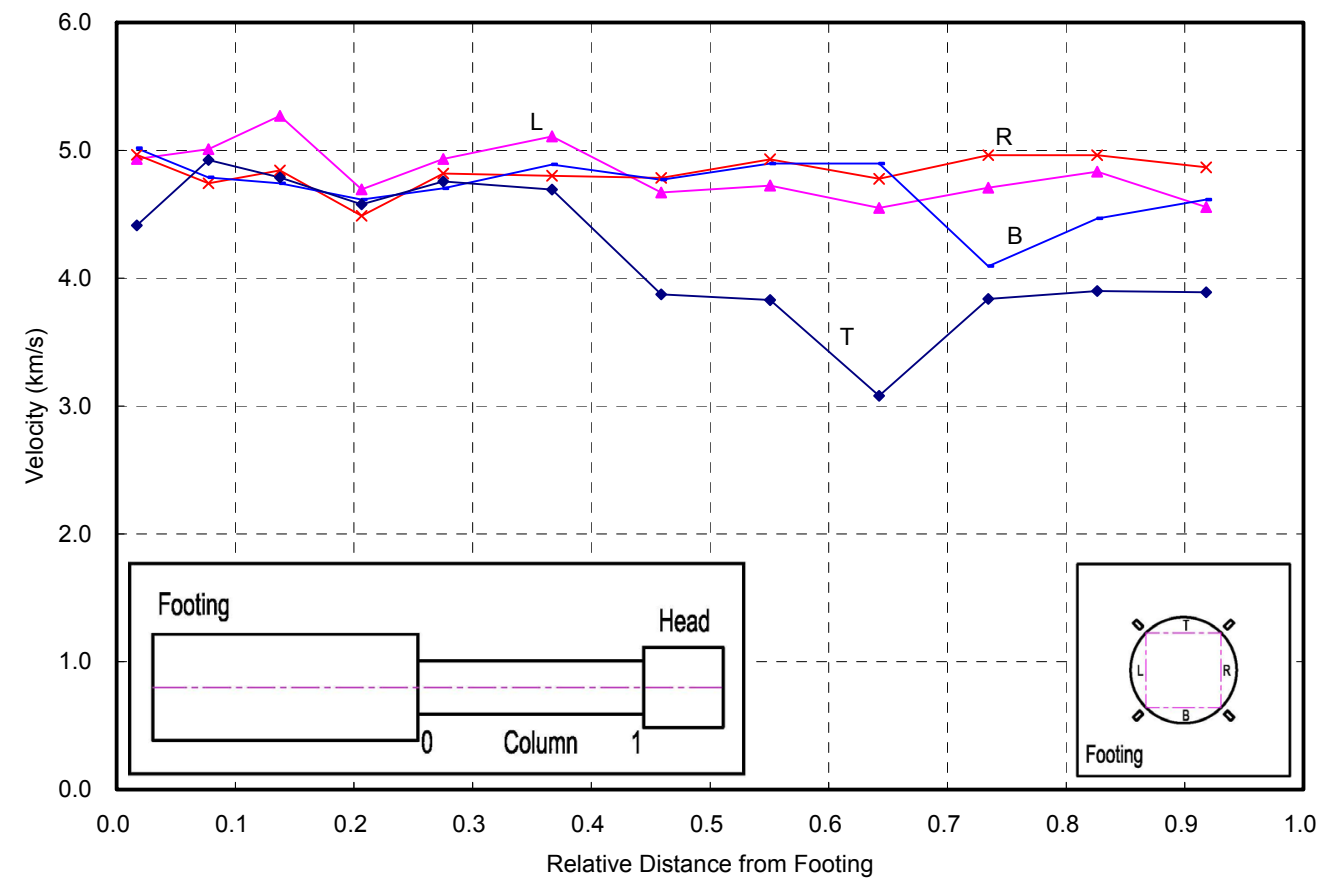

(f) Specimen LC

Figure 6.4 Velocity Measurements in the B, L, R and T Directions for Each Specimen 


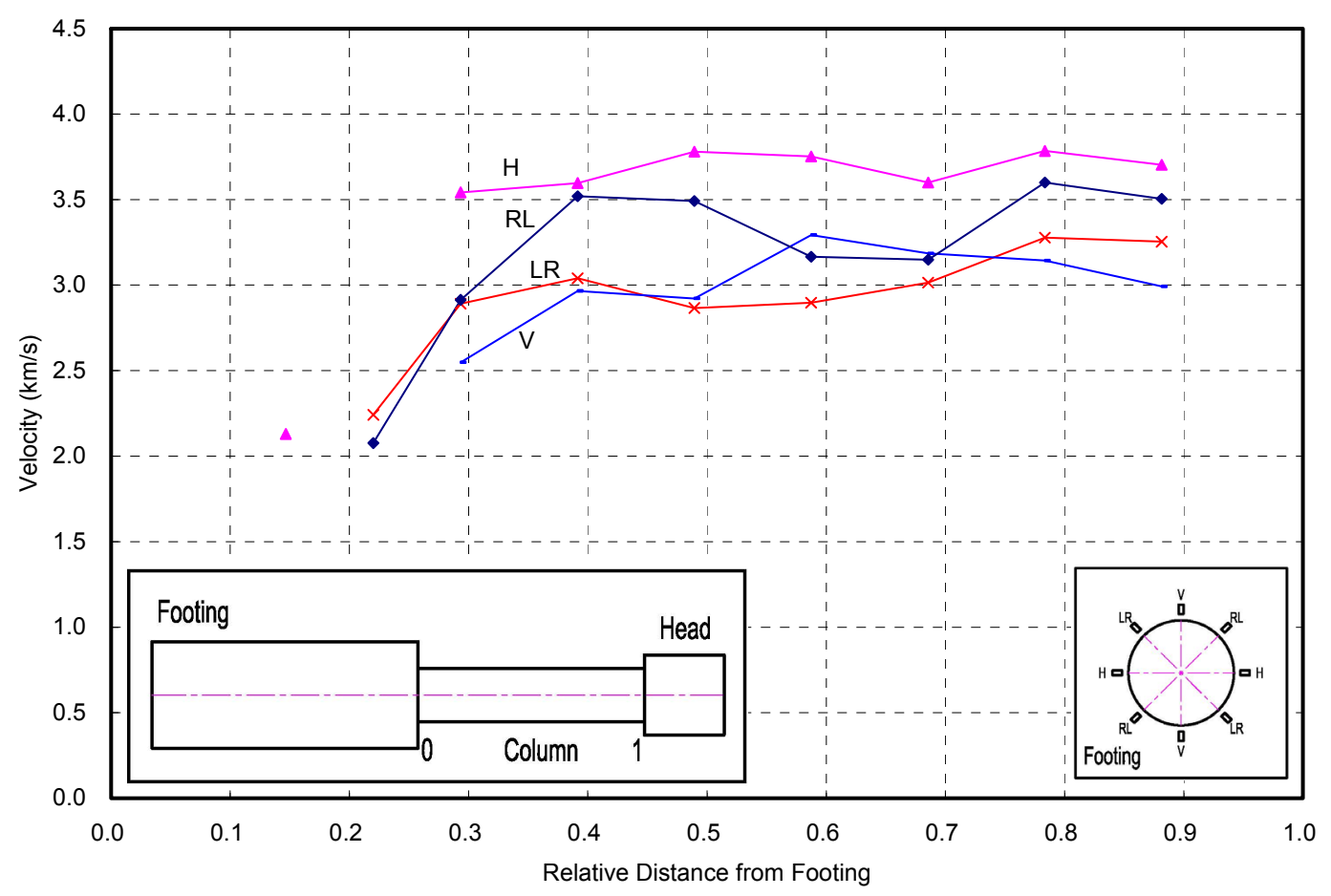

(a) Specimen RC

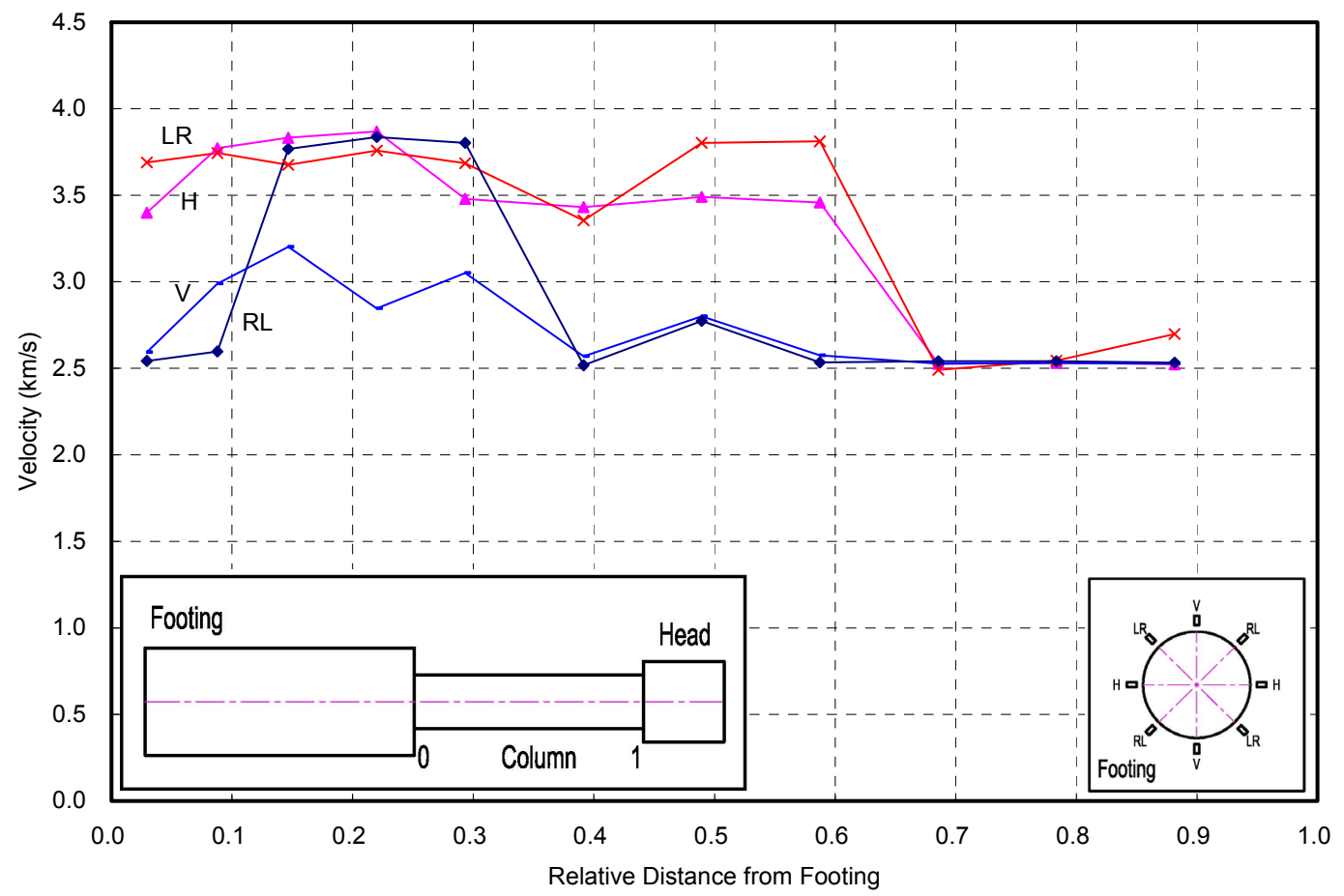

(b) Specimen Y 


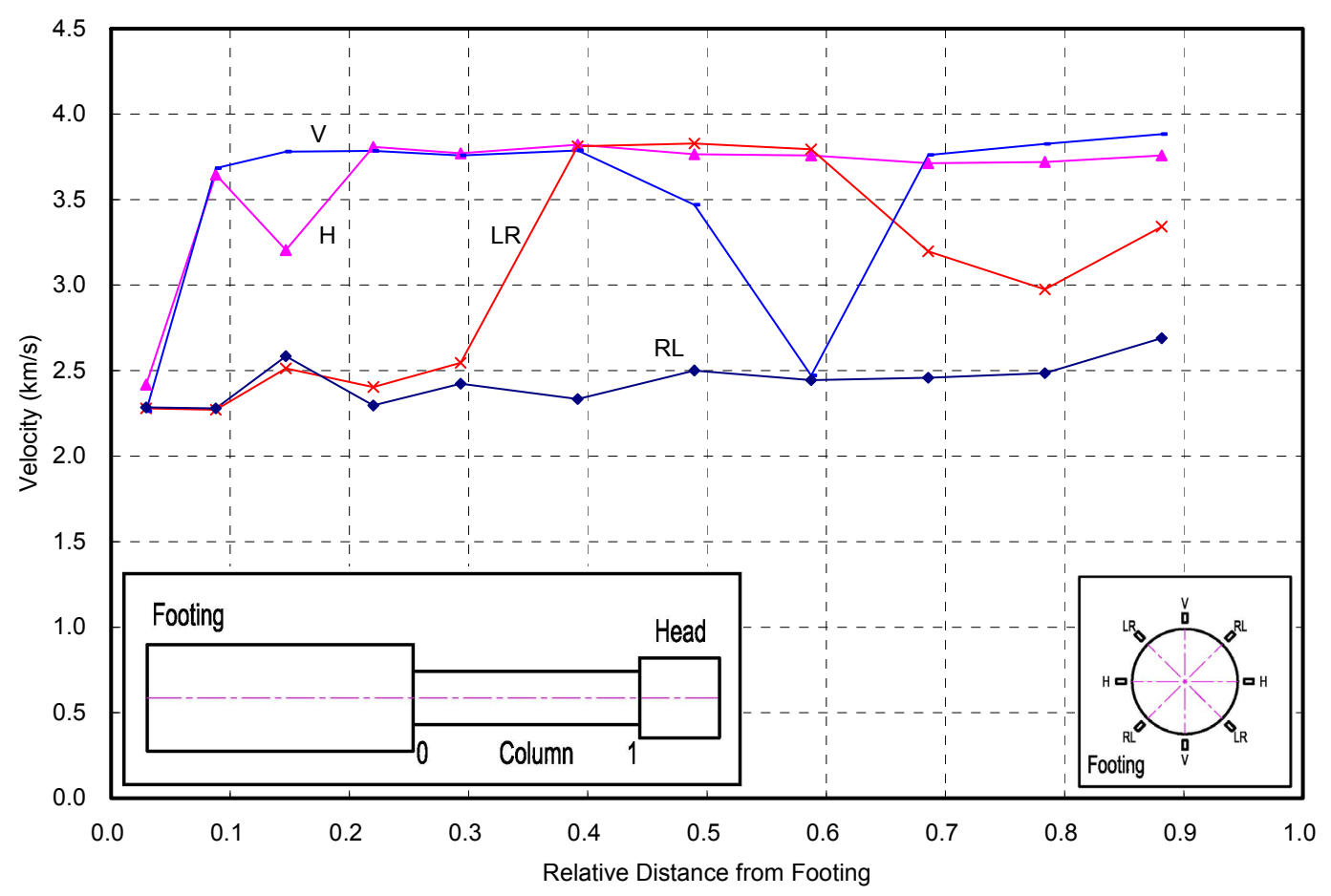

(c) Specimen G

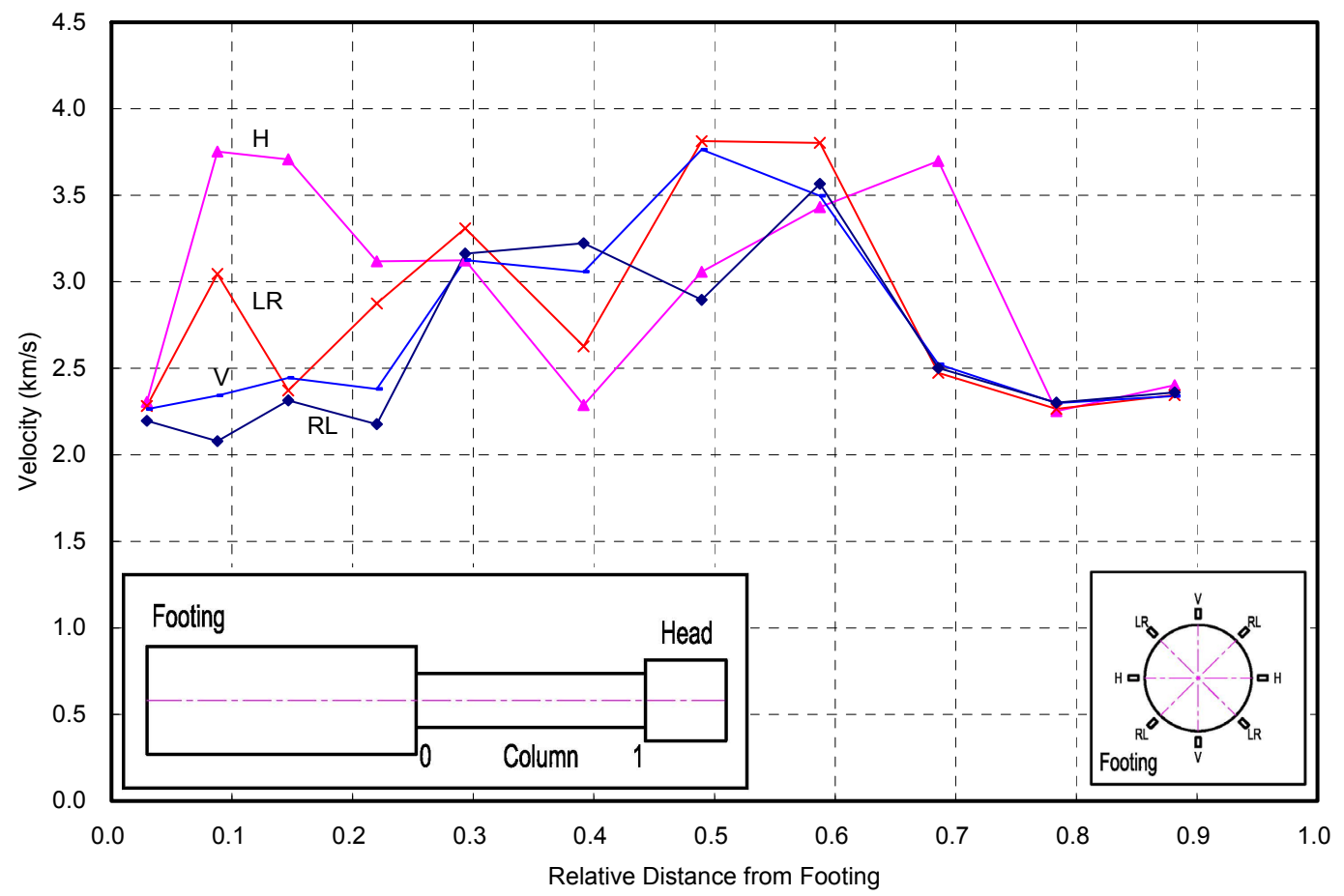

(d) Specimen $\mathrm{H}$ 


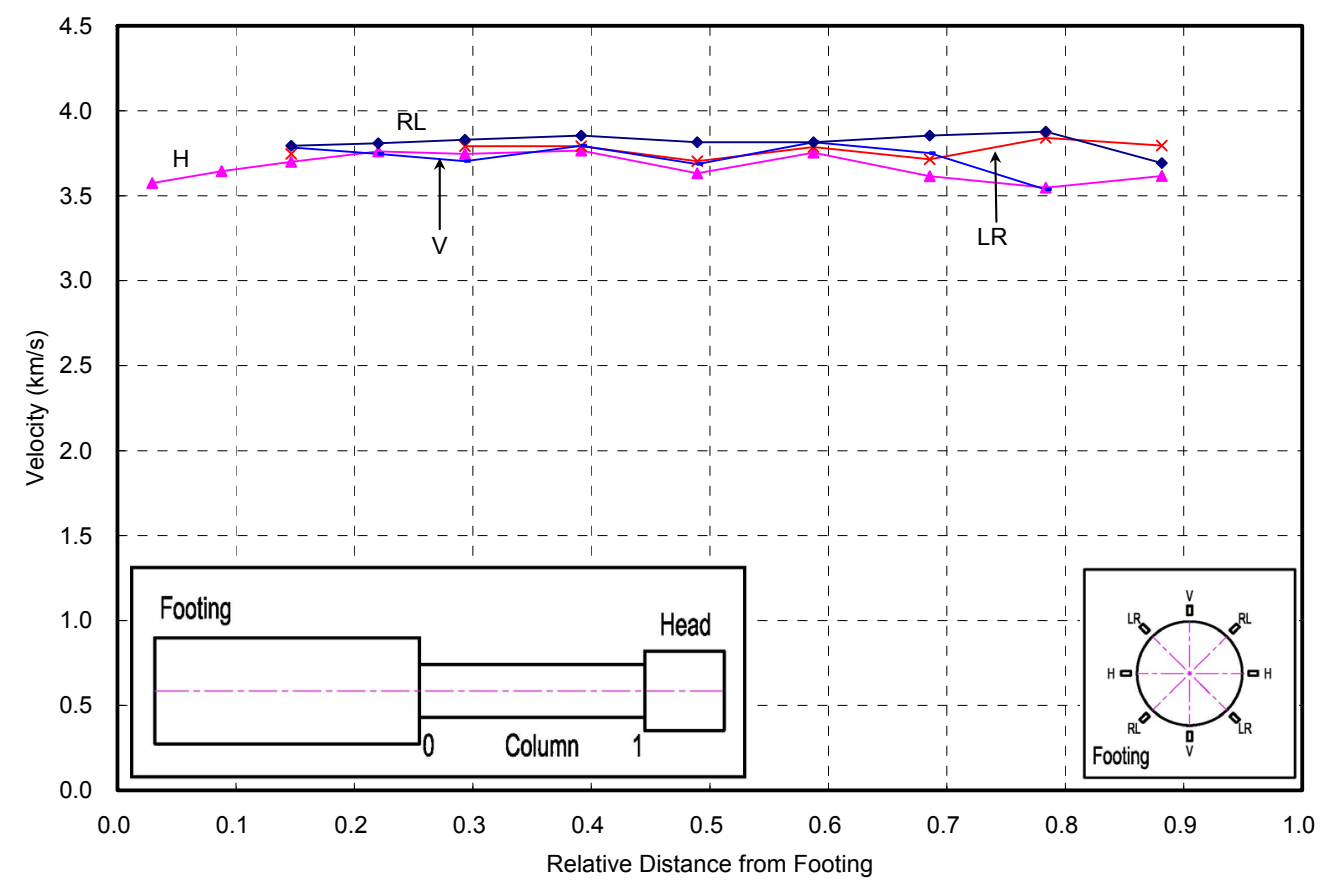

(e) Specimen SC

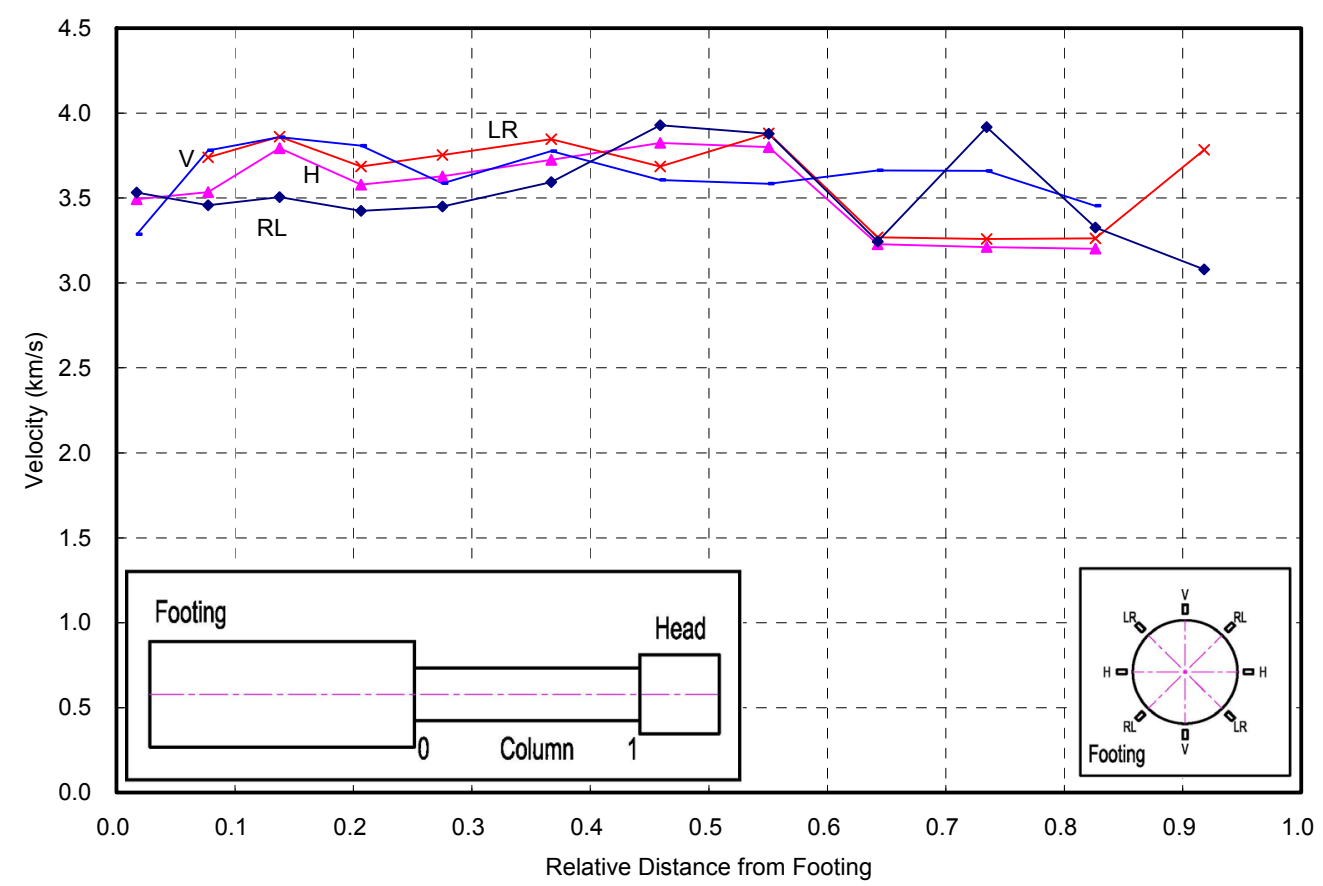

(f) Specimen LC

Figure 6.5 Velocity Measurements in the H, LR, RL and V Directions for Each Specimen 


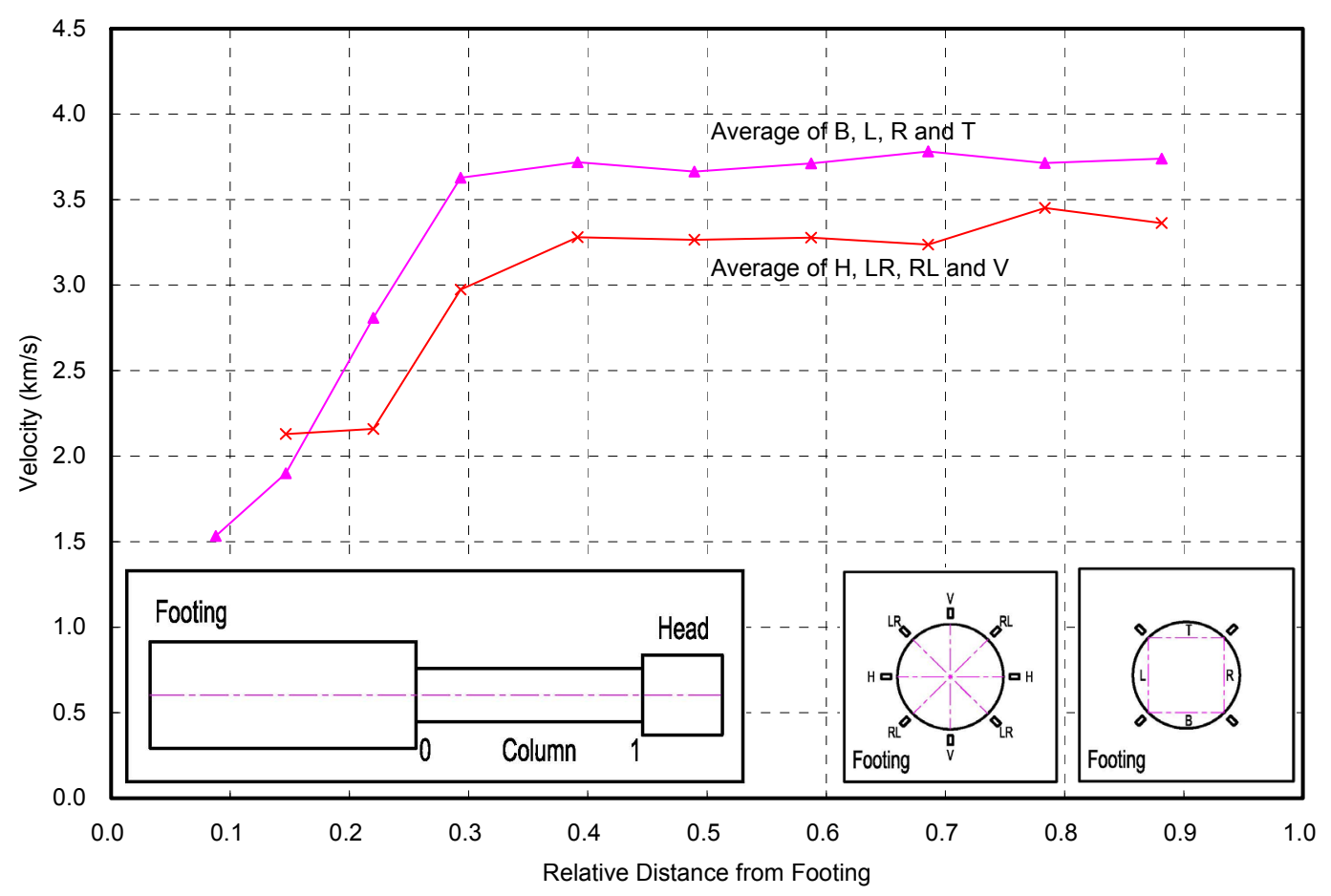

(a) Specimen RC

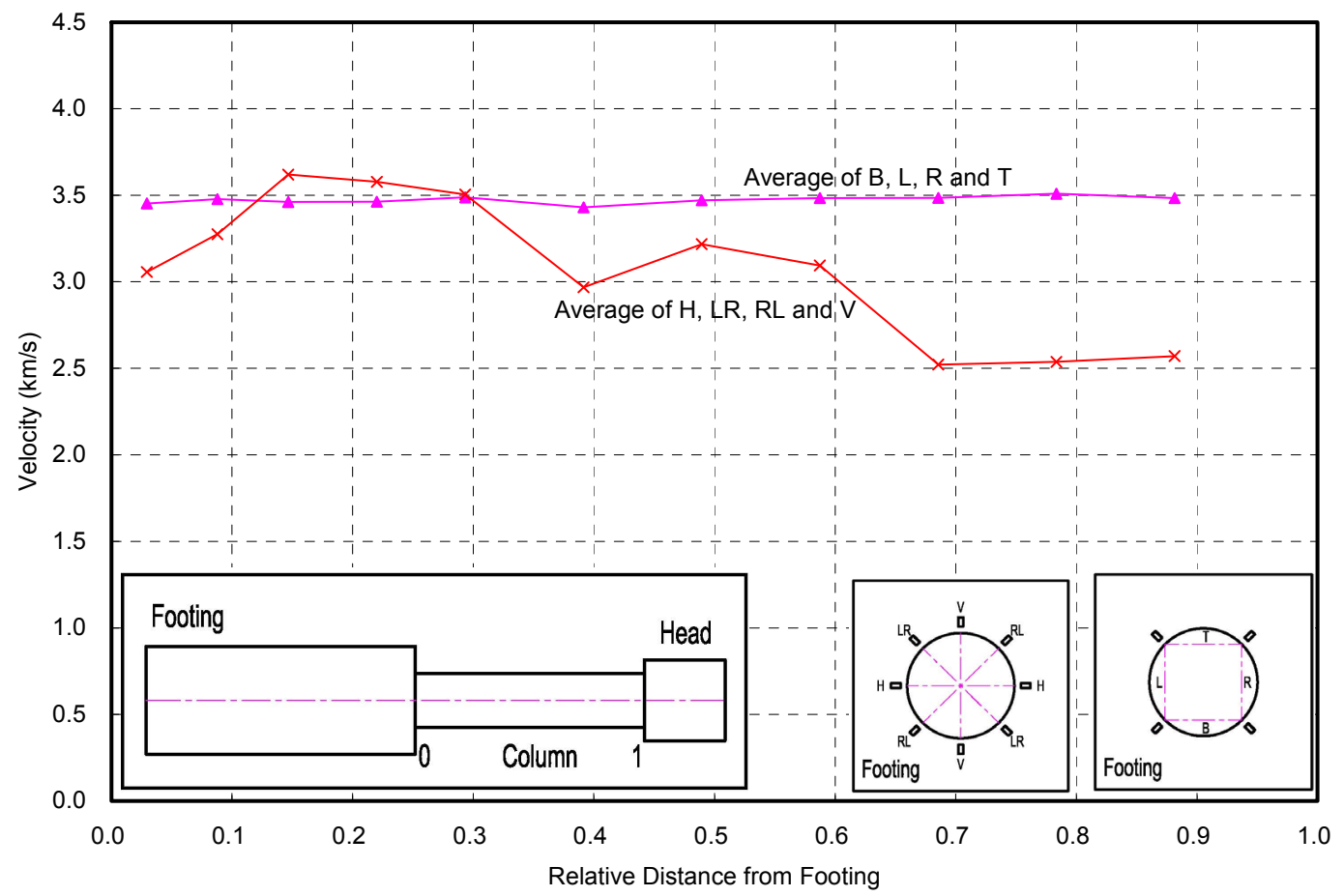

(b) Specimen Y 


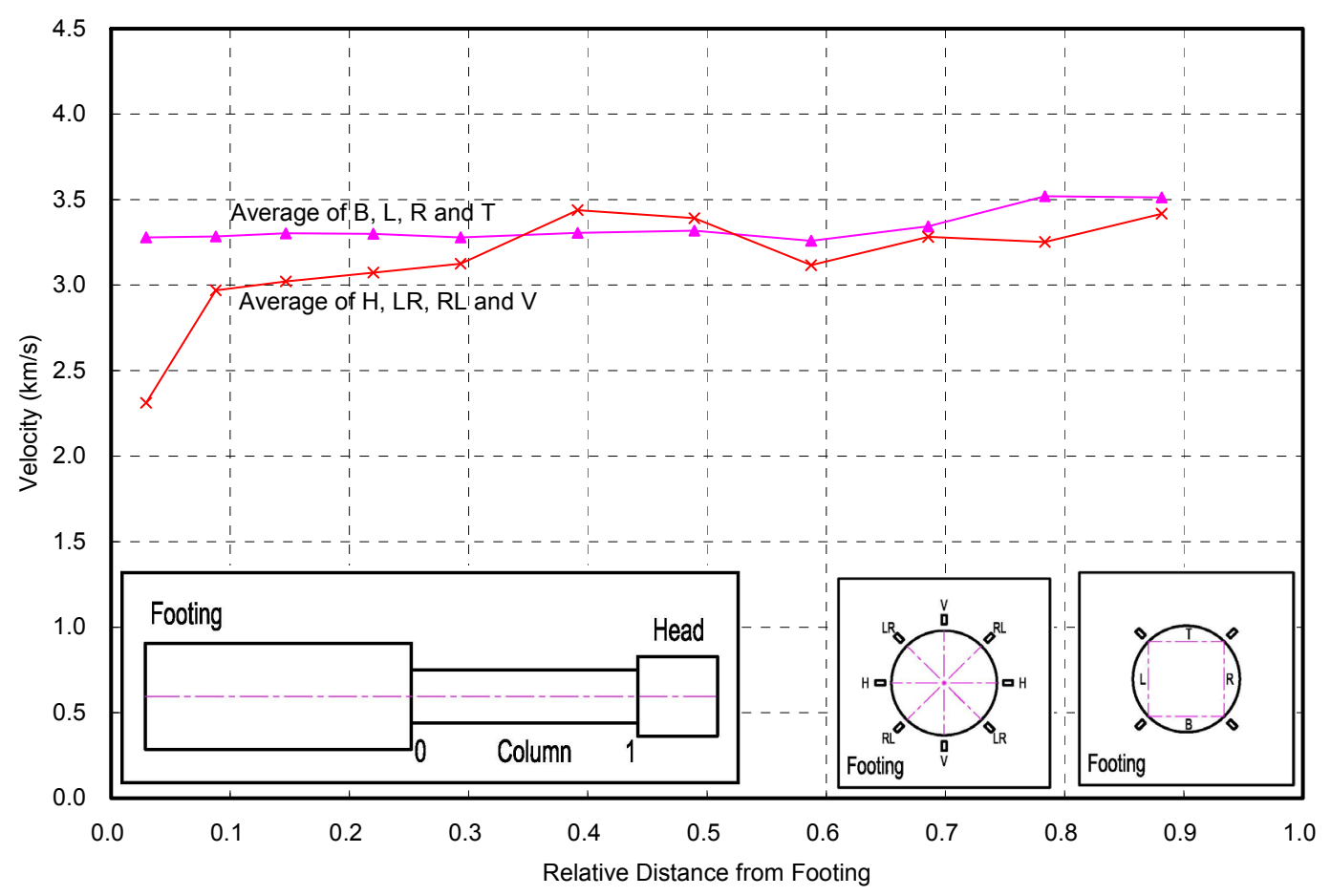

(c) Specimen G

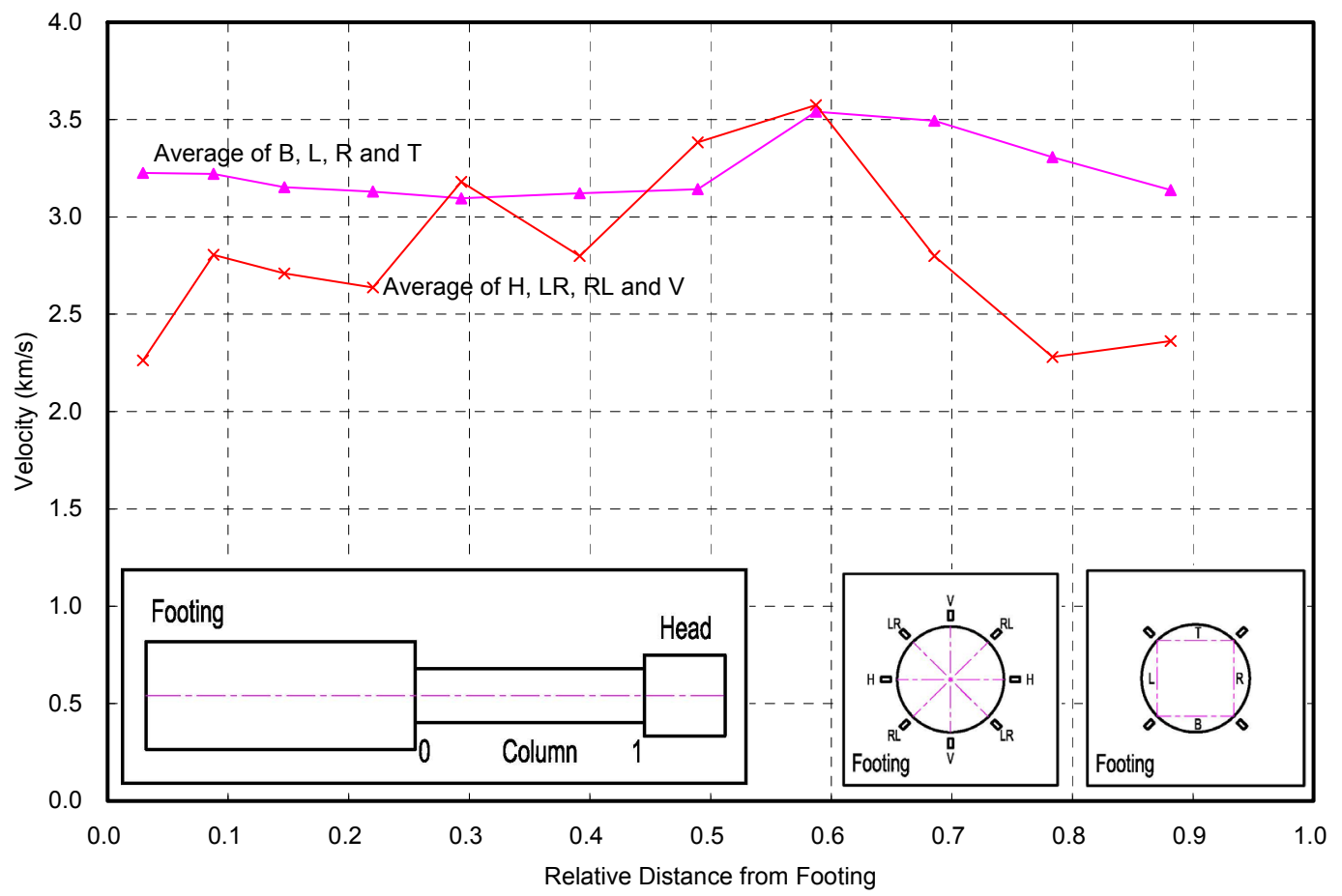

(d) Specimen $\mathrm{H}$ 


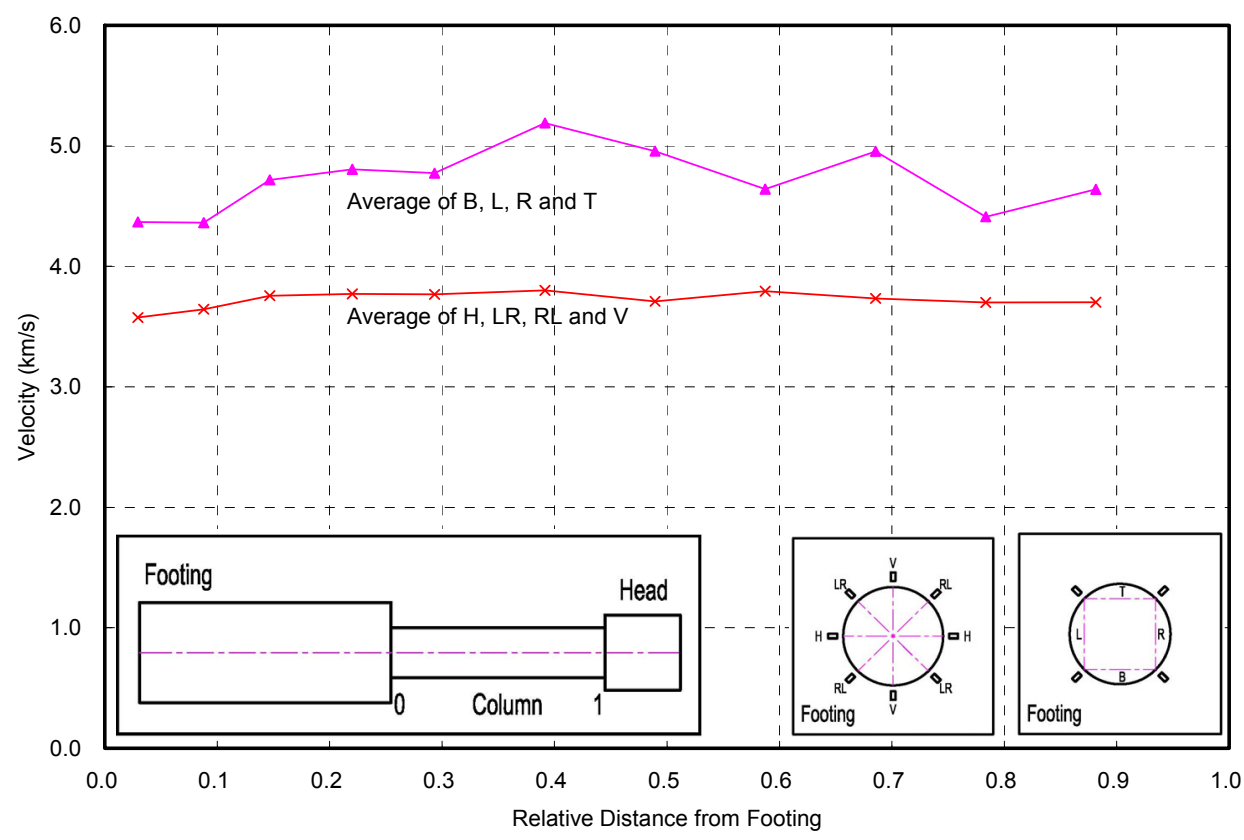

(e) Specimen SC

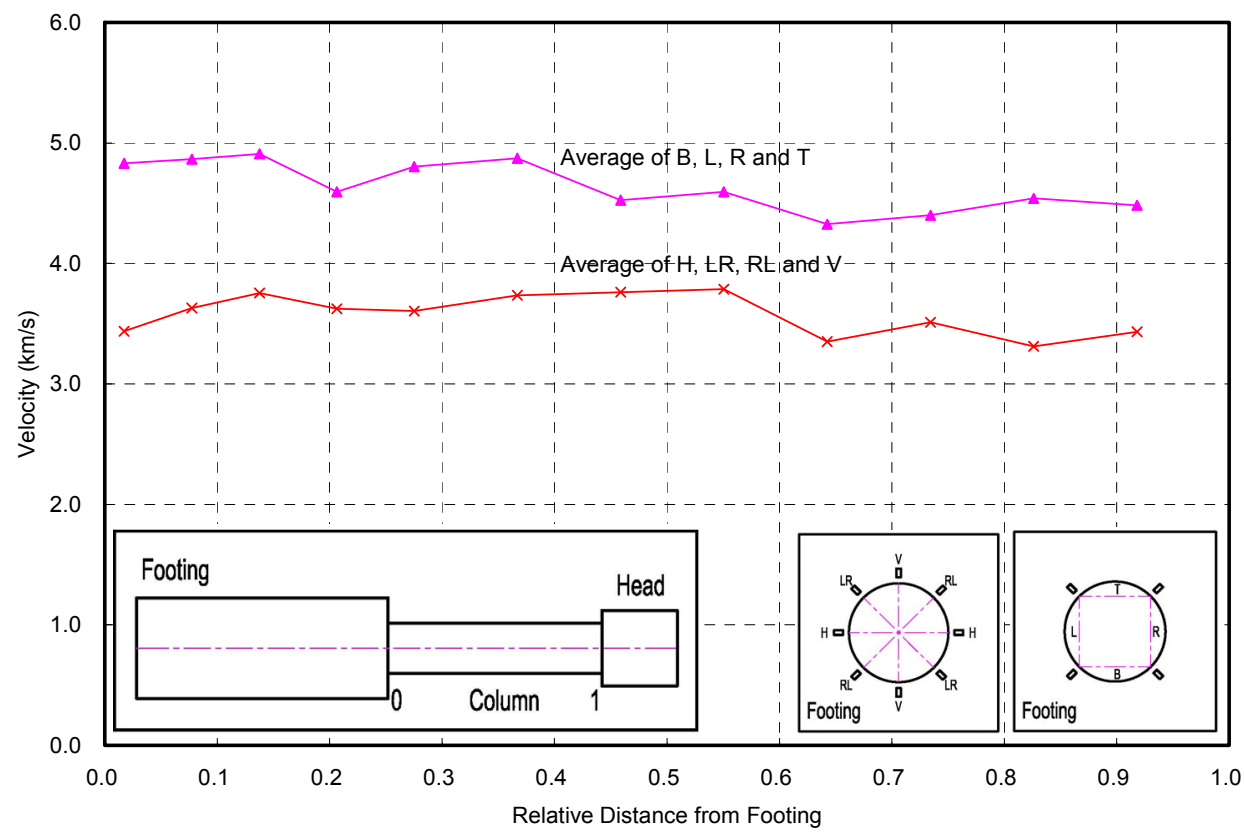

(f) Specimen LC

Figure 6.6 Average Velocity Measurements in the Two Direction Groups for Each

Specimen 


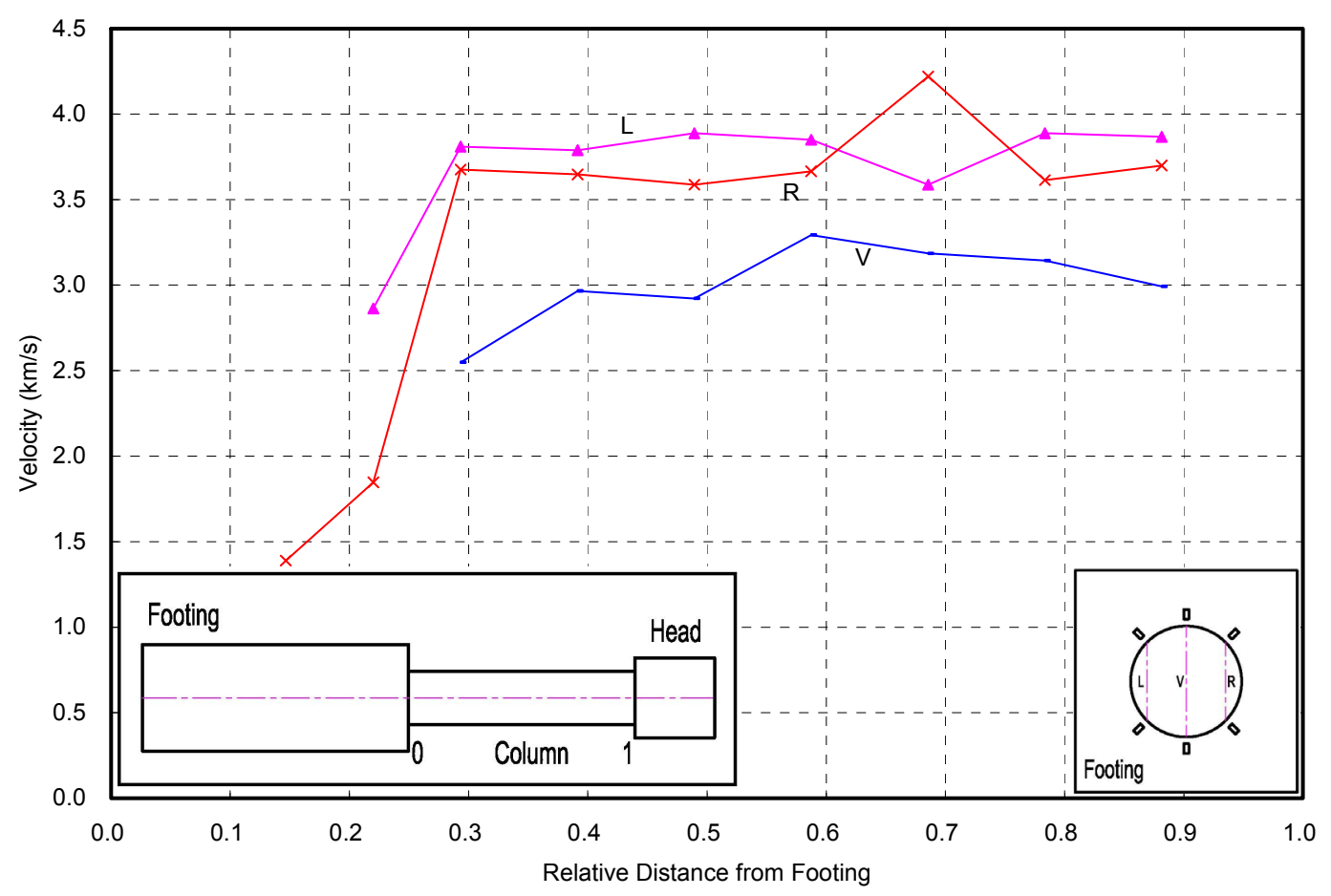

(a) Specimen RC

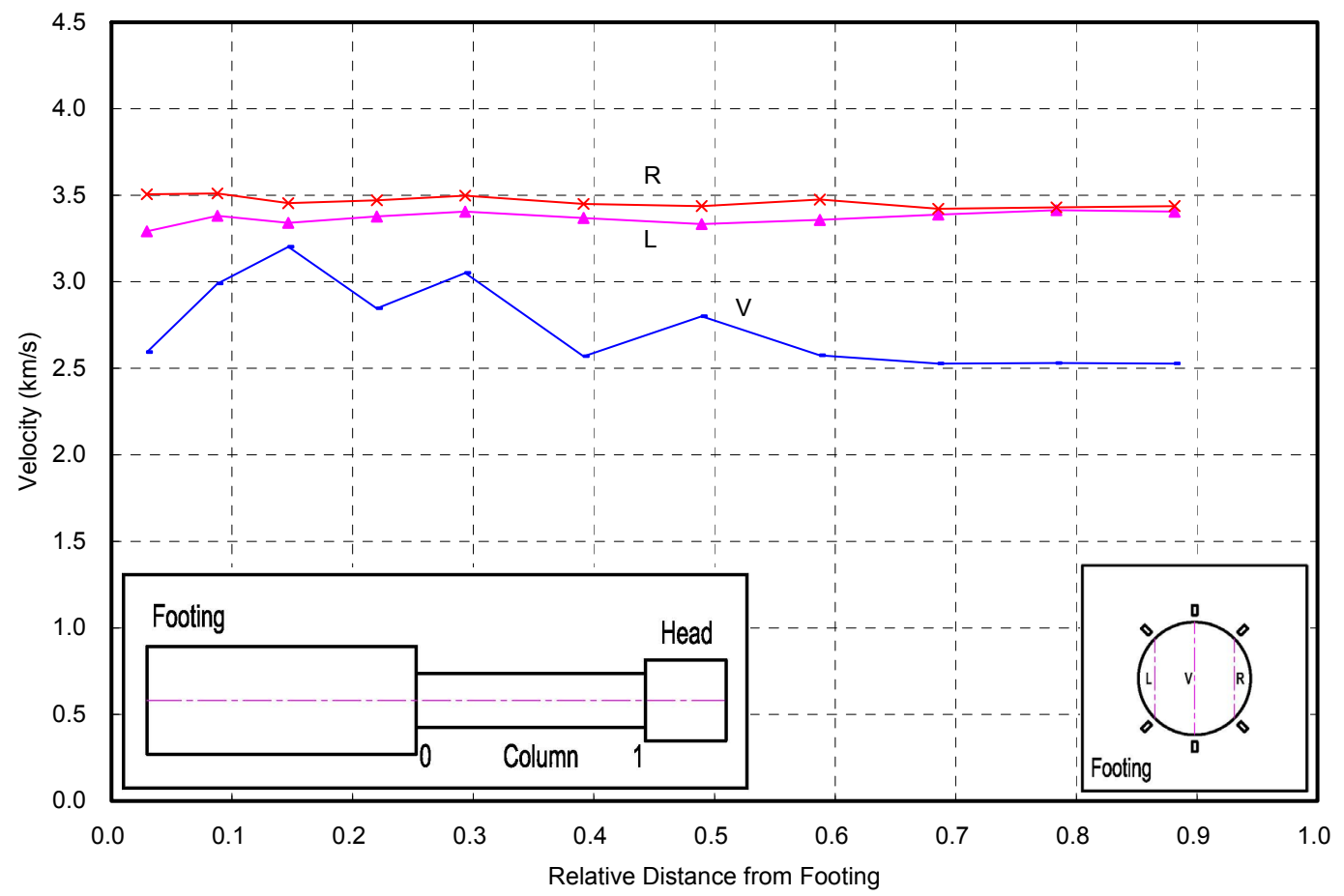

(b) Specimen Y 


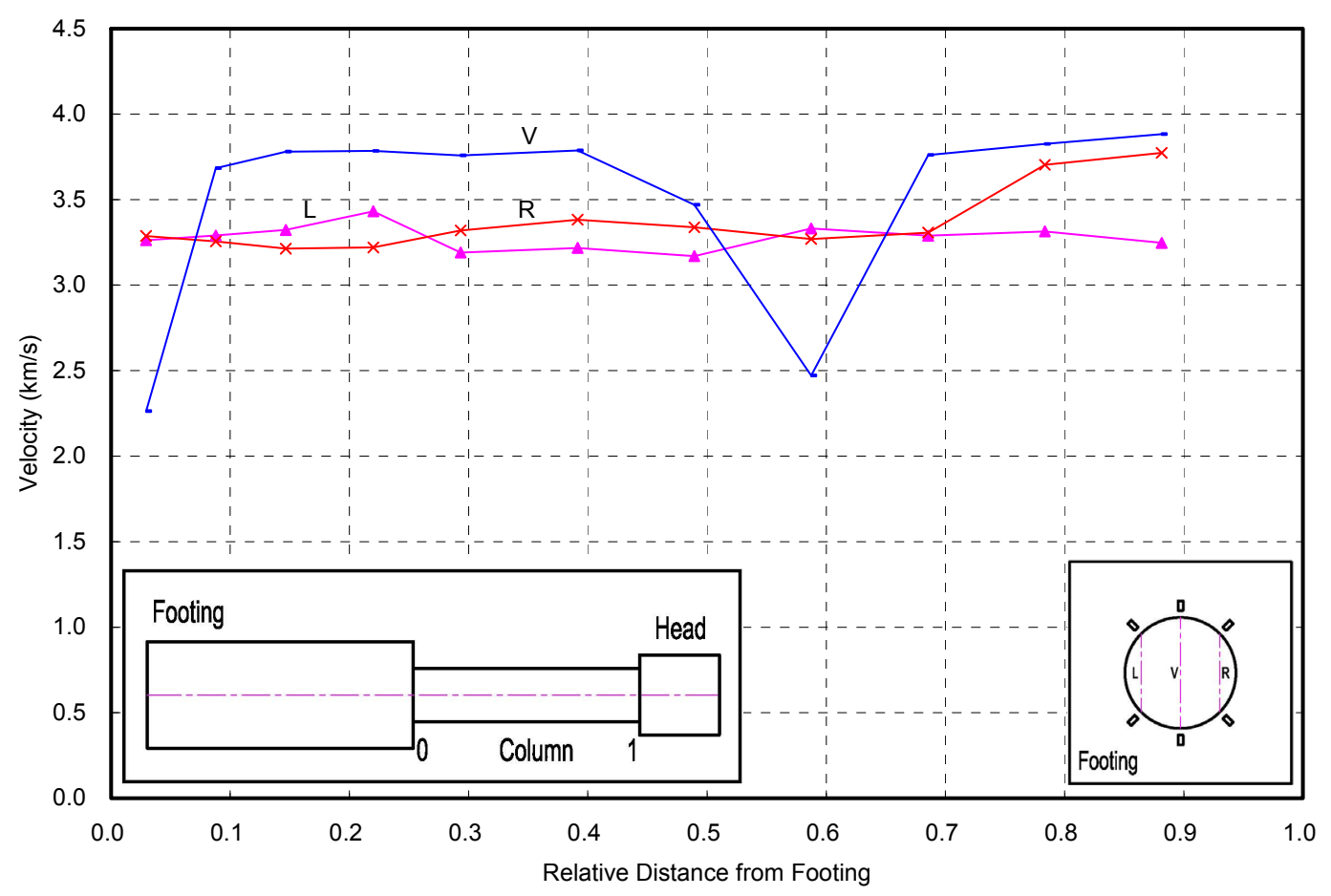

(c) Specimen G

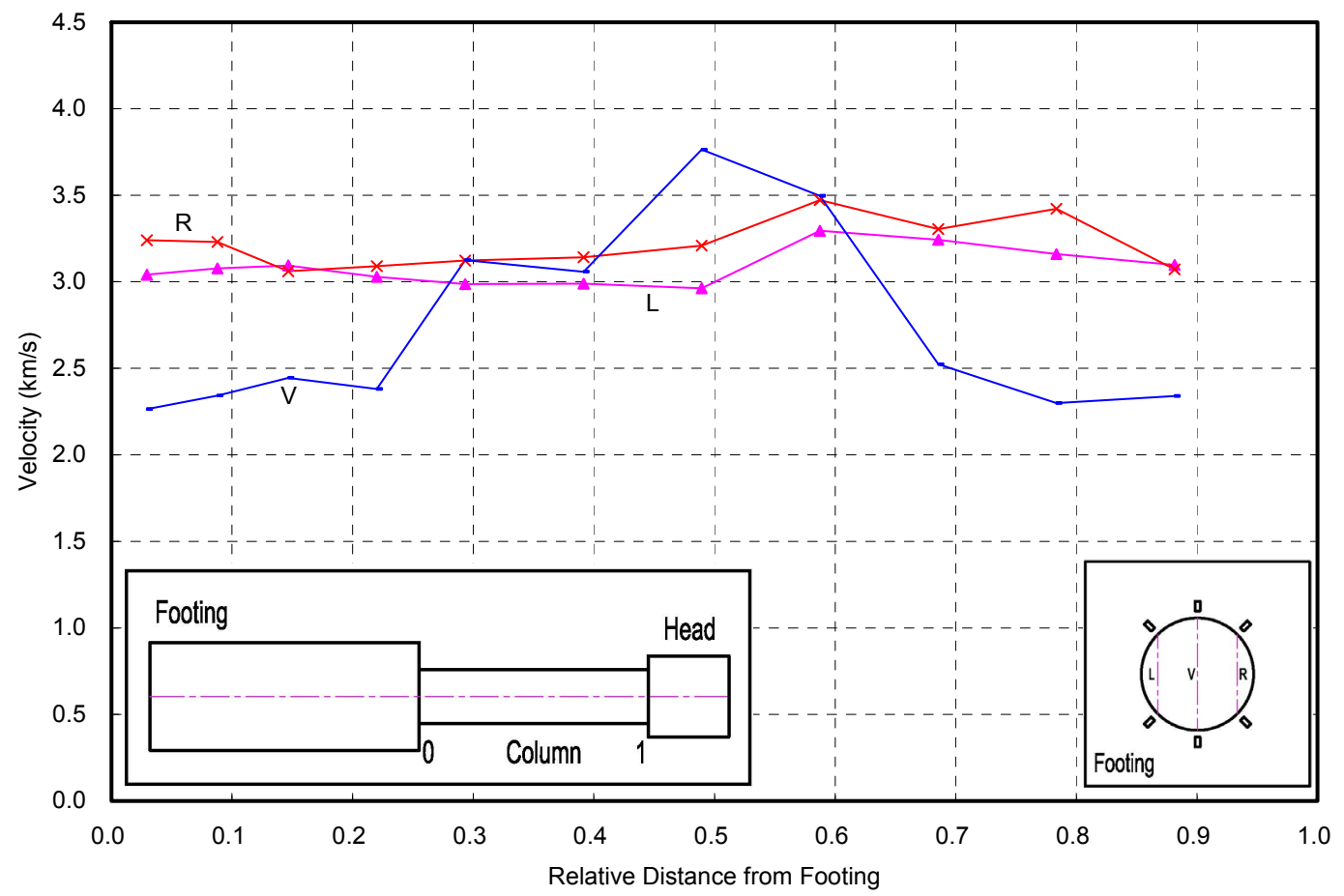

(d) Specimen H 


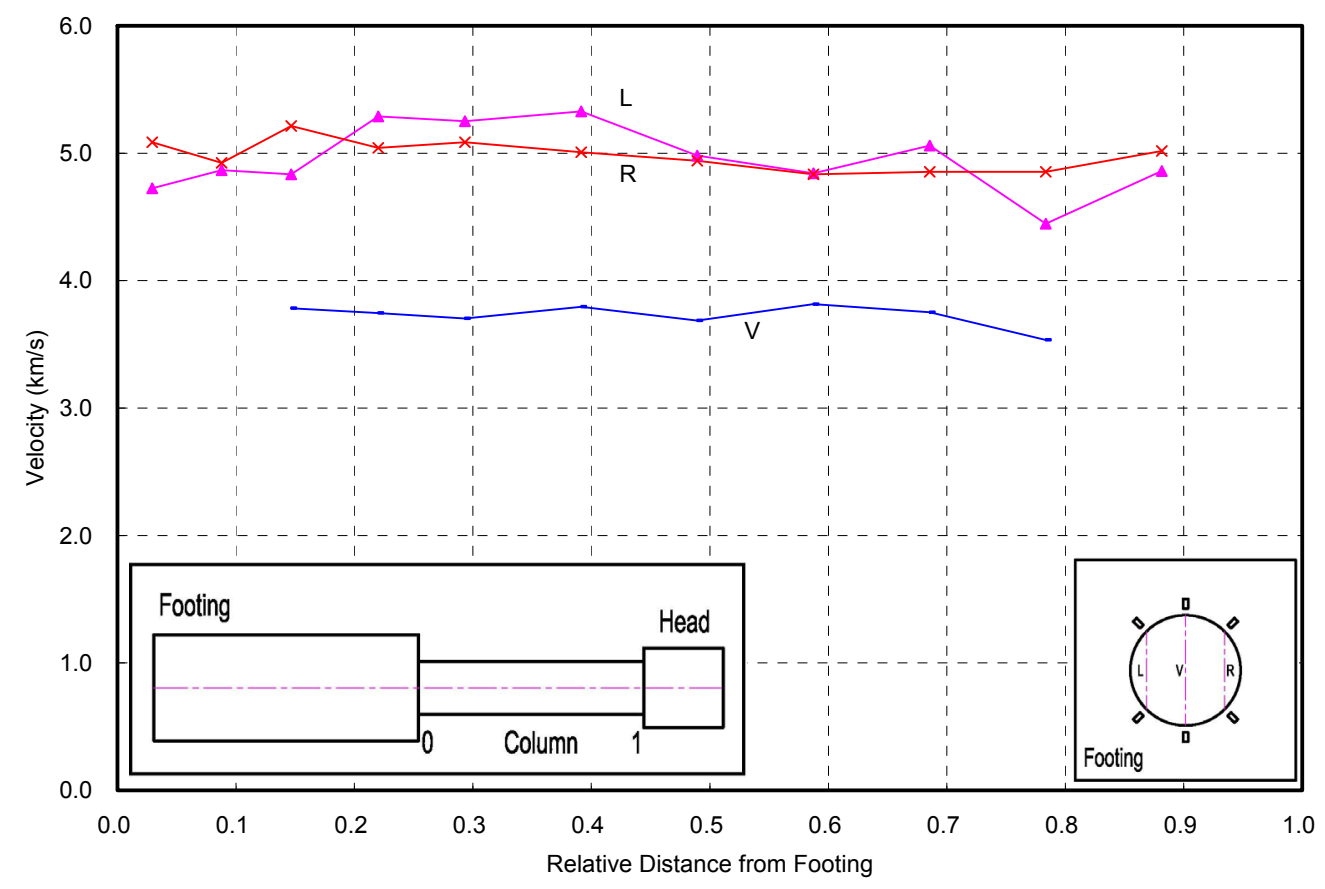

(e) Specimen SC

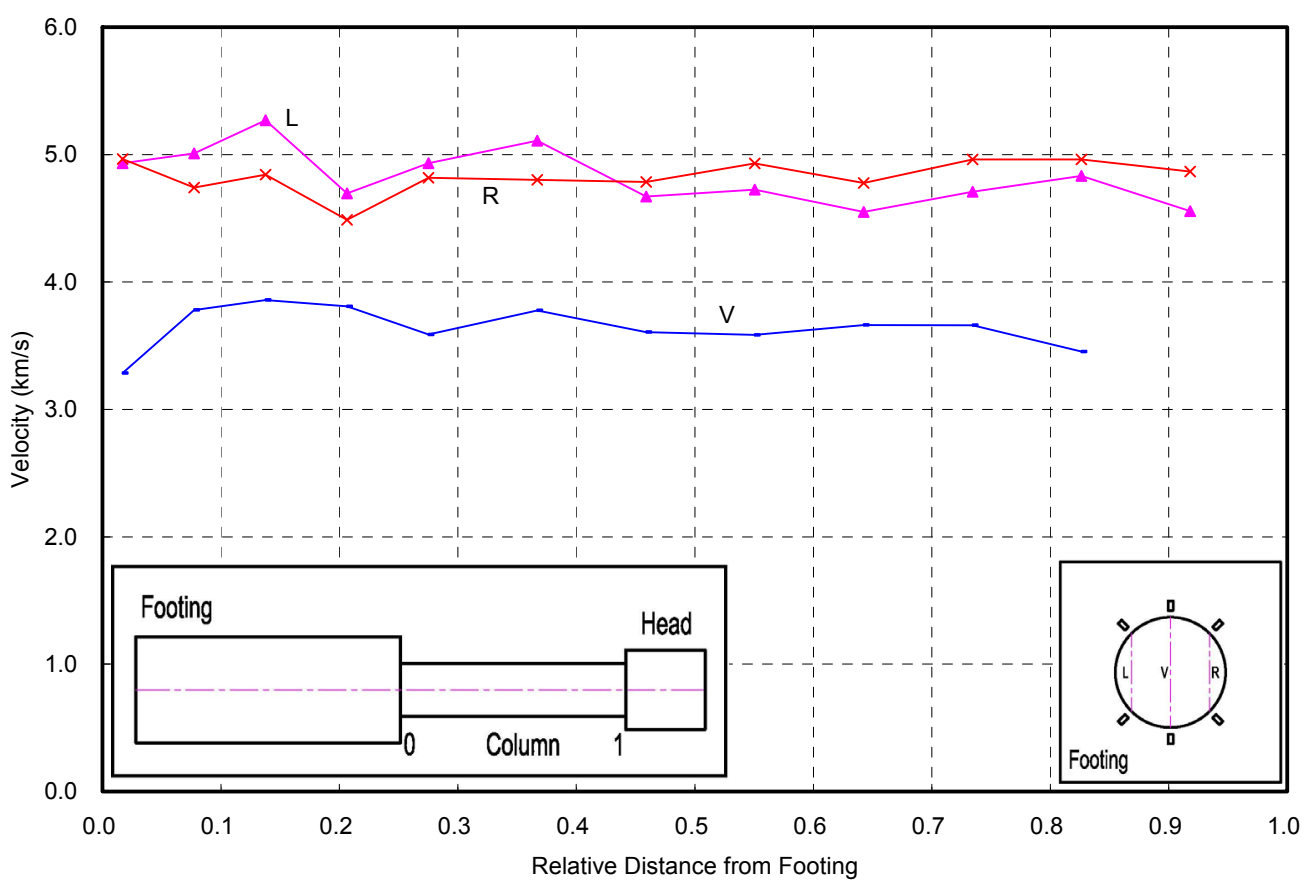

(f) Specimen LC

Figure 6.7 Velocity Measurements in the L, R and V Directions for Each Specimen 


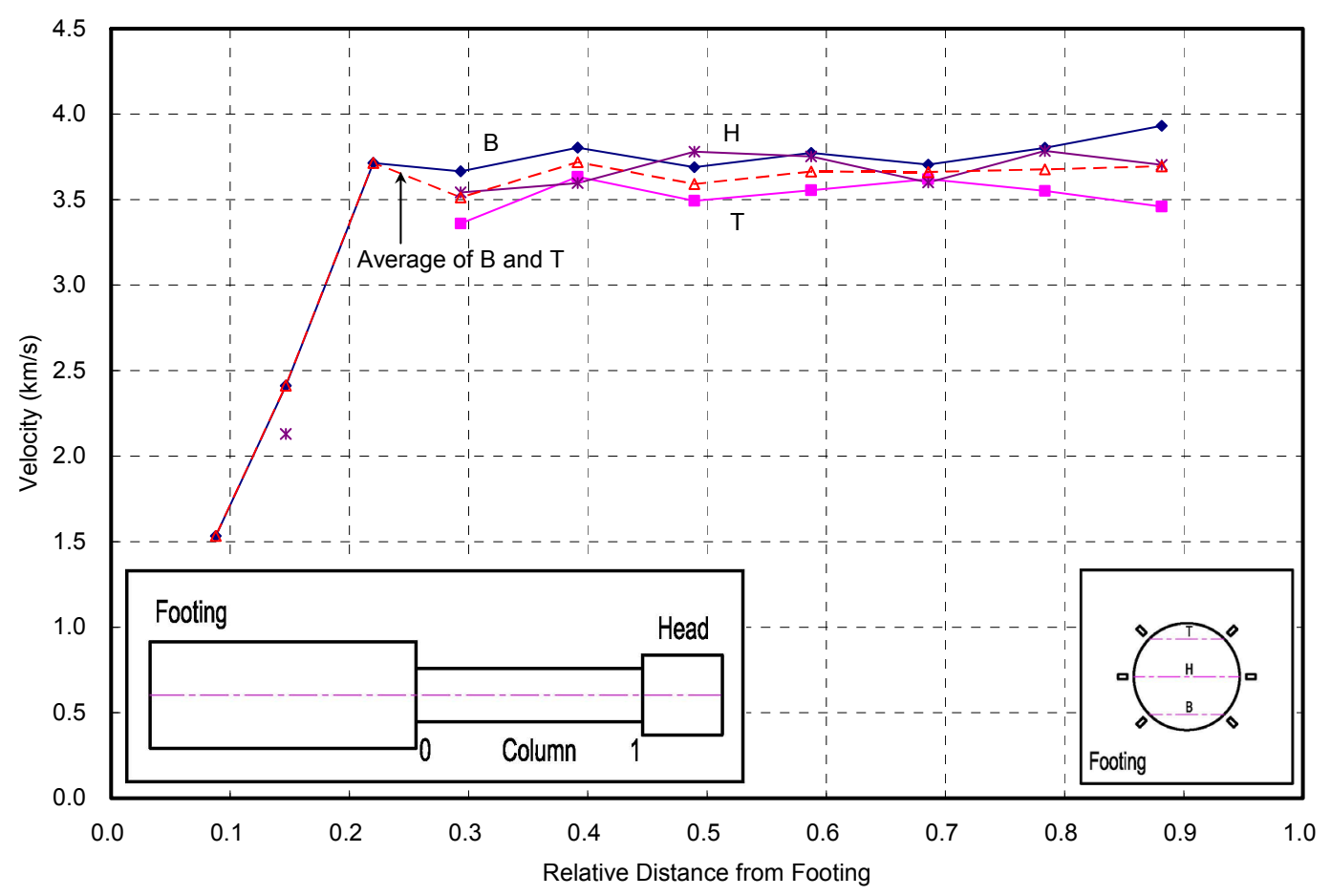

(a) Specimen RC

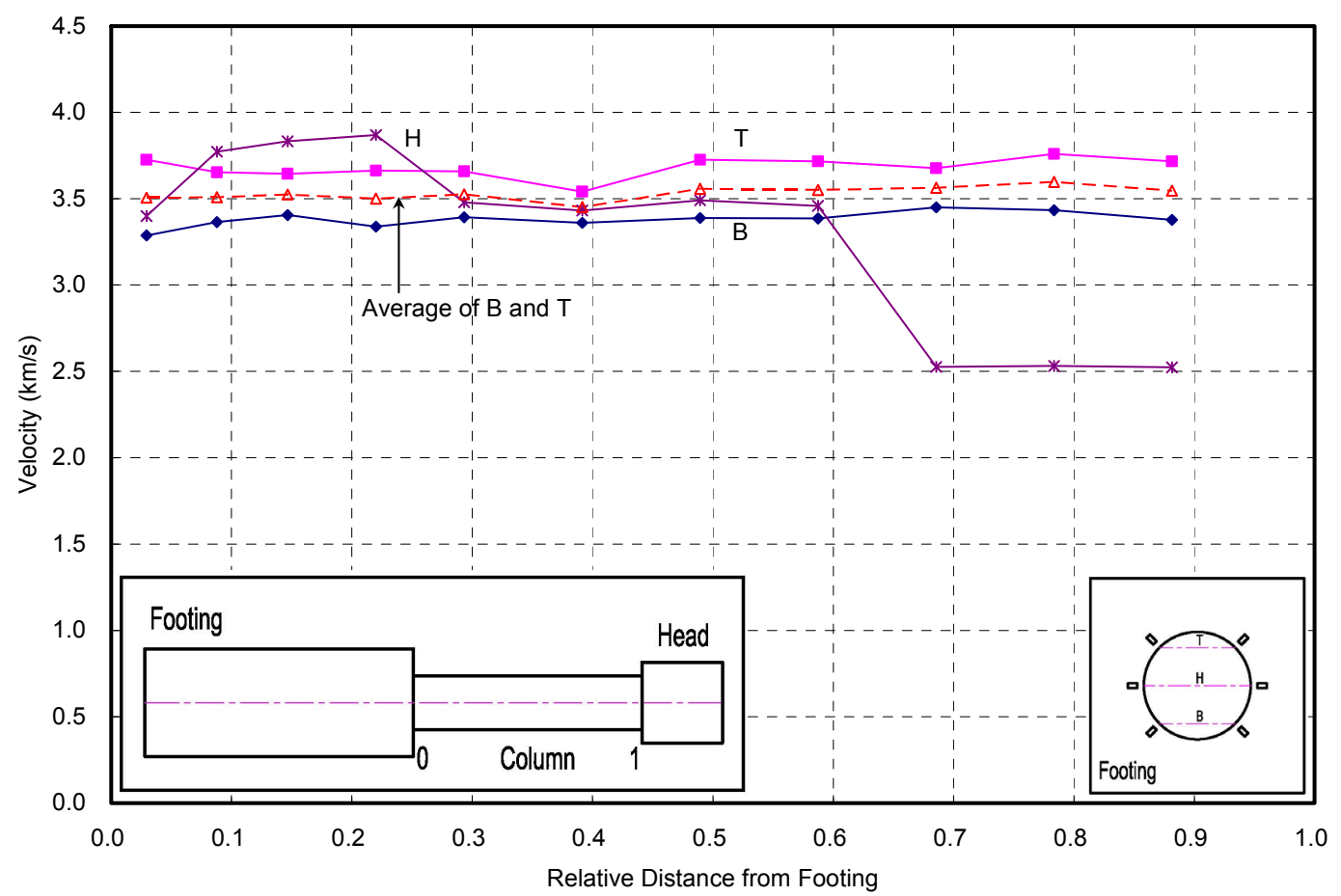

(b) Specimen Y 


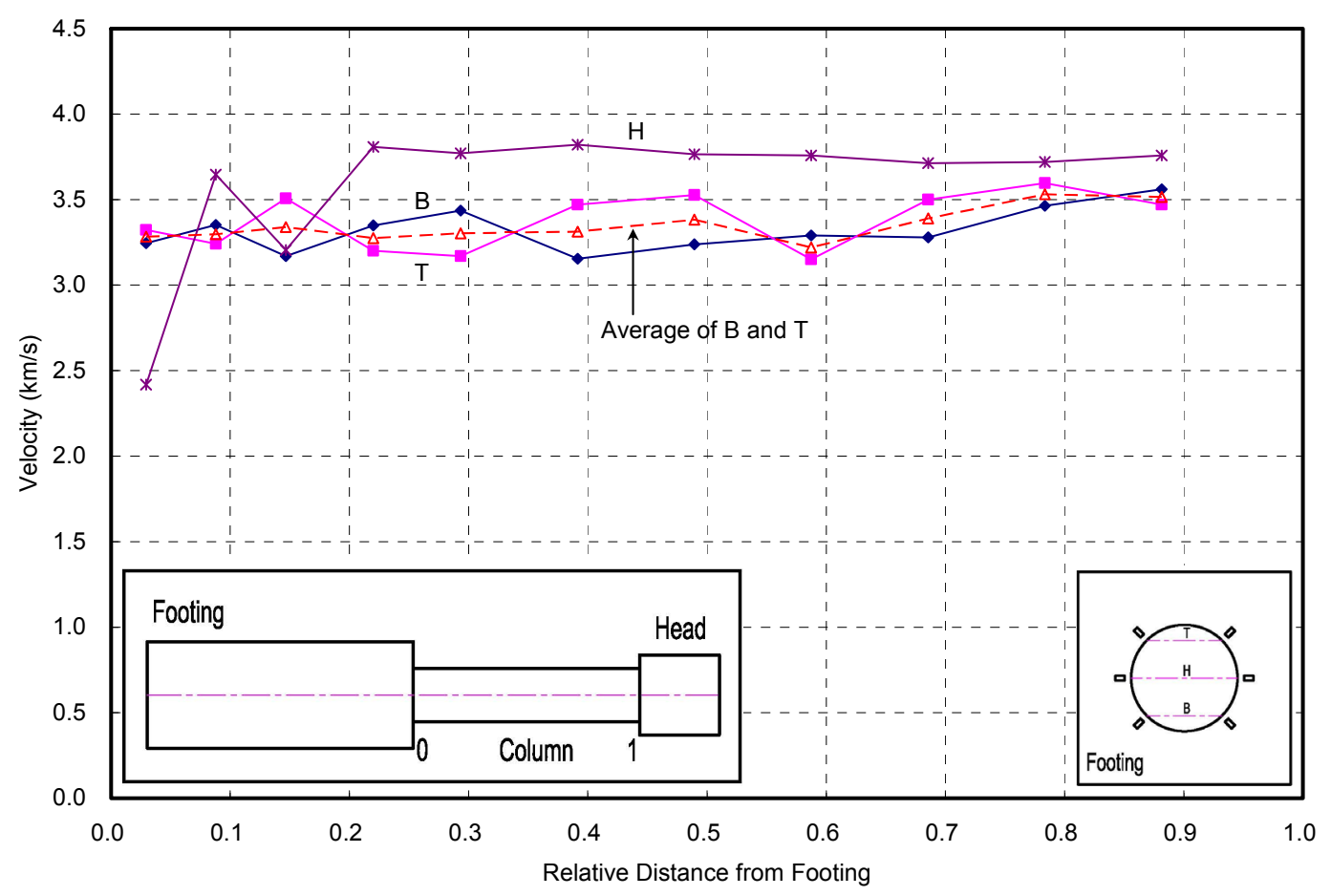

(c) Specimen G

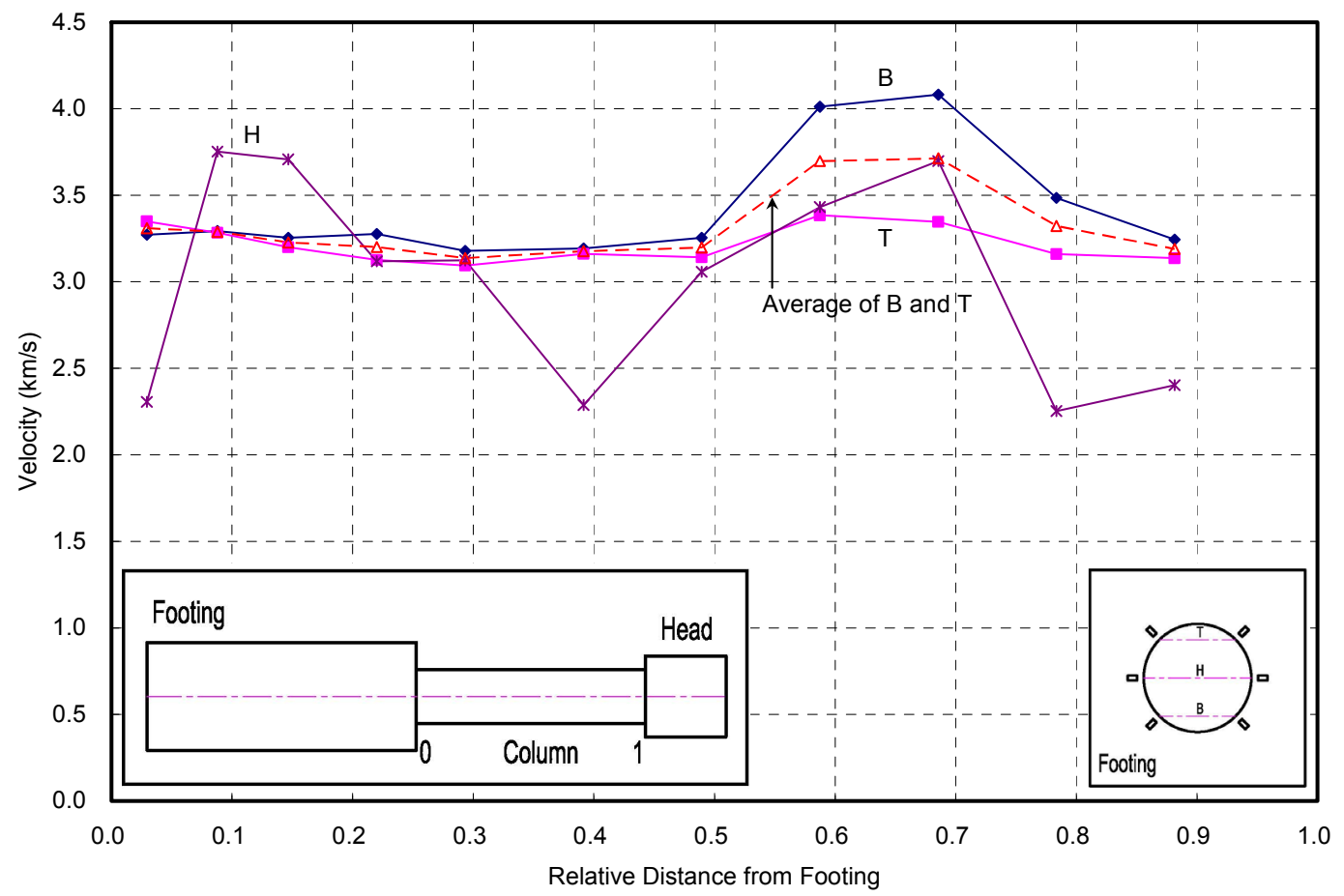

(d) Specimen H 


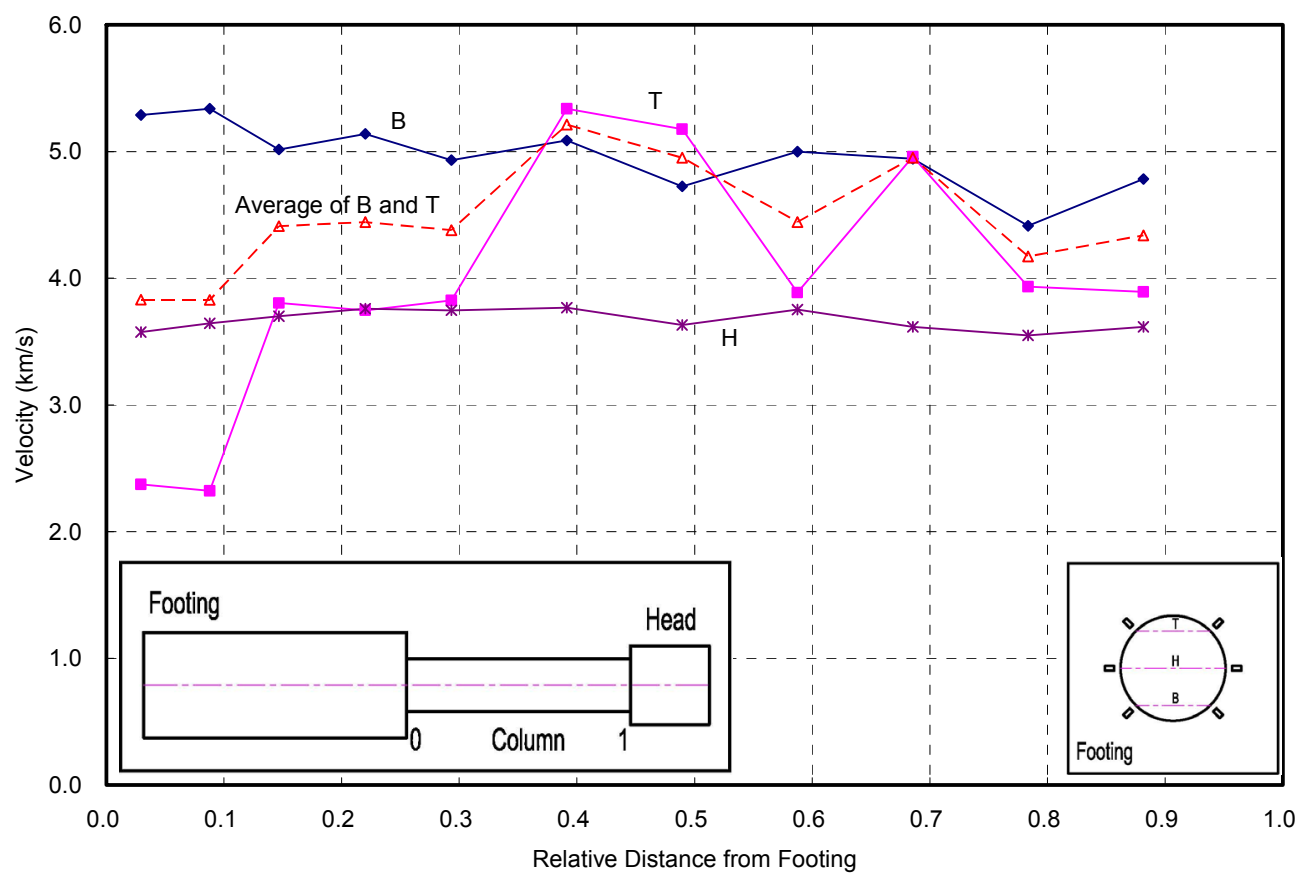

(e) Specimen SC

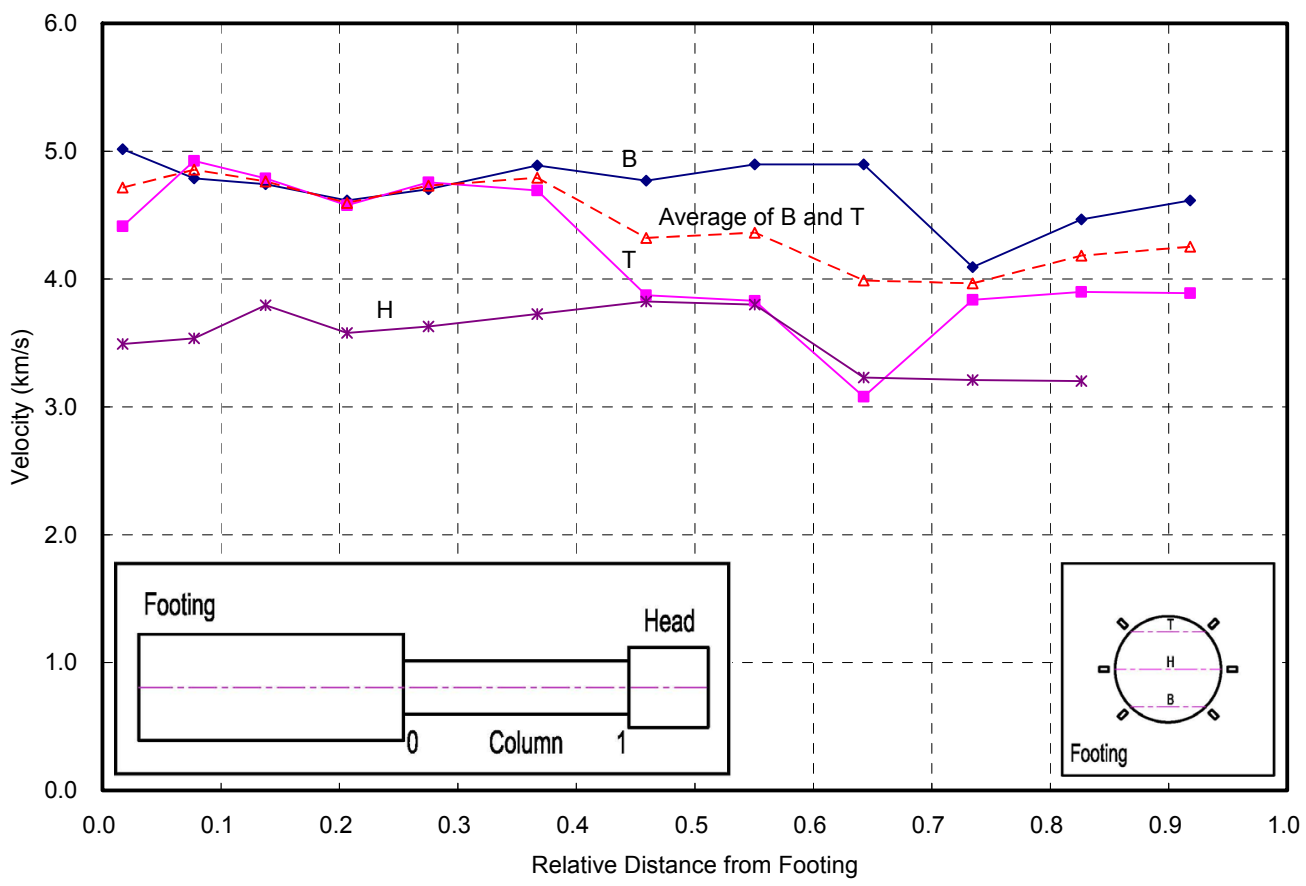

(f) Specimen LC

Figure 6.8 Velocity Measurements in the B, H and T Directions for Each Specimen 


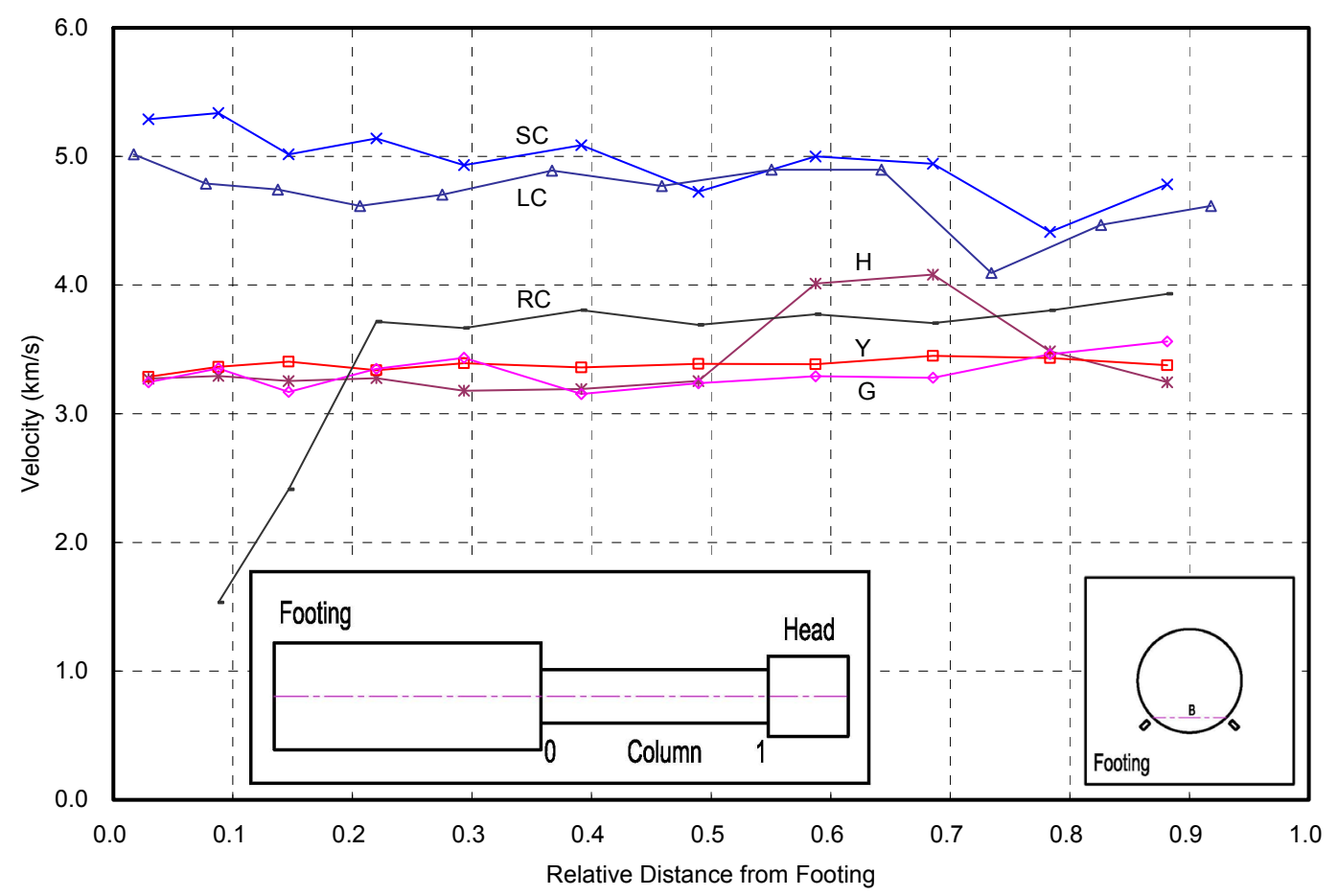

(a) Direction B

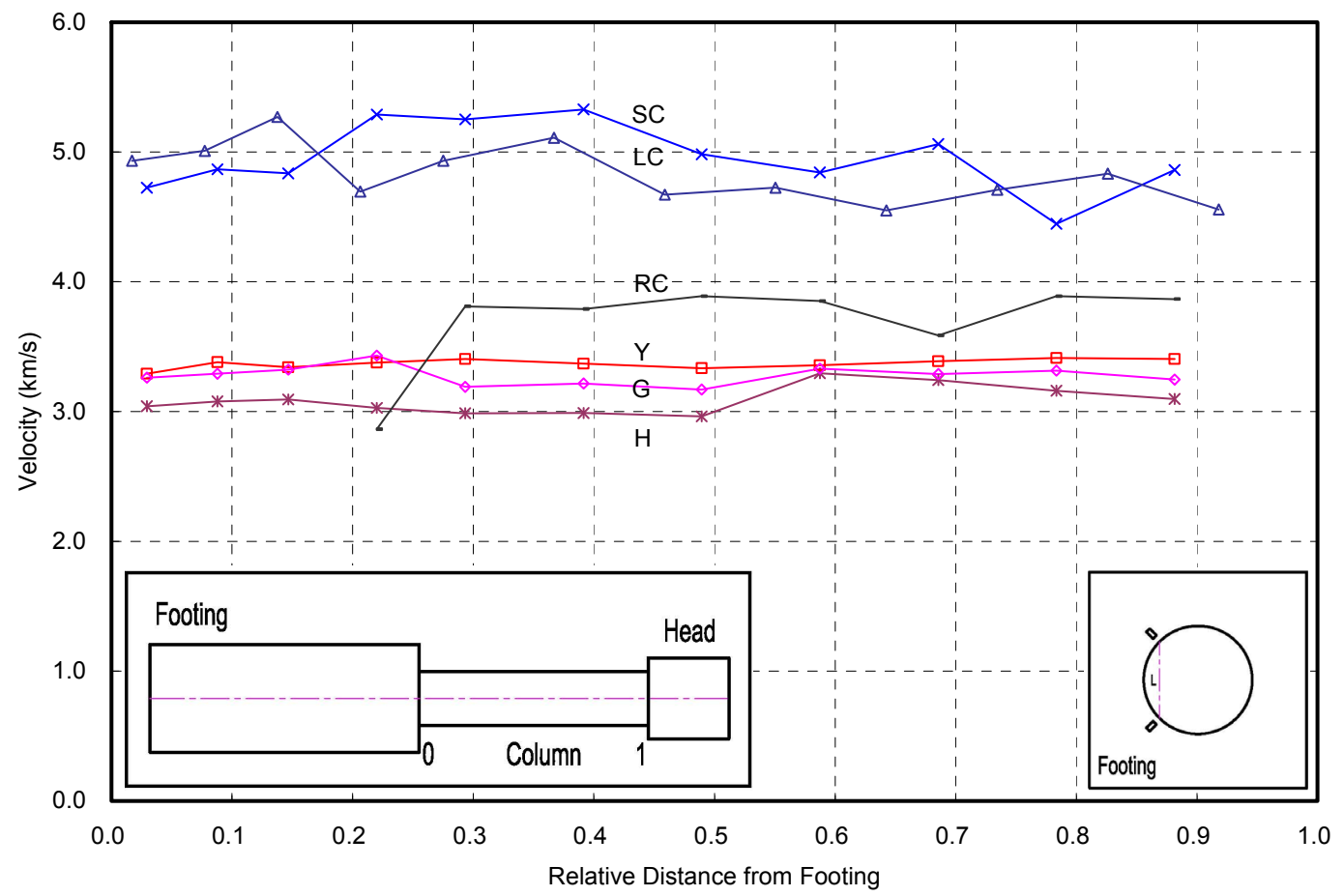

(b) Direction L 


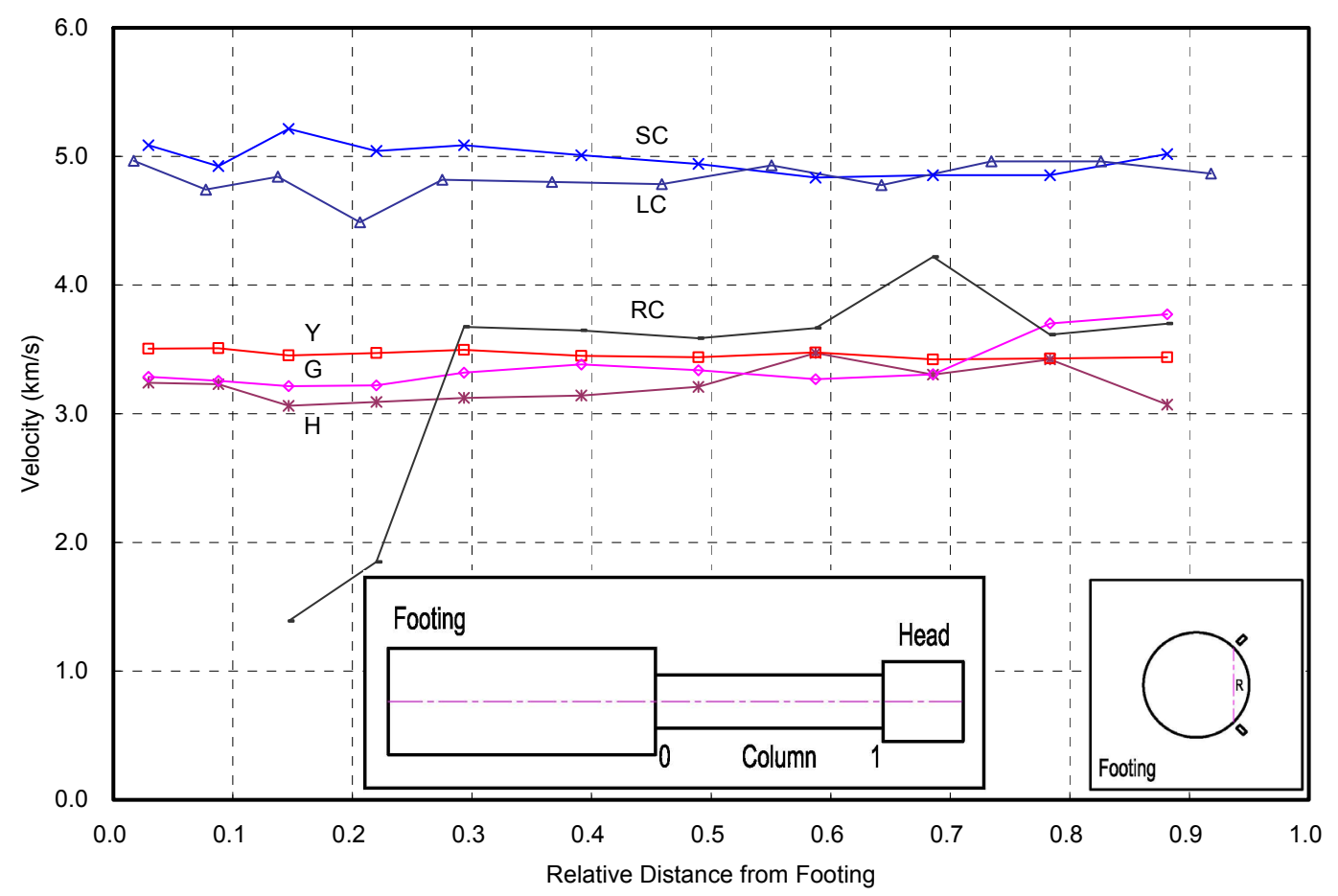

(c) Direction R

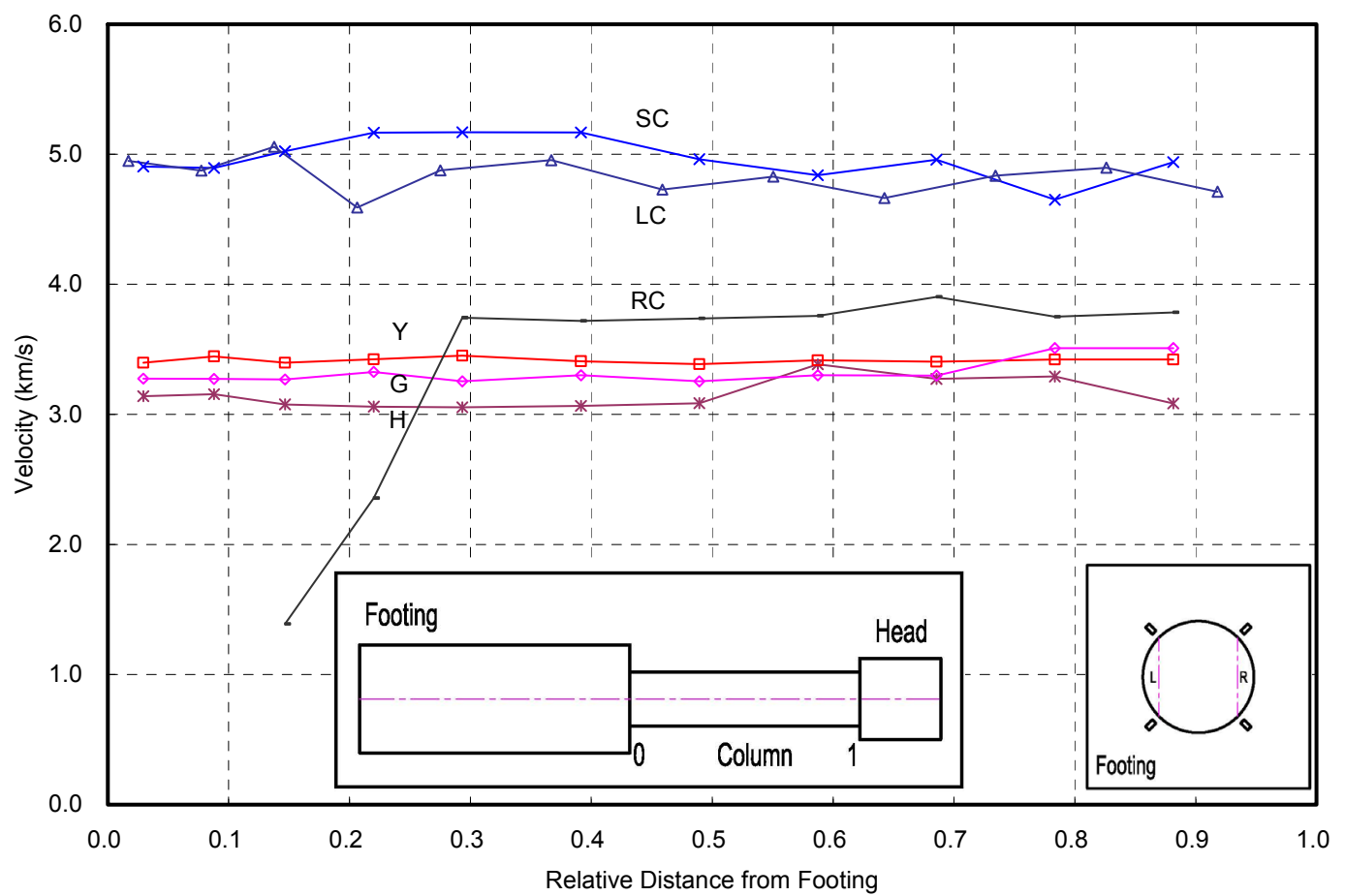

(d) Average of Directions L and R 


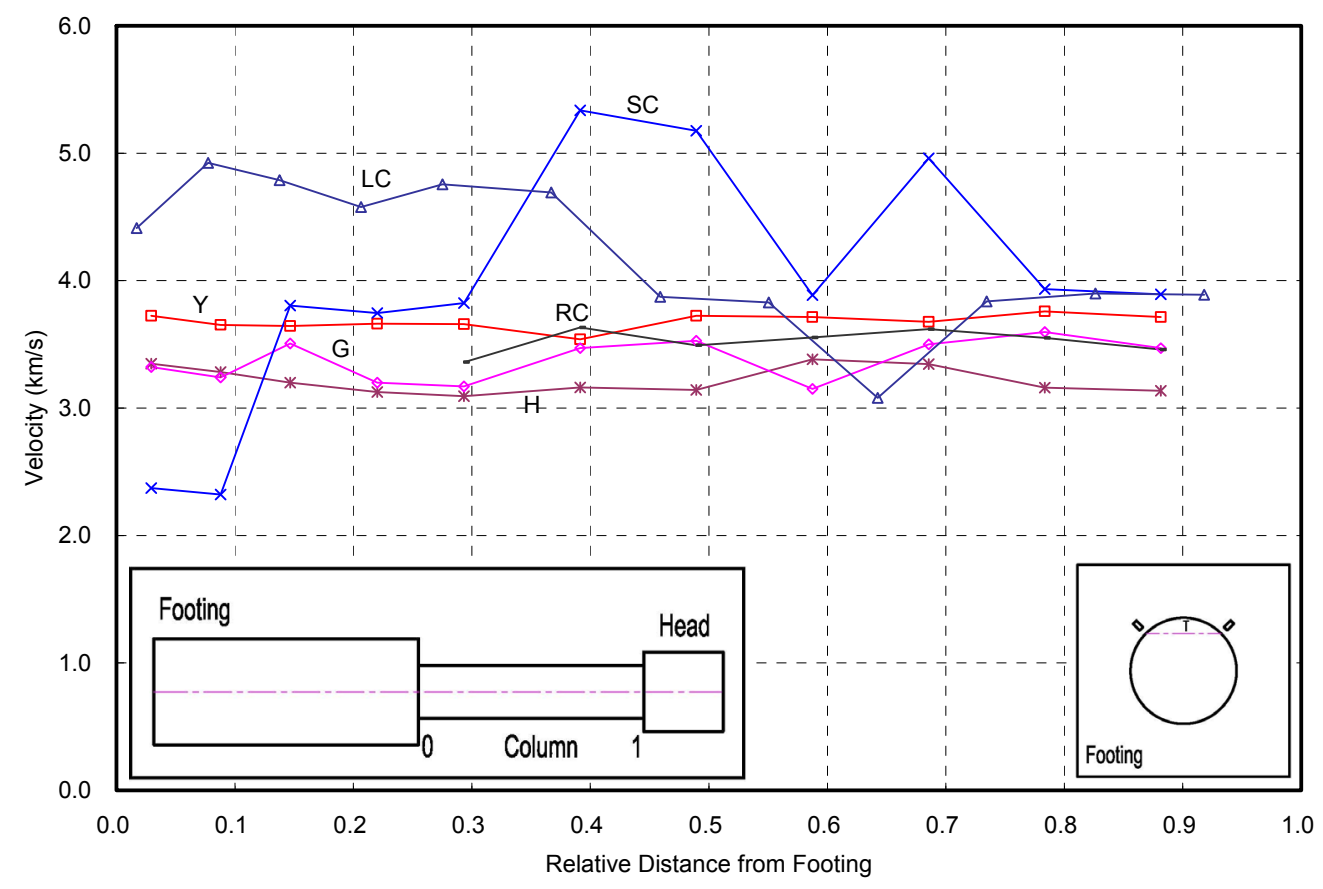

(e) Direction T

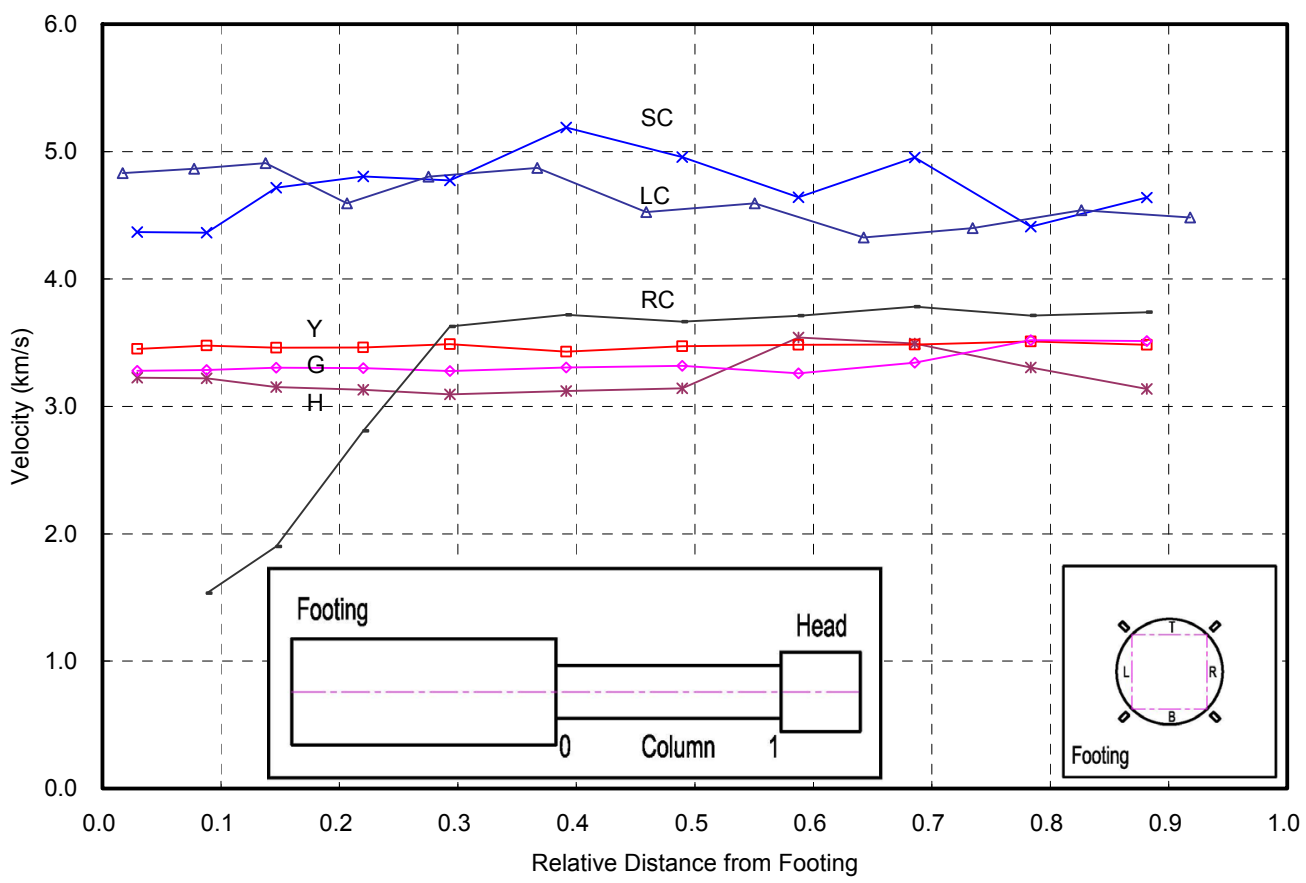

(f) Average of Directions B, L, R and T

Figure 6.9 Velocity Measurements in the B, L, R and T Directions for All Specimens 


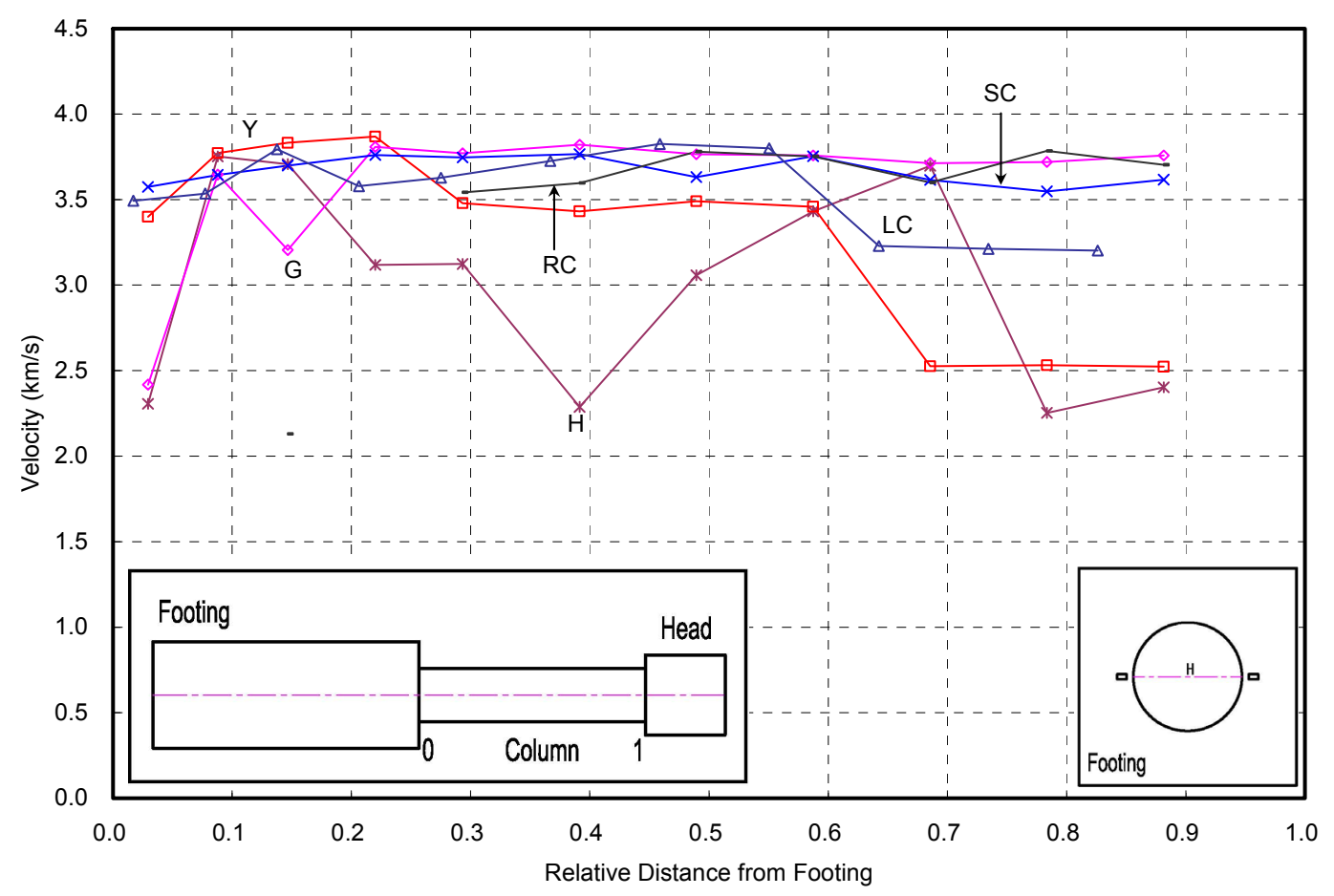

(a) Direction $\mathrm{H}$

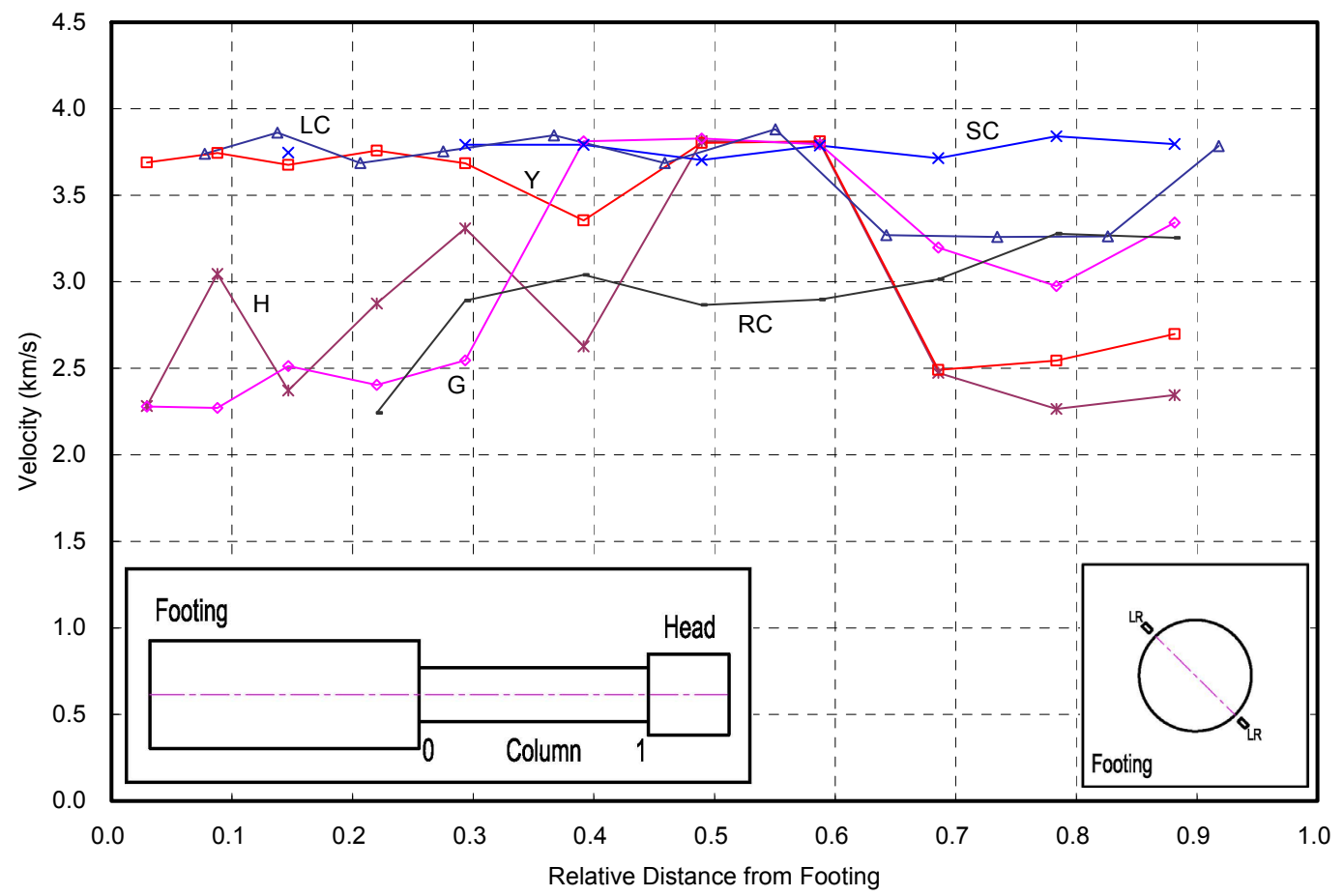

(b) Direction LR 


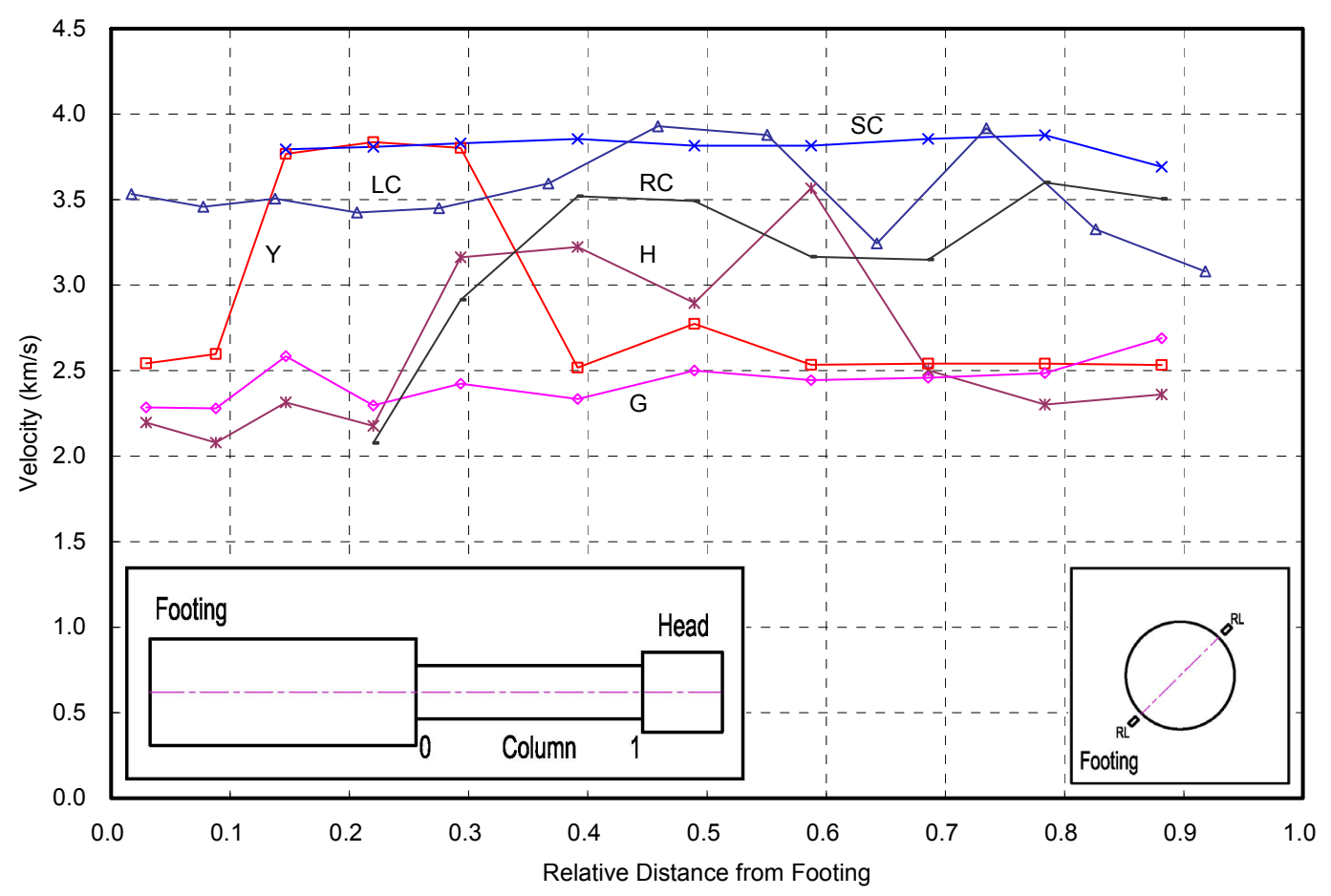

(c) Direction RL

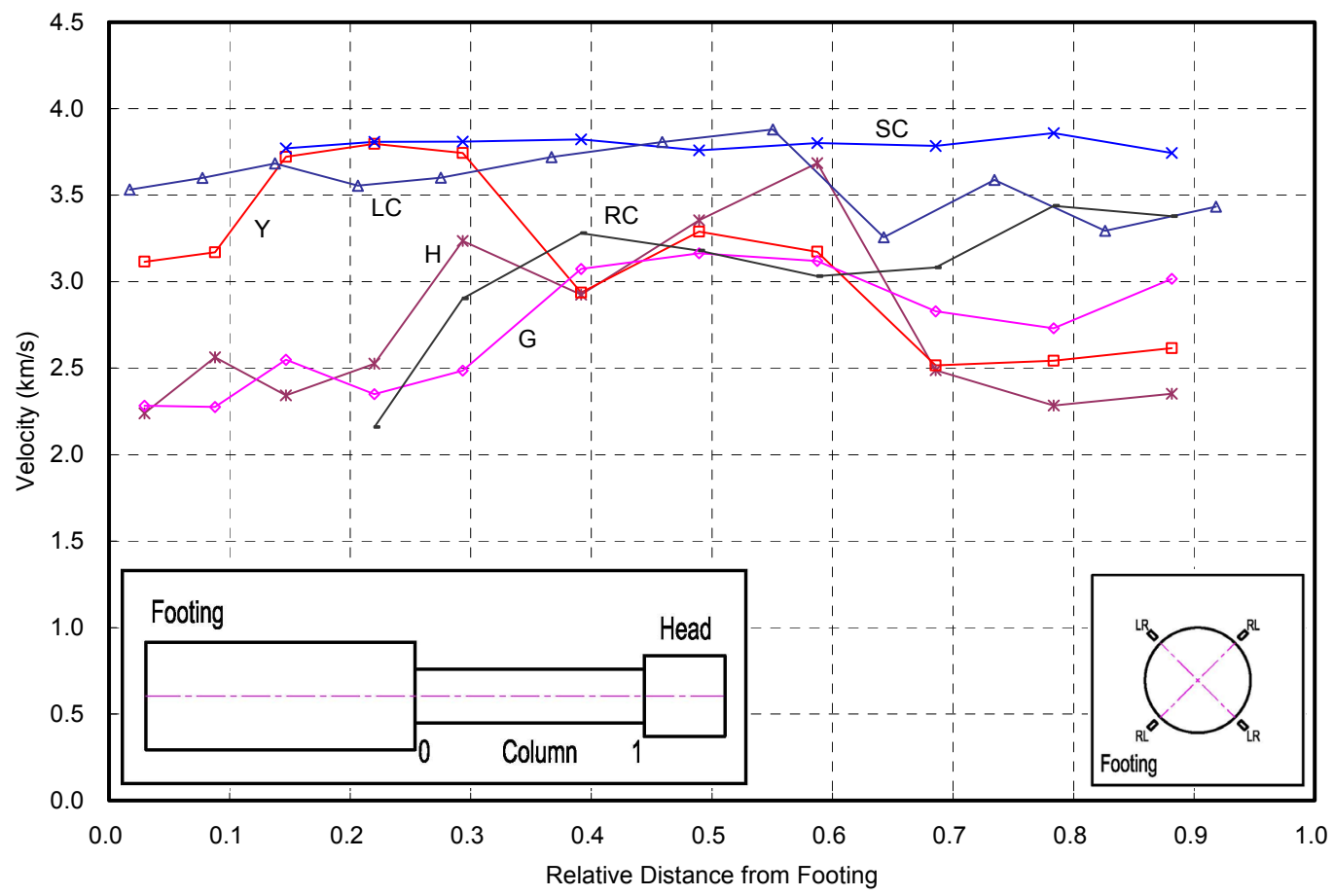

(d) Average of Directions LR and RL 


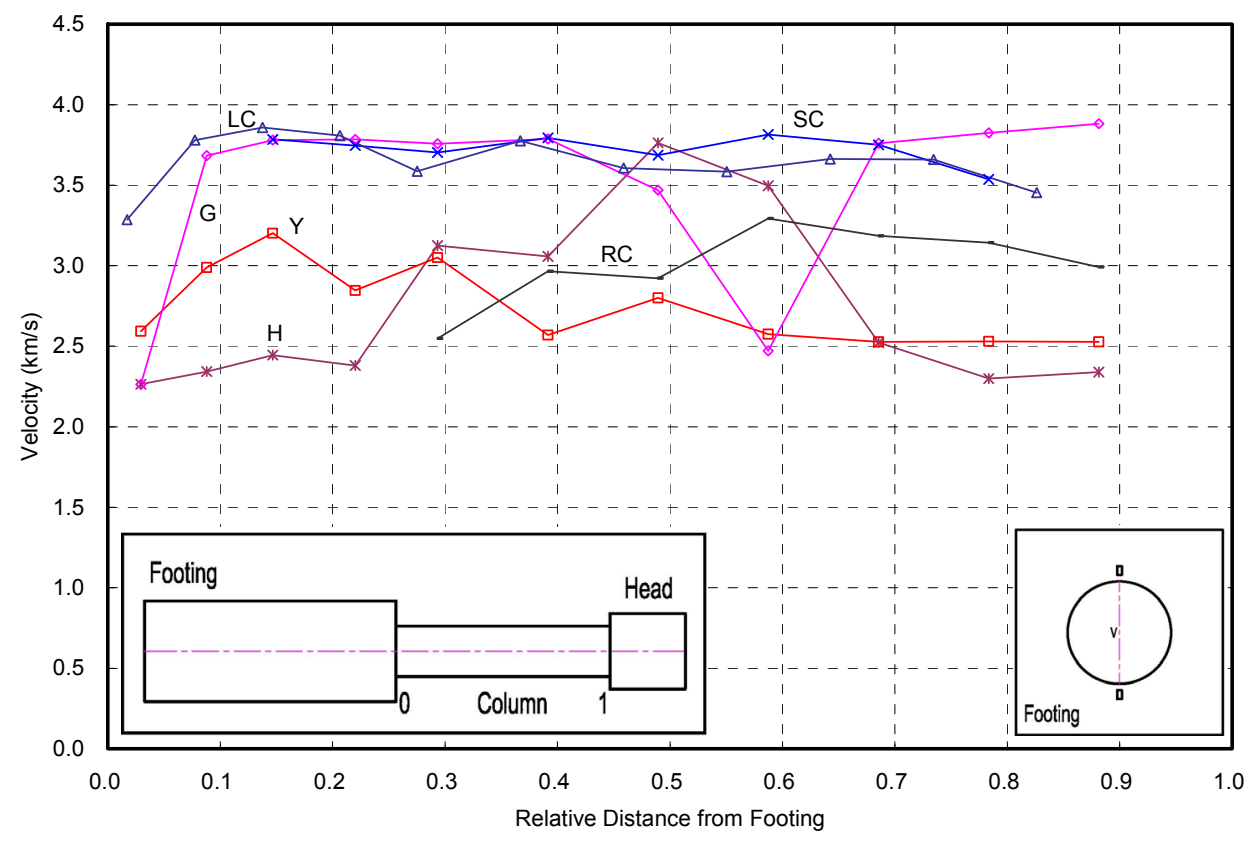

(e) Direction V

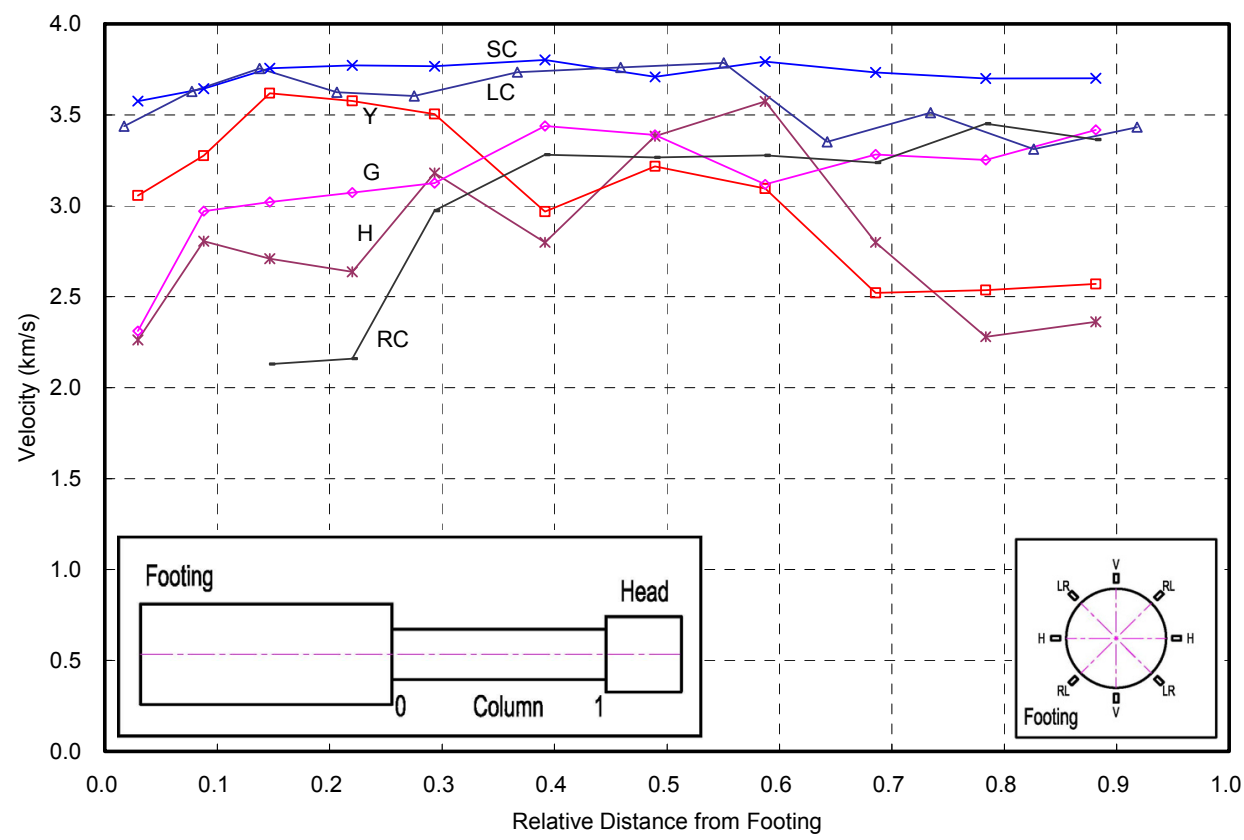

(f) Average of Directions H, LR, RL and V

Figure 6.10 Velocity Measurements in the H, LR, RL and V Directions for All Specimens 


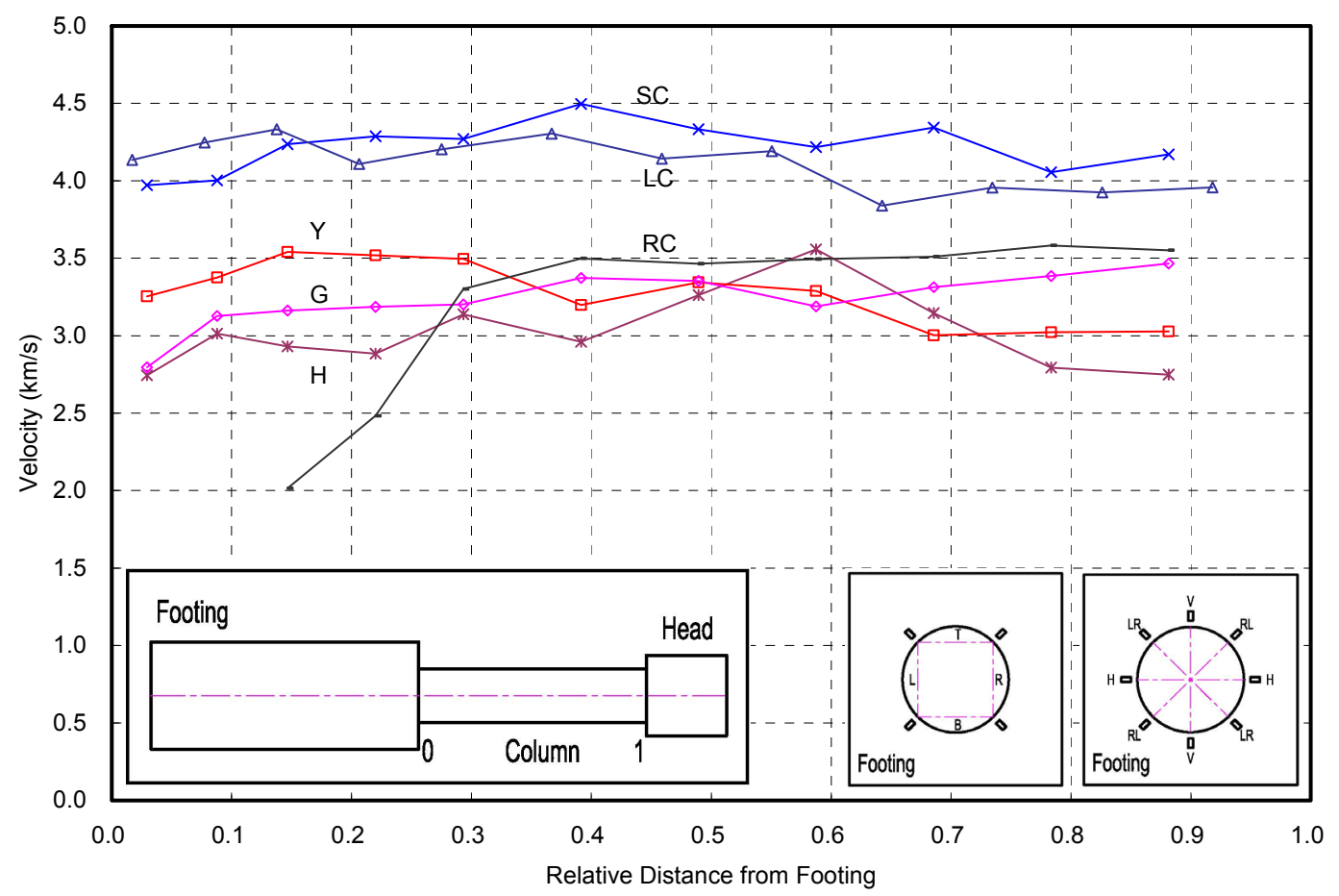

Figure 6.11 Average Velocity Measurements in Various Directions for All Specimens

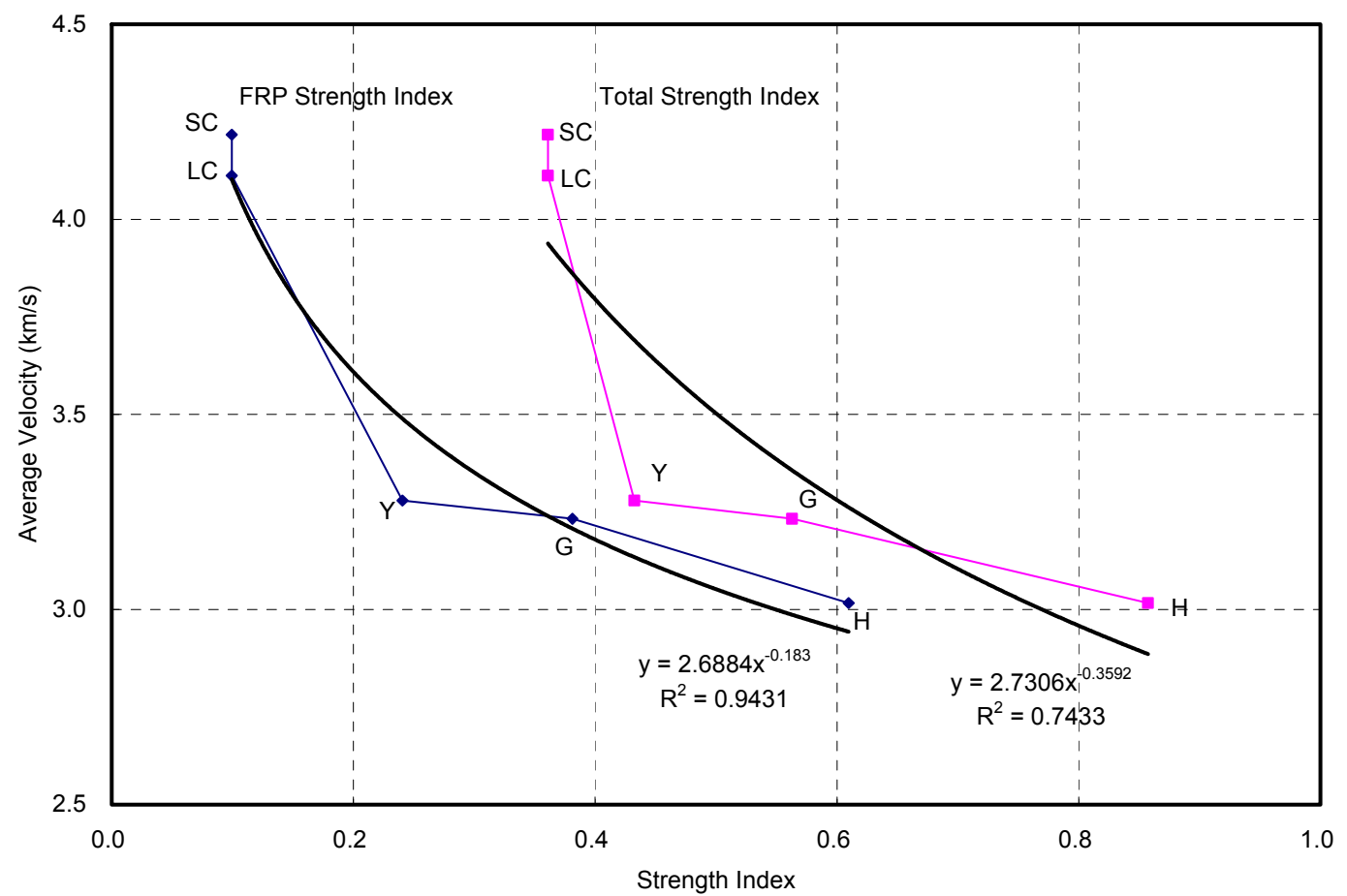

Figure 6.12 Average Velocity Measurements versus Strength Index 


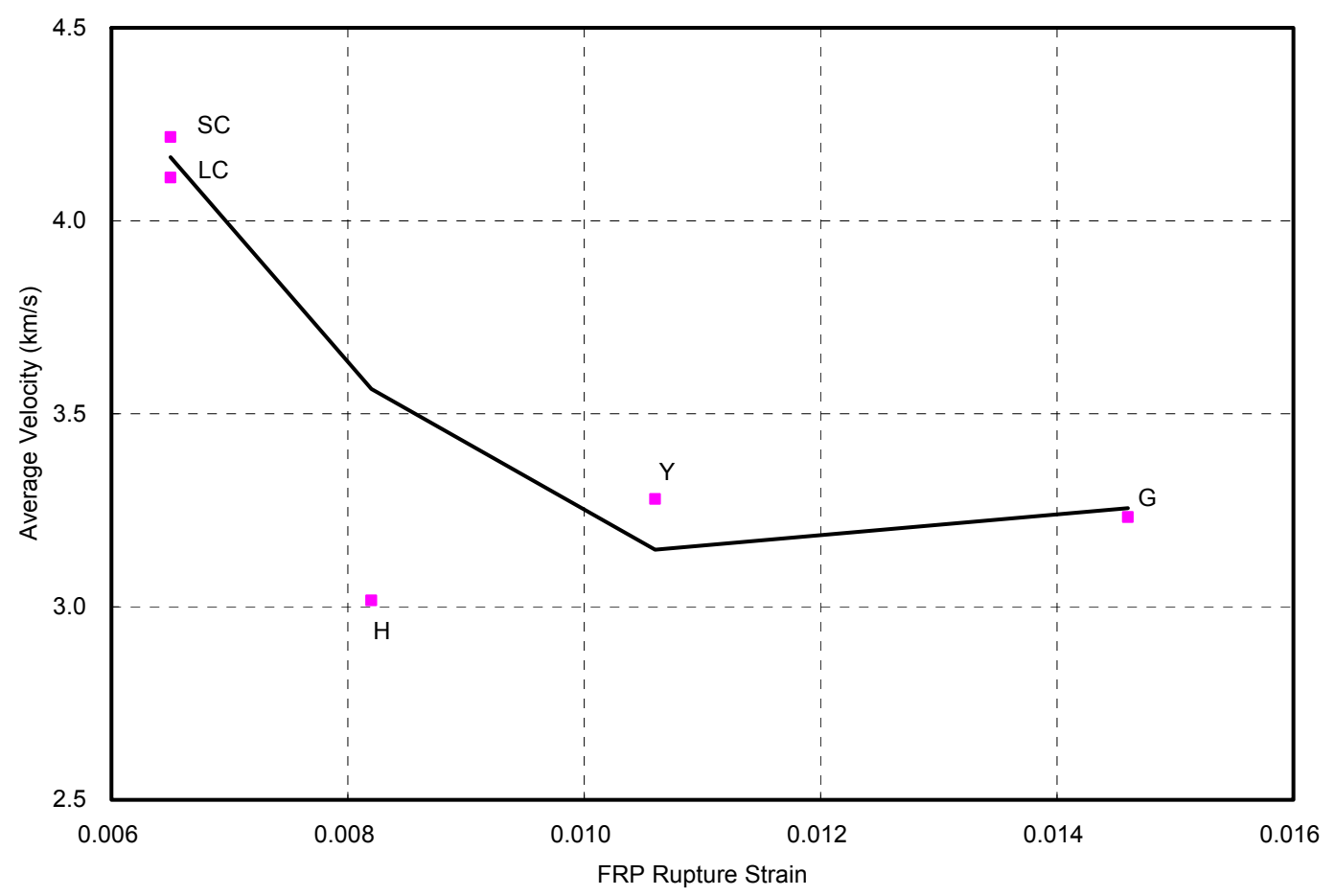

Figure 6.13 Average Velocity Measurements versus FRP Rupture Strain 


\section{CHAPTER 7 ANALYTICAL MODELING}

\subsection{INTRODUCTION}

Analytical tools for push-over and hysteretic modeling of CFFT columns were developed using ANSYS 11.0 (academic product) (2007), a general purpose finite element program, and OpenSees 2.0 (http://opensees.berkeley.edu/); the latter has been developed by UC Berkeley for primary usage in earthquake engineering simulation. The models were able to trace the monotonic and hysteretic moment-curvature and loaddeflection of a cantilever RC or CFFT column with different FRP fiber architecture subjected to a constant axial loading and a monotonic push-over or reverse cyclic lateral loading. The results from these two analytical methods were compared.

Modeling of CFFT columns followed some basic assumptions, as follows: (a) plane sections, including concrete and FRP, remain plane and normal to the neutral axial after bending, (b) buckling of the tube was neglected assuming perfect concrete fill and no stress concentration near loading points, and (c) slippage of FRP tube was neglected because of its sufficient embedment in the footing.

After the analytical models were validated against test data of previous sections, a comprehensive parametric study was carried out for different FRP reinforcement index and different FRP laminate architecture, shear span-to-depth ratio, and reinforcement index of mild or MMFX steel. The responses of typical CFFT columns to three representative earthquake records are also investigated. 


\subsection{HYSTERETIC MODELING USING OPENSEES}

\subsubsection{Element Descriptions}

Modeling of RC and CFFT columns was performed using the non-linear beamcolumn element option of OpenSees 2.0, which is based on the non-iterative (or iterative) force formulation, and considers the spread of plasticity along the element. The program enables the iterative form of the flexibility formulation, which can improve the rate of global convergence at the expense of more local element computations.

The load-displacement response of the element was calculated based on sectional analysis and curvature integration over the element length. The sectional analysis follows conventional strip method, discretizing sections into a number of integration strips or layers. For each layer, force-deformation relationship is adopted from the constitutive material models, as discussed later in this chapter. The material interactions within the section (e.g., FRP and/or mild steel confinement effect for concrete core) are considered at the materials level rather at the sectional analysis, as also discussed later in this chapter. The integration along the element is based on Gauss-Lobatto quadrature rule with two integration points at the element ends.

\subsubsection{Concrete Material Modeling}

CONCRETE01 material model of OpenSees was chosen to construct a uniaxial Kent-Scott-Park concrete material object (Scott et al. 1982) with no tensile strength and degraded linear unloading/reloading stiffness according to the work of Karsan and Jirsa (1969). For the CFFT column, the bilinear confinement model of Samaan et al. (1998) was used as the envelope curve for the concrete core material, and was provided as input 
for the CONCRETE01 material model in the program. To account for crushing of concrete cover, the strength in the concrete cover is reduced to $0.3 f^{\prime}$, once the compressive strain exceeds 0.006 . Crushing of concrete core was monitored by the strain computed manually by both models. Figure 7.1 shows a typical hysteretic stress-strain response output for concrete, with compressive stresses and strains shown as negative.

\subsubsection{Steel Material Modeling}

Both mild and MMFX steel reinforcement was modeled using STEEL01 material model of OpenSees. This uniaxial bilinear steel material model has kinematic hardening and optional isotropic hardening described by a non-linear evolution equation. As presented by Sumpter et al. (2009), the ASTM A1035 steel (an MMFX steel used in their study) has a yielding-experienced linear behavior up to a stress level of approximately $552 \mathrm{MPa}(80 \mathrm{ksi})$, followed by a negligibly small reduction in the elastic modulus up to $690 \mathrm{MPa}(100 \mathrm{ksi})$, and then nonlinear behavior up to a maximum strength of 1,186 MPa (172 ksi) at 5\% strain. Figure 7.2 shows the stress-strain relationship of MMFX and G60 steel (Sumpter et al. 2009).

In this study, A1035 steel was also applied for MMFX steel, simply denoted as G100 with a yielding strength of $690 \mathrm{MPa}(100 \mathrm{ksi})$ with the same elastic modulus of mild steel and an ultimate strength of 1,172 $\mathrm{MPa}(170 \mathrm{ksi})$, whereas mild steel is denoted as G60 with $414 \mathrm{MPa}(60 \mathrm{ksi})$ yielding strength and $621 \mathrm{MPa}(90 \mathrm{ksi})$ ultimate strength. Figure 7.3 shows typical hysteretic stress-strain responses of both G60 and G100 steel reinforcement. Failure of steel materials in each case was detected by monitoring the strains to reach 0.05 throughout the analysis. 


\subsubsection{FRP Material Modeling}

For Specimen Y, the FRP tube was modeled in the longitudinal direction with the following stress-strain relationship, based on manufacturer data and coupon tests (Shao 2003):

$$
\sigma=(\varepsilon / A B S(\varepsilon)) \times(-3.08+\sqrt{9.49+13,423 \times A B S(\varepsilon)}) \quad A B S(\varepsilon) \leq 0.05
$$

The above relationship was cast into a uniaxial tri-linear hysteretic material model with degraded unloading stiffness, but without any pinching or damage effect. An empirical value of 0.3 was selected for parameter $\beta$ in the model to simulate the degraded unloading stiffness. Failure of the FRP tube was detected by monitoring its strains to reach 0.05 . Figure 7.4 shows a typical hysteretic stress-strain response output for the FRP tube in Specimen $\mathrm{Y}$ in the longitudinal direction. The unsymmetrical response came from different in-situ stress conditions of FRP tube under cyclic loading, corresponding with the unsymmetrical responses of steels in Figure 7.3.

Based on the linear elastic behavior of coupon tests for Specimens G, H, SC and LC as presented in Chapter 5, an elastic uniaxial material model with a minimum and maximum strain were applied. The model can automatically indicate the failure of FRP materials. The modulus of elasticity and ultimate strain for FRP materials were input according to the coupon test results in the longitudinal directions.

\subsubsection{Structural Modeling}

Each column was divided into eight nodes with seven elements for modeling; one for each quarter height of the column from column head, and four within the quarter height near column footing, i.e., the plastic hinge region (see Figure 7.5). Geometric 
features of the cross section consisted of a concrete core, steel reinforcement and the cover material, i.e., FRP tube or unconfined cover concrete. Each component was modeled with a fine mesh to capture stress conditions across the section. The column was only fixed at the base, and was constructed as a 2-D problem with three degrees of freedom for each node.

\subsection{HYSTERETIC MODELING USING ANSYS}

Zheng (2007) presented a simplified analytical method using ANSYS for hybrid FRP-concrete bridge structures under blast loading. It incorporated the concept of equivalent section with virtual materials that would generate the same moment-curvature as that of the original section. The methodology was favorably validated with a 3-D blast simulation using the nonlinear explicit code LS-DYNA 3-D. The simplified analytical method transformed a 3-D complex analysis into a 2-D domain with much less number of elements and nodes, saving significant computation time and alleviating convergence problems.

This study extends the methodology from the blast resistant evaluation of Zheng (2007) into the earthquake engineering simulation, and fully validates the analytical method with cyclic experimental results, as shown in the followed sections.

\subsubsection{Extended Equivalent I-Section with Virtual Materials}

The equivalent section proposed by Zheng (2007) transformed the original section geometry of a hybrid FRP-concrete column into an I-shaped section, whereby the web thickness is considered to be negligible, and the entire section is lumped into two flanges with a small finite small thickness, hence limited stress variation within the flange 
thickness. The section performance is therefore fingerprinted by the stress-strain curve of the virtual material defined at the two flanges.

In this extended study, however, the web thickness was considered for the stressstain analysis, with further emphasis on an identical flexural stiffness of the analytical model with original structure. This was attributed to a macro-scale strain rate under simulation of cyclic and push-over loading. Figure 7.6 illustrates the extended equivalent section concept. The stress-strain curve of the virtual material is defined directly from the moment-curvature response of the original cross section applying classical engineering mechanics of materials. Figure 7.7 shows a typical transformation from (a) momentcurvature response of the original section into (b) the stress-strain model of the virtual material as the input constitutive model for the ANSYS program, as will be discussed later in the following sections.

\subsubsection{Element Descriptions}

The columns are modeled using 2-noded 3-D finite strain beam element BEAM188 (ANSYS 11.0, 2007). The adopted BEAM188 element has six degrees of freedom at each node, including translations in the $\mathrm{x}, \mathrm{y}$, and $\mathrm{z}$ directions and rotations about the $\mathrm{x}, \mathrm{y}$, and $\mathrm{z}$ axes. The nodal configuration, geometry, and coordinate system of BEAM188 element are shown in Figure 7.8. BEAM188 is defined by nodes I and $\mathrm{J}$ in the global coordinate system. The orientation key point $(\mathrm{K})$, if used, defines a plane (with I and $\mathrm{J}$ ) containing the $\mathrm{x}$ and $\mathrm{z}$ axes of the element. The beam element is a one-dimensional line element in space, which can be used with any cross-section. I-shape cross section with a finite flange and web was used in this case, as shown in Figure 7.9. 
BEAM188 is based on the Timoshenko beam theory, i.e., a first order shear deformation theory in which transverse shear strain is assumed to be constant throughout the cross-section. In other words, plane sections remain undistorted after deformation. This element includes stress stiffness terms, which enable the elements to analyze flexural, lateral, and torsional stability problems. It is well-suited for linear, large rotation, and/or large strain nonlinear applications. Elasticity, creep, and plasticity models are also supported by this element.

The structural mass of each member is modeled using MASS21 element (ANSYS 11.0 2007). MASS21 is a single-noded element with up to six degrees of freedom: three translations in the nodal $\mathrm{x}, \mathrm{y}$, and $\mathrm{z}$ directions and three rotations about the nodal $\mathrm{x}, \mathrm{y}$, and $\mathrm{z}$ axes. The mass element includes concentrated mass components (Force*Time ${ }^{2} /$ Length) along the element coordinate axes, and rotary inertias (Force*Length*Time ${ }^{2}$ ) about the element coordinate axes. In this study, one of the end nodes for each column element is defined as mass node. The coordinate system for this element is shown in Figure 7.10.

The lumped mass formulation is used throughout to construct the mass matrix for the column's distributed mass and mass moment of inertia. For the purpose of comparison, a typical case was analyzed once with the lumped mass formulation and once with the consistent mass formulation. Only negligible differences were observed between the results of the two formulations.

\subsubsection{Virtual Material Modeling}

The nonlinear plastic material model was applied in this study with multilinear kinematic hardening options using the Besseling model (Besseling 1958), also called the 
sublayer or overlay model, so that the Bauschinger effect is included. It also uses Rice's model (Rice 1971) where the total plastic strains remain constant by scaling the sublayers. The model allows defining up to forty stress-strain curves under different temperature gradients, and is compatible with BEAM188 element. Figure 7.11 shows the nonlinear plastic material model with multilinear kinematic hardening (ANSYS 11.0, 2007).

\subsubsection{Structural Modeling}

With the concept of extended equivalent I-shape cross section and virtual materials developed in this study, the finite element column model was developed, as shown in Figure 7.12. The finite element mesh was established with 31 mass nodes and 30 finite strain beam elements. The column was only fixed at the base, and was constructed as a 2-D problem with three degrees of freedom at each node.

\subsection{MODEL VALIDATION}

Four series of model validation with cyclic tests are provided, including hysteretic analysis using OpenSees and ANSYS, as well as push-over analysis using OpenSees and ANSYS. In addition, modeling of monotonic tests using OpenSees is presented.

Figure 7.13 to Figure 7.18 show comparisons of the cyclic test data with the OpenSees and ANSYS hysteretic model predictions for each specimen. In each figure, the experimental and simulation results are delineated. In general, very good agreement is noted in all cases. As stated in Chapter 3, Specimen RC was an inadvertently pre-loaded and thus experienced damage in the push direction. The hysteretic models, however, clarified that the experimental result in the pull direction is valid. The simulation of all 
other specimens further confirmed that the experimental result in the pull direction is more representative than that in the push direction.

The stress-strain relationship of each ANSYS material model was transformed from moment-curvature response of OpenSees push-over simulation as discussed later. It is shown that ANSYS models predicted the envelope curve very closely with the cyclic tests and OpenSees simulation. However, they did not perform as well as OpenSees when compared with cyclic tests in the loading/unloading paths. This may be attributed to the plastic material model of ANSYS. Plastic material model that is suitable for concrete in ANSYS is only available for SOLID65 element, which does not lend itself to the virtual material concept in this study. However, the ANSYS model performed very well in pushover simulation as discussed below.

Figure 7.19 to Figure 7.24 show the push-over simulation of OpenSees and ANSYS for the specimens as compared with cyclic test results. In each figure, the experimental and simulation results are delineated. Very good agreements between the two sets are noted in all specimens. It should be noted that push-over simulation essentially matches with the envelope curve of the cyclic simulation, as no damage or pinching effects were considered in the hysteretic models.

Figure 7.25 to Figure 7.30 show the OpenSees modeling of monotonic tests for all specimens. In each figure, the experimental and simulation results are delineated. It is noted that Specimens Y and LC show very good agreements between simulation and the tests, while other cases exhibited some variations, primarily due to the fact that the specimens had different levels of damage from cyclic tests before monotonic testing. 
Generally, OpenSees distinguishes itself in hysteretic modeling, whereas ANSYS outperforms in push-over simulation. In all cases, ANSYS requires less effort in reducing convergence problems than OpenSees, once provided with a reliable sectional analysis for its constitutive virtual material model.

\subsection{PARAMETRIC STUDY}

The OpenSees hysteretic model for CFFT columns developed and verified in previous sections was used to carry out a parametric study. The basic model for the parametric study was essentially the same as that used for validation of the model against experimental work of the present study.

\subsubsection{Parameters}

Based on a comprehensive literature review of parameters for CFFTs, the following three main parameters were selected: column span-to-depth ratio $\left(L / D_{o}\right)$, thickness of the FRP tube, and type and amount of steel reinforcement. To limit the size of the case study matrix, only one parameter at a time was considered as variable. For each parameter, four values were selected in their practical range, with one value identified as the base value, which was kept constant for studying other parameters.

Table 7.1 shows the parameters and their selected values. The shaded areas in the table represent the base value for each parameter. Column Y in the table denotes CFFT columns for the parametric study with the filament-wound glass FRP tubes as that used in Specimen Y. The thickness parameter of Column Y series is expressed as the outside diameter-to-FRP thickness ratio $\left(D_{o} / t\right)$ of the column. Column $\mathrm{G}$ denotes CFFT columns in the parametric study with the fabric-wrapped glass FRP tubes as that used in Specimen 
G. The definition is the same for Column $\mathrm{H}$ with fabric-wrapped hybrid FRP tubes and Column $\mathrm{C}$ with fabric-wrapped carbon FRP tubes. For CFFT columns with fabricwrapped tubes, the thickness parameter is expressed in terms of FRP layers, i.e., 1, 2, 3, or 4 plies.

Based on the discussion in Chapter 4, a span-to-depth ratio $\left(L / D_{o}\right)$ of 2.5 was also investigated in this study, apart from 5, 7.5, and 10 as identified with flexure-dominant behavior. Two rebar types of MMFX and mild steel were considered, each with $1 \%$ and $2 \%$ reinforcement ratio.

\subsubsection{Response Measures}

Three response measures were selected to study the effect of different parameters: normalized moment-deflection hysteretic response, normalized moment-deflection envelope curve, and normalized cumulative dissipated energy.

Figure 7.31 to Figure 7.33 show the parametric study results for the hysteretic normalized moment-deflection of Column Y series. Figure 7.34 to Figure 7.36 show normalized moment-deflection envelope curves and Figure 7.37 to Figure 7.39 show the cumulative energy capacity for Column Y series. Failure in all cases was determined by rupture of FRP tube, after mild steel reached its ultimate strength at $621 \mathrm{MPa}(90 \mathrm{ksi})$, or MMFX steel reached its strength at $965 \mathrm{MPa}(140 \mathrm{ksi})$ and a strain of 0.05 . Concrete core remained within $50 \% \sim 80 \%$ of ultimate strain following Samaan's model (1998).

Figure 7.40 to Figure 7.42 show the parametric study results for the hysteretic normalized moment-deflection of Column G series. Figure 7.43 to Figure 7.45 show normalized moment-deflection envelope curves and Figure 7.46 to Figure 7.48 show the 
cumulative energy capacity for Column G series. Failure was governed by concrete crushing as FRP first ruptured at $\mu$ of 3 or 4 , whereas rebar did not reach its ultimate strain, especially in those cases with higher steel reinforcement index. Some FRP rupture may also lead to failure of rebar rupture at earlier stages with lower steel strength index or higher FRP strength index.

Figure 7.49 to Figure 7.51 show the parametric study results for the hysteretic normalized moment-deflection of Column H series. Figure 7.52 to Figure 7.54 show normalized moment-deflection envelope curves and Figure 7.55 to Figure 7.57 show the cumulative energy capacity for Column H series. In the analysis of these series, FRP tube first ruptured at $\mu$ of 3 or 4 . However, rebar and concrete all reached their respective ultimate strains, indicating a balanced failure. Lower steel strength index or higher FRP strength index may also lead to rebar rupture failure at earlier stages. Moreover, smaller amount of FRP may lead to higher deformation capacity at the expense of lower load bearing capacity as Column H with 1 ply distinguishes itself in Figure 7.51.

Figure 7.58 to Figure 7.60 show the parametric study results for the hysteretic normalized moment-deflection of Column C series. Figure 7.61 to Figure 7.63 show normalized moment-deflection envelope curves and Figure 7.64 to Figure 7.66 show the cumulative energy capacity for Column C series. Rupture of FRP did not lead to rebar failure at earlier stages in Column $\mathrm{C}$ series. Column $\mathrm{C}$ with 1 ply almost yielded a balanced failure condition of concrete crushing with rebar rupture at an ultimate strain of 0.05 and $\mu$ of 8 . Furthermore, Figure 7.60 shows that for Column $\mathrm{C}$ series, increasing of FRP layer does not lead to substantially higher load bearing capacity, whereas it actually reduces the deformation capacity. 


\subsubsection{Parameter Impact on Response Measure}

To better understand the impact of each parameter on the response measures of columns with different FRP architecture, following analogy was drawn. Figure 7.67 to Figure 7.69 show the effects of the three parameters on the maximum normalized moment of each column series. It is clearly shown that higher steel reinforcement or FRP reinforcement both directly lead to a higher flexural capacity. Effect of flexural span is not as significant as steel reinforcement and FRP tube.

Figure 7.70 to Figure 7.72 show the effects of the three parameters on the maximum drift ratio of each column series. In Figure 7.70, Column Y series showed a descending relationship in contrast to other columns. This may be attributed to the different failure criteria for Column Y, i.e., FRP rupture rather than rebar rupture or concrete crushing as in other columns. The most significant factor for the maximum drift ratio is the flexural span-to-depth ratio, as indicated in Figure 7.71.

Figure 7.72 shows that for Column Y series, higher FRP reinforcement index may increase the deformation capacity, as also reported by Zhu et al. (2006b). For Columns G, $\mathrm{H}$ and $\mathrm{C}$ series, however, a higher FRP reinforcement index may lead to a lower deformation capacity, confirming an earlier study by Shao (2003). The difference in the two trends in Figure 7.72 may be attributed to different failure criteria, as discussed for Figure 7.70 .

Figure 7.73 to Figure 7.75 show the effects of the three parameters on the maximum normalized cumulative dissipated energy of each column series. The increase of steel reinforcement and flexural span-to-depth ratio both increase the energy dissipation. The different trends for different FRP architecture in Figure 7.75 may be 
attributed to different failure phenomenon in these columns. Since Column Y series had higher deformation capacity with higher FRP strength index, its cumulative energy also increases along with the FRP strength index. Columns G, $\mathrm{H}$ and $\mathrm{C}$ series all demonstrated a lower deformation capacity for thicker FRP tube.

\subsubsection{Re-evaluation of Total Reinforcement Index versus Normalized Moment}

In Chapter 4, a direct relationship between total reinforcement index and normalized moment was presented from the results of cyclic and monotonic tests. The existence of an optimum reinforcement index without over-confining the concrete was also pointed out. In this section, both simulation results from parametric study and other test results from the literature are synthesized together with the data from Chapter 4, unveiling the broad-based relationship between the two parameters.

Figure 7.76 to Figure 7.79 show the effects of total reinforcement index on maximum normalized moment of each column series. A linear relationship may be drawn in all cases with high fidelity, especially for higher strength indices, as in Columns Y, G, and $\mathrm{H}$ series. Furthermore, Figure 7.80 shows a broad-based data range incorporating results of parametric study as well as test data from Chapters 3 and 4, and other test

results from Li (2008), Zhu et al. (2006a), Shao et al (2005b), Fam et al. (2007), and Van Den Einde et al. (2007). The figure shows a linear relationship until a total reinforcement index of 1.0, after which the correlation is weak.

\subsection{PERFORMANCE UNDER STRONG GROUND MOTIONS}

With the knowledge of cyclic performance of CFFTs under different parameters, a set of transient analysis of hybrid FRP-concrete columns under strong ground motions 
was also carried out using OpenSees. The CFFT columns with different FRP tubes were specified as Columns $\mathrm{Y}, \mathrm{G}, \mathrm{H}$ and $\mathrm{C}$, following the same nomenclature as that stated in Section 7.5.1. All columns had a $41.37 \mathrm{MPa}$ (6 ksi) unconfined 28-day concrete compressive strength, a $610 \mathrm{~mm}$ (24 in.) column outside diameter $\left(D_{o}\right)$, a $7.5 \mathrm{~L} / D_{o}$ ratio, $1 \%$ mild steel Grade 60 reinforcement ratio, and a $10 \% P / P_{o}$ ratio, where $P$ is the axial load, $P_{o}$ is $f^{\prime} A_{g}$. The $D_{o} / t$ Ratio of Column $\mathrm{Y}$ is 50 , whereas Columns G, H, and C all used 2 layers of FRP fabrics. This arrangement corresponded to total reinforcement indices of $0.45,0.45,0.67$, and 0.23 for Columns $\mathrm{Y}, \mathrm{G}, \mathrm{H}$, and $\mathrm{C}$, respectively.

Figure 7.81 to Figure 7.83 show the ground acceleration time histories for the three selected earthquake records, respectively from Tabas (Iran 1978), Sylmar (California, USA 1971), and Llollelo (Chile 1985). Of the selected quakes, Tabas had the highest ground acceleration with an extended period of shake, Sylmar spanned a much shorter time period with an abrupt stroke, while Llollelo had an apparent higher frequency and higher energy input.

Responses of the four CFFT columns to the three earthquakes are depicted in terms of time histories of column base shear in Figure 7.84 to Figure 7.87 for Tabas, Figure 7.92 to Figure 7.94 for Sylmar, and Figure 7.98 to Figure 7.101 for Llollelo earthquakes. Time histories of maximum lateral displacement are shown in Figure 7.88 to Figure 7.91 for Tabas, Figure 7.95 to Figure 7.97 for Sylmar, Figure 7.102 to Figure 7.105 for Llollelo earthquakes.

It is of interest to note that Columns $\mathrm{Y}$ and $\mathrm{G}$ were designed with the same level of FRP reinforcement indices, hence leading to identical initial responses in all three earthquakes. However, Column G failed in all three earthquakes due to FRP rupture, 
whereas Column Y withstood all three strong ground motions without any failure in FRP tube, owing to its more flexible off-axis FRP architecture.

Both Columns $\mathrm{G}$ and $\mathrm{H}$ failed in all three earthquakes due to FRP rupture. However, Column $\mathrm{H}$ with a higher reinforcement index generally performed better than Column G. Meanwhile, Column C with a lower FRP reinforcement index survived in Tabas and Llollelo earthquakes, even with FRP ruptured in these two cases. This conformed the earlier findings in the pseudo-static parametric study that higher FRP reinforcement index may lead to failure at earlier stages of loading.

Column Y exhibited a much better performance with higher base shear and lower column top displacement than Column $\mathrm{C}$ in Tabas earthquake, while they showed almost the same level of base shear and top displacement in Llollelo earthquake. This may indicate that Column Y sustains stronger ground acceleration than Column C, due to its higher, albeit moderate, FRP reinforcement index.

Figure 7.106 to Figure 7.111 show the comparison of responses to the three earthquakes for each CFFT column in terms of time histories of column base shear. Figure 7.108 Figure 7.113 show the comparison of responses to the three earthquakes for each CFFT column in terms of time histories of maximum lateral displacement.

It is shown that CFFT columns are more sensitive to Sylmar earthquake, since even Column Y had its highest response in terms of base shear and lateral displacement. Moreover, Columns $\mathrm{G}, \mathrm{H}$, and $\mathrm{C}$ all failed immediately at the abrupt stroke and developed lower base shear and lateral displacement than those in Tabas earthquake. On the other hand, Tabas earthquake caused significantly larger lateral displacements in all CFFT columns as compared to the Llollelo earthquake. 
In general, Column Y with off-axis filament-wound glass FRP tube exhibited a superior seismic performance to all other CFFTs. Moreover, higher FRP reinforcement ratios may lead to a brittle system failure, while a well-engineered FRP reinforcement configuration may significantly enhance the seismic performance of CFFT columns. 
Table 7.1 Parameter Matrix

\begin{tabular}{|c|c|c|c|c|}
\hline Parameters & Case 1 & Case 2 & Case 3 & Case 4 \\
\hline Span-to-Depth Ratio $\left(L / D_{o}\right)$ & 2.5 & 5 & 7.5 & 10 \\
\hline Steel Reinforcement & $1 \%$ Grade 60 & $2 \%$ Grade 60 & $1 \%$ Grade 100 & $2 \%$ Grade 100 \\
\hline$D_{o} / t$ Ratio (Column $\left.Y\right)$ & 25 & 50 & 75 & 100 \\
\hline FRP Layers $($ Column G, H, C) & 1 Ply & 2 Plies & 3 Plies & 4 Plies \\
\hline
\end{tabular}




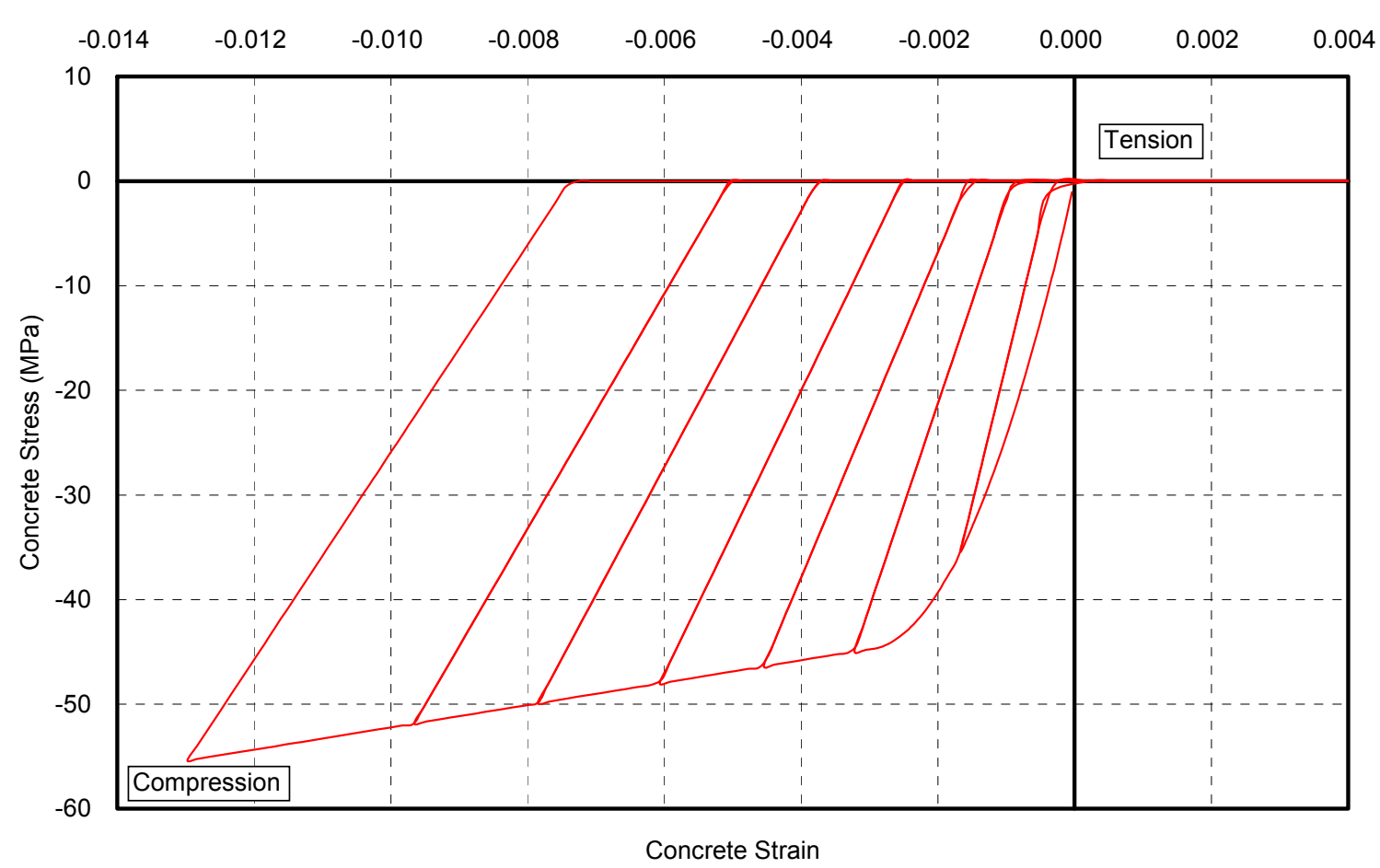

Figure 7.1 Typical Hysteretic Stress-Strain Curve of Concrete Model

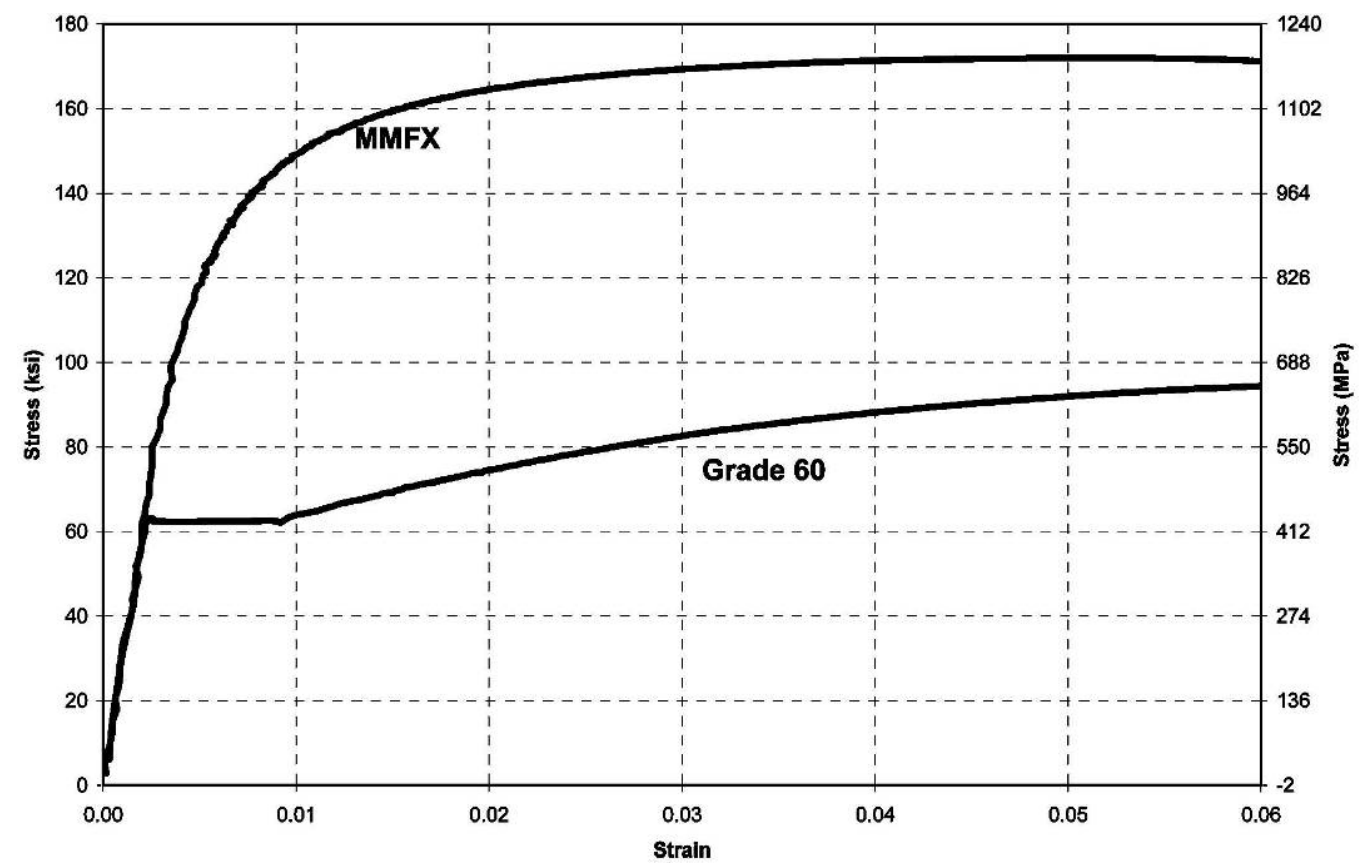

Figure 7.2 Stress-Strain Relationship of MMFX and Grade 60 Steel (Sumpter et al. 2009) 


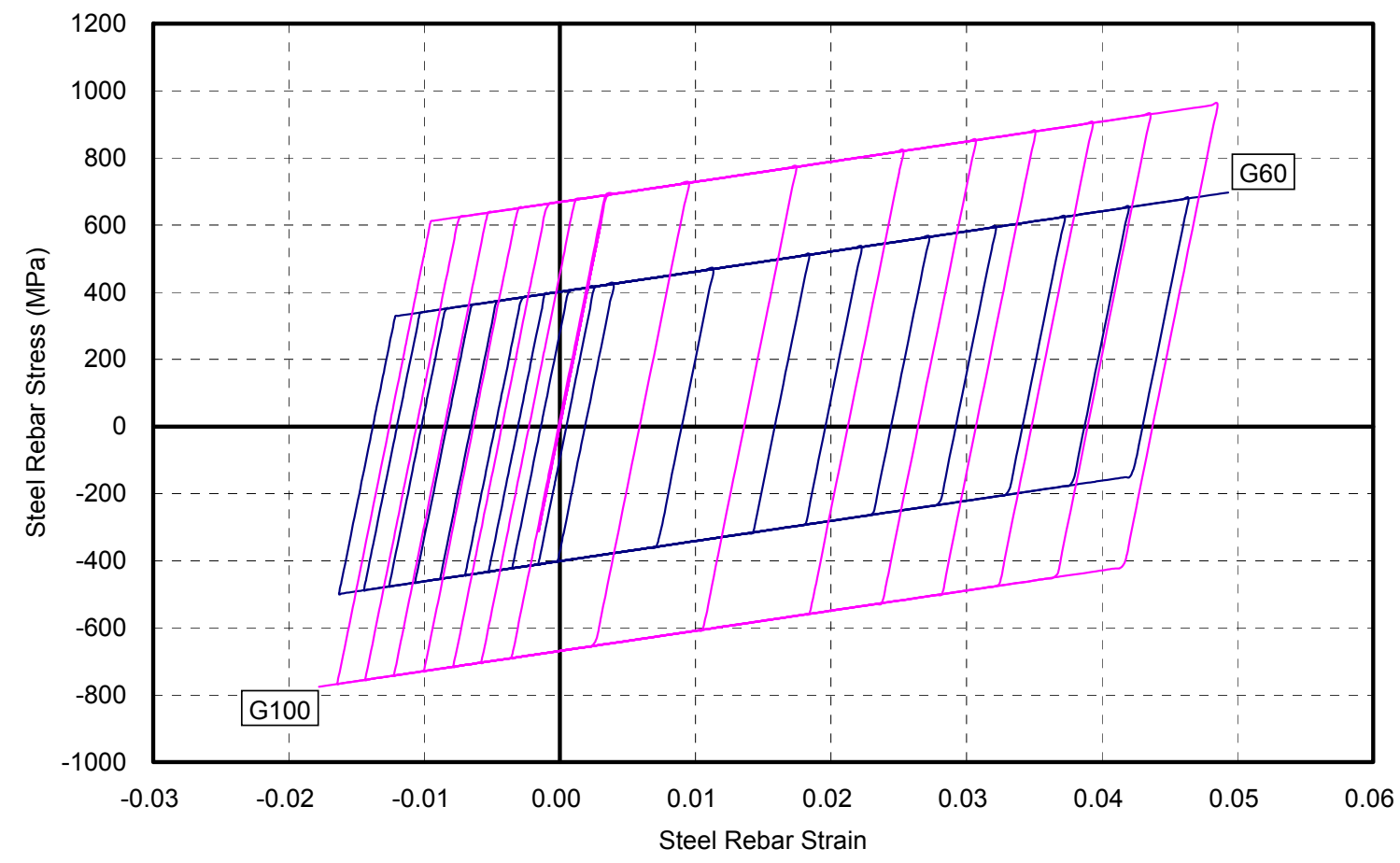

Figure 7.3 Typical Hysteretic Stress-Strain Response of Steel Reinforcement

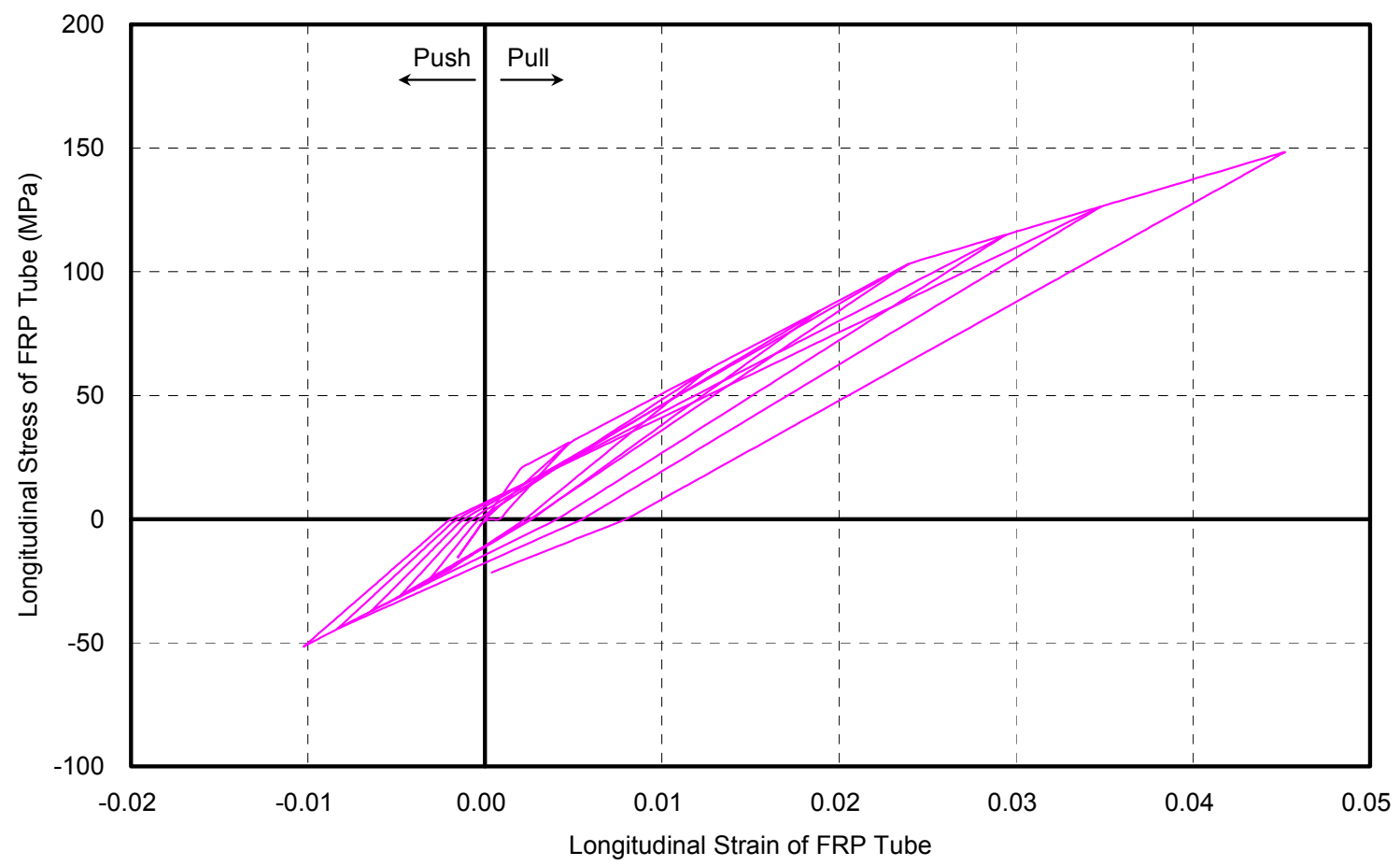

Figure 7.4 Typical Hysteretic Stress-Strain Response of FRP Tube for Column Y 


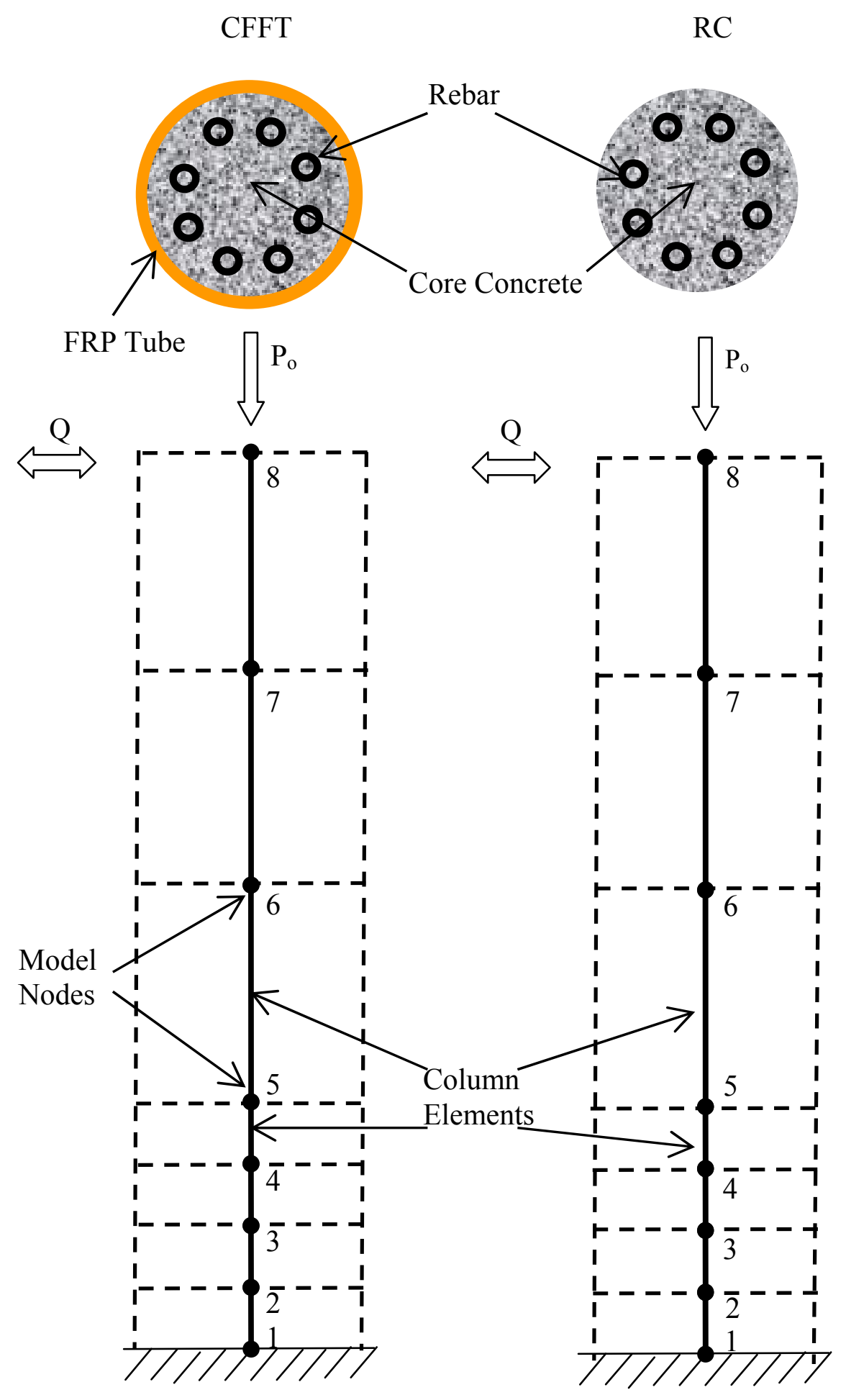

Figure 7.5 Analytical Model for CFFT and RC Columns 
Discretized Original CFFT Section

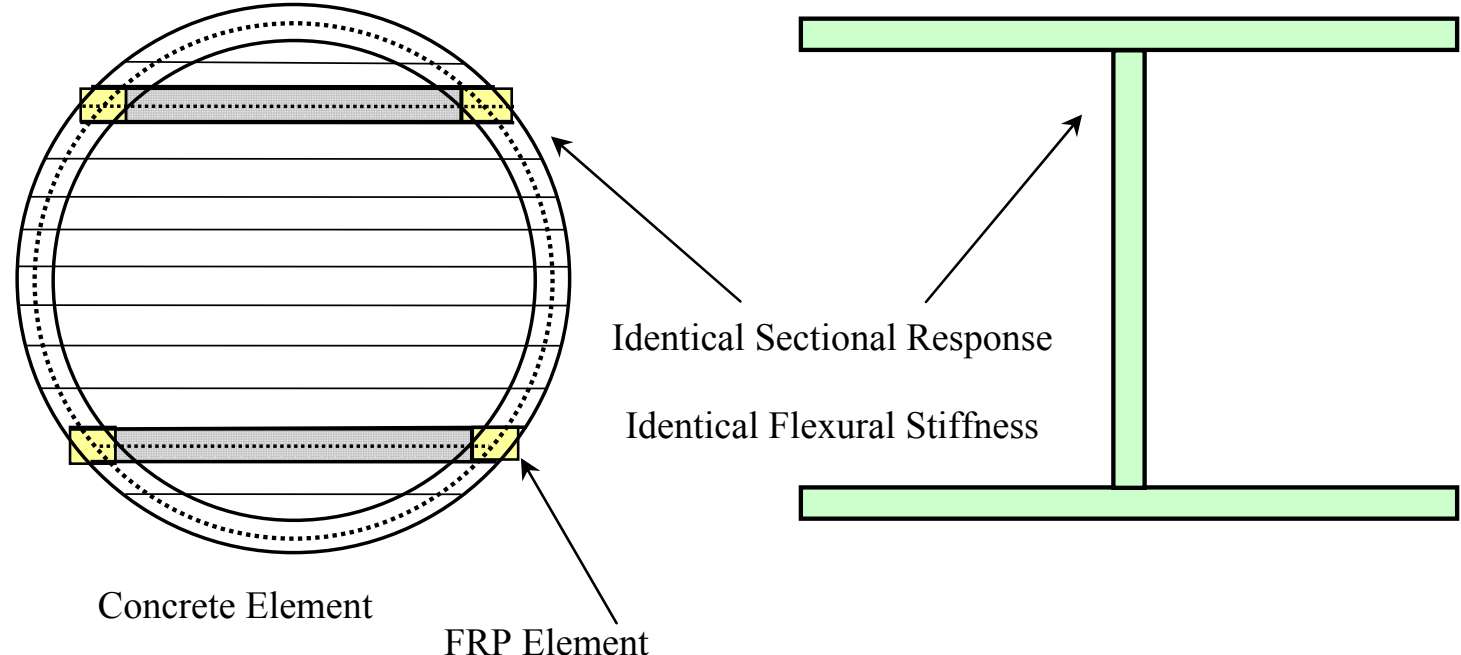

Figure 7.6 Illustration of the Extended Equivalent Section Concept

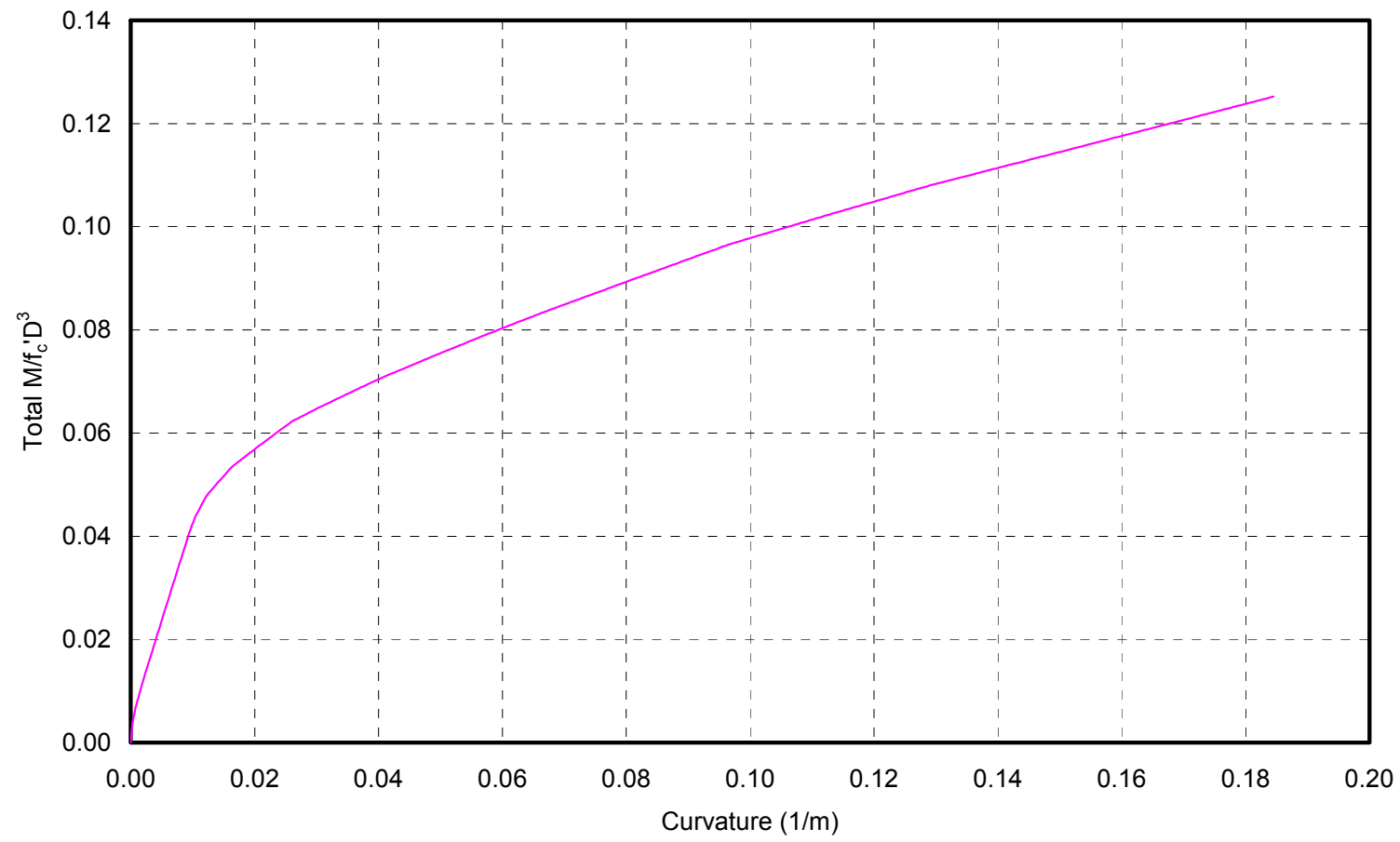

(a) Moment-Curvature Response of the Original Section 


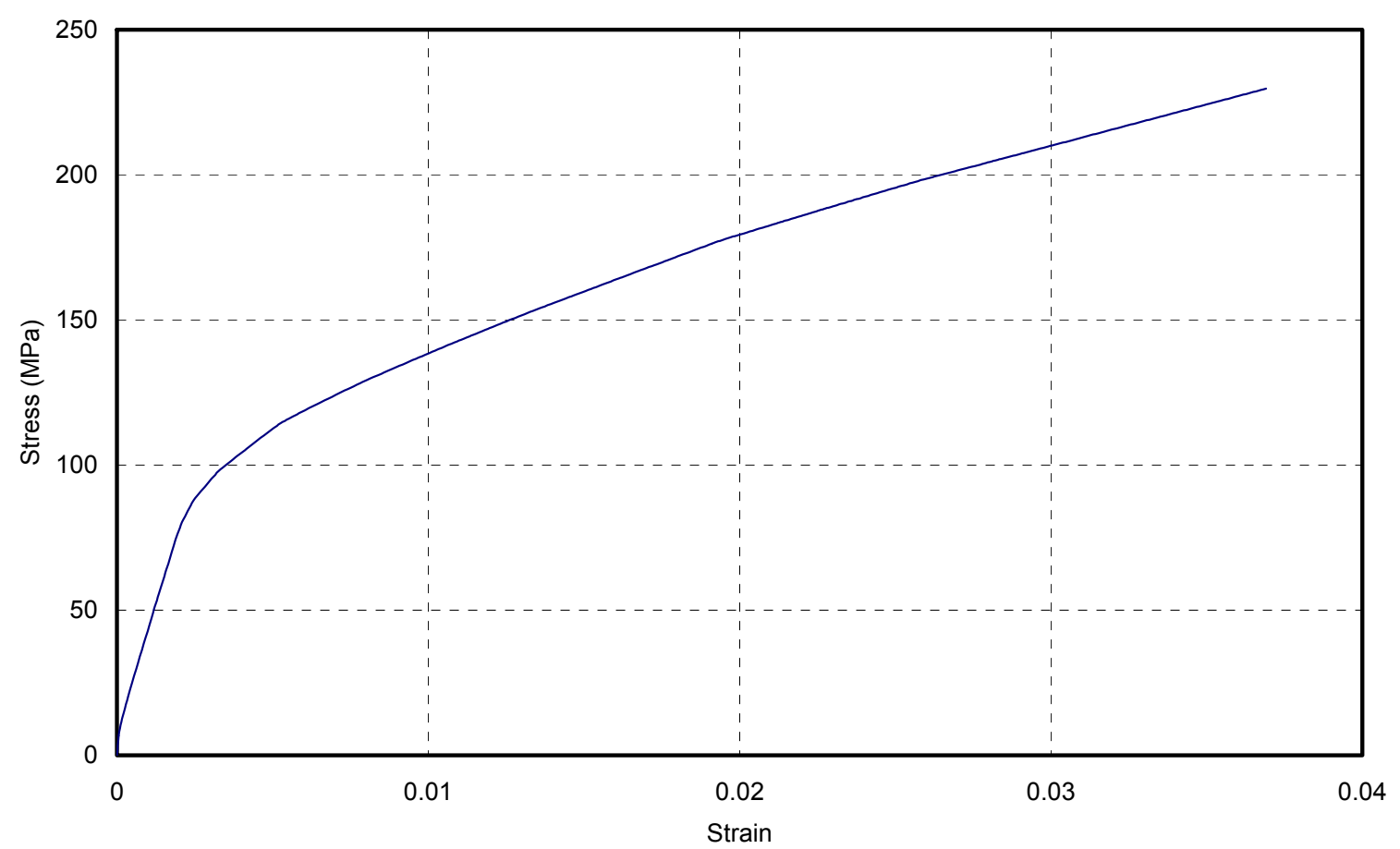

(b) Stress-Strain Input for the Virtual Material Section

Figure 7.7 Transformation from Moment-Curvature Response to Stress-Strain Input

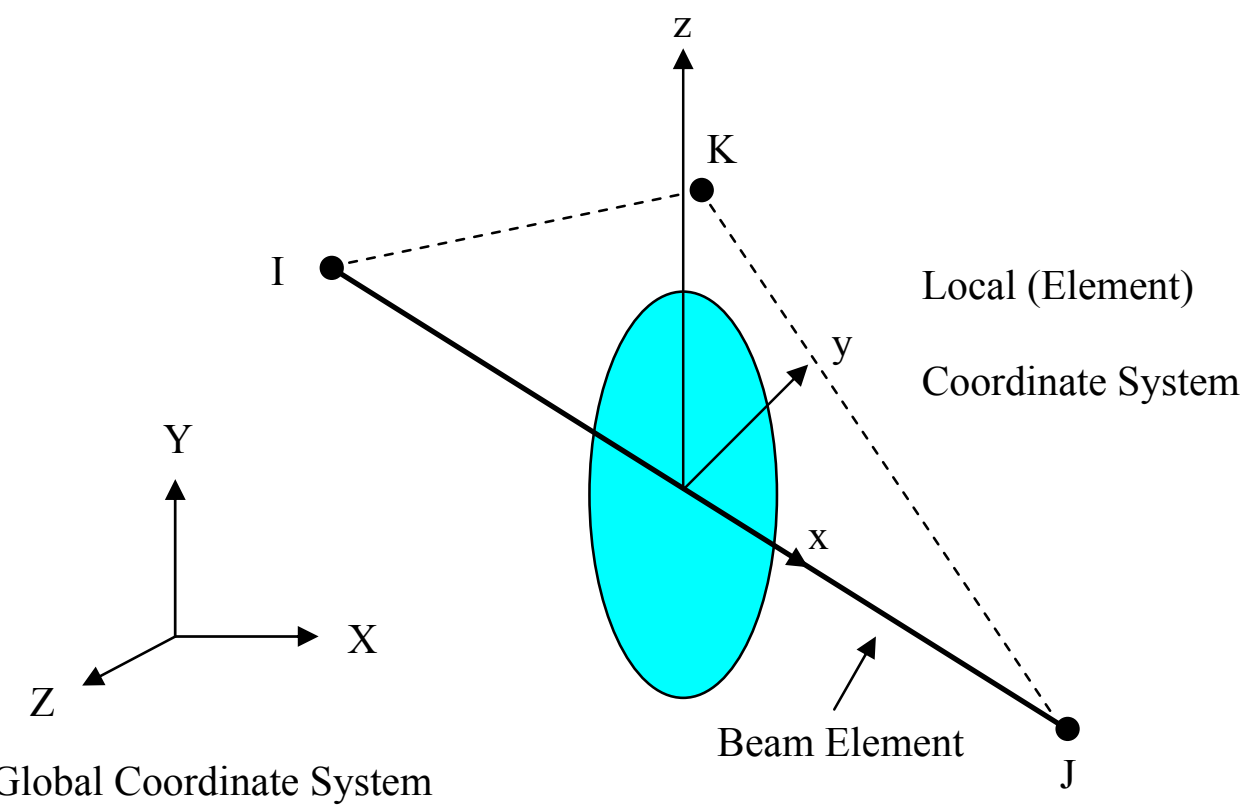

Figure 7.8 BEAM188 Geometry (ANSYS 11.0, 2007) 


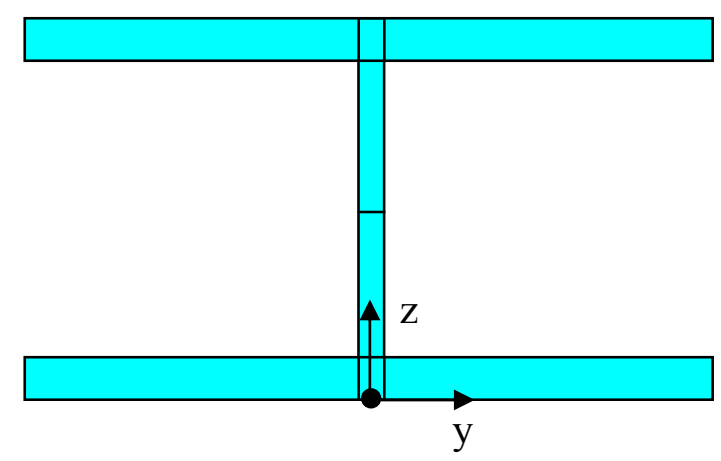

Figure 7.9 Geometry of I-Shape Cross Section (ANSYS 11.0, 2007)

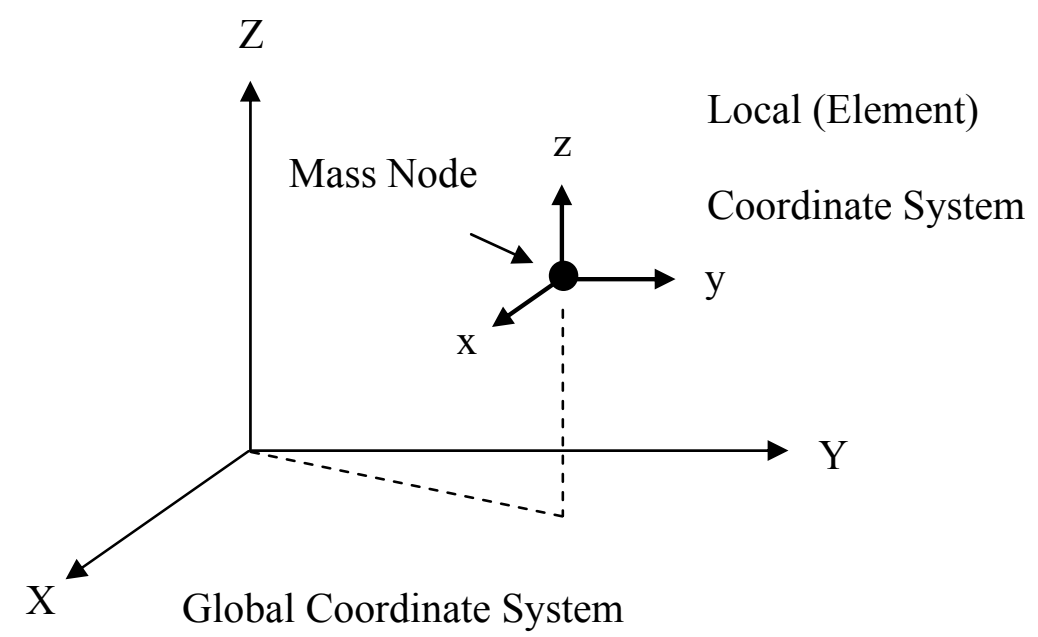

Figure 7.10 Geometry of MASS21 Element (ANSYS 11.0, 2007) 


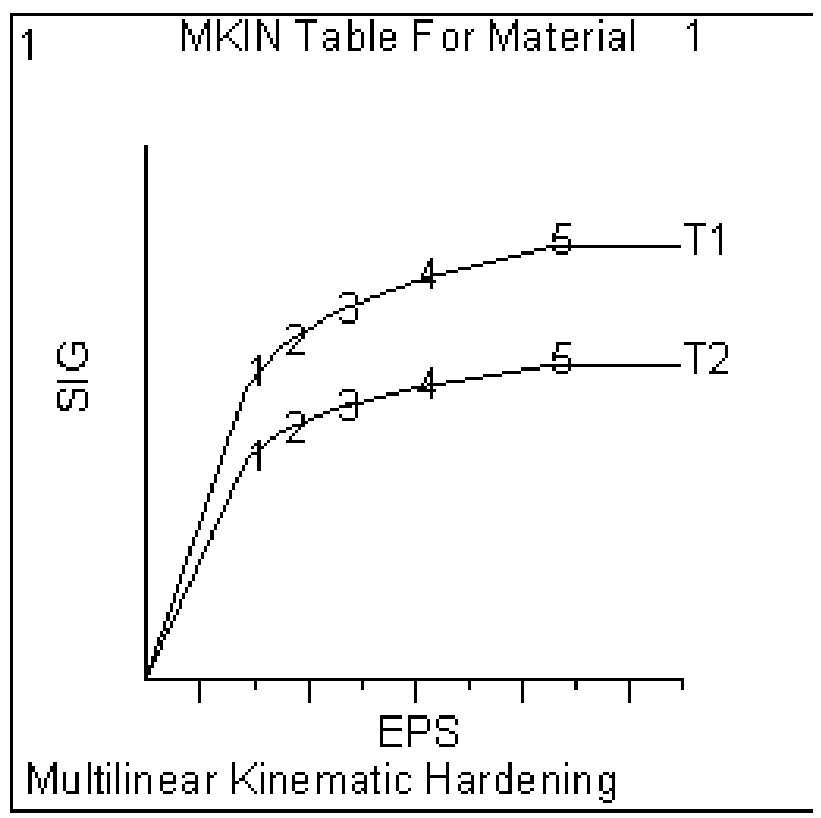

Figure 7.11 Nonlinear Plastic Material Model with Multilinear Kinematic Hardening (ANSYS 11.0, 2007)

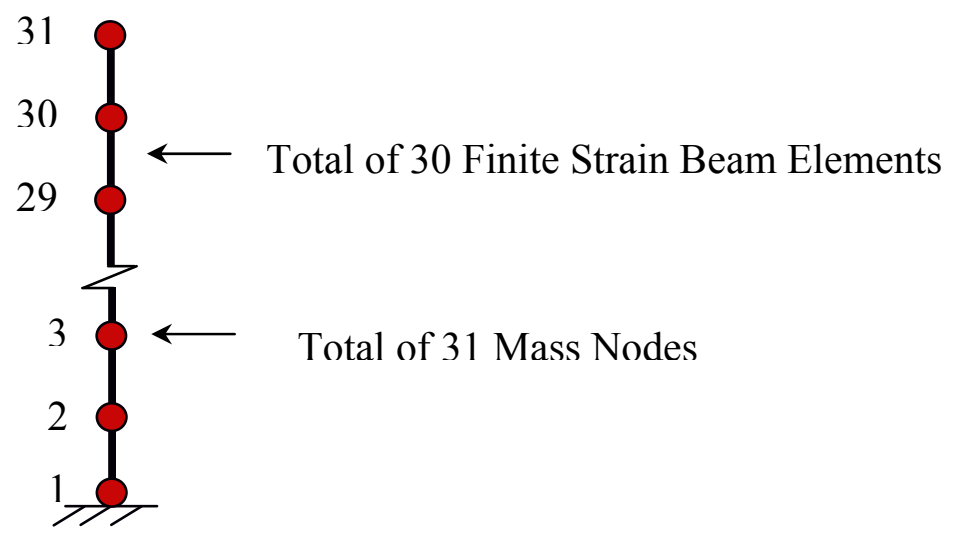

Figure 7.12 Simplified Column Model for ANSYS 


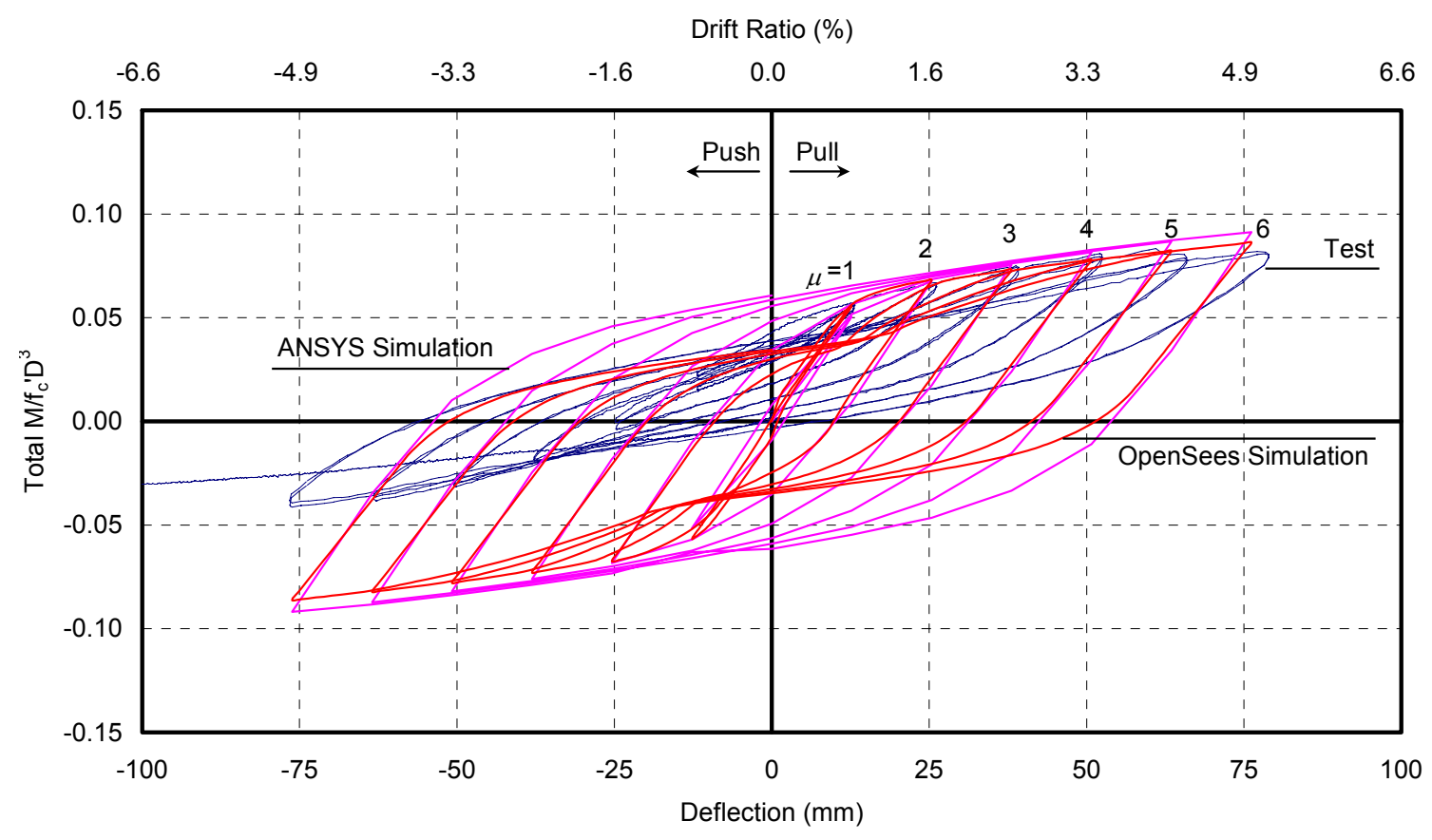

Figure 7.13 Moment-Deflection Hysteretic Simulation of Specimen RC

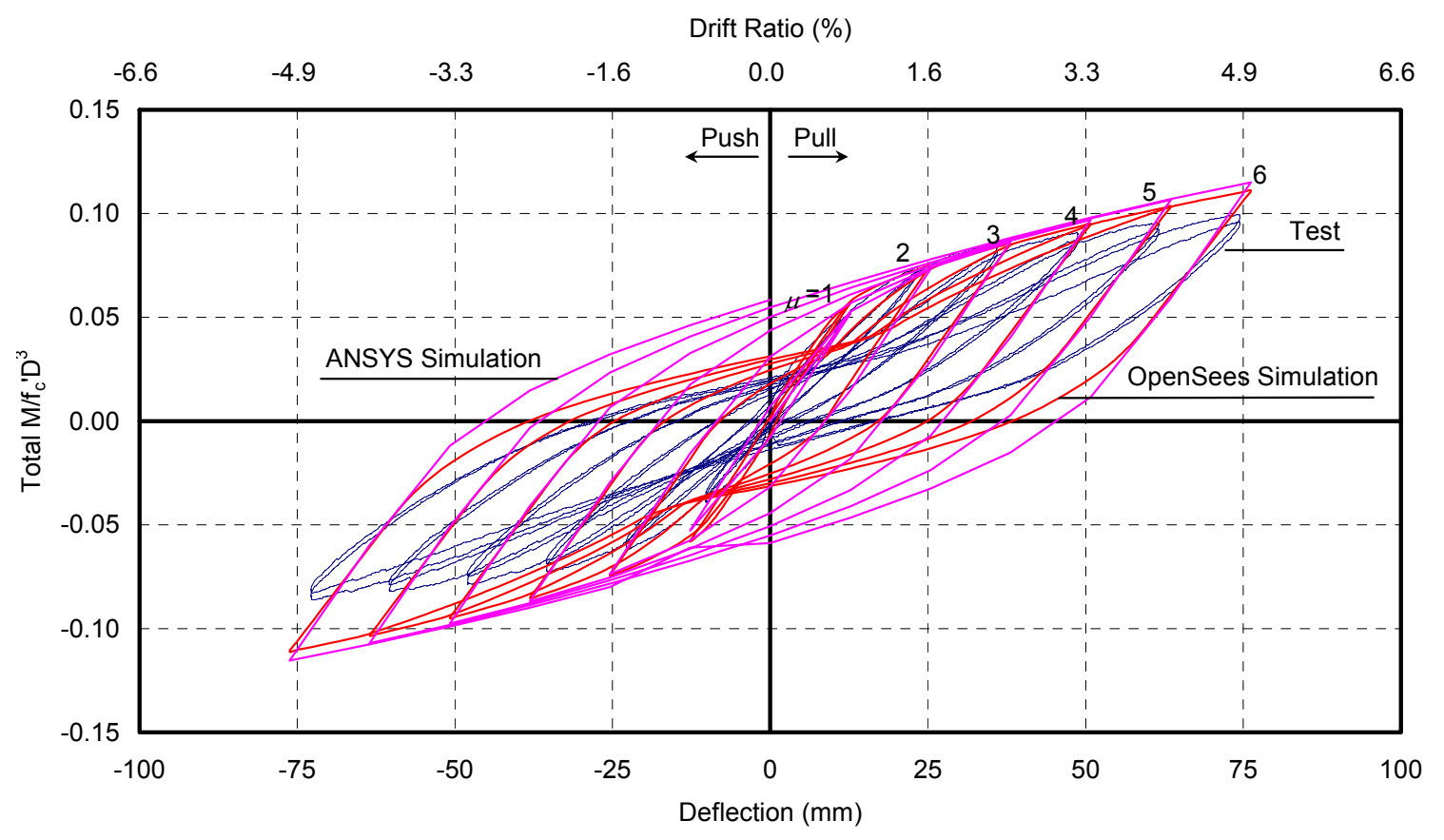

Figure 7.14 Moment-Deflection Hysteretic Simulation of Specimen Y 


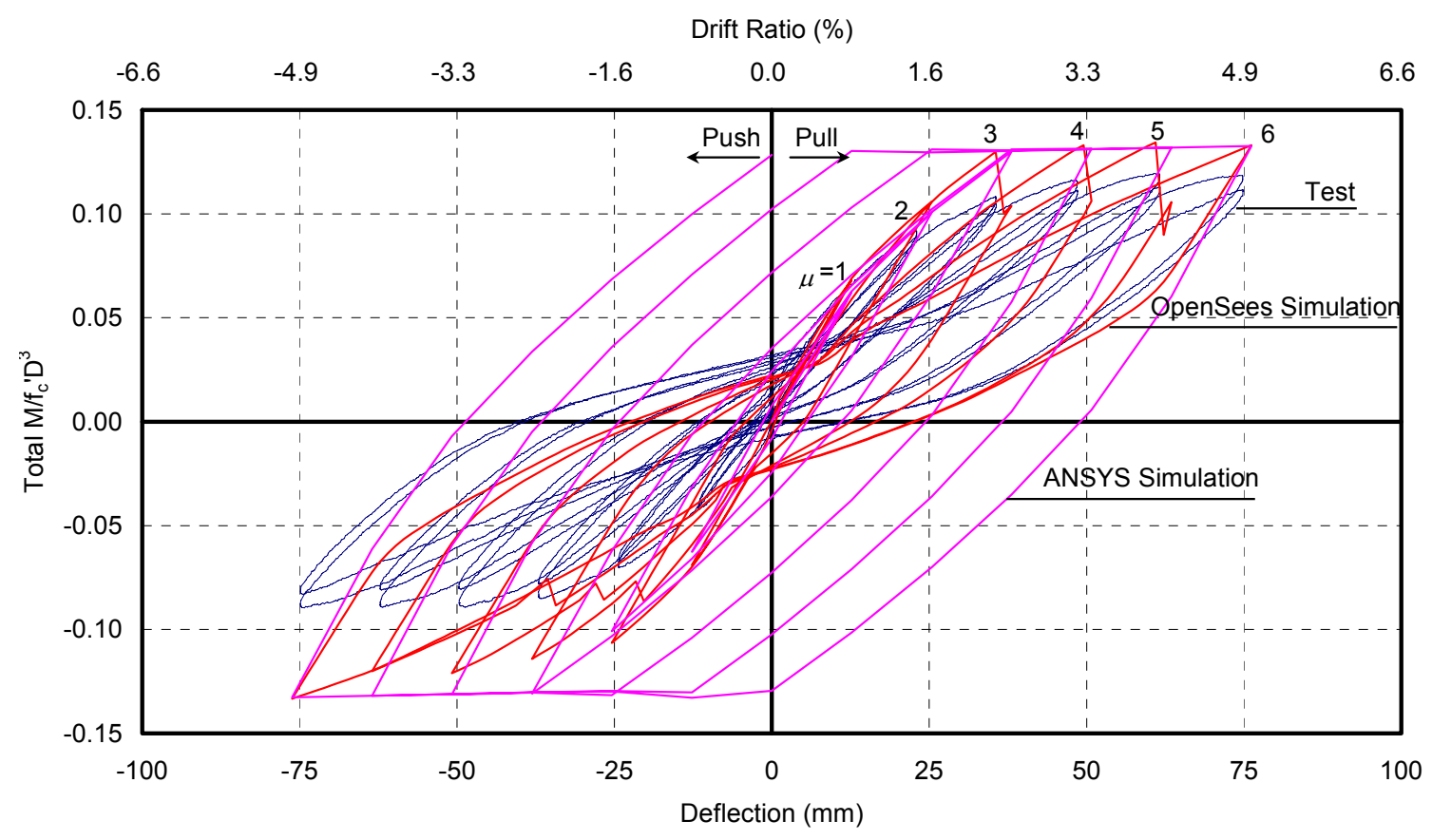

Figure 7.15 Moment-Deflection Hysteretic Simulation of Specimen G

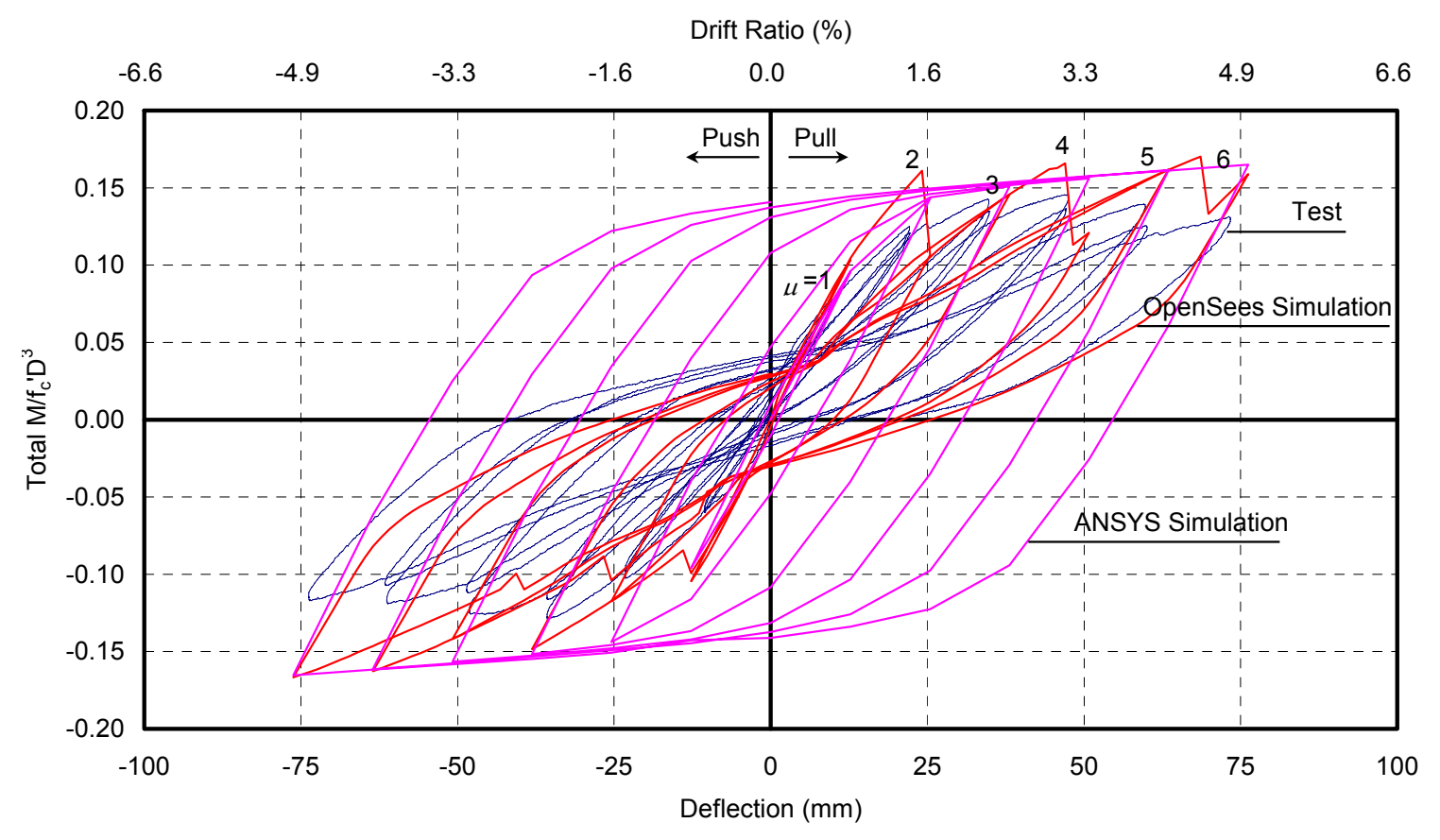

Figure 7.16 Moment-Deflection Hysteretic Simulation of Specimen H 


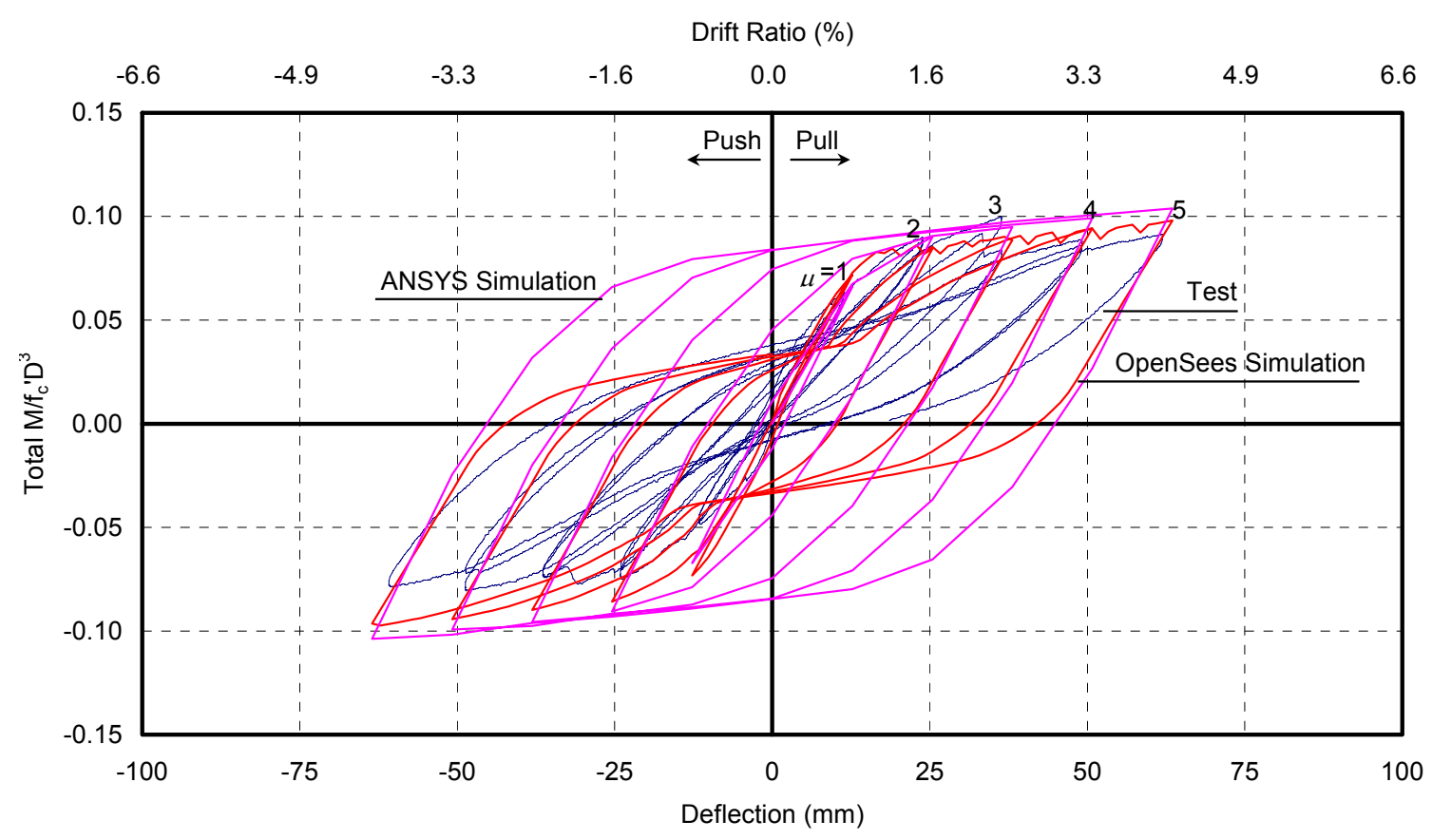

Figure 7.17 Moment-Deflection Hysteretic Simulation of Specimen SC

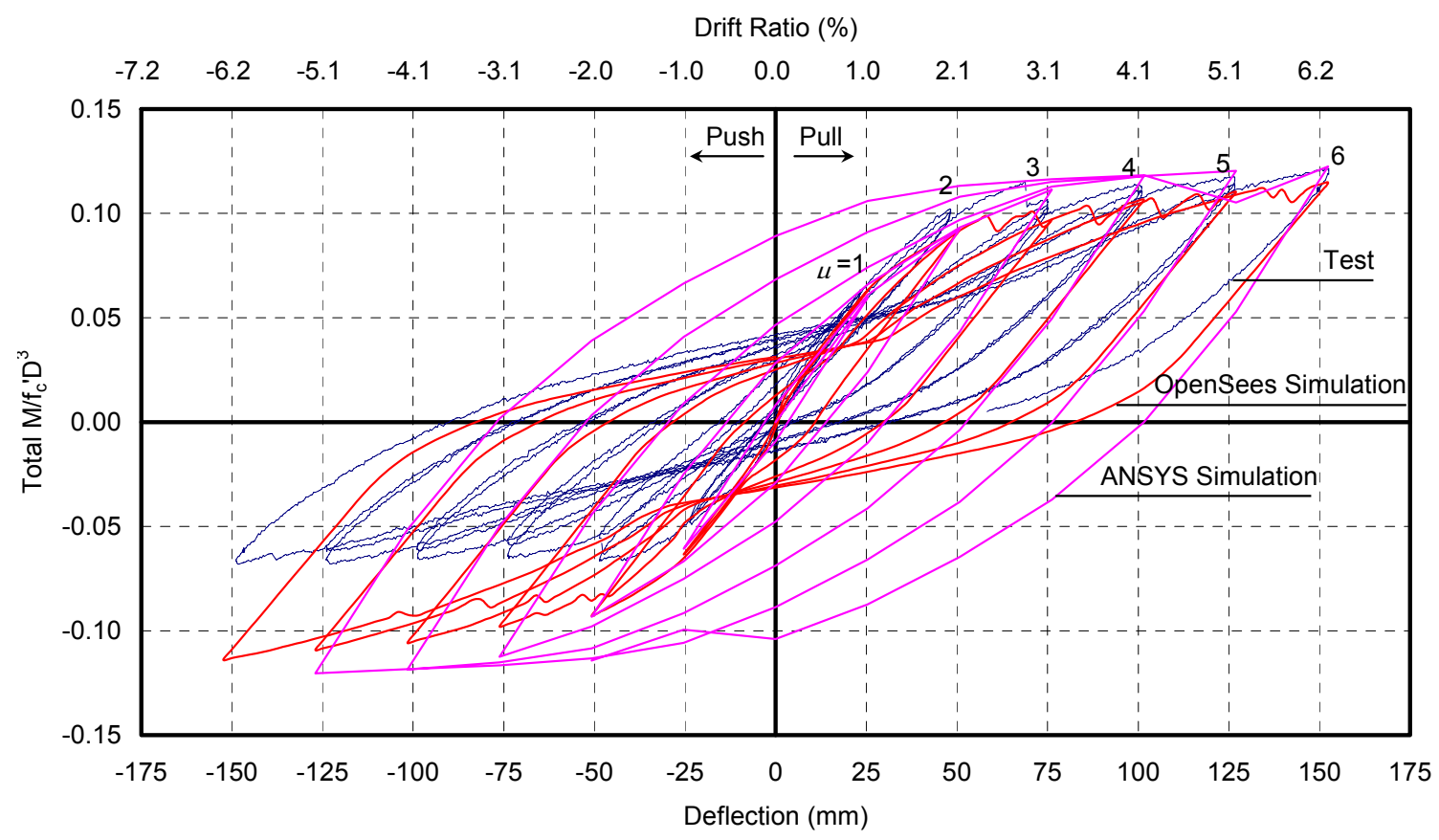

Figure 7.18 Moment-Deflection Hysteretic Simulation of Specimen LC 


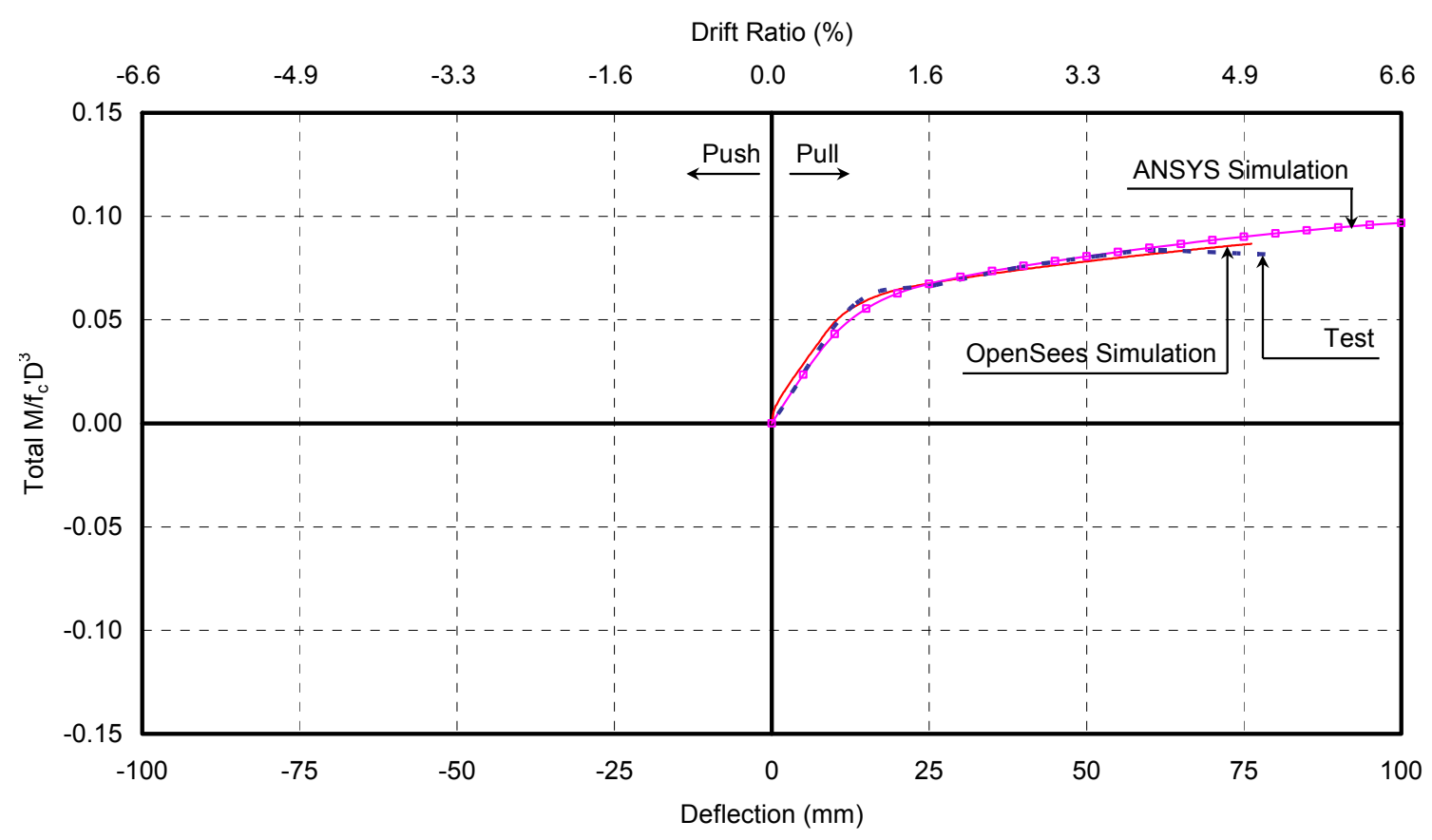

Figure 7.19 Moment-Deflection Push-Over Simulation of Specimen RC

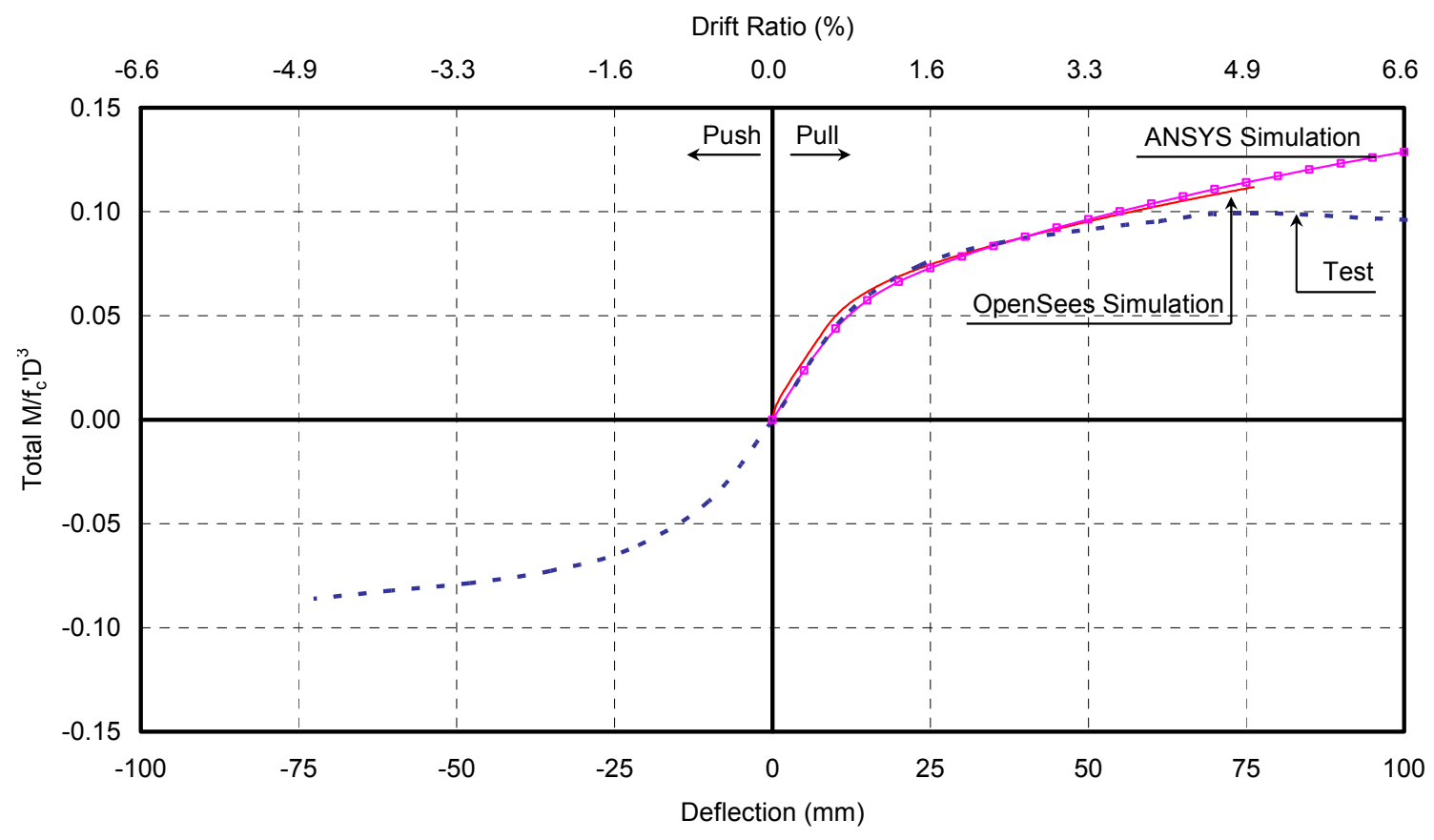

Figure 7.20 Moment-Deflection Push-Over Simulation of Specimen Y 


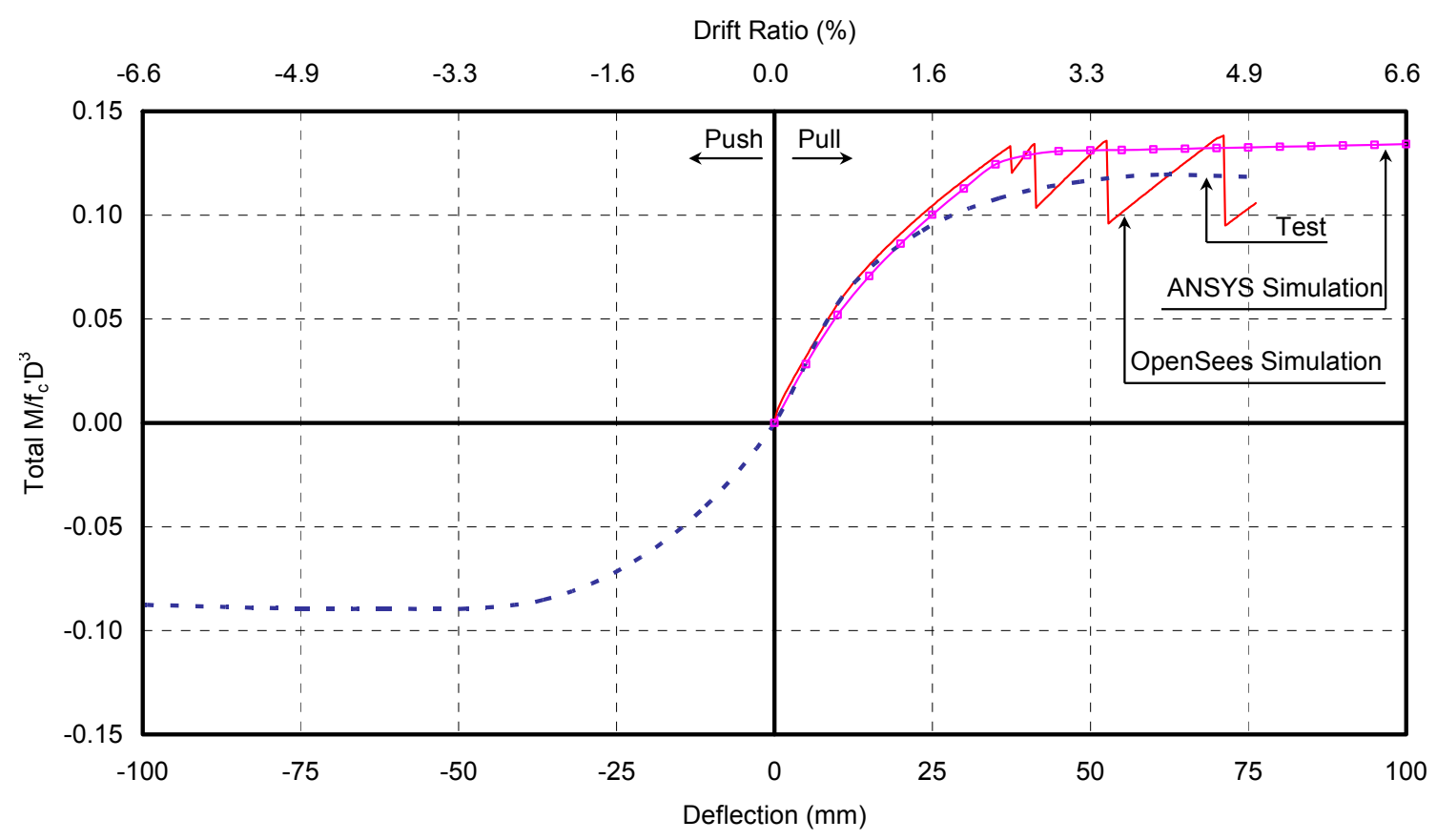

Figure 7.21 Moment-Deflection Push-Over Simulation of Specimen G

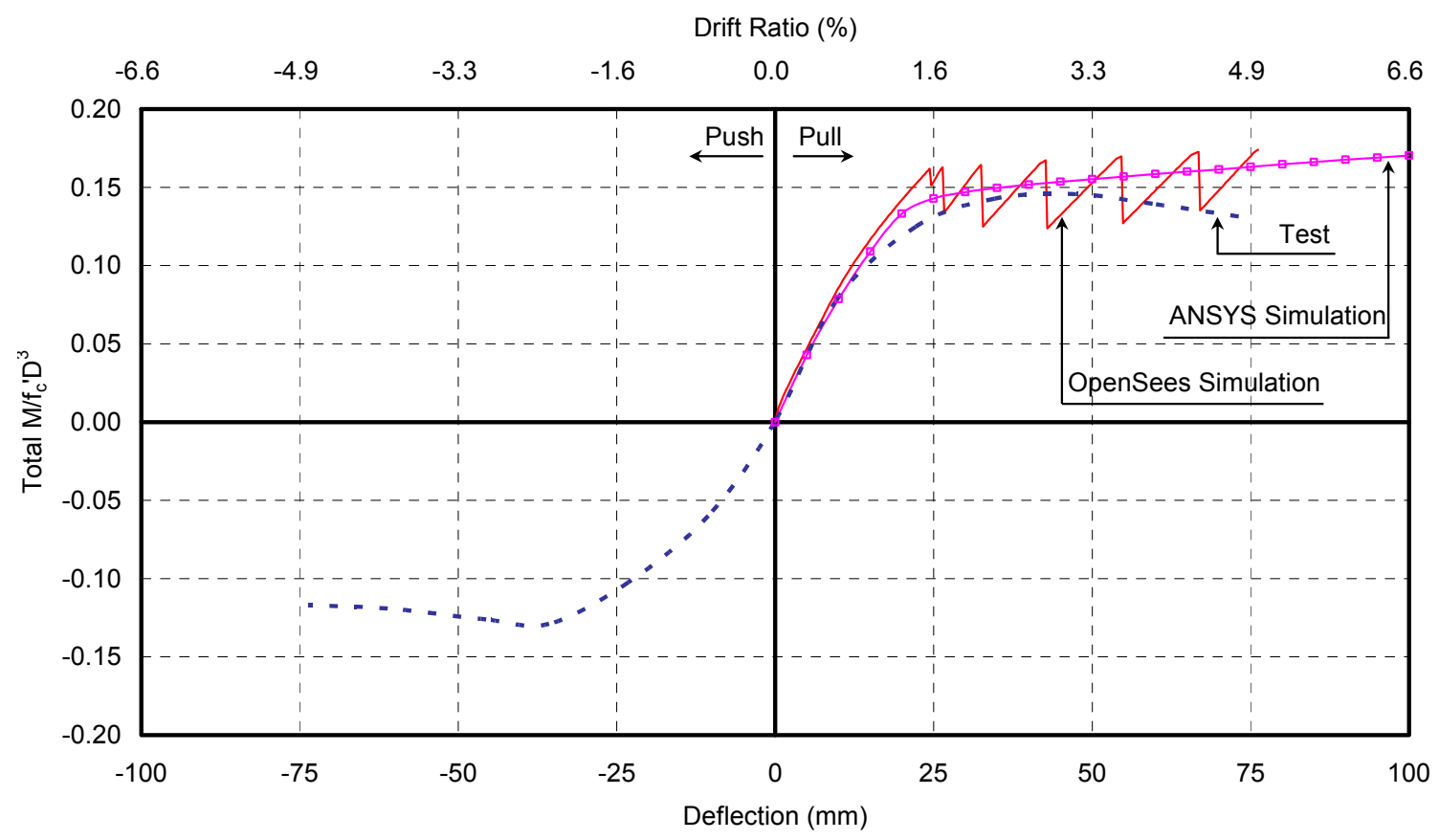

Figure 7.22 Moment-Deflection Push-Over Simulation of Specimen H 


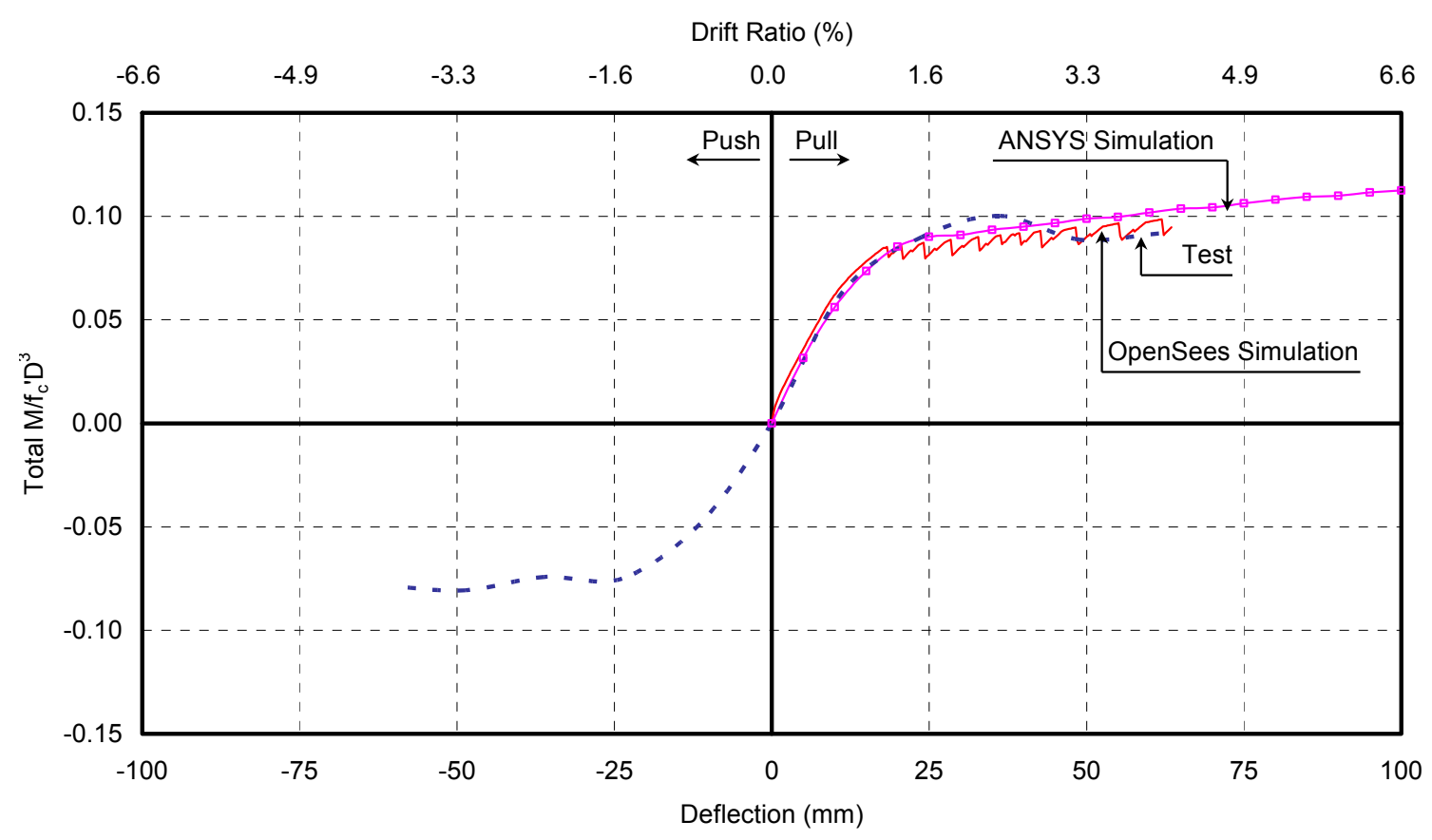

Figure 7.23 Moment-Deflection Push-Over Simulation of Specimen SC

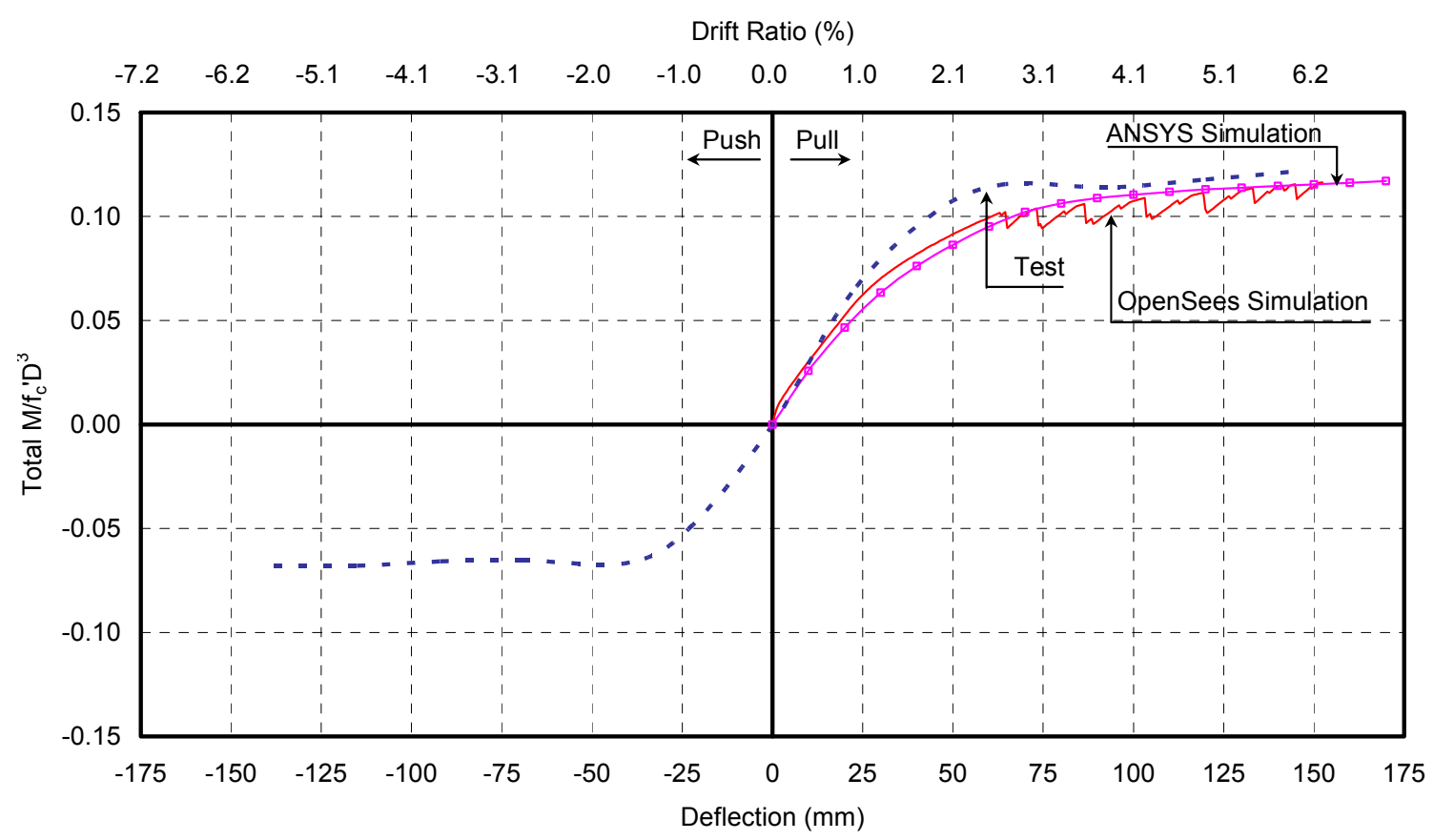

Figure 7.24 Moment-Deflection Push-Over Simulation of Specimen LC 


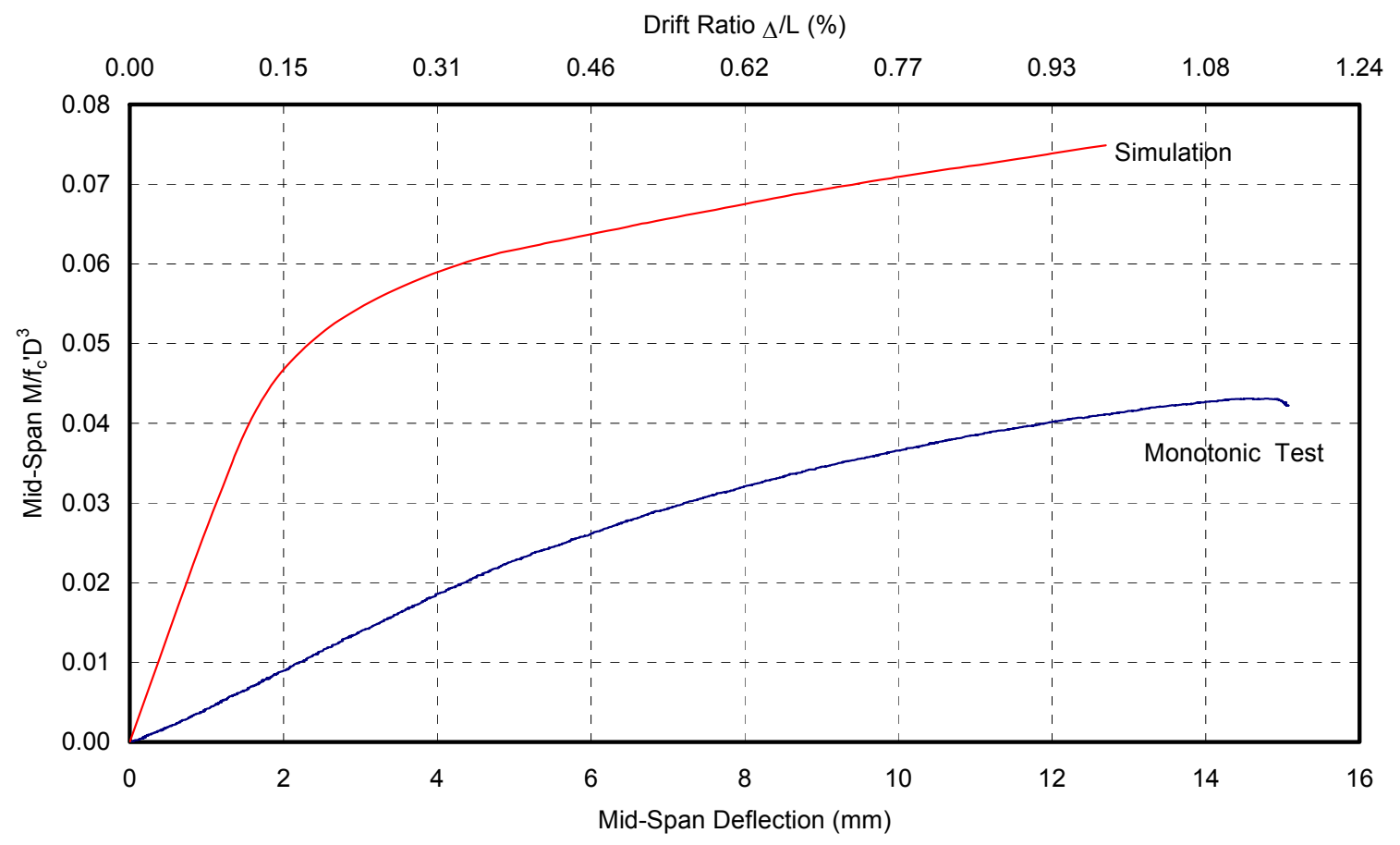

Figure 7.25 Monotonic Flexural Simulation of Specimen RC by OpenSees

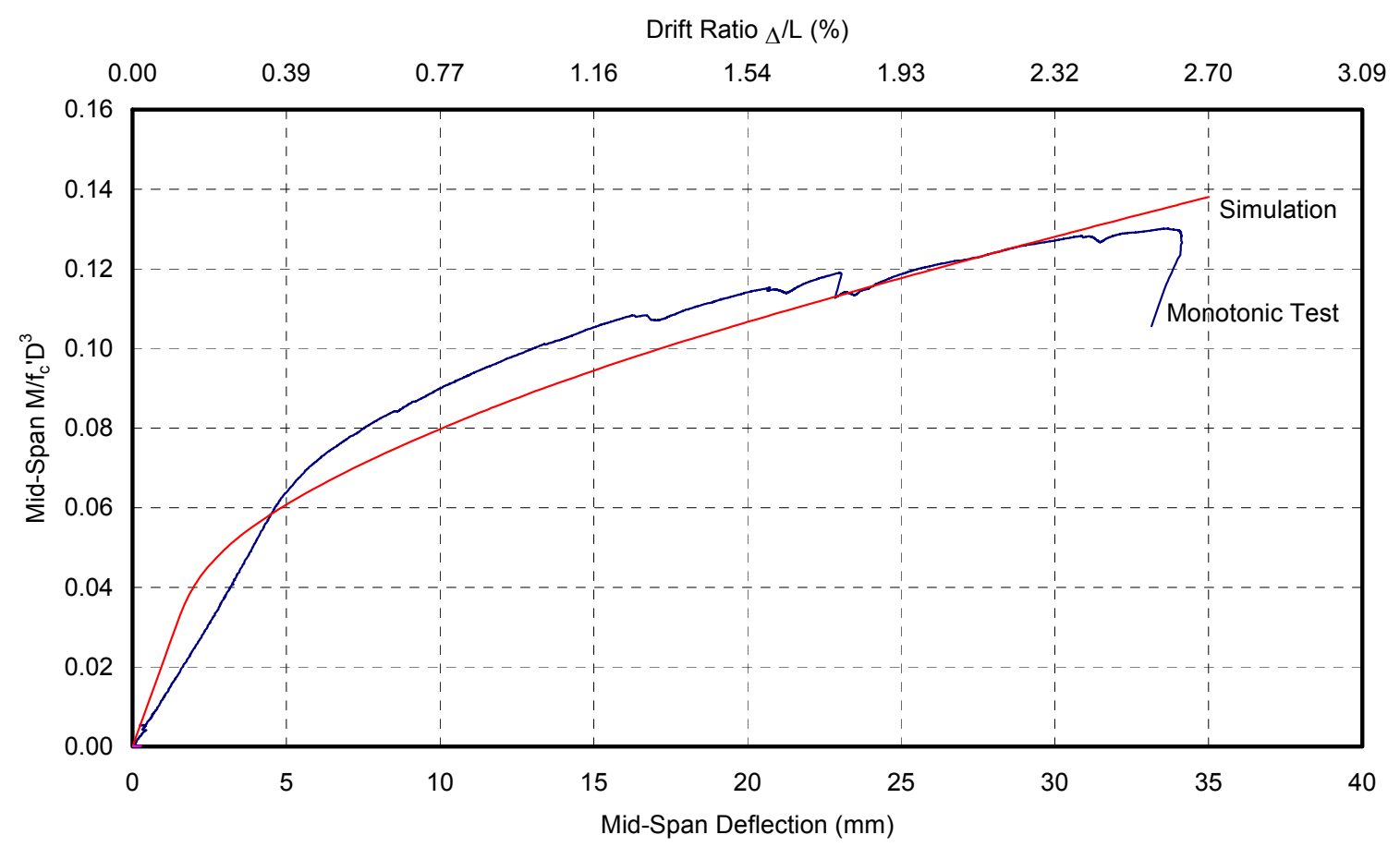

Figure 7.26 Monotonic Flexural Simulation of Specimen Y by OpenSees 


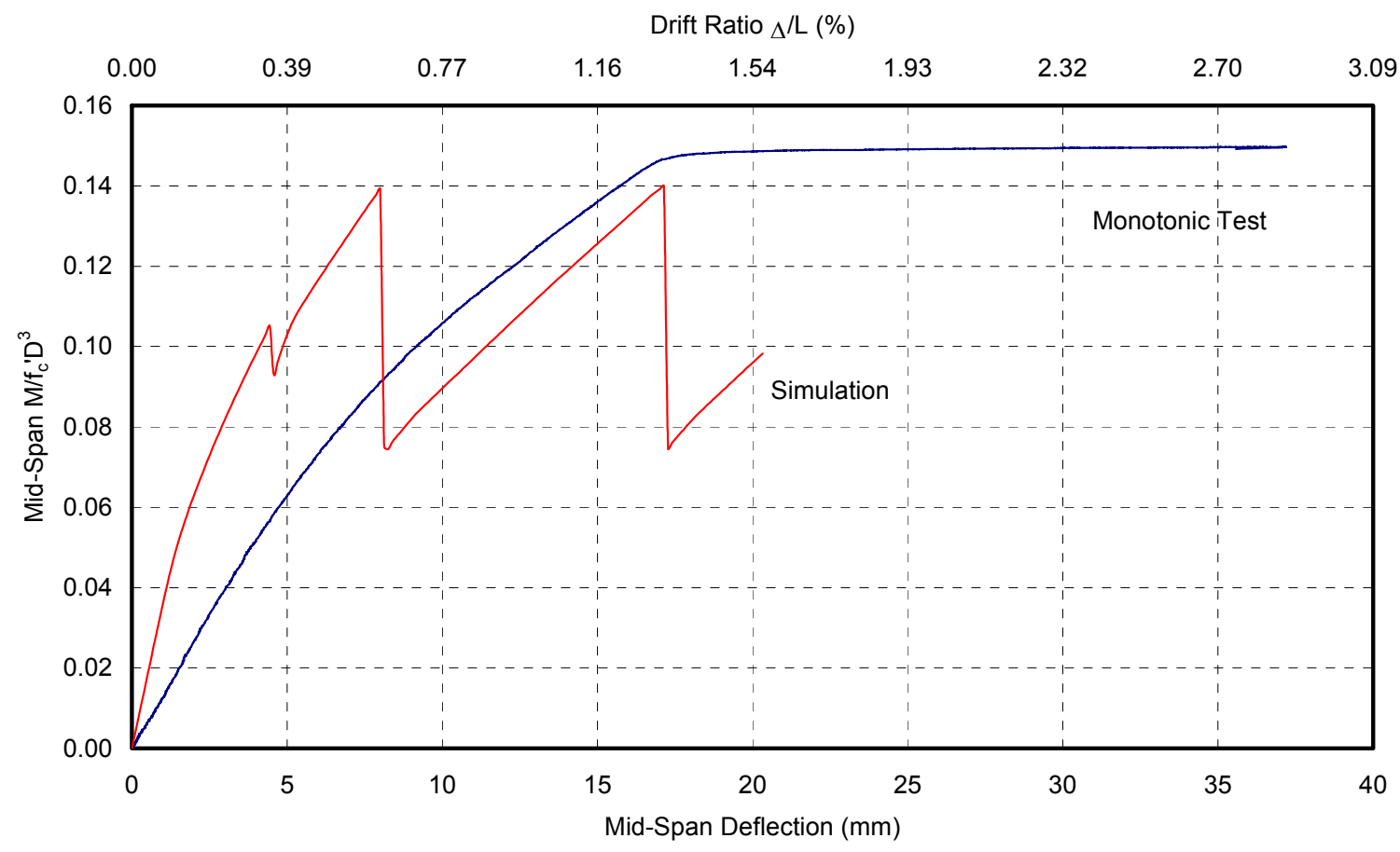

Figure 7.27 Monotonic Flexural Simulation of Specimen G by OpenSees

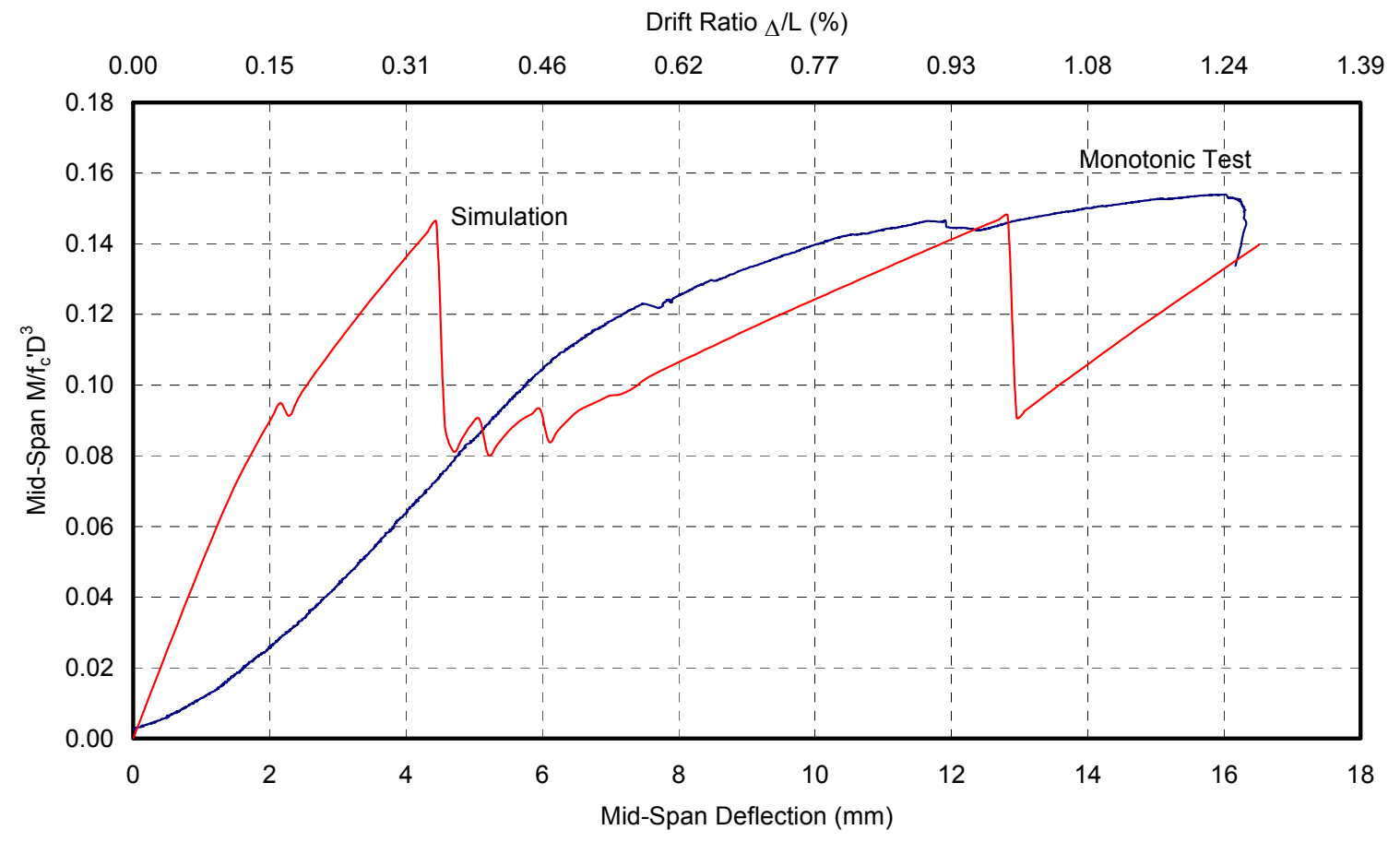

Figure 7.28 Monotonic Flexural Simulation of Specimen H by OpenSees 


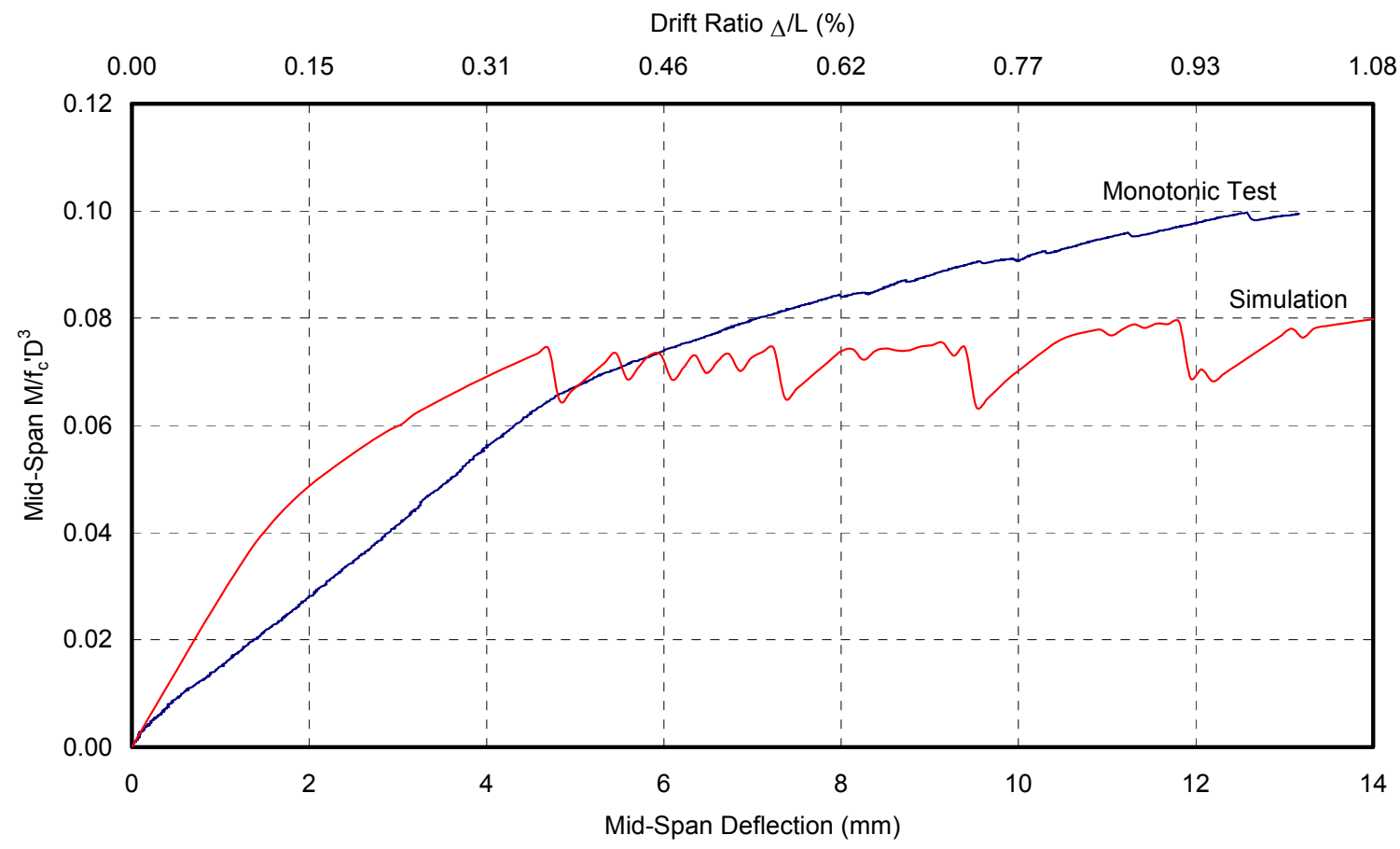

Figure 7.29 Monotonic Flexural Simulation of Specimen SC by OpenSees

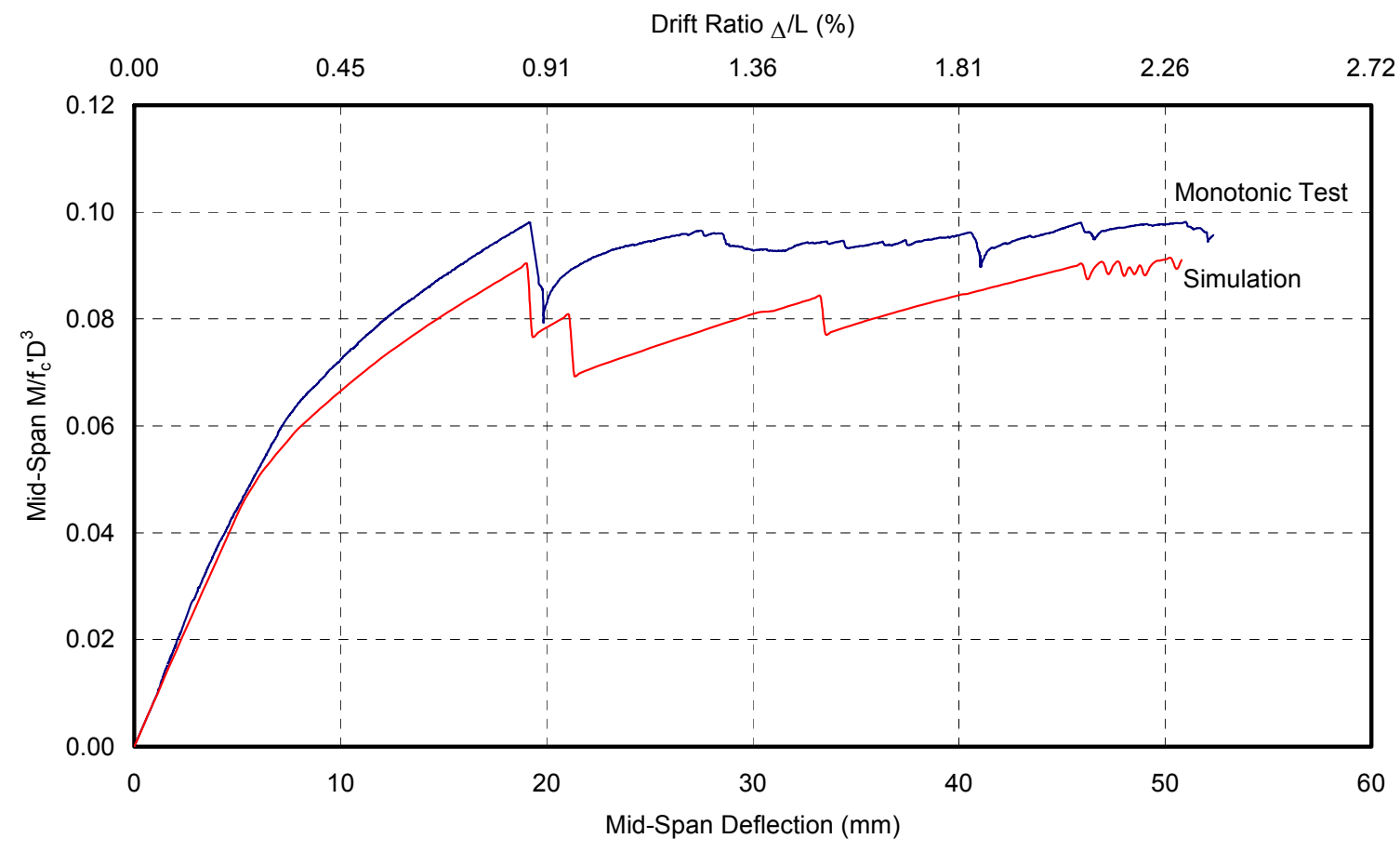

Figure 7.30 Monotonic Flexural Simulation of Specimen LC by OpenSees 


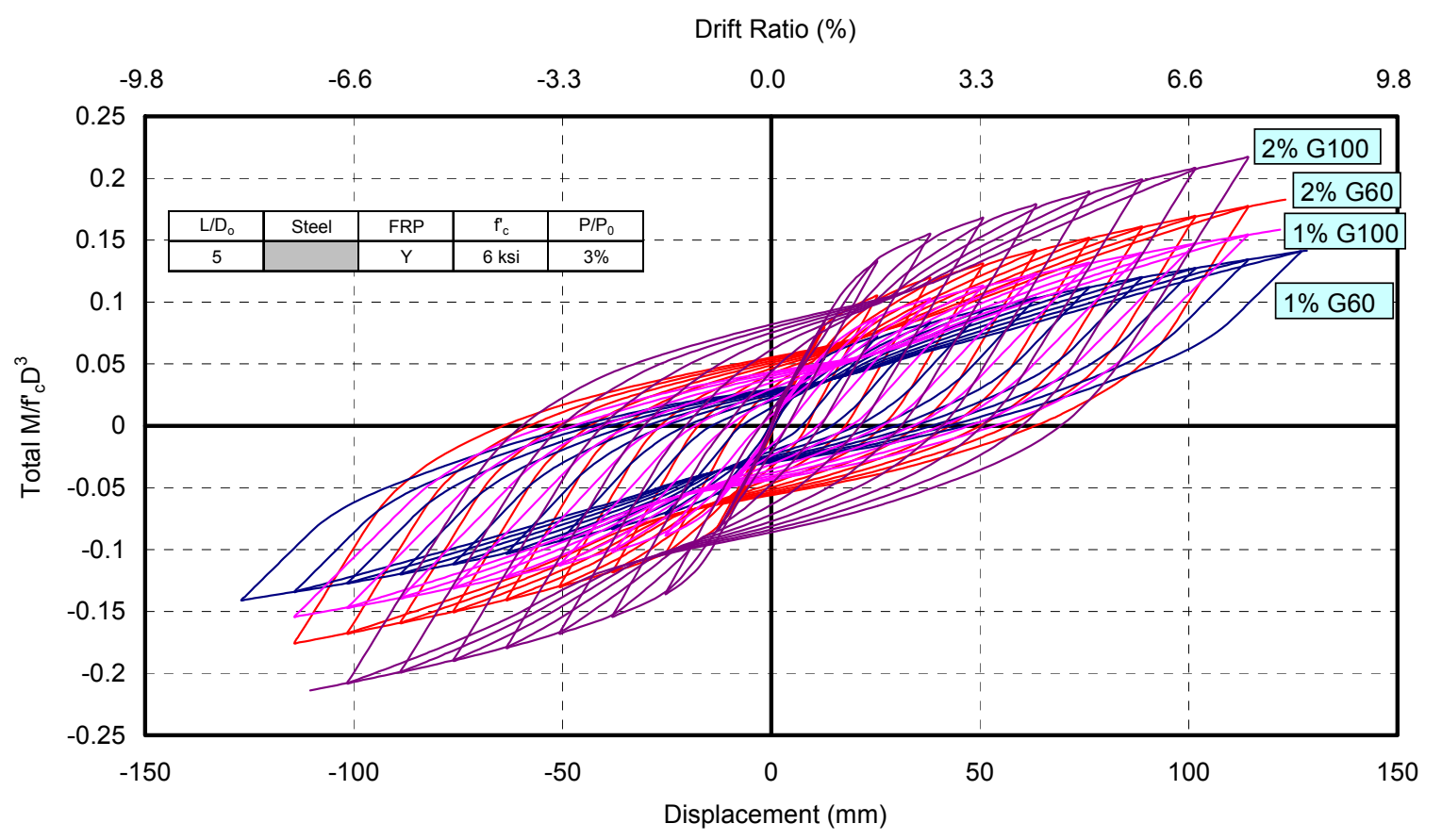

Figure 7.31 Effect of Steel Reinforcement on Hysteretic Response of Column Y

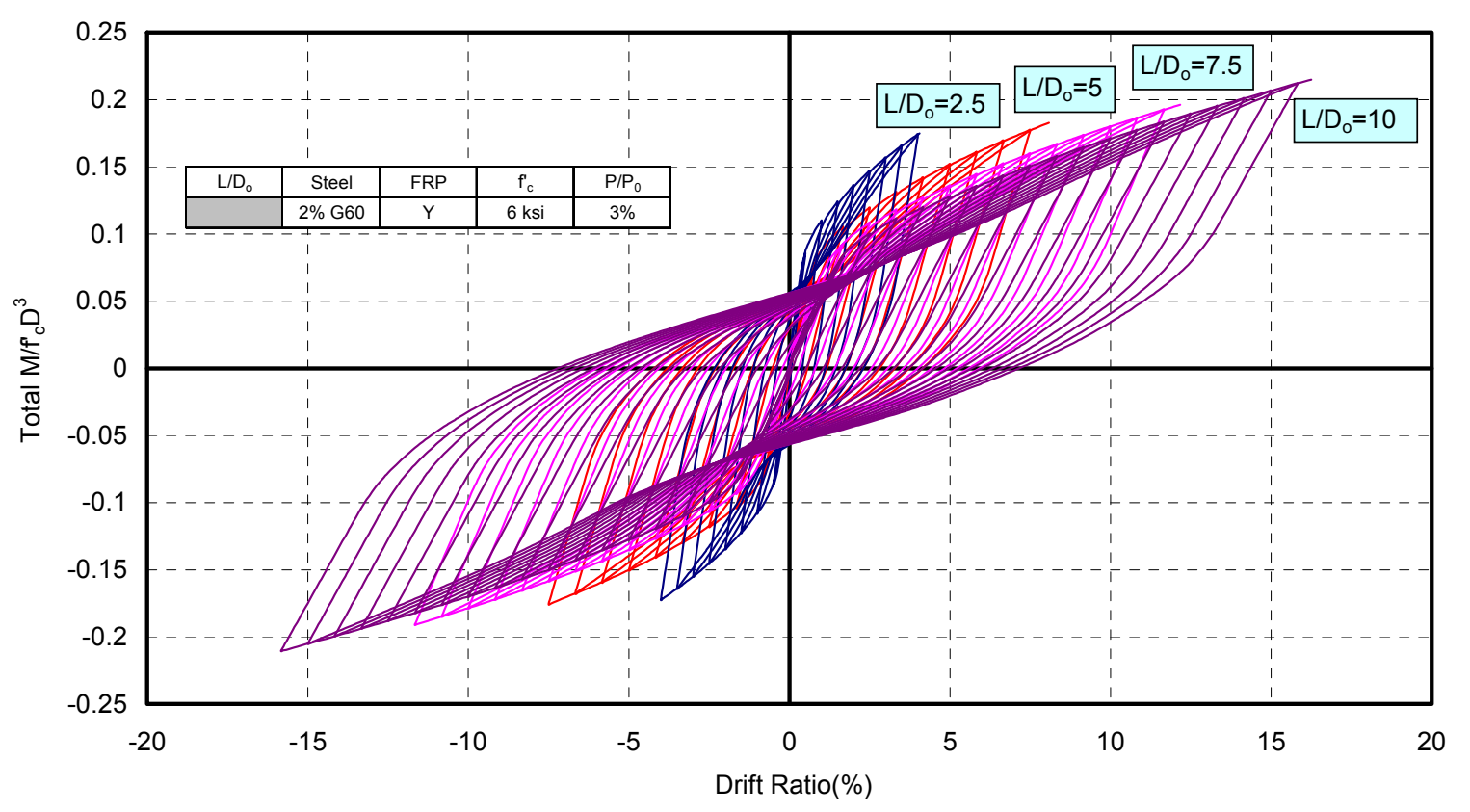

Figure 7.32 Effect of $L / D_{o}$ Ratio on Hysteretic Response of Column Y 


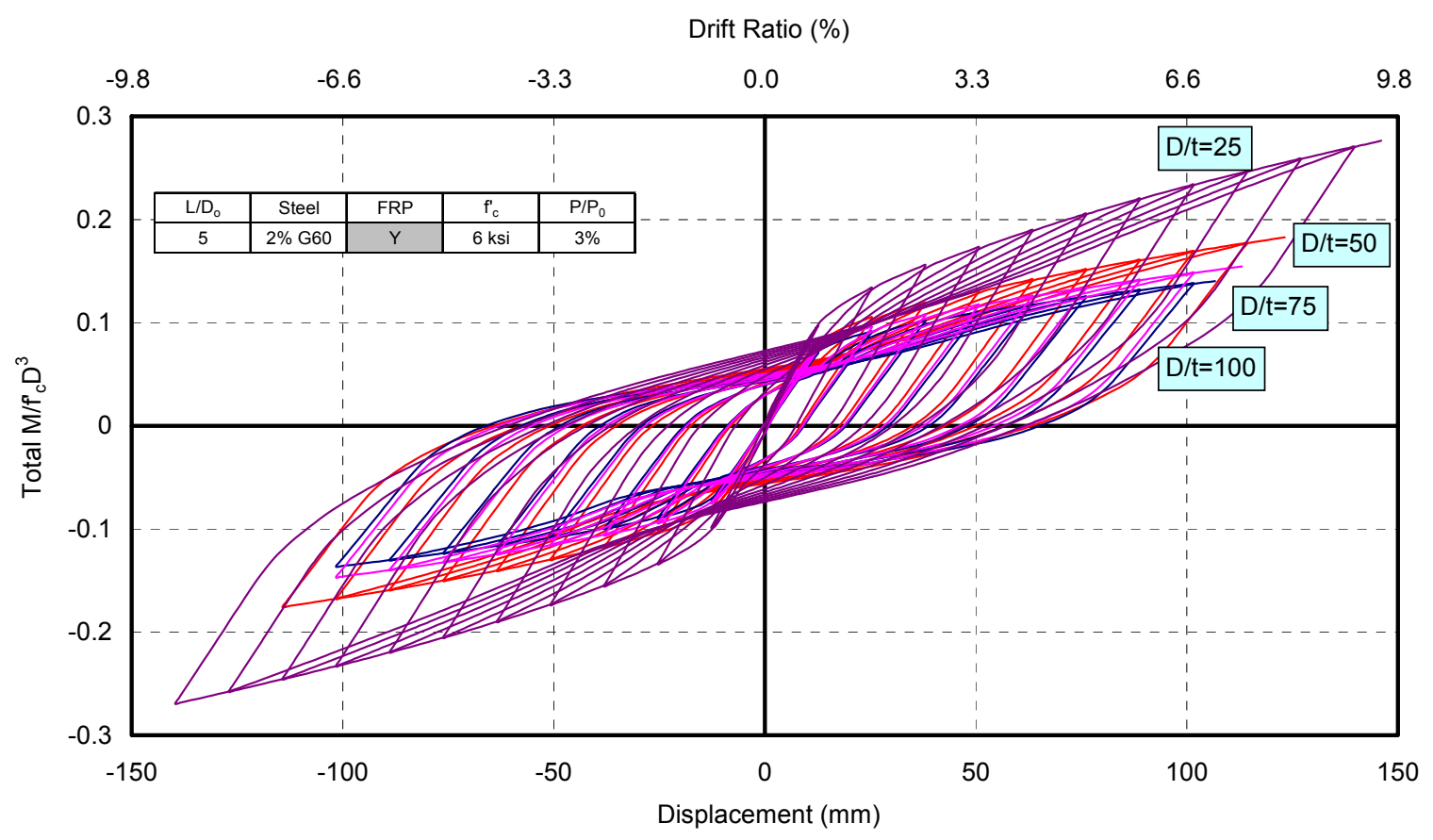

Figure 7.33 Effect of FRP Tube Thickness on Hysteretic Response of Column Y

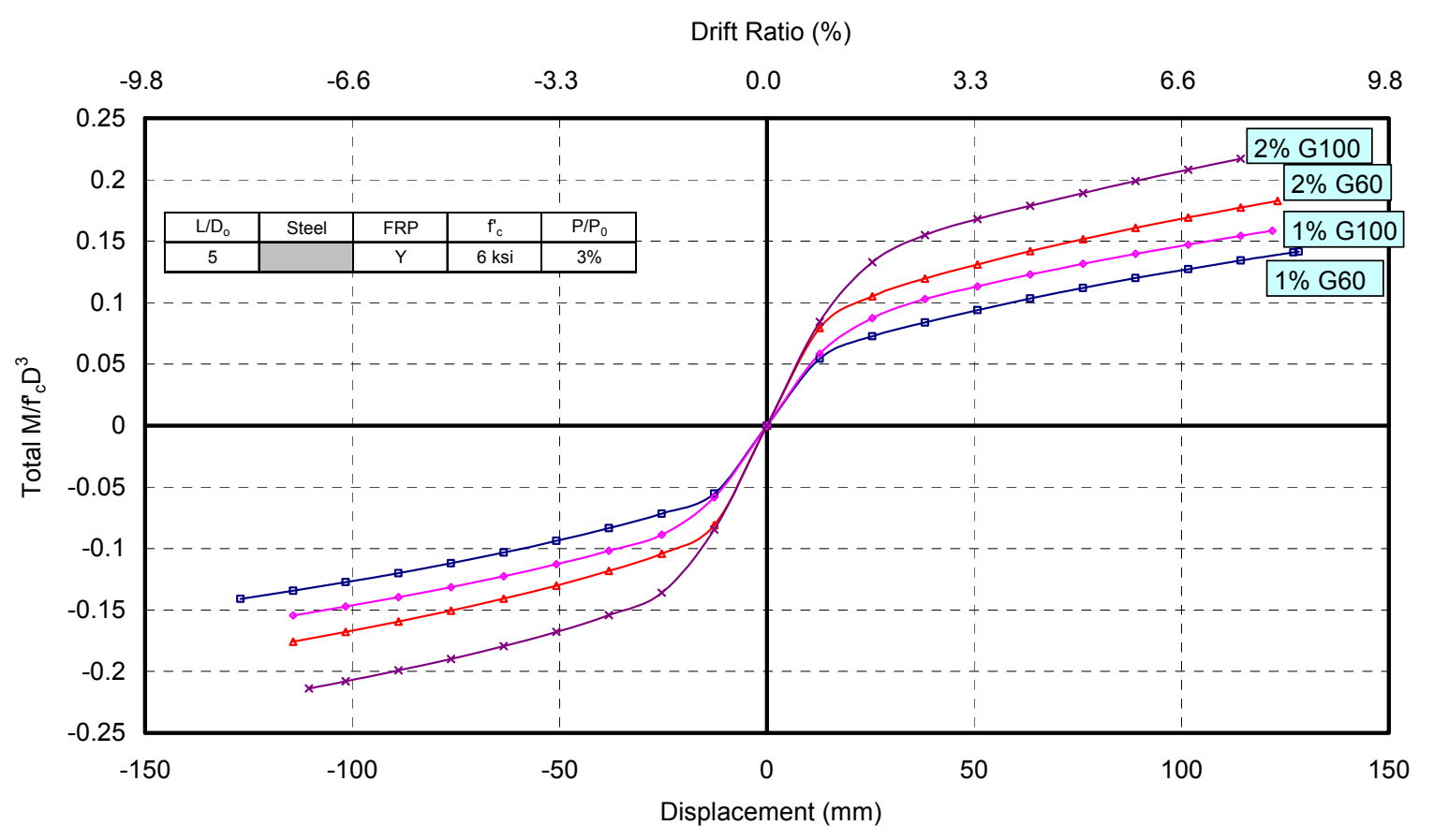

Figure 7.34 Effect of Steel Reinforcement on Response Envelope of Column Y 


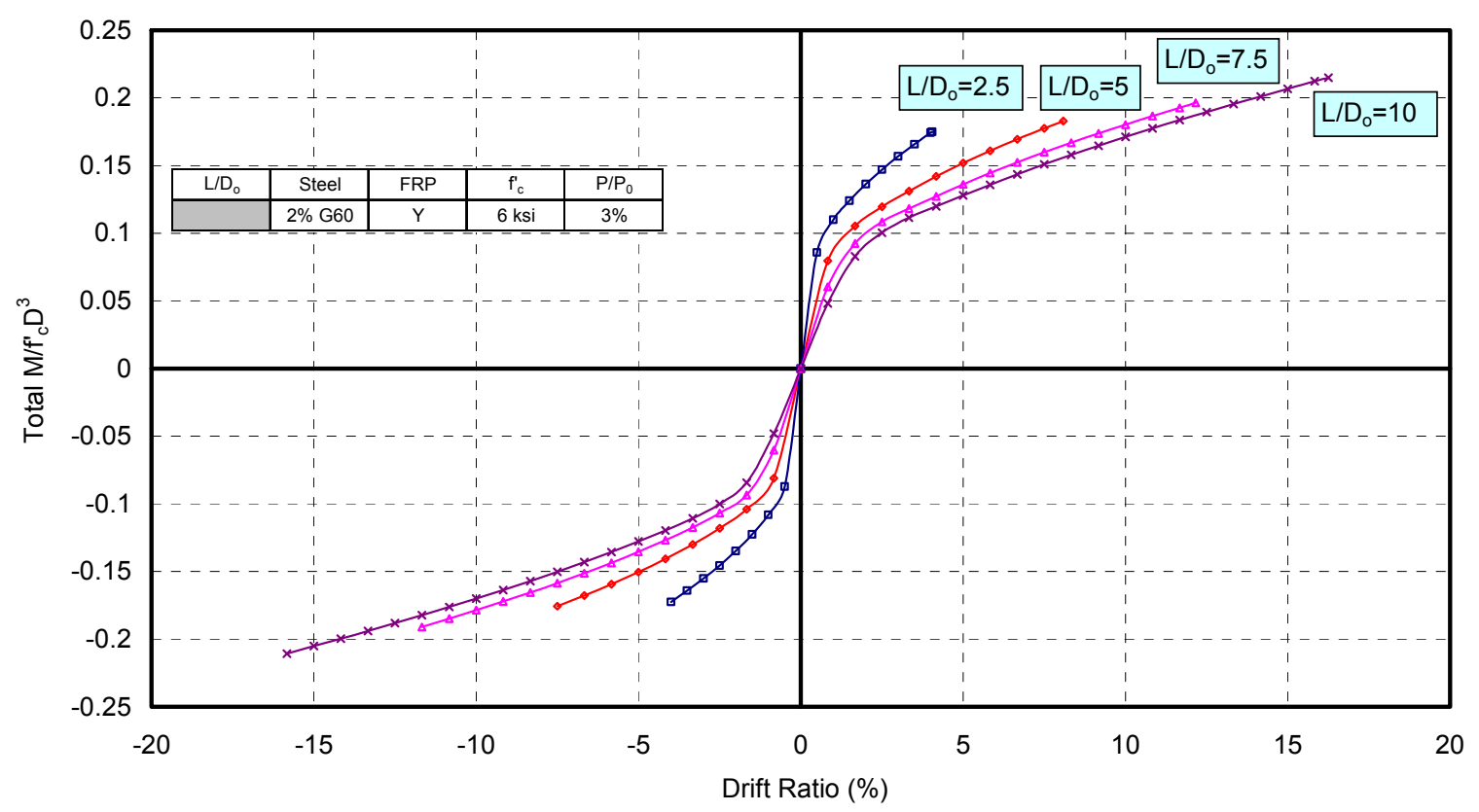

Figure 7.35 Effect of $L / D_{o}$ Ratio on Response Envelope of Column Y

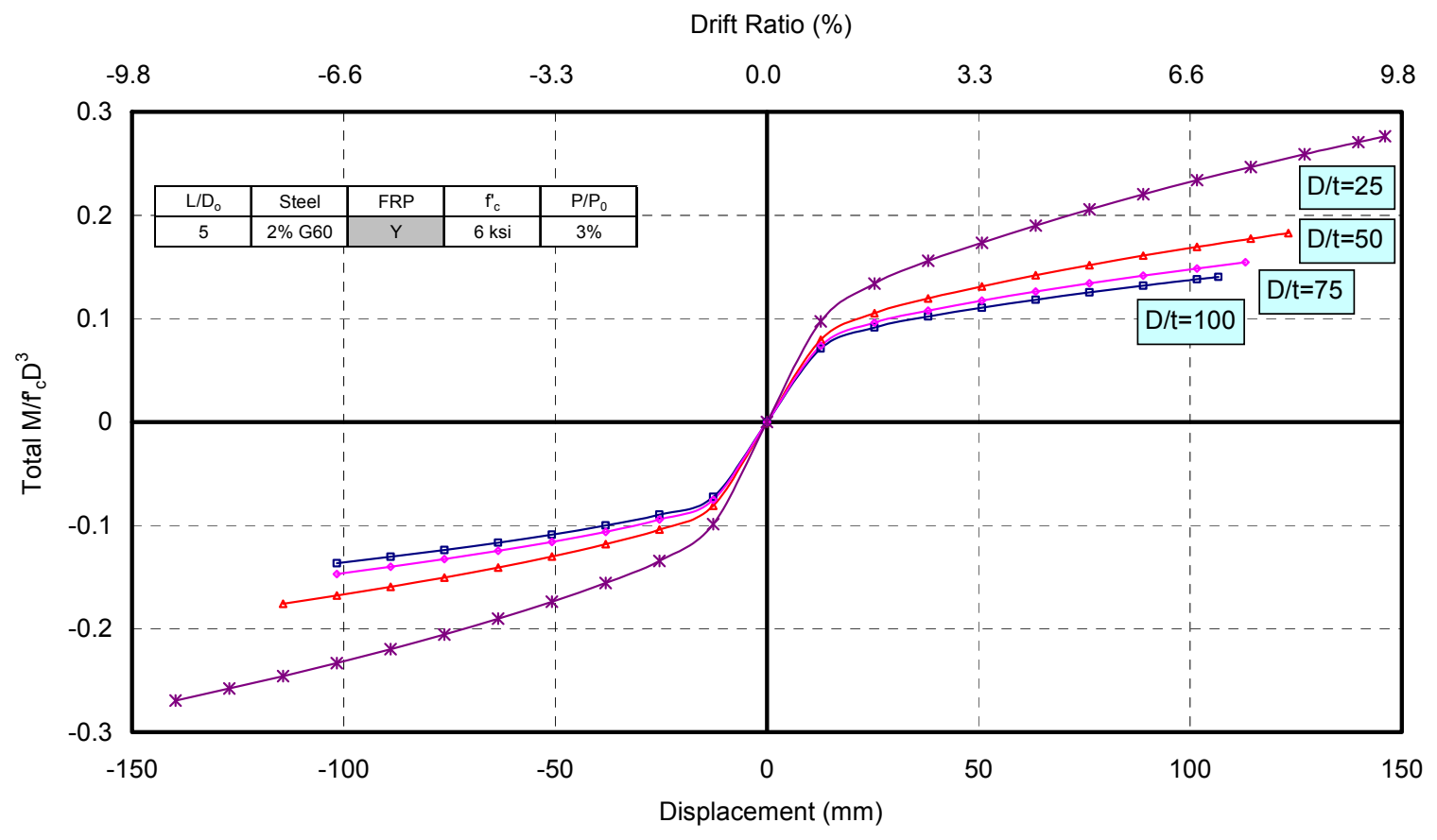

Figure 7.36 Effect of FRP Tube Thickness on Response Envelope of Column Y 


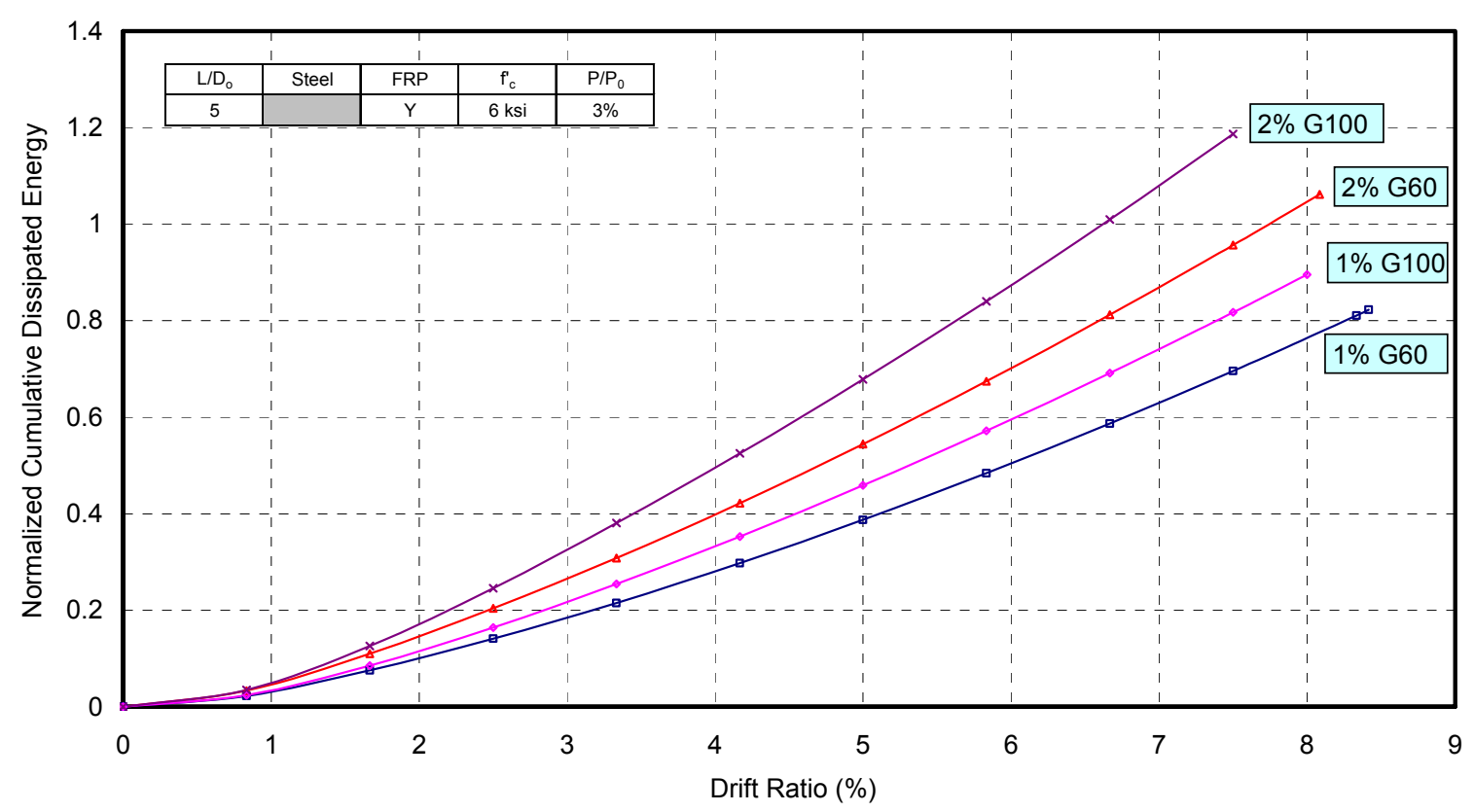

Figure 7.37 Effect of Steel Reinforcement on Normalized Cumulative Dissipated Energy of Column Y

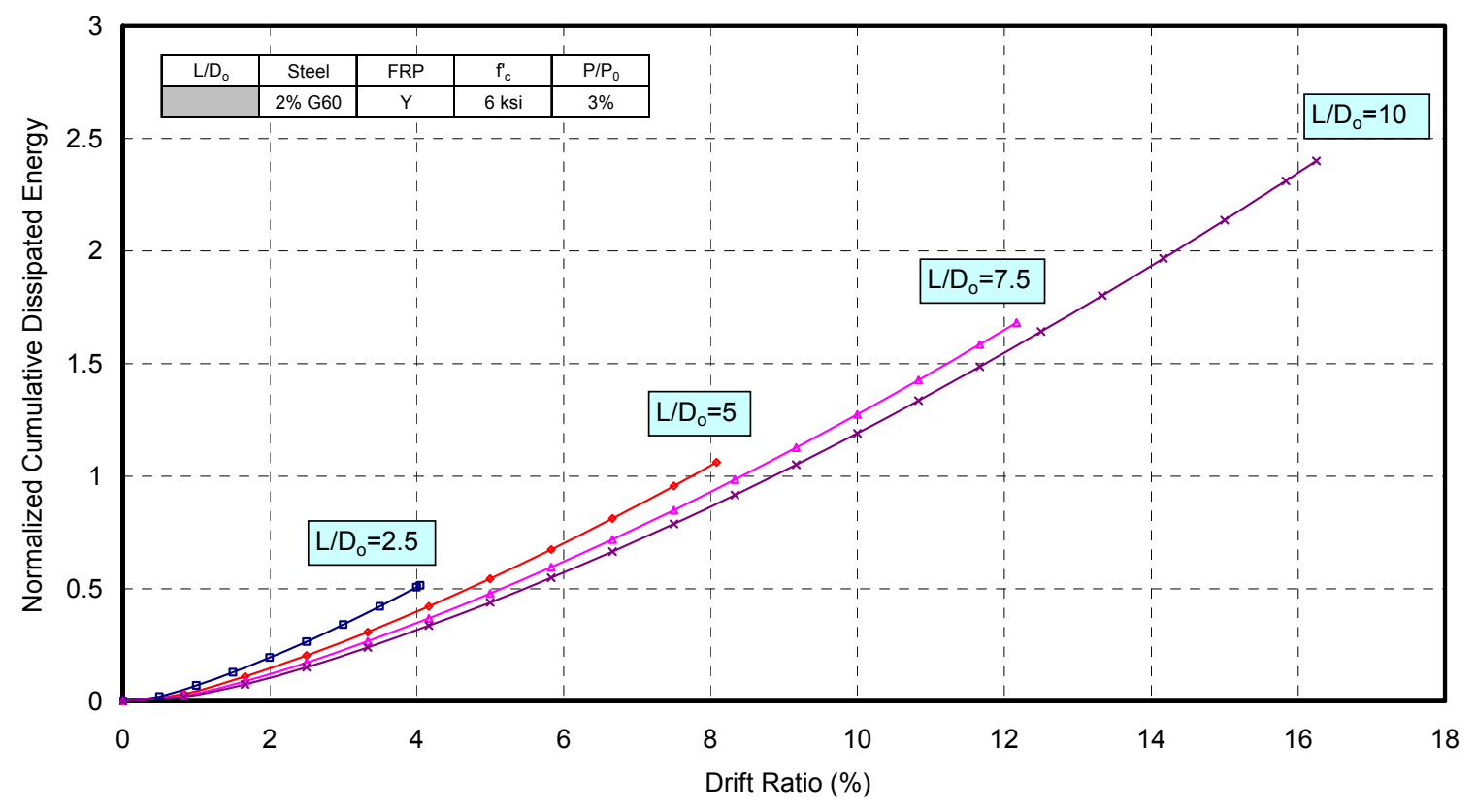

Figure 7.38 Effect of $L / D_{o}$ Ratio on Normalized Cumulative Dissipated Energy of Column Y 


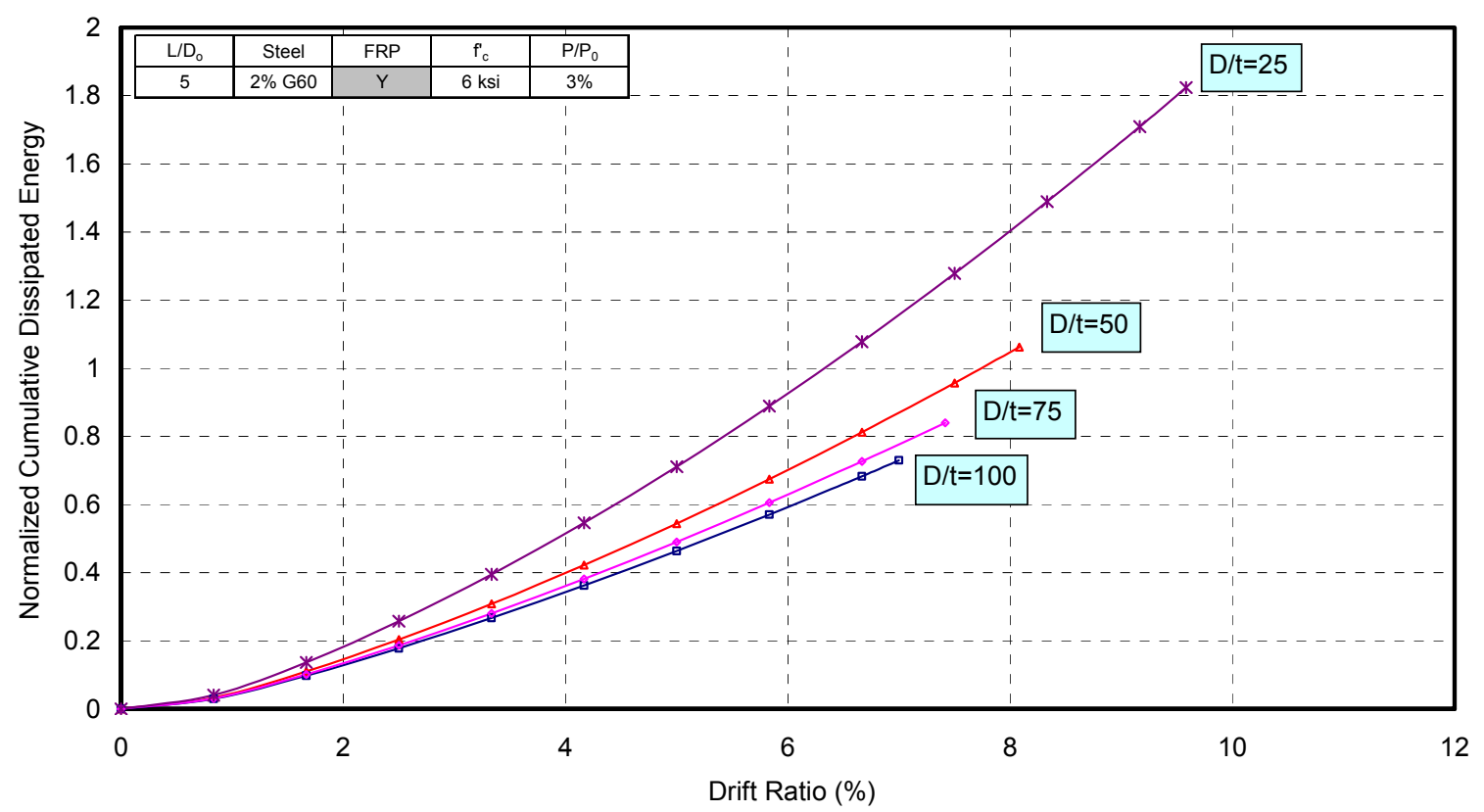

Figure 7.39 Effect of FRP Tube Thickness on Normalized Cumulative Dissipated Energy of Column Y

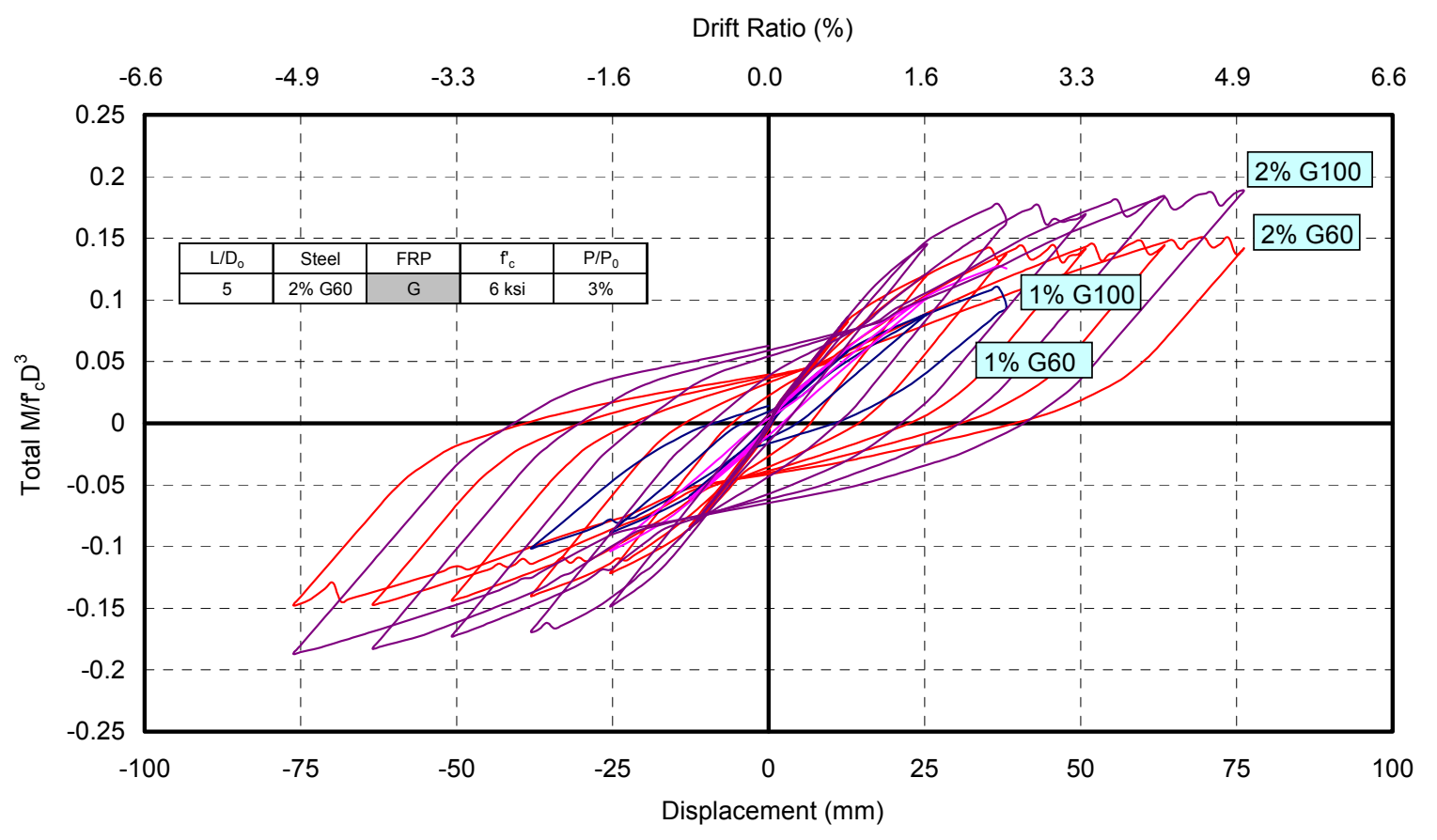

Figure 7.40 Effect of Steel Reinforcement on Hysteretic Response of Column G 


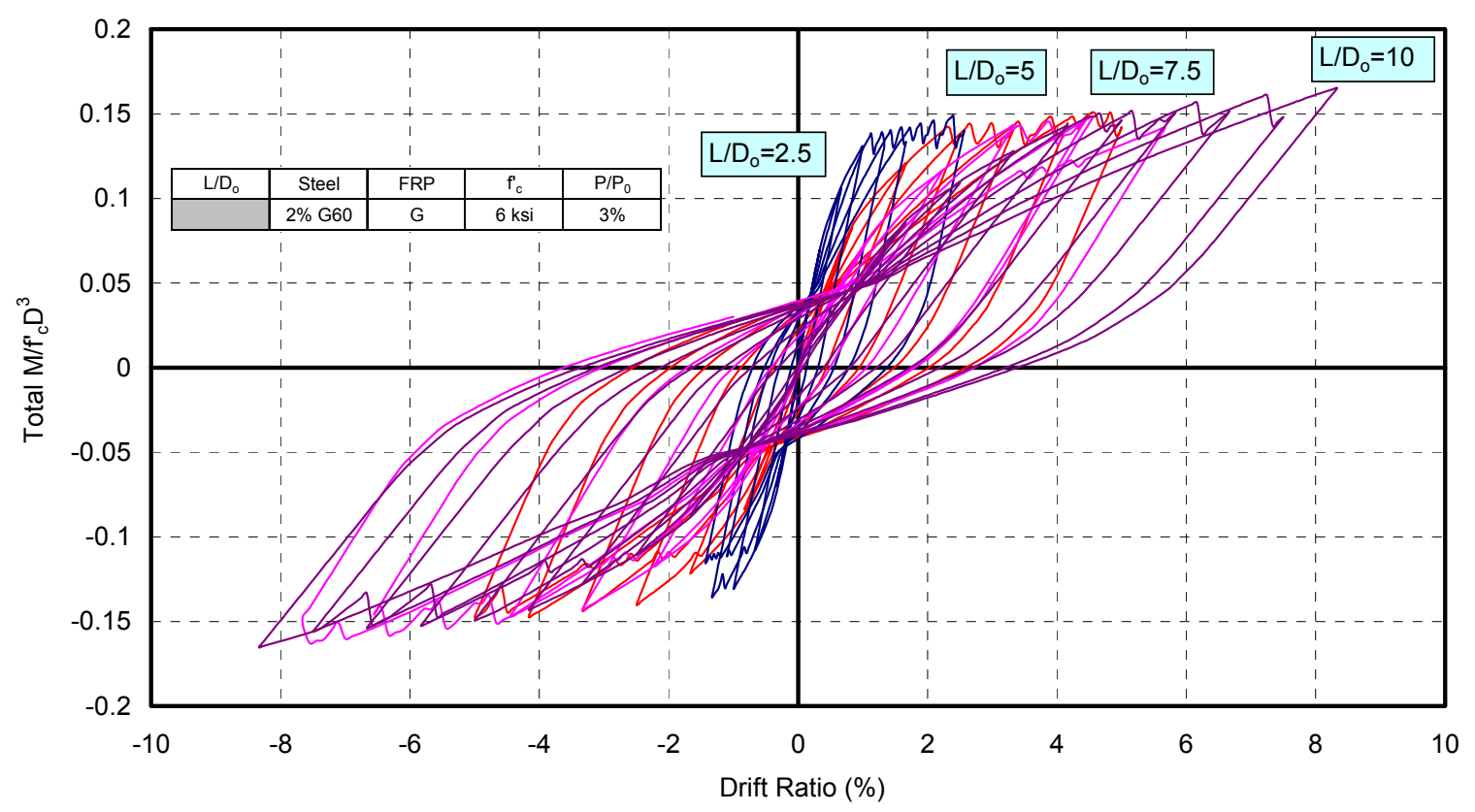

Figure 7.41 Effect of $L / D_{o}$ Ratio on Hysteretic Response of Column G

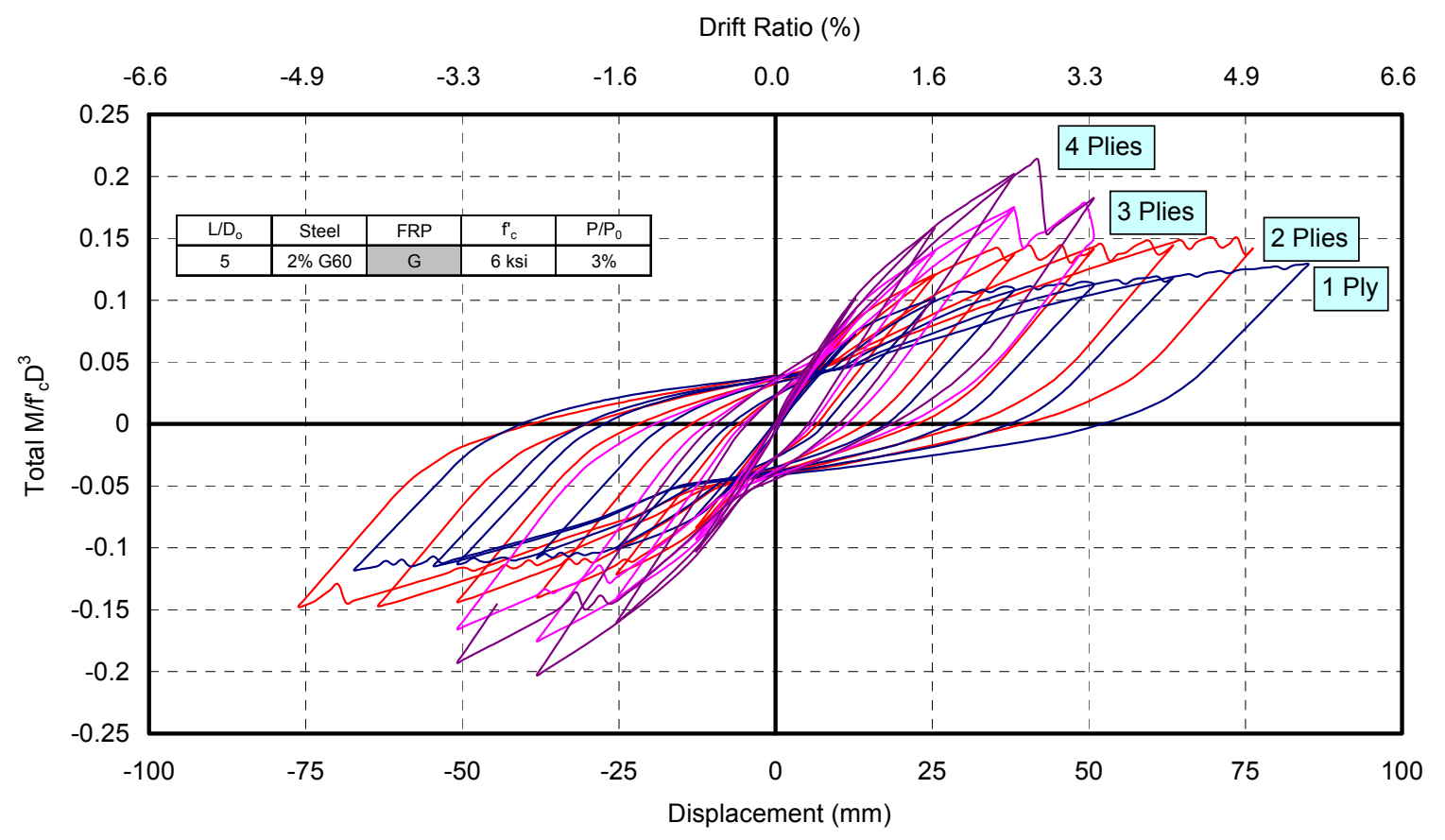

Figure 7.42 Effect of FRP Tube Thickness on Hysteretic Response of Column G 


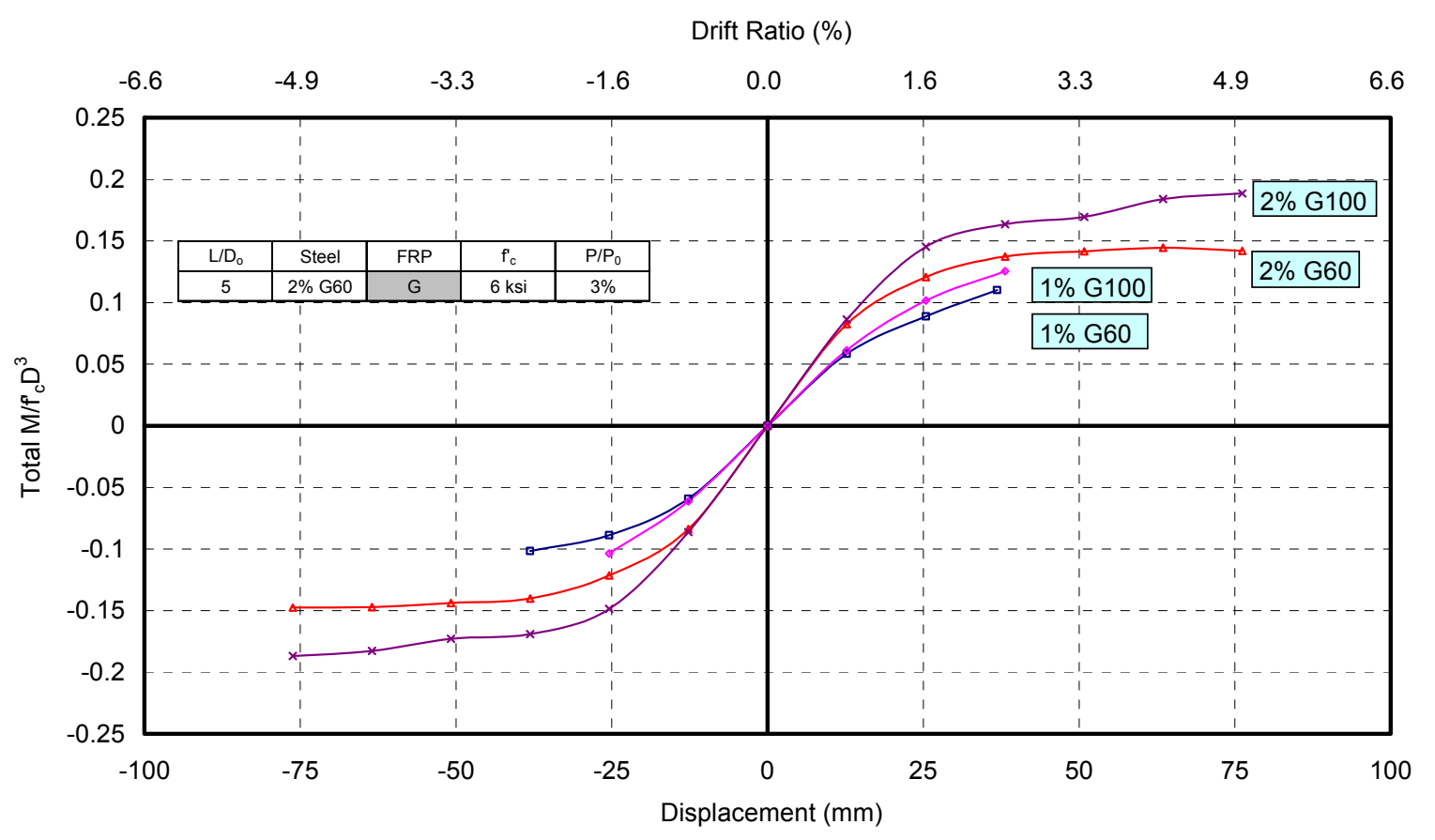

Figure 7.43 Effect of Steel Reinforcement on Response Envelope of Column G

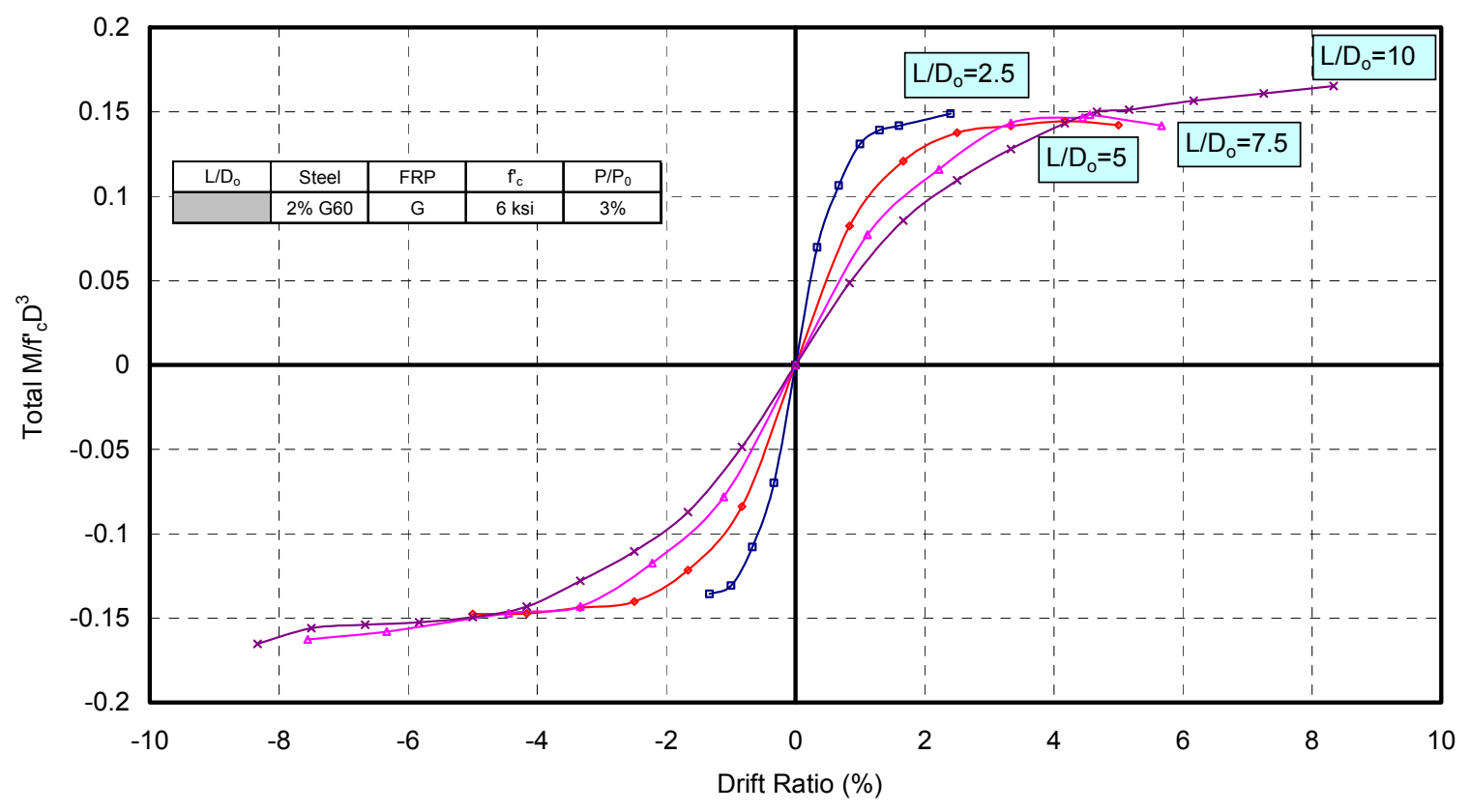

Figure 7.44 Effect of $L / D_{o}$ Ratio on Response Envelope of Column G 


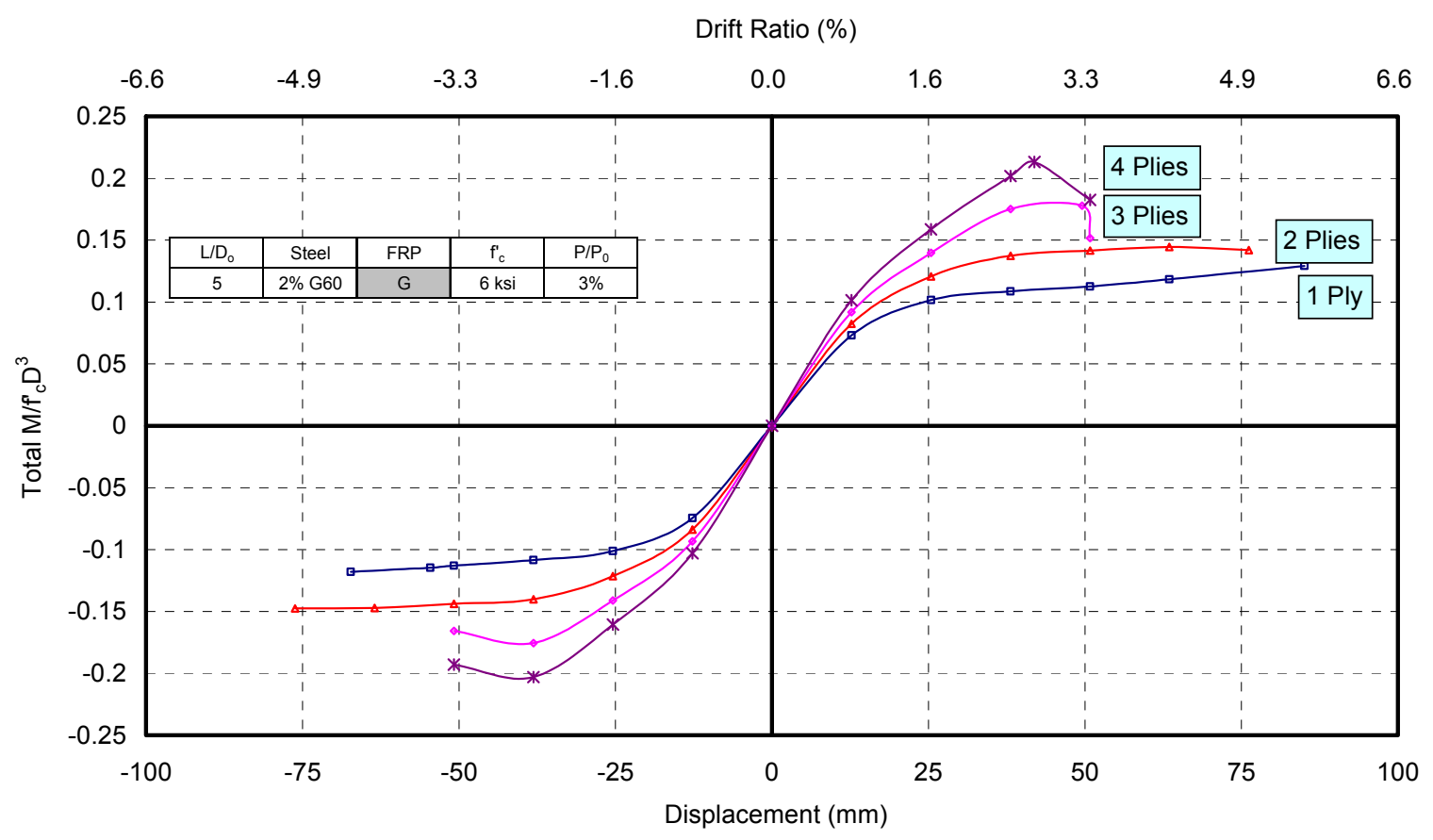

Figure 7.45 Effect of FRP Tube Thickness on Response Envelope of Column G

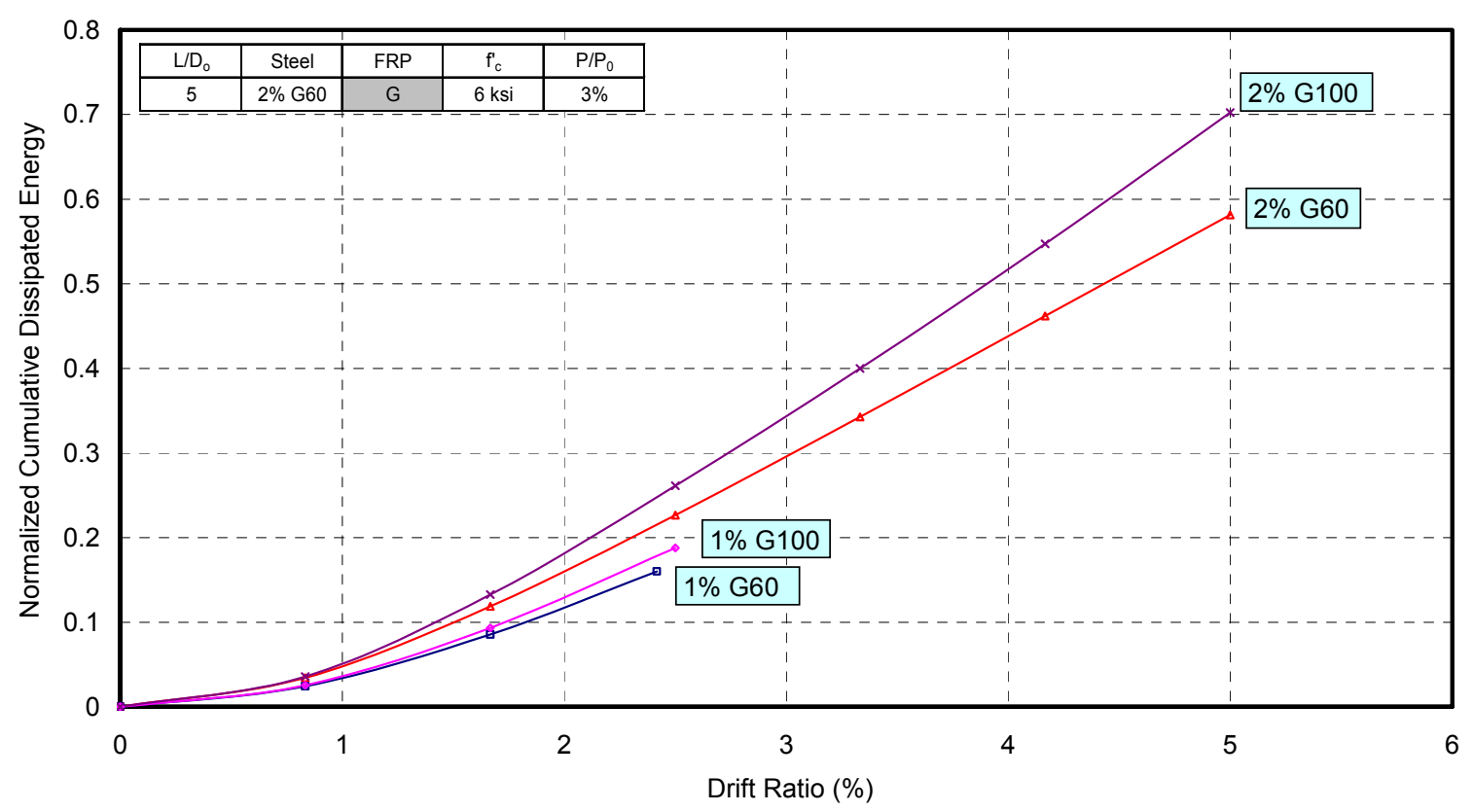

Figure 7.46 Effect of Steel Reinforcement on Normalized Cumulative Dissipated Energy of Column G 


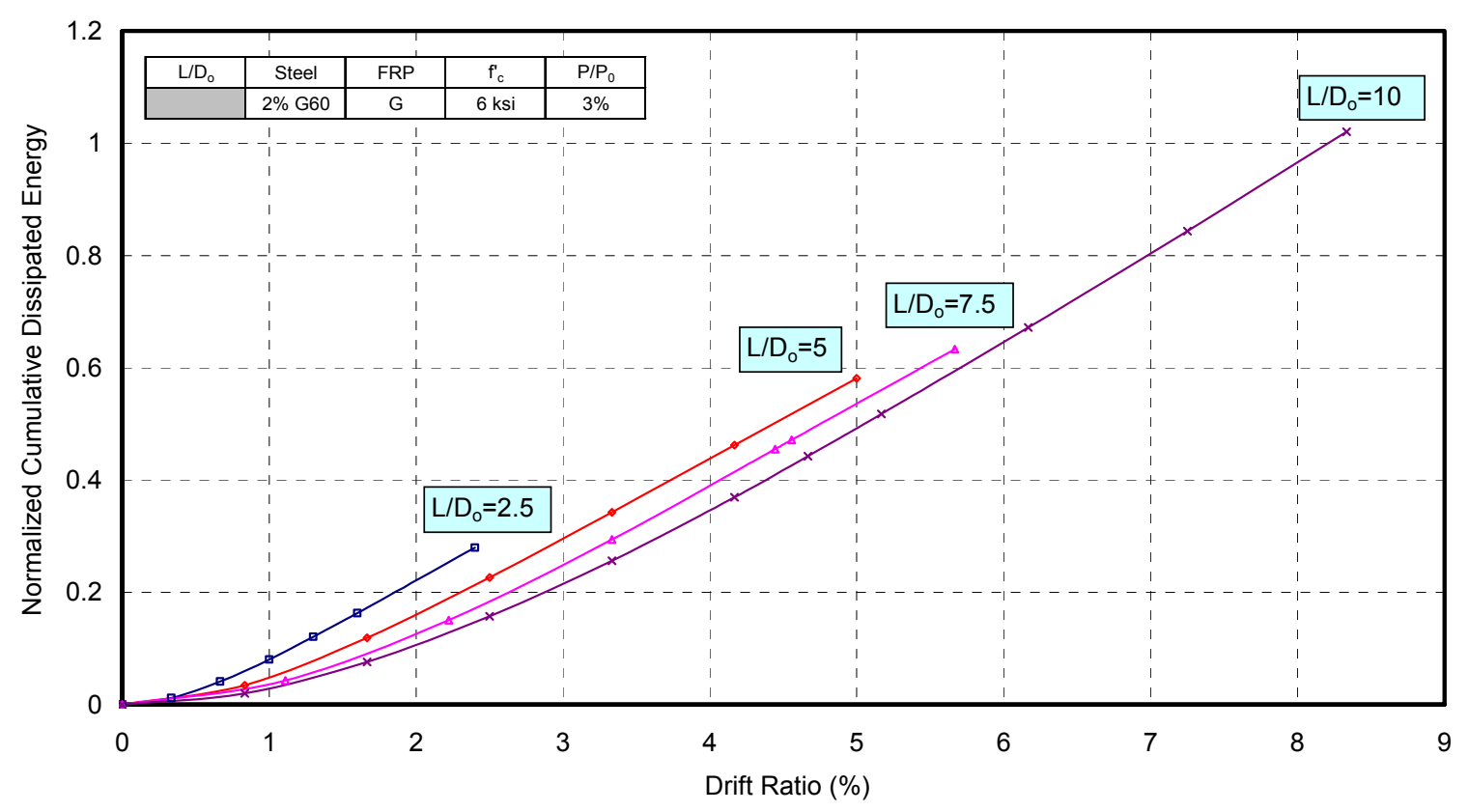

Figure 7.47 Effect of $L / D_{o}$ Ratio on Normalized Cumulative Dissipated Energy of Column G

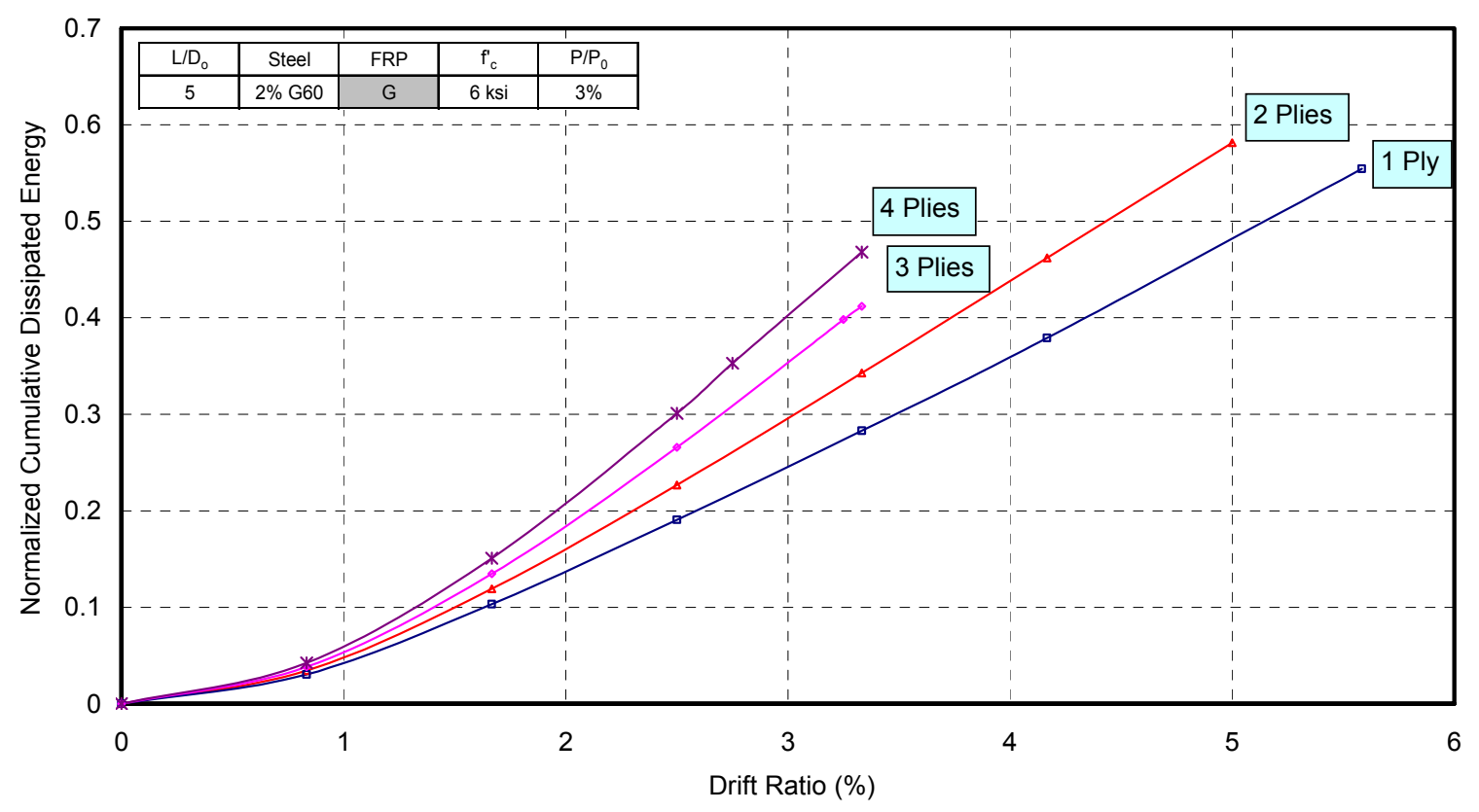

Figure 7.48 Effect of FRP Tube Thickness on Normalized Cumulative Dissipated Energy of Column G 


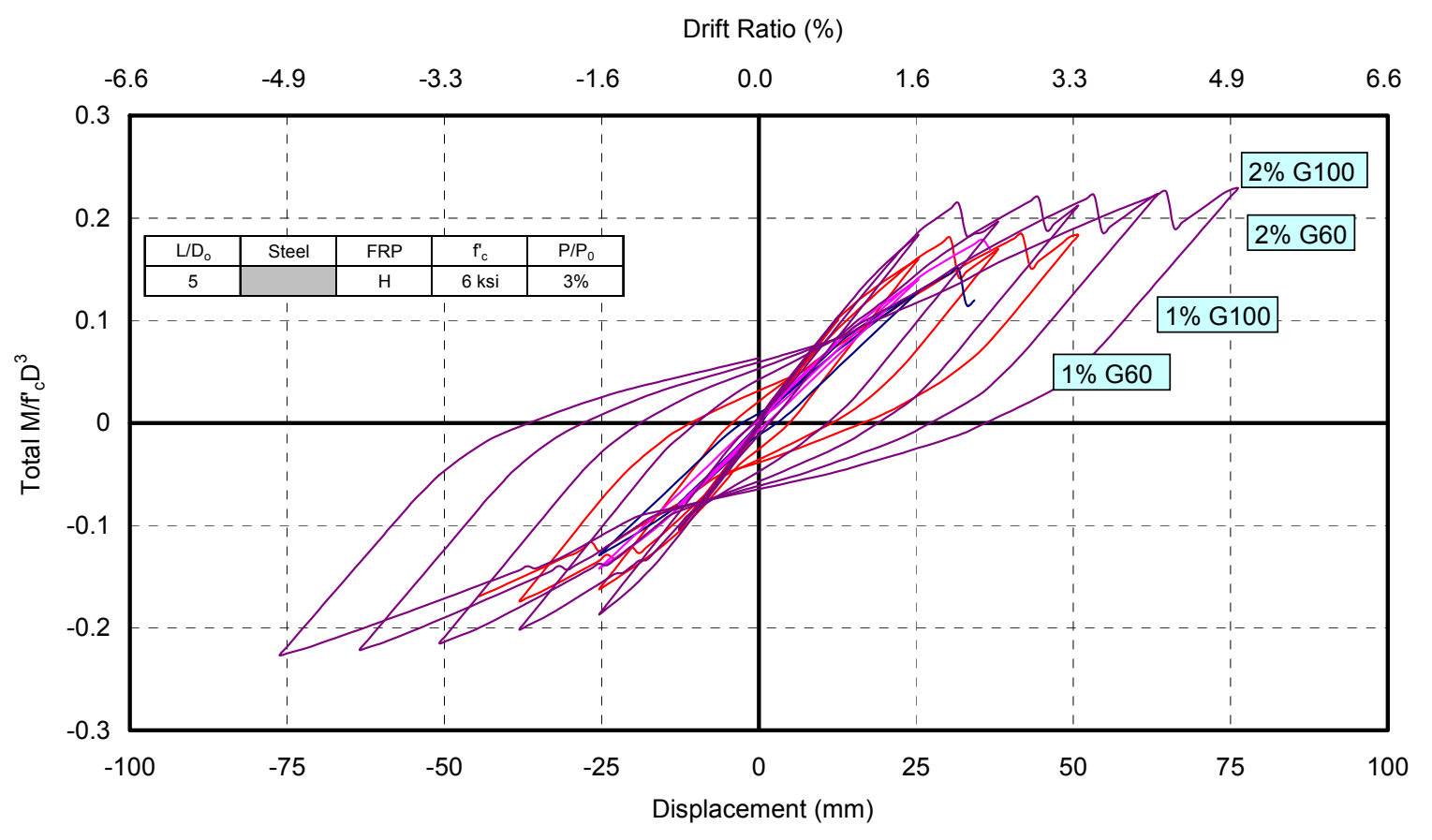

Figure 7.49 Effect of Steel Reinforcement on Hysteretic Response of Column H

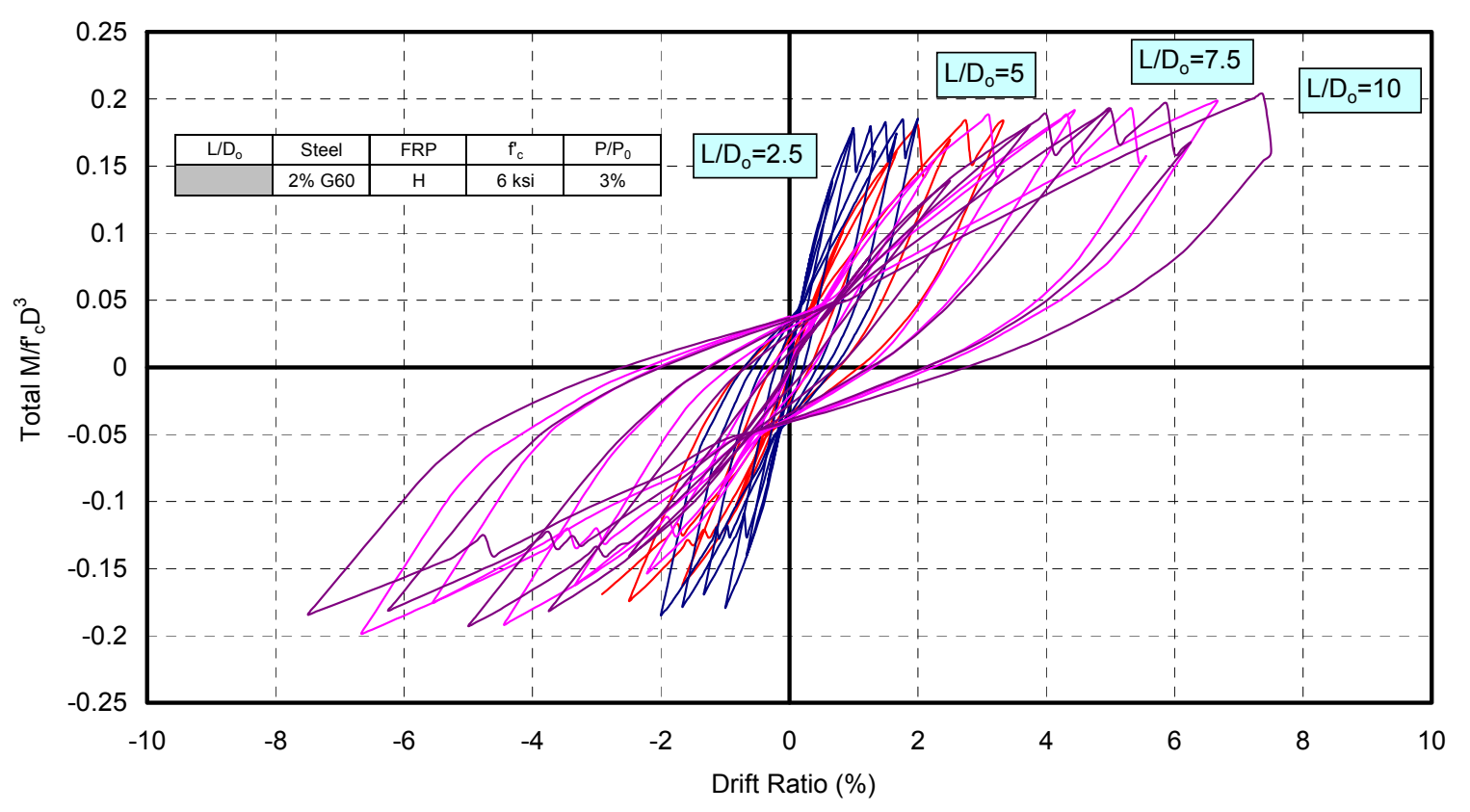

Figure 7.50 Effect of $L / D_{o}$ Ratio on Hysteretic Response of Column $\mathrm{H}$ 


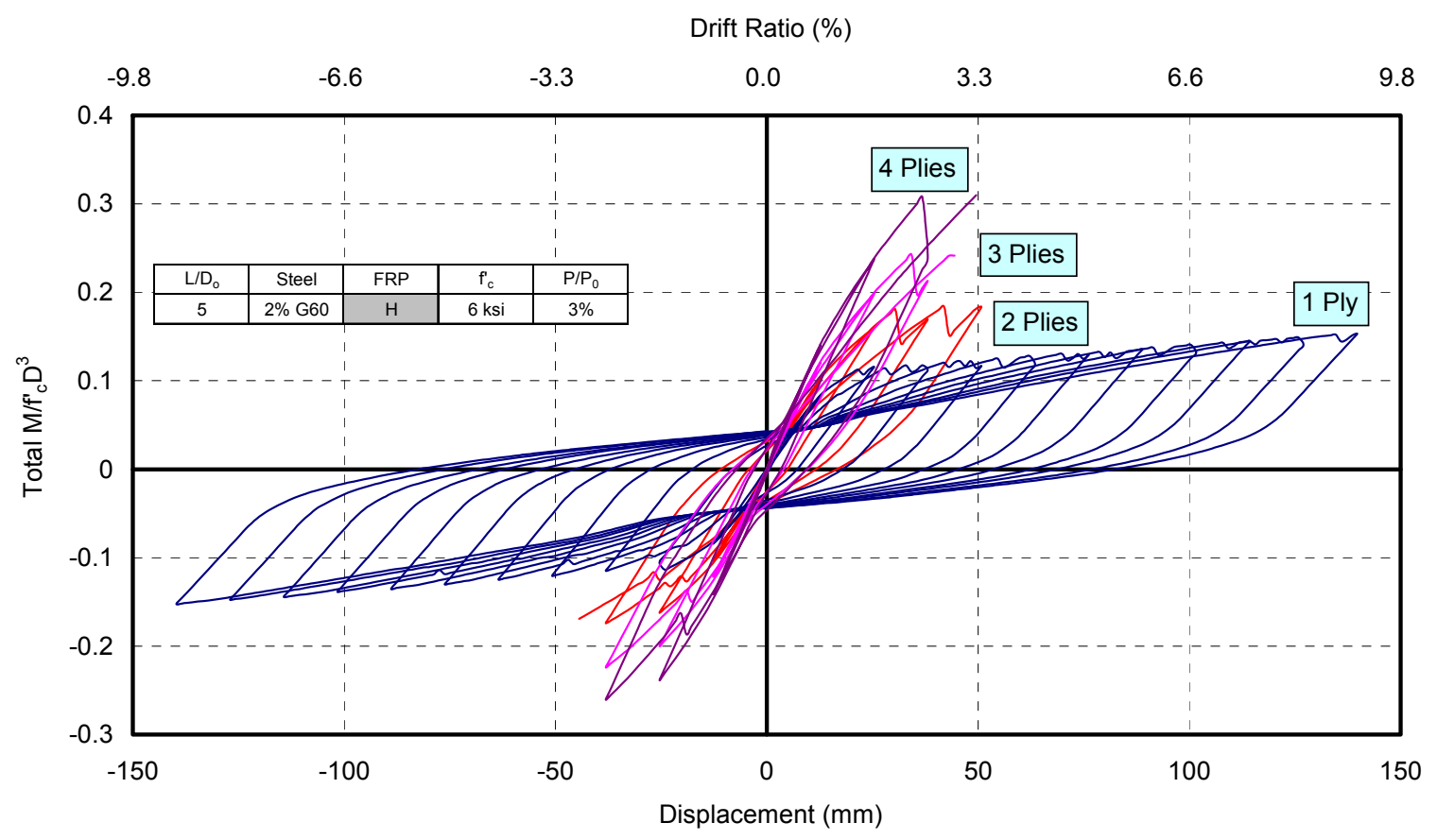

Figure 7.51 Effect of FRP Tube Thickness on Hysteretic Response of Column H

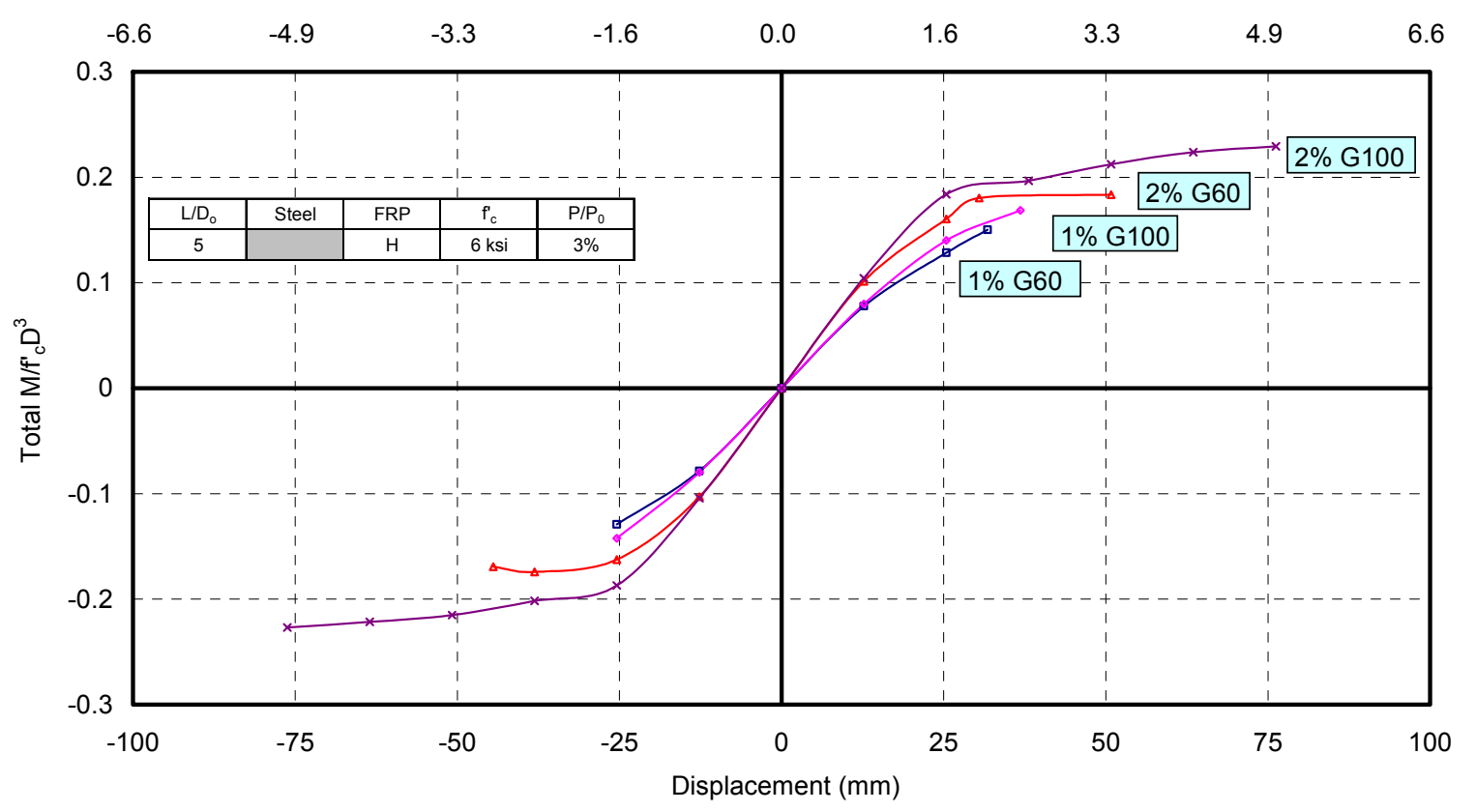

Figure 7.52 Effect of Steel Reinforcement on Response Envelope of Column H 


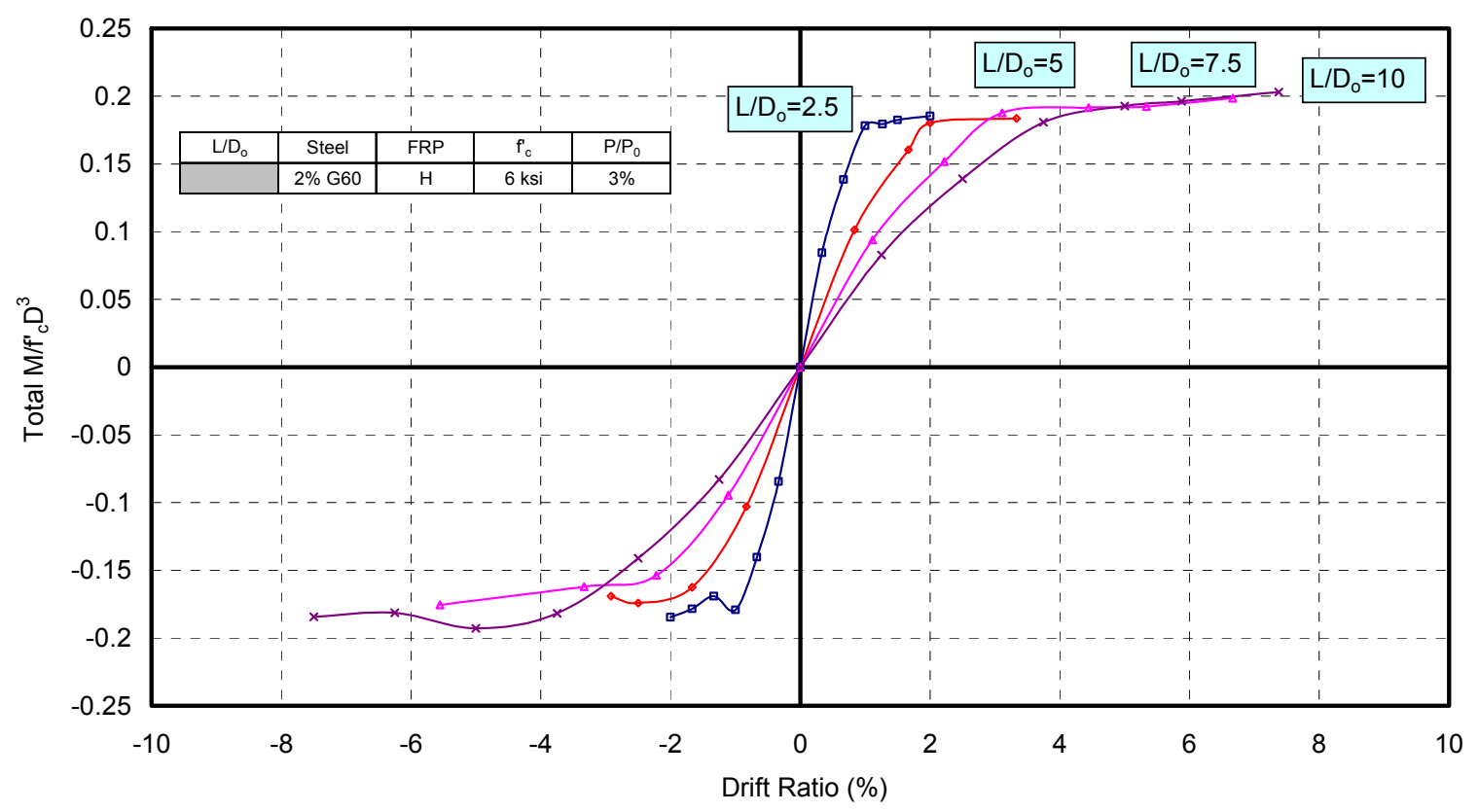

Figure 7.53 Effect of $L / D_{o}$ Ratio on Response Envelope of Column $\mathrm{H}$

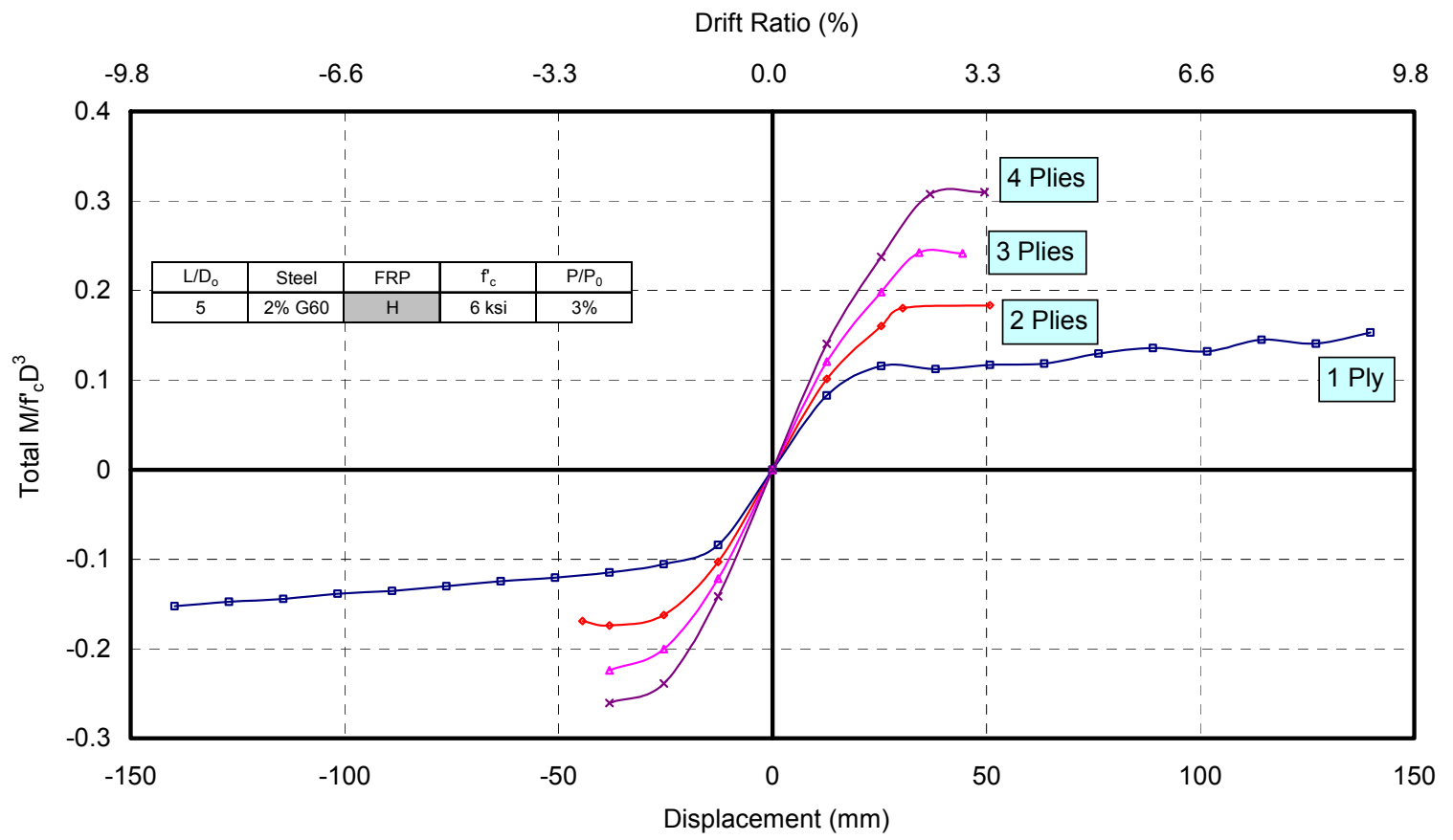

Figure 7.54 Effect of FRP Tube Thickness on Response Envelope of Column H 


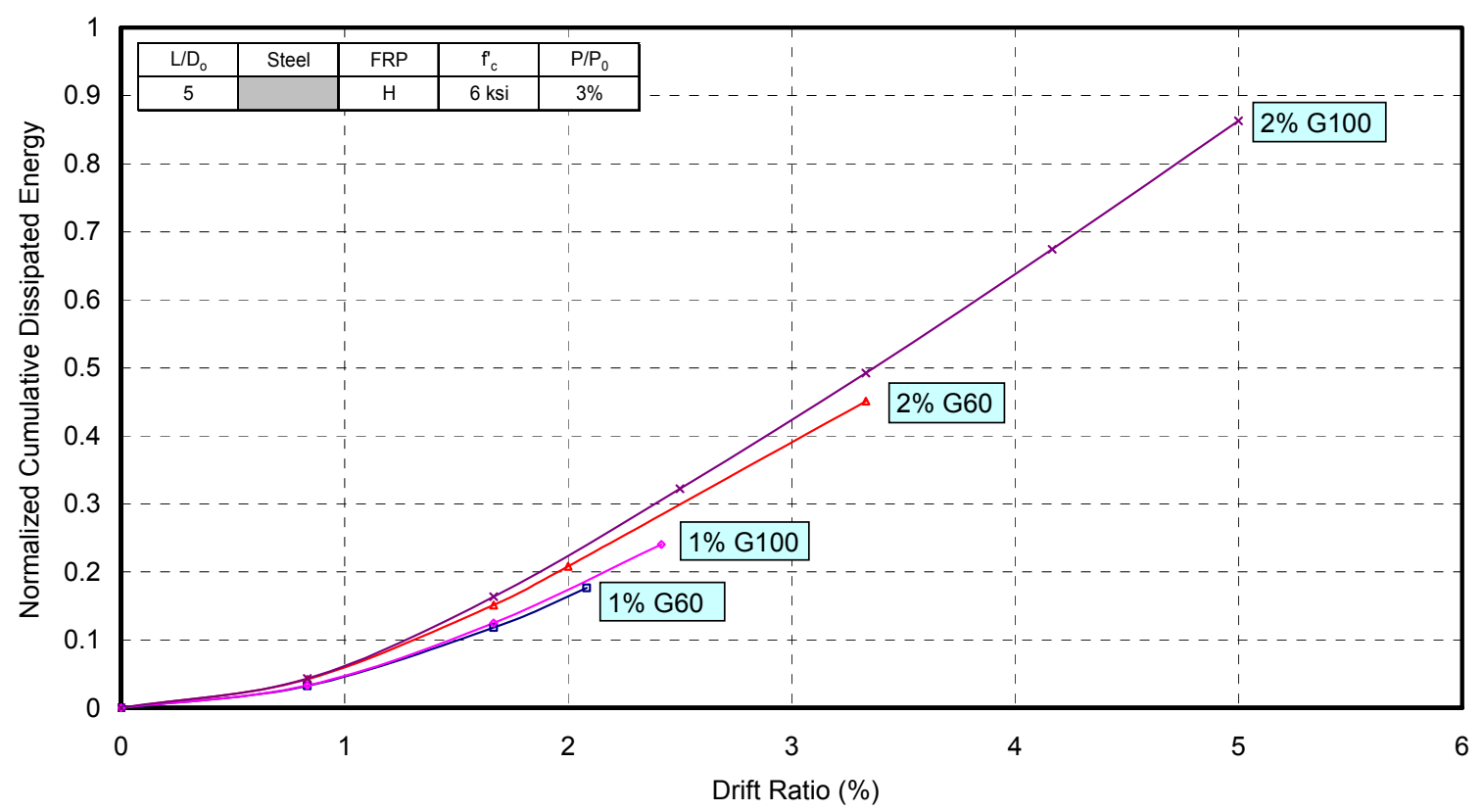

Figure 7.55 Effect of Steel Reinforcement on Normalized Cumulative Dissipated Energy of Column H

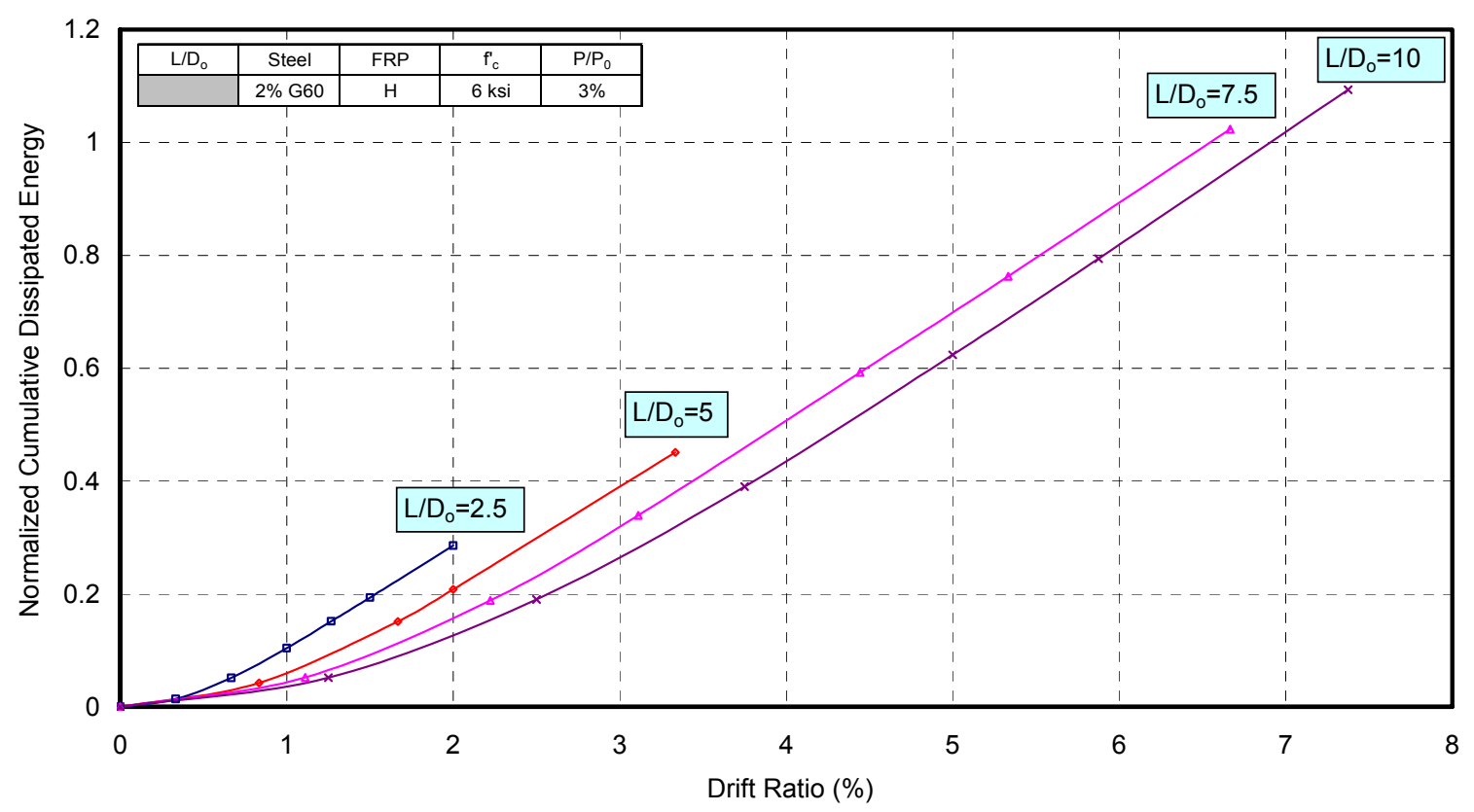

Figure 7.56 Effect of $L / D_{o}$ Ratio on Normalized Cumulative Dissipated Energy of Column H 


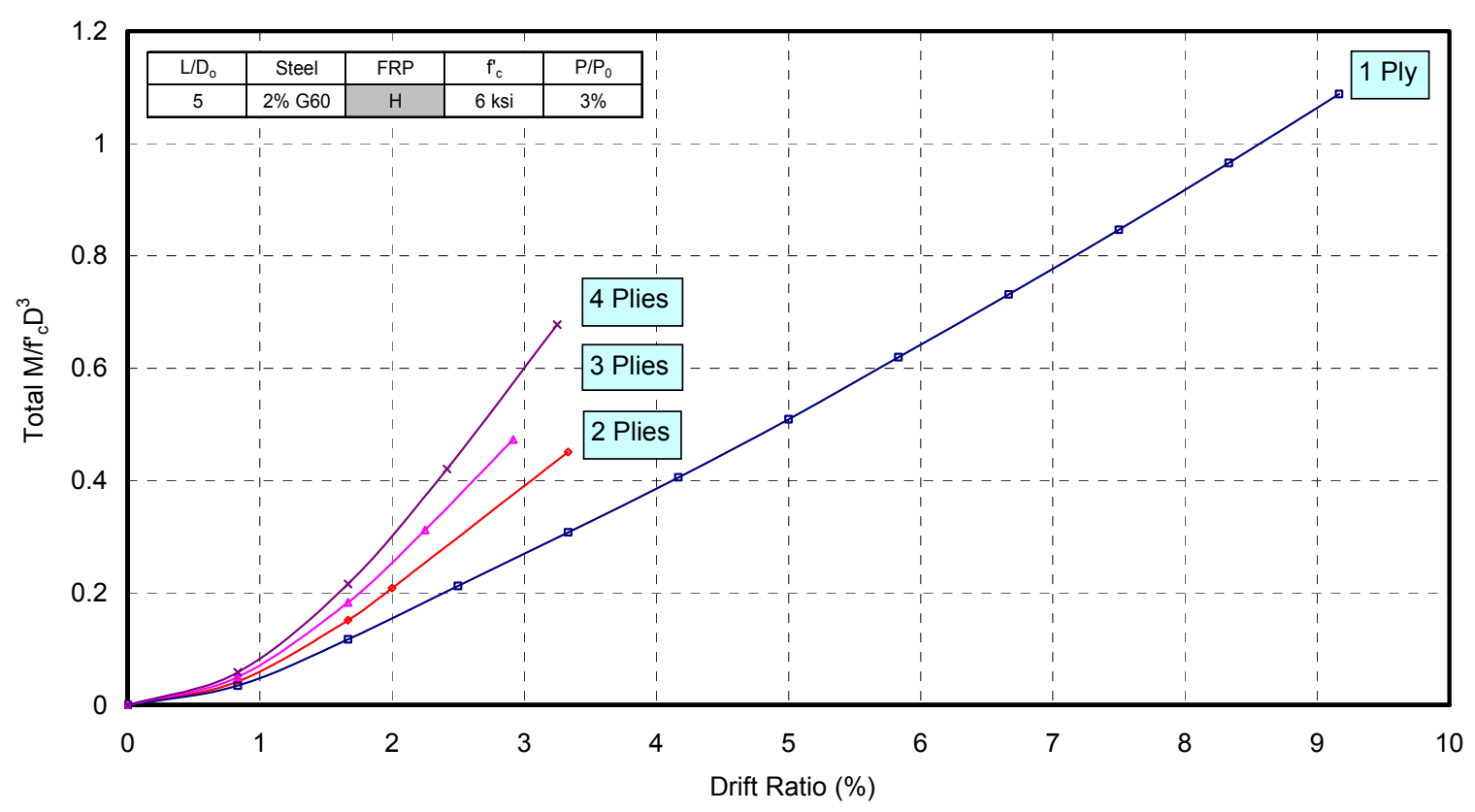

Figure 7.57 Effect of FRP Tube Thickness on Normalized Cumulative Dissipated Energy of Column H

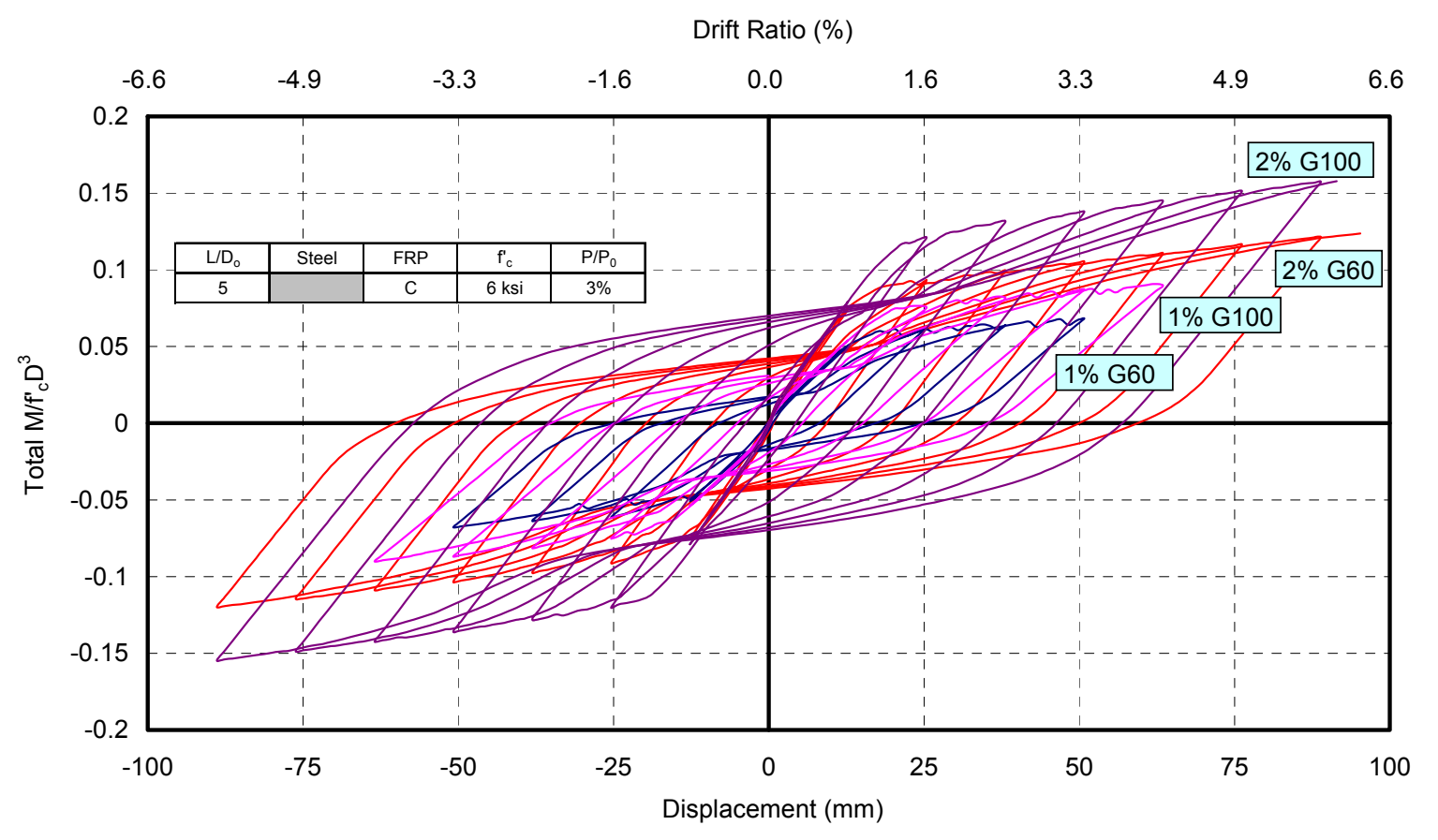

Figure 7.58 Effect of Steel Reinforcement on Hysteretic Response of Column C 


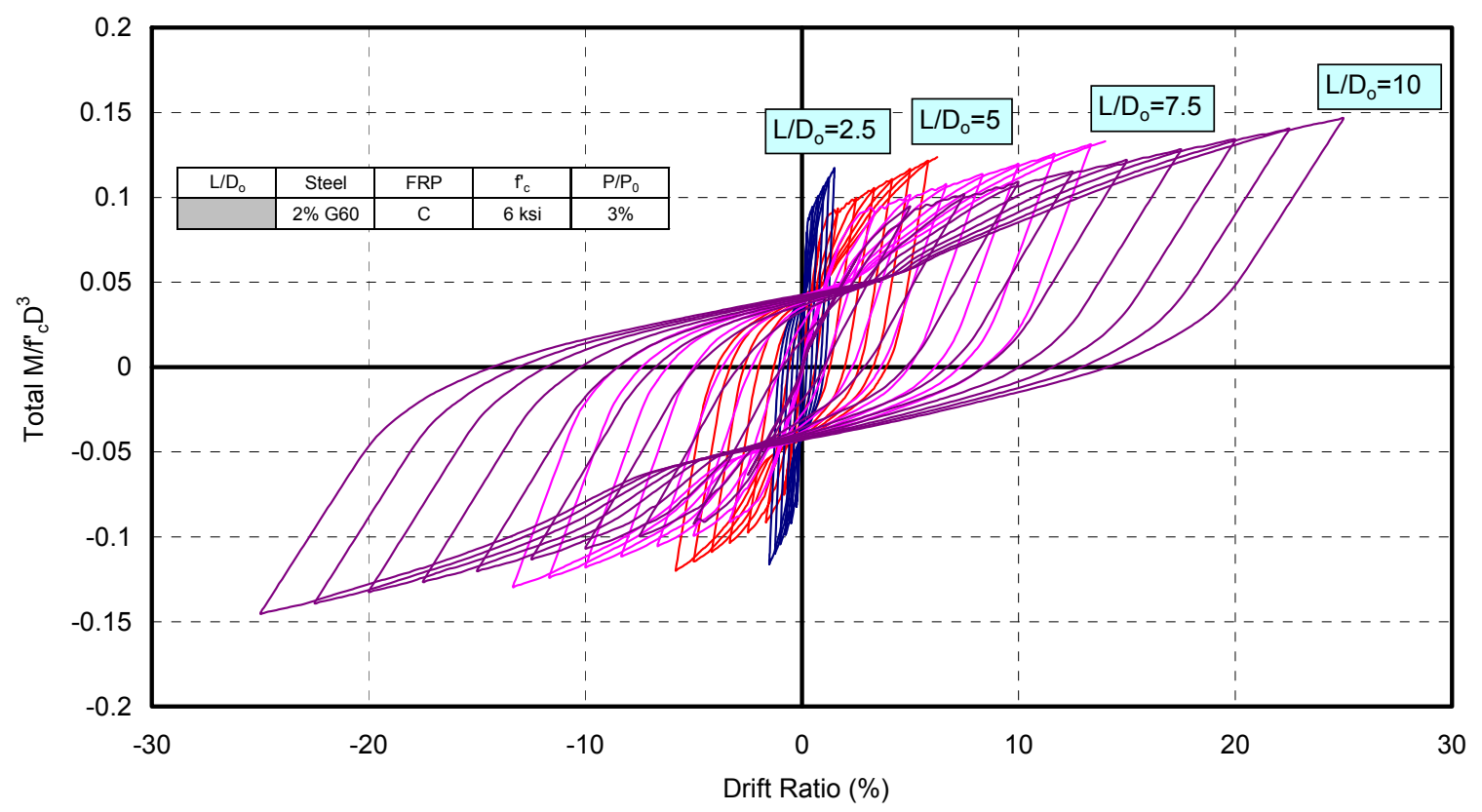

Figure 7.59 Effect of $L / D_{o}$ Ratio on Hysteretic Response of Column C

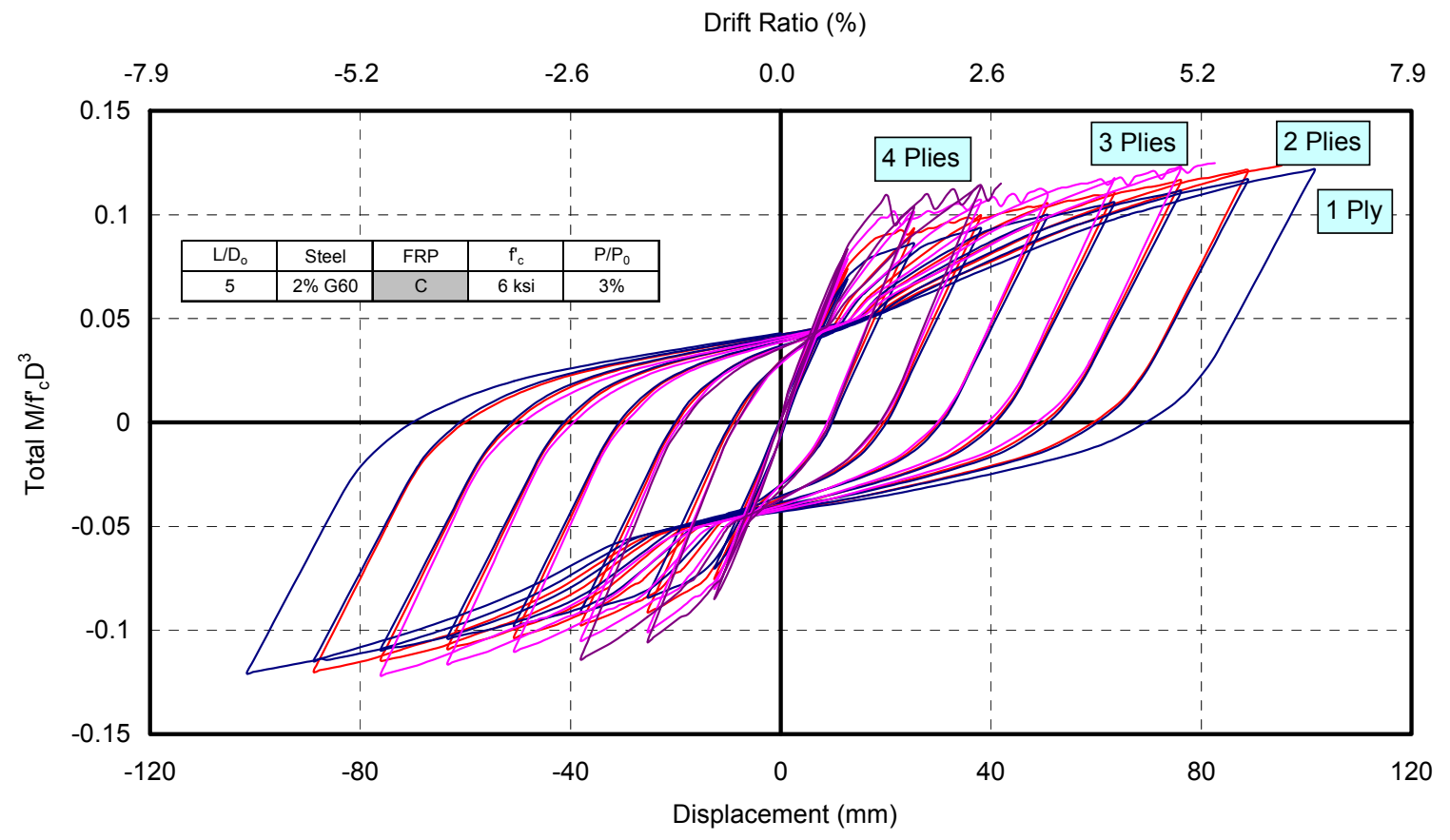

Figure 7.60 Effect of FRP Tube Thickness on Hysteretic Response of Column C 


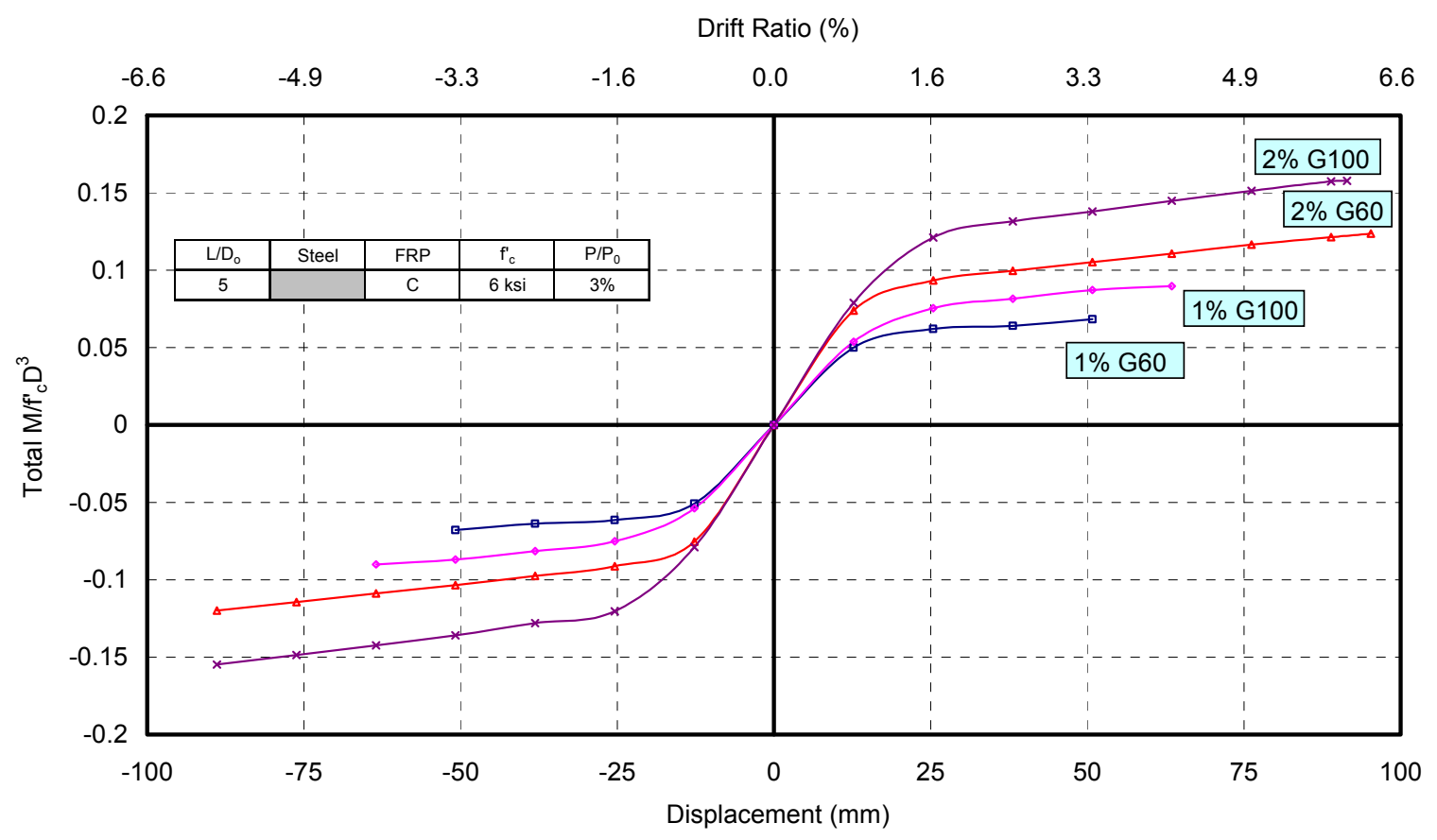

Figure 7.61 Effect of Steel Reinforcement on Response Envelope of Column C

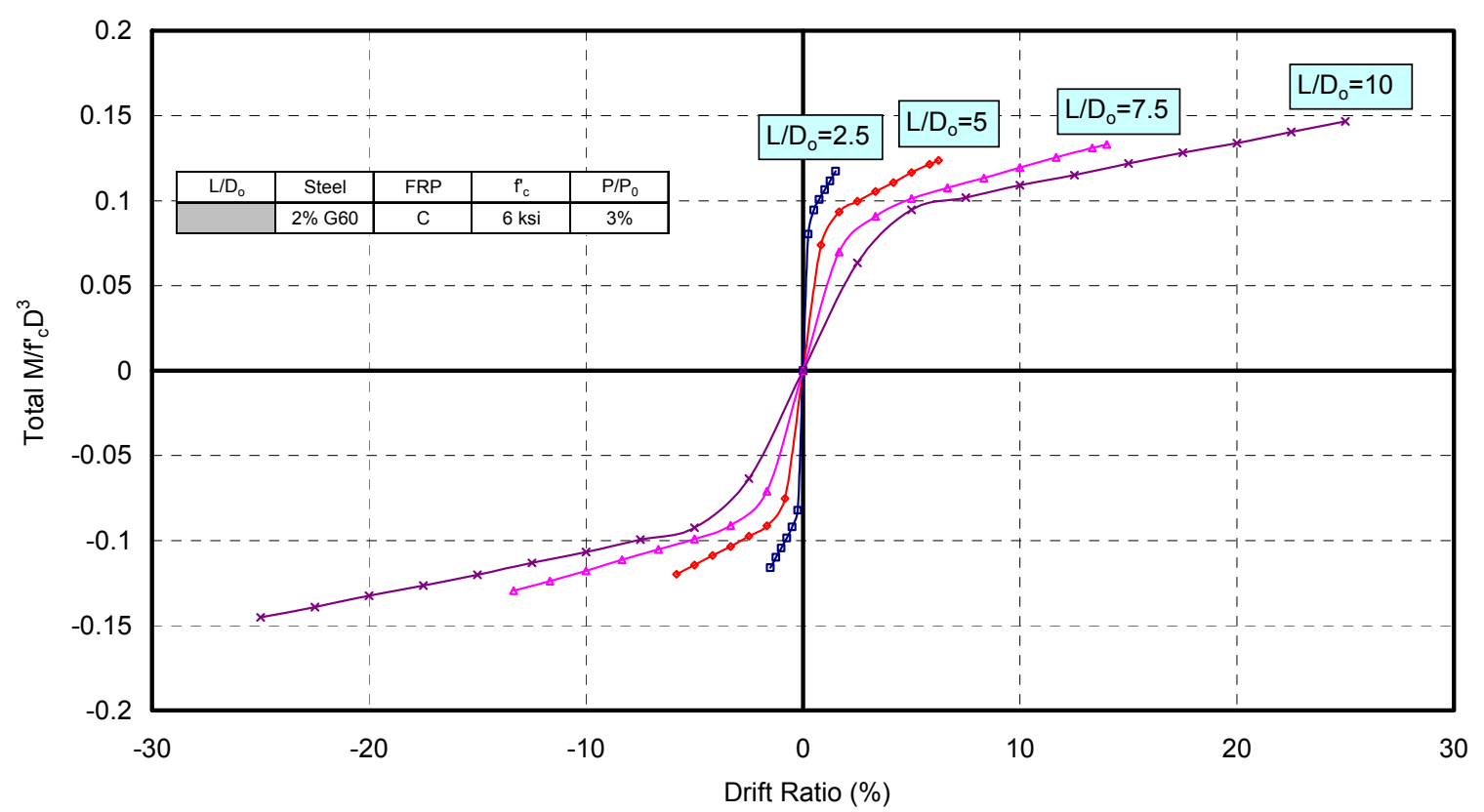

Figure 7.62 Effect of $L / D_{o}$ Ratio on Response Envelope of Column C 


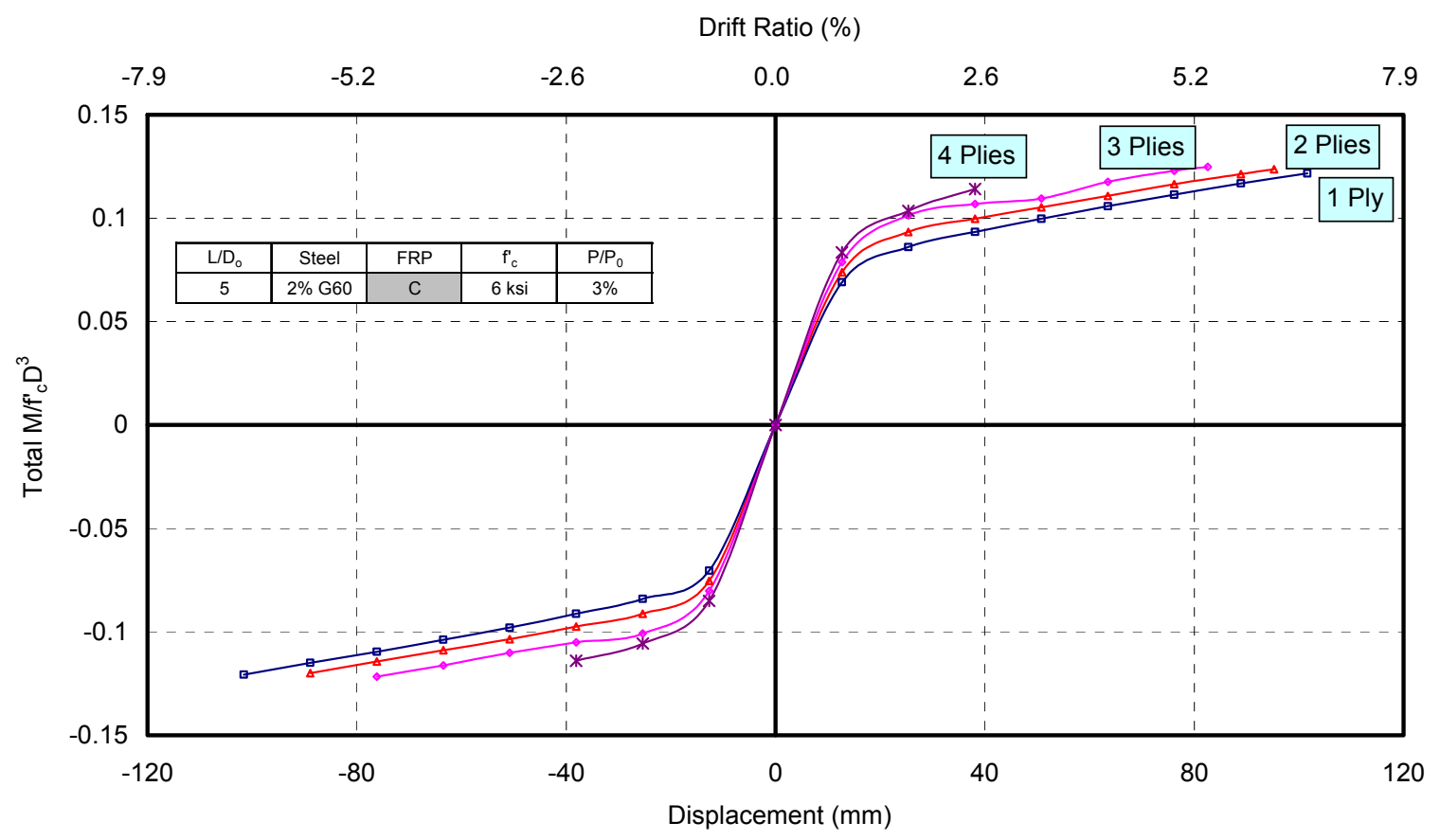

Figure 7.63 Effect of FRP Tube Thickness on Response Envelope of Column C

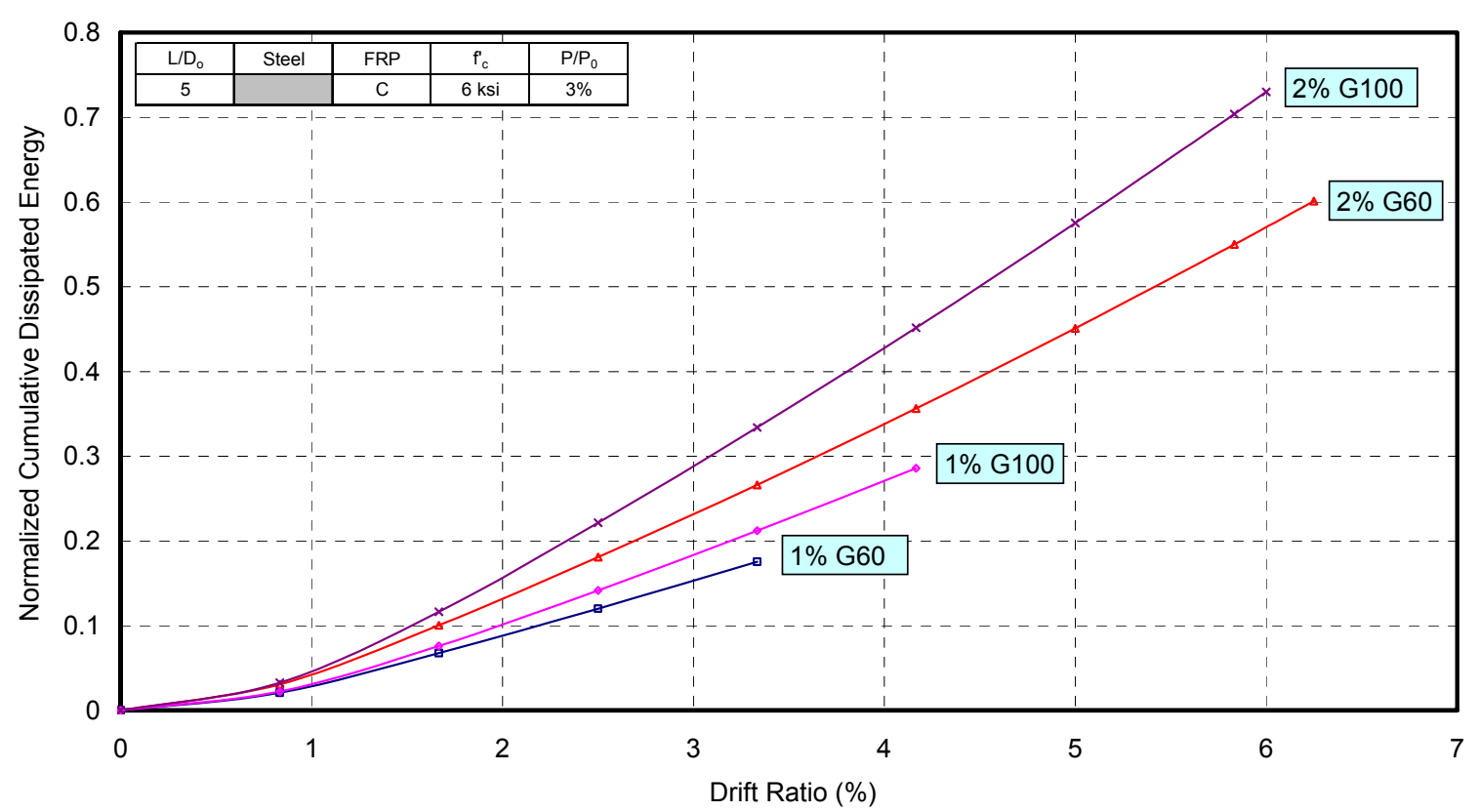

Figure 7.64 Effect of Steel Reinforcement on Normalized Cumulative Dissipated Energy of Column C 


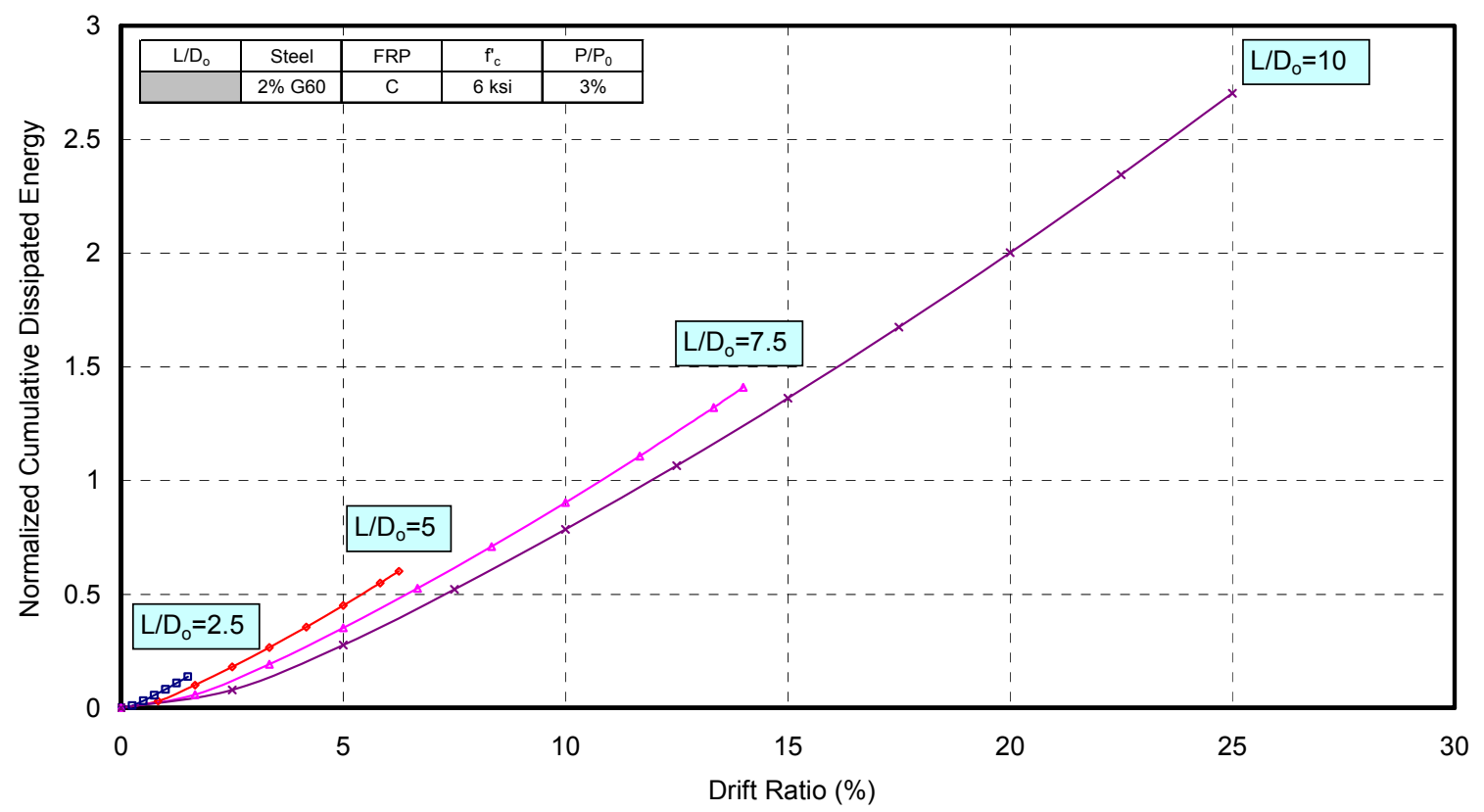

Figure 7.65 Effect of $L / D_{o}$ Ratio on Normalized Cumulative Dissipated Energy of

\section{Column C}

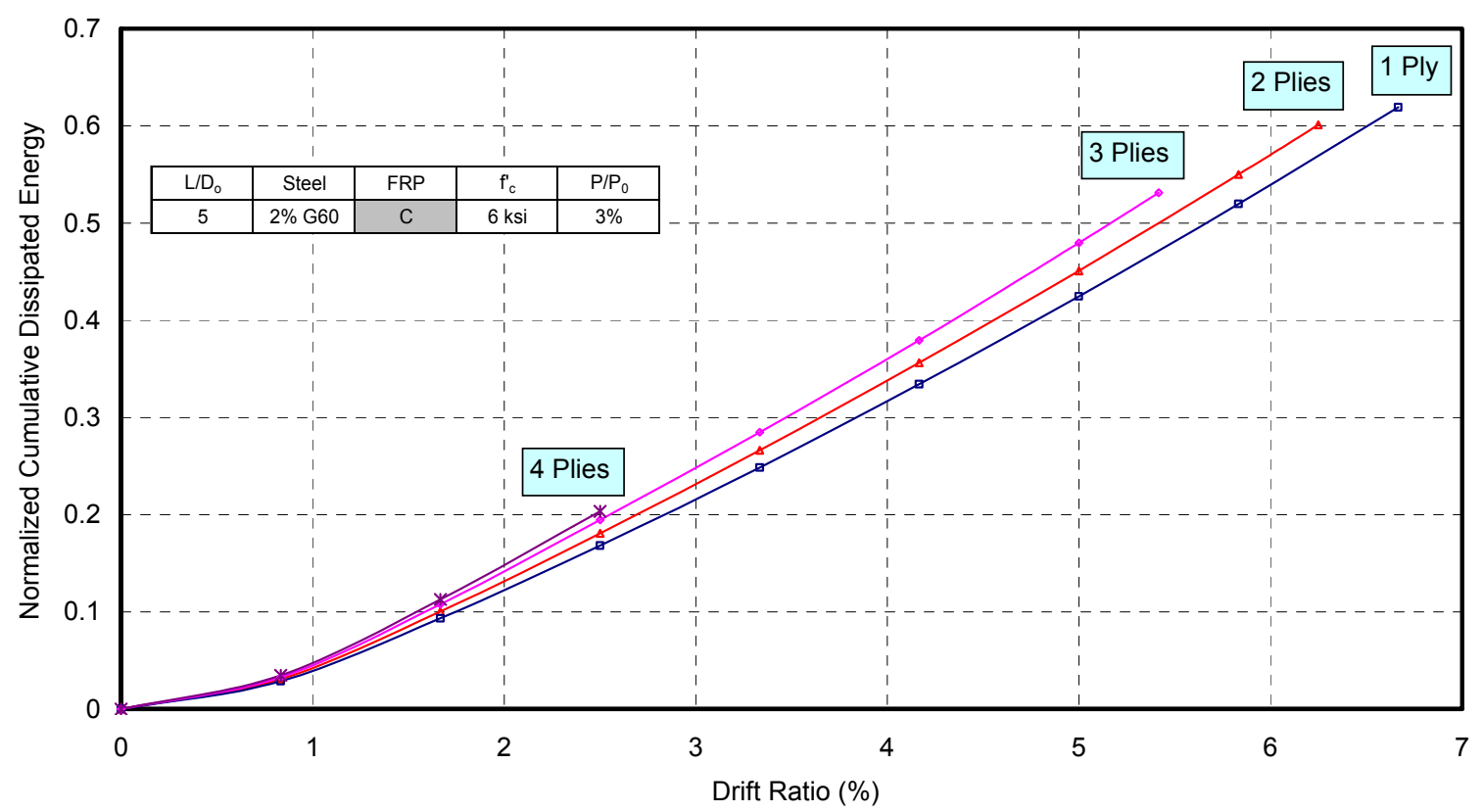

Figure 7.66 Effect of FRP Tube Thickness on Normalized Cumulative Dissipated Energy

of Column C 


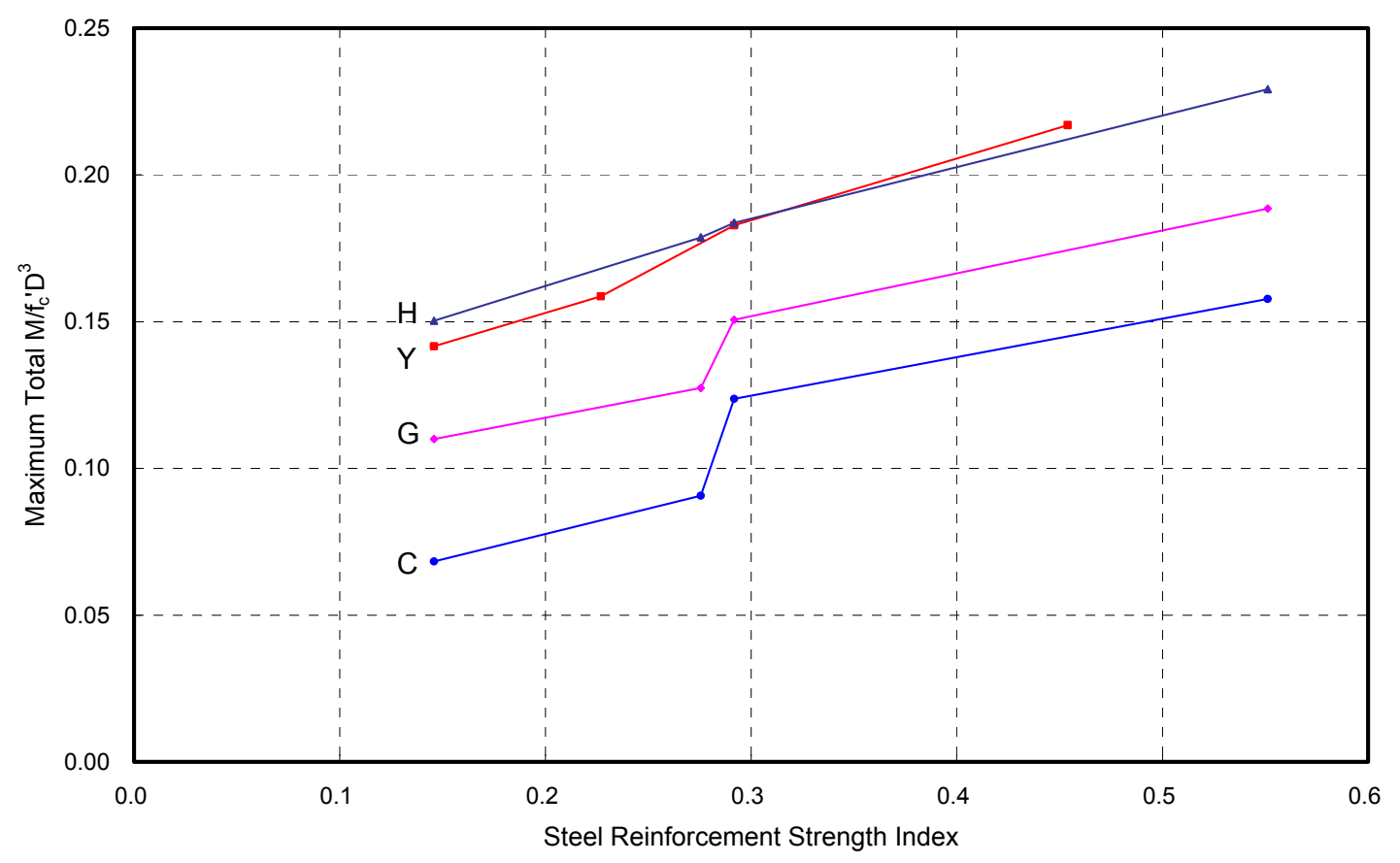

Figure 7.67 Effect of Steel Reinforcement Strength Index on Maximum Total Normalized

Moment

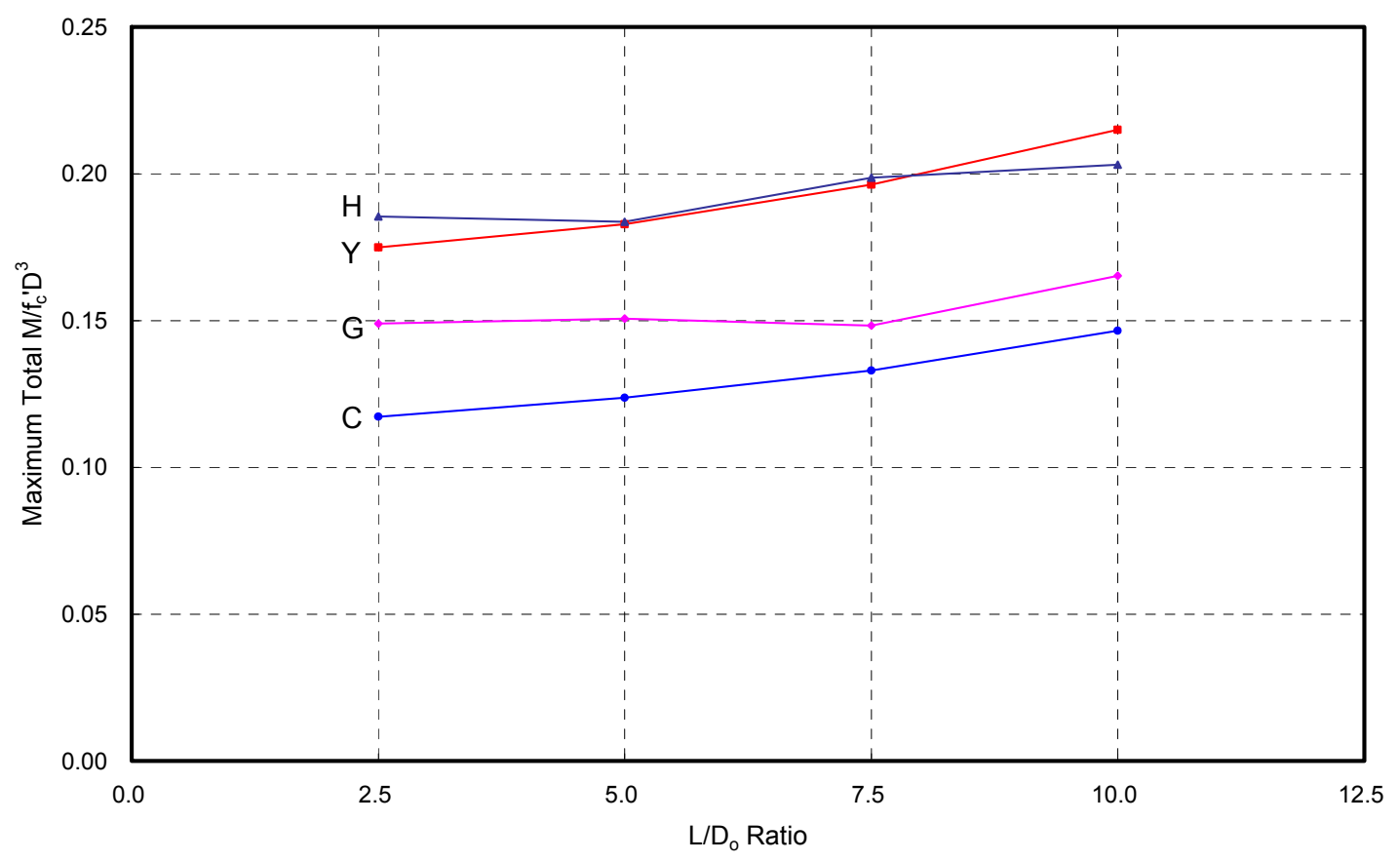

Figure 7.68 Effect of $L / D_{o}$ Ratio on Maximum Total Normalized Moment 


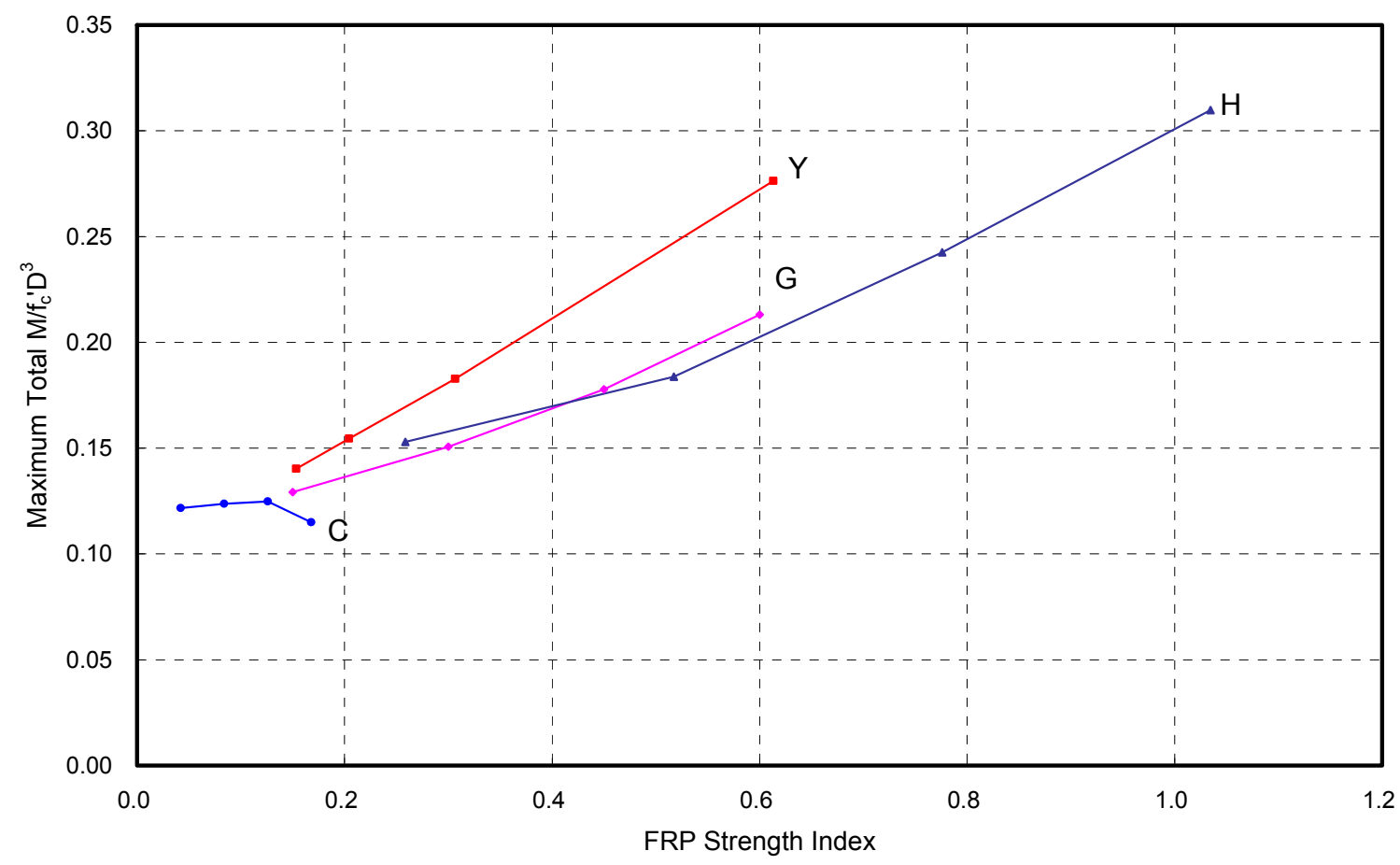

Figure 7.69 Effect of FRP Strength Index on Maximum Total Normalized Moment

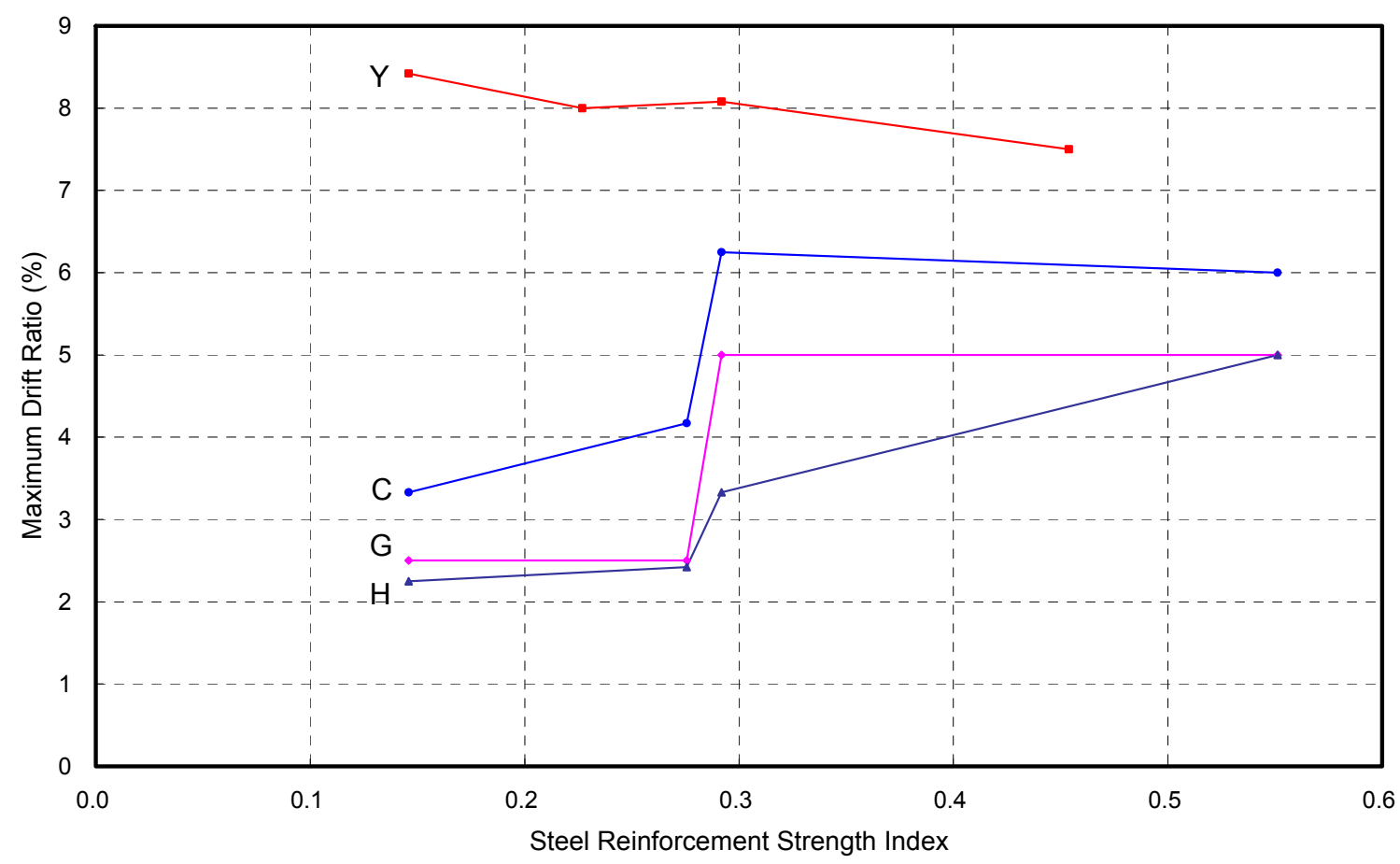

Figure 7.70 Effect of Steel Reinforcement Strength Index on Maximum Drift Ratio 


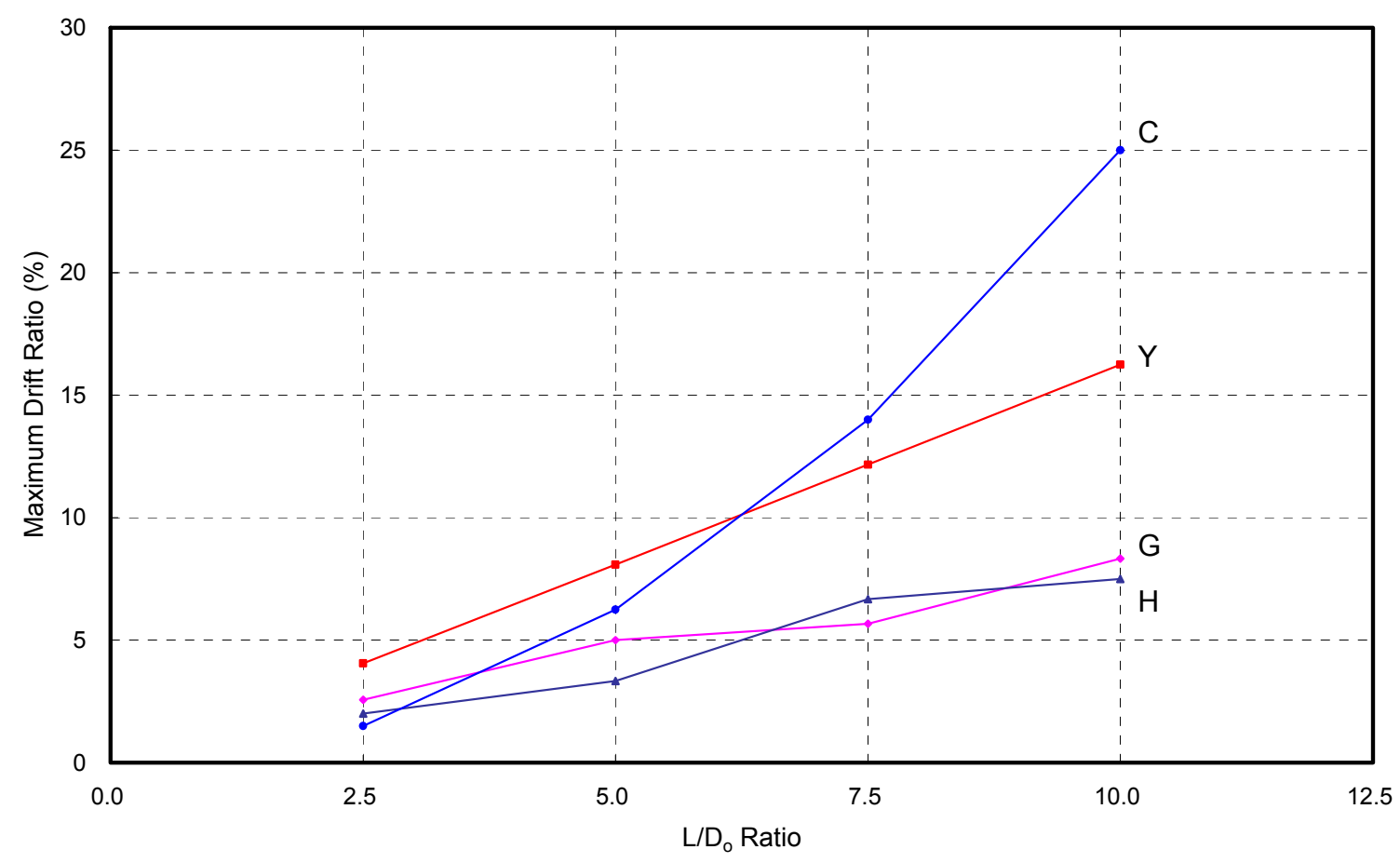

Figure 7.71 Effect of $L / D_{o}$ Ratio on Maximum Drift Ratio

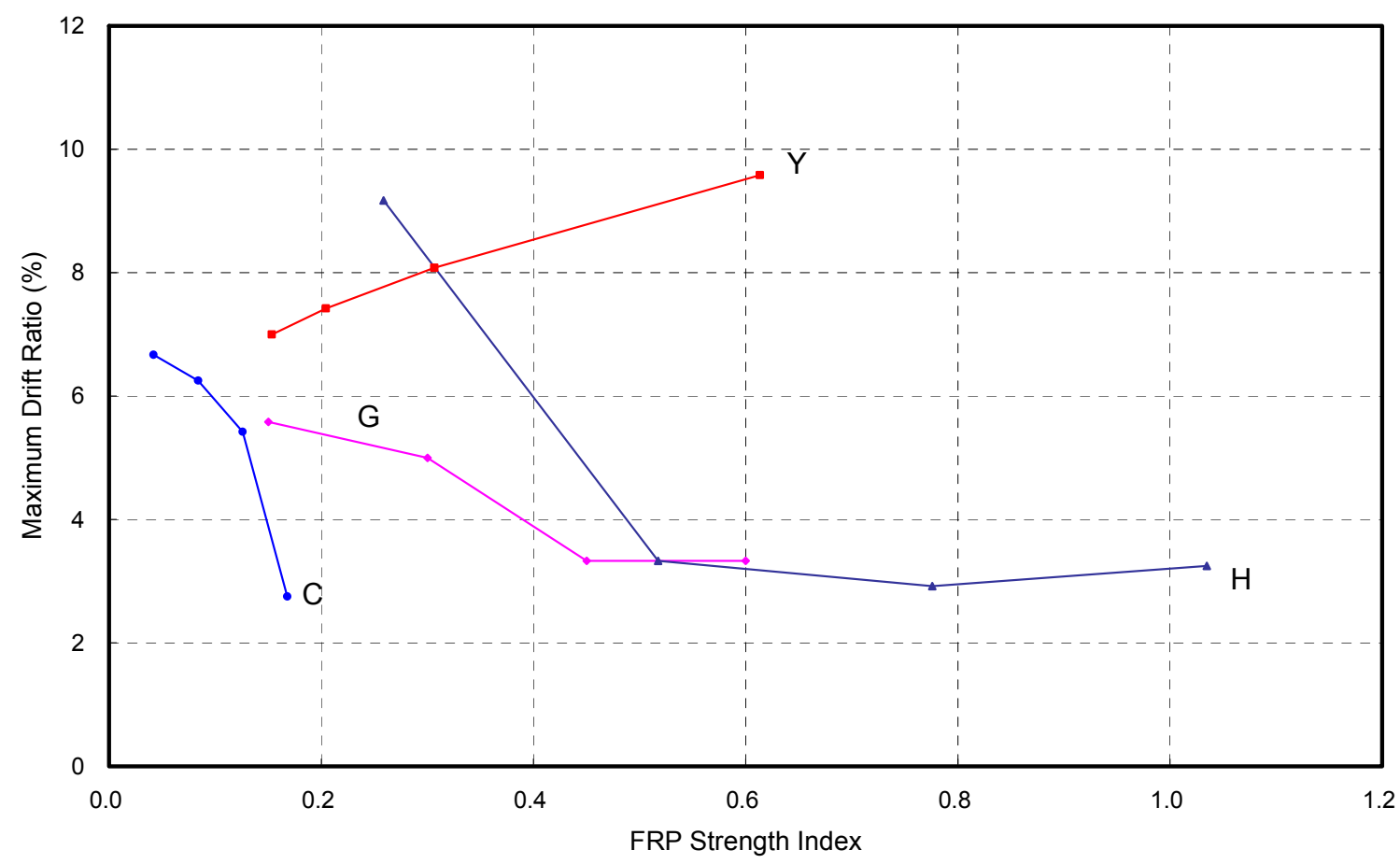

Figure 7.72 Effect of FRP Strength Index on Maximum Drift Ratio 


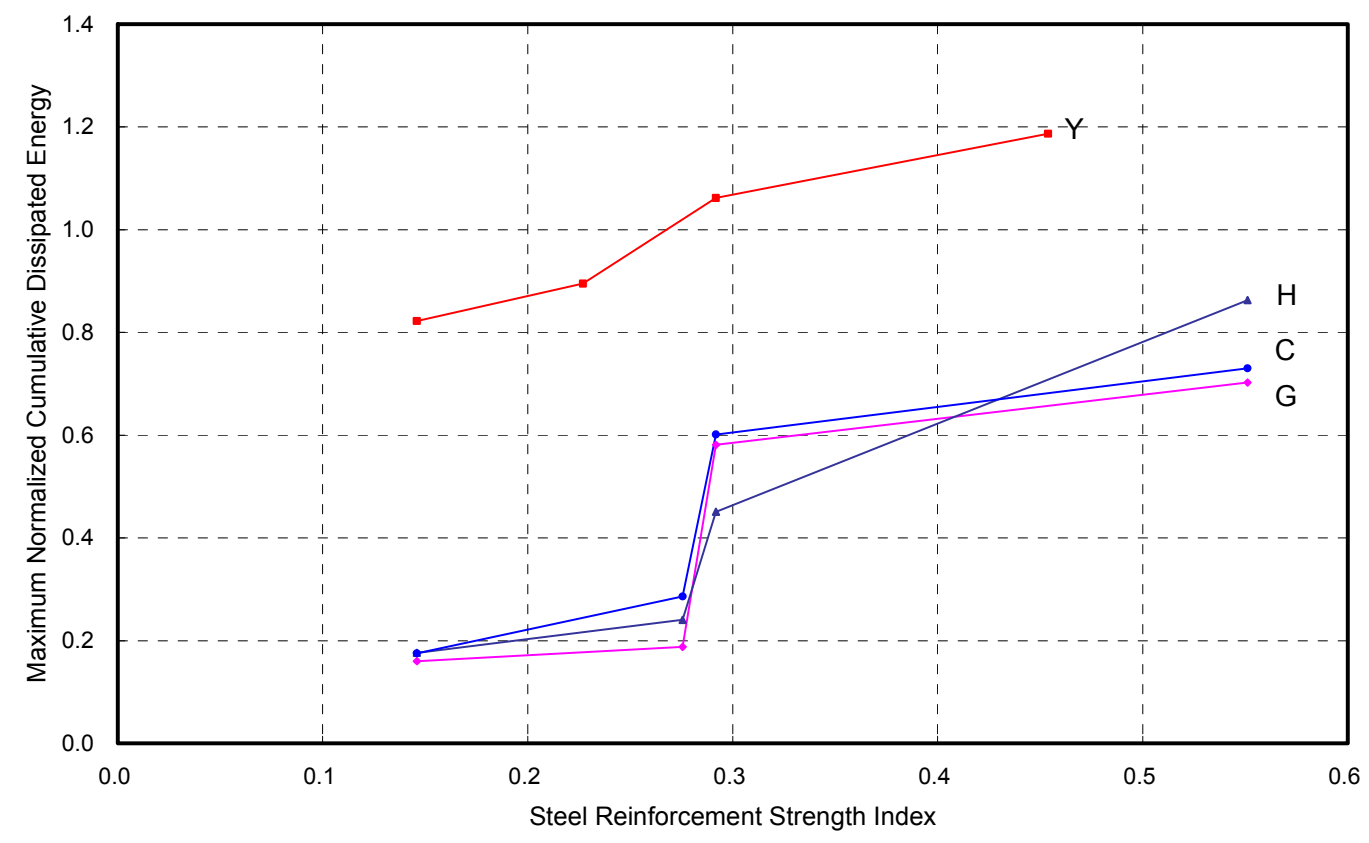

Figure 7.73 Effect of Steel Reinforcement Strength Index on Maximum Normalized Cumulative Dissipated Energy

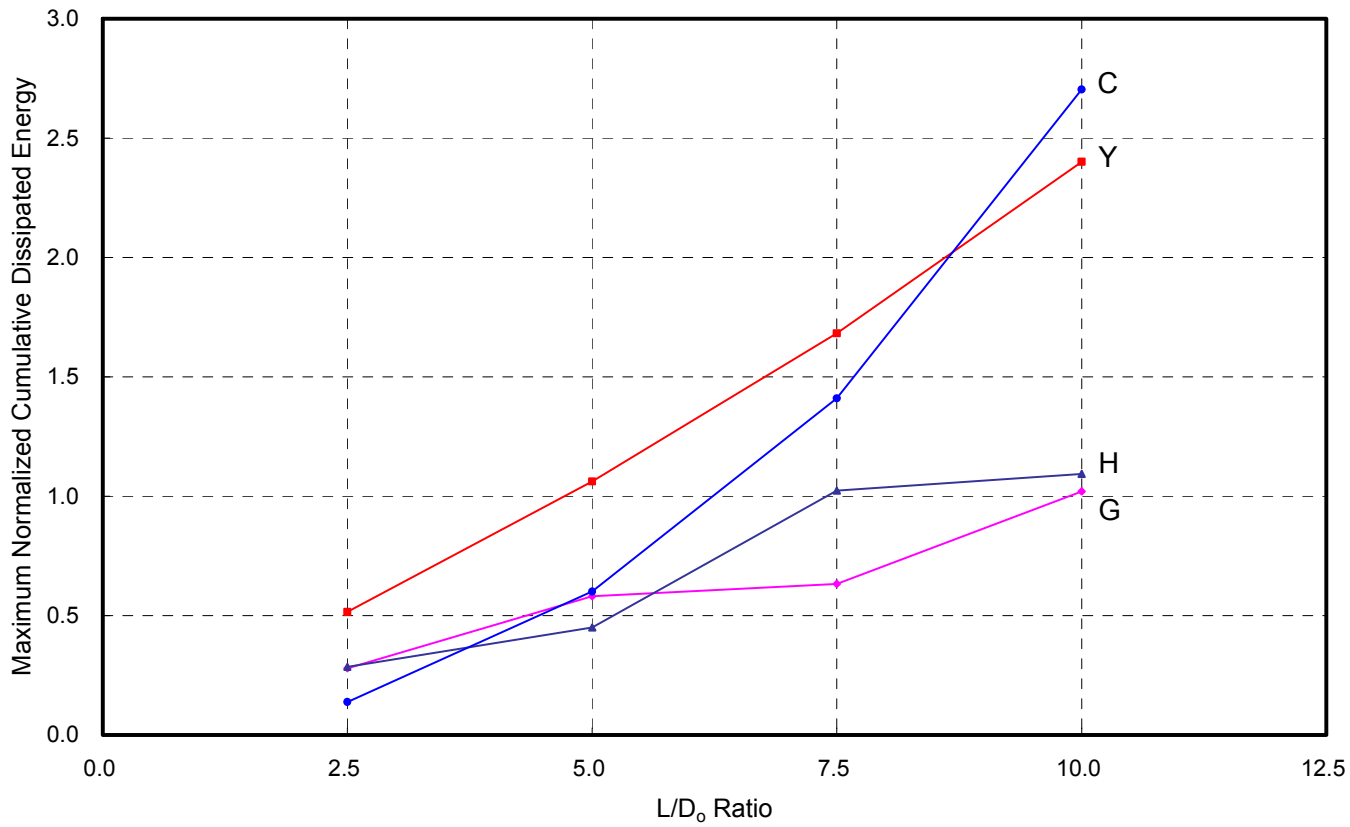

Figure 7.74 Effect of $L / D_{o}$ Ratio on Maximum Normalized Cumulative Dissipated Energy 


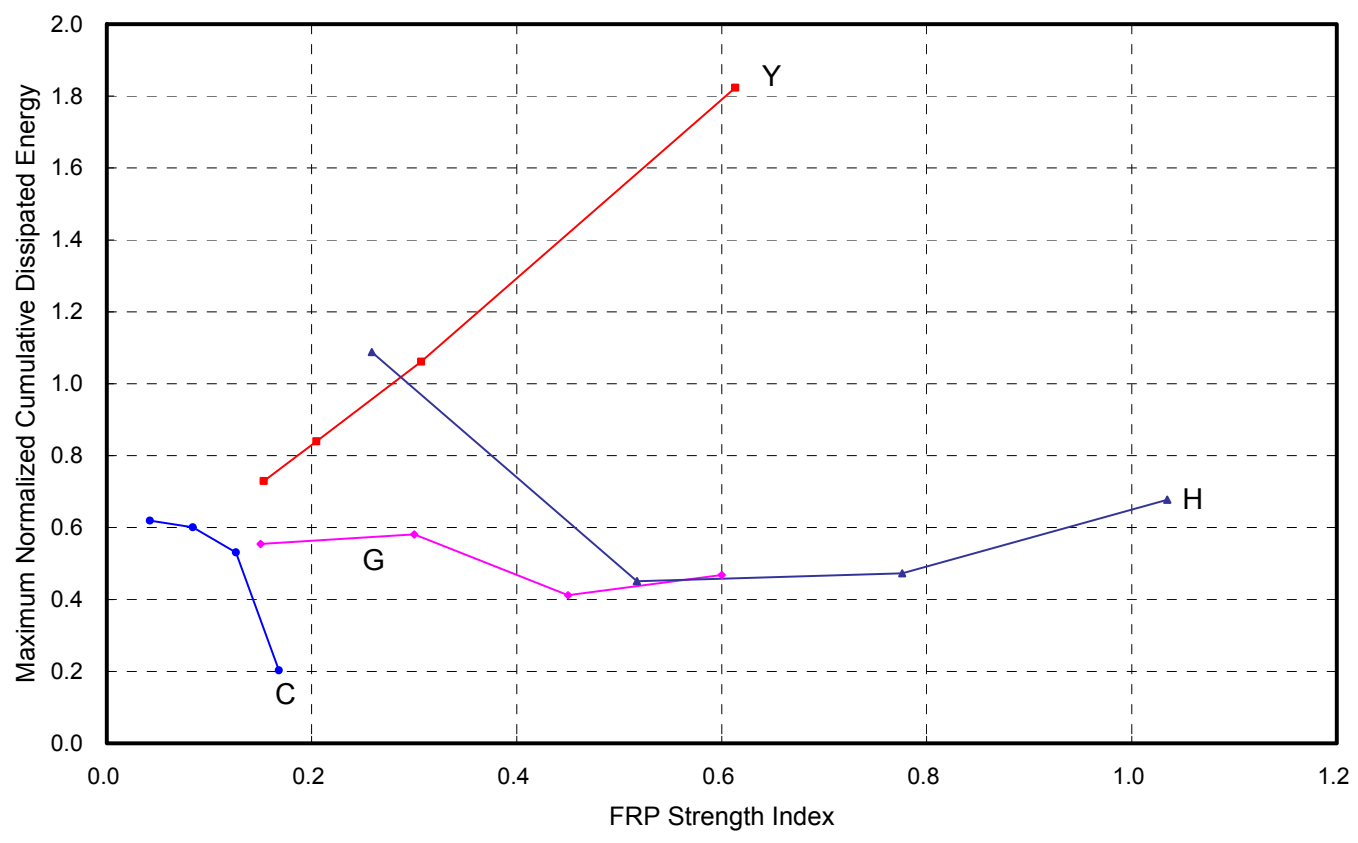

Figure 7.75 Effect of FRP Strength Index on Maximum Normalized Cumulative Dissipated Energy

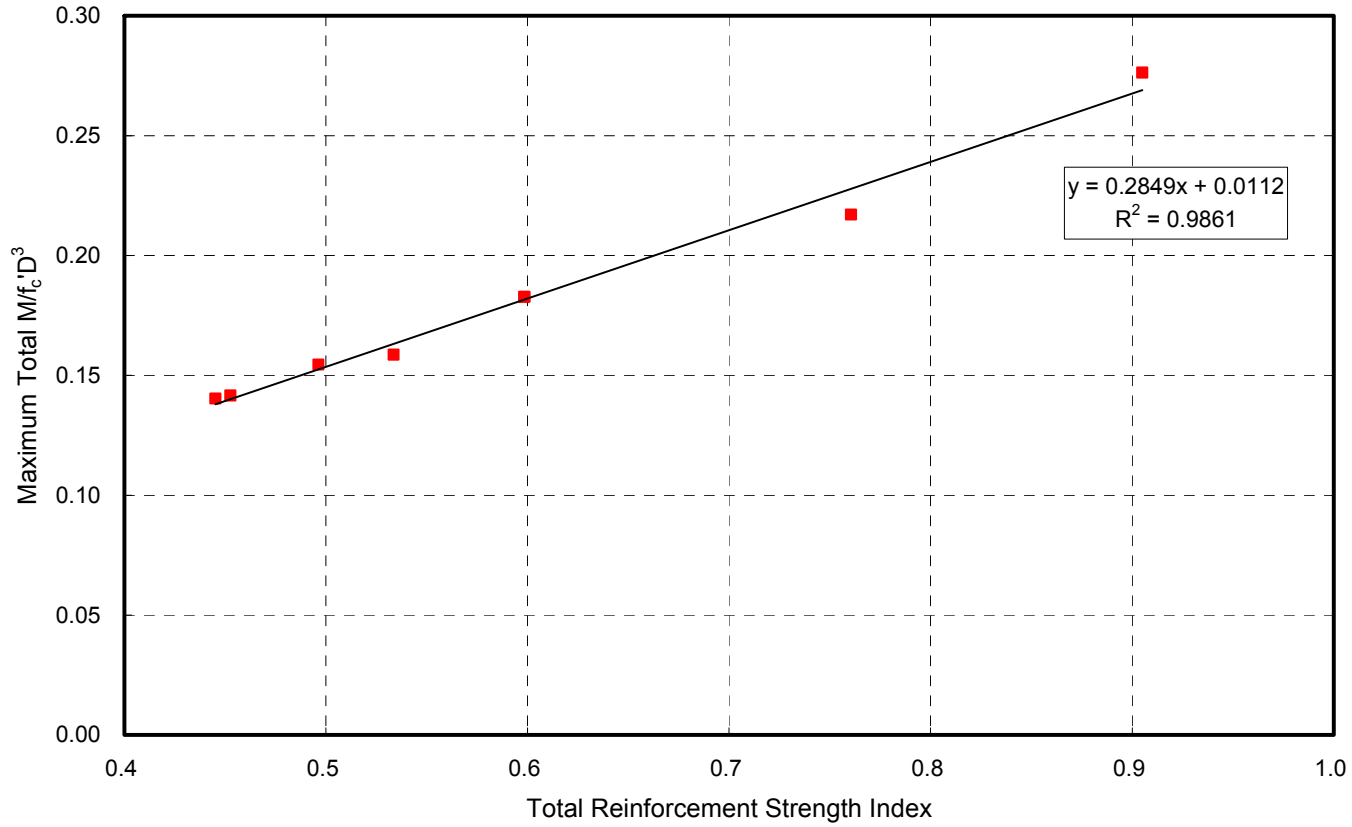

Figure 7.76 Effect of Total Reinforcement Index on Maximum Total Normalized Moment of Column Y 


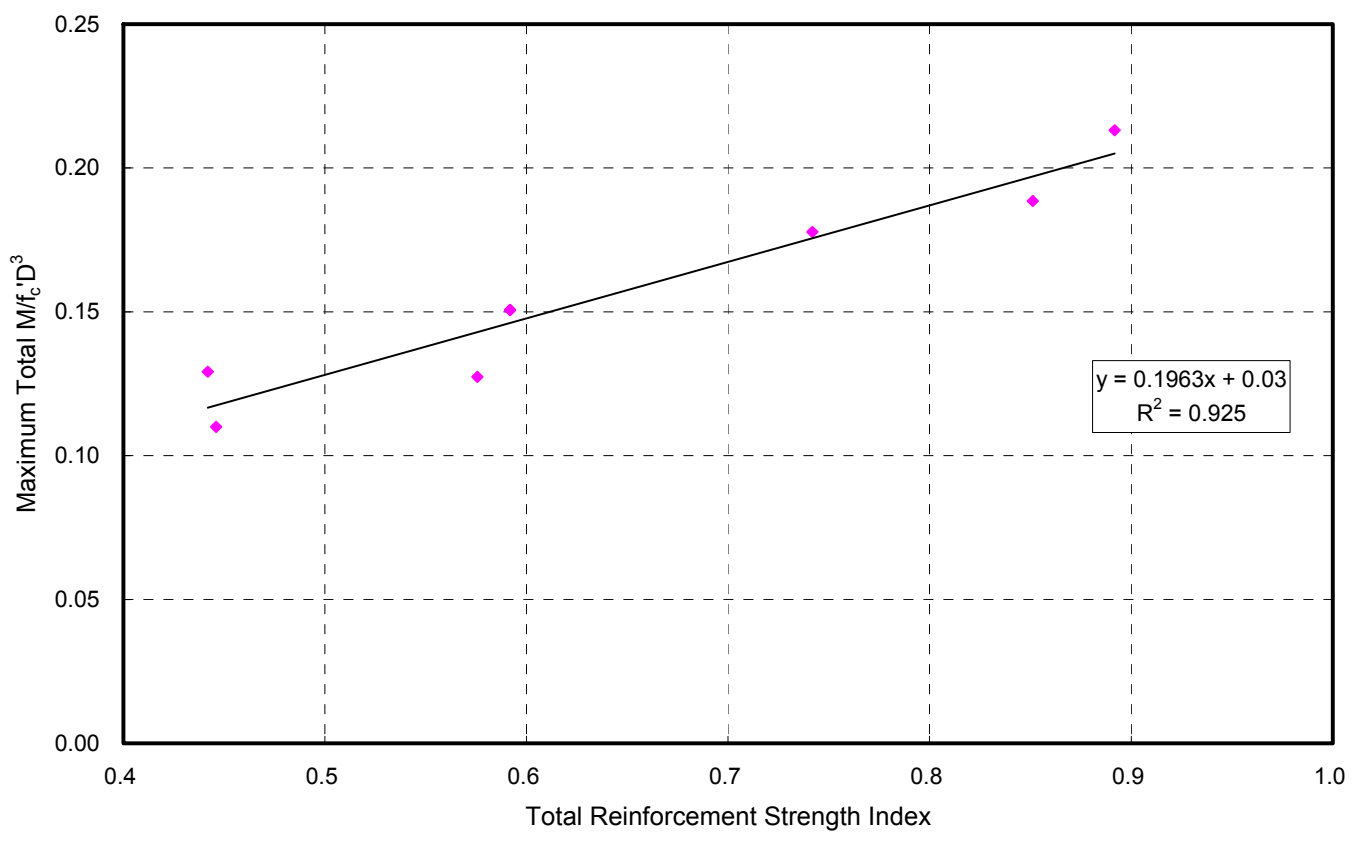

Figure 7.77 Effect of Total Reinforcement Index on Maximum Total Normalized Moment of Column G

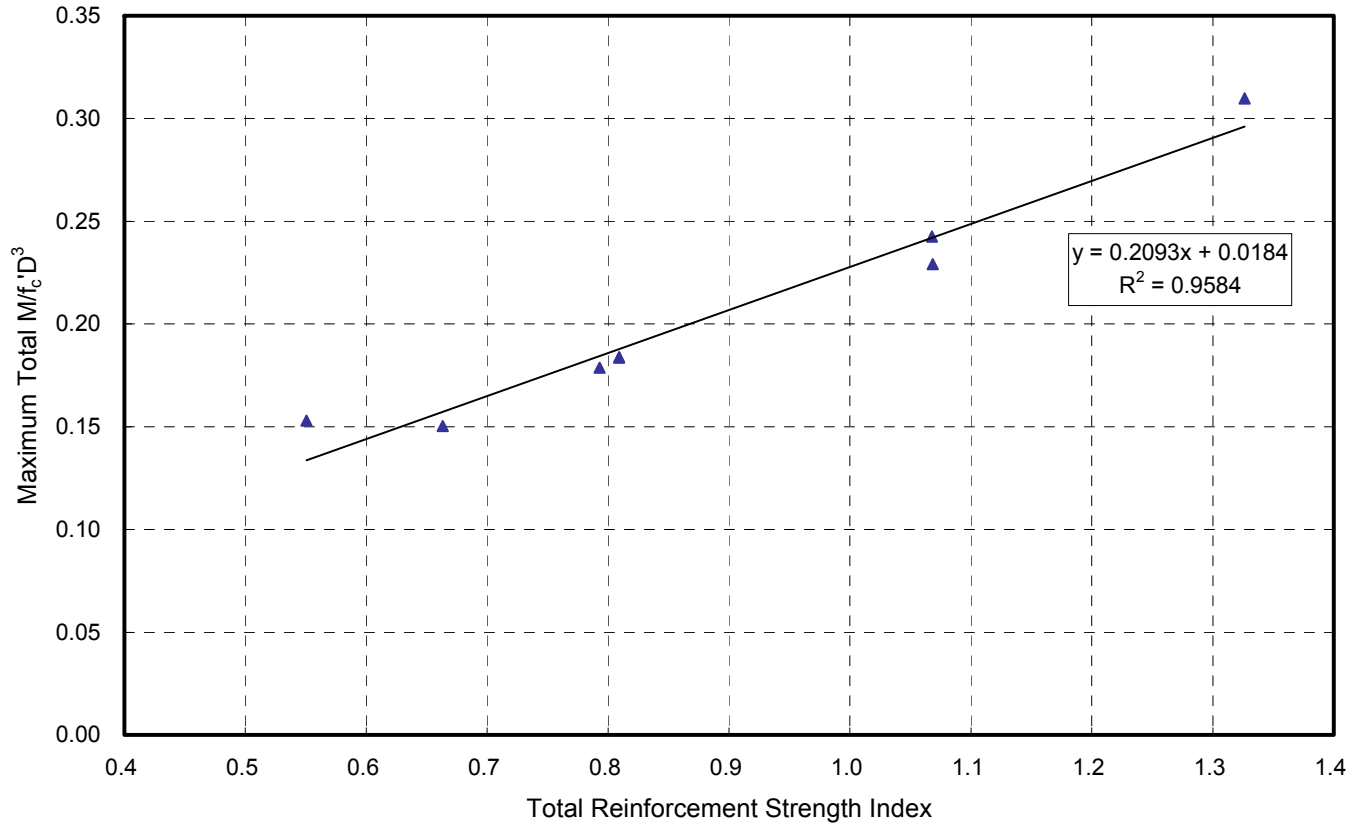

Figure 7.78 Effect of Total Reinforcement Index on Maximum Total Normalized Moment of Column $\mathrm{H}$ 


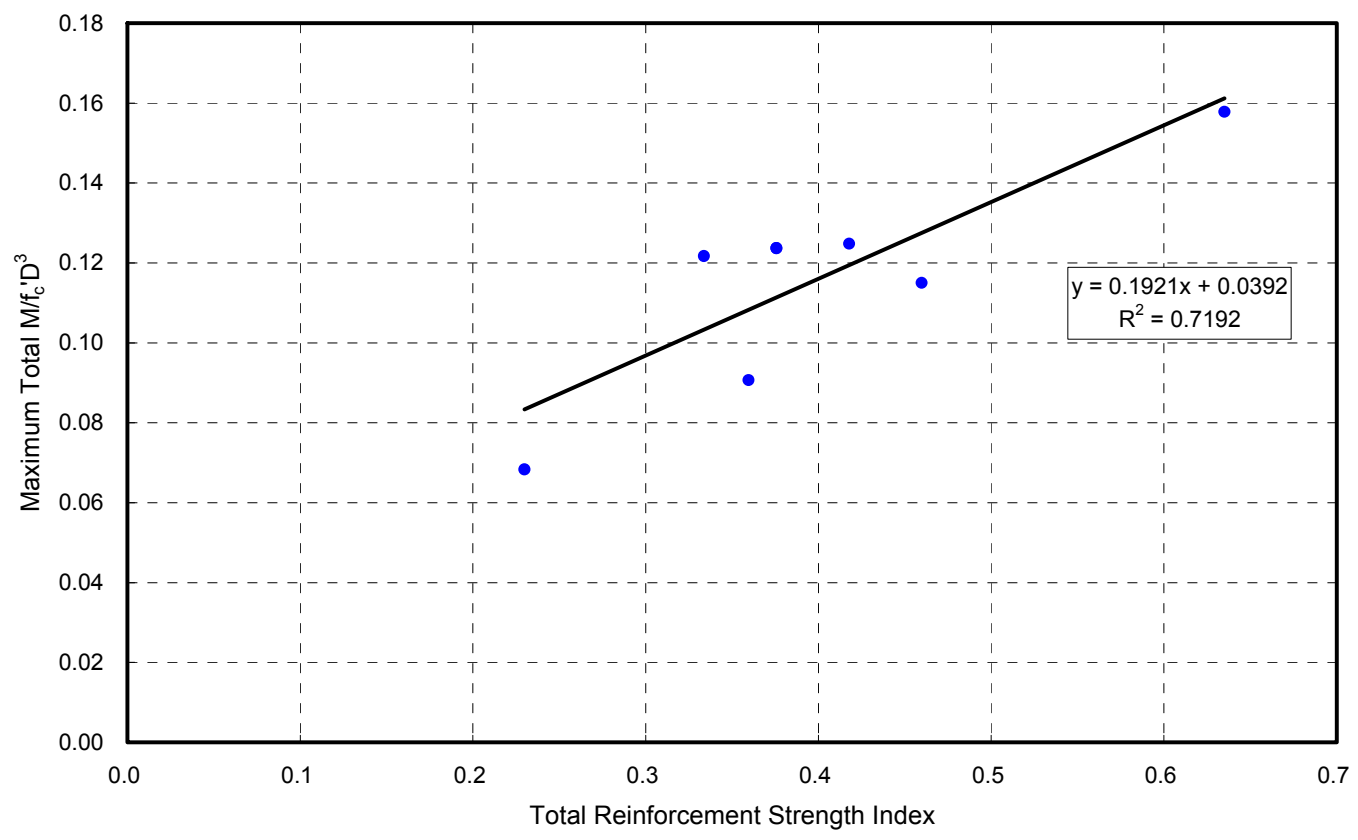

Figure 7.79 Effect of Total Reinforcement Index on Maximum Total Normalized Moment of Column C

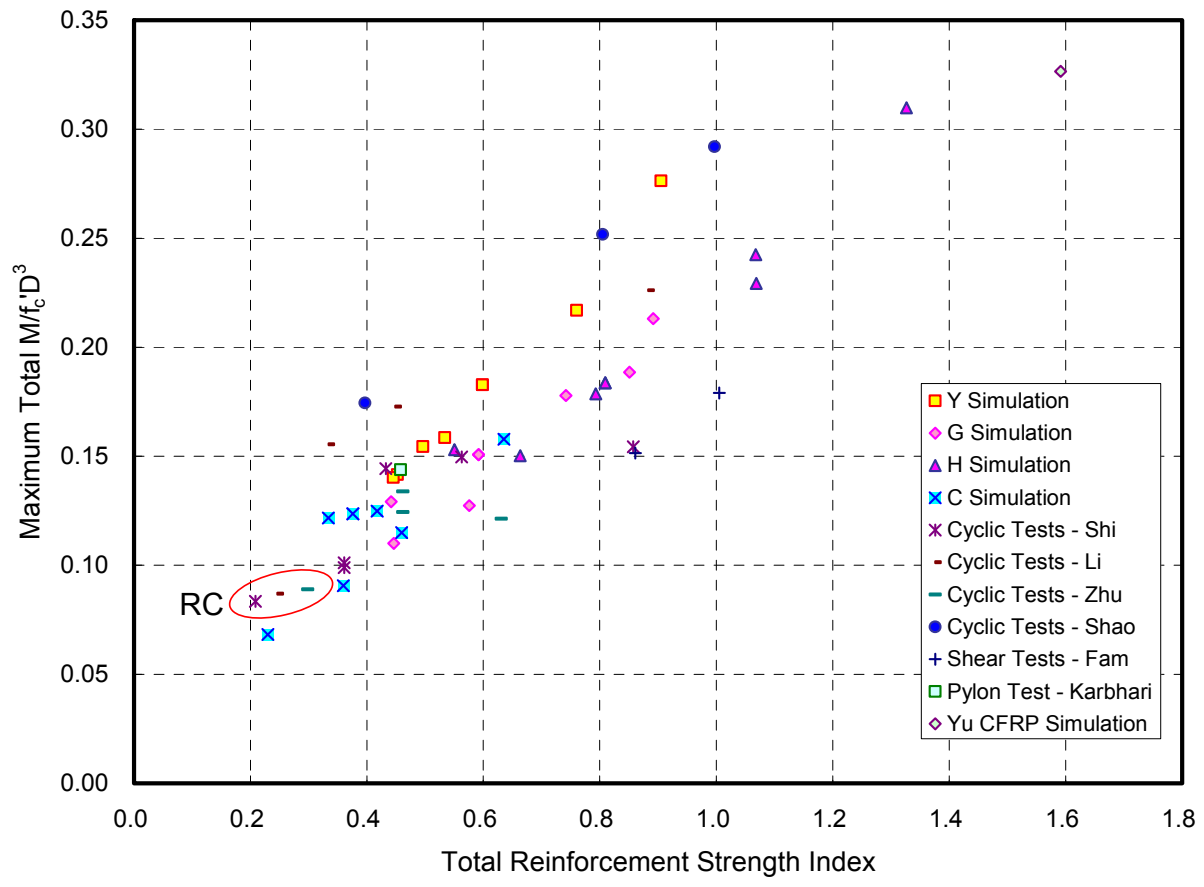

Figure 7.80 Total Reinforcement Index versus Maximum Total Normalized Moment 


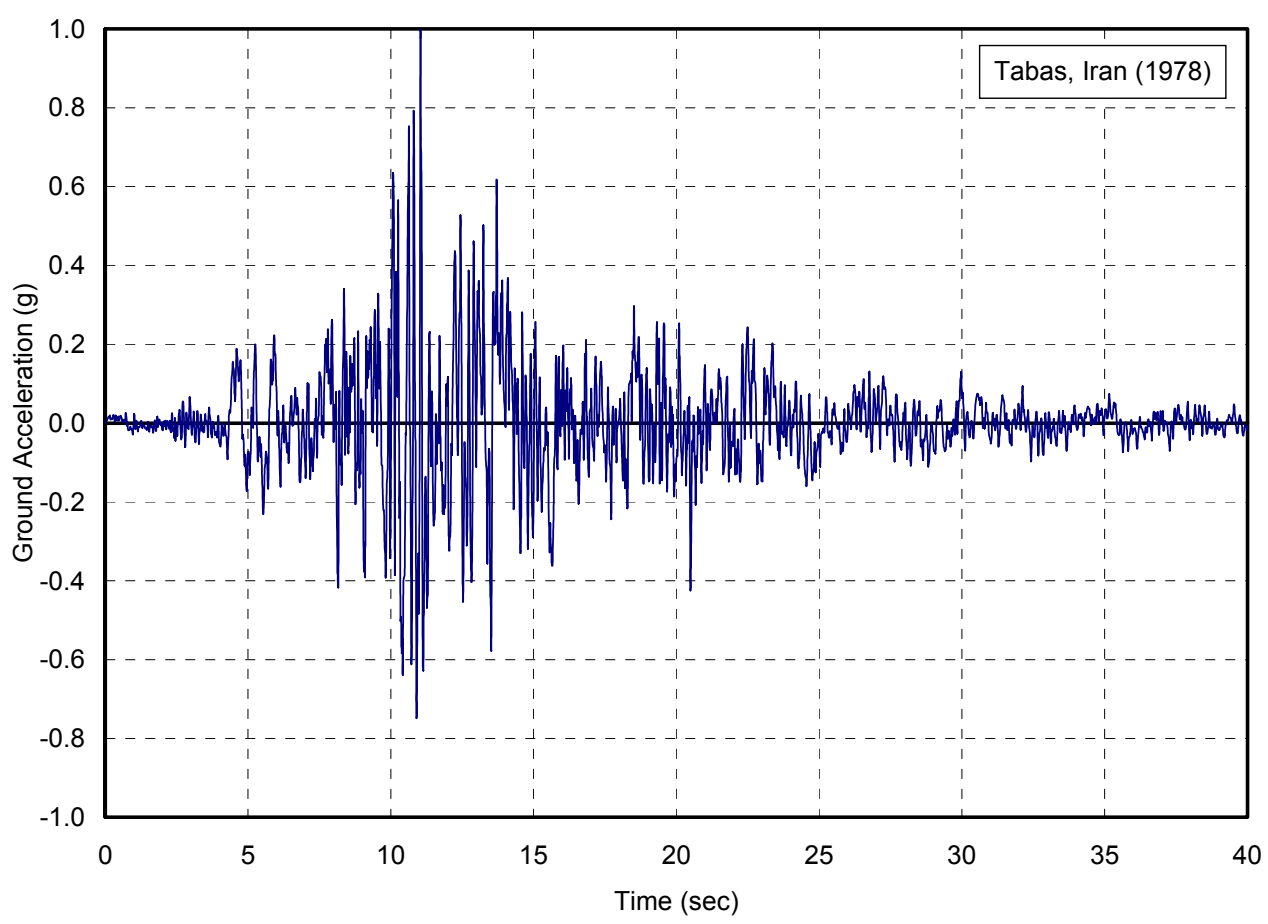

Figure 7.81 Tabas Earthquake Ground Acceleration Time History

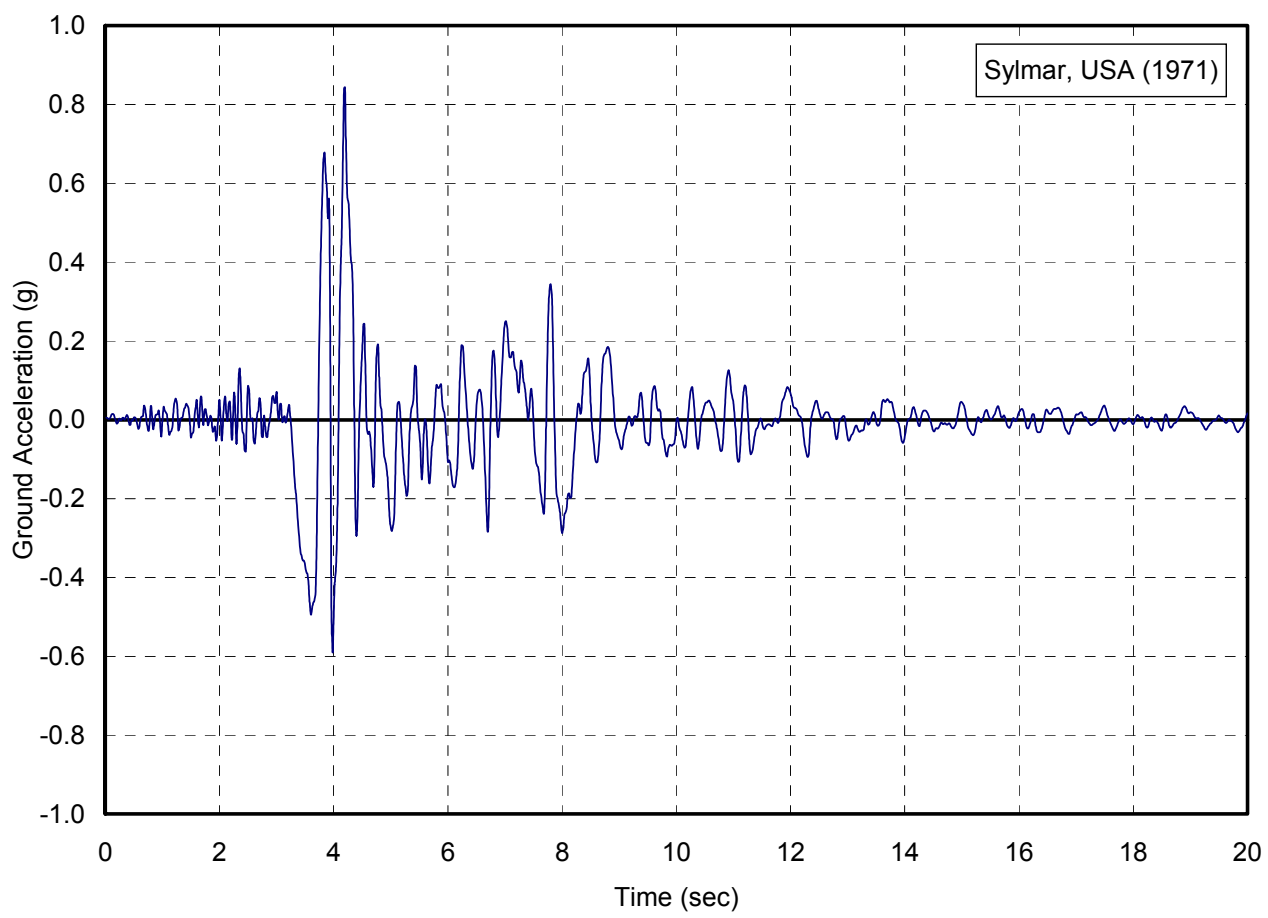

Figure 7.82 Sylmar Earthquake Ground Acceleration Time History 


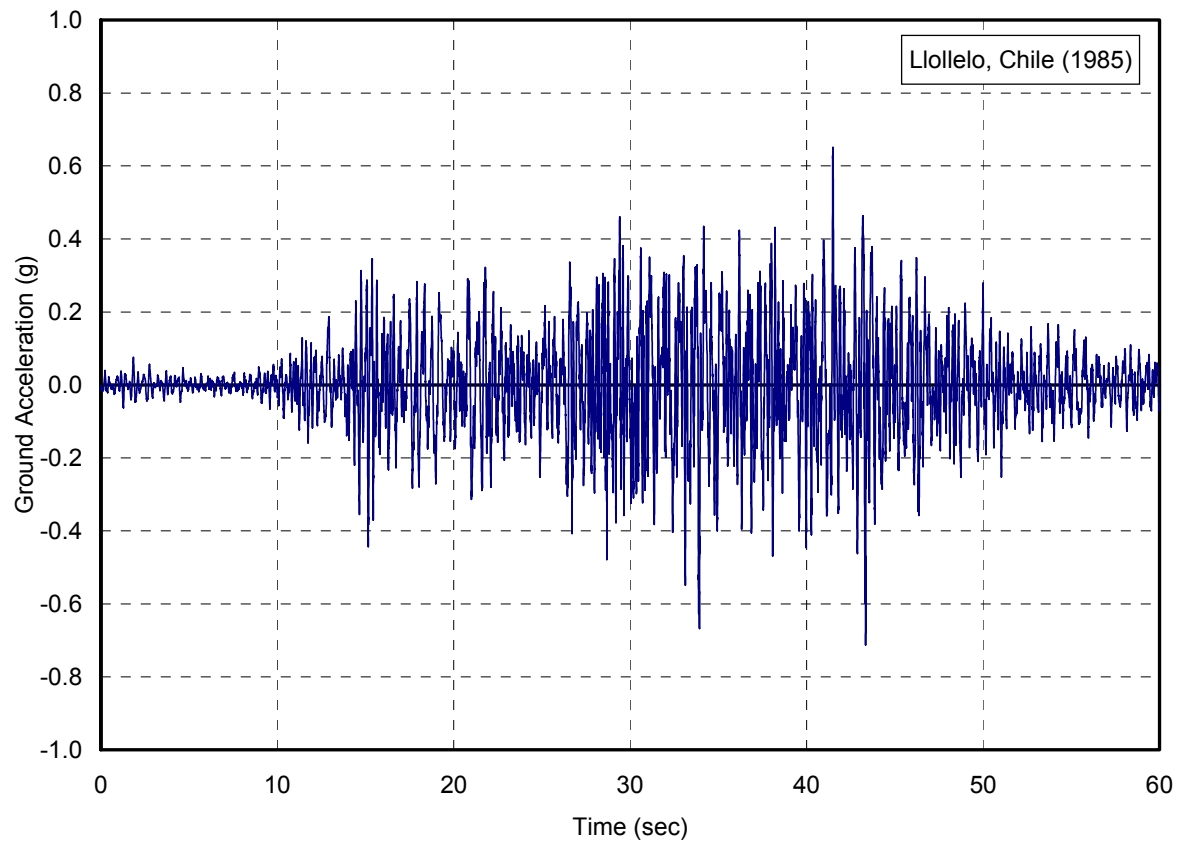

Figure 7.83 Llollelo Earthquake Ground Acceleration Time History

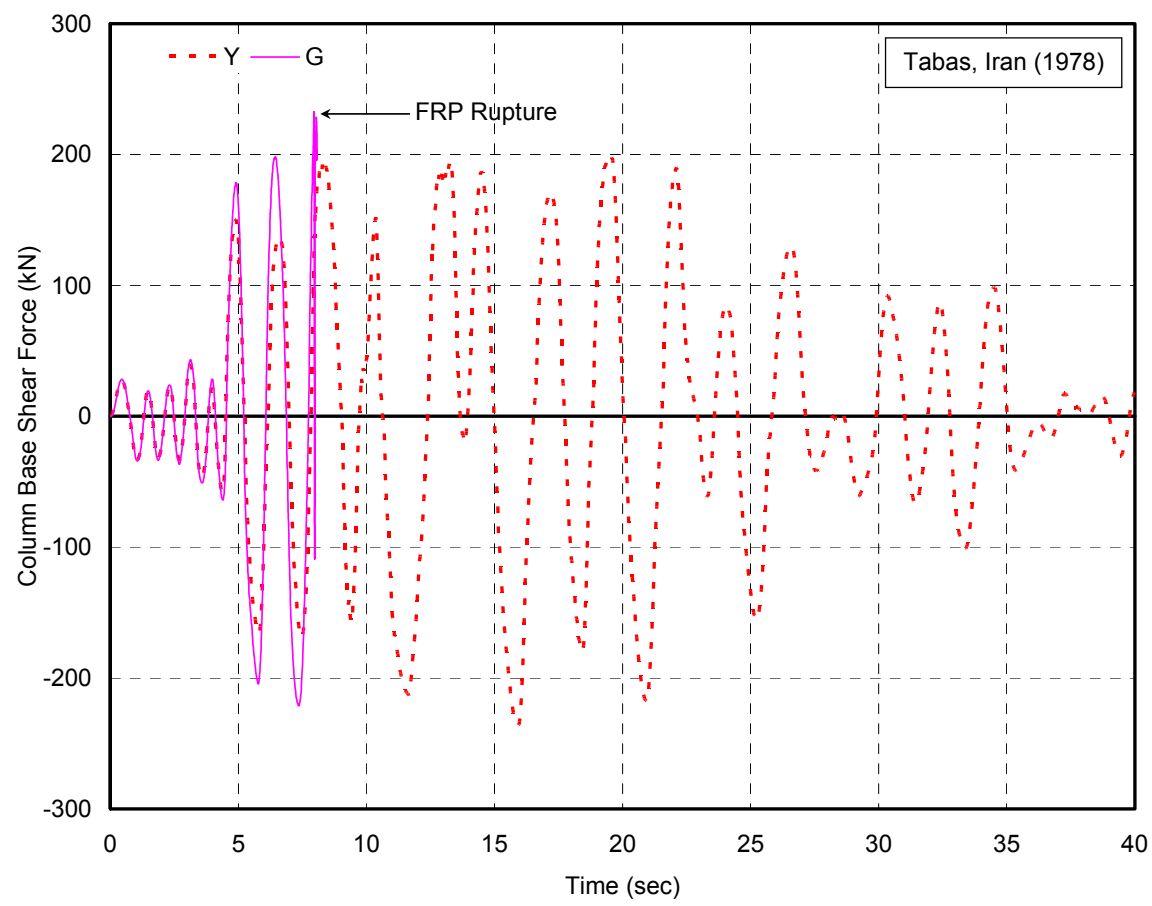

Figure 7.84 Column Base Shear Force Response Time Histories of Columns Y and G for

Tabas Earthquake 


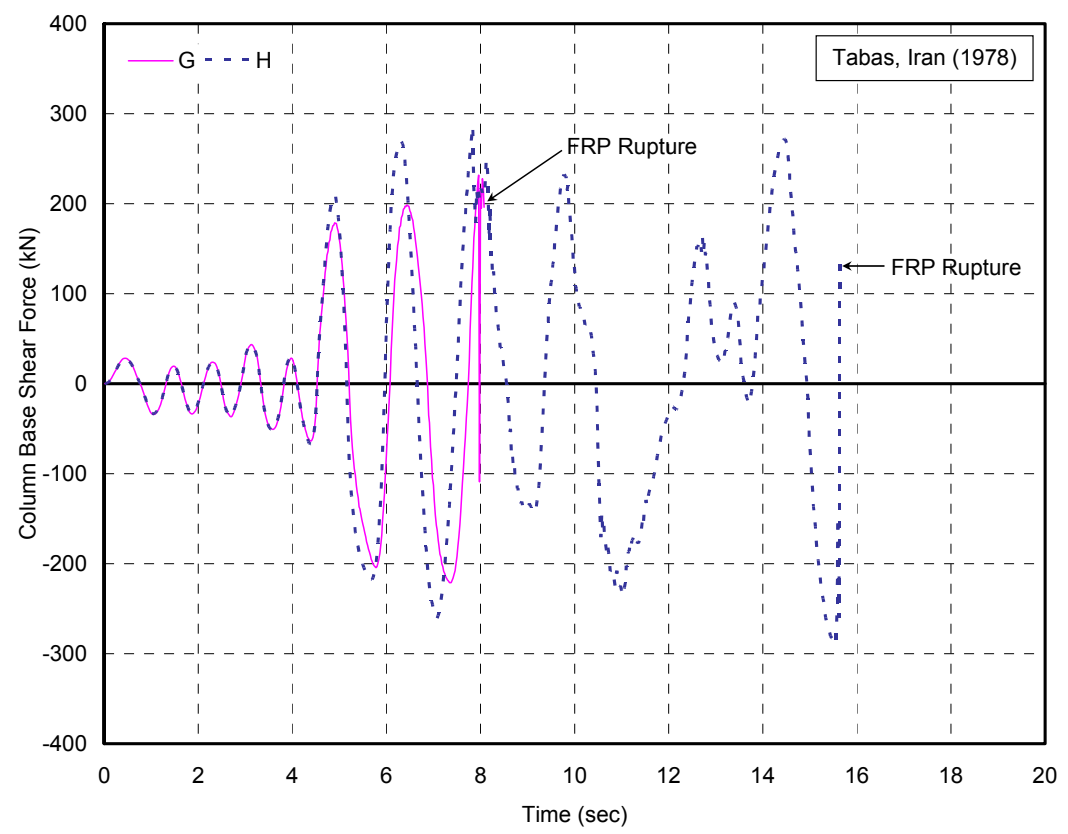

Figure 7.85 Column Base Shear Force Response Time Histories of Columns G and H for Tabas Earthquake

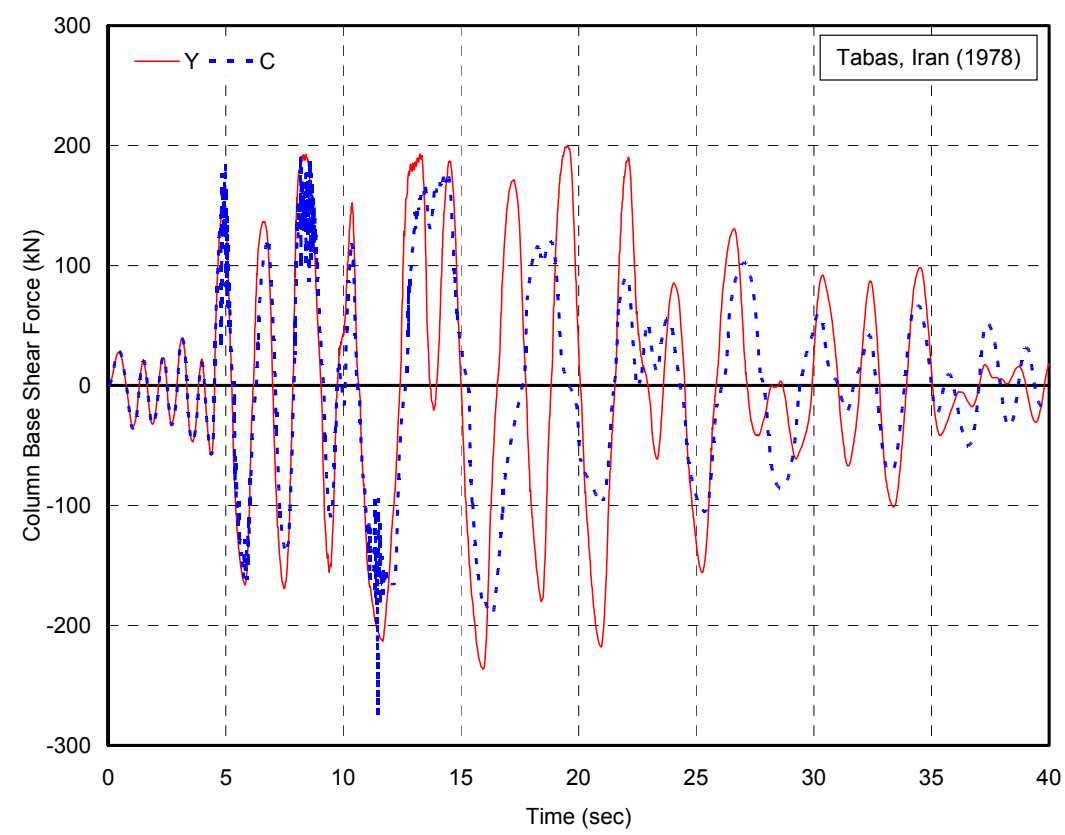

Figure 7.86 Column Base Shear Force Response Time Histories of Columns Y and C for

Tabas Earthquake 


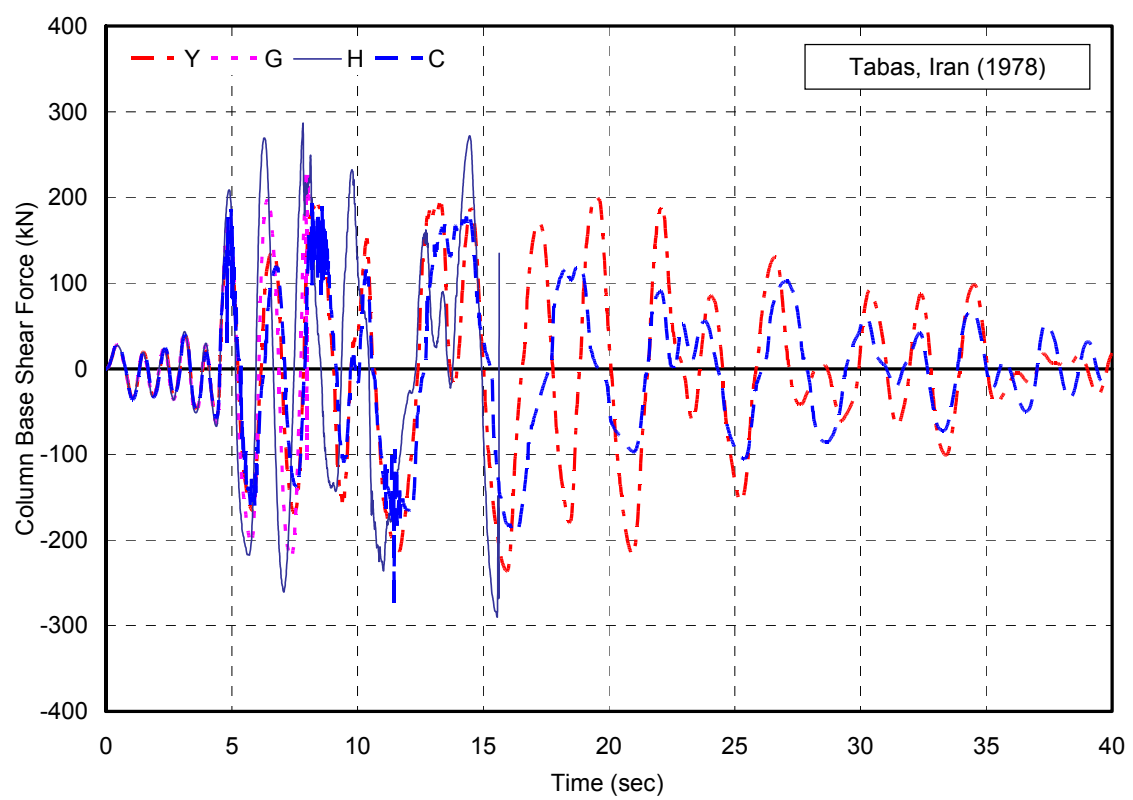

Figure 7.87 Column Base Shear Force Response Time Histories of All Columns for Tabas Earthquake

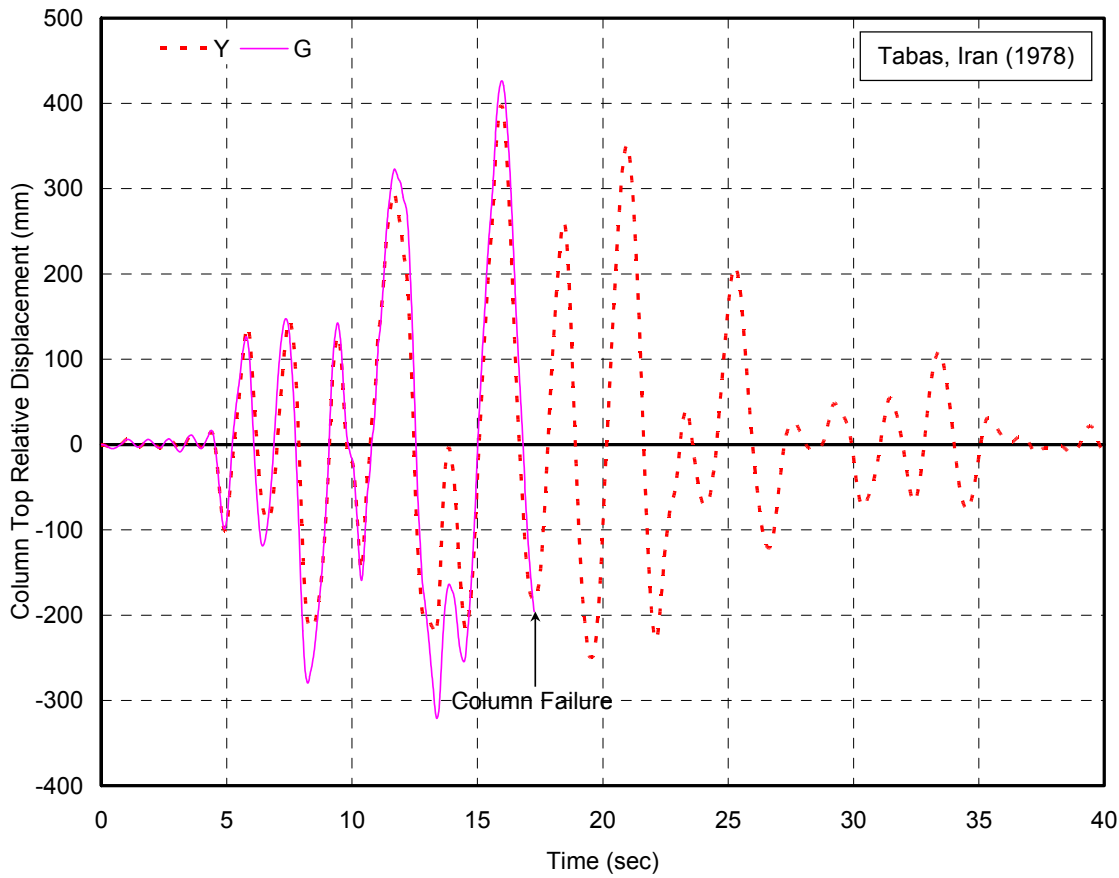

Figure 7.88 Column Displacement Response Time Histories of Columns Y and G for Tabas Earthquake 


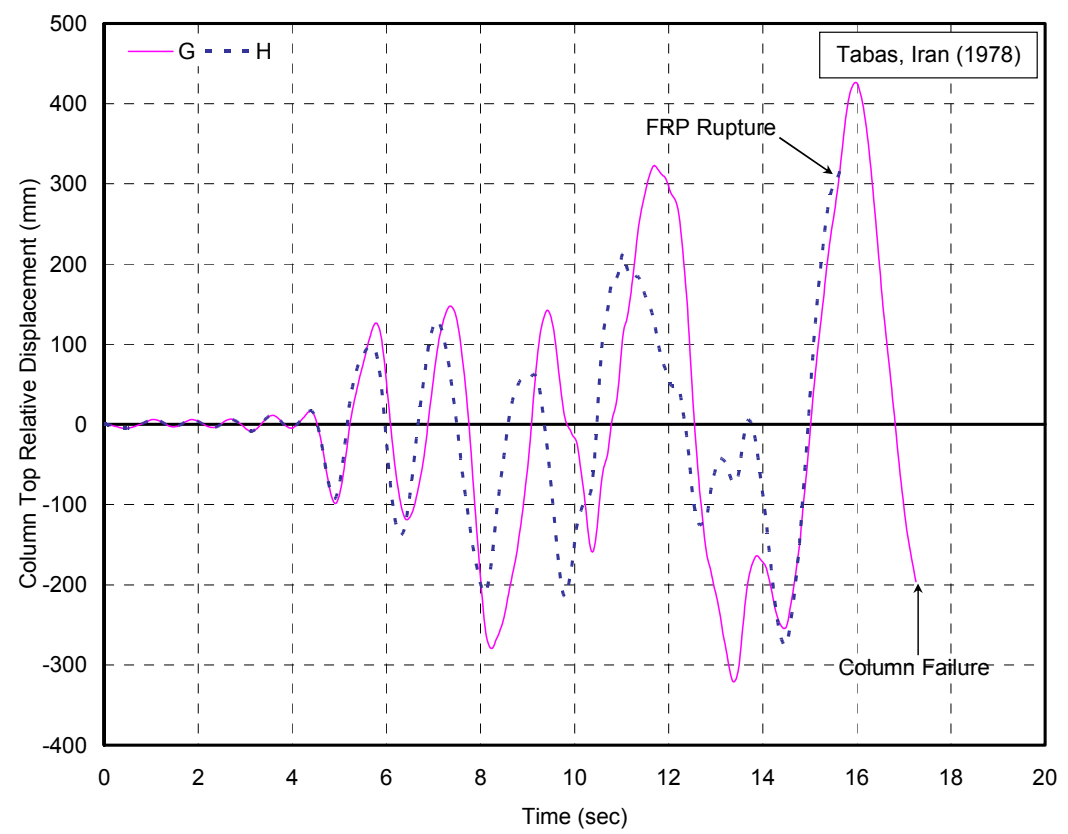

Figure 7.89 Column Displacement Response Time Histories of Columns G and H for Tabas Earthquake

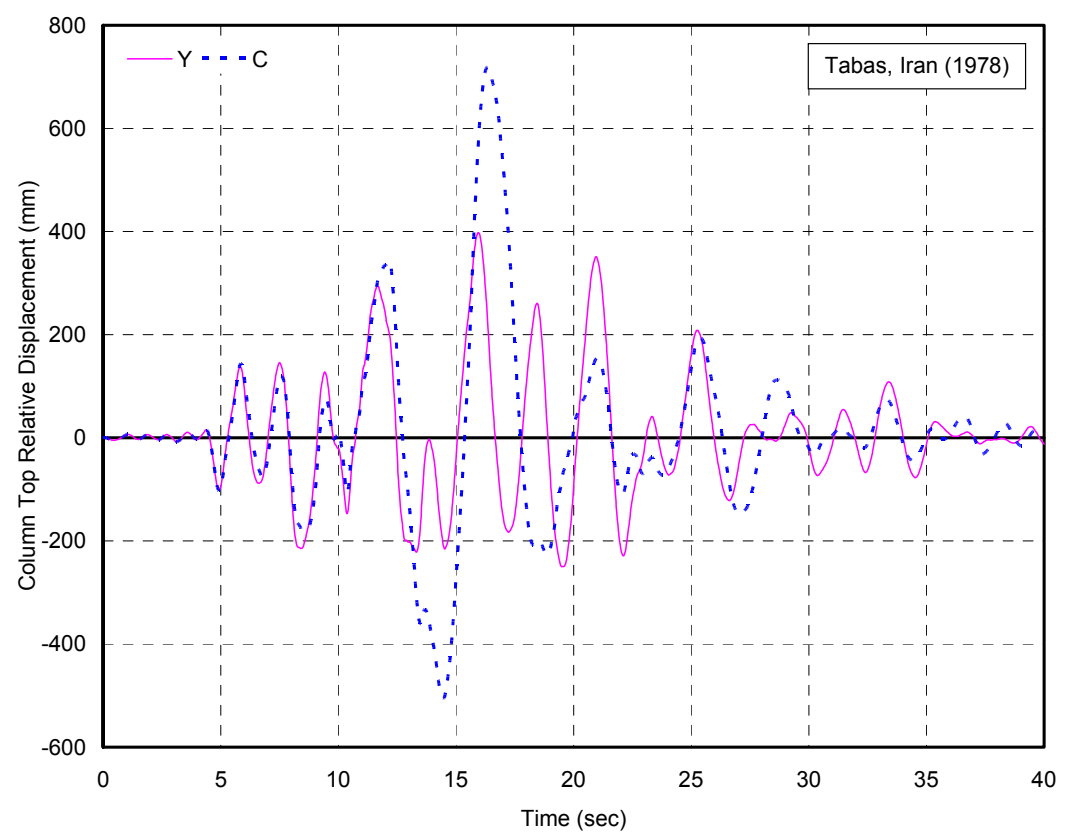

Figure 7.90 Column Displacement Response Time Histories of Columns Y and C for Tabas Earthquake 


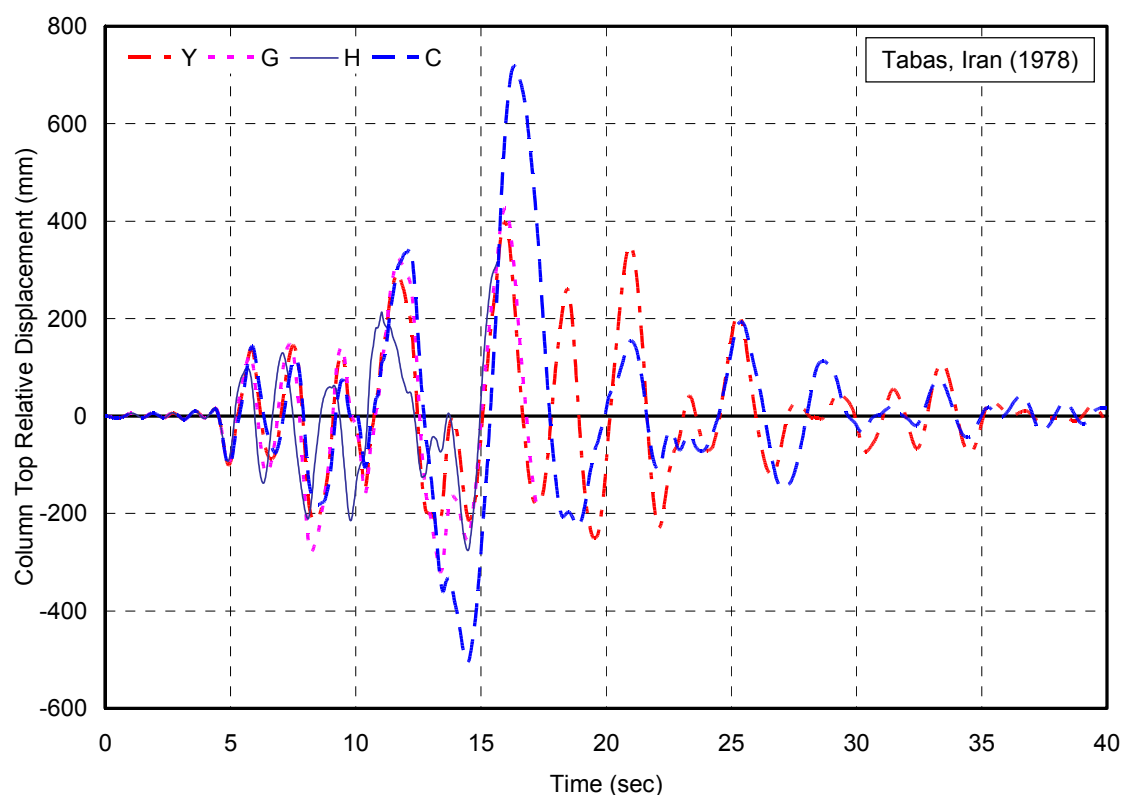

Figure 7.91 Column Displacement Response Time Histories of All Columns for Tabas Earthquake

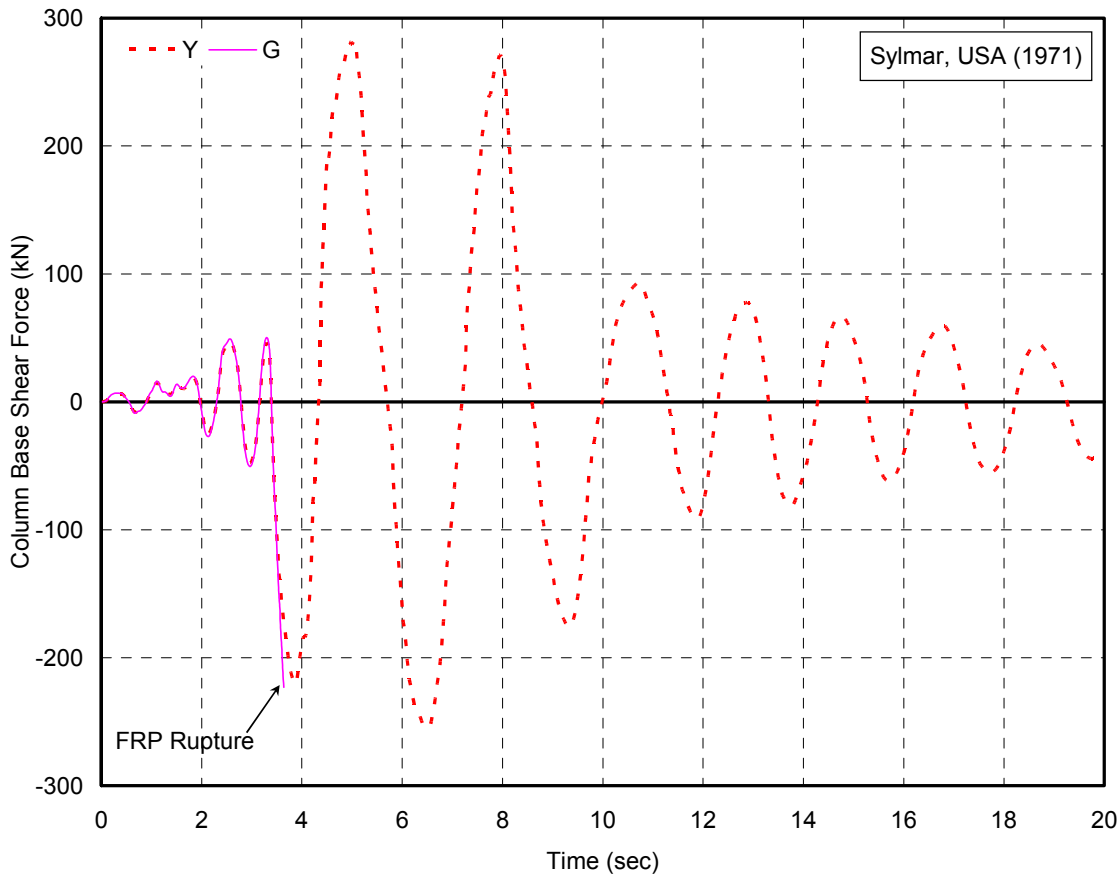

Figure 7.92 Column Base Shear Force Response Time Histories of Columns Y and G for Sylmar Earthquake 


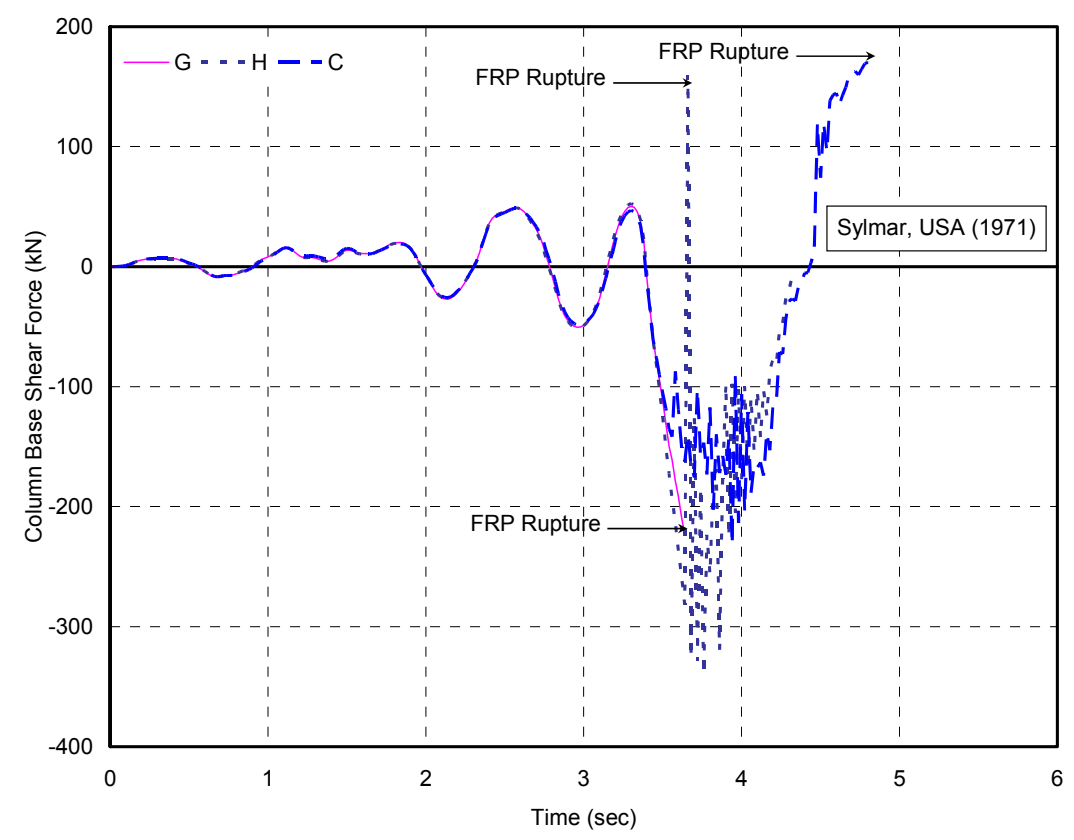

Figure 7.93 Column Base Shear Force Response Time Histories of Columns G, H, and C for Sylmar Earthquake

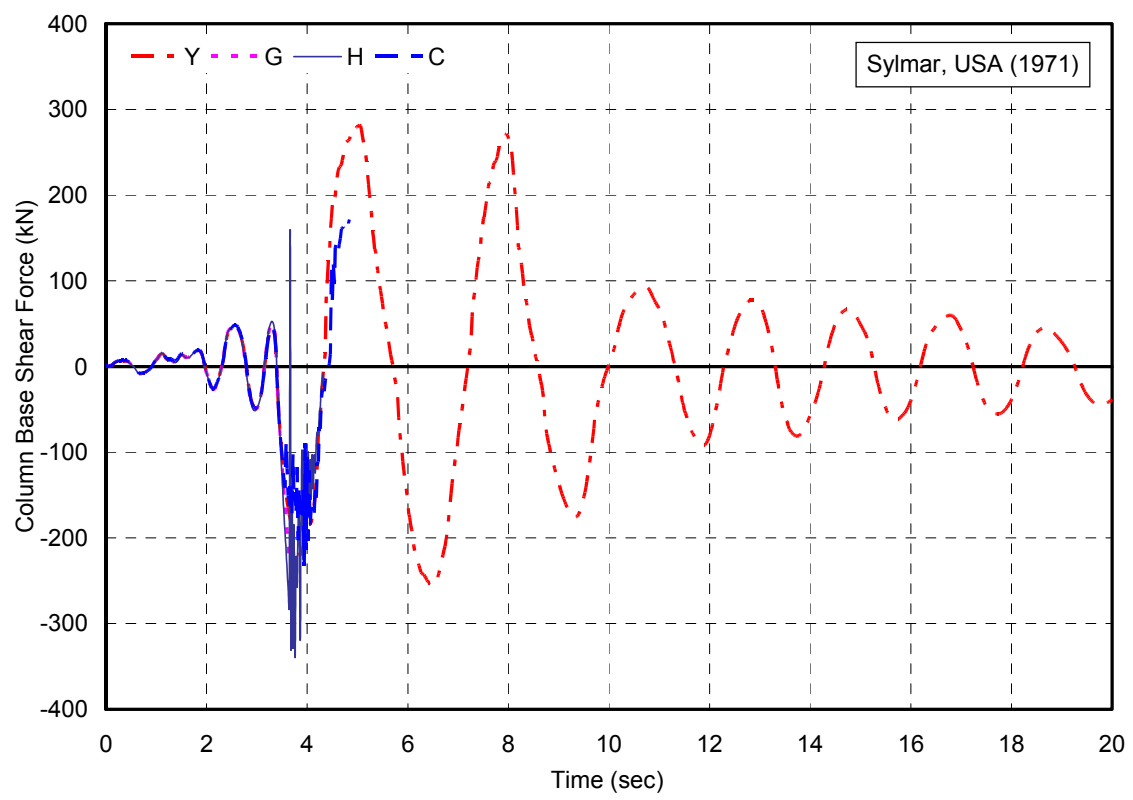

Figure 7.94 Column Base Shear Force Response Time Histories of All Columns for Sylmar Earthquake 


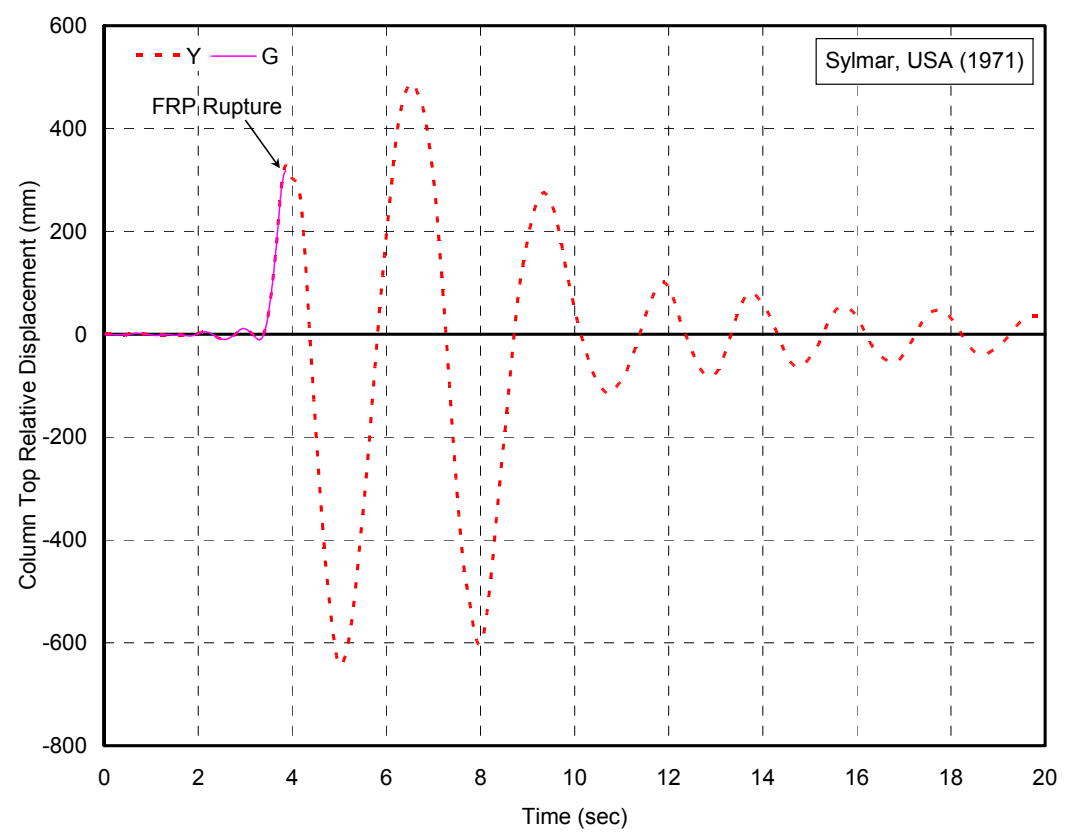

Figure 7.95 Column Displacement Response Time Histories of Columns Y and G for Sylmar Earthquake

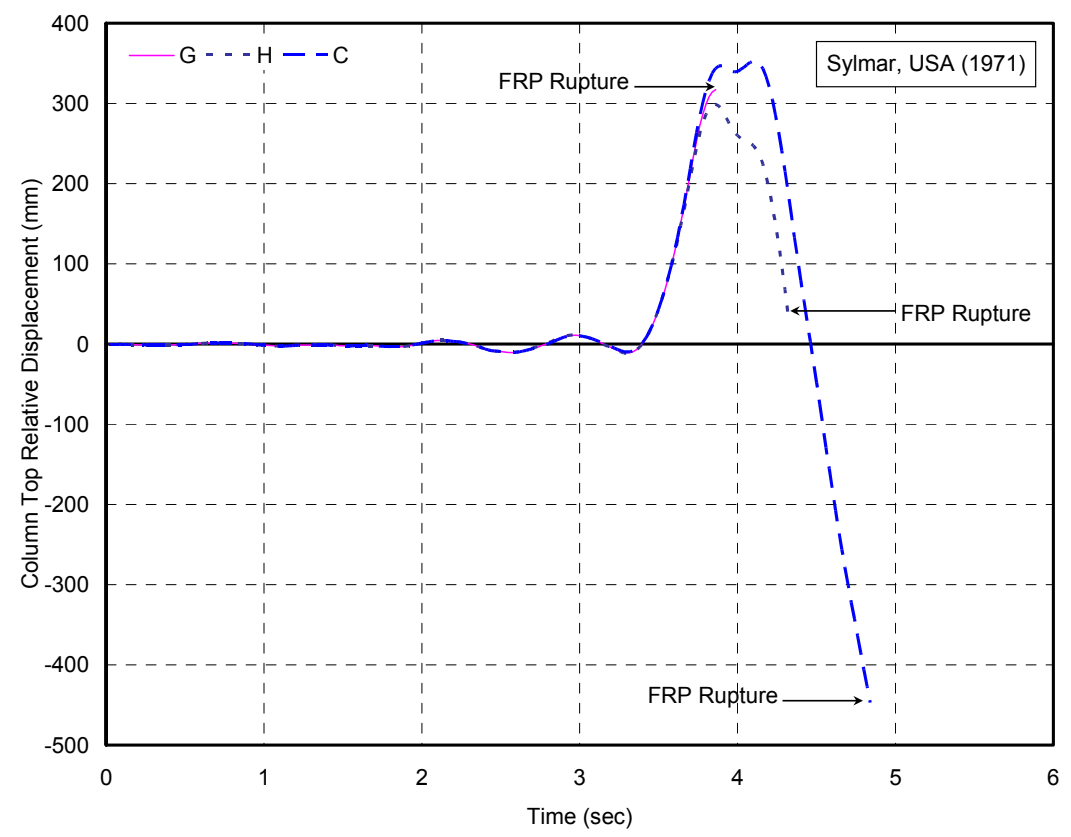

Figure 7.96 Column Displacement Response Time Histories of Columns G, H, and C for Sylmar Earthquake 


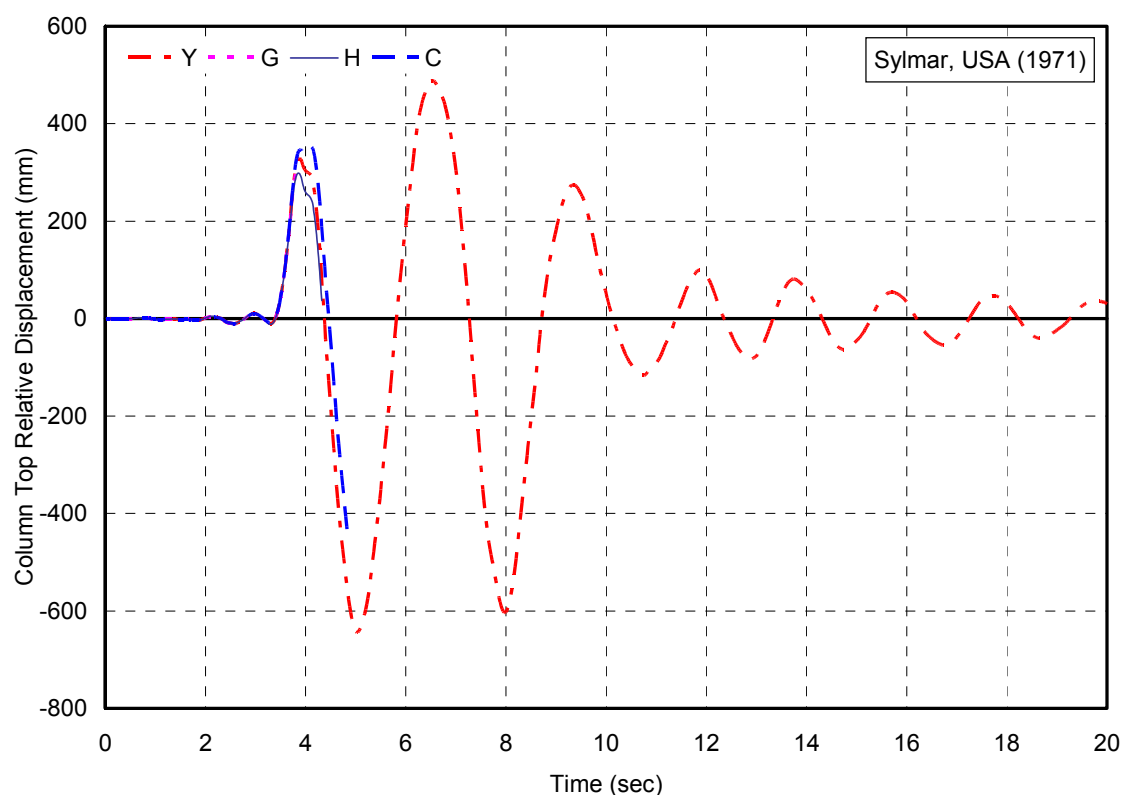

Figure 7.97 Column Displacement Response Time Histories of All Columns for Sylmar Earthquake

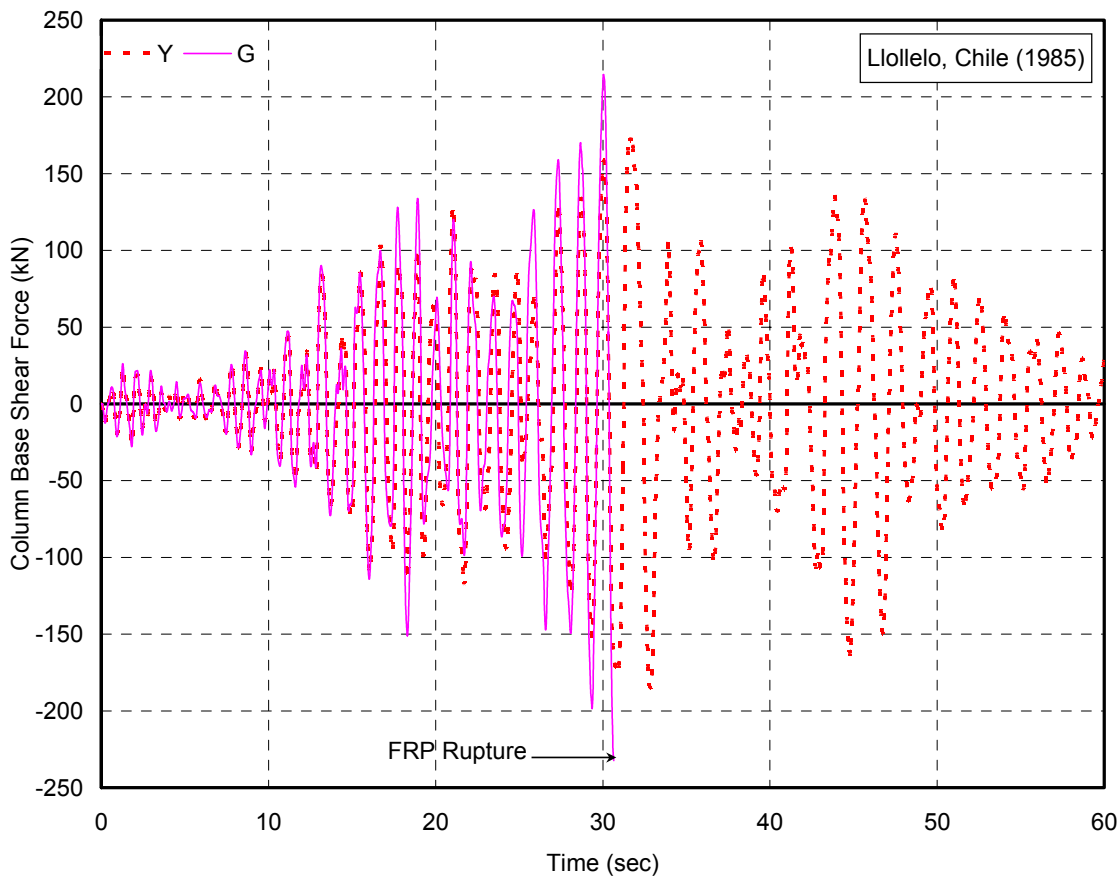

Figure 7.98 Column Base Shear Force Response Time Histories of Columns Y and G for Llollelo Earthquake 


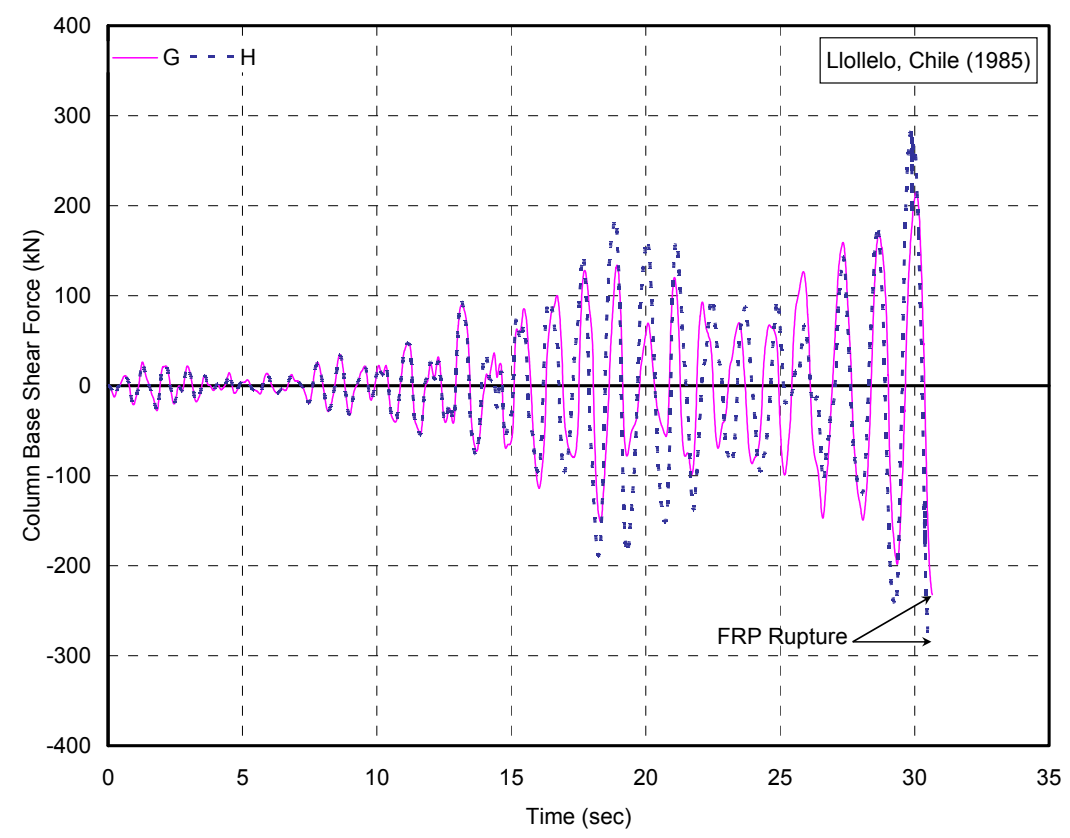

Figure 7.99 Column Base Shear Force Response Time Histories of Columns G and H for Llollelo Earthquake

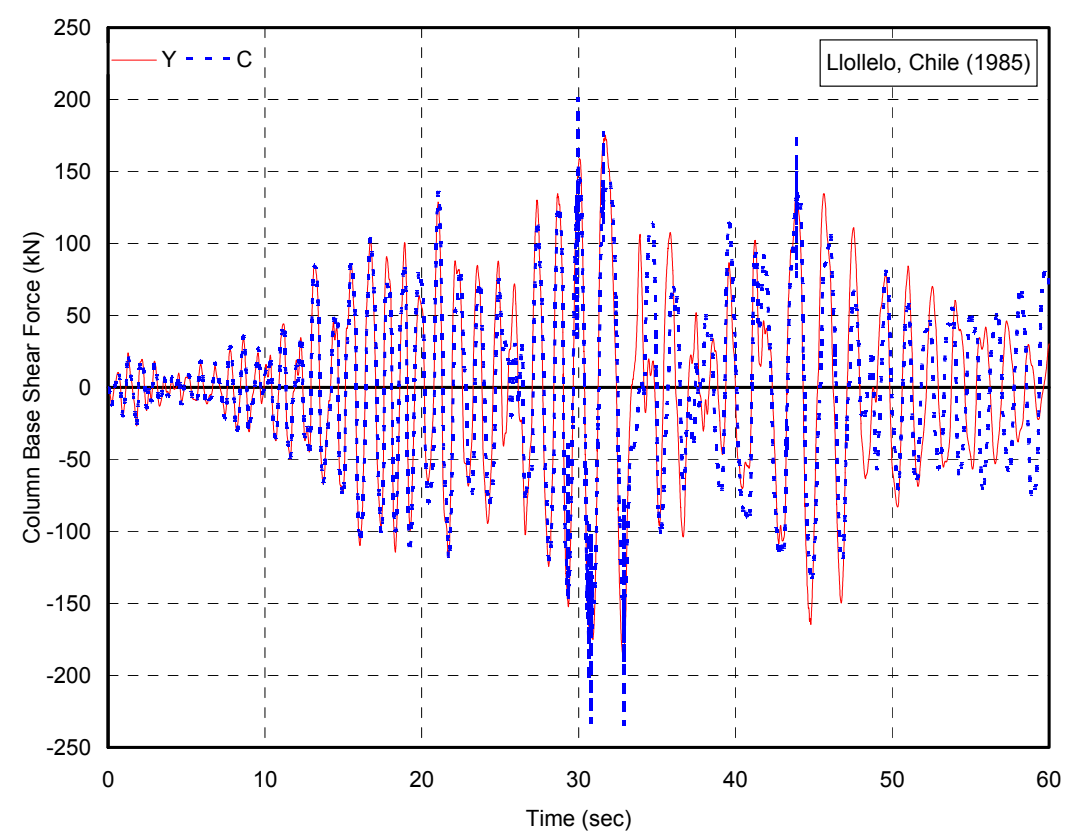

Figure 7.100 Column Base Shear Force Response Time Histories of Columns Y and C for Llollelo Earthquake 


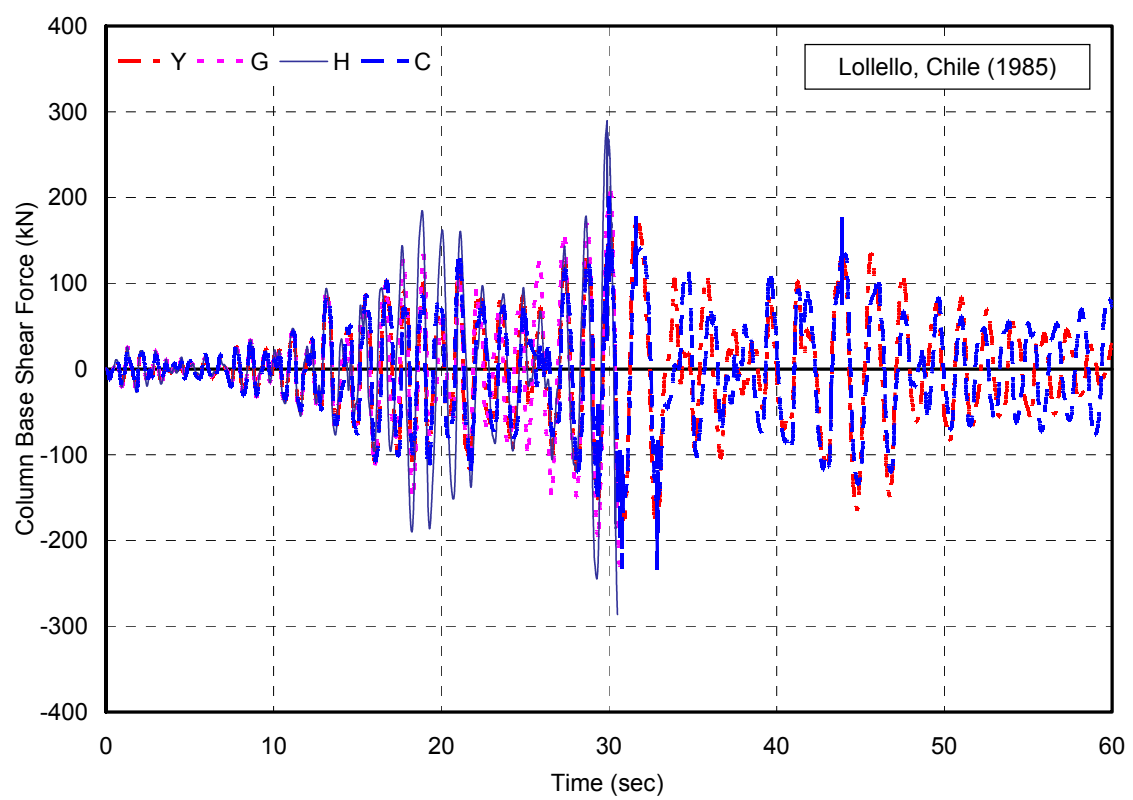

Figure 7.101 Column Base Shear Force Response Time Histories of All Columns for Llollelo Earthquake

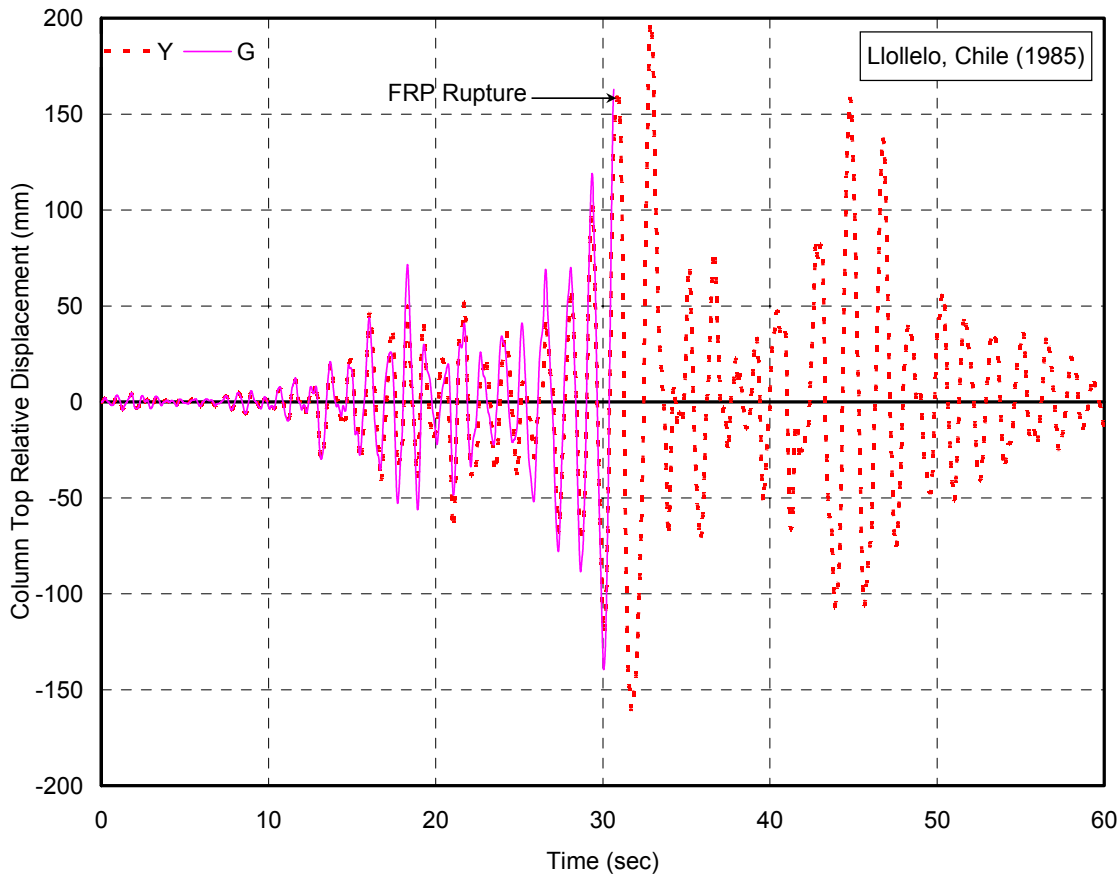

Figure 7.102 Column Displacement Response Time Histories of Columns Y and G for Llollelo Earthquake 


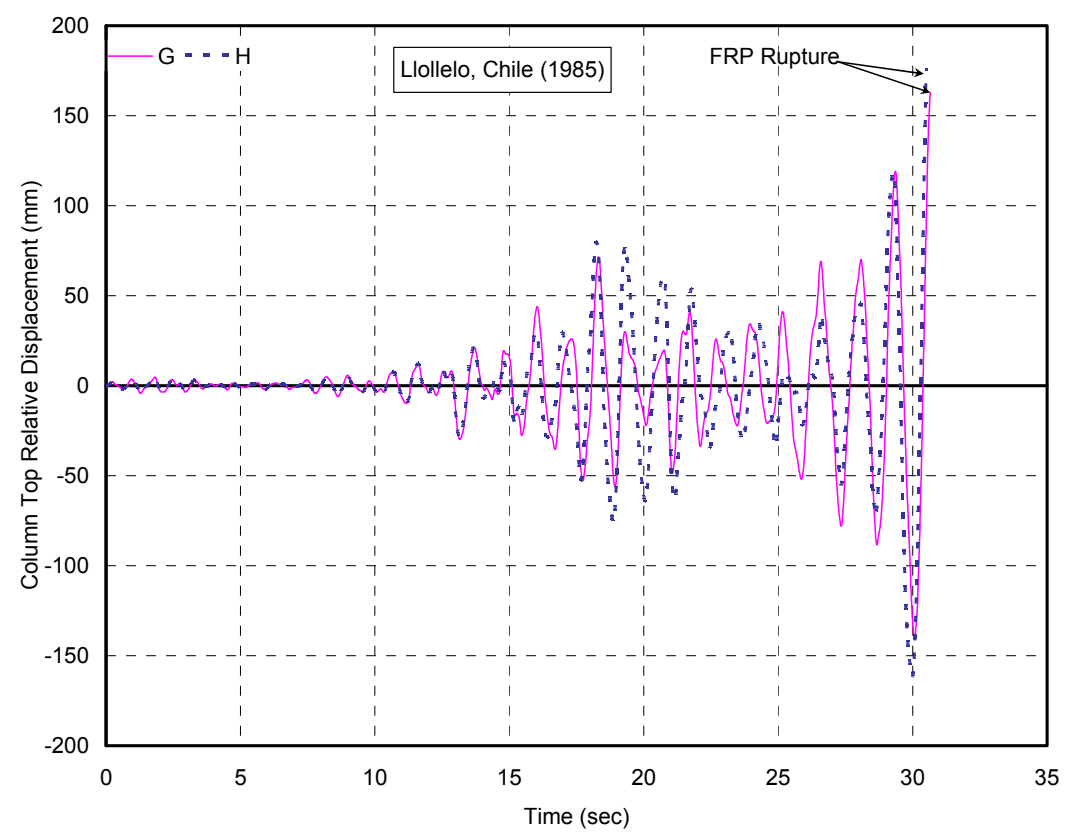

Figure 7.103 Column Displacement Response Time Histories of Columns G and H for Llollelo Earthquake

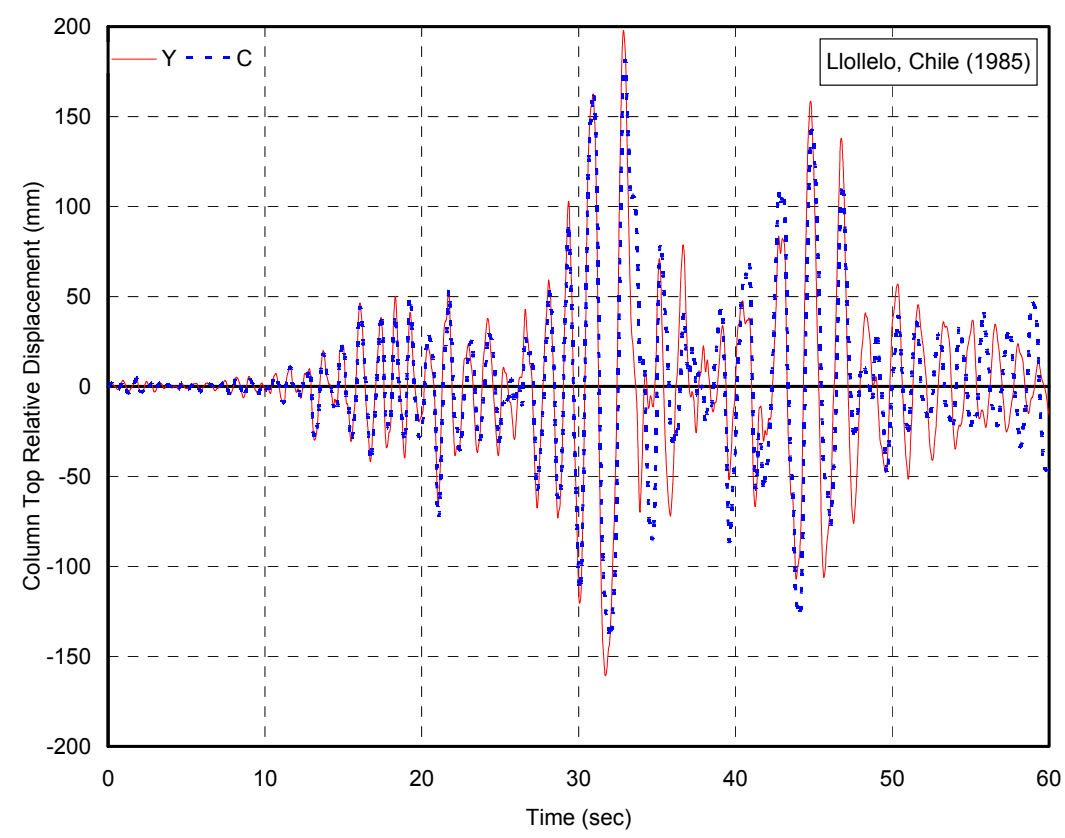

Figure 7.104 Column Displacement Response Time Histories of Columns Y and C for Llollelo Earthquake 


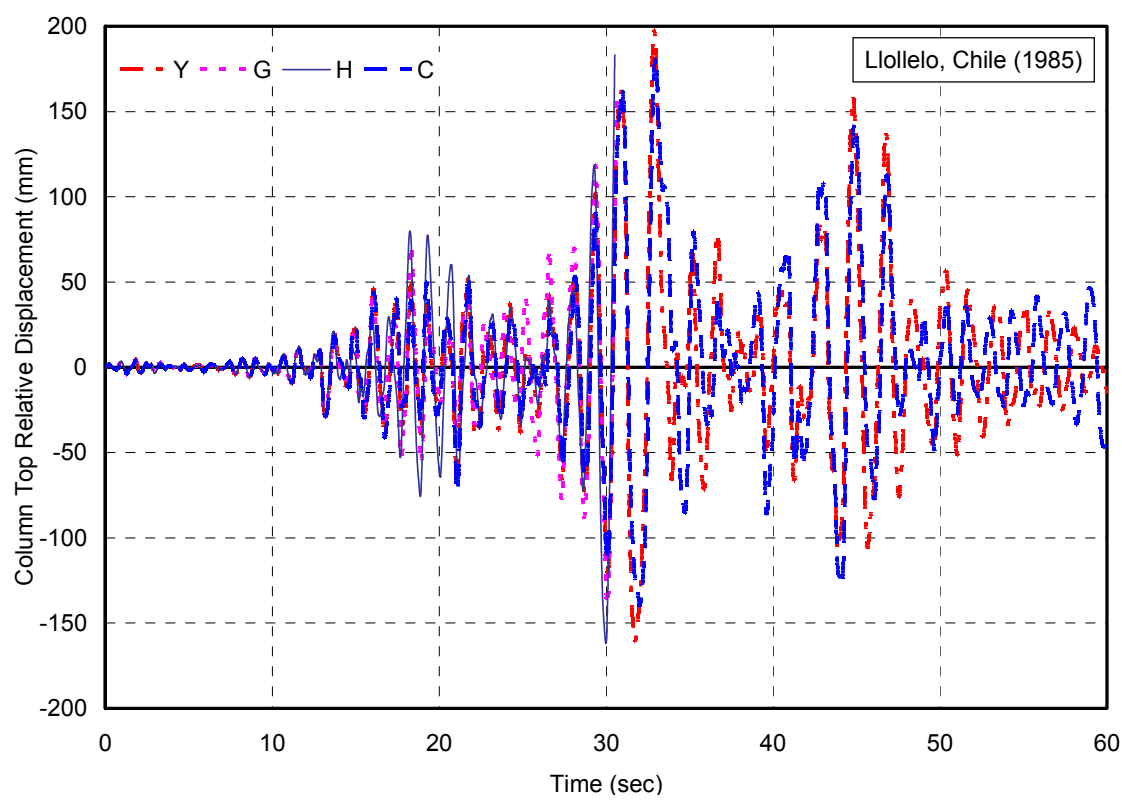

Figure 7.105 Column Displacement Response Time Histories of All Columns for Llollelo Earthquake

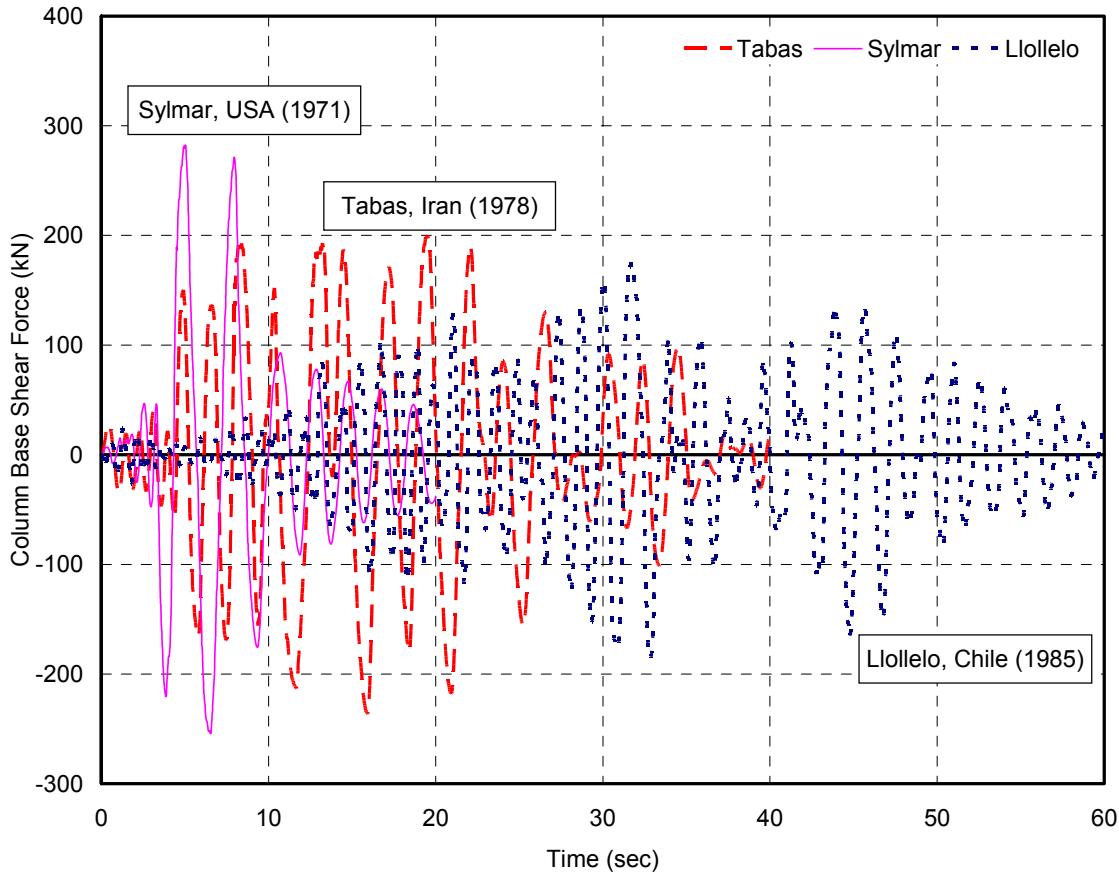

Figure 7.106 Column Base Shear Force Response Time Histories of Column Y for All Earthquakes 


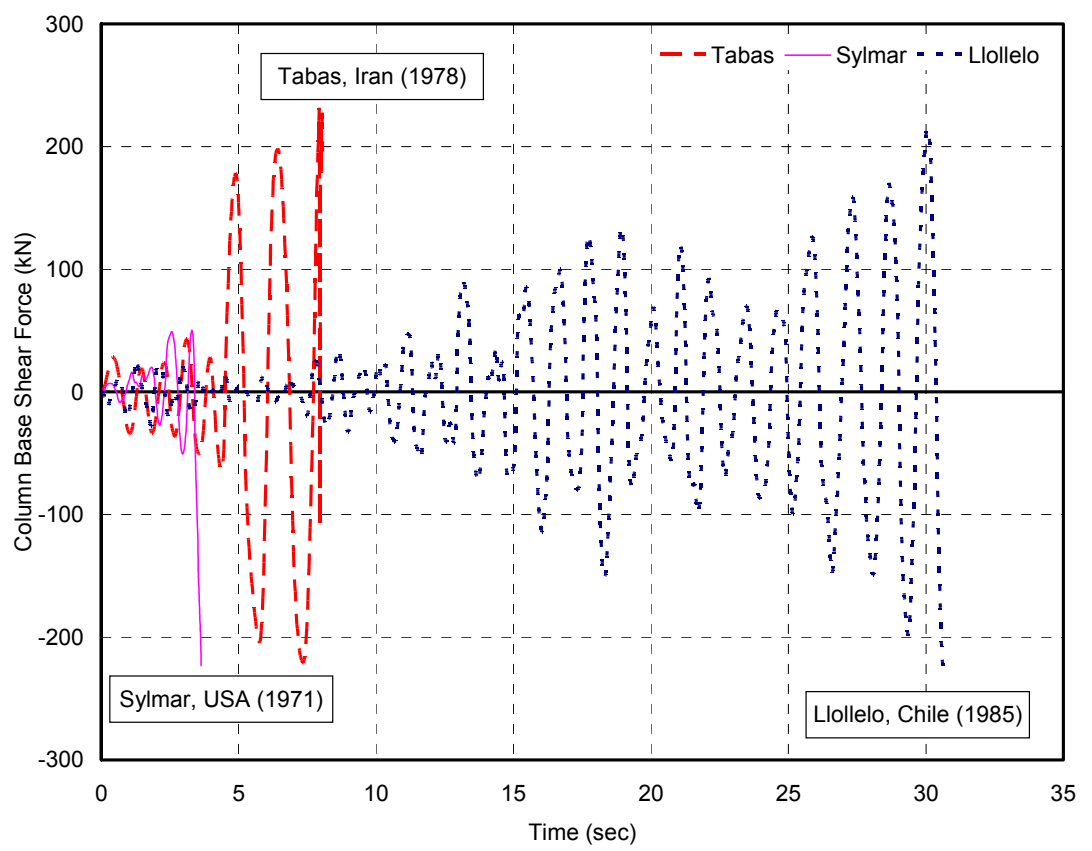

Figure 7.107 Column Base Shear Force Response Time Histories of Column G for All Earthquakes

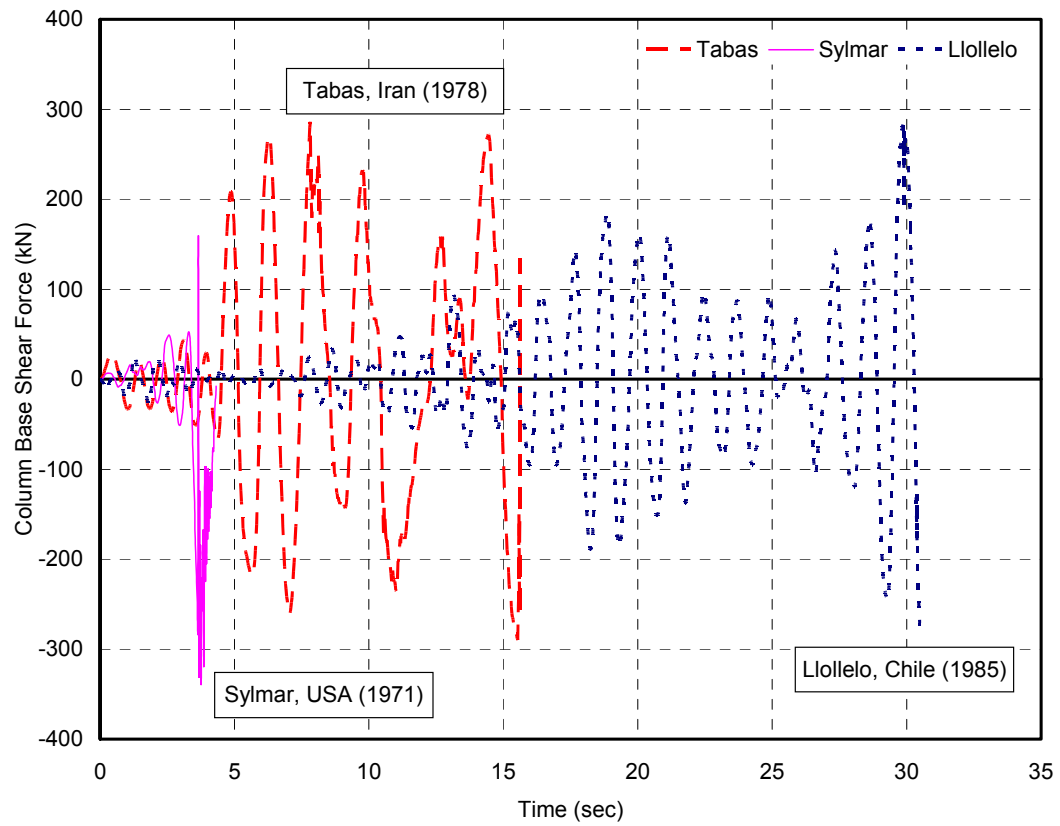

Figure 7.108 Column Base Shear Force Response Time Histories of Column H for All Earthquakes 


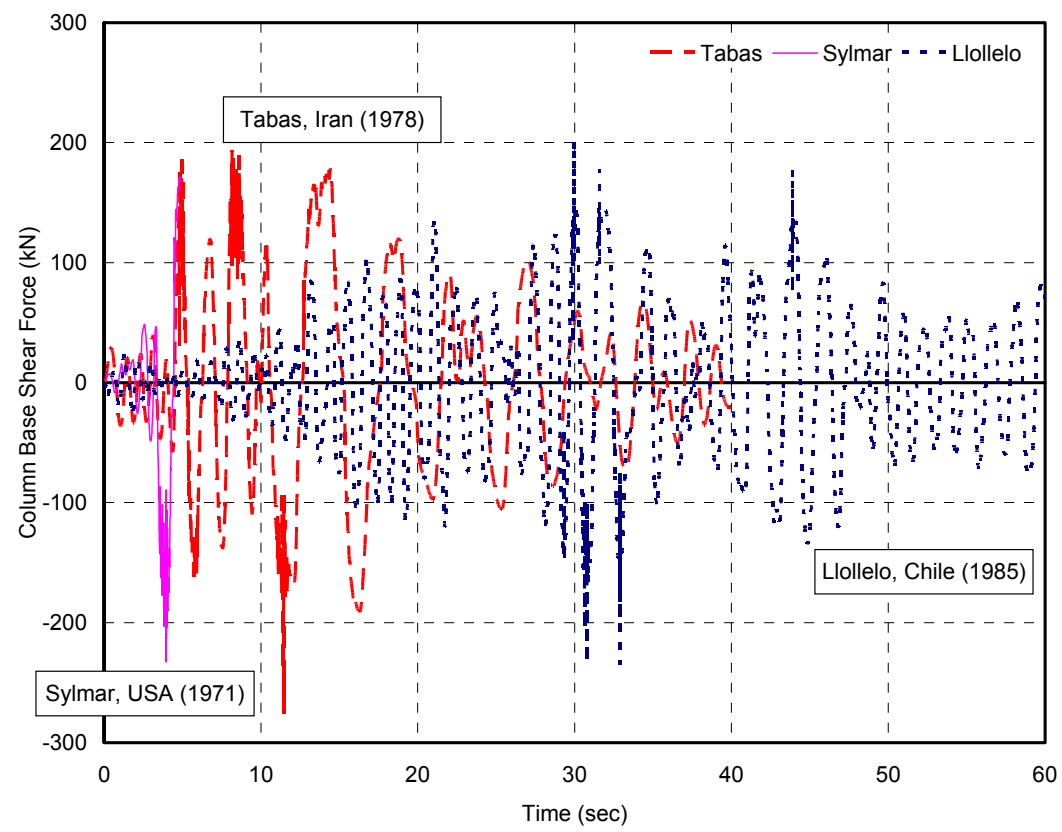

Figure 7.109 Column Base Shear Force Response Time Histories of Column C for All Earthquakes

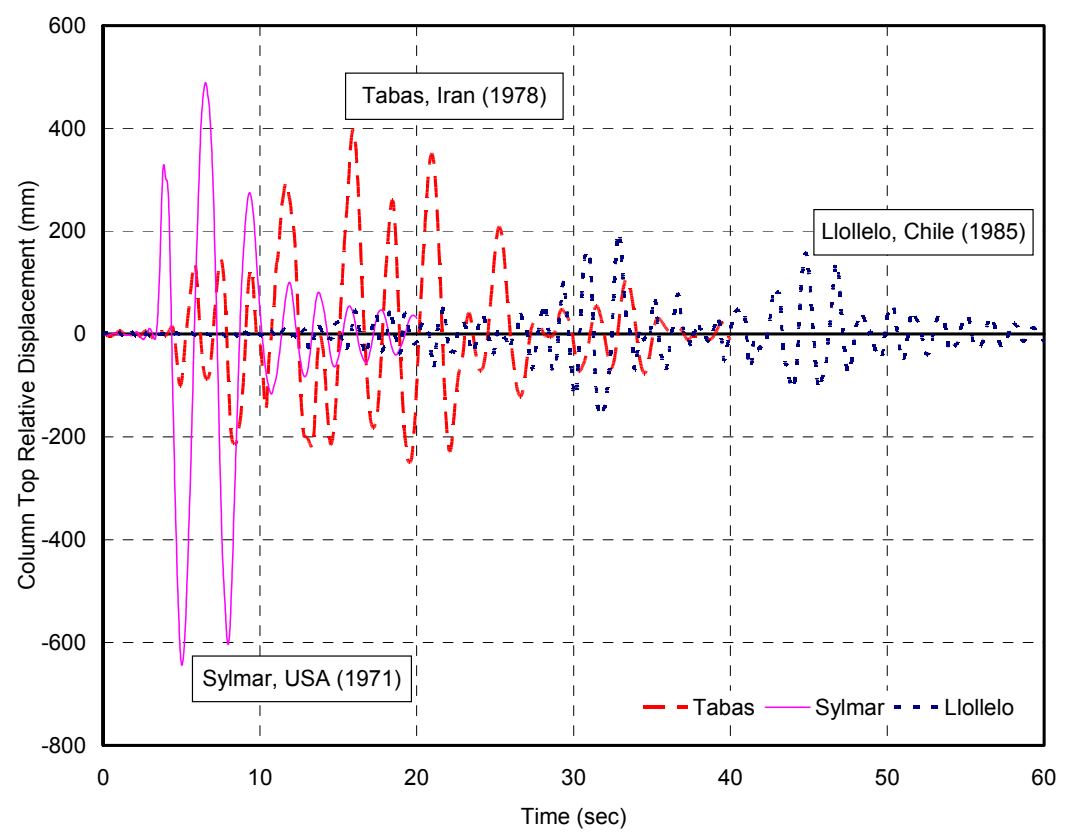

Figure 7.110 Column Displacement Response Time Histories of Column Y for All Earthquakes 


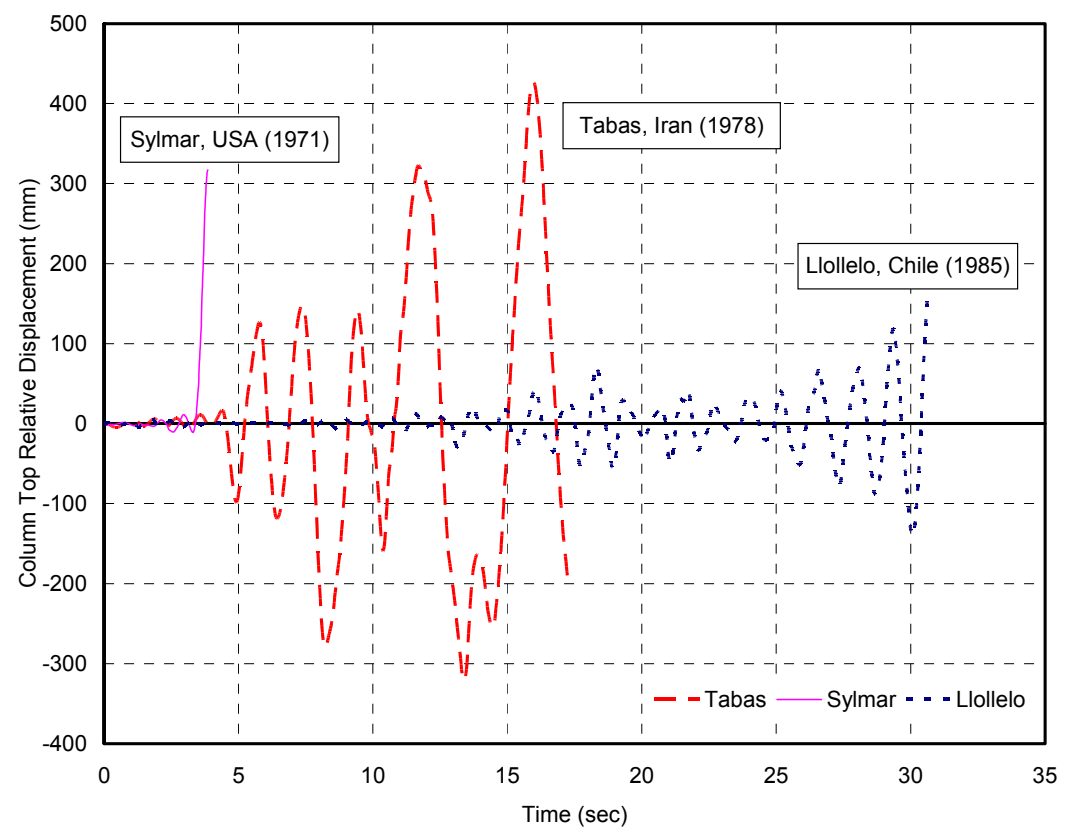

Figure 7.111 Column Displacement Response Time Histories of Column G for All Earthquakes

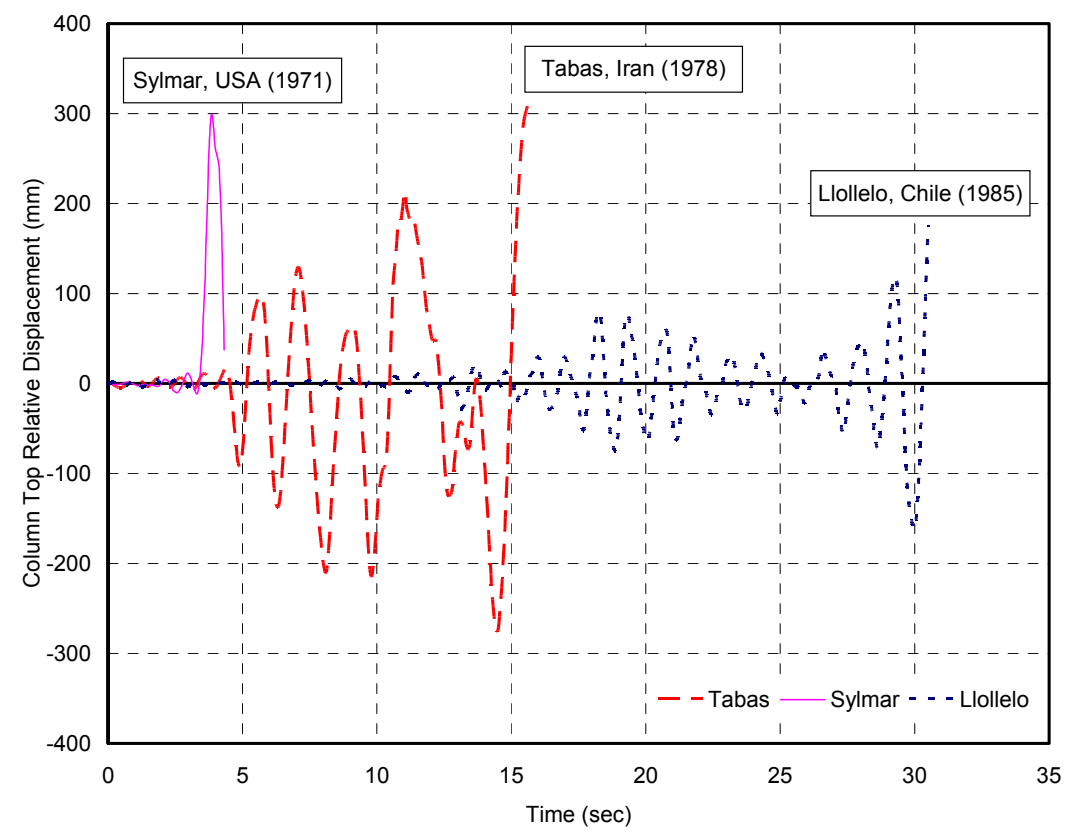

Figure 7.112 Column Displacement Response Time Histories of Column H for All Earthquakes 


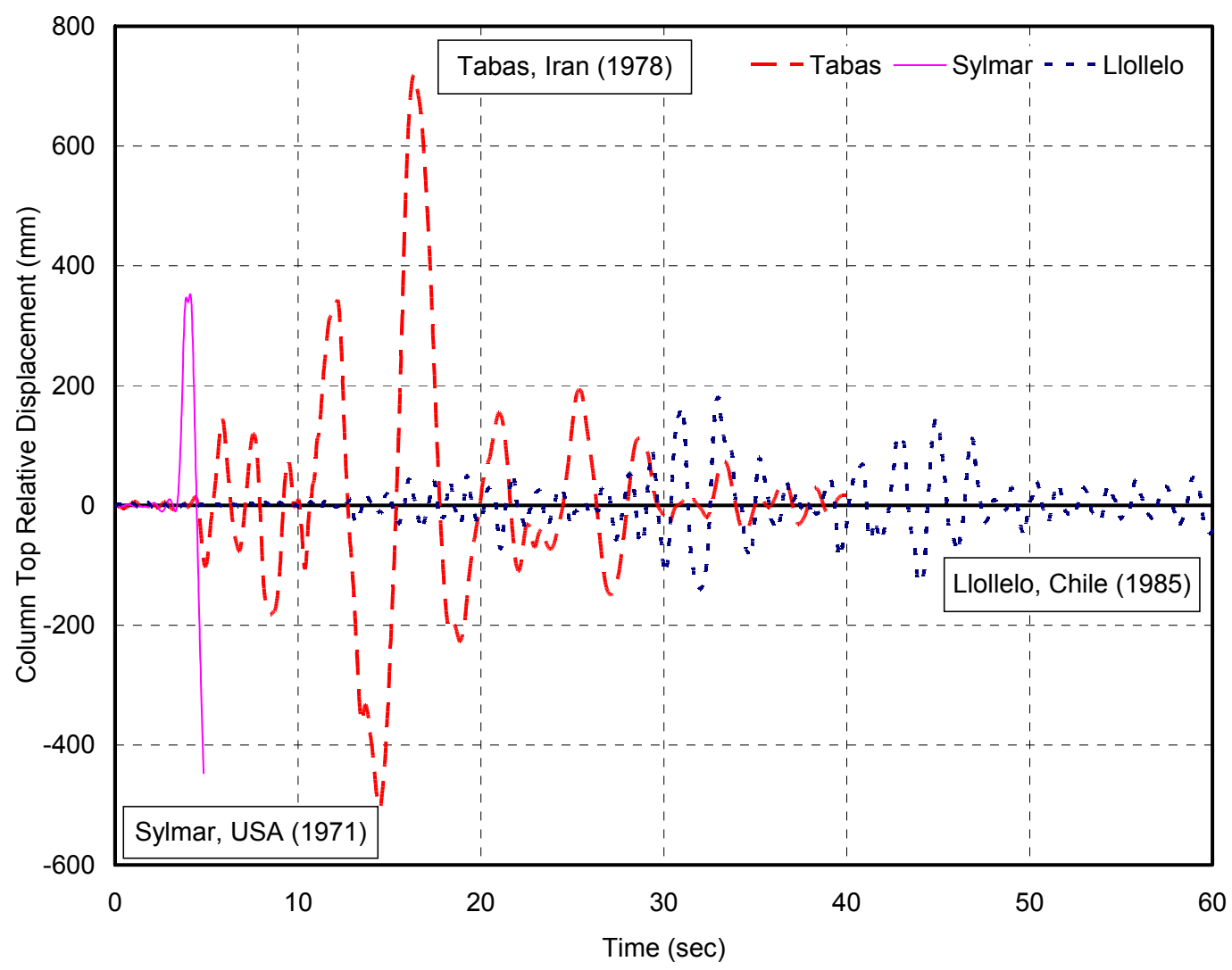

Figure 7.113 Column Displacement Response Time Histories of Column C for All Earthquakes 


\section{CHAPTER 8 CONCLUSIONS AND FUTURE RESEARCH}

\subsection{SUMMARY}

As part of a multi-university research program funded by NSF, a comprehensive experimental and analytical study of seismic behavior of hybrid FRP-concrete column is presented in this dissertation. Experimental investigation includes cyclic tests of six large-scale CFFT and RC columns followed by monotonic flexural tests, a nondestructive evaluation of damage using ultrasonic pulse velocity in between the two series of tests, and tension tests of sixty-five FRP coupons.

It is shown that only specimens with carbon FRP cracked, whereas specimens with glass or hybrid FRP did not show any visible cracks throughout cyclic tests. Further monotonic flexural tests showed that carbon fiber specimens experienced flexural cracks in tension and crumpling in compression. Glass or hybrid specimens, on the other hand, all had FRP local buckling failure. Filament-wound fiberglass specimen exhibited an FRP burst crushing, whereas fabric-wrapped glass and hybrid specimens showed crumpling cracks. All FRP coupons exhibited a linear elastic stress-strain response. Most failures were lateral brittle ruptures for bi-directional coupons, and longitudinal splitting for unidirectional coupons.

Two analytical models using ANSYS and OpenSees were developed and favorably verified against both cyclic and monotonic flexural tests. The results of the two methods were compared. A parametric study was also carried out to investigate the main parameters on the seismic performance measures. The responses of typical CFFT columns to three representative earthquake records were also investigated. 


\subsection{CONCLUSIONS}

Based on the comprehensive experimental and analytical studies reported in this dissertation, following conclusions could be drawn:

1. Compared with conventional RC column, hybrid FRP-concrete column possesses higher flexural strength and energy dissipation with an extended plastic hinge region.

2. Among all CFFT columns, hybrid glass/carbon lay-up demonstrated the highest flexural strength mainly because of its high reinforcement index. It also had the highest initial stiffness due to its high FRP/concrete stiffness ratio. Moreover, at the same drift ratio, the specimen was considered as the best in term of energy dissipation.

3. Specimens with fiberglass tubes exhibited the highest ductility due to higher flexibility of glass FRP composites. Furthermore, ductility of CFFTs showed a strong correlation with the rupture strain of FRP. On the other hand, fiberglass and hybrid lay-up may lead to higher pinching effect than those with carbon fibers.

4. Slippage between FRP tube and concrete core was larger in tension than in compression, similar to the sectional strain response. Filament-wound fiberglass specimen had the largest slippage amongst all specimens because of its smooth surface. However, slippage was not significantly different among the various CFFT specimens.

5. Glass FRP specimens exhibited the smallest residual deflections and loads, an important feature in seismic applications when considering possible repair. 
Carbon FRP tubes, on the other hand, led to the largest residual deflections and loads, while hybrid lay-up was in between the two groups.

6. Under combined shear and flexural effects with shear span-to-depth ratios of typical bridge substructures, it is expected that behavior of CFFT columns will still be governed by flexure. With proper FRP architecture, shear failure is not expected to be critical for CFFT specimens with as short a shear span-to-depth ratio as 1.0 , with or without steel reinforcement or end restraints.

7. Cyclic and monotonic flexural tests showed that flexural strength increases with the reinforcement index based on unconfined concrete compressive strength, but depicts a descending branch when considering the confined concrete compressive strength. Hence, one can optimize reinforcement index for achieving a design moment without over-confining in the hoop direction.

8. Further parametric study and comparison with other test results from the literature indicated that flexural strength tends to have a linear correlation with total reinforcement strength index up to an index of 1.0.

9. Parametric study showed that different FRP architecture and rebar type may lead to different failure modes for CFFT columns. For columns with linear elastic FRP composites, FRP ruptures first, followed by rebar rupture and/or concrete crushing. For columns with lower steel strength index or higher FRP strength index, FRP rupture may lead to rupture of rebar at earlier stages. Moreover, smaller amount of FRP may lead to higher deformation capacity at the expense of lower load bearing capacity. 
10. Transient analysis of strong ground motions showed that Column Y with off-axis filament-wound glass FRP tube exhibited a superior seismic performance to all other CFFTs. Moreover, higher FRP reinforcement ratios may lead to a brittle system failure, while a well-engineered FRP reinforcement configuration may significantly enhance the seismic performance of CFFT columns.

\subsection{FUTURE RESEARCH}

This study has shown that FRP composites may provide higher strength and ductility for use in earthquake engineering applications. An optimized configuration with conventional or innovative materials (high performance concrete or steel reinforcement) may be worthy of further investigation to improve the seismic performance. Durability is

another issue to explore. Moreover, fire and blast performance may also attract researchers for the hybrid configurations of innovative materials with conventional construction. 


\section{LIST OF REFERENCES}

Ahmad, I., Zhu, Z., and Mirmiran A. (2008a). "Behavior of Short and Deep Beams Made of Concrete-Filled Fiber-Reinforced Polymer Tubes." Journal of Composites for Construction, ASCE, Vol. 12, No. 1, pp. 102-110.

Ahmad, I., Zhu, Z., and Mirmiran A. (2008b). "Fatigue Behavior of Concrete-Filled Fiber-Reinforced Polymer Tubes." Journal of Composites for Construction, ASCE, Vol. 12, No. 4, pp. 478-487.

ANSYS. (2007). ANSYS Theory Reference Manual, Release 11.0 ANSYS Inc.

ASTM D 3039. (2006). "Standard Test Method for Tensile Properties of Polymer Matrix Composite Materials." ASTM Standards D 3039, West Conshohocken, PA.

ASTM D 638. (2004). "Standard Test Method for Tensile Properties of Plastics." ASTM Standards D 638, West Conshohocken, PA.

ASTM D 695. (2002). "Standard Test Method for Compressive Properties of Rigid Plastics." ASTM Standards D 695, West Conshohocken, PA.

Besseling, J.F. (1958). "A Theory of Elastic, Plastic and Creep Deformations of an Initially Isotropic Material". Journal of Applied Mechanics, Vol. 25, pp. 529-536.

Cole B., and Fam, A. (2006). "Flexural Load Testing of Concrete-Filled FRP Tubes with Longitudinal Steel and FRP Rebar." Journal of Composites for Construction, ASCE, Vol. 10, No. 2, pp. 161-171.

Davol, A., Burgueño, R., and Seible, F. (2001). "Flexural Behavior of Circular Concrete Filled FRP Shell." Journal of Structural Engineering, ASCE, Vol. 127, No. 7, pp. 810-817.

De Lorenzis, L., and Tepfers, R. (2003). "Comparative Study of Models on Confinement of Concrete Cylinders with Fiber-Reinforced Polymer Composites." Journal of Composites for Construction, ASCE, Vol. 7, No. 3, pp. 219-237.

Fam, A., and Rizkalla S. (2001a). "Behavior of Axially Loaded Concrete-Filled Circular Fiber-Reinforced Polymer Tubes." ACI Structural Journal, ACI, Vol. 98, No. 3, pp. 280-289.

Fam, A., and Rizkalla S. (2001b). "Confinement Model for Axially Loaded Concrete Confined by Circular Fiber-Reinforced Polymer Tubes." ACI Structural Journal, ACI, Vol. 98, No. 4, pp. 451-461. 
Fam, A., and Rizkalla S. (2002). "Flexural Behavior of Concrete-Filled Fiber-Reinforced Polymer Circular Tubes." Journal of Composites for Construction, ASCE, Vol. 6, No. 2, pp. 123-132.

Fam, A., Pando M., Filz G., and Rizkalla S. (2003a). "Precast Piles for Route 40 Bridge in Virginia Using Concrete Filled FRP Tubes." PCI Journal, PCI, Vol. 48, No. 3, pp. $32-45$.

Fam, A., Flisak B., and Rizkalla S. (2003b). "Experimental and Analytical Modeling of Concrete-Filled Fiber-Reinforced Polymer Tubes Subjected to Combined Bending and Axial Loads." ACI Structural Journal, ACI, Vol. 100, No. 4, pp. 499-509.

Fam, A., Schnerch, D., and Rizkalla S. (2005a). "Rectangular Filament-Wound Glass Fiber Reinforced Polymer Tubes Filled with Concrete under Flexural and Axial Loading: Experimental Investigation." Journal of Composites for Construction, Vol. 9, No. 1, pp. 25-33.

Fam, A., Mandal S., and Rizkalla S. (2005b). "Rectangular Filament-Wound Glass Fiber Reinforced Polymer Tubes Filled with Concrete under Flexural and Axial Loading: Analytical Modeling." ACI Structural Journal, Vol. 102, No. 3, pp. 383-392.

Fam, A., Mandal S. (2006). "Prestressed Concrete-Filled Fiber-Reinforced Polymer Circular Tubes Tested in Flexure." PCI Journal, Vol. 51, No. 4, pp. $42-54$.

Fam, A., Cole B., and Mandal S. (2007). "Composite Tubes as an Alternative to Steel Spirals for Concrete Members in Bending and Shear." Construction and Building Materials, Elsevier, Vol. 21, No. 2, pp. 347-355.

Fam, A., Kong, A., Green, M. (2008a). "Effects of Freezing and Thawing Cycles and Sustained Loading on Compressive Strength of Precast Concrete Composite Piles." PCI Journal, PCI, Vol. 53, No. 1, pp. 109-120.

Fam, A. (2008b). "Development of a Novel Pole Using Spun-Cast Concrete inside GlassFiber-Reinforced Polymer Tubes." PCI Journal, PCI, Vol. 53, No. 3, pp. 100-113.

Fan, L., Zhou, W., and Xue, Y. (2000). "Preliminary Study of Seismic Performance of FRP Tube Confined Concrete Short Columns." Proc., 1st Chinese National Conf. of Application Technology of FRP Materials in Civil Engineering, National Diagnosis and Rehabilitation of Industrial Building Research Center, Beijing, 113-117 (in Chinese).

Helmi, K., Fam, A., Mufti, A., and Hall, J. (2006). "Effects of Driving Forces and Bending Fatigue on Structural Performance of a Novel Concrete-Filled FibreReinforced-Polymer Tube Flexural Pile." Canadian Journal of Civil Engineering, NRCC, Vol. 33, No. 6, pp. 683-691. 
Helmi, K., Fam, A., Mufti, A. (2008). "Fatigue Life Assessment and Static Testing of Structural GFRP Tubes Based on Coupon Tests." Journal of Composites for Construction, ASCE, Vol. 12, No. 2, pp. 212-223.

Karsan, I. D., and Jirsa, J. O. (1969). "Behavior of Concrete under Compressive Loading." Journal of Structural Division, ASCE, Vol. 95, No. ST12.

Lam, L. and Teng, J. G. (2002). "Strength Models for Fiber-Reinforced Plastic-Confined Concrete.” Journal of Structural Engineering, ASCE, Vol. 128, No. 5, pp. 612-623.

Li, B. (2008). "Seismic Performance of Hybrid Fiber Reinforced Polymer-Concrete Pier Frame Systems." Ph.D. Dissertation, Florida International University, Miami, Florida.

Mandal S., Hoskin, A., and Fam, A. (2005). "Influence of Concrete Strength on Confinement Effectiveness of Fiber-Reinforced Polymer Circular Jackets." Journal of Composites for Construction, ASCE, Vol. 9, No. 1, pp. 34-43.

Mandal S., and Fam, A. (2006). "Modeling of Prestressed Concrete-Filled Circular Composite Tubes Subjected to Bending and Axial Loads." Journal of Structural Engineering, ASCE, Vol. 132, No. 3, pp. 449-459.

Mirmiran, A., and Shahawy, M. (1995). "A Novel FRP-Concrete Composite Construction for the Infrastructure." Proceedings of the ASCE Structures Congress XIII, Boston, MA, 1663-1666.

Mirmiran, A., and Shahawy, M. (1997a). "Behavior of Concrete Columns Confined by Fiber Composites.” Journal of Structural Engineering, ASCE, Vol. 123, No. 5, pp. 583-590.

Mirmiran, A., and Shahawy, M. (1997b). "Dilation Characteristics of Confined Concrete." Mechanics of Cohesive-Frictional Materials, Wiley InterScience, Vol. 2, No. 3, pp. 237-249.

Mirmiran, A., Cabrera, S., Samaan, M., and Shahawy, M. (1998a). "Design, Manufacture, and Testing of a New Hybrid Column." Construction and Building Materials, Elsevier, Vol. 12, No.1, pp. 39-49.

Mirmiran, A., Shahawy, M., Samaan, M., El Echary, H., Mastrapa, J.C., and Pico, O. (1998b). "Effect of Column Parameters on FRP-Confined Concrete." Journal of Composites for Construction, ASCE, Vol. 2, No. 4, pp. 175-185.

Mirmiran, A., Shahawy, M., and Samaan, M. (1999a). "Strength and Ductility of Hybrid FRP-Concrete Beam-Columns.” Journal of Structural Engineering, ASCE, Vol. 125, No. 10, pp. 1085-1093. 
Mirmiran, A., Shahawy M., and Echary, H. (1999b) "Acoustic Emission Monitoring of Hybrid FRP-Concrete Columns." Journal of Engineering Mechanics, ASCE, Vol. 125, No. 8, pp. 899-905.

Mirmiran, A., Shahawy, M., El Khoury, C., and Naguib, W. (2000b). "Large BeamColumn Tests on Concrete-Filled Composite Tubes." ACI Structural Journal, ACI, Vol. 97, No. 2, pp. 268-276.

Mirmiran, A., Philip, S. (2000c). "Comparison of Acoustic Emission Activity in SteelReinforced and FRP-Reinforced Concrete Beams." Construction and Building Materials, Elsevier, Vol. 14, No. 6-7, pp. 299-310.

Mirmiran, A., Shahawy, M., and Beitleman, T. (2001a). "Slenderness Limit for Hybrid FRP-Concrete Columns." Journal of Composites for Construction, ASCE, Vol. 5, No. 1, pp. 26-34.

Mirmiran A., and Wei, Y. (2001b). "Damage Assessment of FRP-Encased Concrete Using Ultrasonic Pulse Velocity." Journal of Engineering Mechanics, ASCE, Vol. 127, No.2, pp. 126-135.

Mirmiran, A., Shao, Y., and Shahawy, M. (2002). "Analysis and Field Tests on the Performance of Composite Tubes under Pile Driving Impact." Composite Structures, Elsevier, Vol. 55, No. 2, pp. 127-135.

Naguib, W., and Mirmiran, A. (2002). "Time-Dependent Behavior of FRP-Confined Concrete Columns." ACI Structural Journal, ACI, Vol. 99, No. 2, pp. 142-148.

Open System for Earthquake Engineering Simulation. http://opensees.berkeley.edu/

Ozbakkaloglu T. and Saatcioglu M. (2006). "Seismic Behavior of High-Strength Concrete Columns Confined by Fiber-Reinforced Polymer Tubes." Journal of Composites for Construction, Vol. 10, No. 6, pp. 538-549.

Ozbakkaloglu T. and Saatcioglu M. (2007). "Seismic Performance of Square HighStrength Concrete Columns in FRP Stay-in-Place Formwork." Journal of Structural Engineering, Vol. 133, No. 1, pp. 44-56.

Ozbakkaloglu T. and Oehlers D. (2008a). "Concrete-Filled Square and Rectangular FRP Tubes under Axial Compression." Journal of Composites for Construction, ASCE, Vol. 12, No. 4, pp. 469-477.

Ozbakkaloglu T. and Oehlers D. (2008b). "Manufacture and testing of a novel FRP tube confinement system." Engineering Structures, Elsevier, Vol. 30, No. 9, pp. 24482459 .

Response-2000 Software. http://www.ecf.utoronto.ca/ bentz/home.shtml 
Rice, J. (1971). "Inelastic Constitutive Relations for Solids: an Internal-Variable Theory and its Application to Metal Plasticity." Journal of Mechanics and Physics Solids, Vol. 19, pp. 433-455.

Saafi, M., Toutanji, H., and Li, Z. (1999) "Behavior of Concrete Columns Confined with Fiber-Reinforced Polymer Tubes." ACI Materials Journal, ACI, Vol. 96, No. 4, pp. 500-509.

Samaan, M., Mirmiran, A., and Shahawy, M. (1998). "Model of Concrete Confined by Fiber Composite." Journal of Structural Engineering, ASCE, Vol. 124, No.9, pp. 1025-1031.

Scott, B.D., Park, R. and Priestley, M. (1982). "Stress-Strain Behavior of Concrete Confined by Overlapping Hoops at Low and High Strain Rates." ACI Journal, Vol. 79, No. 1, pp. 13-27.

Seible, F., Burgueño, R., Abdallah, M. G., and Nuismer, R. (1996). “ D evelopment of Advanced Composite Carbon Shell Systems for Concrete Columns in Seismic Zones." Proc., $11^{\text {th }}$ World Conf. on Earthquake Engineering, Pergamon-Elsevier Science, Paper No. 1375, Oxford, U.K.

Seible, F., Karbhari, V. M., and Burgueno, R. (1999). "Kings Stormwater Channel and I5/Gilman Bridges, USA." Structural Engineering International: Journal of the International Association for Bridge and Structural Engineering, IABSE, Vol. 9, No. 4, pp. 250-253.

Shao, Y. (2003). "Seismic Performance of FRP-Concrete Beam-Column." Ph.D. Dissertation, North Carolina State University, Raleigh, North Carolina.

Shao, Y., and Mirmiran, A. (2004). "Nonlinear Cyclic Response of Laminated Glass FRP Tubes Filled with Concrete." Composite Structures, Elsevier Science Ltd., Vol. 65, No. 1, pp. 91-101.

Shao, Y., and Mirmiran, A. (2005a). "Fiber Element Model for Cyclic Analysis of Concrete-Filled FRP Tubes." Journal of Structural Engineering, ASCE, Vol. 131, No. 2, pp. 292-303.

Shao, Y., and Mirmiran, A. (2005b). "Experimental Investigation of Cyclic Behavior of Concrete-Filled FRP Tubes." Journal of Composites for Construction, ASCE, Vol. 9, No. 3, pp. 263-273.

Shao, Y., Zhu, Z., and Mirmiran, A. (2006). "Cyclic Modeling of FRP-Confined Concrete with Improved Ductility." Cement \& Concrete Composites, Elsevier, Vol. 28, No. 10, pp. 959-968. 
Spoelstra, M., and Monti, G. (1999). "FRP-Confined Concrete Model." Journal of Composites for Construction, ASCE, Vol. 3, No. 3, pp. 143-150.

Sumpter, M., Rizkalla, S., and Zia P. (2009). "Behavior of High-Performance Steel as Shear Reinforcement for Concrete Beams." ACI Structural Journal, ACI, Vol. 106, No. 2, pp. 171-177.

Teng, J. G. and Lam, L. (2004). "Behavior and Modeling of Fiber Reinforced PolymerConfined Concrete." Journal of Structural Engineering, Vol. 130, No. 11, pp. 17131723.

Teng, J., Yu, T., Wong, Y., and Dong, S. (2007). "Hybrid FRP-Concrete-Steel Tubular Columns: Concept and Behavior." Construction and Building Materials, Elsevier, Vol. 21, No. 4, pp. 846-854.

Van Den Einde, L., Karbhari, V.K., and Seible, F. (2007). "Seismic Performance of a FRP Encased Concrete Bridge Pylon Connection." Composites Part B: Engineering, Elsevier, Vol. 38, No. 5-6, pp. 685-702.

Yamakawa, T., Komesu, K., Zhong, P., and Satoh, H. (2001). "Seismic Performance of Aramid Fiber Square Tubed Concrete Columns with Nonmetallic Reinforcement." Proceeding of Inernational Conference on FRP Composites in Civil Engineering, editor: J. G. Teng, Vol. II, 1329-1336.

Yu, T., Wong, Y., Teng, J., Dong, S., and Lam, E. (2006). "Flexural Behavior of Hybrid FRP-Concrete-Steel Double-Skin Tubular Members." Journal of Composites for Construction, Vol. 10, No. 5, pp. 443-452.

Yuan, H., Xue, Y., Li, X., and Zhang, M. (2002). "Study on A Novel Hybrid GFRP/CFRP Composite Beam." Proc., 2nd Chinese National Conference of Application Technology of FRP Materials in Civil Engineering, Tsinghua University Publication, Beijing, 296-305 (in Chinese).

Zheng, R. (2007). "Performance of FRP-Concrete Bridges under Blast Loading." Ph.D. Dissertation. Florida International University, Miami, Florida.

Zhu, Z., Mirmiran, A., and Shahawy, M. (2004). "Stay-in-Place FRP Forms for Precast Modular Bridge Pier System." Journal of Composites for Construction, ASCE, Vol. 8, No. 6, pp. 560-568.

Zhu, Z., Ahmad, I., and Mirmiran, A. (2005). "Effect of Column Parameters on Axial Compressive Behavior of Concrete-Filled FRP Tubes." Journal of Advances in Structural Engineering, Multi-Science Publishing, Vol. 8, No. 4, pp. 443-449.

Zhu, Z., Ahmad, I., and Mirmiran, A. (2006a). "Seismic Performance of Concrete-Filled FRP Tube Columns for Bridge Substructure." Journal of Bridge Engineering, ASCE, Vol. 11, No. 3, pp. 359-370. 
Zhu, Z., Ahmad, I., and Mirmiran, A. (2006b). "Fiber Element Modeling for Seismic Performance of Bridge Columns Made of Concrete-Filled FRP Tubes." Engineering Structures, Elsevier, Vol. 28, No. 10, pp. 2023-2035.

Zhu, Z., Mirmiran, A., and Saiidi, M.S. (2006c). "Seismic Performance of Fiber Composite Tubed Reinforced Concrete Bridge Substructure," Transportation Research Record No. 1976, Design of Structures, Part 7 - Structural Fiber Reinforced Plastics, Transportation Research Board, National Research Council, Washington, D.C., pp. 197-206.

Zhuo, W., Fan, L., and Xue, Y. (2001). "Shaking Table Testing of Simply Supported Bridges with Prefabricated GFRP Tube Jacketed RC Columns." Proc., Int. Conf. on FRP Composites in Civil Engineering, J. G. Teng, ed., Vol. II, 1337-1344.

Zhuo, W., and Fan, L. (2005). "The Concept and Seismic Performance of GFRP Tube Concrete Composite Piers." Journal of Fuzhou University (Natural Science), Vol. 33, No. 1, pp. 73-79 (in Chinese). 